\title{
CORPUS VASORUM ANTIQUORUM
} ÖSTERREICH

GRAZ, ORIGINALSAMMLUNG DES INSTITUTS FÜR ARCHÄOLOGIE DER KARL-FRANZENS-UNIVERSITÄT

$$
\text { BAND } 1
$$

BEARBEITET VON

MARIA CHRISTIDIS, STEPHAN KARL, GABRIELE KOINER, GERDA SCHWARZ

WIEN 2014

VERLAG DER ÖSTERREICHISCHEN AKADEMIE DER WISSENSCHAFTEN 


\section{CORPUS \\ VASORUM ANTIQUORUM}

ÖSTERREICH

GRAZ, ORIGINALSAMMLUNG DES INSTITUTS FÜR ARCHÄOLOGIE

DER KARL-FRANZENS-UNIVERSITÄT

BAND 1 



\section{CORPUS \\ VASORUM ANTIQUORUM}

\section{ÖSTERREICH}

GRAZ, ORIGINALSAMMLUNG DES INSTITUTS FÜR ARCHÄOLOGIE DER KARL-FRANZENS-UNIVERSITÄT

\section{BAND 1}

BEARBEITET VON

MARIA CHRISTIDIS, STEPHAN KARL, GABRIELE KOINER, GERDA SCHWARZ

WIEN 2014

VERLAG DER ÖSTERREICHISCHEN AKADEMIE DER WISSENSCHAFTEN 
Vorgelegt von w. M. ANDREas PüLz in der Sitzung vom I4. Juni 2013

Mit 84 Tafeln, 20 Textabbildungen und 22 Beilagen

Herausgegeben von der Österreichischen Akademie der Wissenschaften

Veröffentlicht mit Unterstützung des

Austrian Science Fund (FWF): PUB I 57-V2 I

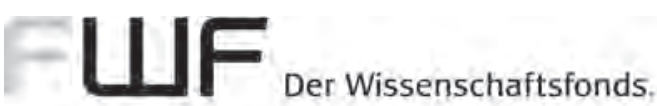

Photographien: (C) Karl-Franzens-Universität, Graz, Johanna Kraschitzer Zeichnungen: Stephan Karl, Johanna Kraschitzer

Bibliografische Information der Deutschen Nationalbibliothek

Die Deutsche Nationalbibliothek verzeichnet diese Publikation in der Deutschen Nationalbibliografie, detaillierte bibliografische Daten sind im Internet über http://dnb.d-nb.de abrufbar.

Diese Publikation wurde einem anonymen, internationalen Peer-Review-Verfahren unterzogen.

This publication has undergone the process of anonymous, international peer review.

Die verwendete Papiersorte ist aus chlorfrei gebleichtem Zellstoff hergestellt, frei von säurebildenden Bestandteilen und alterungsbeständig.

$$
\begin{aligned}
& \text { Alle Rechte vorbehalten. } \\
& \text { ISBN 978-3-700I-7529-2 } \\
& \text { Copyright (C) 20I4 by }
\end{aligned}
$$

Österreichische Akademie der Wissenschaften, Wien

Satz: Grasl FairPrint, 2540 Bad Vöslau

Druck und Bindung: Wograndl Druck GmbH, 72 Io Mattersburg

http://hw.oeaw.ac.at/7529-2

http://verlag.oeaw.ac.at/ 
INHALT

Vorwort

Seite Tafel

Zyprisch

Zyprisch Bronzezeitlich

(G. Koiner)

Griechisch

Attisch Protogeometrisch

Attisch Frühgeometrisch

Attisch Mittelgeometrisch

Attisch Spätgeometrisch

Argivisch Spätgeometrisch

Attisch Subgeometrisch

Protoattisch

Protokorinthisch

Korinthisch

Ostgriechisch

(S. Karl)

Attisch Schwarzfigurig

Attisch Rotfigurig

Attisch Weißgrundig

(G. Schwarz)

Attische Glanzton-Ware

$\begin{array}{ll}25 & 7 \\ 28 & 8 \\ 29 & 9-\text { II } \\ 34 & \text { I I-I5 } \\ 44 & \text { I6 } \\ 46 & \text { I7 } \\ 48 & \text { I7 } \\ 50 & \text { I } 8 \\ 52 & \text { I9-29 } \\ 59 & 30\end{array}$

$62 \quad 3 I-37$

$69 \quad 38-58$

$88 \quad 59$

(M. Christidis / G. Schwarz)

Böotisch Schwarzfigurig

(M. Christidis / G. Schwarz)

Elisch

(M. Christidis)

Italisch

Etruskisch

$96 \quad 64-65$

(G. Schwarz)

Apulisch Rotfigurig

$\begin{array}{rr}98 & 66-68 \\ \text { IO4 } & 69-73 \\ \text { IIO } & 74-76 \\ \text { II4 } & 77-78 \\ \text { II7 } & 78-84\end{array}$

(M. Christidis) 
Verluste

Zyprisch Bronzezeitlich

(G. Koiner)

Attisch Schwarzfigurig

I I9

(G. Schwarz)

Attische Glanzton-Ware

I I9

(M. Christidis)

Verzeichnisse

I. Konkordanz: Inventarnummern - Tafeln - Beilagen - I 20 Abbildungen

II. Konkordanz: alte und aktuelle Inventarnummern I2 I

III. Maler, Werkstätten, Gruppen, Klassen I2I

IV. Fundorte, Sammlungen, Vorbesitzer I22

V. Inschriften und Dipinti $\quad$ I22

VI. Darstellung $\quad$ I 22

VII. Dekor

$\mathrm{I} 24$

VIII. Technische Besonderheiten

I 24

IX. Beilagen und Textabbildungen

I 25

X. Technische Parameter der

I 25

Beilagen

Tafeln 


\section{VORWORT}

Der erste Band des CVA Graz, Karl-Franzens-Universität enthält insgesamt 93 Objekte (davon drei Verluste), die von Werkstätten aus dem griechischen Osten über Zypern und das griechische Mutterland bis nach Etrurien stammen, also nicht nur räumlich, sondern auch zeitlich einen weiten Bogen umspannen. Dies ist auch der Grund dafür, weshalb sich eine ungewöhnlich hohe Zahl von BearbeiterInnen zu diesem Projekt zusammengefunden hat: einerseits sollte der zeitliche Rahmen für die Fertigstellung in Grenzen gehalten werden, andererseits aber doch den speziellen Anforderungen, die die so unterschiedlichen Gattungen antiker Keramik stellen, Rechnung getragen werden. Die meisten der vorgelegten Stücke sind ganz bzw. nahezu ganz erhaltene Vasen, von denen 49 Exemplare bereits in einem kleinen Katalog des Jahres I 993 vorgestellt wurden ${ }^{\mathrm{T}}$.

Die Vasen sind Teil der Originalsammlung des Instituts, die aus einer Lehrsammlung hervorgegangen ist und bereits im Jahre I 865 als „archäologisches Cabinet“ von Karl Schenkl ins Leben gerufen wurde ${ }^{2}$. Schenk1, von I 863 bis I 875 Inhaber der Lehrkanzel für Griechisch und großer Verfechter einer umfassenden Konzeption der Altertumswissenschaften, sah in den Objekten Hilfsmittel bei der Ausbildung der Studierenden der Klassischen Philologie. In diesem Zusammenhang sei ein Curiosum angemerkt: Nicht unwillkommen dürfte dem Ministerium die Ankündigung gewesen sein, dass sich das Kabinett ausschließlich durch die Abhaltung populärwissenschaftlicher Vorträge sowie durch Spenden und Schenkungen selbst zu erhalten gedachte. Wenn man den Zustand der Vasensammlung heute betrachtet, so gewinnt man den Eindruck, das Ministerium habe sich an diesen angenehmen Zustand gewöhnt, der jedoch den heutigen Ansprüchen sowohl von ästhetischer als auch von konservatorischer Seite nicht mehr gerecht werden kann. So wurden für die Vasen zwar am Ende des letzten Jahrtausends moderne Vitrinen angeschafft, doch konnten einige neuzeitliche Übermalungen aus Kostengründen nicht mehr rechtzeitig entfernt werden (zu den vorgenommenen Restaurierungen vgl. unten).

Die Stücke sind mit Beschreibung und teilweise mit Foto bzw. Zeichnung in einem älteren Inventarbuch mit dem Registerbuchstaben G (für Originalsammlung) erfasst. Dieses ältere von zwei heute noch vorhandenen Inventarbüchern wurde von Franz Gosch unter Leitung des Institutsvorstandes Rudolf Heberdey (I9II-I933) im Wintersemester I9II/I2 begonnen. Gosch führte die Inventarisierung bis zu seiner Anstellung an der Universitätsbibliothek im Jahre I9I4 und schloss seine Beschreibung der Objekte mit Nummer G I09. Bis zum Jahr I 944/45 wurde das Inventarbuch bis G 232 weiter fortgeführt. Nach dem 2. Weltkrieg konnten nur wenige Stücke noch angefügt werden, sodass das Inventar nunmehr mit G 255 schließt. Die Inventarisierung der Scherbensammlung wird in einer eigenen Liste fortgeführt. Das jüngere Inventarbuch wurde von Arnold Schober (I936-I945), dem Nachfolger Heberdeys auf dem Lehrstuhl für Klassische Archäologie, begonnen und stellt mehr oder weniger ein Duplikat dar. Neben dem älteren Inventarbuch haben sich jedoch sämtliche Erwerbungslisten der ersten Inventarisierung erhalten, die seit der Gründung des Kabinetts bis I 875 von Schenkl geführt wurden. Zusätzlich erschließt sich aus dem älteren, I9I I/I 2 begonnenen Inventarbuch eine weitere Inventarisierung durch Friedrich Pichler im Jahre I 875/76 (dieses Inventar fehlt spurlos). Die archivalischen Quellen geben einen nahezu lückenlosen Einblick zu den frühen Erwerbungen, aber auch zu Verlusten (siehe Verzeichnis am Ende dieses Bandes). So hat sich die allererste Erwerbung des Grazer archäologischen Kabinetts aus dem Jahr I 866 erhalten: die Schulterlekythos G I, alte Inv.-Nr. II I (Schenkl) bzw. III I (Pichler), die der steiermärkische Landesarchivar Josef von Zahn dem Kabinett schenkte.

Der Band beginnt mit sechs zyprischen Ganzgefäßen, die von Gabriele Koiner bearbeitet wurden. Die Stücke stammen aus der frühen bis späten Bronzezeit und repräsentieren einen breiten Querschnitt der bronzezeitlichen Keramikproduktion Zyperns. Die früh- bis mittelzyprische Red Polished Ware ist vertreten durch die Schalen G 2 I 2, einem aus dem Norden der Insel stammenden Exemplar, sowie G 2046 aus dem Süden Zyperns. Die Kugelschale G 2 I I, die man wahrscheinlich auch der Red Polished Ware zuordnen kann, ist heute verschollen. Die Henkeltasse G 2 Io und die Schnabeltasse G 208 sind charakteristische Repräsentanten der mittel- bis spätzyprischen White Painted Ware und finden gute Vergleiche im Norden Zyperns. G 208 wurde gemeinsam mit einer ähnlichen Kanne im Universalmuseum Joanneum (Archäologiemuseum 4 I 89) von Paul Åström in den Band der Swedish Cyprus Expedition über die späte Bronzezeit auf Zypern aufgenommen (SCE IV IC). Der Krug der White Slip Ware G 209 und das fragmentierte Zwillingsgefäß der Base-ring Ware G 57 sind typische Vertreter der spätbronzezeitlichen Waren, die von Zypern in die östliche Ägäis, die Levante und nach Ägypten exportiert wurden.

Lehner - Lorenz - Schwarz, Vasen. In diesem Katalog wurden G 42 und G 42 a getrennt behandelt.

2 Zur wechselvollen Geschichte der Originalsammlung des Instituts für Archäologie an der Karl-Franzens-Universität Graz vgl. Lehner, Originalsammlung. 
Die Erwerbungsgeschichte und die Herkunft der meisten Gefäße sind derzeit nicht zu klären. Während das Kompositgefäß der Base-Ring Ware G 57 bereits im I9. Jahrhundert in die Sammlung gekommen war, entstammen die Gefäße G 208-209, G 210, G 2 I 2 und das verschollene Gefäß G 2 I I wahrscheinlich alle einem Ankauf aus dem Jahre I940. Nur von einer erst 20 I0 erfolgten Schenkung, der Schale G 2046, ist zumindest bekannt, dass sie in den I97oer-Jahren in Kairo erworben wurde.

Von den geometrischen, korinthischen, protoattischen und ostgriechischen Vasen werden in diesem Band von Stephan Karl insgesamt I 7 ganz bzw. nahezu ganz erhaltene Gefäße und zwölf Fragmente vorgelegt. Deckel und Gefäßkörper werden bei zwei Objekten, dem spätgeometrischen Deckel-Skyphos $G_{42}$ und $G_{42}$ a und der korinthischen Lekanis G 4I, zusammen aufgeführt, da sie nachweislich gemeinsam in die Sammlung gelangten und von der Bestimmung her kein Zweifel besteht, dass sie auch füreinander hergestellt wurden. Im Zuge der Auswahl der geometrischen und korinthischen Keramik für das CVA wurden all jene Fragmente aus der umfangreichen Scherbensammlung berücksichtigt, die entweder durch ihre ornamentale bzw. figürliche Bemalung oder durch besondere Details eine über die allgemein typologische Zuordnung hinausführende Aussage ermöglichen.

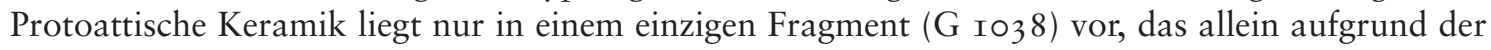
Kuriosität einer Anpassung an die bekannte Kanne des Malers der Widderkanne Aigina K 566 Aufnahme im CVA gefunden hat. Hinsichtlich der ostgriechischen Keramik wurde auf die Vorlage des Bestandes der Fragmente aus Smyrna und Ephesos verzichtet, die teilweise an einem anderen Ort publiziert wurden ${ }^{3}$. Zur Publikation gelangt in diesem Band nur das ostgriechische Granatapfelgefäß G 56. Aufgrund des aktuellen Erhaltungszustandes und der damit verbundenen Unsicherheiten in der Bestimmung wurde ein hybrides Gefäß, die (proto)geometrische Pyxis G 254, die im Jahre 2002 aus dem Besitz von Edith Trenczak angekauft wurde, nicht in diesem Band aufgenommen.

Mangelhaft sind weiterhin exakte Angaben zur Herkunft der Gefäße, die im Tausch mit dem NM Athen erworben wurden, aber auch zur Scherbensammlung aus demselben Museum. Dazu geben derzeit die am Institut für Archäologie verwahrten Archivalien keine Auskunft. Beide Erwerbungen stehen mit Heberdey in Verbindung. Der Tausch von 20 vollständig bis nahezu ganz erhaltenen Gefäßen und Lampen (G 90-I09) muss lt. älterem Inventarbuch um I9I2/I3 erfolgt sein.

Besser informiert sind wir über den Tausch von zwei Marmorfragmenten vom Erotenfries des Theaters von Ephesos, die sich seit I87I an der Universität Graz befanden, mit dem Hofmuseum in Wien (heute Kunsthistorisches Museum) gegen zwei Gipskopien von ephesischen Skulpturen (D I70, D 42I) im Jahre I9I3/I4. Die Scherbensammlung wurde der Karl-Franzens-Universität Graz in den I9Io/2oer-Jahren geschenkt. Sie besteht aus insgesamt etwa I 50 Stücken (bei Heranziehen der tatsächlich mit „Mus. Ath.“ beschrifteten Stücke). In ihr sind in der Hauptsache die älteren griechischen Vasenstile repräsentiert: mykenisch ( 50), kykladisch ( 20) und geometrisch ( 40; attisch, korinthisch, argivisch); daneben wurden auch einige archaisch-korinthische, attisch-schwarzfigurige bzw. auch attisch-rotfigurige sowie hellenistische Scherben abgetreten.

Auf herstellungstechnische Spuren wird bei der Beschreibung der frühgriechischen Gefäße besonderer Wert gelegt, um den Prozess der einzelnen Arbeitsschritte so weit wie möglich rekonstruieren zu können. Gerade in solchen Angaben liegt ein wesentliches Potential für ein besseres Verständnis hinsichtlich des Zustandekommens von Dekorsystemen oder auch der individuellen Handschrift des Töpfers bzw. Malers. Für töpfertechnische Details wären noch in einem viel größeren Umfang, als es für diesen Band möglich war, Untersuchungen mittels Computertomografie von besonderer Bedeutung. Unter der Bezeichnung Keramikart werden im Text Eigenschaften des Scherbens in einfacher Weise beschrieben, wie sie sich optisch mit Hilfe eines Mikroskops bei etwa 20-facher Vergrößerung zu erkennen geben. Keramikart entspricht im englischen Sprachgebrauch fabric oder dem Begriff Scherben ${ }^{4}$. Da dafür eine, wenn auch minimale, frische Bruchfläche erzeugt werden musste, bleibt eine solche Charakterisierung auf die in diesem Band vorgelegten Fragmente aus der Scherbensammlung beschränkt; erkenntlich sind diese an der höheren Inventarnummer ab G 255 (dazu gehört auch G 99). Die in diesem Band vorgestellten zwölf Fragmente aus der Scherbensammlung werden nicht nur im Beilagenteil als Profilzeichnung, sondern allesamt auch als Textabbildung in Form einer Umzeichnung vorgelegt. Bei fünf Gefäßen G 44, G 56, G 90 und G 96-97 war es ebenfalls notwendig, Umzeichnungen der schlecht sichtbaren bzw. nur mehr in Negativspuren erhaltenen Bemalung zu erstellen.

Gliederung, Klassifikation und Datierung der geometrischen und korinthischen Keramik orientieren sich an den grundlegenden Arbeiten von Vincent R. d'A. Desborough PGP, John N. Coldstream GGP, Cornelis W. Neeft PSA und Darrell A. Amyx CVP. Angaben von absoluten Jahreszahlen ergeben sich aus der zeitlichen Stellung innerhalb der einzelnen Stilphasen, denen die Vase zugeschrieben wird; diese können für die frühgriechische Geschichte bestenfalls Näherungswerte an

3 M. Kerschner - I. Kowalleck - M. Steskal, Archäologische Forschungen zur Siedlungsgeschichte von Ephesos in geometrischer, archaischer und klassischer Zeit. Grabungsbefunde und Keramikfunde aus dem Bereich von Koressos, ÖJh Ergh. 9 (Wien 2008) 26 Taf. 41-42.

4 V. Gassner, Materielle Kultur und kulturelle Identität in Elea in spätarchaischer-frühklassischer Zeit. Untersuchungen zur Gefäß- und Baukeramik aus der Unterstadt, Velia-Studien 2 (Wien 2003) 26. 
eine Wirklichkeit darstellen. Der geometrische Dekor wird nach dem von Norbert Kunisch verfassten Kompendium „Ornamente geometrischer Vasen“ (Köln I988) bezeichnet.

Die attische Keramik des 6. und 5. Jhs. v. Chr. ist durch zehn schwarzfigurige sowie I 8 rotfigurige und zwei weißgrundige Gefäße vertreten und wurde von Gerda Schwarz bearbeitet. Die Anordnung der Vasen folgt Beazley's Listen. Leider sind in der Sammlung nicht alle gängigen Formen vorhanden, besonders schmerzlich empfindet man das Fehlen großer Gefäße wie beispielsweise des Kraters. Am prominentesten vertreten ist der attisch-rotfigurige Stil und dieser mit einem echten Schmuckstück, einer Hydria des Berliner Malers (G 30). Sir John Beazley hat dieses Stück offenbar gesehen und zugeschrieben - die näheren Umstände bleiben im Dunkeln. Ebenso unklar ist, auf welchen Wegen die drei fragmentierten Schalen G I94, G I98 und G I97 nach Graz gelangten, die in ARV² 4I6,5; 809,I4; I 296,29 unter „Vienna, Univ.“ figurieren, wo Beazley sie offensichtlich kennengelernt hat. Es ist anzunehmen, dass die attisch-rotfigurigen Fragmente G I94 und G I96-200 durch Vermittlung Schobers von der Universität Wien nach Graz abgetreten wurden; in Form einer Schenkung, wie sie zwischen Universitätsinstituten und Museen durchaus üblich war. Dies muss noch vor I937 stattgefunden haben. Diese sechs außergewöhnlichen Stücke stammen ursprünglich wohl, wie dies G I97 nahelegt, aus dem großen Wiener Sammelposten aus „Orvieto“5.

Der Erhaltungszustand der beiden weißgrundigen Lekythen G 33 und G 34 hat sich seit der Abfassung des älteren Inventars $G$ bezüglich der figürlichen Darstellungen dramatisch verschlechtert. Damals konnte man an beiden Stücken noch Reste der Darstellung ausmachen. Ob das nahezu völlige Verschwinden der figürlichen Malerei mit einer einige Jahrzehnte zurückliegenden unsachgemäßen Reinigung der Gefäße zusammenhängt, vermag niemand mehr mit Sicherheit zu sagen. Tatsache ist, dass es für die Sammlung aus finanziellen Gründen nie einen verantwortlichen Betreuer gegeben hat und ihre Interessen immer nur „nebenbei“ wahrgenommen wurden.

Bei der Beschreibung und Interpretation figürlich dekorierter Feinkeramik wurde der Frage nach der Bedeutung der Bilder mehr Raum gewährt, als ihn etwa rein ornamental verzierte Stücke verlangen, weshalb manche Diskussion recht umfangreich ausgefallen ist. Malerzuschreibungen wurden, sofern bereits ausgesprochen, übernommen, andere korrigiert (G I) oder neu versucht. Leider gelang es nicht, bei allen nicht zugewiesenen Gefäßen einen Maler namhaft zu machen, was als Herausforderung für jene Vertreter der Archäologenzunft gelten kann, die sich trotz aller Kontroversen $^{6}$ der heute weitgehend akzeptierten Methode der Malerzuweisung verpflichtet fühlen. Ihre Vorschläge werden mit Spannung erwartet.

Der Beitrag von M. Christidis zu dem vorliegenden Band umfasst sechs attische Vasen der GlanztonWare (G 45-48 und G I95), eine siebte (G $5 \mathrm{I}$ ) wurde von G. Schwarz, der sie schon in dem eingangs erwähnten Führer anvertraut war, hinzugefügt. Außer dem wahrscheinlich aus Böotien stammenden Deckel G 107, der jedoch auf Grund schlüssiger Indizien nicht mit Sicherheit zugewiesen werden kann, gehört noch eine Lekythos aus Elis G 75 zum Beitrag von M. Christidis. Das Hauptkontingent stellen jedoch insgesamt I4 unteritalische Vasen dar (apulisch, kampanisch, sizilisch, lukanisch-apulisch). Alle sind nahezu zur Gänze und hervorragend erhalten. Vier rotfigurige Gefäße (G I I, G I 5-I 6 und G 25) konnten von Arthur D. Trendall und Alexander Cambitoglou bestimmten Malern und Werkstätten zugewiesen werden. Die Gliederung und Klassifikation der rotfigurigen Vasen wurden nach den Standardwerken von Trendall und Cambitoglou (RVAp I-II; RVAp Suppl. I-II; LCS; LCS Suppl. I-III; RVP) vorgenommen; für die Gnathia-Ware wurden die Arbeiten von Green, Bonn und Webster, Classification herangezogen.

Dem Restauratorenteam Robert Fürhacker und Anne-Kathrin Klatz konnten aus finanziellen Gründen nicht alle Stücke zur konservatorischen und restauratorischen Bearbeitung sowie Untersuchung der historischen Restaurierungen übergeben werden, doch leisteten sie etwa bei der Restaurierung der Hydria G 30, die stark übermalt ist, und der Amphora G 20, die auseinandergenommen und neu zusammengesetzt werden musste, einfühlsame und akribische Arbeit. Ebenfalls ermöglicht wurden die konservatorischen Arbeiten am Alabastron G 28, das nach Entfernen der Gipsergänzung einer dringend notwendigen Entsalzung unterzogen wurde, um ein weiteres Abblättern des craquellierten Malschlickers zu verhindern. Zwei der unteritalischen Gefäße wurden von den Restauratoren mittels Computertomografie ( $G_{2}$ ) und UV-Fluoreszenz ( $G_{25}$ ) untersucht, um historische Restaurierungen abzuklären; an der elischen Lekythos $\left(G_{75}\right)$ wurden die unsachgemäßen Klebungen ersetzt. Den genannten Restauratoren sei an dieser Stelle für ihren Einsatz herzlich gedankt. Leider reichten die außeruniversitären Finanzmittel nicht aus, alle Gefäße dieser umsichtigen restauratorischen bzw. konservatorischen Behandlung durch dieses Expertenteam zu unterziehen. Dass auch das zweite korinthische Alabastron $(G$ 27) diesem Team anvertraut und wie das genannte aus demselben Grabkontext stammende Alabastron G 28 restauratorisch bearbeitet werden konnte, ist Manfred

K. Patsch, Die Archäologische Sammlung der Wiener Universität, AA 1891, 178-182.

6 Vgl. B. Kreuzer, Warum heute noch Malerzuschreibungen? Das Beispiel Lydos, in: S. Schmidt - J. H. Oakley (Hrsg.), Hermeneutik der Bilder. Beiträge zu Ikonographie und Interpretation griechischer Vasenmalerei, CVA Deutschland Beih. 4 (München 2009) 143-152. 
Cassani aus München zu verdanken, der im Zuge einer Besichtigung der Originalsammlung des Instituts spontan die Restaurierungskosten dazu übernahm. Auch in Zukunft wird die Karl-Franzens-Universität Graz als Bewahrer von authentischen Zeugnissen aus der Antike gefordert sein, ihrer Verantwortung in der Pflege dieser archäologischen Sammlung mit Exponaten von zum Teil übergeordneter Bedeutung weiterhin entsprechend nachzukommen.

Den entsagungsvollen Part des Profilzeichnens übernahm Johanna Kraschitzer, die auch die Photovorlagen anfertigte und neben den allgemeinen Maßen auch sämtliche Volumens- und Gewichtsmessungen durchführte.

Die Farbbestimmung richtet sich nach dem Farbsystem der Munsell-Soil-Color-Charts (New York 2000). Die deutsche Farbbenennung soll die Lesbarkeit erleichtern.

Die Messung der Fassungsvolumina erfolgte grundsätzlich durch Einfüllen von leicht verfügbarem Material bis zur Maximalhöhe der Lippe eines Gefäßes unter Beachtung einer optimalen Ausfüllung des Hohlraumes; dafür wurde bei kleinen Gefäßen feiner Sand, bei mittelgroßen und großen Gefäßen Reis verwendet. Die Berechnung basiert auf der jeweiligen Rohdichte des verwendeten Materials; dafür wurden Bezugswerte für Io $\mathrm{ml}$ Sand und $50 \mathrm{ml}$ Reis erhoben. Die Messungen wurden pro Gefäß zweimal zur Absicherung wiederholt. Das Volumen wird gerundet auf ganze Zahlen in Milliliter angegeben. Einige Gefäße konnten aus verschiedenen Gründen nicht mit dieser einfachen Methode vermessen werden. So wurden die Volumina des Aryballos G 26 und des Granatapfelgefäßes G 56 aus den dreidimensionalen CT-Daten extrahiert ${ }^{7}$ und von zwei Gefäßen mit weiter Mündung (G 96, G 238) mit Hilfe des Programms „Calcul de capacité de récipients“ des Centre de Recherches en Archéologie et Patrimoine, Programm der Freien Universität Brüssel (http://lisaserver. ulb.ac.be/capacity/) aus den jeweiligen Profilzeichnungen ermittelt. Die große Amphora G I 6 konnte mit keiner der Methoden vermessen werden.

Das Gewicht wird unabhängig vom Erhaltungszustand - fragmentiert oder vollständig - bei jedem Objekt angegeben, unter der Bedingung, dass es keine Ergänzungen oder sonstige die Keramikmasse beeinflussende Faktoren wie starke Sinterschichten oder andere Ablagerungen aufweist. Rezente Übermalungen fallen nicht darunter, da sich diese kaum auf das Gesamtgewicht auswirken sollten. Bei dieser soweit regelmäßigen Gewichtsangabe geht es weniger darum, eine Vergleichbarkeit von Gefäßtypen untereinander zu erlauben, sondern um eine standardisierte Angabe einer Objekteigenschaft, wie dies ähnlich zu den Längenmaßen gilt. Die Objekte wurden bei ähnlichen klimatischen Verhältnissen, wie sie im archäologischen Museum vorherrschen, gewogen (Temperatur etwa I9-2I ${ }^{\circ} \mathrm{C}$ und Luftfeuchtigkeit etwa 45-55\%). Die Messungen wurden pro Gefäß einmal zur Absicherung wiederholt. Bei Gefäßen, die aus Fragmenten zusammengesetzt sind und bei denen vorauszusehen ist, dass der Kleber das Gewicht geringfügig erhöht, erfolgt die Angabe in eckiger Klammer. Das Gewicht wird auf ganze Zahlen gerundet in Gramm angegeben.

In der Erstellung des Layouts war Johanna Kraschitzer der Beilagenteil anvertraut, während Maria Christidis für den Tafelteil verantwortlich zeichnet. Beiden Kolleginnen sei für ihr Engagement, mit dem sie das Fortschreiten der Arbeit begleiteten und unterstützten, aufrichtig gedankt. Von den Mitarbeitern am Institut seien Elisabeth Trinkl und Manfred Lehner für stets gerne und reichlich gewährte Hilfeleistung bedankt. In diesen Dank sind außer den im Text eigens genannten Kollegen noch Heinrike Dourdoumas, Anastasia Georgiadou, Giada Giudice, Victoria Sabetai, Andrea Schidlowski und Lauren L. Walker einzuschließen.

Der vorliegende Band entstand als Kooperation zwischen der Österreichischen Akademie der Wissenschaften und dem Institut für Archäologie der Karl-Franzens-Universität Graz. Seitens der ÖAW betreute Claudia Lang-Auinger als Koordinatorin des CVA-Projektes Österreich sehr einfühlsam und gewissenhaft das Werden des Bandes. Viele wertvolle Hinweise werden ihr verdankt, ebenso Hadwiga Schörner, die sich mit Claudia Lang-Auinger die schwierige Aufgabe des Korrekturlesens teilte.

Trotz aller Helfer wäre der Band ohne die nötige Finanzierung nicht zustande gekommen. Teilweise konnte die Bearbeitung der Keramik, aber auch die notwendigste Restaurierung durch Finanzierungsbeiträge der Stadt Graz, Kulturamt (Subvention für das Projekt „Universitätsmuseum“) und des Landes Steiermark, Abteilung 3 - Wissenschaft und Forschung (Subvention CVA) verwirklicht werden. Dem FWF - Wissenschaftsfonds ist für die Gewährung eines Druckkostenzuschusses zu danken. Und immer wieder gelang es Peter Scherrer, Leiter des Instituts für Archäologie und Vizerektor für Forschung und Nachwuchsförderung an der Karl-Franzens-Universität Graz, universitätsinterne Geldmittel flüssig zu machen, um so das Projekt zum Abschluss zu bringen. Ihm ist für seinen Einsatz, sein stetes Interesse und seinen Zuspruch ganz besonders zu danken.

Graz, am 4. Februar 20I4 Maria Christidis, Stephan Karl, Gabriele Koiner, Gerda Schwarz

\footnotetext{
S. Karl - D. Jungblut - J. Rosc, Berührungsfreie und nicht invasive Untersuchung antiker Keramik mittels industrieller Röntgen-Computertomografie, mit einem Beitrag von R. Erlach, in: E. Trinkl (Hrsg.), Interdisziplinäre Dokumentations- und Visualisierungsmethoden, CVA Österreich, Beih. 1 (Wien 2013) 99-101.
} 


\section{ABGEKÜRZT ZITIERTE LITERATUR}

Zitierweise und Abkürzungen entsprechen den Empfehlungen des Deutschen Archäologischen Instituts, wie sie im Archäologischen Anzeiger 2005, 309-399 gedruckt und im Internet unter http:// www.dainst.org/index_I4I_de.html veröffentlicht sind. Ergänzend zu diesen Richtlinien gelten folgende Abkürzungen:

ABL

ABV

$\operatorname{Add}^{2}$

Agora VIII

Agora XII

Agora XXIII

Agora XXX

Alexandropoulou, Gnathia

Amyx, CVP

Art of Ancient Cyprus Boston

$\mathrm{ARV}^{2}$

Bakır, Kolonettenkrater

BAPD

Benson, ECW

Bernardini, Lecce

Boardman, ABFV

Boardman, ARFV I

Boardman, ARFV II

Boardman, RFVA I
C. H. E. Haspels, Attic Black-Figured Lekythoi (Paris I936).

J. D. Beazley, Attic Black-Figure Vase-Painters (Oxford I956).

Th. H. Carpenter - T. Mannack - A. Mendonca, Beazley Addenda. Additional References to ABV, $\mathrm{ARV}^{2}$ and Paralipomena ${ }^{2}$ (Oxford I989).

E. T. H. Brann, Late Geometric and Protoattic Pottery, The Athenian Agora VIII (Princeton I962).

B. A. Sparkes - L. Talcott, Black and Plain Pottery of the 6th, $5^{\text {th }}$ and 4 th C. B. C., The Athenian Agora XII (Princeton I970).

M. B. Moore - M. Z. Philippides, Attic Black-Figured Pottery, The Athenian Agora XXIII (Princeton 1986).

M. B. Moore, Attic Red-Figured and White-Ground Pottery, The Athenian Agora XXX (Princeton I979).

A. Alexandropoulou, Gnathia- und Westabhangkeramik: eine vergleichende Betrachtung (Paderborn 2002).

D. A. Amyx, Corinthian Vase-Painting of the Archaic Period (Berkeley I988).

Art of Ancient Cyprus, Museum of Fine Arts, Boston (Boston I972).

J. D. Beazley, Attic Red-figure Vase-Painters ${ }^{2}$ (Oxford I963).

T. Bakır, Der Kolonettenkrater in Korinth und Attika zwischen 625 und 550 v. Chr., Beiträge zur Archäologie 7 (Würzburg I974).

Beazley Archive Pottery Database No.

J. L. Benson, Earlier Corinthian Workshops. A Study of Corinthian Geometric and Protocorinthian Stylistic Groups, Allard Pierson Series, Scripta Minora I (Amsterdam I989).

M. Bernardini, Museo Provinciale "S. Castromediano" Lecce: Vasi dello Stile di Gnathia. Vasi a vernice nera (Bari I96I).

J. Boardman, Athenian Black Figure Vases (London I974).

J. Boardman, Athenian Red Figure Vases I: The Archaic Period (London I975).

J. Boardman, Athenian Red Figure Vases II: The Classical Period (London I989).

J. Boardman, Rotfigurige Vasen aus Athen I: Die archaische Zeit (Mainz I98I). 
Boardman, RFVA II

Boardman, SFVA

Bouzek, Prag

Braun - Haevernick, Kabirenheiligtum

Brommer, Theseus

Brouskari, Kerameikos

Buitron-Oliver, Douris

Burow, Attisch schwarzfigurige J. Burow, Attisch schwarzfigurige Keramik, in: Archaische

Keramik

Keramik aus Olympia, OF 28 (Berlin/New York 2000) 203-3 I 6.

La cité des images

Coldstream, GGP

Coldstream, KNC

Cook, EGP

Cook, Protoattic

Corinth VII I

Corinth VII 2

Corinth VII 5

Corinth XIII

Corinth XV 3

Courbin, CGA

Davison, Workshops

J. Boardman, Rotfigurige Vasen aus Athen II: Die klassische Zeit (Mainz I99I).

J. Boardman, Schwarzfigurige Vasen aus Athen (Mainz I977).

J. Bouzek, Die attisch-geometrische Keramik im Nationalmuseum in Prag und in den anderen tschechoslowakischen Sammlungen, Sborník Národního Musea v Praze, Serie A, I3, I959, 97-I3 8.

K. Braun - Th. E. Haevernick, Bemalte Keramik und Glas aus dem Kabirenheiligtum bei Theben, Das Kabirenheiligtum bei Theben 4 (Berlin I98I).

F. Brommer, Theseus. Die Taten des griechischen Helden in der antiken Kunst und Literatur (Darmstadt I982).

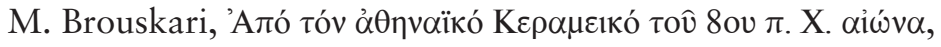
ADelt Suppl. 27 (Athen I979).

D. Buitron-Oliver, Douris. A Master-Painter of Athenian RedFigure Vases, Kerameus 9 (Mainz I995).

C. Bérard - J.-P. Vernant (Hrsg.), La cité des images, Religion et Societé en Grèce Antique (Lausanne 1984).

J. N. Coldstream, Greek Geometric Pottery. A Survey of Ten Local Styles and Their Chronology, Updated Second Edition (Exeter 2008).

J. N. Coldstream, The Protogeometric and Geometric Pottery, in: J. N. Coldstream - H. W. Catling (Hrsg.), Knossos North Cemetery. Early Greek Tombs, BSA Suppl. 28 (London I996) I9-420.

R. M. Cook, in: R. M. Cook - P. Dupont, East Greek Pottery (London/New York I998) I-I4I.

J. M. Cook, Protoattic Pottery, BSA 35, I934/I935, I65-219.

S. S. Weinberg, The Geometric and Orientalizing Pottery, Corinth VII I (Cambridge I943).

D. A. Amyx - P. Lawrence, Archaic Corinthian Pottery from the Anaploga Well, Corinth VII 2 (Princeton I975).

M. K. Risser, Corinthian Conventionalizing Pottery, Corinth VII 5 (Princeton 200I).

C. W. Blegen - H. Palmer - R. S. Young, The North Cemetery, Corinth XIII (Princeton I964).

A. N. Stillwell - J. L. Benson, The Potters' Quarter. The Pottery, Corinth XV 3 (Princeton I984).

P. Courbin, La Céramique Géometrique de l'Argolide, Bibliothèque des Écoles Françaises d'Athènes et de Rome 208 (Paris I966).

J. M. Davison, Attic Geometric Workshops, Yale Classical Studies I6 (Rom I96I).

Dehl-von Kaenel, Malophoros C. Dehl-von Kaenel, Die archaische Keramik aus dem Malophoros-Heiligtum in Selinunt. Die korinthischen, lakonischen, ostgriechischen, etruskischen und megarischen Importe sowie die ,argivisch-monochrome' und lokale Keramik aus den alten Grabungen (Berlin I995). 
Desborough, PGP

Dikaios, Enkomi

Ducat, Vases plastiques

Essenwein, Katalog

Forti, Gnathia

FR

Frankel, Ashmolean Museum

Frankel - Webb, Deneia

Frankel - Webb,

Marki Alonia

Frankel - Webb,

Karmi Palealona

Georgiadou, Totenkult

Gjerstad, Studies

Green, Bonn

Hayes, Ontario

Higgins, Terracottas

Hoffmann, Grabritual

Hurschmann - Hoffmann Knoll, Skulpturensammlung

Kahane, Entwicklungsphasen

Karageorghis, Athens

Karageorghis, Cesnola Collection

Karageorghis, Copenhagen
V. R. d'A. Desborough, Protogeometric Pottery (Oxford I952).

P. Dikaios, Enkomi. Excavations I948-I958 (Mainz I969).

J. Ducat, Les vases plastiques rhodiens archaïques en terre cuite, BEFAR 209 (Paris I966).

A. Essenwein, Katalog der vom steiermärkischen Vereine zur Förderung der Kunstindustrie veranstalteten ersten Ausstellung kunstgewerblicher Erzeugnisse älterer und neuerer Zeit (Graz I 865).

L. Forti, La ceramica di Gnathia (Neapel I96I).

A. Furtwängler - K. Reichhold - F. Hauser - E. Buschor - C. Watzinger - R. Zahn, Griechische Vasenmalerei (München I904I932).

D. Frankel, Early and Middle Bronze Age Material in the Ashmolean Museum, Oxford, SIMA XX 7 (Göteborg I983).

D. Frankel - J. Webb, The Bronze Age Cemeteries at Deneia in Cyprus, SIMA CXXXV (Sävedalen 2007).

D. Frankel - J. Webb, Marki Alonia. An Early and Middle Bronze Age Settlement in Cyprus. Excavations I995-2000, SIMA CXXIII 2 (Jonsered 2006).

D. Frankel - J. Webb, The Bronze Age Cemeteries at Karmi Palealona and Lapatsa in Cyprus. Excavations by J. R. B. Stewart, SIMA CXXXVI (Sävedalen 2009).

A. Georgiadou, Totenkult und elische Grabkeramik spätklassischer und hellenistischer Zeit (Thessaloniki 2005).

E. Gjerstad, Studies on Prehistoric Cyprus (Uppsala I926).

J. R. Green, Gnathia Pottery in the Akademisches Kunstmuseum Bonn (Mainz I976).

J. W. Hayes, Greek and Italian Black-Gloss Wares and Related Wares in the Royal Ontario Museum. A Catalogue (Toronto I984).

R. A. Higgins, Catalogue of the Terracottas in the Department of Greek and Roman Antiquities, British Museum II (London I959).

A. Hoffmann, Grabritual und Gesellschaft: Gefäßformen, Bildthemen und Funktionen unteritalisch-rotfiguriger Keramik aus der Nekropole von Tarent, Internationale Archäologie 76 (Rahden 2002).

R. Hurschmann - A. Hoffmann - K. Knoll, Die Lebenden und die Seligen. Unteritalisch-rotfigurige Vasen der Dresdener Skulpturensammlung (Mainz 2003).

P. Kahane, Die Entwicklungsphasen der attisch-geometrischen Keramik, AJA 44, I940, 464-482.

V. Karageorghis, Ancient Cypriote Art in the National Archaeological Museum of Athens (Athen 2003).

V. Karageorghis, Ancient Art from Cyprus. The Cesnola Collection in the Metropolitan Museum of Art (New York 2000).

V. Karageorghis, Ancient Cypriote Art in Copenhagen. The Collections of the National Museum of Denmark and the $\mathrm{Ny}$ Carlsberg Glyptotek (Nicosia 200I). 
Karageorghis,

Medelhavsmuseet

Karageorghis - Olenik, Eretz Israel Museum

Karageorghis, Pierides Stiftung

Karageorghis - Vassilika Wilson, Fitzwilliam Museum

Karl, Knabl

Karl, Richard Knabl

Kerameikos I

Kerameikos IV

Kerameikos V I

Kerameikos VI 2

Kerameikos VII 2

Kerameikos IX

Kerameikos XIII

Kraiker, Aigina

Krug, Binden

Kunst der Schale

Kunze, Disiecta Membra

Kurtz, AWL

Lambrugo, Gela

Lanza, Torino

Lanza-Catti, Puglia
V. Karageorghis, The Cyprus Collection in the Medelhavsmuseet (Nicosia 2003).

V. Karageorghis - Y. Olenik, The Potter's Art of Ancient Cyprus in the Collection of the Eretz Israel Museum Tel Aviv (Tel Aviv I997).

V. Karageorghis, L'Art Chypriote antique au Musée de la Fondation Piéridès, Antike Kunst auf Zypern im Museum der Pierides-Stiftung (Larnaca I985).

V. Karageorghis - E. Vassilika - P. Wilson, The Art of Ancient Cyprus in the Fitzwilliam Museum, Cambridge (Cambridge I999).

S. Karl, Die apulischen Gefäße des Vorstadtpfarrers zu St. Andrä in Graz, Richard Knabl, in: G. Koiner - M. Lehner - Th. Lorenz G. Schwarz (Hrsg.), Akten des Iо. Österreichischen Archäologentages Graz 2003, VIKAGraz 6 (Wien 2006) 8I-87.

S. Karl, in: G. Wrolli, Richard Knabl (I 789-I 874) - ein steirischer Priester und Altertumswissenschaftler des I9. Jahrhunderts, Zeitschrift des historischen Vereins für Steiermark 96, 2005, 297-308.

W. Kraiker - K. Kübler, Die Nekropolen des I 2. bis Iо. Jahrhunderts, Kerameikos I (Berlin I939).

K. Kübler, Neufunde aus der Nekropole des I I. und Io. Jahrhunderts, Kerameikos IV (Berlin I943).

K. Kübler, Die Nekropole des Io. bis 8. Jahrhunderts, Kerameikos V I (Berlin I954).

K. Kübler, Die Nekropole des späten 8. bis frühen 6. Jahrhunderts, Kerameikos VI 2 (Berlin I970).

E. Kunze-Götte - K. Tancke - K. Vierneisel, Die Nekropole von der Mitte des 6. bis zum Ende des 5. Jahrhunderts. Die Beigaben, Kerameikos VII 2 (München I999).

U. Knigge, Der Südhügel, Kerameikos IX (Berlin I976).

B. Bohen, Die geometrischen Pyxiden. Mit einem Beitrag von N. Schlager, Kerameikos XIII (Berlin I988).

W. Kraiker, Aigina. Die Vasen des Io. bis 7. Jahrhunderts v. Chr. (Berlin I95I).

A. Krug, Binden in der griechischen Kunst. Untersuchungen zur Typologie (6.-I. Jh. v. Chr.) (Mainz I968).

K. Vierneisel - B. Kaeser (Hrsg.), Kunst der Schale, Kultur des Trinkens (München I990).

E. Kunze, Disiecta Membra attischer Grabkratere, AEphem I953/I954, I62-I7I.

D. C. Kurtz, Athenian White Lekythoi. Patterns and Painters (Oxford I975).

C. Lambrugo, Profumi di argilla. Tombe con unguentari corinzi nella necropoli arcaica di Gela, Studia Archaeologica I 85 (Rom 2013).

E. Lanza, Ceramica di Gnathia al Museo di Antichità di Torino (Mantova 2005).

E. Lanza-Catti, La ceramica di "Gnathia” al Museo Nazionale Jatta di Ruvo di Puglia: ipotesi di ricontestualizzazione, Antenor Quaderni I I (Rom 2008). 
Langdon,

From Pasture to Polis

LCS

LCS Suppl. I

LCS Suppl. II

LCS Suppl. III

Lefkandi I

Lefkandi III

Lehner - Lorenz - Schwarz, Vasen

Lehner, Originalsammlung

Lemos,

Protogeometric Aegean

Lissarrague, Frauen

Lohmann, Grabmäler

Lo Porto, Timmari

Lo Porto, Torino

Lord Smithson, Areopag

Lubsen-Admiraal, Zintilis Collection

Mayo - Hamma, Magna Graecia

Mee - Steel, Liverpool

Meligunìs - Lipára II
S. Langdon (Hrsg.), From Pasture to Polis. Art in the Age of Homer, Museum of Art and Archaeology, University of Missouri in Columbia, Ausstellungskatalog (Columbia I993).

A. D. Trendall, The Red-Figured Vases of Lucania, Campania and Sicily (Oxford I967).

A. D. Trendall, The Red-Figured Vases of Lucania, Campania and Sicily, First Supplement, BICS Suppl. 26 (London I970).

A. D. Trendall, The Red-Figured Vases of Lucania, Campania and Sicily, Second Supplement, BICS Suppl. 3I (London I973).

A. D. Trendall, The Red-Figured Vases of Lucania, Campania and Sicily, Third Supplement, BICS Suppl. 4I (London I983).

M. R. Popham - L. H. Sackett - P. G. Themelis (Hrsg.), The Iron Age, Text/Plates, Lefkandi I (Oxford I979/ı980).

M. R. Popham - I. S. Lemos (Hrsg.), The Toumba Cemetery, Plates, Lefkandi III (Oxford I996).

M. Lehner - T. Lorenz - G. Schwarz, Griechische und italische Vasen aus der Originalsammlung des Instituts für Klassische Archäologie der Karl-Franzens-Universität Graz, VIKAGraz I (Graz 1993).

M. Lehner, Zur Originalsammlung des Archäologischen Museums der Universität Graz, in: G. Erath - M. Lehner - G. Schwarz (Hrsg.), Komos, Festschrift für Thuri Lorenz zum 65. Geburtstag (Wien I997) 279-285.

I. S. Lemos, The Protogeometric Aegean. The Archaeology of the Late Eleventh and Tenth Centuries BC, Oxford Monographs on Classical Archaeology (Oxford 2002).

F. Lissarrague, Frauen, Kästchen, Gefäße. Einige Zeichen und Metaphern, in: E. D. Reeder (Hrsg.), Pandora. Frauen im klassischen Griechenland (Mainz I995) 9I-IOI.

H. Lohmann, Grabmäler auf unteritalischen Vasen (Berlin I979).

F. G. Lo Porto, Timmari. L'abitato, le necropoli, la stipe votiva, Archaeologica 98 (Rom I99I).

F. G. Lo Porto, La Collezione Cipriota del Museo di Antichità di Torino (Rom I986).

E. Lord Smithson, A Geometric Cemetery on the Areopagus: I 897, I932, I947, with Appendices on the Geometric Graves found in the Dörpfeld Excavations on the Acropolis West Slope in I 895 and on Hadrian Street („Phinopoulos' Lot“) in I 898, Hesperia 43, I974, 325-390.

S. M. Lubsen-Admiraal, Ancient Cypriote Art. The Thanos N. Zintilis Collection (Athen 2004).

M. E. Mayo - K. Hamma (Hrsg.), The Art of South Italy. Vases from Magna Graecia, Catalogue of Exhibition, Richmond, Virginia Museum of Fine Arts (Richmond I982).

C. Mee - L. Steel, The Cypriote Collections in the University of Liverpool and the Williamson Art Gallery and Museum, SIMA XX I7 (Jonsered I998).

L. Bernabò-Brea - M. Cavalier (Hrsg.), Meligunìs - Lipára II. La necropoli greca e romana nelle Contrada Diana (Palermo I965). 
Merrillees, Opium Trade

Morel, Céramique
R. S. Merrillees, Opium Trade in the Bronze Age Levant, Antiquity 36, 1962, 287-292; Neuauflage in: On Opium, Pots, People and Places. Selected Papers. An Honorary Volume for Robert S. Merrillees (Sävedalen 2003) 2-9.

J.-P. Morel, Céramique campanienne. Les formes, BEFAR 244 (Rom I98I).

Morris, Black and White Style S. P. Morris, The Black and White Style. Athens and Aigina in the Orientalizing Period, Yale Classical Monographs 6 (New Haven I984).

Mylonas, Eleusis

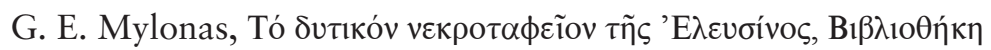

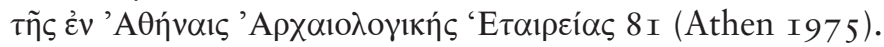

Myres, Handbook

J. L. Myres, Handbook of the Cesnola Collection of Antiquities from Cyprus, The Metropolitan Museum of Art (New York I9I4, Reprint I974).

Neeft, Addenda

C. W. Neeft, Addenda et Corrigenda to D. A. Amyx, Corinthian Vase-Painting in the Archaic Period, Allard Pierson Series, Scripta Minora 3 (Amsterdam I99I).

Neeft, PSA

C. W. Neeft, Protocorinthian Subgeometric Aryballoi, Allard Pierson Series 7 (Amsterdam I987).

Nielsen - Sørensen, Odense University

Nys - Recke, Kult-Tisch

Pandora

Para

Payne, NC

Richter - Milne, Shapes

Robertson, Vase-Painting

Rocco, Protoattica

Rombos, Iconography

RVAp I

RVAp II

RVAp Suppl. I

RVAp Suppl. II
A. M. Nielsen - L. W. Sørensen, The Vase Collection in the Odense University, SIMA XX 22 (Jonsered 200I).

K. Nys - M. Recke, Kult-Tisch. Kyprische Keramik im Kontext, Eine Ausstellung in der Antikensammlung der Justus-LiebigUniversität Gießen I6. Januar-I2. April 20I0, Akamas 5 (Gießen 20I0).

E. D. Reeder (Hrsg.), Pandora. Frauen im klassischen Griechenland (Mainz I995).

J. D. Beazley, Paralipomena. Additions to Attic Black-Figure Vase-Painters and to Attic Red-Figure Vase-Painters (Oxford I97I).

H. Payne, Necrocorinthia. A Study of Corinthian Art in the Archaic Period (Oxford I93I).

G. M. A. Richter - M. J. Milne, Shapes and Names of Athenian Vases (New York I935).

M. Robertson, The Art of Vase-Painting in Classical Athens (Cambridge 1992).

G. Rocco, La ceramografia protoattica. Pittori e botteghe (7IO630 a. C.), Internationale Archäologie I I I (Rahden 2008).

T. Rombos, The Iconography of Attic Late Geometric II Pottery, Studies in Mediterranean Archaeology and Literature 68 (Jonsered I988).

A. D. Trendall - A. Cambitoglou, The Red-Figured Vases of Apulia I (Oxford I978).

A. D. Trendall - A. Cambitoglou, The Red-Figured Vases of Apulia II (Oxford I982).

A. D. Trendall - A. Cambitoglou, First Supplement to the RedFigured Vases of Apulia, BICS Suppl. 42 (London I983).

A. D. Trendall - A. Cambitoglou, Second Supplement to the RedFigured Vases of Apulia, BICS Suppl. 60 (London I99I-I992).

A. D. Trendall, The Red-Figured Vases of Paestum, British School at Rome (Hertford I987). 
Sabetai, Vases

SCE I

SCE IV IA

SCE IV IB

SCE IV IC

Schauenburg, Studien I-IX/X

Schefold, SB II

Schefold, SB III

Schefold - Jung, SB IV

Schilardi, Polyandrion I-III

Schürmann, Karlsruhe

Schwarz, Komostänzer

Servadei, Theseus

South - Russell - Schuster Keswani, Vasilikos Valley Project

Souyoudzoglou-Haywood, Dublin

Splitter, Vasenbilder

Sport dans la Grèce antique

Thomsen, Wirkung

TonArt
V. Sabetai, Small Vases, Small Monuments II: The Red-Figured Lekythoi from the Benaki Museum Collection, Mouseio Benaki 8, 2008, 63-89.

E. Gjerstad - J. Lindros - E. Sjöqvist - A. Westholm, Finds and Results from the Excavations in Cyprus I927-I93 I, The Swedish Cyprus Expedition I (Stockholm I934).

P. Dikaios - J. R. Stewart, The Stone Age and the Early Bronze Age in Cyprus, The Swedish Cyprus Expedition IV IA (Lund I962).

P. Åström, The Middle Cypriote Bronze Age, The Swedish Cyprus Expedition IV IB (Lund I972).

P. Åström, The Late Cypriote Bronze Age. Architecture and Pottery, with a Contribution by M. R. Popham, The Swedish Cyprus Expedition IV IC (Lund I972).

K. Schauenburg, Studien zur unteritalischen Vasenmalerei I (Kiel I 999); II (Kiel 2000); III (Kiel 200I); IV/V (Kiel 2002); VI (Kiel 2003); VII/VIII (Kiel 2005); IX/X (Kiel 2006).

K. Schefold, Die Götter- und Heldensagen der Griechen in der spätarchaischen Kunst (München I978).

K. Schefold, Die Götter- und Heldensagen der Griechen in der klassischen und hellenistischen Kunst (München I98I).

K. Schefold - F. Jung, Die Urkönige, Perseus, Bellerophon, Herakles und Theseus in der klassischen und hellenistischen Kunst (München I988).

D. Schilardi, The Thespian Polyandrion $(424$ B. C.): The Excavations and Finds from a Thespian State Burial Bd. I: Text, Bd. II: Catalogue, Bd. III: Tafeln (Princeton I977).

W. Schürmann, Katalog der kyprischen Antiken im Badischen Landesmuseum Karlsruhe, SIMA XX 9 (Göteborg I984).

G. Schwarz, Komostänzer in Graz. Eine archäologische Spurensuche, in: G. Erath - M. Lehner - G. Schwarz (Hrsg.), Komos, Festschrift für Th. Lorenz zum 65. Geburtstag (Wien I997) I 25-I 28.

C. Servadei, La figura di Theseus nella ceramica Attica. Iconografia e Iconologia del mito nell'Atene arcaica e classica (Bologna 2005).

A. South - P. Russell - P. Schuster Keswani, Vasilikos Valley Project 3. Kalavassos - Ayios Dhimitrios II. Ceramics, Objects, Tombs, Specialist Studies, SIMA LXXI 3 (Göteborg I989).

C. Souyoudzoglou-Haywood, Cypriot Antiquities in Dublin. The Collections of the National Museum of Ireland and the University College Dublin (Nicosia 2004).

R. Splitter, Vollendetes Leben. Vasenbilder aus Apulien (Kassel 2006).

D. Vanhove (Hrsg.), Le Sport dans la Grèce antique. Du Jeu à la compétition (Brüssel I992).

A. Thomsen, Die Wirkung der Götter. Bilder mit Flügelfiguren auf griechischen Vasen des 6. und 5. Jahrhunderts v. Chr. Image \& Context 9 (Berlin/Boston 20II).

M. Bentz - W. Geominy - J. M. Müller (Hrsg.), TonArt. Virtuosität antiker Töpfertechnik (Petersberg 20I0). 
Trendall, RFVSIS

Ure, Rhitsona

Ure, Black Glaze Pottery

Vagnetti u. a., Collezioni cipriote

Villa, Stanford University $\mathrm{Mu}-$ seum

Walker, Floral Ware

Walters, Catalogue

Webb, Nicholson Museum

Webster, Classification

Wehgartner, AWK

Winbladh, Cypern

Wolters - Bruns, Kabirenheiligtum

Xagorari-Gleißner, Merenda

Young, Graves

Young, Phaleron
A. D. Trendall, Red Figure Vases of South Italy and Sicily. A Handbook (London I989).

P. N. Ure, Sixth and Fifth Century Pottery from Excavations Made at Rhitsona by R. M. Burrows in 1909 and by P. N. Ure and A. D. Ure in I92I and 1922 (Oxford I927).

P. N. Ure, Black Glaze Pottery from Rhitsona (Oxford I9I3).

. Vagnetti - V. Karageorghis - M. Bettelli - S. di Paolo, Collezioni archeologiche cipriote in Italia I (Rom 2004).

P. Villa, Early and Middle Bronze Age Pottery of the Cesnola Collection in the Stanford University Museum, SIMA XX I (Lund I969).

L. L. Walker, Boiotian Black Figure Floral Ware: a Re-Analysis of the Southern Style. With an Introduction to Floral Groups from Haliartos (Montreal 2004).

B. Walters, Catalogue of the Greek and Etruscan Vases in the British Museum I 2: Cypriote, Italian, and Etruscan Pottery (London I9I2).

J. M. Webb, Cypriote Antiquities in the Nicholson Museum at the University of Sydney, SIMA XX 20 (Jonsered 200I).

T. B. L. Webster, Towards a Classification of Apulian Gnathia, BICS I 5 , I968, I-33.

I. Wehgartner, Attisch weißgrundige Keramik. Maltechniken, Werkstätten, Formen, Verwendung, Keramikforschungen 5 (Mainz I983).

M.-L. Winbladh, Cypern. Möte mellan kulturer. Om Cyperns arkeologi och Cypernsamlingarna i Medelhavsmuseet, Medelhavsmuseet Skrifter I 8 (Stockholm I992).

P. Wolters - G. Bruns, Das Kabirenheiligtum bei Theben I (Berlin I940).

M. Xagorari-Gleißner, Die geometrische Nekropole von Merenda. Die Funde aus der Grabung von I. Papadimitriou I960-6I, Würzburger Studien zur Sprache \& Kultur 7 (Dettelbach 2005).

R. S. Young, Late Geometric Graves and a Seventh Century Well in the Agora, Hesperia Suppl. 2 (Princeton I939).

R. S. Young, Graves from the Phaleron Cemetery, AJA 46, I942, $23-57$. 


\section{CHRONOLOGIE}

$\begin{array}{ll}\text { FZ } & \text { Frühzyprisch } \\ \text { MZ } & \text { Mittelzyprisch } \\ \text { SZ } & \text { Spätzyprisch } \\ \text { SPG } & \text { Spätprotogeometrisch } \\ \text { FG } & \text { Frühgeometrisch } \\ \text { MG } & \text { Mittelgeometrisch } \\ \text { SG } & \text { Spätgeometrisch } \\ \text { SubG } & \text { Subgeometrisch } \\ \text { FPK } & \text { Frühprotokorinthisch } \\ \text { MPK } & \text { Mittelprotokorinthisch } \\ \text { SPK } & \text { Spätprotokorinthisch } \\ \text { TR } & \text { Übergangsstil (Transitional) } \\ \text { FK } & \text { Frühkorinthisch } \\ \text { MK } & \text { Mittelkorinthisch } \\ \text { SK } & \text { Spätkorinthisch } \\ \text { FPA } & \text { Frühprotoattisch } \\ \text { MPA } & \text { Mittelprotoattisch } \\ \text { OA } & \text { Ostgriechisch archaisch }\end{array}$

\section{WAREN}

$\begin{array}{ll}\text { BR } & \text { Base-ring Ware } \\ \text { RP } & \text { Red Polished Ware } \\ \text { RPBT } & \text { Red Polished Black-topped Ware } \\ \text { WP } & \text { White Painted Ware } \\ \text { WS } & \text { White Slip Ware }\end{array}$




\section{ZYPRISCH BRONZEZEITLICH}

\section{TAFEL 1}

\section{1-4. Halbkugelige Schale mit Schnuröse}

Beilage 1, 1.

G 21 2. Aus „Cypern“. Erworben I940.

H 9,9 cm. - Dm Rand I 4,6 cm. - Dm max. I 5,9 cm. - Gewicht 465 g. - Volumen I050 $\mathrm{ml}$.

Unpubliziert.

Zustand: Das Gefäß ist ungebrochen, an der Lippe sind geringe Abschlagungen festzustellen. Ein Sinterfleck zieht sich neben der Schnuröse an der Innen- und Außenseite von der Lippe abwärts auf den Gefäßkörper. Unterhalb des Sinterflecks sind bis fast zum Gefäßboden, etwa ein Viertel des Gefäßes umfassend, rotbraune, rezent aufgebrachte Malspuren sichtbar, die vielleicht eine Fehlstelle der Oberfläche nach Entfernen von Sinter zudecken sollten. An der Außenseite sind Wurzelspuren zu sehen.

Technik: Das Gefäß ist handgeformt. Die Oberfläche ist an der Außenseite glänzend rotbraun mit rötlichen Flecken $(5$ YR $5 / 8$, yellowish red; 7.5 YR 5/6-8, strong brown), an der Außenseite der Lippe und an der Innenseite glänzend schwarz poliert (RPBT; 7.5 YR 2.5/I, black). Der Scherben ist grau (7.5 YR 4/I, dark gray).

Form: Halbkugelige Schale mit rundem Boden und nach innen geneigtem Mündungsrand. An der Mündung befindet sich eine Knubbe mit einer horizontal gebohrten Schnuröse.

Red Polished II-III Black-topped Ware, Frühzyprisch II-Mittelzyprisch II, 2075-I725

Zur Technik: Zur helleren Farbe des Scherbens im Vergleich mit anderen RP-Waren und der Verwendung bestimmter Tone: Frankel - Webb, Deneia, 58 f.; Frankel - Webb, Marki Alonia, I I I. Zur Feinheit der Textur des Scherbens mit nur wenigen kleinen schwarzen oder weißen Einschlüssen, seinem weichen oder mittelweichen Brand, seiner geringeren Robustheit verglichen mit monochromen RP-Schalen: Frankel - Webb, Marki Alonia, I I I. Zum hohen Oberflächenglanz: Frankel - Webb, Marki Alonia, I I . Zum hauptsächlichen Vorkommen von hochpolierten Gefäßen in Nordzypern: SCE IV IA, 227.

Zur Form: SCE IV IA, 333 Typ XIII F² a Abb. CXXXIX 2. 4. 6-7. IO-I2. I4-I6. I9.

Zur Größenclusterung mit Randdurchmesser I2, I 4 und I 6 cm: Frankel - Webb, Marki Alonia, I I I. Die Schalen mit Randdurchmesser von ca. I $6 \mathrm{~cm}$ sind größer als Black Polished Schalen oder andere RP-Schalen und weisen eine größere Wandstärke auf: Frankel - Webb, Deneia, 58 f.; Frankel - Webb, Marki Alonia, I I I.

Weitere Vergleiche: Frankel - Webb, Deneia, 58 f. Text Abb. 4.4 I; Frankel - Webb, Karmi Palealona, I46 Nr. I7 Abb. 3.Io I Taf. 4 k; Frankel - Webb, Marki Alonia, I I I Textabb. 4.27 Abb. 4.20 Taf. 43; Lubsen-Admiraal, Zintilis Collection, 7 I Kat. 95 (Z. 234). 96 (Z. 45 A, Kat. 96 aus Sotira; beide RP II/III, FZ III-MZ I); Karageorghis - Vassilika - Wilson, Fitzwilliam Museum, 9 Kat. I3-I 4 (GR.4a.I892; GR.2a.I 892, RP II BT, Tamassos); Karageorghis, Copenhagen, 8. I 3 Kat. I 4 (I 5525 , RP II BT); Nys - Recke, Kult-Tisch, I 5 Kat. 9 (K II-6/78, RP II, FZ I-MZ I); Schürmann, Karlsruhe, 9 Kat. I (B 2628, RP II, FZ II-MZ); Frankel, Ashmolean Museum, 55 Kat. 323 Taf. 22 (I953.209, FZ III-MZ II); Win- bladh, Cypern, 2 I (L 3 I 4 B:I 7, RP II, Lapithos); Webb, Nicholson Museum, 30-32 Kat. 8-I9: Form und oben gerade abschließende Schnuröse am besten bei 3 I Kat. I3 $(47 \cdot 476$, RP II BT, FZ III); hohe Formähnlichkeit auch bei 3 I Kat. I 2 (47.478). I 5 (47.469). I 6 (47.477, fast alle Schalen aus Pano Dhikomo Mavro Nero). Mit tiefer angesetzten Schnurösen: CVA Göteborg, Public Collections Taf. I, 2 (Röhss 77-6I, RP II, FZ II). 4 (GA I 865 FZ II-III); Karageorghis - Olenik, Eretz Israel Museum, 38 f. Kat. 6-7 (MHP 3060. MHP 264).

Zur Datierung: SCE IV IA, 38 I f.: RP II (FZ II-MZ III); RP III (FZ III-MZ III). Zur Einordnung in RP II und RP III: Die halbkugeligen RPBT Schalen wurden in der älteren Literatur als RP II klassifiziert, neuere Forschungen stellen sie zu RP III: R. Merrillees, The Principles of Cypriot Bronze Age Pottery Classification, in: J. A. Barlow - D. L. Bolger - B. Kling (Hrsg.), Cypriot Ceramics Reading the Prehistoric Record (Philadelphia, University of Pennsylvania I99I) 237-240 bes. 239; Frankel - Webb, Deneia, $58 \mathrm{f}$. Unverzierte RPBT Schalen am häufigsten in FZ III, wurden wahrscheinlich nur bis MZ II hergestellt, werden ab MZ I langsam abgelöst durch RPBT Schalen mit Ritzdekor, waren in MZ III nicht mehr in Gebrauch: Frankel - Webb, Deneia, 58 f. Im Zentrum und an der Südküste scheinen diese Schalen mit MZ I außer Gebrauch gekommen zu sein: Frankel - Webb, Marki Alonia, I I I.

\section{TAFEL 2}

\section{1-5. Halbkugelige Schale mit Horizontalhenkel}

Beilage 1, 2.

G 2046. Fundort unbekannt. Erworben 2010 von Karin Gether, Schenkung. Ehemals Privatbesitz, Herkunft Kairo, I970er-Jahre.

H 5,9 cm. - H mit Henkel 9,2 cm. - Dm Rand 9,6 cm. - Dm Henkel I, ० x o,6 cm. - Wandstärke o,6 cm. - Gewicht I 57 g. Volumen 24I ml.

Unpubliziert.

Zustand: Das Gefäß ist ungebrochen, die Gefäßoberfläche innen und außen bestoßen. Abschlagungen an der Lippe. Im Schaleninneren und an der Lippe schwarze Flecken.

Technik: Das Gefäß ist handgeformt und außen poliert. Der Scherben ist rotbraun $(2.5$ YR $4 / 6$, red), die Oberfläche außen fleckig braun bis rötlich $(2.5$ YR $4 / 6-8$, red; 2.5 YR 5/6, red). Die Kalkmagerung ist zum Teil unter Hinterlassung kleiner Löcher herausgebrochen. Unterhalb des Mündungsrandes befindet sich innen eine fast durchlaufende horizontale Ritzlinie.

Form: Halbkugelige Schale mit rundem Boden und leicht nach innen geneigter Lippe. Horizontalhenkel diagonal von der Lippe aufsteigend und oben gerade abgeschnitten. Der Henkelquerschnitt hat eine trapezoidale Form.

Dekor: Am oberen Henkelabschluss außen je ein kleiner hornartiger Fortsatz, dazwischen drei parallele vertikale Ritzlinien nach innen gerichtet. An der Lippe eine Knubbe mit einer vertikalen Ritzung.

Red Polished III Ware, Mittelzyprisch I-II, I 900-I725

Zur Technik: Gefleckte Außenseite: Vagnetti u. a., Collezioni cipriote, 66 f. Kat. 89 Taf. XXI (Cortona, Museo dell'Accademia Etrusca 2102); CVA Göteborg, Public Collections Taf. 2, 4 (GA 
I 876, RP III, FZ III-MZ II); CVA Wien, Kunsthistorisches Museum 4 Taf. 4, I-2 (IV 4373, RP III, MZ II).

$\mathrm{Zu}$ Form und Dekor: SCE IV IA, 335 Typ XIII L Abb. CXLII 6-8 (bowl with horizontal handle, RP III, MZ I-II); Frankel - Webb, Marki Alonia, I 3 Nr. Io (bowls with horizontal handle) Textabb. 4.30 Abb. 4.23 Taf. 43; I 50 Textabb. 4.58 (Marki Alonia, Phasen G-I, MZ I-II); Ritzungen und hornartige Fortsätze auf den Henkeln an P 733I. P 9i69. P 9409. P i i944. P I 5 I69. P I 5953: selten im Norden, aber sehr häufig im Zentrum und im Süden der Insel; V. Karageorghis, Excavations at Kition I. The Tombs (Nicosia I974) 4-8, Tomb 6 Kat. 7-8. I I. I6. 23. 44. 52 (RP III-IV) Taf. VIII. CVIII; Tomb 8 Kat. 5-6 Taf. IX. CXI (RP III). Exemplare mit drei- bis vierfacher vertikaler Ritzung und hornartigen Fortsätzen des Henkels und Ritzung der Knubbe: Vagnetti u. a., Collezioni cipriote, 66 f. Kat. 89 Taf. XXI (Cortona, Museo dell'Accademia Etrusca 2102); CVA Firenze, Regio Museo Archeologico I, II C a Taf. I, I 2 (70625). I3 (70624); Frankel, Ashmolean Museum, 20 Kat. 27-28 (I953.27I; I953.272, RP III, MZ I-II); Villa, Stanford University Museum, I4 Kat. 26 Taf. II. XI (4497, RP III). Exemplare mit hornartigen Fortsätzen am Henkel und gegenüberliegend an der Mündung befindlicher Knubbe: CVA Göteborg, Public Collections Taf. 2, 4 (GA I 876, RP III, FZ III-MZ II); CVA Brit. Mus. I, II C a Taf. I, I 8 (Walters, Catalogue, C 23, Phoinikiais); Frankel, Ashmolean Museum, 20 Kat. 24 (I 888.676, RP III, MZ II). 29 (I953.273, RP III, MZ I-II): teilweise mit Ritzungen am Henkel; Villa, Stanford University Museum, I 4 Kat. 25 Taf. II. XI (2630); Lo Porto, Torino, 53 Kat. 5 Taf. 2 (480I, RP III, MZ I-II); CVA Wien, Kunsthistorisches Museum 4 Taf. 4, I-2 (IV 4373, RP III, MZ II).

Zur Datierung: SCE IV IA, 38 I f.: RP III (FZ III-MZ III).

\section{TAFEL 3}

\section{1-6. Henkeltasse}

Beilage 1, 3.

G 2 го. Aus „Cypern“. Erworben I940.

H erh. 7,9 cm. - Dm Rand 6,4 cm. - H ohne Henkelansatz 6,5 cm. - Gewicht I 28 g. - Volumen $84 \mathrm{ml}$.

Unpubliziert.

Zustand: Henkel abgebrochen, Abschlagung an der Lippe. Sinterflecken außen und innen. Kleine Abschlagungen an der Gefäßoberfläche.

Technik: Das Gefäß ist handgeformt. Scherben und Überzug sind hellorange (5 YR 6/6, reddish yellow), links unterhalb des Henkels ist der Überzug hellbraun (IO YR 8/3, very pale brown). Die Außenseite des Gefäßes ist fein poliert. Der Dekor ist rotbraun bzw. dunkelrot glänzend (2.5 YR 3/6, dark red).

Form: Es handelt sich um eine kleine handgeformte Tasse mit rundem Boden, kugelförmigem Körper, trichterförmiger Mündung mit gerader Lippe und einem vertikalen Schlaufenhenkel von der Schulter zum Mündungsrand.

Dekor: Am Gefäßboden kreuzen sich zwei parallele Linien mit drei parallelen Linien. Den oberen Teil des Gefäßbauches schmückt eine vierfache Zickzacklinie, eingebunden in einfache horizontale Linien an der Schulter und im unteren Drittel des Gefäßbauches. Die Lippe ist mit einer horizontalen Linie dekoriert. Der untere Henkelansatz wird von drei parallelen Linien hakenförmig eingefasst. Die Zickzacklinien überlappen an den Schnittstellen zu Karomustern. An den Seiten des unteren Henkelansatzes ist jeweils ein breiter Strich, an der Oberseite ein schmaler, diagonal verlaufender Strich angebracht. An der Oberseite des oberen Henkelansatzes sind zwei parallele, schräg verlaufende Striche geführt.
White Painted III Ware, Mittelzyprisch II-III, I800-I600

Zur Technik: Der orangefarbene Scherben und Überzug sowie der glänzend rotbraune Dekor sprechen für eine Klassifizierung in WP II: SCE IV ıB, I2, oder in WP III Früh: SCE IV IB, I 8; Frankel Webb, Deneia, 7 I f.; glänzend rote Bemalung als frühes Merkmal auch bei Nys - Recke, Kult-Tisch, I 8. Für eine Zusammenlegung von WP III und WP IV plädieren Frankel - Webb, Deneia, 7I f. Farbabbildungen vergleichbarer Stücke bei: Lubsen-Admiraal, Zintilis Collection, I I 4 Kat. 220 (Z. I08, cup, WP III-IV, MZ II, I 800-I 725); Karageorghis, Athens, 34 Kat. 47 (I2377, juglet, WP III, MZ II-III). 48 (deep bowl, WP III, MZ II).

Zur Form: SCE IV IB, I3. I 8 f. Typ II b (WP III, deep bowl); 50 Typ III g Abb. XII I I (WP IV, deep bowl). Bestes Beispiel in Form und Dekoration: SCE IV ıB, I 8 f. Abb. V I I (Cyprus Museum Neg. G592, WP III-IV, Lapithos, Grab 320, 39); SCE I, Taf. XXXIV I (WP III-IV, Lapithos, Grab 320, 39). Außerdem in ähnlicher oder leicht variierter Form: SCE I, Taf. CVI 8 (WP III, Lapithos, Grab 3 I 5 A. 2); SCE IV IB, I9 Abb. V Io (WP III früh, Lapithos, Grab 3 I 5 A.Io); 50 Abb. XII IO-I3, bes. XII I I (Lapithos, Grab 3 I 5 A.70); J. L. Myres, A Bronze Age Cemetery at Lapithos, BSA 4I, I940-I945, 78-85 Taf. 28, I Reihe I; Frankel - Webb, Deneia, 73, T I 85, Pıо; T 294, P3; T 294, P28; T 2 I 5, Pi 8; T 2 I 5, Pi 8 Abb. 4.36 (cup or small deep bowl); Frankel - Webb, Karmi Palealona, 225 Kat. 2.33 Abb. 4.27; CVA Brit. Mus. I, II C a Taf. 6, 20 (Walters, Catalogue, C 266, Phoinikiais); R. Laffineur - F. Vandenabeele (Hrsg.), Cypriote Antiquities in Belgium, SIMA XX I 3 (Göteborg I990) 58 Kat. 38 Taf. 25, 7 (Morlanwelz, Royal Museum of Mariemont, Nicolas Severis Coll. NS 6I, WP III-IV, MZ II-III, Famagusta?); Nielsen - Sørensen, Odense University, I 2 Kat. A.44 Taf. 9, 2 (OUKL I74, WP IV, MZ II); Frankel, Ashmolean Museum, 38 Taf. I3 Kat. I64-I66 (I888.I255; I885.530; I963.I639, WP IV, MZ II-III); Villa, Stanford University Museum, 24 Kat. 92 Taf. VII. XVI (3082, WP III-IV); Webb, Nicholson Museum, 49 Kat. 88 (58.I4I, WP IV, MZ II-III, Nicosia, Ag. Paraskevi); CVA Wien, Kunsthistorisches Museum 4 Taf. 20, 5 (IV 3240, WP III-IV, MZ II-III).

Zum Dekor: SCE IV IB, 26; Frankel - Webb, Deneia, $73 \mathrm{f}$. Exakter Vergleich im Dekor: SCE IV IB, I 8 f. Abb. V I I (WP III, deep bowl, Typ II b, Lapithos, Grab 3 I 5 A.Io); SCE I, Taf. 34, I (WP III-IV, Lapithos). Sich kreuzende Strichgruppen auf der unteren Gefäßhälfte: SCE IV ıB, I 9 Abb. V I I (WP III, Lapithos, Grab 3 I 5 A.Io); CVA Wien, Kunsthistorisches Museum 4 Taf. 20, 5 (IV 3240, WP III-IV); Frankel - Webb, Deneia, 73 f. T 294, $\mathrm{P}_{3}$ Abb. 4.36. Mehrfachzickzacklinien auf der oberen Gefäßhälfte: Frankel - Webb, Deneia, 73 f. T 294, P28 Abb. 4.36; Frankel, Ashmolean Museum, 38 Taf. I3 Kat. I64 (I888.I255, WP IV, MZ II-III). Die Kombination von Mehrfachzickzacklinien auf der oberen Gefäßhälfte und sich kreuzenden Mehrfachlinien auf der unteren Gefäßhälfte ist auch auf Schalen zu finden: SCE IV IB, I9 Abb. V 8 (WP II-III, Vounos, Tomb 40.7); 49 Abb. XII 4-5 (WP IV, Lapithos); Frankel - Webb, Deneia, 72 f. Abb. 4.33 T 34, P96; CVA Cambridge, Fitzwilliam Museum 2, II c Taf. 8, 38 (C.E.F. 9, Leondari Vouno); Souyoudzoglou-Haywood, Dublin, 25 Kat. 35 (UCD 495, WP V); Nys - Recke, Kult-Tisch, I 8 Kat. I7 (K II-2I/o9); CVA Lund I, Museum of Classical Antiquities Taf. 3, I (LA 769); Nielsen - Sørensen, Odense University, I3 Kat. A.47 Taf. 9, 5 (OUKL I72, WP IV, MZ II). Schrägstriche an der Henkeloberseite an Gefäßen desselben Typs: SCE IV ıB, Abb. V ıо. I ; Abb. XII ıо-I3; Frankel - Webb, Deneia, 73 f. T 56, P 52; T 789, P8 I Abb. 4.36; Frankel, Ashmolean Museum, 38 Taf. I 3 Kat. I64-I66 (I 888. I2 55; I885.530; I963.I639, WP IV, MZ II-III).

Zur Datierung: SCE IV IA, 38 I f.: WP II (MZ I-II); WP III (MZ II-III). 


\section{TAFEL 4}

\section{1-5. Schnabelkanne}

Beilage 1, 4.

G 208. Aus „Cypern“. Erworben I940.

H erh. I6,0 cm. - Dm max. I0,9 cm. - Querschnitt des Henkels I,4 X 0,7 cm. - Gewicht [222 g]. - Volumen (ohne Hals) $498 \mathrm{ml}$. SCE IV IC, 56 Typ V C I a Nr. 9; 67 Nr. 3.

Zustand: Das Gefäß ist fast komplett erhalten, die Mündung teilweise abgebrochen. Rezent in mehrere große Teile zerbrochen und wieder zusammengesetzt. Spuren von Klebstoff an den Bruchstellen und auf der Oberfläche. Bemalung zum Teil abgeplatzt. Sinterspuren an Mündung und Henkel, kleine Sinterflecken auch am Gefäßkörper.

Technik: Das Gefäß ist handgeformt. Die Oberfläche ist mit einem Überzug versehen, in dem Wischstriche zu sehen sind. Scherben hellbraun (IO YR 8/3-4, very pale brown). Überzug matt hellbraun in leichten Schattierungen $(7.5 \mathrm{YR} \mathrm{8/3-4}$, pink; IO YR $8 / 3-4$, very pale brown). Dekor matt dunkelgrau bis dunkelbraun (2.5 YR 3/I, dark reddish gray; 7.5 YR 3/I, very dark gray; 7.5 YR 3/2, dark brown).

Form: Aus dem kugeligen Körper mit rundem Boden entwickelt sich aus einer leicht abgeschrägten Schulter ein kurzer, schlanker Hals mit schnabelförmig ausladender Mündung. Der erhaltene Mündungsrand ist nach innen umgebogen. Ein vertikaler Henkel mit rechteckigem Querschnitt ist an der Schulter und am Hals unterhalb der Mündung angesetzt.

Dekor: Die untere Hälfte des Bauches ist mit abwechselnd dreiund vierfach parallelen vertikalen Linien geschmückt, von denen sich die Vierfachlinien in der Mitte des Bodens kreuzen. Die Mitte des Gefäßbauches wird durch ein Band von zwei parallelen horizontalen Linien mit eingeschriebener Zickzacklinie markiert, darüber befindet sich ein breiteres Band mit zwei Horizontallinien und einem eingeschriebenen gegitterten Zickzackband, darüber ein schmäleres Band mit zwei horizontalen Linien und eingeschriebener Zickzacklinie. Der Hals ist mit einem horizontalen Streifenmuster geschmückt. Vertikale Linien zieren das Innere des Schnabels. Der Henkel weist auf seiner Außenseite eine zweifache Zickzacklinie auf, die aus dem Wellenlinien-Band der Schulter hochgezogen wurde. Aus diesem Band wurden auch die beiden Linien an den Henkelrändern entwickelt, die jeweils in einer punktförmigen Verdickung an der Ansatzstelle am Hals enden.

White Painted VI Ware, Spätzyprisch I, I600-I450

Zur Technik: SCE IV IC, 53 f. (WP VI).

Zur Form: SCE IV ıB, 70 Typ V C I a; SCE IV IC, 56 Typ V C I a Nr. 9 (WP VI); Gjerstad, Studies, I7 I f. Jug Nr. 3 (WP V).

Zum Dekor: SCE IV iB, 70 Typ V C I a; SCE IV IC, 56 Typ V C I a Nr. 9. Allgemein: SCE IV IC, 65-69, Motiv Nr. 3 (drei vertikale parallele Linien). 4 (vier vertikale parallele Linien). 27 (Wellen- oder Zickzacklinie). 28 (gerahmte Wellen- oder Zickzacklinie). 5 I (gegittertes Dreieck); bes. 66 zur Dekoration von Kannen; 67 Nr. 3 zur Grazer Schnabelkanne G 208. Vergleiche mit horizontaler, gerahmter Zickzacklinie oder horizontalen Linien in der Bauchmitte, mit sich kreuzenden Linien am Gefäßboden und mit gegitterten Zickzacklinien, Rauten oder horizontalen Elementen in der oberen Hälfte des Bauchs: SCE IV IC, 56 Abb. 28 a (Pendayia, WP VI); Gjerstad, Studies, I7 I f. Jug Nr. I. 3 (WP V); Karageorghis, Athens, 37 Kat. 55 (I 22 I 5, WP V, MZ III); B. Arda - A. B. Knapp - J. M. Webb, The Collection of Cypriote Antiquities in the Hunterian Museum, University of Glasgow, SIMA
XX 26 (Sävedalen 2005) 24 Kat. 5 Taf. I (D.226, WP VI, SZ IA); C. Ioannides - J. Bouzek, The Cypriote Pottery in Prague, Eirene 3, I 964, I I I-I I 4, bes. I I 4 Taf. X Kat. I I (Prag, Nationalmuseum II75, WP VI). Zickzackbänder am oberen Gefäßbauch und sich kreuzende Linien am Boden: SCE IV IC, 57 Abb. 28 c (Arpera, WP VI); Webb, Nicholson Museum, 53 Kat. IO3 (52.4I3, WP VI, SZ I). Askoi mit sich kreuzenden Linien auf der unteren Gefäßhälfte, gegitterten Zickzacklinien, Dreiecken und gerahmten Wellenlinien: S. Brehme u. a., Antike Kunst aus Zypern. Antikensammlung, Museum für Vor- und Frühgeschichte, Münzkabinett, Staatliche Museen zu Berlin (Berlin 2002) 4 I f. Kat. I 5 (Ant. TC 6682,79, WP V); CVA Brit. Mus. I, II C a Taf. 5, 33 (Walters, Catalogue, C 706 Taf. IV). Zweiteilung des Bauches durch horizontale Linien und vertikale, sich am Boden kreuzende Strichgruppen auf der unteren Bauchhälfte: SCE IV ${ }_{\mathrm{I}}$ C, 57 Typ V D 2 a 8 Abb. 28 b (Graz, Universalmuseum Joanneum, Archäologiemuseum 4 I 89, WP VI); 58 Abb. 28 d (Hannover, Kestner-Museum 3536); Lubsen-Admiraal, Zintilis Collection, I 23 Kat. 244 (Z. 3 I 5 bis, WP V, SZ I); B. Csornay-Caprez, Cypriote Antiquities (Rom 2000) 38 Kat. 5I Taf. XVII. XXXVIII (Budapest, Museum of Fine Arts SzM T.827, WP VI, SZ IA-B); CVA Firenze, Regio Museo Archeologico I, II C a Taf. 3, 4 (70536). 9 (70594); Mee - Steel, Liverpool, 4 I Kat. I92 Taf. 36 (Williamson Art Gall. BI I, WP V, MZ III); CVA Brit. Mus. I, II C a Taf. 5, I 8 (Walters, Catalogue, C 273, Kanne, Enkomi). 33 (Walters, Catalogue, C 706 Taf. IV, Askos); Frankel, Ashmolean Museum, 40 f. Kat. I79 (I9I I.325, WP V, MZ III); 4 I Kat. I80 Taf. I4 (I948. I57, WP V, MZ III, 3 Zonen mit Dreiecken, Zickzack und vertikalen Linien); 42 Kat. I 86 (I938.337, WP VI, dreifache Zickzacklinien in der oberen Hälfte). I 87 ( I9I I.326, WP V-VI). I 88 ( I953.287, WP V-VI) Taf. I 5; CVA Louvre 4, II $\mathrm{C}$ a Taf. 3, I 5 (AM 406). 2 I (AM 959); Villa, Stanford University Museum, 20 f. Kat. 66. 67 Taf. V. XIV (774. 3402 , beide WP V-VI). 2 I Kat. 68 Taf. V. XV (776, WP V-VI, schraffierte große Rauten in der oberen Hälfte); 2 I Kat. 70 Taf. V. XV (3420, WP VI, Soft Triglyphic Style); Webb, Nicholson Museum, 53 Kat. IO2 (6I.52, WP VI).

\section{TAFEL 5}

\section{1-5. Krug oder Humpen}

Beilage 1, 5.

G 209. Aus „Cypern“. Erworben I940.

H I 4,8 cm. - Dm Rand 9,5 cm. - Dm Fuß 5,9 cm. - Dm max. I I, O cm. - Volumen $678 \mathrm{ml}$.

Unpubliziert.

Zustand: Oberer Henkelansatz und zwei Drittel des Standrings fehlen und sind in Gips ergänzt. Sinterspuren am Boden, Bauch, Henkel, Hals und Innenseite des Bodens. Am Hals, Mündungsrand und im Inneren des Gefäßes sind rötliche Ablagerungen feststellbar. Die Bemalung ist abgeplatzt, wahrscheinlich mit der Entfernung von Sinter abgezogen worden.

Technik: Das Gefäß ist handgeformt. Der graue Scherben (Iо YR 5/I, gray) ist mit hellem Schlicker ( IO YR 8/3, very pale brown) überzogen, seidig poliert und mit braunem, mattem Dekor verziert ( IO YR 3/2, very dark grayish brown; IO YR 3/3, dark brown; IO YR 4/2, dark grayish brown; IO YR 4/3, brown). Die Innenseite des Gefäßes ist mit hellem Schlicker überzogen, poliert ist nur der Bereich unterhalb der Mündung zwischen den Dekorstreifen.

Form: Der Krug oder Humpen besitzt über einem Standring einen kugeligen Bauch, der fließend in einen hohen, sehr breiten, leicht konkaven Hals mit ausschwingender Mündung übergeht. 
Ein vertikaler Bandhenkel verbindet Mündungsrand und Schulter. Am oberen Henkelansatz saß wahrscheinlich eine Griffzunge.

Dekor: Am Gefäßboden befinden sich innerhalb des Standrings eine umlaufende kreisförmige Linie und ein Linienkreuz, das über die Ringlinie auf den Standring hinausläuft. Am Bauch wechseln sich vertikale gegitterte Rautenbänder, vertikale Leitermuster und vertikale, einfache Rautenbänder ab. Die gegitterten Rauten werden rechts und links jeweils von einer schwarzen Linie gerahmt. Um die Mitte des Bauches legt sich horizontal ein Band aus ungefüllten Rauten. Die Schulter wird durch ein horizontales, gegittertes Rautenband und eine horizontale Linie abgesetzt. Am Hals wechseln sich vertikale doppelte gegitterte und einfache Rautenbänder $a b$. Die doppelten Rautenbänder sind rechts und links mit jeweils einer dunklen Linie, teilweise die Ecken der Rauten abschneidend, gerahmt. Die Mitte des Halses ist durch ein horizontales einfaches Rautenband markiert. Am Hals sind in einer vertikalen Linie unter dem Henkel fünf kurze, diagonale Viererstrichgruppen gemalt. An der Henkelaußenseite befindet sich in der Mitte und an den Außenkanten jeweils ein längs verlaufendes Band, den oberen Henkelansatz unten umfasst eine horizontale Linie. An der Mündung sind umlaufend kurze vertikale parallele Striche angebracht, nach innen setzen sich vier Gruppen mit jeweils vier vertikalen parallelen Begrenzungsstrichen fort, die Gruppen von kurzen vertikalen Strichen flankieren.

White Slip II Ware, Spätzyprisch II, I450-I 200

Zur Technik: SCE IV IC, 447 Abb. 52. 53 (WS II Early Stage).

Zur Form: SCE IV IC, 469 Tankard Typ I B Abb. LXXXV, 6. Schief stehende WS Gefäße: South - Russell - Schuster Keswani, Vasilikos Valley Project, I05 Abb. 49 K-AD I48; Abb. 49 Taf. XXIV K-AD I 52; Taf. XXVIII K-AD 370. Schief stehende BR Gefäße: SCE IV IC, Abb. 55, 2 (Humpen) Abb. L IO-I I. I3 (Humpen) Abb. LII I4; LIII 3-6 (Flaschen).

Zum Dekor: Ähnlicher Dekor, aber ohne horizontales Rautenband: SCE I, 468-475 Taf. CXIV 6 (Enkomi Grab 2, 2I); SCE IV IC, 469 f. Abb. LXXXV 5 (Enkomi); Dikaios, Enkomi, I 382 f. Kat. 362 (WS I); III Taf. 203, I4; South - Russell - Schuster Keswani, Vasilikos Valley Project, I05 K-AD I48 Abb. 49; CVA Bruxelles, Musées Royaux du Cinquantenaire I, II C Taf. I, 20 (A I 507); CVA Brit. Mus. I, II C a Taf. 7, I (Walters, Catalogue, C 248, Enkomi). I4 (Walters, Catalogue, C 247 Taf. II, Enkomi); Myres, Handbook, 33 f. Kat. 284; CVA Wien, Kunsthistorisches Museum 4 Taf. 49, 4-5 (IV 4380). Ohne vertikale Rautenketten am Hals: CVA Frankfurt I Taf. I, 2-3 (VF $\beta$ 202). Doppellinie mit Strichgruppen am Hals: CVA Firenze, Regio Museo Archeologico I, II C a Taf. 4, 5 (8I445). Breite horizontale Bänder mit Strichgruppen am Hals: SCE IV IC, 448 Abb. 52 (Stockholm, Nationalmuseum); Art of Ancient Cyprus Boston, Kat. 7 (72.86, WS I, SZ I); CVA Copenhague, Musée National I, II C Taf. 24, I (5803); Souyoudzoglou-Haywood, Dublin, 38 Kat. 59 (NMI I934:I9, WS II, SZ II); CVA Brit. Mus. I, II C a Taf. 7, I 5 (Walters, Catalogue, C 245, Enkomi). I7 (Walters, Catalogue, C 249, Kourion, breites Band fortgesetzt durch einfaches horizontales Rautenband unter dem Henkel); 8, I 2 (Walters, Catalogue, C 246, Enkomi); Mee Steel, Liverpool, 20 Kat. 77 Taf. I 5 (Liverpool Univ. C237, WS II, SZ II). An der Schulter doppeltes horizontales Gitterband mit dazwischen geschalteter Rautenkette: Karageorghis, Pierides Stiftung, Kat. I Io (Krug WS II, SZ II); K. O. Eriksson, The Creative Independence of Late Bronze Age Cyprus. An Account of the Archaeological Importance of White Slip Ware, DenkschrWien XXXVIII (Wien 2007) I 27 Abb. 29 a (WS II Early Vessels, Kalavassos Ag. Dimitrios Grab 4). Vertikale Strichmuster statt vertikaler Rautenketten: SCE IV IC, 449 Abb. 53, 9 (Cyprus Museum A I39I); CVA Rodi, Museo Archeologico I, II C Taf. 2, I. Strichgruppen an der Mündungsinnenseite: Karageorghis, Cesnola Coll- ection, 38 Kat. 53 (74.5 I.I057, Krater, WS II, SZ II); M. Fortin, Les collections d'antiquités chypriotes de l'Université Laval et du Musée de l'Amérique française (Québec, Canada), SIMA XX I6 (Jonsered I996) 24 f. Kat. 86 (Univ. Laval L.3 I, WS I, SZ I); Karageorghis, Medelhavsmuseet, 76 Kat. 74 (NM Ant I 598, Krater, WS II früh, SZ II); Kat. 75 (NM Ant I 5 I 5 , Humpen, WS II früh, SZ II); 77 Kat. 76 (NM ant I 595, Humpen, WS II früh, SZ II); 78 f. Kat. 80 (NM Ant I 5 I7, Schale, WS II, SZ II). Querstriche unter dem Henkel: CVA Brit. Mus. I, II C a Taf. 7, I4 (Walters, Catalogue, C 247 Taf. II, Enkomi); Ungenaue Rahmung der doppelten Rautenbänder: CVA Wien, Kunsthistorisches Museum 4 Taf. 49, 4-5 (IV 4380).

\section{TAFEL 6}

\section{1-6. Kleiner Doppelkrug (Bilbil)}

Beilage 1, 6.

G 57. Fundort unbekannt. Erworben vor I9II/I 2.

H erh. 5,8 cm. - Dm Fuß 3, I cm. - Dm max. 5,2 cm. - Gewicht 32 g. - Volumen (ohne Hals) $35 \mathrm{ml}$.

Unpubliziert.

Zustand: Hals am Ansatz abgebrochen, Henkel knapp oberhalb des Ansatzes abgebrochen. Zwischen den Relieflinien am Gefäßkörper und dem Henkelansatz eine große Abplatzung, die die Kontaktfläche eines zweiten angesetzten, heute verlorenen Gefäßes markiert. Kleine Abplatzung am Fuß.

Technik: Das Gefäß ist handgeformt. Die Oberfläche ist poliert, fleckig rotbraun bis dunkelbraun $\left(7.5 \mathrm{YR}_{3} / 2\right.$, dark brown; 7.5 YR 4/6, strong brown; 5 YR 5/6, yellowish red) und weist kleine Löcher auf. Der Scherben ist grau bis braun (7.5 YR 5/I, gray; 7.5 YR 5/2, brown). In der Gefäßwand sind drei Ausbuchtungen sichtbar, die von beim Brand entstandenen Gasblasen geformt wurden. In der großen Abplatzung am Bauch kennzeichnet eine Eintiefung die Ansatzstelle für die zweite Hälfte des Doppelgefäßes.

Form: Das Gefäß besitzt einen kugeligen Körper mit abgesetztem, trompetenförmigem Fuß und schmalem Standring. Der abgebrochene Hals wies ursprünglich eine lange, schlanke Form mit trichterförmig ausladender Mündung auf. Von der Schulter zur Lippe führte ein vertikaler, beide Gefäße umschließender Henkel, dessen Rest am unteren Ansatz einen vertikalen Grat in der Mitte der Henkelaußenseite zeigt.

Dekor: Am Körper befinden sich zwei mittig dicht nebeneinander gesetzte, vertikal vom Fuß Richtung Halsansatz verlaufende Relieflinien.

\section{Base-ring I Ware, Spätzyprisch I-II, I600-I 200}

\section{Zur Technik: SCE IV IC, I37 (BR I). I73 f. (BR II).}

Zur Form: Doppelkrüge bzw. Kompositgefäße: SCE IV IC, I 68 f. Typ XII A a (composite vase, BR I) I94 f. (BR II) Abb. XLIX 8 (BR I); Gjerstad, Studies, I86. I 88 Jug Nr. 3; M. OhnefalschRichter, Kypros, the Bible and Homer. Oriental Civilization, Art and Religion in Ancient Times (London I 893) 34 Abb. 34 b (Ayia Paraskevi); Dikaios, Enkomi, I 339 Kat. 34 (Grab 2; BR I); III Taf. I93, 2; CVA Baltimore, Robinson Collection I, II C Taf. 2, 3 (ohne Inv., Heliopolis, Ägypten); Art of Ancient Cyprus Boston, Kat. I 5 (65.II72); A. Fairbanks, Catalogue of Greek and Etruscan Vases I (Cambridge I928) 43 Kat. I33 Taf. IX (72.I3, Alambra); CVA Cambridge, Fitzwilliam Museum 2, II c Taf. 8, 42 (G. 2); Karageorghis - Vassilika - Wilson, Fitzwilliam Museum, 24 Kat. 44 (E.79.1932, BR I); Karageorghis, Copenhagen, 26 Kat. 
46 (AAcıo, BR I); CVA Copenhague, Musée National I, II C Taf. 24, 9 (AAcıo, Ägypten); Souyoudzoglou-Haywood, Dublin, 45 Kat. 75 (UCD I 22, BR I, SZ I-II); 35 f. Kat. 53 (NMI I934:I 2, mit Bemalungsspuren, BR II); CVA Firenze, Regio Museo Archeologico I, II C a Taf. 3, 2 I (82429, BR II); Nys - Recke, KultTisch, 30 Kat. 38 (Lg-P 56, BR I, SZ I-II A2); K. Lembke (Hrsg.), Zypern. Insel der Aphrodite, Katalog zur Sonderausstellung Roemer- und Pelizaeus-Museum Hildesheim (Hildesheim 20I0) I67 Kat. 028 (Heidelberg, Antikenmuseum der Universität KY IO, BR I); CVA Karlsruhe 2 Taf. 44, 8 (ohne Inv.); Schürmann, Karlsruhe, I 4 Kat. 26 (H 48, BR I, Ägypten); CVA Kassel 2 Taf. 6I, 6 (T 584 , BR bemalt, SZ I A-B, ca. I 5 50-I 400); Karageorghis, Pierides Stiftung, I 6 Kat. 9I (BR I); CVA Brit. Mus. I, II C a Taf. 9, I9 (Walters, Catalogue, C I 20, Maroni). 2 I (Walters, Catalogue, C I 17). 24 (Walters, Catalogue, C I I 8, Enkomi). 26 (Walters, Catalogue, C II9, Enkomi); Karageorghis, Cesnola Collection, 4I Kat. 58 (74.5 I.I I 8, BR I, SZ I); Myres, Handbook, 40 Kat. 358 (74.5 I.I I 85). 359 (74.5 I.I I 84); CVA Fogg Museum and Gallatin Collections, II C a Taf. I, 7 (339I); Nielsen - Sørensen, Odense University, I6 Kat. A.68 Taf. I4, 4-5 (OUKL I83, BR I, SZ I/ II); CVA Louvre 4, II C a Taf. 2, I 2 (AM I 84); V. Karageorghis, Ancient Cypriote Art in Russian Museums (Nicosia 2005) 99 Kat. H 5 (St. Petersburg, Eremitage 5 3985, BR I, SZ I); N. Kershaw (Hrsg.), Ancient Art from Cyprus. The Ringling Collection (Sara- sota I983) 47 Kat. 69 (S.N. 28.IoI, I 5. Jh.); CVA Sèvres, Musée National I, II C a Taf. 9, 22 (3308); Karageorghis, Medelhavsmuseet, 72 Kat. 67 (MM I 5404, BR I, SZ I); V. Karageorghis - C.-G. Styrenius - M.-L. Winbladh, Cypriote Antiquities in the Medelhavsmuseet, Stockholm, Medelhavsmuseet Memoir 2 (Stockholm I977) 29 Taf. V 3 (I096I, BR I, SZ I); Winbladh, Cypern, 28 ( I096I); CVA Stuttgart I Taf. 2, I I (KAS 392, SZ I); Karageorghis - Olenik, Eretz Israel Museum, 90 f. Kat. 43 (MHP 6884, weiß bemalt, BR II); Lo Porto, Torino, 69 Kat. 65 Taf. 7 (402 I, BR I).

Zur Ähnlichkeit der Gefäßform mit einer Mohnkapsel und der Verwendung der Gefäße für den Opiumhandel: Merrillees, Opium Trade, 289 bzw. 4. Der Nachweis von Opium in BR-Gefäßen: K. Koschel, Opium Alkaloids in a Cypriote Base Ring I Vessel (Bilbil) of the Middle Bronze Age from Egypt, ÄgLev 6, I996, I 59-I66; E. Pászthory, Opium im alten Ägypten. Untersuchung des Rückstandes in einem „Bilbil“-Krug aus dem Ostdelta des Nils, Chemie in unserer Zeit, 30, 2, I996, 96-IO2.

Zum Dekor: Parallele vertikale Relieflinien in BR I: SCE IV IC, I 49-I 5I. I70 f. Motiv Nr. 2. Parallele vertikale Linien auf Krügen: CVA Brit. Mus. I, II C a Taf. 9, 40 (Walters, Catalogue, C I48, Klavdia, Larnaka); Einzelgefäß mit Ritzverzierung: Frankel - Webb, Deneia, 9I Abb. 4.55 Kat. T 787, P55 (BR I). Vertikale Linien als Schlitze, aus denen der Milchsaft der Mohnkapsel floss: Merrillees, Opium Trade, 289 bzw. 4. 


\section{GRIECHISCH}

\section{ATTISCH PROTOGEOMETRISCH}

\section{TAFEL 7}

\section{1-3. Kleeblattkanne}

Beilage 2, 1. Abb. 1.

G 99. Fundort unbekannt. Erworben in den I9I0/20er-Jahren durch Rudolf Heberdey, Schenkung des NM Athen (Scherbensammlung).

H erh. I 2,2 cm. - B/L Kleeblattmündung erh. 7,0 cm/rek. 7,5 cm. - Wandstärke 0,45-o,6 cm. - Dm Hals 4,3 cm. - Dm Bauch rek. I3,4 cm. - Querschnitt Henkel 2, I/O,9 cm. - Gewicht I05 g.

Unpubliziert.

Zustand: Gefäßfragment; erhalten sind Teil der Mündung und des Halses, der Henkel sowie Ansatz der Schulterwandung. Beschriftung in schwarzer Tusche auf der Innenseite: „Mus. Ath.“.

Keramikart: Farbe des Bruches hellbraun bis rötlichgelb (7.5 YR 6/4-6, light brown - reddish yellow); hart; fein $(<0,2 \mathrm{~mm})$, ohne Dunkelglimmer; einzelne größere rotbraune Eisenoxid-Konkretionen (bis $0,5 \mathrm{~mm}$ ); fein mit Karbonatpseudomorphosen (bis o, I mm) durchsetzt.

Technik: Oberfläche außen fein geglättet; im Inneren grobe Drehwülste, feine Drehrillen und diagonale Stressfalten. Farbe des Tongrundes: blassbraun (IO YR 6/3, pale brown). Der schwarz verfärbte und metallisch glänzende Malschlicker ist homogen aufgetragen. Die konzentrischen Halbkreise wurden unter Verwendung eines zentrierten neunteiligen Kammpinsels gezogen; Sanduhr aus zwei gekreuzten Linien mit ausgemalten Dreiecksflächen.

Form: Kleeblattkanne mit bauchigem Gefäßkörper, schmalem, leicht konkavem Hals und einem nach außen gebogenen, leicht abgesetzten und abgerundeten Rand. Ein randständiger Vertikalhenkel mit langovalem Querschnitt.

Dekor: Gefäßbauch durchgehend bemalt. Auf der Schulterzone drei Reifen, darüber stehende konzentrische Halbkreise mit jeweils neun Bögen und einer im Zentrum eingepassten Sanduhr, die leicht nach rechts gedreht ist. Hals und Mündung durchgehend bemalt. Um den unteren Henkelansatz ein dicker Strich. Auf der Außenseite des Henkels eine Reihe von Querstrichen, die Henkelkanten sind bemalt, ebenso die Lippe.

SPG, letztes Viertel Iо. Jh.

Zur Erwerbung: Die Vergabe der niedrigen Inv.-Nr. G 99 für ein Objekt aus der Scherbensammlung erfolgte aufgrund des Verlustes des ursprünglichen Objektes unter dieser Nummer zu einem späteren Zeitpunkt. Aus einem ähnlichen Erwerbungskontext wie die Grazer Kleeblattkanne stammt ein Schulterfragment einer Kanne, das sich am Institut für klassische Archäologie der KarlsUniversität Prag befindet: Bouzek, Prag, i I I f. Nr. I Abb. I Taf. 8; CVA Prague, Université Charles I Taf. 7, I Abb. 9, 2 (22. 3I). Es stammt aus einem Ensemble von Scherben, die das griechische Unterrichtsministerium der Karls-Universität Prag im Jahre 1922 schenkte; siehe dazu Jan Bouzek in: CVA Prague, Université Charles 2, 7. 79. Dieses Fragment ist dem Grazer Stück in Form, Maßen und Bemalung so eng verwandt, dass erst ein direkter Vergleich die Zugehörigkeit zu ein und derselben Kanne ausschließen konnte. Für neue Aufnahmen und schließlich der Autopsie des Stückes in Prag am 4. Juli 2013 ist Jan Bouzek und Jiři Musil (beide Prag) zu danken.

Zur Technik: Zur Anwendung eines zentrierten mehrteiligen Kammpinsels für das Ziehen von konzentrischen Kreisen bzw. Halbkreisen siehe J. K. Papadopoulos - J. F. Vedder - T. Schreiber, Drawing Circles: Experimental Archaeology and the Pivoted Multiple Brush, AJA I02, I998, 507-529.

Zur Form: Kleeblattkannen werden im Laufe der protogeometrischen Periode schlanker, der Gefäßkörper eiförmiger und der Standring schmäler; dies gibt den Kannen im SPG eine besondere Eleganz; zur Formentwicklung siehe Desborough, PGP, 45-66; Lemos, Protogeometric Aegean, 69.

Zum Dekor: Die dekorative Bemalung beschränkt sich bei diesen Kleeblattkannen auf den Bauch, der mit einem Ornamentband oder einfachen Reifen verziert ist, und auf die Schulter, die auch durchgehend bemalt sein kann. Vincent R. d'A. Desborough unterscheidet zwei Klassen; davon lässt die erste die Schulterzone für die Dekoration frei; siehe Desborough, PGP, 48-53. Diese besteht zumeist aus stehenden konzentrischen Halbkreisen; siehe Lemos, Protogeometric Aegean, 62-72 bes. 69 f.; vgl. Lefkandi I, 3I632 I; Coldstream, KNC, 396 f.

Zum Typ: Diese Kannenform wird zumeist mit vier stehenden konzentrischen Halbkreisen bemalt, wobei die Anzahl der Bögen, die zentralen Ornamente innerhalb der Halbkreise und die Elemente zwischen den Halbkreisen wie kreuzschraffierte Rauten, in Gruppen hängende Tropfen oder vertikale Punktreihen variieren. Der Kannentyp ohne Zwischenelemente, bei dem die Halbkreise eine Sanduhr einschließen oder ausschließlich aus konzentrischen Halbkreisen bestehen, wird als 48-Typ-Oinochoe nach Grab 48 vom Athener Kerameikos bezeichnet und der Phase SPG zugewiesen: Lord Smithson, Areopag, 383; M. B. Moore in: CVA Metr. Mus. 5, 34. Aus diesem Grab stammen sechs Kleeblattkan-

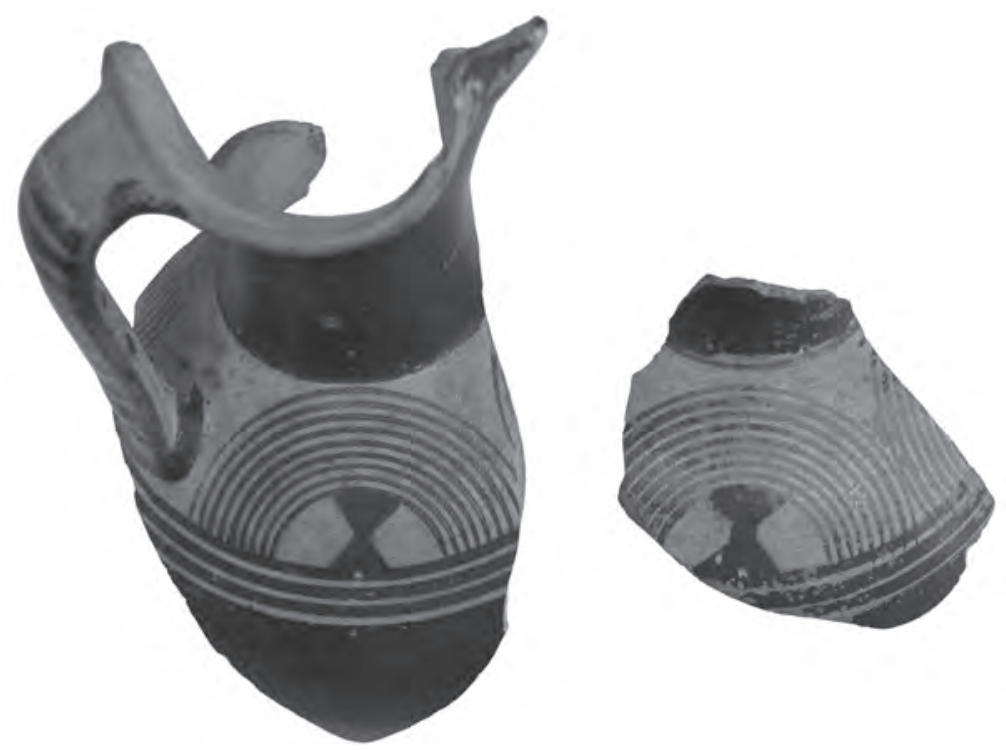

Abb. I: Kleeblattkanne - Vergleich der Fragmente Prag 22. 3 I und G 99 (Foto Karl) 
nen dieses Typs ohne Sanduhr; siehe Kerameikos IV, 45 Taf. I6 (207I-2074. 2079. 2082); Desborough, PGP, 48 Taf. 8; Lemos, Protogeometric Aegean, 69 Taf. 35, 3-4. 48-Typ-Oinochoen mit einem dem Kannenfragment G 99 gleichen Dekorschema, d. h. mit Sanduhr (jedoch mit achtfachen Halbkreisen) stammen aus Athen: Lord Smithson, Areopag, 383 Taf. 80; CVA Athènes, Musée National I, III H d Taf. 2, I (I 5322); aus Kalyvia Kouvara: A. Fairbanks, Catalogue of Greek and Etruscan Vases in the Museum of Fine Arts, Boston, I. Early Vases, Preceding Athenian BlackFigured Ware (Boston I928) 76 Nr. 258 Taf. 22 (I4.740); vom Hymettos: M. K. Langdon, A Sanctuary of Zeus on Mount Hymettos, Hesperia Suppl. I6 (Princeton I976) 55 Nr. I90 Taf. I7 (Athen, NM H 496); CVA Metr. Mus. 5 Taf. 24, 5-I 6 (30.I I 8.I 8. 30.I I 8.20. 30.I I 8.40). Zu Kannen dieses Dekorschemas mit siebenfachen Halbkreisen, vgl. Lefkandi III, Nr. 39-2 Taf. 4I; E. Lord Smithson, The Protogeometric Cemetery at Nea Ionia, I949, Hesperia 30, I96I, I 57 Nr. 9-Io Taf. 25, 7-8; P. Gercke - U. Naumann, Tiryns-Stadt I97 I, AAA 7, I974, 22 Abb. I 2. Konzentrische Halbkreise mit Sanduhr, die sich aus neun Bögen wie beim Grazer Stück zusammensetzen, sind selten. Derselben Werkstatt ist - unter Verwendung des gleichen oder eher desselben Kammpinsels (Abstand des ersten Pinsels von der Zentrierspitze I 5,8 $\mathrm{mm}$; des neunten Pinsels 33,5 mm) - die genannte Kleeblattkanne Prag 22. 3 I zuzuweisen. Die Unterschiede liegen dazu im Detail: beim Prager Stück ist die Oberfläche etwas weniger geglättet, die Bemalung etwas rascher gezogen und die kantigen Drehwülste auf der Innenseite setzen etwas höher an. Trotz dieser kleinen Differenzen könnten diese zwei Kannen durchaus zu demselben Herstellungsprozess einer Serie von Kleebattkannen mit diesem Dekorschema (mit Sanduhr, ohne Zwischenmotive) gehören. Eine Parallele mit neun Bögen stammt aus Merenda, wobei nur zwei Reifen die dekorierte Schulterzone von der durchgehend bemalten Bauchzone trennen: Xagorari-Gleißner, Merenda, 79 Nr. I99 Abb. 9 a Taf. 7 (I 47).

\section{4-5. Kantharos}

\section{Beilage 2, 2. Abb. 2.}

G 96. Aus Attika. Erworben um I9 I 2/I3 durch Rudolf Heberdey, Tausch mit dem NM Athen.

H 9,7 cm. - Dm Rand I 5,4 cm. - B mit Henkeln 20,6 cm. - Dm Boden 6,6 cm. - Querschnitt Henkel o,8/2, I cm. - Gewicht [380 g]. - Volumen I I $45 \mathrm{ml}$.

Unpubliziert.

Zustand: Das Gefäß ist bis auf ein größeres herausgebrochenes Randstück komplett erhalten; eine entlang von Haarrissen rechtwinkelig ausgebrochene, etwas kleinere Scherbe wurde wieder eingesetzt. Die Gefäßwandung ist von sehr langen Haarrissen durch- zogen. Oberfläche stark verwittert; der Malschlicker bis auf wenige Reste abgeplatzt. Die ursprüngliche Bemalung ist trotz des schlechten Erhaltungszustandes gut zu rekonstruieren. Weiße Sinterspuren befinden sich an mehreren Stellen der Oberfläche, so z. B. an den Außenseiten der Henkel. Die gesamte Oberfläche ist schleierartig und fleckig mit einer hellen Sinterschicht überzogen. Beschriftung in schwarzer Tusche auf der Unterseite: „Mus. Athen“.

Technik: Oberfläche außen gut geglättet; im Inneren grobe Drehwülste. Sehr hart gebrannt. Farbe des Tongrundes: hellgelblichbraun bis hellblassbraun (IO YR 6/4-7/4, light yellowish brown - very pale brown). Der noch in kleinsten Resten erhaltene, dunkelbraun bis schwarz verfärbte und metallisch glänzende Malschlicker homogen aufgetragen.

Form: Hohes bauchiges Gefäßbecken auf einem niedrigen Standring und mit einer leicht abgesetzten, nach außen umbiegenden und spitz auslaufenden Lippe. Zwei gegenständige randständige Vertikalhenkel mit langovalem Querschnitt.

Dekor: Die Außenseite des Gefäßes ist durchgehend bis auf ein tongrundiges Band an der Lippe bemalt. Die Außenseiten der Henkel sind mit einer Reihe von Querstrichen verziert, die Kanten bemalt. Die Gefäßinnenseite ist durchgehend bis auf ein schmales Lippenband bemalt, am Boden im Zentrum eine kleine tongrundige Kreisfläche.

SPG - FG I, spätes Io. Jh. bis frühes 9. Jh.

Zur Form: Der Kantharos G 96 besitzt einen wenn auch nur schwach ausgeprägten Standring. Zur Formentwicklung siehe P. Courbin, Les origines du canthare attique archaïque, $\mathrm{BCH} 77$, I953, 322-345; Desborough, PGP, IO2-IO6. Kantharoi tauchen im Formenrepertoire attischer Töpfer erst im SPG auf; vgl. Coldstream, GGP, I I; Coldstream, KNC, 400. Der Kantharos auf niedrigem Standring erscheint spät im SPG; siehe Coldstream, GGP, 9. I I; Lemos, Protogeometric Aegean, 54. Kantharoi werden zum bevorzugten Trinkgefäß im FG I. Eine weiter entwickelte Form zeigt ein Kantharos aus Brunnen K I 2:2 von der Athener Agora: J. K. Papadopoulos - D. Ruscillo, A Ketos in Early Athens: An Archaeology of Whales and Sea Monsters in the Greek World, AJA 106, 2002, I90 Abb. 6 (P 20608; FG II); vgl. dazu hinsichtlich des niedrigen Standringes, jedoch mit tieferem Gefäßkörper und einfachem Lippenband: CVA Brit. Mus. I I Taf. 50, 95 (GR I977-5-2I.I; FG II-MG I). Im SPG waren ansonsten dunkelgrundige Kantharoi mit Kegelfuß gebräuchlich; vgl. z. B. die Exemplare aus Grab 44: Kerameikos IV, 43 Taf. 2 I (2026); Desborough, PGP, I02 f. Taf. I 2; oder aus Grab 20: Kerameikos I, I95 Taf. 70 (730); außerhalb Attikas stammen Kantharoi aus Lefkandi: Lefkandi I, I93. 349 Nr. 2-3 Taf. I90; Lefkandi III, Nr. 54-5 bis 54-6 Taf. 60; aus Knossos: Coldstream, KNC, 248 Nr. I2 I Abb. I42 Taf. 229; aus Aigina: V. Jarosch-Reinholdt, Die geometrische Keramik von Kap Kolonna, Ägina - Kolonna 4 (Wien 2009) 25. I73 Nr. 782 Beil. 38 Taf. 64 (ST 455 I; SPG-FG I).
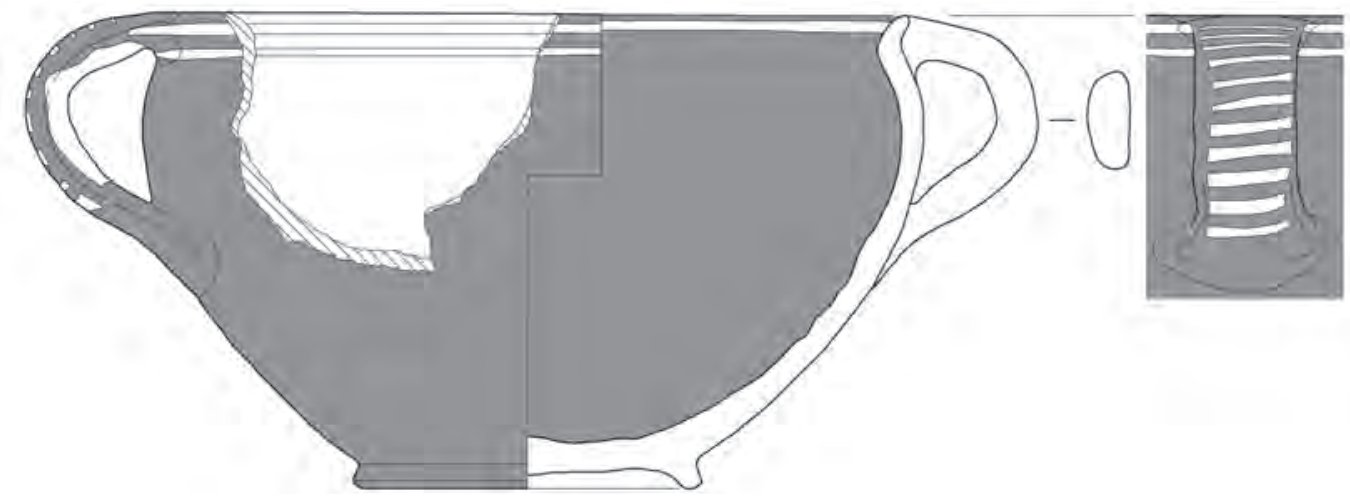

Abb. 2: Umzeichnung des Kantharos G 96 im Maßstab I:2 (Zeichnung Karl) 
Zum Dekor: Zu Gefäßen, die bis auf tongrundige Lippenbänder sowie eine einzige Ornamentzone, den mit Querstrichen versehenen Henkelaußenseiten, durchgehend bemalt sind, siehe Desborough, PGP, I 23-I 25. Die dunkelgrundigen Kantharoi werden im FG I von solchen mit zunächst kleinen Bildfeldern zwischen den Henkeln (mit Mäander oder anderem Strichmuster) abgelöst; vgl. z. B. die Kantharoi aus Grab D I 6:2: R. S. Young, An Early Geometric Grave near the Athenian Agora, Hesperia I 8, I949, 295 f. Nr. I7-20 Taf. 67. 69 (P I9244-I9247); Desborough, PGP, IO3 f.
Taf. I 5; Coldstream, GGP, Io Taf. I b; oder aus Grab D I6:4: C. W. Blegen, Two Athenian Grave Groups of about 900 B. C., Hesperia 2I, I952, 29I f. Nr. I 8-I9 Taf. 75 a-b (P 20179: mit Kegelfuß; P 201 80: mit Standring); Coldstream, GGP, I I Taf. I o-p.

Zum Typ: Ein dem Kantharos G 96 bis auf kleinste Abweichungen in Formgebung und Maßen identisches Exemplar stammt aus Grab 26: Kerameikos IV, 33 f. Taf. 2I (9I9; SPG); P. Courbin, Les origines du canthare attique archaïque, $\mathrm{BCH} 77, \mathrm{I953}, 325$ Abb. 3; Desborough, PGP, IO2 f. Taf. I 2. 


\section{ATTISCH FRÜHGEOMETRISCH}

\section{TAFEL 8}

\section{1-3. Schulterhenkelamphora}

Beilage 2, 3.

G I00. Aus Attika. Erworben um I9I2/I3 durch Rudolf Heberdey, Tausch mit dem NM Athen.

H erh. 30,2 cm. - Dm Rand I6,0 cm. - Dm Bauch rek. 2I,6 cm. - Querschnitt Henkel 3,3/I,2 cm.

Lehner - Lorenz - Schwarz, Vasen, I3 Nr. I Abb. I (M. Lehner).

Zustand: Gefäßfragment; aus insgesamt I6 größeren Einzelscherben zusammengesetzt; es fehlt der gesamte untere Teil und von der Rückseite der Bereich unter der Henkelzone sowie ein Teil eines Henkels; eine größere Fehlstelle in der Schulterzone und kleinere im Bereich des Halses mit Gips ergänzt und schwarz retuschiert. Bei Erwerbung war das Gefäß mit einem rekonstruierten Unterteil aus Gips ergänzt, der in den I980er-Jahren abgenommen wurde. Von der historischen Restaurierung zeugen noch Gips-Verstriche über einigen größeren Abplatzungen entlang der Bruchlinien im Inneren und Leimreste entlang dieser Bruchstellen. Innen ist zum Teil die Oberfläche abgeplatzt und stark verwittert; sie neigt besonders zum Absanden. Bemalung stellenweise abgerieben, sonst aber in einem guten Zustand; auf dem Malschlicker liegen über die gesamte Oberfläche versprengt schleierartige Sinterreste auf.

Technik: Gefäßkörper und Hals separat getöpfert und zusammengesetzt. Oberfläche außen geglättet. Farbe des Tongrundes: hellbraun bis hellblassbraun (7.5 YR 6/4 - IO YR 7/4, light brown - very pale brown). Der schwarz bis dunkelbraun glänzende Malschlicker wurde homogen und dick aufgetragen. Die zwei Ornamentbänder sind mit umlaufenden Reifen umrissen; das Feld zwischen den Henkeln trapezförmig ausgespart.

Form: Langgezogener bauchiger Gefäßkörper mit einer rund verlaufenden Schulter, einem hohen leicht abgesetzten Hals, der in eine weit ausladende Mündung übergeht. Die Lippe ist innen verstärkt und schräg abgestrichen, der Rand abgerundet. Auf Höhe der Schulter zwei kreisförmig gebogene Vertikalhenkel mit langovalem Querschnitt.

Dekor: Das Gefäßfragment ist bis auf ein Bauchband, ein Horizontalfeld zwischen den Henkeln, ein Halsband und die Henkelaußenseiten durchgehend bemalt. Um den Bauch ein Doppelaxt-Strichgruppen-Fries zwischen je zwei Reifen, mit Gruppen von jeweils I3 oder I4 Strichen. Die Horizontalfelder zwischen den Henkeln bestehen aus einem nach oben weisenden Hundszahn zwischen je drei Horizontalstrichen. Im Halsband ein Fries aus Doppeläxten und Strichgruppen zwischen je zwei Reifen. Die Anzahl der Vertikalstriche in diesem Fries ist unterschiedlich: am häufigsten I 3 Striche, jedoch auch Gruppen von elf Strichen und am Ende des Frieses eine Abfolge, vom Betrachter aus gesehen nach links, aus acht Strichen, Doppelaxt und fünf Strichen. Die Außenseiten der Henkel zeigen eine Reihe von Querstrichen, die Kanten sind bemalt.

FG II - MG I, zweites bis drittes Viertel 9. Jh.

Zur Form: Schulterhenkelamphoren leiten sich aus SPG ab und werden bis FG II akzentuierter, erhalten einen den Halshenkelam- phoren angepassten schlankeren Gefäßkörper und wirken mit der elegant ausschwingenden Mündung weniger plump; zur Formentwicklung siehe Coldstream, GGP, I4. I7; N. Kourou in: CVA Athens, National Museum 5, 67. Der hohe Hals der Grazer Form verweist auf MG I; von der Form her älter sind z. B. Schulterhenkelamphoren aus Grab I4: Kerameikos V I, 220 Taf. 42 (4I 2; FG II); Coldstream, GGP, I3 Taf. 2 a; oder von unbekanntem Fundort: CVA Athens, National Museum 5 Abb. 39 Taf. 77, I-4; 78, I (2 I 267; FG II). Mit dem Amphorenfragment G Ioo von der Formgebung her verwandt sind Exemplare aus Grab 76: Kerameikos V I, 262 Taf. 44 (234; MG I) bzw. aus Eleusis: Coldstream, GGP, I7 Taf. 31 (700; MG I). Bei diesem Typ einer Amphora kann die Form ihrer Schulterhenkel variieren. Schulterhenkelamphoren wurden normalerweise für Bestattungen von Frauen verwendet; im Gegensatz zu den Halshenkelamphoren, die für Männergräber typisch sind, - vgl. die um diese Gefäße gewundenen und somit unbrauchbar gemachten Schwerter -; siehe dazu Desborough PGP, 5; A. M. D’Onofrio, Athenian burials with weapons: The Athenian warrior graves revisited, in: A. Mazarakis Ainian (Hrsg.), The „Dark Ages“ revisited, Acts of an international symposium in memory of William D. E. Coulson, University of Thessaly, Volos, I4-I7 June 2007, Volume II (Volos 20II) 645-673. Zu einer umfassenden Auswertung der Grabbefunde des Athener Kerameikos hinsichtlich des sozialen Status und der Scheidung geschlechtsbezogener Bestattungssitten siehe bes. J. Whitley, Style and Society in Dark Age Greece. The changing face of a pre-literate society I I00-700 BC, New Studies in Archaeology (Cambridge I99I) 97-I37; bes. I32-I33 (für FG - MG I).

Zum Dekor: Die Verwendung von Doppelaxt-StrichgruppenFriesen ist besonders ab MG I beliebt, findet aber Vorläufer in der Lippendekoration von Halshenkelamphoren im FG I; siehe Coldstream, GGP, I 8 f.; bes. I 8 Anm. 7; möglicherweise sogar noch in der protogeometrischen Periode beginnend; siehe die Halshenkelamphora CVA Berlin Io Beil. I, 3 Taf. I, 3-4; 2, I (3 I004; SPG). Auf Schulterhenkelamphoren werden sie im oberen Bereich des Halses eingesetzt, oder in den umlaufenden Bändern am maximalen Bauchdurchmesser, durchaus kombiniert mit älteren Motiven wie dem Hundszahn, vgl. die genannte Amphora aus Eleusis oder die bereits am Übergang zu MG II stehende Schulterhenkelamphora aus Grab I 2: Kerameikos V I, 2 I 7 Taf. 44 (890). Frühe Beispiele mit einem solchen Motiv liegen in der genannten Schulterhenkelamphora Athen, Kerameikos-Museum 4I 2 oder in der angeblich aus Megara stammenden Halshenkelamphora vor: CVA Athens, National Museum 5 Taf. 7, I-3 (I3678; FG II). Das Hochrücken der Horizontalfelder auf dem Grazer Stück weit über den untersten Ansatz der Henkel ist ungewöhnlich.

Zum Typ: Der reduzierte Dekor in den Horizontalfeldern zwischen den Henkeln, der allein aus einem Hundszahn besteht, steht im auffälligen Gegensatz zur entwickelten Form der Schulterhenkelamphora G ıоo; Parallelen scheinen dazu nicht vorzuliegen. Nach Ornamentik und Form ist sie wohl zeitlich vor der Schulterhenkelamphora auf Schlaufenfüßen aus Palaia Kokkinia anzusetzen: CVA Athens, National Museum 5 Taf. 79, I-3 (I8476; MG I), die ein Horizontalfeld mit vierfachem Parallel-Zickzack über Hundszahn aufweist, sowie ebenfalls vor einer fragmentierten Schulterhenkelamphora aus Grab 75 b: Kerameikos V I, 262 Taf. 43. I47 (I 288; MG I/II), bei der das Mündungsstück eine nahezu identische Bemalung und Positionierung des Ornamentbandes zeigt, dagegen die Bemalung des Bauchfrieses und des Horizontalfeldes zwischen den Henkeln bereits umfangreicher und entwickelter ist. 


\section{ATTISCH MITTELGEOMETRISCH}

\section{TAFEL 9}

\section{Halshenkelamphora}

Beilage 3, 1. Abb. 3.

G 718. Fundort unbekannt. Erworben in den I910/20er-Jahren durch Rudolf Heberdey, Schenkung des NM Athen (Scherbensammlung).

H erh. Iо, $5 \mathrm{~cm}$. - B erh. 8,2 cm. - Wandstärke 0,7-I, I cm. Dm Hals rek. I I, 2 cm. - Dm max. rek. I4, 8 cm. - Gewicht IO2 g. Unpubliziert.

Zustand: Wandstück; erhalten ist ein Stück des Halses und der Schulteransatz. Oberfläche gut erhalten; vereinzelt kegelförmige Absprengungen durch Einschlüsse in der Keramik. Der Malschlicker zum Teil abgeplatzt. Im Inneren Kalksinterreste. Beschriftung mit schwarzer Tusche auf der Innenseite: „Mus. Ath.“.

Keramikart: Farbe des Bruches: gelblichrot ( 5 YR 5/6, yellowish red); sehr hart; fein (<0,2 mm); ohne Dunkelglimmer; einzelne größere rotbraune Eisenoxid-Konkretionen (bis $0,5 \mathrm{~mm}$ ); von weißlichen Karbonatpseudomorphosen (O, I mm) durchsetzt.

Technik: Das separat geformte Halsstück an der Schulter angesetzt. An der Angarnierungsstelle außen eine Kerbe, auf der Innenseite unförmige Dellen, die auf das Andrücken des Halsstückes auf der Schulter zurückgehen. Oberfläche außen fein geglättet. Farbe des Tongrundes: hellbraun (7.5 YR 6/4, light brown). Der dunkelbraun verfärbte und glänzende Malschlicker dick und homogen aufgetragen; beim Liniendekor etwas lasierender. Das Vertikalfeld zwischen den Henkeln rechtwinkelig ausgespart, wobei unten am Gefäßumbruch und oben über dem oberen Henkelansatz je ein umlaufender Reifen das Feld von den durchgehend bemalten Flächen abgrenzen.

Form: Leicht nach außen stehende und schwach konkave Wandung des Halses einer Halshenkelamphora mit Rest des oberen Ansatzes eines Vertikalhenkels.

Dekor: Zwischen den Henkeln befindet sich am ansonsten durchgehend bemalten Hals ein Bildfeld. Dieses ist durch jeweils drei Horizontalstriche in drei Ornamentbänder geteilt. In der Mitte ein fünffaches Parallel-Zickzack; darüber und darunter Horizontalfelder mit einem nach oben weisenden Hundszahn.

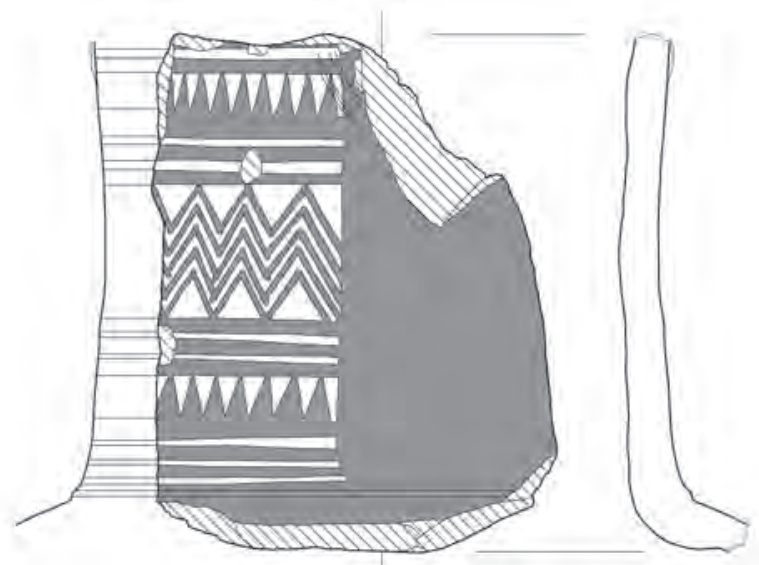

Abb. 3: Umzeichnung der Halshenkelamphora G 7 I 8 im Maßstab I:2 (Zeichnung Karl)
MG I, zweite Hälfte 9. Jh.

Zur Form: Halshenkelamphoren mit einem hohen vertikalen Hals werden unter dem Formtyp I klassifiziert; zur Entwicklung der Form im MG siehe Coldstream, GGP, I7; N. Kourou in: CVA Athens, National Museum 5, I3. Eine formgleiche Halshenkelamphora mit etwa ähnlichen Ausmaßen stammt aus Grab 37: Kerameikos V I, 233 Taf. 29 (866; MG I; H 59 cm); Coldstream, GGP, I 6 Taf. $3 \mathrm{~d}$.

Zum Dekor: Das mehrfache Parallel-Zickzack, im FG II eingeführt, ist ab MG I beliebt (vor allem auf Pyxiden und Skyphoi), siehe Coldstream, GGP, I4 f. I9. Die Kombination von mehrfachem Parallel-Zickzack und Hundszahn in einem Ornamentband findet sich u. a. im MG I auf einer Bauchhenkelamphora vom Athener Kerameikos (vor dem Dipylon): CVA Athens, National Museum 5 Abb. 52 Taf. 96, I-2; 97, I-2 (2 I9); auf der Schulterhenkelamphora auf Schlaufenfüßen aus Palaia Kokkinia: CVA Athens, National Museum 5 Taf. 79, I-3 (I 8476); im MG II auf einer Halshenkelamphora: CVA Tübingen 2 Taf. 7, I-2 (S./IO I 245); im Schulterfeld einer Schulterhenkelamphora unbekannten Fundorts: CVA Athens, National Museum 5 Taf. 78, 2-3 Abb. 40 (2 I 202); im Henkelfeld von Kannen, wie aus Grab I I und 23: Kerameikos V I, 216. 225 Taf. 73 (379. 862; MG I/II, MG II); oder aus Grab 4 von Aspropyrgos: ADelt 53, I998, Chron. 77 Taf. 42 c (A 775; MG I). Ein fünffaches Parallel-Zickzack besitzen die Halshenkelamphora aus dem genannten Grab I I: Kerameikos V I, 2 I 6 Taf. 30 (859; MG I) oder die Bauchhenkelamphora aus Grab I 2 der Nekropole an der Kriezis-Straße östlich vom Dipy-

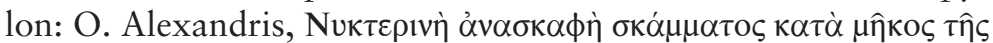

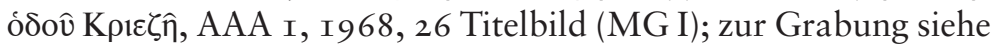
ADelt 22, I967, Chron. 92-96. Ein sechsfaches Parallel-Zickzack zeigt die Halshenkelamphora aus Grab $\Gamma$ I 6 von Eleusis: Mylonas, Eleusis, I 2 Nr. I65 Taf. 24 I b. 242 a (MG I). Zum Dekorationsschema siehe H. Marwitz, Kreis und Figur in der attisch-geometrischen Vasenmalerei, JdI 74, I959, 95-IO3; vgl. die Gruppe II b Tab. 3 .

Zum Typ: Mit dem Grazer Exemplar verwandt ist eine etwas später entstandene Halshenkelamphora: CVA Brit. Mus. I I Taf. I, 3 (GR I977.I 2-7.I; MG I). Bei dieser Amphora ist im Horizontalfeld das vierfache Parallel-Zickzack oben und unten von Feldern mit verzahnten Halbstrichen begleitet. Dieses Ornamentsystem, reduziert auf das untere Feld mit Halbstrichen, findet sich auf einer Halshenkelamphora aus Grab I von Marathon: G. So-

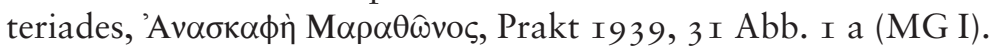
Ein Ornamentdekor mit Parallel-Zickzack über Hundszahn zeigt eine weitere außerhalb Athens gefundene Halshenkelamphora, aus Grab 2004-4 von Korinth: C. A. Pfaff, Geometric Graves in the Panayia Field at Corinth, Hesperia 76, 2007, 5I 7 f. Nr. 74 Abb. 55 (C-2004-I7; MG I); diesmal mit vierfachem ParallelZickzack über Hundszahn. Die Amphora ist jedoch mit einer Gesamthöhe von $37,2 \mathrm{~cm}$ wesentlich kleiner. Ein mit dem Ornamentfeld auf der Halshenkelamphora G 7 I 8 identischer Streifen - auch in der Feinheit der Ausführung - umläuft den Hals der genannten Bauchhenkelamphora Athen NM 219. Sie wird von N. Kourou um 850-830 datiert und mit weiteren Amphoren der Werkstatt von Athen 2 I 6 zugewiesen; siehe dazu N. Kourou, A New Geometric Amphora in the Benaki Museum: the Internal Dynamics of an Attic Style, in: O. Palagia (Hrsg.), Greek Offerings, Essays on Greek Art in Honour of John Boardman (Oxford I997) 43-53. 


\section{Flache Pyxis}

Beilage 3, 3. Abb. 4.

G 730. Aus Athen; möglicherweise aus den Grabungen des Jahres I 897 am Nordhang des Areopags. Erworben I 908/Io durch Hans Schrader. Ehemals Slg. Hans von Prott (Athen).

H erh. 3,8 cm. - B erh. 3,7 cm. - Wandstärke 0,6-0,75 cm. Dm max. rek. 24,4 cm. - Gewicht 8 g.

Unpubliziert.

Zustand: Wandstück; erhalten Teil des Bauches. Oberfläche gut erhalten; minimale Abplatzungen des Malschlickers. Das Stück ist durch sekundäre Hitzeeinwirkung reduzierend verbrannt. Beschriftung in schwarzer Tusche auf der Innenseite: „Athen/Prott“.

Keramikart: Farbe des Bruches: Außenzone schwarzdunkelgrau ( I $_{\text {YR }} 3 /$ I, very dark gray), Kern und innen hellbräunlichgrau (2.5 Y 6/2, light brownish gray); hart; fein (<0,2 mm); ohne Dunkelglimmer; mit weißlichen Karbonatpseudomorphosen fein durchsetzt, einzelne größere rotbraune Eisenoxid-Konkretionen (bis $0,5 \mathrm{~mm}$ ).

Technik: Oberfläche außen fein geglättet und poliert; im Inneren feine Drehrillen und Glättungsspuren. Farbe des Tongrundes: außen dunkelgrau (IO YR 4/I, dark gray), innen rötlichgrau bis gräulichrot (2.5 YR 5/I-2, reddish gray - weak red). Der dunkelgrau bis schwarz verfärbte, glänzende Malschlicker ist homogen und präzise aufgetragen.

Form: Flache Pyxis mit bauchiger Wandung.

Dekor: Umlaufender, linksläufiger und gegenständig schraffierter Mäander, darüber drei Reifen. Der Wechsel in der Schraffurrichtung ist mit kleinen Füllwinkeln überbrückt.

MG, spätes 9. Jh. bis erstes Viertel 8. Jh.

Zur Erwerbung: Das Fragment stammt möglicherweise aus den Grabungen am Nordhang des Areopags unter der Leitung von Wilhelm Dörpfeld im Winter I 897; siehe dazu W. Dörpfeld, Funde, AM 22, I 897, 478 und ausführlich Lord Smithson, Areopag, 329-334. Dabei wurde eine kleine Grabgruppe der geometrischen Zeit entdeckt. Prott selbst nahm an diesen Grabungen teil; siehe J. Stroszeck, „Ein ergreifendes Bild der Trauer“. Antikenrezeption auf dem Ersten Friedhof von Athen. Zur Grabstele des Epigraphikers Hans von Prott (I869-I903), Thetis I 5, 2008, I43 Anm. 5. Das Fundmaterial aus diesen Grabungen wurde 1903 offiziell an Studiensammlungen Deutschlands abgetreten; der größte Teil befindet sich in den Staatlichen Museen von Berlin, ein Stück an der Universität Heidelberg: CVA Heidelberg 3 Taf. I I 2, 4-5 (G 49), ein weiterer Rest am DAI Athen. Aus der in diesem Bereich 1932 entdeckten Brandschüttung des Grabes I I 8:2 stammt eine auch im Erhaltungszustand besonders gut zu vergleichende flache Pyxis: Lord Smithson, Areopag, 36I Nr. 7 Taf. 77 e (P 28007; MG I). Für Bildmaterial dieser stark fragmentierten Pyxis ist Craig Mauzy (Athen) zu danken.

Zur Form: Das Fragment G 730 gehört zu einer Standardpyxis mit flachem Gefäßkörper. Zur Form siehe Coldstream, GGP, I7; Kerameikos XIII, 27-40, bes. 3I-38. Aufgrund des rekonstruierten Durchmessers von $24,4 \mathrm{~cm}$ ist das Grazer Stück nicht nur in der Bemalung mit einer großen Pyxis aus Grab I 3 auf das Engste verbunden: Kerameikos V I, 219 Taf. 53; Kerameikos XIII, 86
Nr. 80 Taf. 7, I-2 (I I92; MG I). Diese Pyxis bildet aufgrund ihrer Größe (Dm Bauch $24 \mathrm{~cm}$ ) eine Ausnahme im MG I, siehe dazu Kerameikos XIII, 3 I f.; Coldstream, GGP, I7 (Dm Bauch bei Pyxiden im MG I sonst nicht über $20 \mathrm{~cm}$ ).

Zum Dekor: Ein umlaufender schraffierter Mäander ist typisch für Pyxiden im MG II; meistens ist das Band unten von einem nach oben weisenden Hundszahn, oben von einem einfachen steilen Zickzack begrenzt; siehe Bouzek, Prag, I3 I f.; Kerameikos XIII, 36; Langdon, From Pasture to Polis, IO2 f. Der Schraffurwechsel im Mäander erfolgt zumeist in zwei Varianten; entweder durch Füllwinkel, wie z. B. bei den Pyxiden: CVA Brit. Mus. I I Taf. 40, 64-65 (GR I969.5-I.I. I977.I2-I.3; MG II); CVA Louvre I6, III H b Taf. Io, I-2 (CA 3257; MG II); Kerameikos XIII, 91 Nr. I 38 Taf. I 2, 4; I3, I (3647; MG II); oder die Schraffurlinien setzen an der letzten Linie der vorhergehenden Schraffurrichtung im spitzen Winkel an, wie z. B. bei der genannten Pyxis Athen, Agora-Museum P 28007 oder der Pyxis CVA Metr. Mus. 5 Taf. 2I, 2-4 (48.I I.5; MG II). Füllwinkel zeigen die der Phase MG II zugewiesenen Pferdepyxiden: CVA Mannheim I Taf. 5, 5 (Cg 67); CVA Tübingen 2 Abb. 8 Taf. I7, I-4 (7450); keine Füllwinkel dagegen besitzt die Pferdepyxis aus dem Grab 69: Kerameikos V I, 257 Taf. 54. 6I; Kerameikos XIII, 98 Nr. I83 Taf. 2I, I (257; MG II; Dm Bauch $24,5 \mathrm{~cm}$ ); Coldstream, GGP, 23 Taf. 4 b. Zum Schraffurwechsel siehe Kerameikos V I, I70-I72. Der Standard-Richtungswechsel der Schraffur im umlaufenden Mäander befindet sich gegenständig an den oberen und unteren Außenecken des Mäanders; d. h. in der Regel folgt nach jeder dritten Richtungsänderung des Mäanders ein Schraffurwechsel. Das Grazer Stück zeigt dagegen zusätzlich einen Wechsel bereits auf mittlerer Höhe des Mäanders.

Zum Typ: Das Fragment G 730 ist mit den genannten Pyxiden Athen, Kerameikos-Museum II92 und Athen, Agora-Museum P 28007 in der kräftigen Mäanderzone, der Feinheit des Mäanders, der leicht bogenförmigen Führung der Schraffurlinien und der Enge des Mäanders zum oberen Reifen eng verwandt. An die Pyxis Athen, Kerameikos-Museum I 92 schließt Barbara Bohen noch weitere Pyxiden an und weist diese der Phase MG I zu; siehe Kerameikos XIII, 86.

\section{3-6. Skyphos}

\section{Beilage 3, 2. Abb. 5.}

G 97. Aus Kalyvia Kouvara, Ostattika. Erworben um I9I2/I3 durch Rudolf Heberdey, Tausch mit dem NM Athen.

H 5,6 cm. - Dm Rand I I, O cm. - B mit Henkeln I 6,3 cm. - Dm Boden 5,3 cm. - Dm Bauch I 2,O cm. - Dm Henkel I,O-I, I cm. Gewicht I9I g. - Volumen 33 I ml.

Unpubliziert.

Zustand: Das Gefäß ist bis auf einige Absplitterungen an der Lippe vollständig erhalten; ein Riss führt vom Rand bis zum Boden. Oberfläche stark verwittert und abgerieben. Die Keramik ist sehr weich und sandet bzw. platzt oberflächlich ab. Der Malschlicker ist nahezu vollständig abgegangen. Einige größere Einschlüsse hinterließen Vertiefungen. Im Inneren und am Boden liegt eine weißliche Sinterkruste auf. Ritzinschrift auf der Unterseite: „28“.

Technik: Auf der Unterseite Abdrehspuren. Keramik mit zahlreichen rotbraunen, bis zu $4 \mathrm{~mm}$ großen Partikeln durchsetzt. Ne-
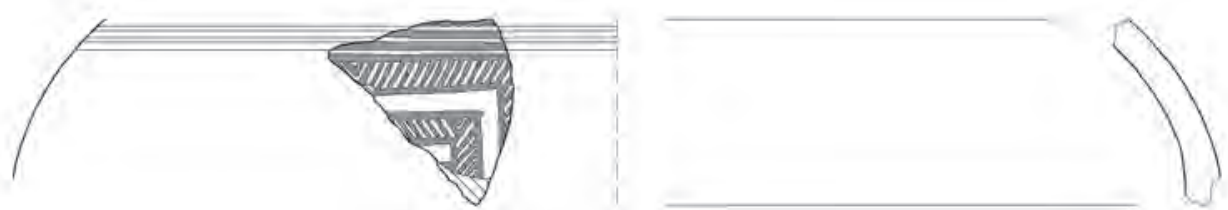

Abb. 4: Umzeichnung der flachen Pyxis G 730 im Maßstab I:2 (Zeichnung Karl) 
ben einem Henkelansatz eine eingedrückte Stelle. Oberfläche geglättet. Farbe des Tongrundes: blassgelb (2.5 Y 7/4, pale yellow). Der dunkelbraun bis rotbraun fleckig verfärbte matte Malschlicker wurde homogen aufgetragen.

Form: Bauchiges niedriges Gefäßbecken auf einer leicht gewölbten, sehr niedrigen Standplatte und mit einem nach außen gebogenen, spitz zulaufenden Rand. Zwei gegenständige, leicht nach oben gerichtete Horizontalhenkel mit rundem Querschnitt.

Dekor: Boden und unterer Gefäßkörper durchgehend bemalt. Darüber drei Horizontalstriche, die bis zu den Henkelansätzen geführt sind, sie enden am äußeren der zwei um die Henkelansätze gezeichneten Striche. In der Henkelzone Horizontalfelder mit einer Reihe von sehr fein gezeichneten, vertikalen, nach rechts gerichteten Winkeln; seitlich ist dieser Dekor durch drei Vertikalstriche getrennt, die zum Teil über den unteren, das Dekorfeld begrenzenden Horizontalstrich führen. Darüber, am Rand, drei Reifen. Die Zwickel zu den Henkelansätzen sind mit achtzackigen Sternen verziert. Entlang der Henkel verlaufen zwei Striche. Innen bis auf ein Lippenband mit einem Reifen und wahrscheinlich einer kleinen Kreisfläche im Zentrum (dort erhebliche Absplitterungen) durchgehend bemalt.

MG, letztes Viertel 9. Jh. bis I. Hälfte 8. Jh.

Zur Erwerbung: Der Skyphos G 97 stammt wie die Kleeblattkanne G 90 (hier Tafel I 5, I-4) aus Kalyvia Kouvara; beide Gefäße sind mit Nummern gekennzeichnet: „28“ (G 97) und „4 I“ (G 90). Zu Kalyvia Kouvara ist wenig bekannt; Gefäße mit dieser Fundortangabe, die in mehreren Museen aufbewahrt werden, weisen auf eine oder mehrere Gräberfelder geometrischer bis archaischer Zeitstel-

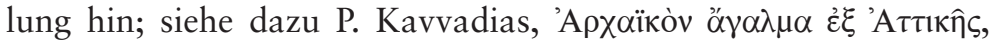
AEphem I902, 43-50; vgl. z. B. CVA Athens, National Museum 5 Textabb. 3 Abb. 22 Taf. 27, I-3 (I4826); A. Fairbanks, Catalogue of Greek and Etruscan Vases in the Museum of Fine Arts, Boston, I. Early Vases, Preceding Athenian Black-Figured Ware (Boston I928) 76 Nr. 258 Taf. 22 (I 4.740).

Zur Form: Skyphoi, die den üblichen Standring auf eine Standfläche reduzieren, erscheinen seit MG II häufiger. Zur Entwicklung der Form siehe Coldstream, GGP, 23. Skyphoiformen mit einem gedrungenen gut gewölbten Becken sowie einer kurzen nach außen gebogenen Lippe stehen in einer älteren Tradition, vgl. formal den Skyphos mit ausgespartem Horizontalfeld aus Grab 37: Kerameikos V I, 233 Taf. 89 (867; MG I); Coldstream, GGP, I6 Taf. 3 e. Spätere Skyphoi besitzen normalerweise höhere und stärker akzentuierte Ränder, wie das Exemplar aus Grab 69: Kerameikos V I, 257 Taf. 9I (256; MG II); Coldstream, GGP, 2I Taf. 4 c.

Zum Dekor: Das Ornamentfeld mit vertikalen Winkeln ist typisch für MG-Skyphoi; zum Winkelmuster siehe Coldstream, GGP, 24 f. Ab MG I wird nicht mehr ein Horizontalfeld für das Ornament auf dem dunkel bemalten Gefäß ausgespart, sondern bei Skyphoi mit Winkeldekor trennen Horizontalstriche, die zwischen den Henkelansätzen gezeichnet werden, die ornamental bemalte Zone vom weiterhin dunkel bemalten Unterteil. In der Regel werden jedoch die Horizontalstriche samt dem Winkelmuster zwischen die Vertikalstriche gesetzt; vgl. den genannten Skyphos Athen, Kerameikos-Museum 256 mit dem Skyphos aus Grab

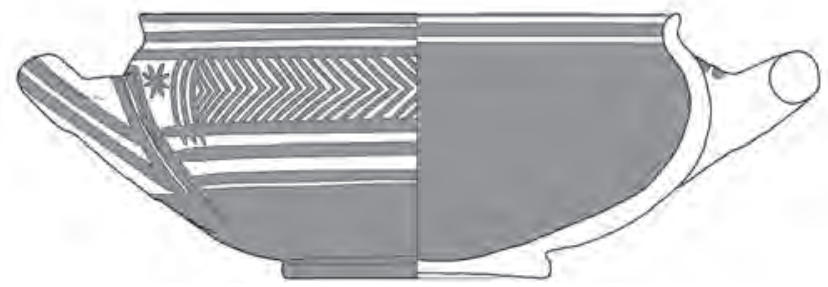

Abb. 5: Umzeichnung des Skyphos G 97 im Maßstab I:2 (Zeichnung Karl)
86: Kerameikos V I, 265 Taf. 9I (829; MG II). In den Zwickeln zu den Henkelansätzen erscheinen seit MG I Füllornamente, wie in diesem Fall von achtzackigen Sternen; siehe dazu Coldstream, GGP, 28; vgl. den Skyphos aus Grab 36: Kerameikos V I, 233 Taf. 89 (2 I 56; MG I). Zum Dekorationsschema siehe H. Marwitz, Kreis und Figur in der attisch-geometrischen Vasenmalerei, JdI 74, I959, 69-8I; vgl. die Gruppe II B a Tab. 3 .

Zum Typ: Eine Parallele zum Skyphos G 97 mit nahezu identischer Strichanzahl (etwa 30) und ebenso feinem Winkelmuster, aber auch in Maßen und Proportion, findet sich in einem Skyphos von einem nicht näher genannten Fundort in Attika: Kahane, Entwicklungsphasen, 472. 48I f. Taf. 2I, 5 (Athen, NM). Von Peter Kahane wird dieser Skyphos der Phase MG I zugewiesen. Sieht man von der gedrungenen Form des Grazer Exemplars ab, werden Skyphoi mit Winkeldekor erst ab MG II besser bekannt; vgl. die genannten Skyphoi vom Athener Kerameikos, aber auch außerhalb Athens wie aus Aigina: V. Jarosch-Reinholdt, Die geometrische Keramik von Kap Kolonna, Ägina - Kolonna 4 (Wien 2009) 32; I 56 Nr. 626-627 Beil. 27 Taf. 52 (Aigina MA I68 I: mit ebenfalls feinem Winkelmuster, jedoch bemalten Henkelaußenseiten; Aigina MA I 682: ähnliche Henkelbemalung; MG II); Kraiker, Aigina, 26 Nr. 3 I Taf. 2.

\section{TAFEL 10}

\section{1-5. Miniaturkessel mit Protomenhenkel}

Beilage 3, 4. Abb. 6.

G 44. Aus Athen, Grabbezirk an der Piräusstraße nordöstlich vom Dipylon. Erworben I 875 durch Wolfgang Helbig in Athen, Ankauf. Ehemals Slg. Athanasios Rhousopoulos (Athen). Alte Inv.Nr. II 57 (Schenkl) bzw. III 57 (Pichler).

$\mathrm{H}$ bis zum Rand 9,8 cm. - $\mathrm{H}$ mit Henkeln und Aufsatz I 2, I cm. - B mit Henkeln I9,8 cm. - Dm Rand I 4, O cm. - Dm Boden 6,2 cm. - Dm Bauch max. I6,6 cm. - Dm Henkel I, 2 cm. - Henkelapplikation: D I, o cm. - L 2,8 bzw. 3, I cm. - Gewicht 383 g. - Volumen I I74 ml.

G. Hirschfeld, Vasi Arcaici Ateniesi, AdI 44, I872, I49 Nr. 62 Taf. K, Io. - Lehner - Lorenz - Schwarz, Vasen, I4-I 6 Nr. 3 Textabb. auf S. I6; Abb. 6-7 (M. Lehner).

Zustand: Das Gefäß ist vollständig erhalten; minimale Absplitterungen an der Lippe. Malschlicker zum größeren Teil abgeplatzt; im Inneren abgerieben. Beschriftung in Bleistift auf der Unterseite: „20“ [Preisangabe in Francs].

Technik: Oberfläche außen fein geglättet; Innenseite mit flachen Drehwülsten. Farbe des Tongrundes: hellblassbraun ( IO YR 7/4, very pale brown). Der dunkelbraun bis oliveschwarz verfärbte, außen glänzende und innen matte Malschlicker wurde zum größten Teil lasierend aufgetragen. Bemalung mit einem breiten Pinsel für die Innenseite und mit einem feineren für den Liniendekor auf der Außenseite; beide Vorgänge auf der Drehscheibe. Strichgruppen an der Lippe und am Henkel mit Hilfe eines zehnteiligen Kammpinsels.

Form: Bauchiger Gefäßkörper auf einer leicht konkav gewölbten Standfläche mit einem nach außen biegenden und rund zulaufenden Rand. Etwas über dem maximalen Bauchdurchmesser zwei gegenständige Horizontalhenkel mit rundem Querschnitt in einem $45^{\circ}$-Winkel. Auf dem Scheitel der Henkel je eine vertikale Applikation, die aus einer mittleren Kalotte mit seitlichen abgerundeten Spitzen besteht.

Dekor: Die Standfläche ist tongrundig. Auf der Gefäßaußenseite eine durchgehend bemalte Fläche und ein Liniendekor aus acht Reifen. Auf Höhe der Henkel ist eine breite Zone für den Dekor 
ausgespart. Sie ist zu den Henkeln durch Vertikalfelder mit einer Reihe von neun bzw. zehn M-förmigen Winkeln zwischen je drei Vertikalstrichen abgegrenzt. In den Horizontalfeldern befinden sich linksläufige schraffierte Mäander mit zwei Windungen, wobei auf einer Seite des Gefäßes dieser Mäander einen Vertikalstrich des Trennelementes mitbenutzt. Die Schraffur im Mäander wechselt auf beiden Gefäßseiten regelmäßig nach dem zweiten, fünften, achten und elften Umbruch. An der Lippe zwei Reifen. In den Zwickeln zum Henkel je eine Punktrosette. In den Henkelfeldern je ein stehendes kreuzschraffiertes Dreieck mit einem an der Spitze ansetzenden, nach oben weisenden Pfeil. An den Außenseiten der Henkel verlaufen zwei Striche, dazwischen eine Reihe von Querstrichen. Die Henkelapplikationen sind durchgehend bemalt. Innen bis auf ein Lippenband durchgehend bemalt. Im Lippenband acht Gruppen zu je zehn kurzen Vertikalstrichen.

MG II - SG I a, zweites Viertel 8. Jh.

Zur Erwerbung: Beim Gefäß G 44 handelt es sich um einen Fundgegenstand aus den Grabungen nordöstlich vom Dipylon der Jahre I 87 I/72, der in G. Hirschfeld, Vasi Arcaici Ateniesi, AdI 44, I872, I 49 unter Nr. 62 Taf. K, Io abgebildet wurde. Dieser Grabbezirk befindet sich südlich der Piräusstraße auf Höhe des ehemaligen Waisenhauses von Georgios Chatzikonstas und westlich der heutigen Plateia Eleutherias. Das Grazer Objekt befand sich bereits I 872 in einer Privatsammlung; es ist anzunehmen, dass es sich dabei um die Slg. Athanasios Rhousopoulos handelt, aus der es im Jahre I 875 erworben wurde.

Zur Technik: Zur Anwendung eines mehrteiligen Kammpinsels für den Reifendekor und für die Strichgruppen, die im MG II beginnt, siehe Coldstream, GGP, 24; zur Technik grundsätzlich siehe J. Boardman, The Multiple Brush, Antiquity 34, I960, 85-89; zum zentrierten Kammpinsel siehe die Kleeblattkanne G 99, hier Tafel 7, I-3.

Zur Form: Das Gefäß G 44 zeigt eine eigenwillige Formgestaltung; nicht nur das Profil, sondern auch die Henkelapplikationen sind ungewöhnlich. Die Form könnte am ehesten als Miniaturkessel angesprochen werden; vgl. z. B. dazu den „Miniaturkessel“ aus Kynosarges: J. N. Coldstream, The BSA's Geometric Collection: Kynosarges et alia, BSA 98, 2003, 335 Nr. K I 2 Abb. I Taf. 42 (MG II-SG I a) oder das als Skyphos bezeichnete Gefäß aus Grab 86: Kerameikos V I, I 24 f. 265 Taf. 94 (830; MG II). Aus diesem Grab stammt die der Phase MG II zugewiesene Schulterhenkelamphora: Kerameikos V I, 265 Taf. 45 (825); Coldstream, GGP, 2I Taf. 5 g. Die Zone zwischen den Henkeln dieser Amphora wird von einem Mäander in zwei Windungen eingenommen, der in seiner technischen Ausführung jenem auf dem Miniaturkessel G 44 äußerst ähnlich ist. Von den Proportionen näher ist der attische (?) Skyphos: CVA Tübingen 2 Taf. 24, I-2 Abb. I9 (5794; SG). In Bezug auf die Protomenhenkel kann ein niedriger Skyphos mit Henkelapplikationen als Vergleich herangezogen werden. Dieser Skyphos stammt aus Grab I4 der Nekropole an der Kriezis-Straße, nicht weit vom

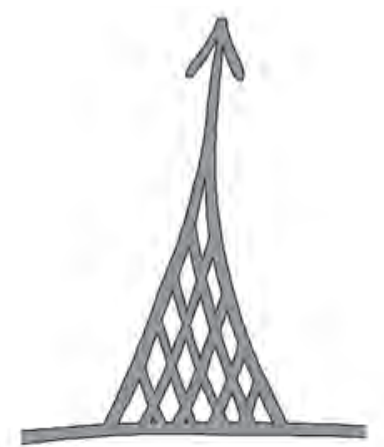

Abb. 6: Umzeichnung des Ornamentes im Henkelfeld des Miniaturkessels G 44 im Maßstab I:I (Zeichnung Karl)
Fundort des Grazer Kessels entfernt: G. Daux, Chronique des fouil-

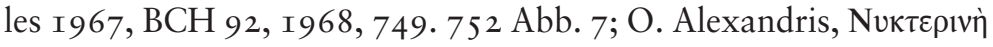

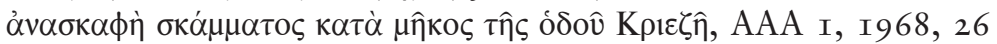
Abb. 9 (aufgrund der Bauchhenkelamphora aus diesem Grab wohl MG II); zur Grabung siehe ADelt 22, I967, Chron. 92-96. Gerade in Hinblick auf die Widderkopfhenkel der monumentalen Grabkratere scheint es sich bei den Protomen auf den Henkeln des Grazer Exemplars am ehesten um Stierköpfe mit Hörnern zu handeln; zu dieser Thematik siehe N. R. Oakeshott, Horned-Head Vase Handles, JHS 86, I966, I 22-I24. Vgl. die Pyxis mit einem Deckel, auf dem ein Stierkopf appliziert ist: CVA Athènes, Musée National I, III H d Taf. I, 9 ( I 53 I 8; MG II). Zur Interpretation der Stierköpfe an Gefäßen als Symbol eines Stieropfers zu Ehren des Toten siehe M. Xagorari-Gleißner, Das Fragment eines spätgeometrischen Grabkraters aus Merenda, in: N. Kreutz - B. Schweizer (Hrsg.), TEKMERIA. Archäologische Zeugnisse in ihrer kulturhistorischen und politischen Dimension, Beiträge für Werner Gauer (Münster 2006) 405.

Zum Dekor: Der Ornamentkontext mit einem Mäander in zwei Windungen, zumeist rechts unten beginnend und links oben endend, ist in Horizontalfeldern von Skyphoi zahlreich vertreten; wie aus Grab I I: Kerameikos V I, 2 I6 Taf. 93 (863; MG I/II); aus Grab 35: Kerameikos V I, 232 Taf. 92 (388; MG II); jeweils mit Punktrosetten in den Zwickeln. Zu Mäanderfeldern, die von seitlichen Vertikalfeldern aus M-förmigen Winkeln eingeschlossen werden, vgl. einen etwas breiteren Skyphos mit Reflexbogenhenkeln aus Grab 86: Kerameikos V I, 265 Taf. 94 (828; MG II); einen Skyphos mit einfachen Henkeln: CVA Brit. Mus. I I Taf. 46, 80 (GR I 842.7-28.83 I; MG II). Zu dem für Trinkgefäße im MG II charakteristischen Mäanderdekor siehe Coldstream, GGP, 25. Zum Liniendekor, der für die attische Keramik nicht üblich ist, jedoch ab MG II vereinzelt auftaucht, siehe Coldstream, GGP, 24.

Zum Typ: Zum Miniaturkessel G 44 lassen sich aus der publizierten Literatur keine in Form und Bemalung entsprechenden Parallelen erbringen. Jedoch wurde aus dem Kunsthandel München, Gerhard Hirsch Nachfolger, München, Katalog 259, Antiken, Los I 87 Taf. 23 (Auktion am Io. Februar 2009) vor kurzem eine Parallele bekannt gemacht. Dieser wesentlich kleinere Miniaturkessel (Dm Rand 8,7-8,9 cm; Dm Boden 6,2 cm; H 5,8-5,9 cm; $\mathrm{H}$ mit Henkeln 7,5/8, $\mathrm{cm}$ ), heute in der Sammlung Cassani/Lang in München (MUC 22), besitzt ein ebenfalls mit einer Standfläche versehenes, jedoch gedrungen bauchiges Gefäßbecken und - dem Grazer Gefäß sehr ähnlich - zwei hochgezogene Horizontalhenkel mit je einer Applikation in Form von zwei diagonal wegstehenden, abgerundeten Spitzen („Hörnerprotome“). Das Gefäß ist in der unteren Hälfte mit vier Bändern bemalt, in der oberen Hälfte sind die breiten Horizontalfelder zwischen den Henkeln, begrenzt durch drei Vertikalstriche, mit je einem Vogel und seitlich je einem achtzackigen Stern dekoriert. Der schraffierte Vogelkörper wirkt aufgrund der Höhe des Horizontalfeldes gestaucht, besitzt einen kurzen Hals und noch kürzere Beine. Entlang den Henkelaußenseiten verlaufen zwei Striche, während die Applikationen durchgehend bemalt sind. Dieses stilistisch ungewöhnliche Gefäß ist zeitlich später als der Miniaturkessel G 44 zu datieren; aufgrund des Vogelmotives und der Konzeption in einem breiten Horizontalfeld am ehesten SG. Dagegen steht das dekorative Schema des Grazer Kessels G 44 noch ganz in der Tradition von MG II; die Form bleibt weiterhin singulär. Das kreuzschraffierte Dreieck mit Pfeilspitze könnte in seiner Positionierung und schwungvollen Zeichnung jünger sein; es ist in der Anlage in etwa mit dem konzentrischen Dreieck samt Fortsatz unter dem Henkel einer Bauchhenkelamphora aus dem Grabbezirk an der Piräusstraße nordöstlich vom Dipylon vergleichbar: CVA Athens, National Museum 5 Taf. IO०-IOI (805); zu diesem Bildzeichen unter dem Henkel vgl. auch M. Weber, Die Bildsprache des Hirschfeldkraters, AM I I 4, I999, 34 Taf. 4, 4. Diese Amphora wird von N. Kourou einer Werkstatt am Übergang von MG II zu SG I zugewiesen; zu diesen traditio- 
nellen Werkstätten, die den linearen MG II-Stil weiter fortführen, aber neue Formen aufnehmen, siehe N. Kourou in: CVA Athens, National Museum 5, 26.

\section{TAFEL 11}

\section{1-4. Kleeblattkännchen}

Beilage 3, 5 .

G 9I. Fundort unbekannt. Erworben um I9I2/I3 durch Rudolf Heberdey, Tausch mit dem NM Athen.

H erh. 5,7 cm. - Dm Bauch 9,3 cm. - Dm Boden 7,6 cm. Querschnitt Henkel (im Ansatz) I,7/0,7 cm. - Gewicht I 32 g.

Lehner - Lorenz - Schwarz, Vasen, I3 f. Nr. 2 Textabb. auf S. I3; Abb. 3 (M. Lehner).

Zustand: Unterer Gefäßteil erhalten, Hals und Henkel abgebrochen, einige Abplatzungen und eine große Kalkaussprengung. Oberfläche leicht bestoßen; Malschlicker zum Teil verwittert. Der an bestimmten Bereichen dick aufgetragene Malschlicker netzartig gesprungen. Auf der Unterseite in Bleistift: „I“.

Technik: Oberfläche außen perfekt geglättet; auf der Unterseite Abdrehspuren. Farbe des Tongrundes: hellbraun bis rosafarben (7.5 YR 6/4-7/4, light brown - pink). Der dunkelgrau bis dunkelbraun verfärbte und matte Malschlicker homogen und stellenweise dick aufgetragen. Reifen auf der Drehscheibe exakt gezogen. Nach dem Bemalen des Gefäßes und noch vor dem Brand wurde ein Stück des Standringes weggeschnitten.

Form: Linsenförmiger Gefäßkörper einer kleinen Kanne auf einem niedrigen breiten Standring mit engem Hals. Ein auf der Schulter aufsitzender Vertikalhenkel mit langovalem Querschnitt.

Dekor: Der Standring ist bemalt, ebenso der Ansatz des Gefäßkörpers bis auf ein tongrundiges Band mit zwei Reifen. Darüber folgen drei Reifen, ein Band aus einem einfachen steilen Zickzack und wiederum drei Reifen. Auf der Schulter befindet sich gegenüber dem Henkelansatz eine Sanduhr aus Vielfachstrichen mit Punktrosetten in den Zwickeln, seitlich jeweils ein stehendes gerahmtes kreuzschraffiertes Dreieck, eine vertikale Punktreihe und ein weiteres Dreieck. Darüber hat sich der Rest eines Reifens erhalten.

MG II - SG I, erstes bis zweites Drittel 8. Jh.

Zur Technik: Beschädigungen, die während der Fertigung eines Gefäßes entstanden, wie Dellen, verzogene Gefäße etc. sind mehr- fach belegt; siehe dazu B. Kaeser, Herstellungs- und Schicksalsspuren, Nachträge, in: M. Bentz (Hrsg.), Vasenforschung und Corpus Vasorum Antiquorum - Standortbestimmung und Perspektiven, CVA Deutschland Beih. I (München 2002) 65-72; C. Dehl-von Kaenel in: CVA Berlin Io, 53.

Zur Form: Kleine Kleeblattkannen auf einem breiten Standring, auch als Lekythos-Oinochoen bezeichnet, erscheinen durch die gesamte geometrische Zeit und sind seit MG I in verschiedenen Formvarianten beliebt, formal aber kaum zu datieren; siehe Coldstream, GGP, I7. 22. Ein ähnliches Profil besitzt das Kännchen aus Grab I2: Kerameikos V I, 2 I 7 Taf. 83 (895; MG I/II). Etwas gestreckter ist ein Kännchen aus Grab I I: Kerameikos V I, 2 I 6 Taf. 83 (864; MG I/II).

Zum Dekor: In der Schulterzone dieser Kleeblattkännchen befinden sich zumeist stehende gerahmte kreuzschraffierte Dreiecke über Reifen oder einem eigenen Ornamentband. Die Zwickel können mit verschiedenen zusätzlichen Ornamentelementen gefüllt werden, wie vertikalen Punktreihen oder einzelnen Sternen und Punktrosetten. Das zentrale Ornament des Schulterdekors, die kreuzschraffierten Dreiecke, ist bereits ab FG bekannt, vgl. die Kännchen aus Grab D I6:2: R. S. Young, An Early Geometric Grave near the Athenian Agora, Hesperia I 8, I949, 293 Nr. I II2 Taf. 67. 69 (P I9233. I9236; FG I). Die Kombination aus vertikalen Punktreihen und kreuzschraffierten Dreiecken findet sich auf diesen Kännchen bis SG II; für MG I vgl. CVA Oxford, Ashmolean Museum 4 Taf. 23, 3-4 Abb. 3, 2 (I936.425); CVA Norway 2 Taf. 45, 260 (Oslo, Museum of Applied Arts 8652); für SG I vgl. das Kännchen Heidelberg G 70 aus Nea Ionia: CVA Heidelberg 3 Taf. I09, 7; I I I, 2; für SG II, jedoch mit rundlicherem Gefäßkörper als im MG, vgl. aus Grab G I2:I4: Young, Graves, 40 f. Nr. I3 Abb. 24; Agora VIII, 39 Nr. 72 Taf. 5 (P 497I). Für die Sanduhr aus Vielfachstrichen mit seitlichen Punktrosetten wie auf dem Kännchen G 9I scheinen keine entsprechenden Parallelen vorzuliegen; in etwa ist sie mit einer Sanduhr auf der Schulter einer kleinen Halshenkelamphora vergleichbar: CVA Athènes, Musée National I, III H d Taf. 4, I 2 ( I I ooo; H 9,7 cm). Das Sockelband mit einem fein und exakt gezeichneten steilen Zickzack findet sich auf einem reicher dekorierten Kännchen aus Grab I3: Kerameikos V I, 2 I9 Taf. 83 (I I4 I; MG I).

Zum Typ: Das Kleeblattkännchen G 9I steht am ehesten in der Nachfolge der genannten, der Phase MG I zugewiesenen Exemplare Oslo, Kunstindustriemuseum 8652, Oxford I936.425 oder aus dem Grab I auf dem Grundstück Papanikolaos in Argos: ADelt 27, I972, Chron. I92 Taf. I34 b; die jedoch kleiner sind und kein zusätzliches Ornamentband unter dem Schulterdekor besitzen. 


\section{ATTISCH SPÄTGEOMETRISCH}

\section{5-6. Tafel 79, 1-2. Monumentaler Krater}

Beilage 4, 1. Abb. 7-8.

G 74I. Aus Athen, Grabbezirk an der Piräusstraße nordöstlich vom Dipylon. Erwerbung unbekannt.

H erh. 8,5 cm. - B erh. I I, $6 \mathrm{~cm}$. - Wandstärke I,4-I,75 cm. Dm max. rek. ca. 62,6 cm. - Gewicht I 55 g.

Unpubliziert.

Zustand: Wandstück. Bruchkanten leicht verwittert und versintert; einige oberflächliche Absplitterungen. Einzelne größere weiße Kalkpartikel im Inneren der Keramik führten zu konischen Absprengungen der Oberfläche. Beschriftung mit Bleistift auf der Innenseite: „Athen“.

Keramikart: Farbe des Bruches: rosafarben (7.5 YR 7/4, pink); hart; fein $(<0,2 \mathrm{~mm})$, ohne Dunkelglimmer; große weiße Körner (bis $8 \mathrm{~mm}$ ); von feinen Karbonatpseudomorphosen durchsetzt; einzelne größere und einige feine rotbraune Eisenoxid-Konkretionen (durchschnittlich o, I mm, teilweise bis $3 \mathrm{~mm}$ ).

Technik: Oberfläche außen fein geglättet; innen grob unter Einsatz eines kantigen Werkzeuges nachgeglättet. Farbe des Tongrundes: hellgelblichbraun bis hellblassbraun ( IO YR 6/4-7/4, light yellowish brown - very pale brown). Der mittel- bis dunkelrotbraun verfärbte und leicht glänzende Malschlicker wurde streifig und unregelmäßig stark aufgetragen. Einige Spritzer des Malschlickers auf der Bildfläche.

Form: Etwa im $45^{\circ}$-Winkel ansteigendes Wandungsstück aus dem unteren Bereich des Gefäßbeckens eines monumentalen Kraters.

Dekor: Unter dem Bildfries - dabei handelt es sich um den untersten Fries dieses Kraters - sitzt ein Reifen, eine Punktreihe sowie ein Liniendekor aus drei breiten Reifen. Als Füllornamente auf dem Bildfries erscheinen Doppeläxte zwischen den Kriegern auf Höhe ihrer Oberschenkel.

Darstellung: Hopliten - Über dem Reifendekor haben sich Reste von drei nach rechts gehenden Hopliten mit Schild und zwei Speeren erhalten. Ihre Füße (mit einer hohen Fußschaufel) berühren und überlappen zum Teil den unteren Reifen, der den Kriegern als Standlinie dient. Am mittleren Hopliten ist die Form seines Schildes gut zu erkennen, es handelt sich um ein sog. Dipylonschild. Beim linken Krieger ist noch ein minimaler Ansatz des Schildes entlang der Bruchkante sichtbar. Der kleine Ansatz links außen stellt wohl den Rest einer der beiden Lanzen dieses Kriegers dar. Vom rechten Hopliten sind nur die unteren Enden der beiden Lanzen erhalten. Gefäßinnenseite tongrundig.

SG I a, um 760. Krater Kunze IV, Werkstatt des Dipylon-Meisters

Zur Erwerbung: Das Fragment G 74I stammt aus dem Grabbezirk an der Piräusstraße nordöstlich vom Dipylon, entweder aus dem Grabungsgebiet von I 871/72 auf einem Grundstück südlich der Piräusstraße auf Höhe des ehemaligen städtischen Waisenhauses von Georgios Chatzikonstas und westlich des Ludwigsplatzes, der heutigen Plateia Eleutherias, bzw. aus dem daran westlich anschließenden Grabungsgebiet von I891/92 auf dem Grundstück Sapuntzakis, das nach Westen bis zur Samouil-Kalogirou-Straße

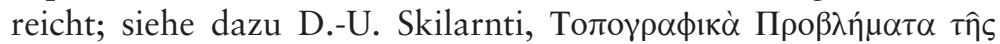

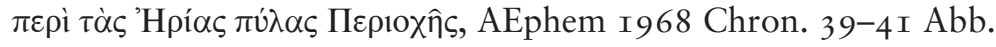
4 zu Nr. 7-9; J. Travlos, Bildlexikon zur Topographie des antiken Athen (Tübingen I97I) 302 Abb. 4I7. Zu neueren Grabungen

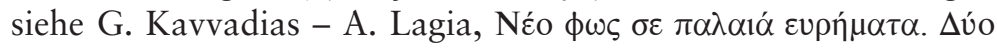

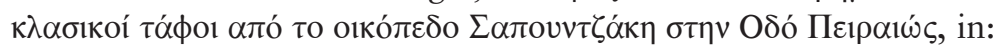
J. H. Oakley - O. Palagia (Hrsg.), Athenian Potters and Painters II (Oxford 2009) 73-75 Abb. I. Wie und wann das Objekt von der Universität Graz erworben wurde, entzieht sich bislang den Archivrecherchen. Fragmente aus den Grabungen des I9. Jhs. wurden damals über den Kunsthandel und private Kontakte zerstreut, später vom NM Athen abgegeben und fanden so Eingang in verschiedene europäische Museen oder Universitätssammlungen, siehe dazu N. Coldstream, The Dipylon Krater Sydney 46.4I: Context, Style, and Iconography, MedA 9/I0, I996/I997, 2 Anm. 6. Das Grazer Fragment gehört aufgrund der Darstellung, der Füllornamente sowie der Figuren und vor allem der technischen Merkmale zu einem von Emil Kunze aus mehreren Fragmenten in den $\mathrm{Mu}-$ seen NM Athen und Louvre zusammengestellten Krater, der nach Kunzes Arbeit die Nummer IV trägt: Kunze, Disiecta Membra, I 67 f.; Davison, Workshops, I40 Nr. I 8; Coldstream, GGP, 3 I Nr. I I Rombos, Iconography, 4I 4 Nr. Io. Der Krater Kunze IV wird (derzeit) aus folgenden Fragmenten zusammengesetzt: - I) Athen, NM 802 (mehrere Fragmente): Kunze, Disiecta Membra, I67 f. Taf. 5, I. 3; 6, I-2; u. a. von den Grabungen I891/92: E. Pernice, Über die Schiffsbilder auf den Dipylonvasen, AM I7, I 892 , 286. 288-290 Nr. I 8-20 Abb. I-3; aber auch von den Grabungen I 87I/72: G. Hirschfeld, Vasi Arcaici Ateniesi, AdI 44, I872, I 52 f. Nr. 78; MonInst IX Taf. 40, 4 (nur das Fragment rechts; das linke ist falsch in der Zeichnung angepasst und gehört zum Krater Kunze III; siehe dazu Kunze, Disiecta Membra, I67 Anm. 3). - 2) Compiègne (ehemals Louvre A 549+559): Kunze, Disiecta Membra, I67 f. Taf. 5, 2; F. Villard in: CVA Louvre I I, 3. - 3) Louvre CA 3362 und 34I7 (je zwei Fragmente): CVA Louvre I I, III H b Taf. 7, I 5-I6; IO, 25-26. - 4) Louvre CA 3425: CVA Louvre I I, III H b Taf. Io, 34; Rez. von E. Kunze, AJA 6I, I957, 307. - 5) Louvre CA 3403, 3428 (je ein Fragment): CVA Louvre I I, III H b Taf. Io, I I; I6, I; Rez. von Kunze a. O. 307 f. - 6) Göttingen $\mathrm{Hu} 533$ s: F. Canciani, Geometrische Keramik in Göttingen, AA I967, 450 f. Nr. 6 Abb. 8. Zum Krater Kunze IV gehören wohl noch weitere Fragmente, so z. B. das Fragment Göttingen Hu 533 1 (Canciani a. O. 453 Nr. 8 Abb. I I), das von Canciani und G. Ahlberg, Prothesis and Ekphora in Greek Geometric Art, SIMA XXXII (Göteborg I97I) 25 Nr. 4 Abb. 4 d dem Krater Louvre A 5 I7 zugewiesen wird, was allein schon aufgrund der unbemalten Innenseite nicht möglich ist. Erschließt sich mit Göttingen Hu 5331

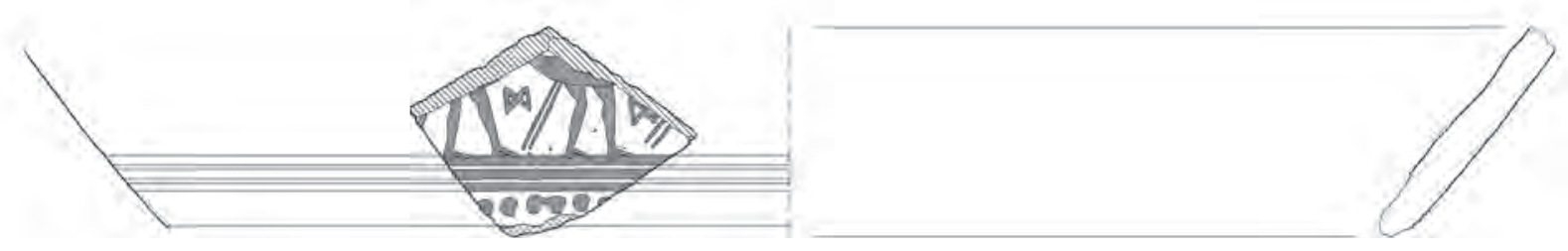

Abb. 7: Umzeichnung des monumentalen Kraters G 74I im Maßstab I:4 (Zeichnung Karl) 
und vielleicht dem Fragment Louvre A 545 (CVA Louvre I I, III H b Taf. 9, I7; Davison, Workshops, 22. I33 f. Abb. 4; Coldstream, GGP, 30 Anm. I) die Hauptszene des Kraters Kunze IV, nämlich eine Prothesis-Darstellung? Zu einer zeichnerischen Rekonstruktion der Henkelzone auf der Rückseite siehe C. Grunwald, Frühe attische Kampfdarstellungen, ActaPraeArch I3/I4, I982, I78 Abb. 28 (Krater I). An Göttingen $\mathrm{Hu} 533$ s passt das Fragment G 74I Bruch an Bruch an. Für die historische Abbildung, die für die Fotomontage verwendet wurde, ist Joachim Heiden (Athen) zu danken. Für die Ermöglichung einer Autopsie des Fragmentes Göttingen Hu 533 s am 26. Januar 2012 ist Daniel Graepler (Göttingen) und Norbert Eschbach (Gießen) zu danken; für weiterführende Informationen Alexandra Christopoulou (Athen), Anastasia Gadolou (Athen) und Anne Coulié (Paris).

Zur Form: Das Fragment G 74I gehört zu einem jener monumentalen Kratere auf hohem Fuß, die nahezu ausnahmslos nur in Attika, besonders in Athen, hergestellt wurden, dort nicht als Grabbeigaben, sondern bereits seit MG I als Grabmarkierungen dienten; siehe dazu F. Poulson, Die Dipylongräber und die Dipylonvasen (Leipzig I905); B. Schweitzer, Die geometrische Kunst Griechenlands. Frühe Formenwelt im Zeitalter Homers (Köln I969) 4I-43; Coldstream, GGP, 20. 33 f.; B. Bohen, Aspects of Athenian Grave Cult in the Age of Homer, in: S. Langdon (Hrsg.), New Light on a Dark Age. Exploring the Culture of Geometric Greece (Columbia I997) 44-55; M. B. Moore, Ships on a „WineDark Sea" in the Age of Homer, MetrMusJ 35, 2000, I3; M. Xagorari-Gleißner, Das Fragment eines spätgeometrischen Grabkraters aus Merenda, in: N. Kreutz - B. Schweizer (Hrsg.), TEKMERIA. Archäologische Zeugnisse in ihrer kulturhistorischen und politischen Dimension. Beiträge für Werner Gauer (Münster 2006) 405; M. B. Moore in: CVA Metr. Mus. 5, 5 f. Zu monumentalen Krateren ohne Ausmalung der Innenseite siehe C. Dehl-von Kaenel in: CVA Berlin Iо, 3 I $\mathrm{f}$.

Zum Dekor: Umlaufende Punktreihen finden sich an Krateren aus der Werkstatt des Dipylon-Meisters am Rand bzw. an der plastischen Leiste am Übergang des Beckens zum Hals (siehe Coldstream, GGP, 36), so auf dem bekannten Krater Louvre A 5I7: CVA Louvre II, III H b Taf. I, I-IO; 2, 5; CVA Louvre I 8, III $\mathrm{H}$ b Taf. 24, I (CA 4632); Coldstream, GGP, 30 Nr. 4 Taf. 7 a; Rombos, Iconography, 4 I 3 Nr. 4 Taf. I 5 b. I7 a. 3 I b; A. Coulié, Deux vases monumentaux du Maître du Dipylon au Musée du Louvre, La Revue des Musées de France, Revue du Louvre I, 2010, 23-26 Abb. 3. I3. I6; eventuell zugehörig CVA Louvre I I, III H b Taf. 9, 7 (CA 3386); auf dem Krater Athen, NM 802: E. Kunze, Bruchstücke attischer Grabkratere, in: R. Lullies (Hrsg.), Neue Beiträge zur klassischen Altertumswissenschaft, Festschrift zum 60. Geburtstag von Bernhard Schweitzer (Stuttgart I954) 53 f. Taf. 5-8; CVA Louvre I I, III H b Taf. Io, 6 (CA 3398); F. Canciani, Geometrische Keramik in Göttingen, AA r967, 45 I f. Nr. 7 Abb. 9-1о (Hu 533 n); Coldstream, GGP, 3 I Nr. I7; Rombos, Iconography, 4I 5 Nr. I7 Taf. I a; auf einem Krater von der Piräusstraße: ADelt 17, I961/I962, Chron. 23 Taf. 22-23; Coldstream, GGP, 3 I Nr. I9; Rombos, Iconography, 4I 5 Nr. I8; auf dem Krater Rodin: CVA Musée National Rodin I Taf. 9, I-2. 4; CVA Tübingen 2 Taf. 26, I (S./IO I465). 2 (S./IO I466); Coldstream, GGP, 3 I Nr. 20; Rombos, Iconography, 4I 5 Nr. 20 Taf. 59 b; CVA Berlin ıo Beil. I4, 7 Taf. I I, I (2 I 55 x); Rezension von M. B. Moore, Bryn Mawr Classical Review 2009.09.49; und auf

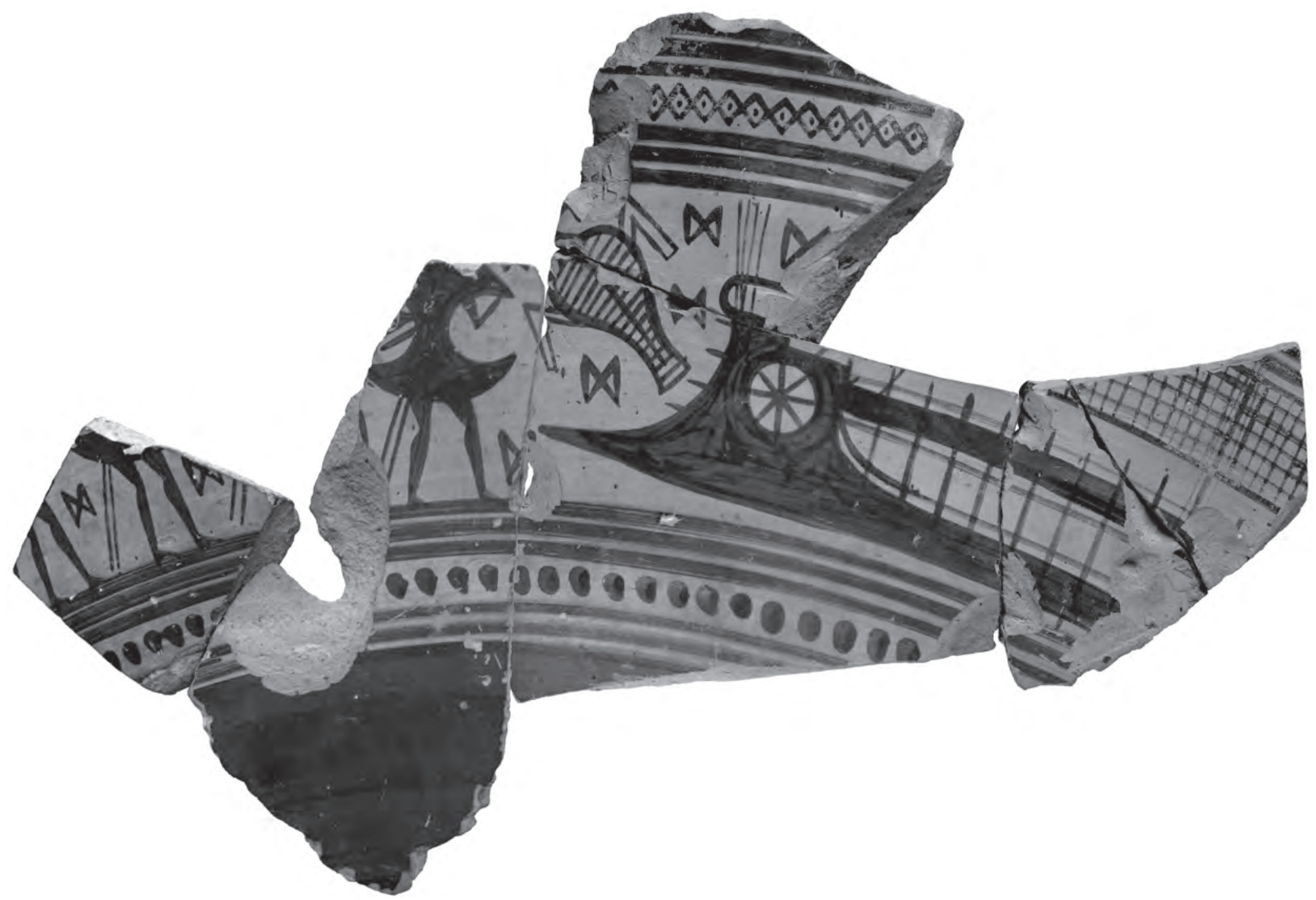

Abb. 8: Krater Kunze IV - Anpassung der Fragmente G 74I und Göttingen Hu 533 s (Foto Karl) sowie Fotomontage mit historischer Aufnahme des Fragmentes Athen, NM 802 von Hermann Wagner I937 (Negativ-Nr. D-DAI-ATH-NM-4300) 
dem Krater Louvre CA 3382: CVA Louvre I I, III H b Taf. 9, I-3; Coldstream, GGP, 3 I Anm. 4; Rombos, Iconography, 4I 8 Nr. 43. Auf Krateren der späteren Villards Gruppe werden Punktreihen zumeist mit Blattfriesen kombiniert, siehe Coldstream, GGP, 3 I f. Nr. 2 I-24 Taf. 8 a; Rombos, Iconography, 4I 5 f. Nr. 2 I-24 Taf. I 7 b. 30 a. 59. Eine alleinige Punktreihe als unterer Abschluss der figürlichen Friese besitzt im SG I a offenbar nur der Krater Kunze IV. Auf die Werkstatt des Dipylon-Meisters geht im SG I a die Erfindung der Doppeläxte in Konturenzeichnung als Füllornamente zurück, siehe Coldstream, GGP, 4I.

Zur Darstellung: Der untere Fries des Kraters Kunze IV ist mit zwei Kriegsschiffen und dazwischen wahrscheinlich je acht oder neun vom Betrachter aus gesehen nach rechts schreitenden Kriegern zu rekonstruieren. Wesentliche Fragmente des Kraters Kunze IV sind aufgrund der Schiff- und Kriegerdarstellungen bereits mehrfach publiziert worden: G. S. Kirk, Ships on Geometric Vases, BSA 44, I949, I02 Nr. I3; I07 Nr. 26 Taf. 39, I-2; J. S. Morrison - R. T. Williams, Greek Oared Ships 900-322 B. C. (Cambridge I968) ig f. 22 Nr. Geom. 5. 8 Taf. 2 b-d; J. L. Benson, Horse, Bird and Man. The Origins of Greek Painting (Amherst I970) I04 Taf. 39, 5; Ahlberg a. O. 206 f. Abb. 6I b-d; G. Ahlberg, Fighting on Land and Sea in Greek Geometric Art (Stockholm I97I) 25 f. Nr. BI. B8 Abb. 25-26. 39. Zur Deutung dieser Kampfbilder im Rahmen einer Inanspruchnahme heroengleicher Kraft und einer Erhöhung aristokratischen Selbstverständnisses in die heroisch-mythische Welt der Ilias siehe E. Kistler, Kriegsbilder, Aristie und Überlegenheitsideologie im spätgeometrischen Athen, GFA 4, 200I, I 59-I 85 ; J. M. Hurwit, Art, Poetry, and the Polis in the Age of Homer, in: Langdon, From Pasture to Polis, 30-36. Zum ikonographischen Wandel der Darstellungen von Kriegern in Parade oder im Kampf bzw. bei ihren Kriegsschiffen - mit einer Spätdatierung der ansonsten in Phase MG II angesetzten frühen Gefäße mit Kriegern - siehe A. Haug, Die Entdeckung des Körpers. Körper- und Rollenbilder im Athen des 8. und 7. Jahrhunderts, Image \& Context Io (Berlin/Boston 20I 2) IO-I I. I79-309; zu den Schiffsszenen, die nicht in Kampfhandlungen eingebunden sind, siehe bes. 296-297.

Zur Werkstatt: John N. Coldstream weist den Krater Kunze IV, zu dem das Fragment G 74I gehört, der Werkstatt des DipylonMeisters zu, genauer einem eng mit dem „Meister“ verbundenen Maler im SG I a, siehe Coldstream, GGP, 3 I Nr. I I. Zur Werkstatt siehe Davison, Workshops, 2I-40. I33-I40; Coldstream, GGP, 29-4I; Rombos, Iconography, 4I3-4I 8; J. N. Coldstream, A New Geometric Amphora from the Dipylon Workshop, in: S. Böhm - K.-V. von Eichstedt (Hrsg.), I@AKH. Festschrift für Jörg Schäfer zum 75. Geburtstag am 25. April 200I (Würzburg 200I) I 2 I-I 24. Zur Problematik, wie viele Malerhände überhaupt an der Herstellung solcher Monumentalgefäße beteiligt waren, vgl. Davison, Workshops, $3 \circ$ f. Kunze nahm u. a. aufgrund des weniger dichten Netzes der Füllornamente, der Symmetrie des Bildaufbaues und der strengen rhythmischen Bezogenheit der Ornamente zu den Figuren an, dass der Krater Kunze IV vor - wenngleich nur kurz vor - dem erwähnten Krater Louvre A 5 I 7 entstanden sei, siehe Kunze, Disiecta Membra, I69 f. Der am Krater Kunze IV über dem Fries mit Hopliten und Kriegsschiffen folgende Fries mit einem Wagenumzug mit Zweigespannen, die vom Betrachter aus nach rechts ziehen, findet eine - bis auf eine leicht differierende Anordnung der Füllornamente - Parallele in dem gerade noch erhaltenen Rest eines solchen Wagenumzug-Frieses auf dem erwähnten Krater Louvre A 5 I 7 des Dipylon-Meisters; vgl. z. B. das erwähnte Fragment Compiègne (ehemals Louvre A 549+559) mit einem losen Fragment, das dem Krater Louvre A 5 I 7 zugewiesen wird: CVA Louvre I I, III H b Taf. I, 6. Zu den kaum zu unterscheidenden Schiffsdarstellungen auf diesen beiden Krateren siehe Morrison - Williams a. O. 27 f. Nr. Geom. 5. 8 (Krater Kunze IV; Schiffmaler I) und Nr. Geom. 9 Taf. 3 a-b (Louvre A 5 I7; Schiff- maler I+). Die Kratere Kunze IV und Louvre A 5 I7 sind stilistisch kaum zu trennen.

\section{TAFEL 12}

\section{1-7. Skyphos mit Deckel}

\section{Beilage 4, 2.}

$\mathrm{G}_{42}$ und G 42 a. Aus Athen, Grabbezirk an der Piräusstraße nordöstlich vom Dipylon. Erworben I 875 durch Wolfgang Helbig in Athen, Ankauf. Ehemals Slg. Athanasios Rhousopoulos (Athen). Alte Inv.-Nr. II 55 (Schenkl) bzw. III 55 (Pichler).

Becken: H ges. 7,2 cm. - B mit Henkeln I 8, 0 cm. - Dm Rand I I, $0 \mathrm{~cm}$. - Dm Bauch I 2, $8 \mathrm{~cm}$. - Dm Boden 7, O cm. - Dm Henkel O,9-I,O cm. - Gewicht 2 I 2 g. - Volumen 503 ml. - Deckel: H 5, I cm. - Dm Rand IO, 2 cm. - Dm max. I I, I cm. - H Falz O, 5 cm. Dm max. Knaufplatte 2,5 cm. - H Knauf $3 \mathrm{~cm}$. - Dm Knaufstiel I, 5 cm. - Gewicht 90 g. - Gesamt: H I I, 5 cm. - Gewicht 302 g.

Lehner - Lorenz - Schwarz, Vasen, I7 f. Nr. 5-6 Textabb. auf S. I 8; Abb. 8. Io (M. Lehner).

Zustand: Beide Gefäßteile bis auf minimale Absplitterungen an Lippe und Kanten vollständig erhalten. Der Malschlicker am unteren Bereich der Außenseite des Beckens zum Teil abgeplatzt. Im Inneren des Beckens einige Kratzspuren und flächige Absplitterungen. Am Rand horizontal abgeriebene Streifen, die durch das Aufsetzen des gut passenden Deckels entstanden sind. Absprengungen aufgrund größerer Einschlüsse in der Keramik. Weiße Sinterkrusten zum Teil auf der Standfläche. Auf der Gefäßunterseite Beschriftung in Bleistift mit der Preisangabe in Francs: „4O/ Kerameik[os]“.

Technik: Keramik mit hellgrauen, bis zu $6 \mathrm{~mm}$ großen Einschlüssen durchsetzt, die Auswölbungen in der Wandung verursachten. Auf der Unterseite des Beckens eine leicht eingedrückte Stelle; Übergänge zum Deckel bzw. zur Knaufplatte durch Kanten betont. Oberfläche beider Gefäßteile außen fein geglättet; im Inneren feine Drehrillen. Farbe des Tongrundes: hellblassbraun (Io YR 7/3-4, very pale brown). Der dunkelbraun bis schwarz verfärbte und etwas glänzende Malschlicker wurde homogen und zum Teil relativ dick aufgetragen; das Innere mit einem breiten Pinsel ausgemalt. Reifen auf der Drehscheibe gezogen.

Form: Auf einer leicht gewölbten, sehr niedrigen Standplatte ein bauchiges Becken mit einem senkrecht hochgezogenen und etwas nach außen gebogenen Rand. Am Becken zwei gegenständige im flachen Winkel nach oben gestellte Horizontalhenkel mit rundem Querschnitt. Auf den Beckenrand passt der sehr flache Deckel mit einer spitz zulaufenden Lippe und einem leicht nach innen versetzten niedrigen spitzen Falz bündig an. Der zylindrische hohe Knauf ist vom Deckel kantig abgesetzt und trägt eine kegelstumpfförmige Platte mit waagrechter Oberseite.

Dekor: Am Gefäßansatz durchgehend bemalte Zone. Der Gefäßbauch wird unten und oben von je drei Reifen gegliedert und umrahmt damit auf Höhe der Henkel eine Bildzone. Am Rand des Beckens, unter der bemalten Lippenspitze, sitzt eine Kette aus einfach punktierten Tangentenkreisen. Die Bildzone ist zwischen den Henkeln auf beiden Seiten in drei Metopen gegliedert, die durch Gruppen aus je drei Vertikalstrichen getrennt sind. Die zentralen Metopen werden durch eine Blattrosette aus acht schraffierten spitzen Blättern um einen Mittelkreis gefüllt. Der Mittelkreis dieser Blattrosette schließt auf einer Gefäßseite ein Kreuz, auf der anderen einen achtzackigen Stern ein. In den Zwickeln der Blätter befinden sich einzelne Punkte. Seitlich wird die Blattrosettenmetope durch Vogelmetopen gerahmt. In diesen befinden sich als Füllornamente in den oberen Zwickeln je eine Punktrosette und 
eine rechtsdrehende Swastika. Eine einzige der vier Vogelmetopen besitzt auch im unteren Zwickel eine Punktrosette. In den vier Zwickeln zwischen den Henkeln und dem Metopenfries befindet sich drei Mal eine Punktrosette mit einer nach unten angesetzten Punktkette, einmal wird der Zwickel durch einen achtzackigen Stern gefüllt. An den Henkelansätzen je drei geschwungene Striche. Auf den Henkeln jeweils drei Striche. Die Gefäßinnenseite ist bis auf ein Lippenband mit einem Reifen und einer kleinen Kreisfläche im Zentrum durchgehend bemalt. Auf der Deckelaußenseite umzieht ein Reifen die Lippe, dann folgt ein Band aus schräg liegenden Parallelstrichen, die zum Teil durch dickere Striche gegliedert werden. Darüber wird ein konzentrisches tongrundiges Band mit einer Kette aus Tangentenklecksen von je drei konzentrischen Reifen eingefasst. Zum Knauf folgen ein breiteres Band und zwei Reifen. Der Knaufstiel und die Außenseite der Platte sind bis auf ein tongrundiges breites Band mit zwei Reifen durchgehend bemalt. Die Oberseite des Knaufes ist durch vier Striche in acht Segmente geteilt. Die Deckelunterseite und der Falz sind tongrundig.

Darstellung: Vögel - In den insgesamt vier Vogelmetopen befindet sich je ein identisch gezeichneter Vogel, antithetisch jeweils zur Mitte ausgerichtet. Der Vogel hat einen nach hinten spitz zulaufenden Körper mit einer separaten Bauchkontur, der Rest ist schraffiert. Die am Körper ansetzenden Beine bestehen aus drei Einzelstrichen. Der Hals mitsamt dem Kopf wurde mit einer breiten geschwungenen Linie gemalt, die verdickt endet. Am Kopf schließt ein dünner gerader Strich für den langen, leicht nach oben gerichteten Schnabel an.

\section{SG I b, um $750-740$}

Zur Erwerbung: Das Objekt wurde später in Becken G 42 und Deckel G 42 a getrennt inventarisiert. Beide wurden jedoch als zusammengehörig erworben, in der erhaltenen Quittung von Athanasios Rhousopoulos vom 24. Okt. I 874 heißt es: „Schale mit Deckel aus dem Kerameikos“.

Zur Form: In einem kontinuierlichen Schwung und ohne Gliederung geht der Bauch in den vertikal hochgezogenen und leicht verdickten Rand über, wie dies für spätgeometrische Skyphoi typisch ist; zur Formentwicklung siehe Coldstream, GGP, 48; zur Form vgl. z. B. den Skyphos: CVA Hannover I Taf. 4, 2 (I958, I). Skyphoi mit Deckel sind eine Erfindung im SG I a, siehe Coldstream, GGP, 460; Brouskari, Kerameikos, 3 I-37; vgl. die Skyphoi mit Doppel-Reflexbogenhenkel, bemalt mit einer TangentenkreisKette am Rand, aus Grab $\Theta$ der Nekropole südlich der Akropolis: Brouskari, Kerameikos, 34 f. Nr. 648 Taf. I9 (I955 EPK 648); aus einem Grab vom Athener Kerameikos: ADelt I8, I963, Chron. 29 f. Taf. 29 b, vorne links. Das letztgenannte Grab ist deswegen bekannt, da in ihm Reste eines monumentalen Grabkraters des Hirschfeld-Malers gefunden wurden, siehe dazu Coldstream, GGP, 4I Nr. 2. Ein bis auf den anderen Henkeltyp in der Form mit dem Skyphos G 42/42 a entsprechendes Gefäß (mit Deckel!) stammt aus Grab 3 des Grabbezirks auf dem Grundstück Sapuntzakis an der Piräusstraße nordöstlich des Dipylon: A. Brückner - E. Pernice, Ein attischer Friedhof, AM I8, I893, I05; S. Wide, Geometrische Keramik aus Griechenland, JdI I 4, I 899, 2 I 4 f. Abb. 99; N. Himmelmann-Wildschütz, Das Isis-Grab in Eleusis, MarbWPr I96I, I 2. I6 Taf. I; Rombos, Iconography, 39 f. 423 Nr. 94 (Athen, NM 723).

Zum Dekor: Ketten aus Tangentenkreise mit Innenpunkten, die seit MG II vorkommen, sind im Repertoire der Werkstatt des Dipylon-Meisters unbekannt. Während Tangentenkreise erstmals in der Werkstatt des Hirschfeld-Malers mit zusätzlichen Punkten neben den Tangenten bereichert werden, sollen Ketten aus Tangentenklecksen eine Erfindung dieser Werkstatt sein, siehe dazu Coldstream, GGP, 24. 36. 43; vgl. den Schöpfbecher aus der Slg. Jean P. Lambros: CVA Bruxelles, Musées Royaux du Cintquante- naire 3, III H b Taf. 2, 9 (A I 942); Coldstream, GGP, 42 Nr. I I; C. Briese - R. Docter, The Lambros Group: a Late Geometric Grave Group between Attica and the East, BABesch 69, I994, I 5-I 8 Nr. I 2 Abb. 30-33. Die achtfache Blattrosette mit Mittelkreis und Füllornamenten in einer Metope findet die engsten Vergleiche auf Gefäßen aus der Werkstatt des Hirschfeld-Malers bzw. aus deren Umkreis; vgl. den Schöpfbecher aus Grab VDAk I vom Athener Kerameikos: B. von Freytag gen. Löringhoff, Ein spätgeometrisches Frauengrab vom Kerameikos, AM 89, I974, I I f. Nr. 7 Taf. 3, I; 6, I-2 (4222); Krater mit seitlichem Ausguss: CVA Copenhague, Musée National 2, III H Taf. 72, 4 a-b (726); Coldstream, GGP, 42 Nr. 7; Kantharos: CVA München 3 Taf. I 20, I; I 2 I, I (850I). Punktrosetten und Swastiken als Füllornamente sind auf Vogelmetopen-Skyphoi geläufig. Zur Swastika, die entweder nur Dekorationselement (siehe J. Bouzek, Homerisches Griechenland im Lichte der archäologischen Quellen, Acta Universitatis Carolinae, Philosophia et Historica, Monographia 29 [Prag I969] I42 f.) oder symbolisch in Zusammenhang mit Vögeln als Sonnensymbolik zu verstehen sein könnte, siehe L. Goodison, Death, Women and the Sun. Symbolism of Regeneration in Early Aegean Religion, BICS Suppl. 53 (London I989) I26. I40-I 44.

Zur Darstellung: Der Skyphos G 42/42 a gehört zur Gruppe der Vogelmetopen-Skyphoi; siehe dazu N. Himmelmann-Wildschütz, Attisch-Geometrisch, MarbWPr I961, 9-14; Y. Backe-Forsberg C. Risberg, Two Late Geometric Bird Skyphoi in the Collection of Classical Antiquities in Uppsala, in: M. Blomberg (Hrsg.), From the Gustavianum Collections in Uppsala 3, Boreas 22 (Uppsala I993) 33 f. Eine Metopengliederung auf Skyphoi entsteht erst spät, als frühestes Beispiel gilt der genannte Skyphos Athen, NM 725 aus Grab 3 des Grabbezirks an der Piräusstraße, siehe Coldstream, GGP, 50. Charakteristisch für die Zwei-Vogel-Gruppe (siehe J. N. Coldstream, Geometric Skyphoi in Cyprus, RDAC I979, 26I f.) sind drei Metopen mit einer Mittelmetope aus einer Blattrosette, Parallel-Zickzack, Stapel von $\Lambda$-förmigen Winkeln, oder Kreise aus Tangentenkreisen mit Mittelkreis und seitlich je einer Vogelmetope. Zur Herkunft des Motivs Blattrosette zwischen antithetischen Vögeln siehe J. L. Benson, Horse, Bird and Man. The Origins of Greek Painting (Amherst 1970) 66. Hinsichtlich des Darstellungsschemas auf dem Skyphos G 42/42 a vgl. einen Skyphos aus der Slg. Jean P. Lambros: Briese - Docter a. O. 20 Nr. I6 Abb. 36 (SG I b-II a; verschollen) oder die vier Vogelmetopen-Skyphoi aus Grab 32: Kerameikos V I, 230 f. Taf. 97 (325-328; SG I). Zum Vogel als sepulkrales Symbol siehe B. Schweitzer, Die geometrische Kunst Griechenlands. Frühe Formenwelt im Zeitalter Homers (Köln I969) 95-97; G. Ahlberg, Prothesis and Ekphora in Greek Geometric Art, SIMA XXXII (Göteborg I97I) I39-I4I.

Zur Werkstatt: Innerhalb der Gruppe von Vogelmetopen-Skyphoi sind mehrere Werkstätten anzunehmen. Eine frühe Werkstatt, die von Athen 725, ist von Yvonne Backe-Forsberg und Christina Risberg überzeugend im Bestand isoliert: Y. BackeForsberg - C. Risberg, Two Late Geometric Bird Skyphoi in the Collection of Classical Antiquities in Uppsala, in: M. Blomberg (Hrsg.), From the Gustavianum Collections in Uppsala 3, Boreas 22 (Uppsala I993) $3 \mathrm{I}-37$. In den Vogeldarstellungen auf dem Skyphos G 42/42 a liegt hingegen eine andere Zeichenweise vor. Derselben Hand ist ein Randstück eines Skyphos aus dem Brunnen D I 2:3 zuzuweisen: E. Brann, Late Geometric Well Groups from the Athenian Agora, Hesperia 30, I96I, I Io Nr. I 45 Taf. 20 (P 25403); weitere Parallelen von Vogelmetopen-Skyphoi vor allem mit Vögeln inkl. Bauchkontur scheinen zu fehlen. Stilistisch eng verwandt sind Vögel auf einem Schöpfbecher: CVA Metr. Mus. 5 Taf. 38, 4-6 (I0.2 I0.3; SG I b). Zieht man das gesamte Erscheinungsbild mit Deckel in Betracht, so steht dem Grazer Stück der genannte Skyphos Athen, NM 723 aus Grab 3 des Grabbezirks an der Piräusstraße nordöstlich des Dipylon nicht allzu fern. Aus diesem Grab stammt der monumentale Grabkrater Athen, NM 
806 (SG I b) eines Malers, der wohl aus der Dipylon-Werkstatt hervorging, jedoch eigenständig ist, siehe dazu Kahane, Entwicklungsphasen, 477 Taf. 25; Coldstream, GGP, 46. Zum Maler von Athen 806 siehe A. Kauffmann-Samaras, La scène de Prothésis „disparue" sur le cratère 806 du Musée National d'Athènes, ADelt 28, I973, Mel. 235-240; W. Gauß - F. Ruppenstein, Die Athener Akropolis in der frühen Eisenzeit, AM II3, I998, 3I-33 Anm. I 6 (mit der zweifelhaften Zuweisung an die Dipylonwerkstatt). Der Skyphos Athen, NM 723 wird von John N. Coldstream zusammen mit Gefäßen, die von Davison, Workshops, 83-86. I 53 f. und in der Folge von Brouskari, Kerameikos, 60-73 und Rombos, Iconography, 352-357. 497-505 unter der Burly-Werkstatt - jedoch mit einem sehr heterogenen CEuvre - zusammengefasst sind, einem „Mannerist Workshop“ zugeschrieben; siehe die Rez. von J. N. Coldstream, JHS 95, I975, 290 f.; C. Dehl-von Kaenel in: CVA Berlin I0, 37. Dabei bilden zwei Kannen den Kern: CVA Louvre I6, III H b Taf. I4, I-2; 5I, I (CA 3452); I 5, I-2; 5 I, 2-3 (CA I 82 I); dazu gehören weiter: CVA Louvre I6, III H b Taf. 26, I-2; 53, I-3 (CA 2506); CVA Tübingen 2 Taf. I4, I-2; I 5, I-3 (W. K./I 2 2657); CVA Berlin Io Beil. 5, 2 Taf. I4, I-4; I 5, I-2 (V.I. 4506). Dem Skyphos Athen, NM 723 ist ein weiterer Skyphos zur Seite zu stellen, der aus Grab I an der Promachos-Straße stammt:

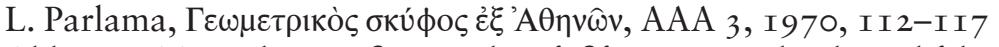
Abb. I-2. Trotz der Größen- und Gefäßformunterschiede und fehlender eindeutiger Kriterien steht der Skyphos G 42/42 a diesen genannten Gefäßen nahe; es finden sich in den Ornamentik sowohl Verbindungen zur Lambros-Werkstatt, zu Gefäßen, die zuletzt von Theodora Rombos der Burly-Werkstatt zugewiesen wurden, als auch zur Werkstatt des Hirschfeld-Malers.

\section{TAFEL 13}

\section{1-2. Standardpyxis}

Beilage 4, 3. Abb. 9.

G 719. Fundort unbekannt. Erworben in den I910/20er-Jahren durch Rudolf Heberdey, Schenkung des NM Athen (Scherbensammlung).

H erh. 7,3 cm. - B erh. I 5,4 cm. - Wandstärke 0,8 5-2, $0 \mathrm{~cm}$. - Dm Boden rek. 33,2 cm. - Dm Bauch rek. 36,9 cm. - Gewicht I $89 \mathrm{~g}$.

Unpubliziert.

Zustand: Bodenstück; erhalten Teil des Bauches und Bodens. Oberfläche etwas verwittert; die Kante des Bodens etwas bestoßen; wenige Absprengungen durch Einschlüsse. Der Malschlicker ist auf der Außenseite - dort wo er nicht dick aufgetragen ist - verblasst. Oberfläche partiell von einem weißen Schleier überzogen. Beschriftung in schwarzer Tusche im Inneren: „Mus. Ath.“.

Keramikart: Farbe des Bruches: rötlichbraun ( 5 YR 5/4, reddish brown); sehr hart; fein (<0,2 mm); ohne Dunkelglimmer; spröde und körnige Oberfläche des Bruches; zahlreich mit weißen Karbonatpseudomorphosen durchsetzt (im Durchschnitt o,०5 mm); viele dunkelgraue bis schwarze, blättrige bis runde Einschlüsse (bis 3 $\mathrm{mm}$ ); einzelne gelblichweiße runde Kalkeinschlüsse (bis 3,5 mm).

Technik: Oberfläche außen gut geglättet. Farbe des Tongrundes: blassbraun bis hellblassbraun (IO YR $6 / 3-7 / 3$, pale brown very pale brown). Der braun bis schwarz verfärbte und sehr matte Malschlicker gleichmäßig aufgetragen. Reifen auf der Drehscheibe gezogen (insgesamt zehn Reifen, davon sind die mittleren sechs für das Schachbrettmuster verwendet).

Form: Große Pyxis mit flachem Boden samt niedrigem Standring und mit einer leicht gekrümmten Wandung.
Dekor: Auf der Unterseite ein konzentrisches Muster, bestehend von innen aus drei Reifen, einer Rautenkette mit Innenpunkten und vier Reifen, einem äußeren breiten Band und auf dem Standring eine Punktreihe. Auf der Gefäßaußenseite hat sich über einem umlaufenden Schachbrettmuster zwischen je zwei feinen Reifen ein Ornamentband aus schraffiertem Zickzack erhalten, in den Zwickeln Doppeläxte. Gefäßinnenseite tongrundig.

SG I b - II a, um $740 / 730$

Zur Form: Aufgrund des charakteristischen Profils der Wandung handelt es sich beim Fragment G 7I9 um eine spätgeometrische Standardpyxis nach der Formtypologie von Barbara Bohen (Formtyp I 2): Kerameikos XIII, 27-40 Abb. 2; Coldstream, GGP, $47 \mathrm{f}$.

Zum Dekor: Ein überbetontes großgliedriges Zickzack, das an prominenter Stelle den Gefäßkörper umläuft, begegnet in der attischen Keramik selten; meistens findet sich ein solches Ornamentband in untergeordneten Dekorzonen, wie z. B. an Steilrandschalen, wie aus Grab 24: Kerameikos V I, 226 Taf. I20 (374. 378; SG I b); aus Grab 72: Kerameikos V I, 259 Taf. I I9 (382; SG I b/SG II a); oder im unteren Bereich der Halsdekoration bei Kannen, wie der am Übergang zu SG II a stehenden hohen Kanne aus Grab 5I: Kerameikos V I, 246 Taf. II3 (I3 I4); oder bei hohen Kannen der Soldier-Bird-Werkstatt aus Grab I von Spata und aus der Slg. Michael Vlastos: Kahane, Entwicklungsphasen, 479. 482, Taf. 27, I-2; Coldstream, GGP, 64 Nr. IO-I I (SG II b). An zentraler Position umläuft ein schraffiertes Zickzack - die Zwickel sind mit Kreisen mit Innenpunkten gefüllt - eine Kanne aus dem Votivdepot H I7:4: Agora VIII, 35 Nr. 40 Taf. 4 (P 532; SG I b/II a); mit achtzackigen Sternen gefüllt die Schulter der hohen Kanne der Werkstatt von Athen 706: CVA Prague, Université Charles I Taf. 9, I-2; IO, I; I6, 3. 5 (80.3; SG I/II); Coldstream, GGP, 5 I Nr. 5. Zum schraffierten Zickzack siehe Kerameikos V I, 93. Ein schraffiertes Zickzack ist scheinbar auf Standardpyxiden unbekannt. Ein umlaufendes Schachbrettmuster an zentraler Stelle zeigen mehrere Gefäße, die aus der Werkstatt des Dipylon-Meisters stammen bzw. in seiner Nachfolge stehen, so eine Halshenkelamphora: CVA München 3 Taf. I06, I-2; I07, 2-4 (6080); Davison, Workshops, 22 Nr. A-5 Abb. 5; Coldstream, GGP, 32 Nr. 32; zwei Kannen: CVA Louvre I6, III H b Taf. I4, I-2; 5 I, I (CA 3452); I 5, I-2; 5 I, 2-3 (CA I 82 I). Auch in der VogelfutterWerkstatt gibt es dazu Beispiele, vgl. eine hohe Kanne: CVA Brit. Mus. I I Taf. I6-I7, 27 (GR I977.I2-7.8; SG II a). Auf Pyxiden ist ein umlaufendes Schachbrettmuster kaum belegt; zu nennen ist eine wesentlich kleinere in das dritte Viertel des 8. Jhs. datierte Standardpyxis aus Grab G I 2:9: Young, Graves, 9I Nr. 4 Abb. 60 (P 4780; Dm Bauch I6,3 cm); Agora VIII, I 27.

Zur Werkstatt: Die für athenische Gefäße untypische Keramikart des Fragmentes G 7I9 scheint eine Produktion außerhalb

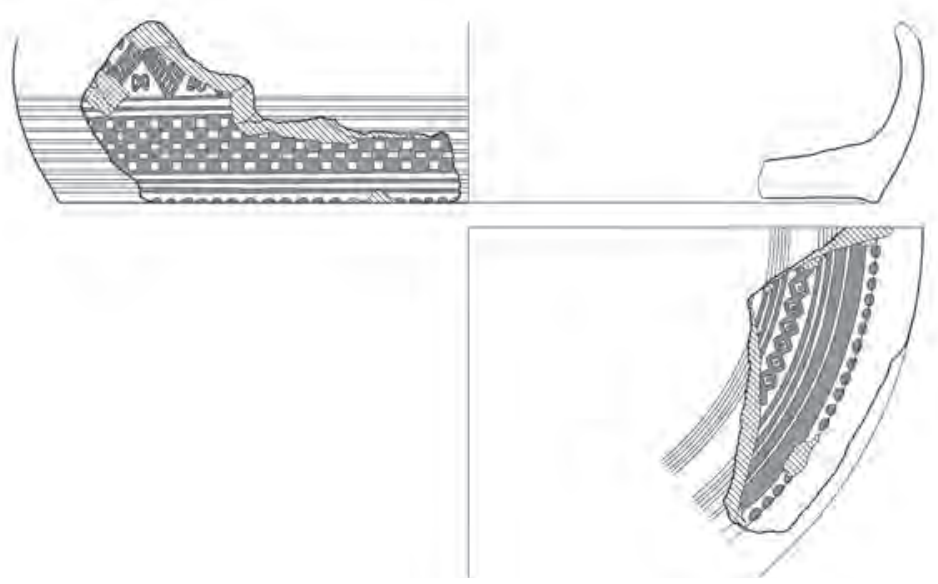

Abb. 9: Umzeichnung der Standardpyxis G 7I9 im Maßstab I:4 (Zeichnung Karl) 
Athens nahezulegen. Neben dem großen Produktionszentrum in Athen gibt es weitere Werkstätten in Attika, die auf lokale Tonlagerstätten zurückgreifen und die erst in letzter Zeit auch in ihren Arbeiten bekannt geworden sind, siehe dazu Coldstream, GGP, 460; für Merenda: Xagorari-Gleißner, Merenda, 3-6; für Thorikos: Rombos, Iconography, 357-362; für Trachones: J. M. Geroulanos, Grabsitten des ausgehenden geometrischen Stils im Bereich des Gutes Trachones bei Athen, AM 88, I973; Rombos, Iconography, 362-368; bes. 363 Anm. 8; siehe auch C. Dehlvon Kaenel in: CVA Berlin Io, I09. Für die Kombination aus umlaufendem Schachbrettmuster und schraffiertem Zickzack lassen sich zwei Parallelen anführen, die zueinander in einer Verbindung stehen, eine Kanne aus Athen: CVA Tübingen 2 Taf. 8, I-2; 9, I-3 (28.5446); H. Siebenmorgen (Hrsg.), Zeit der Helden. Die „dunklen Jahrhunderte“ Griechenlands I 200-700 v. Chr., Ausstellungskatalog Badisches Landesmuseum Karlsruhe, 25.I0.2008-I 5.02.2009 (Darmstadt 2008) 228 f. Nr. I37 Abb. (Y. Leylek); Rombos, Iconography, 422 Nr. 84 Taf. 2 a, und eine Kanne mit einem „abgearbeiteten“ hohen Hals: CVA Heidelberg 3 Taf. Io8, I-3 (G 59). Beide Kannen zeigen Doppeläxte als Füllornamente, die Kanne Heidelberg G 59 sogar im Ornamentband mit Zickzack; zu diesem Füllornament, das auf die Werkstatt des Dipylon-Meisters zurückgeht, siehe Coldstream, GGP, 4I. An der Kanne Tübingen 28.5446 ist dieser Einfluss in den liegenden Steinböcken mit zurückgewendeten Köpfen auch deutlich zu sehen. Die Kanne Heidelberg G 59 wirkt dazu wesentlich provinzieller, zu dieser steht jedoch das Pyxidenfragment G 719 in enger Verbindung, wenn nicht sogar wegen der identischen und ebenso nachlässigen Malweise aus derselben Werkstatt herrührend. Karl Kübler sieht in den Kannen Tübingen 28.5446 und Heidelberg G 59 einen inselgriechisch-attischen Mischstil; siehe Kerameikos VI 2, 55 f. Anm. I38. Zu den stilistischen Verbindungen zwischen attischer, euböischer und inselgriechischer Keramik während der

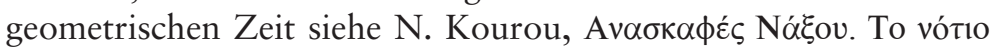

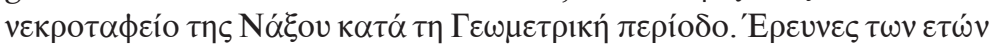

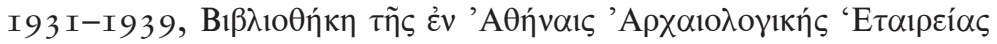
I93 (Athen I999) 90-I06; zur SG-Keramik und zur Variabilität der Stile siehe Kourou a. O. I00-106. I23-I26; vgl. dazu auch C. Dehl-von Kaenel in: CVA Berlin Io, Io6 f. Eine naturwissenschaftliche Keramikanalyse des Pyxidenfragmentes G 7 I 9 könnte vielleicht Klärung bringen.

\section{3-4. Pferdepyxis}

Beilage 4, 4. Abb. 10.

G 729. Aus Athen. Erworben I908/I0 durch Hans Schrader. Ehemals Slg. Hans von Prott (Athen).

H erh. 7,2 cm. - B erh. 9,6 cm. - Wandstärke 0,7-I,7 cm. - Dm Boden rek. 39,6 cm. - Dm Bauch rek. 42,6 cm. - Gewicht 94 g. Unpubliziert.

Zustand: Bodenstück; erhalten Teil des Bauches und Bodens. Bruchkanten scharf; Oberfläche außen stark bestoßen und angekratzt. Beschriftung in schwarzer Tusche auf der Innenseite: "Athen/v. Prott“.

Keramikart: Farbe des Bruches: im Kern rötlichbraun ${ }_{5}$ YR 5/4, reddish brown), außen gelblichbraun (Io YR 5/4, yellowish brown); sehr hart; fein (<0,2 mm); ohne Dunkelglimmer; zahlreich von weißlichen Karbonatpseudomorphosen durchsetzt; wenige rotbraune Eisenoxid-Konkretionen (bis o,I mm); kaum größere Einschlüsse (bis o,2 mm).

Technik: Oberfläche außen fein geglättet, innen feine Drehrillen und Spuren einer Nachglättung mit einem kantigen Werkzeug. Farbe des Tongrundes: hellbraun bis hellgelblichbraun (7.5 YR 6/4 -
IO YR 6/4, light brown - light yellowish brown). Der dunkelbraun bis schwarz verfärbte und glänzende Malschlicker lasierend aufgetragen, die Quadrate im Schachbrettmuster sind klecksartig und pastos ausgefüllt. Sowohl im Inneren als auch außen Farbkleckse des Malschlickers.

Form: Große Pyxis mit einem flachen Boden samt schwach ausgeprägtem Standring und einer leicht gekrümmten, nahezu senkrecht ansteigenden Wandung.

Dekor: Auf der Gefäßunterseite hat sich der Rest einer konzentrischen Rautenkette mit Innenpunkten erhalten, darum drei konzentrische Reifen, auf dem Standring ein Punktfries. Auf der Gefäßaußenseite ein Reifen, darüber eine Rautenkette mit Innenpunkten, von je zwei Reifen eingefasst. Darüber ein MetopenTriglyphen-Fries aus einem Feld mit einer linksdrehenden schraffierten Swastika mit zusätzlichen Haken und einem Triglyphenfeld mit einem Schachbrettmuster zwischen schmalen Vertikalfeldern mit schräg liegenden Parallelstrichen, getrennt durch je drei Vertikalstriche. Die Swastika wechselt im rechten oberen Haken die Schraffurrichtung.

\section{SG I b - II a, um 740/730}

Zur Form: siehe die Standardpyxis G 7 I9, hier Tafel I3, I-2. Die Größe des rekonstruierten Bauchdurchmessers von etwa $42 \mathrm{~cm}$ sowie der charakteristische Metopen-Triglyphen-Fries weisen darauf hin, dass dieses Fragment zu einer Pferdepyxis zu ergänzen ist, siehe dazu Kerameikos XIII, 38-40; Bouzek, Prag, I34-I36.

Zum Dekor: Pferdepyxiden sind ab SG I b zumeist mit einem Metopen-Triglyphen-Fries versehen; siehe Coldstream, GGP, 50. Eine Kombination aus Feldern mit schraffierten Swastiken mit zusätzlichen Haken, Triglyphenfelder mit Schachbrettmuster sowie Rautenketten mit Innenpunkten in einem Bauchfries findet sich ab Ende SG I b auf Gefäßen verschiedener Werkstätten außerhalb und innerhalb der klassischen Tradition, so auf einer Kanne der Werkstatt von Athen 706 (linksdrehend): CVA Tübingen 2 Taf. Iо. I I, I-3 (S./Iо I090); Coldstream, GGP, 5 I Nr. I I; Rombos, Iconography, 42 I Nr. 7I Taf. 2 b; auf einer Kanne der Werkstatt der Swastika mit zusätzlichen Haken (linksdrehend): H. Froning, Katalog der griechischen und italischen Vasen, Museum Folkwang Essen (Essen I982) 6I-65 Abb. (I79); auf einer Amphora der Werkstatt der Swastika mit zusätzlichen Haken (rechtsdrehend): Coldstream, GGP, 66 Nr. 6 Taf. I 2 b-c; Louvre I 6 Taf. 27, I-2; 52, I-3 (CA I 823), Rombos, Iconography, 476 Nr. 243 Taf. 73 b; eine hohe Kanne aus Grab 5/6 der Nekropole an der Erysichthonos- und Nileos-Straße, die im Vergleich mit Athen, NM 77 I (Coldstream, GGP, 66 Nr. 2) wohl der Werkstatt der Swastika mit zusätzlichen Haken zuzuweisen ist (rechtsdrehend): ADelt 22, I967, Chron. 80 Taf. 80 d; sowie auf zwei Kannen der VogelfutterWerkstatt (linksdrehend): CVA Bochum I Taf. 6, 5; 7, I-2 (S 466); D. M. Robinson - C. G. Harcum - J. H. Iliffe, A Catalogue of the Greek Vases in the Royal Ontario Museum of Archaeology, Toronto (Toronto I930) 28 f. Nr. I I 7 Taf. 8 (C. 20I); Rombos, Iconography, $475 \mathrm{Nr}$. 242. Zu den genannten Werkstätten siehe Davison, Workshops, 55-62; Coldstream, GGP, 5I-53. 66-70;

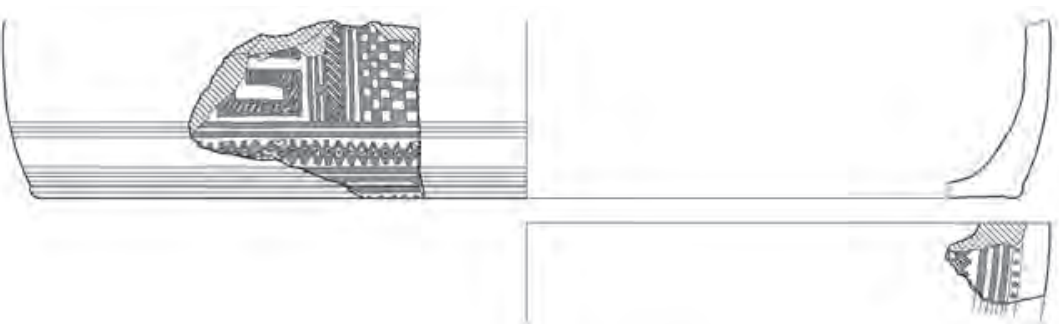

Abb. ıo: Umzeichnung der Pferdepyxis G 729 im Maßstab I:4 (Zeichnung Karl) 
Rombos, Iconography, 42I. 470-477. Rautenketten mit Innenpunkten sind auf Standardpyxiden seit SG I üblich; siehe allgemein Kerameikos XIII, 39; vgl. z. B. V. Jarosch-Reinholdt, Die geometrische Keramik von Kap Kolonna, Ägina - Kolonna 4 (Wien 2009) 33 f. I 20 Nr. 272 Beil. I I Taf. 25 (Fgr. 208-5; SG I). Zwei statt drei Reifen als Trennung unter dem Fries ist unkanonisch, doch in einzelnen Beispielen auch in der Vogelfutter-Werkstatt bei kleineren Gefäßen belegt; so z. B. bei der Steilrandschale Oxford I927.4447: Coldstream, GGP, 68 Nr. I9 Taf. I 2 e.

Zur Werkstatt: Größe, Dekorabfolge und Ornamente verbinden das Pyxidenfragment G 729 mit zwei Pyxiden, die von Barbara Bohen der Pyxidenwerkstatt von Louvre A 567 zugewiesen werden: CVA Louvre I6, III H b Taf. 2I, I-2; 22, I-2; 23, I Abb. 2 (A 567; SG I b); CVA Berlin ıо Taf. I 5, 3-6; I6, I-4 Beil. 3, 8 (V.I. 3 I43; SG II a); zur Werkstatt siehe Kerameikos XIII, 75 f.; C. Dehl-von Kaenel in: CVA Berlin ı。, $4 \circ$ f. Das Grazer Exemplar ist mit einem rekonstruierten Durchmesser von knapp über 40 $\mathrm{cm}$ in dieser Gruppe etwas größer als die bislang dieser Werkstatt zugewiesenen Pyxiden, die einen maximalen Bauchdurchmesser von 34-35 cm besitzen. Charakteristisch für die Pyxidenkörper dieser Werkstatt ist die Dekorabfolge am Gefäßbauch: Metopen mit Swastika und Rauten sowie Horizontalfelder mit Doppelmäander wechseln mit Triglyphen aus Schachbrettmustern zwischen Vertikalfeldern aus schräg liegenden Parallelstrichen ab. Ein weiteres Kriterium für diese Zuordnung könnte die enge Beziehung des Grazer Stückes zur genannten Kanne Bochum S 466 des Vogelfutter-Malers sein. Auf dieser Kanne befindet sich in der Bauchzone eine nahezu deckungsgleiche Dekorabfolge. Die Pyxiden aus der Werkstatt Louvre A 567 stehen nach Bohen der Vogelfutter-Werkstatt nahe, wenn nicht sogar aus dieser Werkstatt stammend; siehe dazu Kerameikos XIII, 76; C. Dehl-von Kaenel in: CVA Berlin Io, 40 f.; vgl. die Steilrandschale der Vogelfutter-Werkstatt aus Grab I der Nekropole an der Erysichthonos- und Nileos-Straße: ADelt 22, I967, Chron. 80 Taf. $80 \gamma$; Rombos, Iconography, 474 f. Nr. 239. Zum Vogelfutter-Maler und seiner Werkstatt siehe Davison, Workshops, 55-62. I 5 I f.; Coldstream, GGP, 67-70; Rombos, Iconography, 470-475. Einer sicheren Zuweisung zur Werkstatt von Louvre A 567 steht aber der fragmentarische Erhaltungszustand des Grazer Stückes entgegen.

\section{5-8. Teller mit Henkeln}

\section{Beilage 5, 1.}

G 43. Aus Athen, Grabbezirk an der Piräusstraße nordöstlich vom Dipylon. Erworben I875 durch Wolfgang Helbig in Athen, Ankauf. Ehemals Slg. Athanasios Rhousopoulos (Athen). Alte Inv.Nr. II 56 (Schenkl) bzw. III 56 (Pichler).

H 4,9 cm. - B mit Henkeln 20,0 cm. - Dm Rand I $5,0 \mathrm{~cm}$. Dm max. Mündung I 5,8 cm. - Dm Boden 6,4 cm. - B Henkel I I,4-I I, $6 \mathrm{~cm}$. - Dm Henkel I, O cm. - Volumen $450 \mathrm{ml}$.

Lehner-Lorenz-Schwarz, Vasen, I $6 \mathrm{Nr} .4$ Abb. $4-5$ (M. Lehner).

Zustand: Das in fünf größere Fragmente mit einigen kleineren Absplitterungen zerbrochene Gefäß wurde wieder zusammengesetzt, die größeren „Verlustscherben“ mit Gips ergänzt und farblich retuschiert. Oberfläche leicht bestoßen und angekratzt. Einige kleine ausgebrannte bzw. ausgewitterte Einschlüsse. In den Vertiefungen Reste einer weißen sinterartigen Schicht.

Technik: Keramik mit einigen teilweise bis zu Io mm großen hellgrauen Einschlüssen durchsetzt, die zu starken Unregelmäßigkeiten in der Wandung führten. Oberfläche außen gut geglättet, im Inneren feine Drehrillen. Auf der Unterseite ist je eine Rille innerhalb und außerhalb des Umbruches der Standfläche zur Wandung mit einem kantigen Werkzeug gezogen. Farbe des Tongrundes: hellblassbraun ( IO YR 7/4, very pale brown). Der mittel- bis dunkelbraun verfärbte matte Malschlicker flüchtig und zum Teil lasierend aufgetragen. Reifen auf der Drehscheibe gezogen. Der Malschlicker im Inneren offenbar durch zu wenig Sauerstoffzufuhr beim Brennvorgang ins Rotbraune verfärbt.

Form: Flaches Gefäßbecken auf einer Standfläche mit einer leicht konischen Erhebung im Gefäßinneren und mit einer gerade abgestrichenen Lippe. Zwei gegenständige breite Horizontalhenkel mit rundem Querschnitt und seitlichen, nach außen stehenden dornartigen Enden.

Dekor: Auf der Gefäßunterseite befindet sich ein I6-zackiger Stern innerhalb zweier konzentrischer Reifen, am Rand der Standfläche ein weiterer Reifen. Auf der Außenseite folgen fünf Reifen, eine umlaufende Punktreihe und wiederum sechs Reifen. In der Zone zwischen den Henkeln sitzt je eine Punktreihe, darüber zwei Horizontalstriche, seitlich als Abschluss zu den Henkelansätzen je drei Vertikalstriche. Die tongrundige Lippe ist mit Strichgruppen von acht, neun oder zehn kurzen Strichen verziert. Das Gefäßinnere ist bis auf eine kleine Kreisfläche auf der Spitze der zentralen Erhebung und einem Band im unteren Bereich des Beckens durchgehend bemalt. Entlang der Henkel führen drei breite Striche.

SG I b - II a, um 740-720

Zur Form: Im SG werden nach Vorläufern im MG II Teller mit seitlichen Reflexbogenhenkeln im Gefäßrepertoire üblich; siehe Kerameikos V I, I37 f.; Young, Graves, I62-I65; Agora VIII, 44; Coldstream, GGP, 49. 87; vgl. mit ähnlichem Profil, jedoch deutlich kleiner, ein Tellerfragment aus Brunnen D I I:5: Young, Graves, I 36 Nr. 79 Abb. I I 4 . I I 6 (P 7487); bzw. mit einem Randdurchmesser von 19,6 cm einen Teller aus Grab 28: Kerameikos V I, 228 Taf. IO3 (27I; SG I b-II a). Die Wandung des Tellerbeckens wird im SG II gerader; vgl. einen Teller mit Punktreihe und Tangentenkreiskette aus Kynosarges: J. N. Coldstream, The BSA's Geometric Collection: Kynosarges et alia, BSA 98, 2003, 335 Nr. K I I Taf. 4I (SG II; Dm Rand I6,9 cm).

Zum Dekor: Ein Reifendekor mit einer Abfolge von Punktreihen ziert viele der einfach bemalten Gefäße, wie Schöpfbecher, z. B. aus Grab 86: Kerameikos V I, 265 Taf. I I I (83 I; MG II); Kännchen, z. B. CVA Copenhague, Musée National 2, III H Taf. 70, 8 (7086); oder Pyxiden, z. B. aus Grab G I 2:I7: Young, Graves, 82 Nr. I I

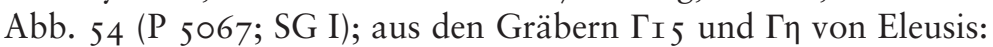
Mylonas, Eleusis, ro9 Nr. I6I Taf. 239 b. 240 c (MG I); I39 Nr. 223 Taf. 260 b (SG I); oder eben Teller, z. B. der genannte Teller Athen, Kerameikos-Museum 27I. Zum Dekor, der von MG I bis SG häufig belegt ist, siehe C. Dehl-von Kaenel in: CVA Berlin Io, 23 f. Zum Zusammenhang des Dekors zwischen Teller und Pyxiden siehe C. Dehl-von Kaenel in: CVA Berlin Io, 33. Der I6-zackige Stern als Füllornament ist eine Innovation im SG I a (in der Werkstatt des Dipylon-Meisters), siehe dazu Coldstream, GGP, 4I.

Zum Typ: Ein zum Teller G 43 nahezu identisches Exemplar befindet sich in Amsterdam, Allard Pierson Museum: CVA Musée Scheurleer I, III H b Taf. 2, 4 (Sch. 596; H 6,5 cm; Dm Rand $\mathrm{I} 6,0 \mathrm{~cm}$ ). Dieser Teller stammt ebenfalls aus der Slg. Athanasios Rhousopoulos. Differenzen liegen vor allem in der Randgestaltung des Amsterdamer Stückes, bei dem das Randprofil nach innen biegt und eine Art von Randfalz ausbildet. Die Teller in Graz und Amsterdam sind aber in ihrem Malduktus und in ihrer technischen Ausführung auf das Engste verbunden. Für neue Aufnahmen und Maße dieses Tellers ist Geralda Jurriaans-Helle (Amsterdam) zu danken. Ähnlich von einfacher Form, jedoch mit Tangentenkreisketten, sind die Teller in Frankfurt am Main, Museum für Vorund Frühgeschichte: CVA Frankfurt I Taf. Iо, 2-3 ( $\beta$ 226; SG; Dm Rand 22,2 cm) und CVA Karlsruhe I Taf. 3, 6 (B I 5 I 4; SG); bzw. aus Grab Io (I 8) I 2 von Thera: E. Pfuhl, Der archaische Friedhof am Stadtberge von Thera, AM 28, I903, I 8 I Nr. 20 Beil. 25, 2 (Dm Rand 2I cm). 


\section{TAFEL 14}

\section{1-2. Steilrandschale auf hohem Fuß}

Beilage 5, 2. Abb. 11.

G 733. Fundort und Erwerbung unbekannt.

Zwei Fragmente: A) H erh. 6,6 cm. - B erh. 8,4 cm. - Wandstärke $0,4-0,55 \mathrm{~cm}$. - B) H erh. 3,8 cm. - B erh. 7, I cm. - Wandstärke 0,45-0,55 cm. - Dm Rand rek. I6,6 cm. - Dm Bauch rek. I4,6 cm. - L Henkel 8, I cm.

Unpubliziert.

Zustand: Zwei Randstücke; erhalten Profil vom Rand bis zum unteren Becken sowie ein Henkel. Fragment A aus zwei Einzelstücken zusammengesetzt; an den Bruchkanten Reste ehemaliger Klebungen, die auf weitere Fragmente hinweisen, die sich jedoch nicht in der Originalsammlung des Instituts für Archäologie der KarlFranzens-Universität Graz befinden; Oberfläche leicht abgerieben, etwas stärker der Rand. Die Kante unter dem Henkel ist besonders stark abgerieben, zusätzlich ist ein Teil regelrecht abgeschliffen.

Keramikart: Farbe des Bruches: hellbraun bis rosafarben $(7.5$ YR 6/4-7/4, light brown - pink); mittelhart; fein (<0,2 mm); ohne Dunkelglimmer; viele zum Teil große rotbraune Partikel (bis 8 $\mathrm{mm})$; zahlreich mit sehr kleinen Karbonatpseudomorphosen ( 0,05 $\mathrm{mm}$ ) durchsetzt; einzelne rotbraune Eisenoxid-Konkretionen (bis $\mathrm{O}, \mathrm{I} \mathrm{mm})$.

Technik: Oberfläche beidseitig geglättet. Farbe des Tongrundes: hellblassbraun (Io YR 7/3-4, very pale brown). Der außen dunkelbraun bis schwarz, innen rot verfärbte und glänzende Malschlicker zügig und stellenweise dick aufgetragen.

Form: Flaches, bauchig einziehendes Becken mit einem leicht nach außen stehenden, konkaven hohen Rand. Zwei gegenständige Horizontalhenkel mit langovalem Querschnitt und nach außen gebogenen flachen Enden. Trotz des Fehlens des eigentlichen Bodens ist das Fragment als Schale auf hohem Fuß zu ergänzen.

Dekor: Das Schalenbecken ist mit drei Reifen, einem breiten Band und drei weiteren Reifen bemalt. Darüber sitzt an der Auswölbung zwischen den Henkeln eine Ornamentzone, von der seitlich fünf Vertikalstriche erhalten sind. Der hohe Rand ist mit einem Metopendekor versehen, der unten von zwei Reifen, oben von einem Reifen begrenzt wird. In diesem Fries befindet sich eine Abfolge von Metopen mit einer rechtsdrehenden schraffierten Swastika und Triglyphen aus einem schmalen Mittelfeld mit einem Stapel M-förmiger Winkel zwischen je einem schmalen Vertikalfeld aus gegenständig schräg liegenden Parallelstrichen. Die Schraffurrichtung im Mäander wechselt nicht. Getrennt werden diese Ornamente durch je drei Vertikalstriche. Die Swastiken sitzen mit ihren Armen an diesen Trennlinien an. Die Lippenspitze ist bemalt. Auf der Gefäßinnenseite auf Höhe des Bauches eine tongrundige Zone zwischen der ungleichmäßigen Ausmalung des Beckenbodens und der Bemalung des Randes, unter der Mündung ein sehr unregelmäßiges breites Lippenband mit einem Reifen. Auf den Henkelaußenseiten wechseln Andreaskreuze mit Gruppen aus meistens drei Vertikalstrichen $a b$.

SG II b, um 720-700

Zur Form: Zur Entwicklung der Steilrandschalen mit ihren charakteristischen Reflexbogenhenkeln, aus denen sich ab SG II b vermehrt Gefäße auf einem durchbrochenen hohen Fuß bilden, siehe Kerameikos V I, 82-87; Young, Graves, 205; Coldstream, GGP, 48. 86; J. N. Coldstream in: CVA Brit. Mus. I I, 39. Formal ähnlich, jedoch mit geradem Rand, ist die kleine Steilrandschale CVA Moscow, Pushkin State Museum 9 Taf. 4, 3-6 (II I b I429; SG II b; Dm Rand I4,5 cm) bzw. mit dem gleichen Randdurchmesser wie das Grazer Exemplar die Steilrandschale CVA Jena I Taf. 4, 5-6 Beil. 3, 2 (V 83; SG I b-II a; Dm Rand r6,6 cm).

Zum Dekor: Eine Abfolge von Metopenfeldern mit Swastiken, die sich auch mit Vögeln und Vierblatt abwechseln können, sowie Triglyphen aus M-Winkeln oder Parallel-Zickzack ist die häufigste Dekoration der Randzone von späten Steilrandschalen. Auf dem Grazer Exemplar können sieben bis maximal acht Metopen rekonstruiert werden. Im Dekor verwandt sind die Steilrandschalen auf hohem Fuß aus Grab Io und 53: Kerameikos V I, 21 5. 248 Taf. I 22-I 23 (872. I328; SG II b). Die genannten Beispiele haben linksdrehende Swastiken. Zum Dekorsystem auf Steilrandschalen (ohne hohen Fuß) siehe S. McNally, An Attic Geometric Vase in the Collection of Mt. Holyoke College, AJA 73, I969, 459-464; bes. 460 Klasse $2 \mathrm{~B}$.

Zum Typ: Eine identische Abfolge des Metopenfrieses aus rechtsdrehenden Swastiken und Triglyphen mit einem Stapel aus M-förmigen Winkeln (jedoch mit schmalem Vertikalfeld aus gleichmäßig schräg liegenden Parallelstrichen) findet sich auf einer Steilrandschale auf hohem Fuß: CVA Brit. Mus. I I Taf. 57, I I4 (GR I963.4-30.I; SG II b); vgl. dazu aus Grab 33: Kerameikos V I, 23 I Taf. I2I (392; SG II b).

\section{3-4. Deckel}

Beilage 5, 3.

G 95. Fundort unbekannt. Erworben um I9I2/I3 durch Rudolf Heberdey, Tausch mit dem NM Athen.

$\mathrm{H}$ ges. 5,2 cm. $-\mathrm{Dm}$ Rand I I, $8 \mathrm{~cm}$. - Dm max. I 2,9 cm. - Dm Knauf oben 3,I cm. - Dm Knauf unten 2,0 cm. - H Knauf I,9 cm. - Gewicht I42 g.

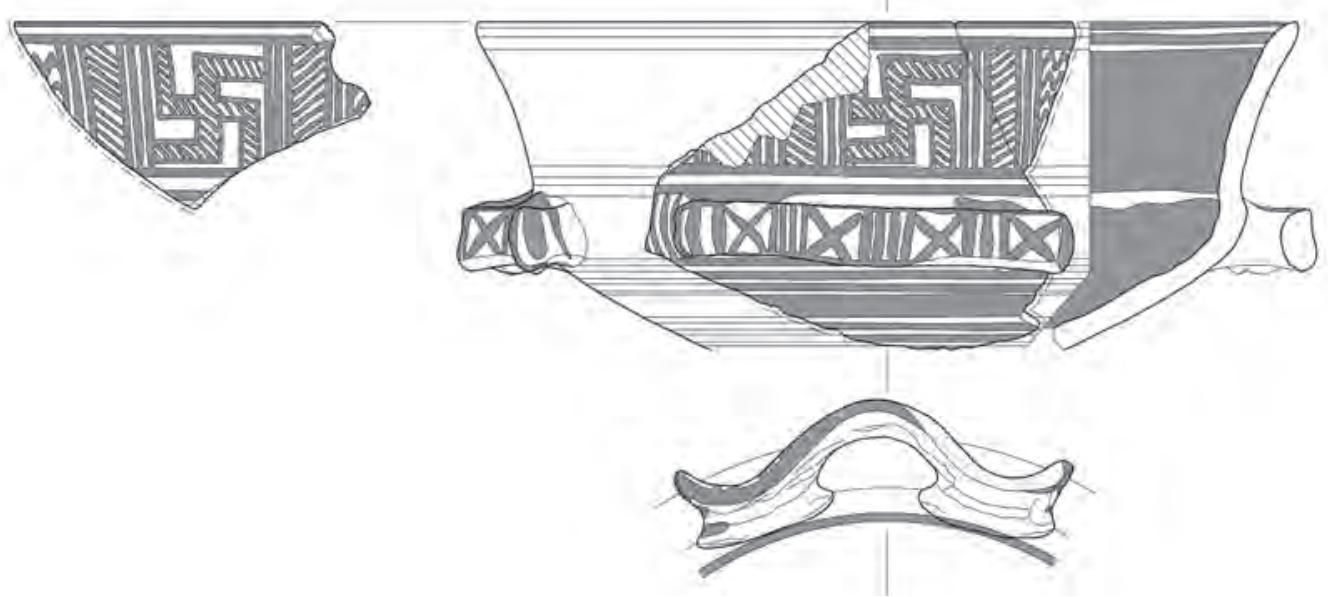

Abb. I I: Umzeichnung der Steilrandschale auf hohem Fuß G 733 im Maßstab I:2 (Zeichnung Karl) 
Lehner - Lorenz - Schwarz, Vasen, i 8 f. Nr. 7 Abb. 9 (M. Lehner).

Zustand: Der Deckel ist vollständig erhalten. Oberfläche bis auf wenige verwitterte Stellen in sehr gutem Zustand. Der Malschlicker ist in ein paar Bereichen abgeplatzt. Einige ausgebrannte Einschlüsse.

Technik: Oberfläche außen fein geglättet; im Inneren Spuren des Drehvorganges und verschiedene Wischspuren. Farbe des Tongrundes: hellgelblichbraun bis hellblassbraun (IO YR 6/4-7/4, light yellowish brown - very pale brown). Der dunkelbraun verfärbte und matte Malschlicker homogen aufgetragen.

Form: Flache, etwas unregelmäßig verzogene Wandung eines Deckels mit einem leicht konischen Knauf. Die Lippe des Deckels ist gerade abgestrichen, der Rand des Knaufes abgekantet. Vermutlich Deckel einer Steilrandschale.

Dekor: Von außen ein zweireihiges Schachbrettmuster, darüber eine Reihe stehender kreuzschraffierter Dreiecke zwischen außen einem und innen zwei Reifen, darüber wieder ein zweireihiges Schachbrettmuster. Nach innen folgen fünf konzentrische Reifen und bis zum Ansatz des Knaufes ein breites Band. Am Hals des Knaufes ein Band und zwei Reifen. Die schräge Kante der Knaufoberseite ist mit vier Strichgruppen aus vier bis fünf kurzen Vertikalstrichen verziert. Auf der Oberseite befindet sich ein Rad mit vier Speichen, um dieses sind vier Strichgruppen aus unregelmäßig gesetzten, drei bis vier kurzen Strichen gezeichnet. Die Radspeichen sind außen winkelförmig verstärkt, die Achse als Kreisfläche angegeben, in den Quadranten befinden sich Punktkleckse. An der Kante des Knaufes ein Reifen.

SG II b, um 720-700

Zur Form: Bei dieser Deckelform handelt es sich mit aller Wahrscheinlichkeit um den Deckel einer Steilrandschale, vgl. den eng verwandten Deckel einer Steilrandschale auf hohem Fuß in Jena V 83: CVA Jena I Taf. 4, 5-6 Beil. 3, 2 (Dm Rand I 5,8 cm) oder die auf den zugehörigen Steilrandschalen aufliegenden Deckel aus Grab ıo: Kerameikos V I, 2 I 5 Taf. I23 (872-873; SG II b). Zur Form siehe die Steilrandschale G 733, hier Tafel I4, I-2.

Zum Dekor: Deckel von Steilrandschalen scheinen einen sehr charakteristischen Dekor zu besitzen, meistens besteht er aus Bändern mit kreuzschraffiertem Wolfszahn oder mit stehenden kreuzschraffierten Dreiecken und aus Bändern mit einem zweireihigen vereinfachten Schachbrettmuster, vgl. die genannten Exemplare Athen, Kerameikos-Museum 872 und 873 , bzw. - das Schachbrettmuster durch eine Rautenkette ersetzend - den Deckel CVA Brit. Mus. I I Taf. 59, I 20 (GR I9 I0.6-I6.3; SG II b; Dm Rand I6 $\mathrm{cm})$. Zum Speichenrad, mit dem die Oberseite der Deckelknäufe verziert sein kann, vgl. z. B. J. Bingen, La nécropole géométrique ouest 4 (I97I et I975), in: H. F. Mussche - J. Bingen - J. Servais, Rapport Préliminaire sur les $9^{\mathrm{e}}, \mathrm{IO}^{\mathrm{e}}, \mathrm{II}^{\mathrm{e}}$ et $\mathrm{I} 2^{\mathrm{e}}$ Campagnes de Fouilles, Thorikos VIII (Gent I984) 78 Nr. 4 Abb. 39 (TC 7I.I420; SG II b).

\section{TAFEL 15}

\section{1-4. Kleeblattkanne}

Beilage 5, 4. Abb. 12.

G 90. Aus Kalyvia Kouvara, Ostattika. Erworben um I9I2/I3 durch Rudolf Heberdey, Tausch mit dem NM Athen.

H 2I,3 cm. - H mit Henkel 2I,7 cm. - B/L Kleeblattmündung 7,5/6,9 cm. - Dm Hals 5,7 cm. - Dm Bauch I 4,7 cm. - Dm Boden
8, o cm. - Dm Henkel I,5-I,6 cm. - Gewicht 607 g. - Volumen I $566 \mathrm{ml}$.

Lehner - Lorenz - Schwarz, Vasen, I9 f. Nr. 8 Textabb. auf S. I9; Abb. 2 (M. Lehner).

Zustand: Vollständig erhalten; Oberfläche stark abgerieben und stellenweise verwittert, der Malschlicker bis auf wenige Reste nicht mehr vorhanden. Eine größere Kalkaussprengung an der Bodenkante, ansonsten minimale Ausbrüche. Dünne Sinterschichten liegen dem Gefäß auf. Beschriftung in Bleistift auf der Schulter:

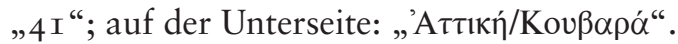

Technik: Oberfläche außen fein geglättet, innen grobe Drehwülste sichtbar. Farbe des Tongrundes: rosafarben bis hellblassbraun ( 5 YR 7/4 - IO YR 8/4, pink - very pale brown). Der dunkelbraun bis schwarz verfärbte und glänzende Malschlicker wurde nachlässig (mit Tropfspuren) und streifig aufgetragen, die Reifen am Bauch sehr unregelmäßig auf der Drehscheibe gezogen. Der unterste und oberste Reifen dient als Begrenzung der bemalten Flächen. Der unterschiedliche Brand verursachte eine fleckig verfärbte Oberfläche.

Form: Über einer leicht gewölbten Standfläche ein nahezu kugeliger Gefäßkörper sowie ein hoher zylindrischer Hals mit einer Kleeblattmündung und einem randständigen Vertikalhenkel mit rundem Querschnitt.

Dekor: Über der Standfläche eine bemalte Zone, wobei die untere bemalte Fläche nicht schlüssig an die obere Begrenzungslinie anschließt. Darüber I 8 Reifen, auf der Schulter eine breite bemalte Zone. Am Hals eine ausgesparte Bildzone, der Rest vom Übergang zur Schulter bis zur Lippe ist durchgehend bemalt, auch die dem Henkel gegenüberliegende Zone. Das Bildfeld wird unten und oben durch je zwei Horizontalstriche eingefasst. Zwischen diesen befindet sich ein dreigliedriges Bild, mit einem zentralen Feld und seitlichen schmalen Feldern aus gleichmäßig schräg liegenden $\mathrm{Pa}$ rallelstrichen zwischen je zwei Vertikalstrichen. Das zentrale Bildfeld ist relativ dicht mit kleinen Füllornamenten bemalt. Am linken Bildrand eine vertikale Reihe von Punkten, zwischen den Beinen des Tieres Reihen von M-förmigen Winkeln bzw. einfachen Winkeln übereinander, rechts oben ein kreuzschraffiertes Dreieck. Die Außenseite des Henkels wurde nachlässig mit einem breiten Strich bemalt, die Lippe ist bemalt.

Darstellung: Pferd - Auf dem Bildfeld ein weidendes Pferd mit Strichmähne in Silhouette nach rechts. Der Pferdekörper nach vorne geneigt, die hohen Hinterbeine in Parallelstellung, die Vorderbeine in einer Schrittstellung, der Kopf relativ klein, die Hufe überbetont, der Schweif des Pferdes reicht bis zur Standlinie. Auffällig die Zeichenweise der Hinterbeine, mit breiten Strichen für die Unterschenkel und zwei dünneren, bogenförmig und parallel geführten Stichen für die Hintermittelfüße.

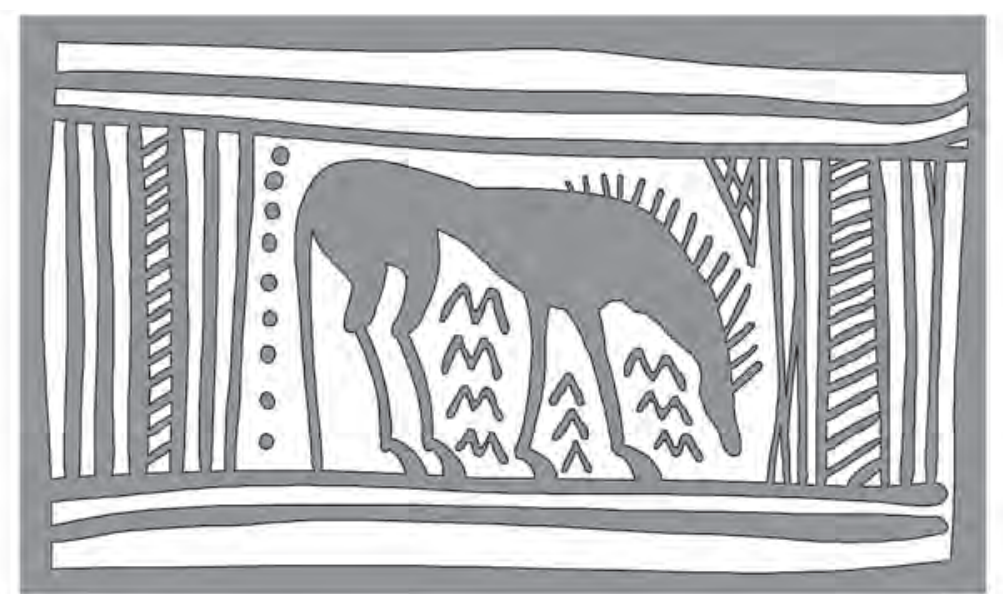

Abb. I2: Umzeichnung des Halsbildes der Kleeblattkanne G 90 im Maßstab I:I (Zeichnung Karl) 
SG II b, um 710/700

Zur Erwerbung: siehe den Skyphos G 97, hier Tafel 9, 3-6.

Zur Form: Die Kleeblattkanne G 90 gehört zu einer geläufigen spätgeometrischen Kannenform mit annähernd kugeligem Gefäßbauch und halb so hohem Hals. Zur Form siehe Coldstream, GGP, 47. 85; Agora VIII, 36. Formal vgl. die etwas ältere Kanne aus Grab K 29 von Trachones: J. M. Geroulanos, Grabsitten des ausgehenden geometrischen Stils im Bereich des Gutes Trachones bei Athen, AM 88, I973, 44 Nr. 3 Taf. 7, 2; 44, 5 (Tr 388; H 22,2 cm; SG I) sowie die späteren Kannen CVA München 3 Taf. I I 2, 3-4 (6406; H 23 cm; SG II) und CVA Berlin Io Taf. 35, 4. 6 Beil. I9, 2 (V.I. 3203 bis; $\mathrm{H}$ 22, I cm; SG II b).

Zum Dekor: Ein Reifendekor am Bauch und ein ausgespartes, meist figurales Halsfeld sind für diesen Kannentyp charakteristisch. Zum Dekorationsschema siehe H. Marwitz, Kreis und Figur in der attisch-geometrischen Vasenmalerei, JdI 74, I959, 8 I-94; vgl. die Gruppe V a Tab. 2. Den Hintergrund mit Reihen von M-förmigen Winkeln zu füllen, die in ihrer Positionierung der Kontur des figuralen Bildes folgen, weist die Kanne an das Ende von SG. Derartige Füllornamente sind z. B. in der Werkstatt von Athen 894 beliebt; vgl. z. B. die für die Werkstatt von Athen 894 namensgebende Halshenkelamphora CVA Athens, National Museum 5 Taf. 42-45 (894). Zur Bedeutung der M-förmigen Winkel siehe G. Ahlberg, Prothesis and Ekphora in Greek Geometric Art, SIMA XXXII (Göteborg I97I) I46-I 5 I. Eine seitliche Rahmung des Henkelbildes aus schmalen Vertikalfeldern mit schräg liegenden Parallelstrichen zeigt die genannte Kanne Berlin V.I. 3203 bis.

Zur Darstellung: Darstellungen von einzelnen Pferden sind auf diesem Kannentyp häufig belegt; vgl. zu stehenden Pferden: aus Grab 9 des Grabbezirks auf dem Grundstück Sapuntzakis an der
Piräusstraße nordöstlich des Dipylon: A. Brückner - E. Pernice, Ein attischer Friedhof, AM I 8, I 893, I I 7 Nr. 8 Taf. 8, 2; aus Brunnen D I I:5: Young, Graves, I 76 Nr. I I 8 Abb. I 22. I 24 (P 7 I77; SG II b); zu weidenden Pferden: aus Brunnen R 9:2: E. Brann, Late Geometric Well Groups from the Athenian Agora, Hesperia 30, I96I, I 37 Nr. P 6 Taf. I 5; Agora VIII, 36 Nr. 5I Taf. 4 (P 2 I 428; SG II b), aus einem Grab am Kerameikos: K. Vierneisel, Die Ausgrabungen am Kerameikos. Südseite der Heiligen Straße, AA I964, 467 Abb. 53. Das Motiv des weidendes Pferdes findet sich u. a. in den Halsbildern von Halshenkelamphoren, wie von der Nekropole bei der Akademie des Platon: BCH 8 I, I957, 508 f. Abb. Io; aus Grab G I 2:4: Young, Graves, 26 Nr. 2 Abb. I3 (P 46I 2; SG II b); aus Thera: CVA Berlin Io Beil. I9, 2 Taf. 54, I-4 (F 390 I; SG II); siehe dazu die Zusammenstellung in C. Dehl-von Kaenel in: CVA Berlin Iо, I07. Zu Kannen mit Liniendekor und einem Henkelfeld mit weidenden Pferden (bzw. Hirschen) siehe Brann a. O. ıо०. Zum Motiv siehe Rombos, Iconography, 2I4-22I.

Zur Werkstatt: Der Kleeblattkanne G 90 steht in Form und Bemalung am ehesten die genannte Kanne Athen, Agora-Museum P 2 I 428 nahe. Diese Kanne wird der Werkstatt von Athen 894 zugeschrieben: Davison, Workshops, 79 Nr. A-5 Abb. I 8 ; Coldstream, GGP, 59 Nr. 35; Rombos, Iconography, 466 Nr. 21 8. Zur Werkstatt von Athen 894 siehe Davison, Workshops, 79-83 (,Stathatou Hand“). I44-I46; Coldstream, GGP, 58-64; Rombos, Iconography, 437-468. In der Spätphase dieser Werkstatt zeigen sich Elemente des beginnenden protoattischen Stils; zum Übergang von SG II b zu FPA siehe C. Brokaw, Concurrent Styles in Late Geometric and Early Protoattic Vase Painting, AM 78, 1963, 63-73; K. A. Sheedy, The Late Geometric Hydria and the Advent of the Protoattic Style, AM I07, I992, I3-28; Rocco, Protoattica, I3-40. Für eine Zuweisung der Grazer Kanne an die Werkstatt von Athen 894 fehlt es jedoch an schlüssigen Indizien. 


\section{ARGIVISCH SPÄTGEOMETRISCH}

\section{TAFEL 16}

\section{Amphora bzw. Kanne}

Beilage 6, 1. Abb. 13.

G 726. Fundort unbekannt. Erworben in den I9Io/20er-Jahren durch Rudolf Heberdey, Schenkung des NM Athen (Scherbensammlung).

H erh. 4,3 cm. - B erh. 8, ० cm. - Wandstärke o,6-0,9 cm. - Dm max. rek. $25 \mathrm{~cm}$. - Gewicht $46 \mathrm{~g}$.

Unpubliziert.

Zustand: Wandstück. Oberfläche verwittert und abgerieben; außen einige kleinere Absplitterungen. Seitlich ist das Fragment sekundär angebrannt. Beschriftung in schwarzer Tusche auf der Innenseite: „Mus. Ath.“.

Keramikart: Farbe des Bruches: rosafarben (7.5 YR 7/4-8/4, pink); mittelhart; fein $(<0,2 \mathrm{~mm})$, ohne Dunkelglimmer; einzelne größere und einige feine rotbraune Eisenoxid-Konkretionen (durchschnittlich o, I mm, teilweise bis o,4 mm); mit wenigen Karbonatpseudomorphosen (bis o, I mm) durchsetzt.

Technik: Oberfläche außen leicht geglättet, feine Drehrillen belassen; auf der Innenseite Spuren des Hochziehens und Verengens. Farbe des Tongrundes: hellblassbraun ( IO YR 7/4, very pale brown). Der dunkelbraun bis rotbraun verfärbte und matte Malschlicker wurde streifig und zum Teil lasierend aufgetragen.

Form: Gekrümmte und schwach geneigte Wandung aus dem Schulterbereich eines geschlossenen bauchigen Gefäßes mit einem an der Schulter angesetzten Vertikalhenkel, entweder von einer Amphora oder einer Kanne.

Dekor: Auf der Schulter hat sich der Rest eines Bildfeldes zwischen den Henkeln erhalten, vom Ansatz des rechts folgenden Henkels durch vier Vertikalstriche getrennt. Rechts davon, unter dem Henkelansatz Reste von drei diagonalen Strichen. Im Bildfeld befindet sich als Füllornament ein aufrecht stehendes konzentrisches Dreieck aus drei Linien.

Darstellung: Pferd - Vom nach rechts stehenden Pferd haben sich der Vorderkörper, der Hals mit Mähne und die Vorderbeine erhalten. Rechts davon führt eine vertikale Wellenlinie, die wohl auf Höhe des Pferdekopfes begann, herab.

SG, zweite Hälfte 8. Jh.

Zur Form: Eine sichere Entscheidung, ob es sich um eine Kanne oder Amphora handelt, kann nicht getroffen werden. Beide Formen sind in der argivischen Keramik geläufig, siehe dazu Courbin, CGA, I 88-192. 197-203; Coldstream, GGP, I 25 f.

Zum Dekor: Stehende konzentrische Dreiecke aus mehrfachen Linien sind als Füllornamente in der argivischen Keramik selten und in wenigen spätgeometrischen Beispielen belegt, so seitlich im
Schulterfeld einer Kanne, die mit heraldischen Pferden dekoriert ist: Coldstream, GGP, I35 f. Taf. 29 a-b (Athen, NM 843; SG II, Miniatur-Stil); oder zentral unter einem Pferd auf einem Kantharos aus Grab 6/2 von Argos: Courbin, CGA, I25. I53 Taf. 6I; P. Courbin, Tombes géométriques d>Argos I (I952-I958), Études Péloponnésiennes 7 (Paris I974) I 6 f. Taf. 23 (C. 4; SG II). Große Füllornamente unter den Pferdebäuchen sind allgemein für die argivische Keramik typisch, jedoch sind meist Fische, Vögel oder tafelförmige Gebilde auf einer Stange dargestellt; vgl. Coldstream, GGP, I30. I34. I38; A. Roes, Fragments de poterie géométrique trouvés sur les citadelles d'Argos, BCH 77, I953, 92; zum symbolischen Charakter dieser Füllornamente siehe T. Rombos, An Argive Late Geometric Vase, in: C. Morris (Hrsg.), Klados, Essays in Honour of J. N. Coldstream, BICS Suppl. 63 (London I995) 235-238.

Zur Darstellung: Darstellungen von Pferden mit einem langgestreckten schlanken Rumpf, einem wesentlich breiteren Hals mit einer dichten Mähne aus kurzen Strichen, kurzen dreieckig gemalten Unterarmen und langgezogenen strichförmigen Vordermittelfüßen, die weit nach vorne gestreckt sind, wie die meist an den Nüstern ansetzende Wellenlinie, sind typisch für den argivischen Stil seit SG I; siehe dazu Courbin, CGA, I 53 f. 403-4I3; Coldstream, GGP, I 29 f.; vgl. z. B. die Pferdedarstellungen auf der großen Pyxis aus Grab 23 von Argos: Courbin, CGA, 246 Taf. roo-ro4; Coldstream, GGP, I 26 Taf. 26; Courbin a. O. 34 f. Taf. 28 (C. 209; SG I); S. Langdon, Beyond the Grave. Biographies from Early Greece, AJA I05, 200I, 584-592 Abb. 2-3; oder auf Fragmenten, ebenfalls aus dem NM Athen stammend: CVA Oxford, Ashmolean Museum 4 Taf. 5I, 6-7. I 5 Abb. f. h (I923.I6I.I-3; SG). Zur Deutung der Darstellung von Pferden als Symbol für den sozialen Status, aber auch als wirtschaftlicher Faktor siehe P. Courbin, La signification du géométrique argien, in: M. Piérart (Hrsg.), Polydipsion Argos. Argos de la fin des palais mycéniens à la constitution de l'état classique, BCH Suppl. 22 (Paris I992) 55-64; C. Dehl-von Kaenel in: CVA Berlin IO, 88; allg. zur Interpretation der argivisch geometrischen Ornamente als Symbole einer realen Lebenswelt siehe J. Boardman, Symbol and Story in Geometric Art, in: W. G. Moon (Hrsg.), Ancient Greek Art and Iconography, Wisconsin Studies in Classics (Madison I983) I6-25. Dem Fragment G 726 stehen stilistisch Pferdedarstellungen auf etwas jüngeren Fragmenten aus Argos nahe, wie Courbin, CGA, 396 Anm. I3; 397 Anm. 6 Taf. I34 (C. I238; SG II); in diesem Fall mit einem Vogel unter dem Pferd; oder wie auf einem Stück aus den älteren Grabungen: J. C. Hoppin, The Vases and Vase Fragments, in: C. Waldstein (Hrsg.), The Argive Heraeum II (Boston I 905) I Io Nr. 20 Taf. 56.

\section{2-3. Runde P,yxis}

Beilage 6, 2. Abb. 14.

G 749. Fundort unbekannt. Erworben in den I9Io/20er-Jahren durch Rudolf Heberdey, Schenkung des NM Athen (Scherbensammlung).

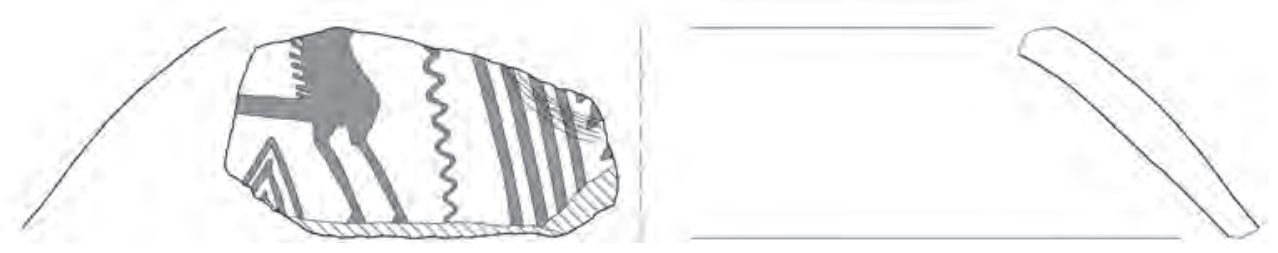

Abb. I3: Umzeichnung der Amphora bzw. Kanne G 726 im Maßstab I:2 (Zeichnung Karl) 
H erh. 5,3 cm. - B erh. I०,7 cm. - Wandstärke 0,7-I, ० cm. Dm Hals I 8,5 cm. - Dm max. rek. 20,8 cm. - Gewicht 72 g. Unpubliziert.

Zustand: Wandstück. Oberfläche gut erhalten; etwas bestoßen und leicht abgerieben. Beschriftung in schwarzer Tusche auf der Innenseite: „Mus. Ath.“.

Keramikart: Farbe des Bruches: Kern rötlichgelb (5 YR 6/6, reddish yellow); Außenzone hellbraun bis hellgelblichbraun (7.5 YR 6/4 - IO YR 6/4, light brown - light yellowish brown); durch den Brand ist die Außenhaut der Keramik gelblicher als der Kern, der ins Rötliche führt; mittelhart; fein $(<0,2 \mathrm{~mm})$; ohne Dunkelglimmer; sehr feiner Scherben; einige dunkelgraue bis schwarze blättchenförmige Einschlüsse (O,I-I,O mm); sehr fein von weißlichen Karbonatpseudomorphosen durchzogen; einige runde, zum Teil sehr große weiße Partikel (durchschnittlich I mm; vereinzelt bis $9 \mathrm{~mm})$.

Technik: Oberfläche außen fein geglättet, poliert und verdichtet; innen leicht geglättet, feinste Drehrillen belassen. Zusätzlich gibt es vertikale Verstrichspuren auf der Innenseite des Halses. Farbe des Tongrundes: hellblassbraun (IO YR 7/3-4, very pale brown). Der dunkelbraun bis dunkelrotbraun verfärbte und matte Malschlicker wurde schnell und ungleichmäßig aufgetragen. Vögel zügig gezeichnet, indem mit einem einzigen Pinselstrich der Kopf, Hals und das nach vorne gestreckte Bein gemalt wurde, danach folgten ein kurzer Strich für den Schnabel, ein gekrümmter Klecks für den Körper und ein Strich für das zweite Bein.

Form: Weite, nahezu senkrecht stehende Wandung des Halses einer Pyxis mit bauchigem Gefäßkörper.

Dekor: Auf der Schulter ein Bildfeld, in dem sich Füllornamente, wie ein waagrecht verlaufendes einfaches Zickzack und offenbar eine schraffierte Raute bzw. ein schraffiertes Zickzack, erhalten haben. Am Übergang zum Hals drei Horizontalstriche und darüber ein Fries mit einer Vogelreihe.

Darstellung: Vögel, Pferd - Von der Bildzone auf der Schulter haben sich Reste der Spitzen der Pferdemähne und Ohren erhalten. Das Pferd scheint vom Betrachter aus gesehen nach links zu stehen. Die Vogelreihe am Hals besteht aus hochbeinigen Vögeln in der kanonischen Richtung nach rechts, mit tropfenförmigem Körper und gesenktem Schnabel.

SG II, letztes Drittel 7. Jh.

Zur Form: Trotz des fragmentarischen Erhaltungszustands kann aufgrund der Glättung der Innenseite und des charakteristischen Profils sowie der fehlenden inneren Bemalung auf die in der ar-

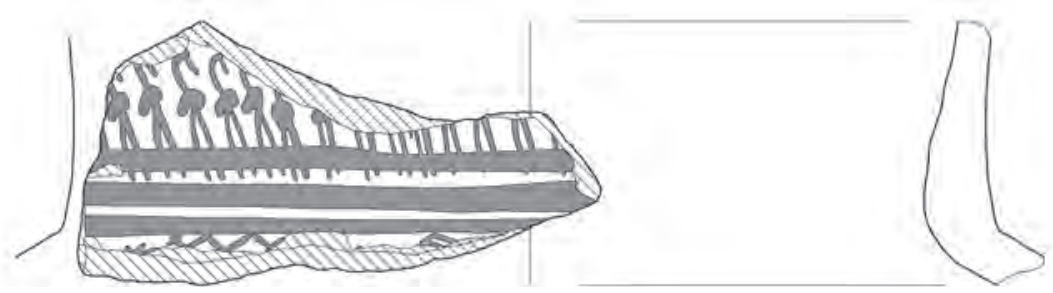

Abb. I4: Umzeichnung der runden Pyxis G 749 im Maßstab I:2 (Zeichnung Karl) givischen Keramik nicht allzu häufige Gefäßform einer runden Pyxis geschlossen werden, die nach Paul Courbin zumindest in einzelnen Fragmenten über die gesamte spätgeometrische Periode belegt ist, siehe dazu Courbin, CGA, 227 f.; Coldstream, GGP, I 26. I 42; von der Form her vgl. eine der wenigen ganz erhaltenen Pyxiden, die runde Pyxis aus Grab 6/I von Argos, mit annähernd gleichem Dm Hals: Courbin, CGA, 75 f. I26. 227 Taf. 79. I 3 ; P. Courbin, Tombes géométriques d>Argos I (1952-I958), Études Péloponnésiennes 7 (Paris I 974) 20 Taf. 22 (C. 43; SG I). Bei dieser Pyxis ist die Innenseite bis etwa $3 \mathrm{~cm} \mathrm{~T}$ bemalt, die gesamte restliche Innenseite tongrundig, wie dies generell für Pyxiden gilt.

Zum Dekor: Am Fragment G 749 haben sich noch Reste von Füllornamenten erhalten: Zickzack und rechts davon - etwas marginaler - ein winkelförmiger Ansatz mit einem Querstrich, der sich am ehesten zu einem schraffierten Zickzack (möglicherweise als Teil eines Eckfeldes in einem Horizontalbild) ergänzen lässt. Diese Kombination findet sich gut vergleichbar, wenn auch spiegelverkehrt, auf einem Fragment aus Argos: Courbin, CGA, 4I 2 Anm. Io Taf. I36 (C. 4524 ; SG II).

Zur Darstellung: Stilisierte Reihen von hochbeinigen, Flamingo-ähnlichen Vögeln sind typisch für die argivische Kunst und finden sich zumeist an Kraterrändern; vgl. z. B. den KantharosKrater aus Grab I von Argos: Courbin, CGA, I 50-I 53. 203. 450 Nr. Io Taf. 28; Coldstream, GGP, I 37 Taf. 29 e; Courbin a. O. I 2 Taf. 20 (C. I; SG II, Schliemann-Werkstatt). Zur Vogelreihe, auch „soldier birds“ genannt, die in der argivischen Keramik weniger standardisiert als im Korinthischen wirken, siehe Courbin, CGA, 396 f.; Coldstream, GGP, I43 f.; zur Entwicklung in Korinth siehe Coldstream, GGP, I05; J. S. Schaeffer, The Corinthian Pottery, in: J. S. Schaeffer - N. H. Ramage - C. H. Greenewalt, The Corinthian, Attic, and Lakonian Pottery from Sardis, Archaeological Exploration of Sardis, Monograph ro (Harvard I997) I I f.; zum Prinzip der Wiederholung als dekoratives Element siehe J. L. Benson, Horse, Bird and Man. The Origins of Greek Painting (Amherst 1970) 68-70. Vergleichbare Vogelreihen finden sich auf Kraterfragmenten, wie aus Aigina-Kolonna: V. Jarosch-Reinholdt, Die geometrische Keramik von Kap Kolonna, Ägina - Kolonna 4 (Wien 2009) I 38 Nr. 430 Beil. I 8 Taf. 38 (ST 4448; SG II); aus Mykene: J. M. Cook, Mycenae I939-I952. Part III. The Agamemnoneion, BSA 48, I953, 40 Nr. A 38 Abb. I0; CVA Heidelberg 3 Taf. I33, 27 (G I09, SG II); von der Insel Melos: Coldstream, GGP, I 33 Nr. 5; CVA Berlin ıо Beil. I 5 Taf. 44, I-4; 45, I-4 (V.I. 4286; SG II, Maler der boxenden Pferde); oder auf einem Pyxidenfragment aus dem argivischen Heraion: CVA Brit. Mus. I I Taf. 62, I 28 (GR I91 2.6-26. I I 5; SG II). Zur Variationsbreite argivischer Vögel vgl. die Kratere aus Asine: O. Frödin - A. W. Persson, Asine. Results of the Swedish Excavations I922-I930 (Stockholm I938) 3 I 6-3 I9 Nr. 3. 5. 7 Abb. 2 I 8, 3-5 (A. W. Persson) oder die Skyphoi mit Reihen von besonders hochbeinigen und schnabellosen Vögeln aus Argos: Courbin, CGA, I 25.213 Taf. 57 (C. 243 I. C. 2540 ; SG II). Dem Fragment G 749 entspricht am ehesten, auch in Beziehung auf die Füllornamente, das genannte Fragment Argos C. 4524 und ein Kantharos-Krater aus Grab I06/2 von Argos: Courbin, CGA, I48. 216-2I8 Taf. 64; Courbin a. O. 55 Taf. 35 (C. 890 ; SG II). 


\section{ATTISCH SUBGEOMETRISCH}

\section{TAFEL 17}

\section{1-3. Tasse}

Beilage 6, 3.

G 98. Aus Attika. Erworben um I9I2/I3 durch Rudolf Heberdey, Tausch mit dem NM Athen.

$\mathrm{H}_{4,2} \mathrm{~cm}$. - H mit Henkel 4,3 cm. - B mit Henkel 9,7 cm. - Dm Rand 7,5 cm. - Dm Boden 3,5 cm. - Gewicht 6I g. - Volumen 79 $\mathrm{ml}$.

Unpubliziert.

Zustand: Das Gefäß vollständig erhalten und nahezu ohne sichtbare Absplitterungen; allein die Lippenspitze ist umlaufend etwas bestoßen. Der Malschlicker ist stellenweise leicht abgerieben. Beschriftung in schwarzer Tusche auf der Unterseite: „А兀тıкń/ Mus. Ath.“.

Technik: Oberfläche beidseitig geglättet. Farbe des Tongrundes: hellblassbraun (IO YR 8/4, very pale brown). Der dunkelbraun bis rot verfärbte und sehr matte Malschlicker streifig und flüchtig aufgetragen. Das Wellenband lasierend mit breitem Pinsel gezogen; das Innere mit demselben Pinsel ausgemalt.

Form: Tasse auf gerader Standfläche mit einer leicht nach außen schwingenden, konkaven Wandung und runder Lippe. Der Übergang der Standfläche zur Wandung ist schräg abgesetzt. Am Becken ein randständiger Vertikalhenkel mit langovalem Querschnitt, der leicht über den Rand hochgezogen ist.

Dekor: Über dem Boden eine bemalte Fläche, darüber in der Hauptzone ein breit gezogenes Wellenband, unten und oben von je einem Horizontalstrich eingefasst. Die dem Henkel gegenüberliegende Zone ist freigelassen, der Dekor dabei durch je einen Vertikalstrich abgegrenzt. Auf der Außenseite des Henkels eine Reihe von Horizontalstrichen, am Beginn und am Ende des Henkels befinden sich breite, unregelmäßig bemalte Flächen. Innen bis auf ein schmales Lippenband durchgehend bemalt.

SubG, erste Hälfte 7. Jh.

Zur Form: Tassen mit konkaver Wandung und schräg abgesetzter Standfläche entwickeln sich aus den dunkelgrundigen Exemplaren mit gerader Wandung im SG, wie z. B. die Tasse aus Grab 56: Kerameikos V I, 250 Taf. I07 (3 I9; SG II b); Coldstream, GGP, 87 Taf. I 5 p; vgl. dazu CVA Berlin ro Taf. 43, 3-4 (1985.36; SG II b); bzw. aus hellgrundigen Tassen, wie jene aus Grab VDAk I vom Athener Kerameikos: B. von Freytag gen. Löringhoff, Ein spätgeometrisches Frauengrab vom Kerameikos, AM 89, I974, I9 Nr. 32-4I Taf. 4, 6 (4248-4257; SG I a/II a). Zur Vielfalt der Tassenformen in den Befunden der Athener Agora siehe Young, Graves, 203; vgl. die Tassen aus Grab G I2:2 und G I2: 4 : Young, Graves, 32-34 Nr. 2-5 Abb. 20 (P 4604-4607; spätes 8. Jh.); 37-39 Nr. IX 2-7 Abb. 24 (P 4963-4968; letztes Viertel des 8. Jhs.); sowie aus Brunnen D I I: 5: Young, Graves, I 56-I 58 Nr. 53-59 Abb. I I I (P 7005. 835 I-8356). Zur Datierung der Brunnenverfüllung in das späte 8. Jh. bis I. Hälfte des 7. Jhs. siehe Agora VIII, I 25.

Zum Dekor: Das breite und flüchtig gemalte Wellenband ist charakteristisch im SubG; damit wird zumeist die Henkelzone bei einfachen Gefäßen, wie Tassen, Becken, Schalen etc., in zügiger Weise dekoriert. Formale Ähnlichkeit, wenngleich das Wellenband wesentlich exakter gezogen ist, besteht in einer Tasse aus Grab 52: Kerameikos V I, 247 Taf. I07 (I333; SG II b). Grab 52 überlagert
Grab 53, das aufgrund einer Fußschale wie Grab 56 SG II b zu datieren ist, siehe Kerameikos V I, 248 Taf. I 22 ( I 328 ); Coldstream, GGP, 84. Die Tasse aus Grab 52 wird bereits an den Übergang zu SubG zu stellen sein. Eine weitere Parallele stammt vom Hymettos: M. K. Langdon, A Sanctuary of Zeus on Mount Hymettos, Hesperia Suppl. I6 (Princeton I976) 66 Nr. 282 Taf. 23 (Athen, NM H 466; SG II b). Ein ähnlich flüchtig gemaltes Wellenband, jedoch ohne vertikale Begrenzungslinien zum Henkel und mit einem weiter geöffneten Gefäßbecken, findet sich auf Tassen aus Gräbern des 7. Jhs., z. B. aus Thorikos: J. Bingen, La nécropole géométrique ouest 4 (I97 I et I975), in: H. F. Mussche - J. Bingen - J. Servais, Rapport Préliminaire sur les $9^{\mathrm{e}}, \mathrm{IO}^{\mathrm{e}}, \mathrm{II}^{\mathrm{e}}$ et $\mathrm{I} 2^{\mathrm{e}}$ Campagnes de Fouilles, Thorikos VIII (Gent I984) I 9 Nr. 54 Abb. 68 (TC 7I.I404, Grab I09); I43 Nr. 79 Abb. 88 (TC 7I.I485, Grab I42); aus Eleusis: Mylonas, Eleusis, 96 Nr. I3 I Taf. 228 (Grab $\Gamma$ Io). Aus Grab $\Delta$ I von Trachones stammt eine formal ähnliche Tasse mit Querstrichen an der Lippe: J. M. Geroulanos, Grabsitten des ausgehenden geometrischen Stils im Bereich des Gutes Trachones bei Athen, AM 88, I973, 42 Nr. 3 Taf. I7, 2; 3 I, I (Tr I79).

Zum Typ: Bei Tasse G 98 handelt es sich um eine PhaleronTasse des SubG Typs; vgl. Coldstream, GGP, 84. 87. Kennzeichen dieses Typs sind formal die konkave kelchförmig ausschwingende Wandung und die schräg abgesetzte Standfläche, im Dekor das Wellenband, die breiten Horizontal- wie auch Vertikalstriche, die dieses Wellenband begrenzen, und die Querstriche am Henkel. Der Typ wird bereits im SG ausgebildet: E. Brann, Late Geometric Well Groups from the Athenian Agora, Hesperia 30, I96I, I0I; Agora VIII, 53 f.; vgl. eine Tasse vom Hymettos mit leicht konkaver Wandung, jedoch höherem Gefäßbecken und mit fein gezogenem Wellenband: CVA Metr. Mus. 5 Taf. 27, 7 (30.I 18.8; spätes 8. Jh.). Zur Entwicklung der SubG Phaleron-Tasse siehe Young, Phaleron, 46 f. mit zahlreichen Beispielen, u. a. aus den Gräbern I I, 27 und 70 vom Beginn bis in das I. Drittel des 7. Jhs.: Young, Phaleron, 28 Nr. 2 Abb. 6; 30 Nr. 2A-B Abb. 8; 32 Nr. 2A-B Abb. I3; sowie aus dem Grab 7I des 3. Viertels des 7. Jhs.: Young, Phaleron, 39 Nr. IA Abb. 22. $\mathrm{Zu}$ den verschiedenen Ausprägungen von Tassen der Phaleron-Gruppe im Verlaufe der 2. Hälfte des 7. Jhs., z. T. mit orientalisierender Bemalung - hinsichtlich der Formentwicklung bereits mit einem deutlich nach außen umgebogenen, hohen Rand -, siehe die Exemplare aus den Gräbern I9I (680-660) und I 52 (700-675) im Bereich der U-Bahn-Station Kerameikos in Athen: L. Parlama - N. Chr. Stampolidis (Hrsg.), The city beneath the city. Antiquities from the Metropolitan Railway Excavations (Athen 2000) 282-284 Nr. 258-262 Abb. (G. Kavvadias); 286287 Nr. 267-269 Abb. (E. Baziotopoulou-Valavani). Die beste Entsprechung zur Tasse G 98, wenn auch mit einem etwas offeneren Becken, findet sich in der Tasse aus Grab 47: Young, Phaleron, 25 Nr. 4 Abb. I. Dieses Grab kann aufgrund der korinthischen Begleitfunde, eines Aryballos (Nr. 3; FPK; entspricht Neeft, PSA, 38 Liste IV-3) und einer Sigma-Kotyle (Nr. I; FPK), in das I. Viertel des 7. Jhs. datiert werden. Den Aryballos datiert Cornelis W. Neeft bereits um 675/670, siehe Neeft, PSA, 307. 379 Anm. I I IO.

\section{4-6. Skyphos}

Beilage 6, 4.

G 53. Aus Athen. Erworben I 868/69 von Friedrich Pichler (Graz), Schenkung. Ehemals Slg. Theodor von Heldreich (Athen). Alte Inv.-Nr. II I I (Schenkl) bzw. III 20 (Pichler). 
H 5,4 cm. - B mit Henkeln I I,7 cm. - Dm Rand 8,4 cm. - Dm Boden 4,4 cm. - Dm Henkel o,8-0,9 cm. - Gewicht 82 g. - Volumen $\mathrm{I} 70 \mathrm{ml}$.

Essenwein, Katalog, 26 Nr. I84.

Zustand: Das Gefäß vollständig erhalten; ein Haarriss in der Randzone; mehrere Abplatzungen und Absplitterungen. Oberfläche und Malschlicker verwittert und stellenweise stark abgeplatzt sowie abgerieben. Einige größere Einschlüsse verursachten trichterförmige Absprengungen, so z. B. im Falle eines durchgehenden Loches an einer Gefäßseite. Die Keramik ist sehr weich und wirkt stark porös. Weiße Sinterreste an der Unterseite.

Technik: Keramik von rotbraunen, bis $3 \mathrm{~mm}$ großen Partikeln und bis I mm großen Kalksteinchen durchsetzt. Oberfläche beidseitig geglättet, auf der Unterseite Abdrehspuren. Farbe des Tongrundes: rötlichgelb bis gelb $(7.5$ YR 7/6 - IO YR 7/6, reddish yellow - yellow). Der schwarz bis rotbraun verfärbte und sehr matte Malschlicker auf der Drehscheibe zum Teil dick aufgetragen; durch unterschiedlichen Auftrag sowie Brand fleckig.

Form: Kleiner Skyphos mit steiler Gefäßwandung auf einer leicht gewölbten Standfläche und mit einer leicht nach außen gebogenen, rund abgestrichenen Lippe; zwei gegenständige Horizontalhenkel mit rundem Querschnitt in einem leichten Winkel nach oben.

Dekor: Auf der Außenseite bis auf die beiden Zonen zwischen den Henkeln durchgehend bemalt. Henkelaußenseiten bemalt. Außerhalb der Henkelansätze jeweils ein dicker Vertikalstrich; die den Henkeln gegenüberliegenden Zonen wurden ausgespart. Innen ist das Gefäß bis auf ein Lippenband und ein breites Band im unteren Gefäßboden durchgehend bemalt.

SubG, erste Hälfte 7. Jh.

Zur Erwerbung: Der Skyphos G 53 wurde durch Friedrich Pichler, dem dritten Mitvorstand des archäologischen Kabinetts der Universität Graz, der archäologischen Sammlung im Studienjahr I 868/69 geschenkt. Das Objekt selbst kaufte Pichler aus einem Konvolut nahezu durchgehend früharchaischer Kleingefäße, hauptsächlich aus Athen stammend, die der Botaniker und ehemalige Direktor des botanischen Gartens in Athen, Theodor von Heldreich, zunächst dem Landesmuseum Joanneum im August I 863 anbot und schließlich I 863/64 durch Vermittlung des Landesarchivars Josef von Zahn an Privatpersonen zum Teil veräußern konnte. Das Gefäß wurde nach dem Ankauf durch Pichler in der ersten Ausstellung des steiermärkischen Kunstindustrievereines im Jahre I 865 präsentiert; siehe dazu Essenwein, Katalog, 26 Nr. I 84.

Zur Form: Die SubG Skyphoi entwickeln sich direkt aus der spätgeometrischen Form und werden ab Beginn des 7. Jhs. kontinuierlich niedriger und breiter; zusätzlich wird der bei den älteren
Beispielen deutlich nach außen gebogene Rand reduziert, bis er nahezu verschwindet; allen gemeinsam ist eine gerade oder technisch bedingte konkave Standfläche; zur Formentwicklung siehe E. Brann, Protoattic Well Groups from the Athenian Agora, Hesperia 30, I96I, 3 I 2; Agora VIII, 48; Young, Graves, 20 I f.; Coldstream, GGP, 88 f. bes. 84 zur Gleichzeitigkeit des SubG Stils mit FPA. Der Skyphos G 53 steht in der Formstufe zwischen einem Skyphos aus Brunnen T I9:3: Agora VIII, 48 Nr. I39 Taf. 8 (P I0223) und einem aus Brunnen J I 8:8: Agora VIII, 48 Nr. I 40 Taf. 8 (P 9005). Zur Datierung der Brunnenverfüllungen siehe Agora VIII, I 29 zu J I 8:8 (3. Viertel 7. Jh.); I3 I zu T I9:3 (spätes 8. Jh. bis Mitte 7 . Jhs.).

Zum Dekor: Die Skyphoi sind in ihrer SubG Ausprägung durch ein tongrundiges Band auf Höhe der Henkel charakterisiert; die Innenseite ist soweit bekannt durchgehend bemalt; vgl. z. B. die genannten Beispiele von der Athener Agora, einen Skyphos vom Hymettos: M. K. Langdon, A Sanctuary of Zeus on Mount Hymettos, Hesperia Suppl. I6 (Princeton I976) 68 Nr. 302 Taf. 24 (Athen, NM H 288; I. Hälfte 7. Jh.) oder mehrere Exemplare aus dem Töpferdepot S I7:2: J. K. Papadopoulos, Ceramicus Redivivus. The Early Iron Age Potter's Field in the Area of the Classical Athenian Agora, Hesperia Suppl. 3 I (Athen 2003) I 59-I65 Nr. I 35-I44 Abb. 2.92-2.IOI. Das Töpferdepot S I7:2 wird bereits in die 2. Hälfte des 7. Jhs. datiert; siehe auch Agora VIII, IO3 f. I3 I. Die Skyphoi aus diesem Befund entsprechen formal dem Exemplar G 53. Daran sind Skyphoi aus Phaleron anzureihen, z. B. die Exemplare aus Grab I7 und 59: Young, Phaleron, 45 Nr. 2 Abb. 30 ; Nr. 2 Abb. 3 I. Dass darüber hinaus noch die Außenseiten und die Ansätze der Henkel bemalt sind, ist wohl als Zeichen der etwas älteren Skyphoi im SubG bzw. ihrer Vorläufer im SG zu werten; vgl. z. B. den genannten Skyphos Athen, Agora-Museum P I0223; einen mit hohem Becken und deutlich nach außen gebogenem Rand aus dem Töpferdepot H I2:17: Papadopoulos a. O. I3 8 Nr. I09 Abb. 2.73 (P I3328); einen Skyphos aus Grab I6: Young, Phaleron, 43 Nr. I Abb. 2; Streufunde von der Athener Agora: Young, Graves, I 24 Nr. 53-54 Abb. 88 (P 4659. 6466); sowie einen Skyphos mit weiter geöffnetem Becken aus Aspropyrgos: ADelt 53, I998, Chron. 77 Taf. 42 f (A 779; Ende 7. Jh.). Der Skyphos G 53 besitzt zusätzlich im Inneren ein tongrundiges konzentrisches Band am Boden.

Zum Typ: Der Skyphos gehört formal und aufgrund der Bemalung zu einer Variante, die am Beginn des Typs im SubG steht. Zur Diskussion siehe Agora VIII, 48; Young, Graves, 20I f.; Young, Phaleron, 47 f. Kennzeichnend für diese Variante sind die bemalten Henkelaußenseiten und die breiten Striche an den Henkelansätzen. Typologisch entspricht der Skyphos G 53 dem genannten, annähernd gleich großen Exemplar Athen, Agora-Museum $\mathrm{P}$ I0223. 


\section{PROTOATTISCH}

\section{7-8. Kanne mit runder Mündung}

Beilage 6, 5. Abb. 15-16.

G I038. Aus Aigina, Kap Kolonna, Apollonheiligtum. Erworben I908/Io durch Hans Schrader. Ehemals Slg. Hans von Prott (Athen).

H erh. 2,4 cm. - B erh. 2,5 cm. - Wandstärke 0,45-0,5 cm. Dm Rand rek. 20 cm. - Gewicht 2,5 g.

Unpubliziert.

Zustand: Randstück. Oberfläche mit wenigen Abplatzungen; der Malschlicker im Inneren zum Teil abgeplatzt. Beschriftung in schwarzer Tusche auf der Innenseite: „Aegina/A. Tpl. Prott“.

Keramikart: Farbe des Bruches: hellblassbraun ( IO YR 7/4, very pale brown); hart; fein (<0,2 mm), ohne Dunkelglimmer; sehr feiner Scherben; vereinzelt rotbraune Partikel (bis o, I mm), einzelne schwarze Partikel (0,025-0,05 mm).

Technik: Oberfläche außen und im erhaltenen Bereich innen geglättet. Farbe des Tongrundes: hellblassbraun ( Iо YR $7 / 3-8 / 3$, very pale brown). Der hellrotbraun (außen) und graubraun (innen) verfärbte und insgesamt matte Malschlicker außen zum Teil lasierend, innen dick aufgetragen.

Form: Kanne mit runder Mündung und einer nach innen schräg abgestrichenen Lippe.

Dekor: Auf der Außenseite über dem Rest eines vertikalen lanzettförmigen Blattes in Umrisszeichnung vier Reifen, die etwas unregelmäßig gezogen sind. Auf der Lippe ein Band mit feinen Querstrichen. Innen im erhaltenen Bereich durchgehend bemalt.

MPA (attisch oder aiginetisch), um 670/650. Widderkanne, Maler der Widderkanne

Zur Erwerbung: Beim Fragment G I03 8 handelt es sich um ein Randstück der bekannten Kanne des Malers der Widderkanne mit der Darstellung von Odysseus und seinen Gefährten bei der Flucht aus der Höhle des Polyphem (Aigina K 566): L. Pallat, Ein Vasenfund aus Aegina, AM 22, I897, 324-330 Abb. 40-4I Taf. 8; Cook, Protoattic, г 89 f. Taf. 53; Kraiker, Aigina, 87 f. Nr. 566 Taf. 44-45; Morris, Black and White Style, 4. 6. 5 I-53; I 23 Nr. 4 Taf. Io; G. Ahlberg-Cornell, Myth and Epos in Early Greek Art. Representation and Interpretation, SIMA C (Jonsered I992) 95 Nr. 79 Abb. I 55; Rocco, Protoattica, I 49 Nr. Ar 2 Taf. 2I, 4. Für die historische Abbildung, die für die Fotomontage verwendet wurde, ist Joachim Heiden (Athen) zu danken. Die Widderkanne wurde im Jahre I894 im Zuge der Grabungen von Valerios Staïs im Bereich des Apollonheiligtums mit weiteren Kleinfunden in einer brunnenähnlichen Grube, wohl einem Bothros, gefunden. Wann Prott während seines Athener Aufenthaltes zwischen I 897 und 1903 die Insel Aigina und den antiken Hauptort am Kap Ko-

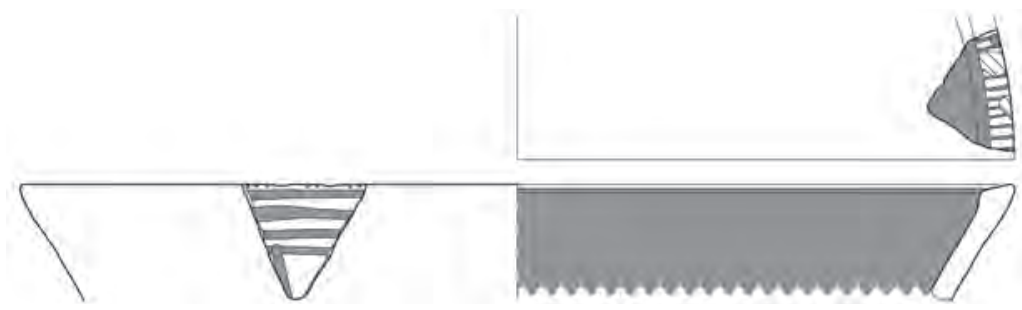

Abb. I 5: Umzeichnung der Kanne G I038 im Maßstab I:2 (Zeichnung Karl) lonna besuchte, ist bislang unbekannt. Die Bezeichnung auf der Scherbe „A. Tpl.“ steht für das damals als Aphroditetempel identifizierte Heiligtum.

Zum Dekor: Waagrechte Reihen mit vertikalen lanzettförmigen Blättern in Umriss, deren Innenflächen alternierend mit Malschlicker ausgemalt sowie mit weißer Farbe aufgesetzt sind, charakterisieren Werke im MPA. Dieses Ornament wird vor allem vom Maler der Widderkanne und dem ihm nahe stehenden Pernice-Maler bevorzugt. Es bleibt jedoch selten, so an der Halszone der Widderkanne; im Sockelfries auf einem Krater aus dem Grabbezirk nordöstlich des Dipylon an der Piräusstraße (Grundstück Sapuntzakis): E. Pernice, Bruchstücke altattischer Vasen, AM 20, I 895, I 2 I-I 26

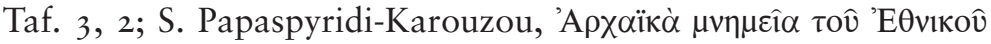
Movбeíov, AEphem I952, I49-I 58 Abb. I2-I 5 Taf. 5-7; Rocco, Protoattica, I 56 Nr. Per3 Taf. 24, 2 (Athen, NM 80I; PerniceMaler) sowie am Bauch einer Amphora aus Brunnen R 17:5: E. Brann, Protoattic Well Groups from the Athenian Agora, Hesperia 30, I96I, 375 Nr. S I Taf. 87; Agora VIII, 92 Nr. 540 Taf. 33 (P 264I 5; Maler der Widderkanne). Weitere Fragmente mit diesem Motiv stammen aus den neuen Grabungen in Aigina-Kolonna: F. Felten - C. Reinholdt - E. Pollhammer - W. Gauß - R. Smetana, Ägina-Kolonna 2007. Vorbericht über die Grabungen des Fachbereichs Altertumswissenschaften/Klassische und Frühägäische Archäologie der Universität Salzburg, ÖJh 77, 2008, 50 Abb. 6, Reihe 2, links; und aus den Altgrabungen im heutigen Stadtgebiet im Bereich der vermuteten Nekropole durch Gabriel Welter: Kraiker, Aigina, 85 Nr. 544 Taf. 42.

Zum Maler: Giulia Rocco fasste zuletzt das Euvre des Malers der Widderkanne zusammen, das in ihrer Liste nun insgesamt elf Gefäße umfasst; siehe dazu Rocco, Protoattica, I43-I 5 I mit Literatur zu älteren Klassifizierungen, vor allem von Richard Eilmann, Kurt Gebauer, John M. Cook, Semni Papaspyridi-Karouzou und Sarah P. Morris, siehe R. Eilmann - K. Gebauer in: CVA Berlin I, 7; Cook, Protoattic, I87-I94; Papaspyridi-Karouzou a. O. I $58-$ I66; Morris, Black and White Style, 5 I-59. I 22 f. Die Insel Aigina gilt nach der Arbeit von Rocco weiterhin als jener Ort, von dem die meisten Gefäße dieses Malers stammen. Gewisse Bedenken, ob alle elf Objekte zwingend einer einzigen Malerpersönlichkeit zuzurechnen sind oder doch eher einer Gruppe von mehreren Ma-

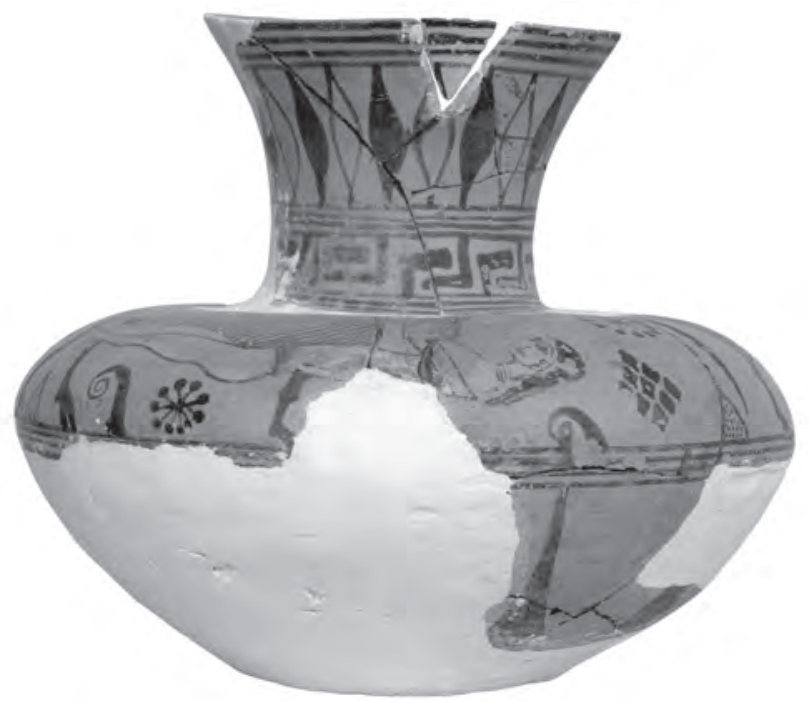

Abb. I6: Widderkanne - Fotomontage des Fragmentes G I03 8 (Foto Kraschitzer) und des Gesamtgefäßes nach historischer Aufnahme von Hermann Wagner um I930 (Negativ-Nr. D-DAI-ATH-Aegina-0224) 
lerhänden, möglicherweise nicht einmal aus derselben Werkstatt, bleiben jedoch seit den Einwänden von Karl Kübler bestehen, siehe dazu Kerameikos VI 2, 300.

Zur Werkstatt: Die Lokalisierung der Werkstatt des Malers der Widderkanne ist bis heute nicht eindeutig geklärt. Aufgrund der Fundstatistik und anhand historischer Überlegungen vermutete Morris, dass es auf Aigina eine eigene Produktion von Feinkeramik gegeben hat, nämlich diejenige der im Black and White Style bemalten Gefäße, siehe Morris, Black and White Style, I9-36. 9 II I9; die Argumente zusammenfassend Rocco, Protoattica, $200 \mathrm{f}$. Die These einer aiginetischen Werkstatt im Zeitraum von etwa 670 bis 640, die für den gesamten Black and White Style verantwortlich ist, wird in der Forschung weitestgehend abgelehnt, siehe die Rez. von E. Walter-Karydi, Gnomon 59, I987, 378-380 und J. B. Carter, AJA 89, I985, 695-697. Überzeugend konnte Elena Walter-Karydi darlegen, dass attische (aber auch korinthische) Keramik kontinuierlich von Aigineten erworben wurde und als Weihebzw. Grabbeigaben Verwendung fand: E. Walter-Karydi, Aigina versus Athens? The Case of the Protoattic Pottery on Aigina, in: J. H. Oakley - W. D. E. Coulson - O. Palagia (Hrsg.), Athenian Potters and Painters. The Conference Proceedings (Oxford I997) 385-394. Heute geht man davon aus, dass der überwiegende Teil der im protoattischen Stil verzierten Gefäße aus Aigina in Attika, vorrangig in Athen, hergestellt wurde, so M. B. Moore in: CVA Metr. Mus. 5, 75 f. Zur attischen Keramik im SG II auf AiginaKolonna siehe V. Jarosch-Reinholdt, Die geometrische Keramik von Kap Kolonna, Ägina - Kolonna 4 (Wien 2009) 34-37. Da in der Keramikart kaum Unterschiede zwischen Gefäßen der Black and White Style-Werkstätten und den eigentlich protoattischen Stücken gemacht werden konnten, musste Morris einen Import attischen Tons nach Aigina für ihre These annehmen. Nur gelegentlich soll auf den lokalen Ton ausgewichen worden sein, wie bei der Widderkanne (Aigina K 566) und einer Amphora (Aigina K 484), siehe Morris, Black and White Style, 20-23. 77 f. Anm. I 52 ; den angeblich hohen Glimmergehalt (nach Morris „silvery mica sparkles“) protoattischer Werke zu Recht bezweifelnd: K. Arafat - C. Morgan, Pots and Potters in Athens and Corinth. A Review, OxfJA 8, I989, 3 I 4 f. Irritierend bleibt jedoch jene Keramikart im Spektrum protoattischer Gefäße, die sehr fein geschlämmt und hart gebrannt ist, die im Bruch hellblassbraun, zum Teil grünlich-gelb verfärbt erscheint, die kleinste, zumeist schwarze und rotbraune Einschlüsse besitzt und keinen Hellglimmer aufweist. Makroskopisch erinnert sie vielmehr an die korinthische Keramik. Technische Unterschiede protoattischer Werke sind allgemein schon früh erkannt worden, siehe R. Eilmann - K. Gebauer in: CVA Berlin I, 6. Wie unterschiedlich die Keramikart bei protoattischen bzw. bei jenen Gefäßen, die als aiginetische Nachbildungen korinthischer Keramik bezeichnet werden, sein kann, erschließt sich mit Vorbehalten aus den kurzen Beschreibungen in Kraiker, Aigina, 77-79 Nr. 484-496; 84-92 Nr. 540-598. Auffallend sind jene frühattischen Stücke, die nach Wilhelm Kraiker den korinthisierenden Werken aus Aigina zumindest in der Farbe der Oberfläche bzw. im Bruch ähnlich sind, wie Nr. 552, die Widderkanne Nr. 566 und Nr. 584-585; alles Beispiele, die dem Maler der Widderkanne selbst bzw. einer Gruppe, die der kykladischen Produktion des Ad-Malers nahesteht, zugewiesen werden; siehe Rocco, Protoattica, 89 Nr. E 2; I 49 f. Nr. Ar 2. 5-6. Die am Randstück G I03 8 der Widderkanne zu beurteilende Keramikart sowie die Oberflächenbehandlung erinnert am ehesten an die von Christiane Dehlvon Kaenel hinsichtlich der Tonqualität definierte erste Gruppe, die sie mit Vorbehalt der aiginetischen Keramik zuweist; siehe C. Dehl-von Kaenel in: CVA Berlin 6, 88. In diese Gruppe fallen jedoch hybride Gefäße in einem protokorinthischen und -attischen Mischstil, die sich im Spektrum MPA Keramik gut identifizieren lassen. Doch auch die Form der Widderkanne, mit ihrem gedrückten Gefäßkörper und runder Mündung, ist, wie dies bereits erkannt wurde (siehe Kerameikos VI 2, I79 Anm. I49; Payne, NC, 5 Anm. I), im Attischen ungewöhnlich und findet eher Parallelen in ostgriechischen Kannen. Zur Annahme regionaler Werkstätten am Saronischen Golf außerhalb des attischen Kerngebietes siehe neuerdings E. Simantoni-Bournia, The Aeginetan versus a West Saronic Gulf Pottery Workshop, in: C. Reinholdt - P. Scherrer - W. Wohlmayr (Hrsg.), Aiakeion, Beiträge zur Klassischen Altertumswissenschaft zu Ehren von Florens Felten (Wien 2009) I 53-I 59. $\mathrm{Zu}$ Kriterien der Identifizierung aiginetischer Keramik siehe W. Gauß - E. Kiriatzi, Pottery Production and Supply at Bronze Age Kolonna, Aegina. An Integrated Archaeological and Scientific Study of a Ceramic Landscape, Ägina - Kolonna 5 (Wien 20I I) 22 f.; vgl. bes. 49 f. zur makroskopischen Gruppe MG 2B; I34-I36 zur petrografischen Gruppe $2 \mathrm{~A}$. Lässt sich also ein eigenständiger Keramikstil, insbesondere auf der Insel Aigina, nicht fassen, so sind doch Differenzen in der Keramikart sowie bestimmte Details der Formgebung und des Stils möglicherweise Anzeichen dafür, dass von einer gewissen Mobilität der Handwerker, durchaus mit Beeinflussungen durch verschiedene Töpferzentren, aber unter Verwendung der lokalen Tone, auszugehen ist; siehe dazu Agora VIII, 24; M. Denoyelle, Le peintre d'Analatos: essai de synthèse et perspectives nouvelles, AntK 39, I996, 7I-87 (zum Spätwerk des Analatos-Malers in Metapont); J. K. Papadopoulos - E. Lord Smithson, The Cultural Biography of a Cycladic Geometric Amphora. Islanders in Athens and the Prehistory of Metics, Hesperia 7I, 2002, I9I-I93; J. K. Papadopoulos, Ceramicus Redivivus. The Early Iron Age Potter's Field in the Area of the Classical Athenian Agora, Hesperia Suppl. 3 I (Athen 2003) I33 (Töpferdepot H I2:I7); I65. I68 (Depot S I7:2); 222-224; zu korinthischen Töpfern in Athen siehe nun J. K. Papadopoulos, The Relocation of Potters and the Dissemination of Style: Athens, Corinth, Ambrakia, and the Agrinion Group, in: J. H. Oakley - O. Palagia (Hrsg.), Athenian Potters and Painters II (Oxford 2009) 233-235 bes. 235 zum Maler der Widderkanne. 


\section{PROTOKORINTHISCH}

\section{TAFEL 18}

1-2. Kotyle

Beilage 6, 6. Abb. 17.

G 766. Fundort unbekannt. Erworben in den I9Io/2oer-Jahren durch Rudolf Heberdey, Schenkung des NM Athen (Scherbensammlung).

H erh. 6,0 cm. - B erh. 4,8 cm. - Wandstärke o,35-०,45 cm. Dm max. rek. I9,8 cm. - Gewicht I3 g.

Unpubliziert.

Zustand: Wandstück. Oberfläche sehr gut erhalten; im Inneren Kratzspuren. Beschriftung in schwarzer Tusche auf der Innenseite: „Mus. Ath.“.

Keramikart: Farbe des Bruches: blassgelb (2.5 Y 7/4, pale yellow); hart; fein (<0,2 mm); ohne Dunkelglimmer; einzelne hellrote Partikel (bis $0,05 \mathrm{~mm}$ ).

Technik: Oberfläche außen fein geglättet und poliert, innen feine Drehrillen. Farbe des Tongrundes: blassgelb (2.5 Y 7/3-8/3, pale yellow). Der hellbraun bis dunkelgrau verfärbte und glänzende Malschlicker homogen aufgetragen; vertikale Stiche lasierend hellbraun. Der feine Reifendekor sehr präzise mit Hilfe eines Kammpinsels auf der Drehscheibe gezogen.

Form: Leicht nach außen stehende, etwas gekrümmte Wandung einer großen Kotyle.

Dekor: Außen über einem Liniendekor aus I 7 erhaltenen Reifen die Henkelzone mit rechts einem spiralförmigen Ornament und links acht Vertikalstrichen. Innen im erhaltenen Bereich durchgehend bemalt.

FPK - MPK I, spätes 8. Jh. bis erstes Viertel 7. Jh.

Zur Form: Die steile Neigung der Wandung und der rekonstruierte Randdurchmesser von etwa $20 \mathrm{~cm}$ sprechen für eine relativ große Kotyle. Zu den protokorinthischen Kotylen siehe allgemein C. Brokaw, The Dating of the Protocorinthian Kotyle, in: L. Freemann Sandler (Hrsg.), Essays in Memory of Karl Lehmann (New York I 964) 49-54; Corinth VII I, 36 f. 39 f.; zur Entwicklung der Kotyle von SG zu FPK siehe C. W. Neeft, Corinthian Fragments from Argos at Utrecht and the Corinthian Late Geometric Kotyle, BABesch 50, I975, 97-I34. Zur Linearkotyle siehe J. S. Schaeffer, The Corinthian Pottery, in: J. S. Schaeffer - N. H. Ramage C. H. Greenewalt, The Corinthian, Attic, and Lakonian Pottery from Sardis, Archaeological Exploration of Sardis, Monograph Io (Harvard I997) 8-I 5.

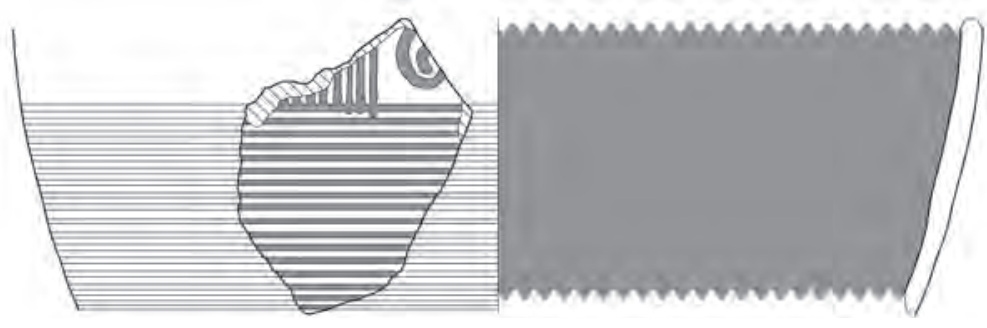

Abb. I7: Umzeichnung der Kotyle G 766 im Maßstab I:2 (Zeichnung Karl)
Zum Dekor: Das spiralförmige Ende in der Henkelzone ist am ehesten als Rest einer Reihe von Spiralhaken zu rekonstruieren, wobei die Positionierung der Haken - entweder von oben oder von unten - unklar bleibt. Ein solcher Dekor in der Henkelzone findet ein Pendant auf einem Krater aus Korinth, der ein Band von nach oben gerichteten Spiralhaken aufweist: Corinth VII I, 37 f. Nr. I 6 Taf. I6 (C-36-557; FPK). Zum Motiv der Spiralhaken siehe K. F. Johansen, Les vases Sicyoniens (Kopenhagen I923) 49-5 I. Spiralhaken als Dekormotiv gibt es seit SG, sind jedoch in der Henkelzone von Kotylen selten. Eine der wenigen Ausnahmen stellt eine fragmentierte Kotyle (rek. Dm Rand $2 \mathrm{I} \mathrm{cm}$ ) aus Korinth dar: Corinth XV 3, 37 Nr. I22 Taf. 7 (KP 209I a-f; FPK). Agnes N. Stillwell und Jack L. Benson ziehen dazu als Vergleich eine Miniaturkotyle einer jedoch weitaus offeneren Variante und wohl späteren Zeitstufe in Oxford heran: CVA Oxford, Ashmolean Museum 2, III c Taf. I, 25 (I92I.I353; FPK-MPK). In der Henkelzone dominieren im FPK sonst eher Fische, Schlangen oder Vögel oder geometrische Motive wie kreuzschraffierte Rautenketten oder Doppeläxte; zu diesen Motiven siehe Brokaw a. O. 52 Anm. I 2. Spiralhaken sind im FPK besonders auf der Schulterzone von Aryballoi beliebt, siehe dazu Neeft, PSA, 33-I 25; bes. 84 Abb. 27, I04 Abb. 3I; vgl. z. B. aus Grab 623 von Pithekussai: G. Buchner - D. Ridgway, Pithekoussai I: La necropoli: Tombe I-723 scavate dal I952 al I96I, MonAnt 55 (Rom I993) $606 \mathrm{f}$. Nr. 6-7 Taf. I76 (I68406-I68407); Neeft, PSA, 43 Liste XII-6; 46 Liste XV-I 2. Aufgrund des Erhaltungszustandes wäre theoretisch auch eine Ergänzung zu einem floralen Muster möglich; wie z. B. auf dem Fragment einer großen Kotyle aus Aigina: Kraiker, Aigina, 4I Nr. I 89 Taf. D. I4; Benson, ECW, 42 Nr. I I Taf. I4, 5 (2369/3069; MPK I; Toulouse-Werkstatt); oder auf einem Kotylenfragment aus Korinth: Corinth XV 3, 36 Nr. I I9 Taf. 7. 80 (KP 2080; FPK). Kurvolineare Elemente sind im FPK besonders in der Cumae-Werkstatt bzw. der Wein-Werkstatt vertreten, siehe dazu Benson, ECW, 28-3 I; vgl. zwei Fragmente von Kotylen-Pyxiden aus der Cumae-Werkstatt: Corinth XV 3, 4I f. Nr. I48. I 50 Taf. 8; Benson, ECW, 29 Nr. Io-I I Taf. 9, I-2 (KP I238. I8I3).

\section{3-8. Ovoider Aryballos}

Beilage 6, 7. Abb. 18 .

G I382. Fundort unbekannt. Erworben I943/44 von Fritz Schachermeyr (Graz), Schenkung. Reg.-Nr. Sch. G 05.

H 6,6 cm. - H Gefäßkörper 5, I cm. - Dm Bauch 3,4 cm. - Dm Boden I,O cm. - Wandstärke $0,3-0,5 \mathrm{~cm}$. - Querschnitt Henkel I,2/O,4 cm. - Gewicht $26 \mathrm{~g}$.

Unpubliziert.

Archäometrie: CT 20I I-267 am 8. Sept. 20I I.

Zustand: Dem Gefäß fehlen Hals und Mündungsteller. An der Oberfläche einige kleinere Verletzungen und Kratzer. Malschlicker beinahe zur Gänze abgeplatzt.

Keramikart: Farbe des Bruches: blassgelb (2.5 Y 8/2, pale yellow); hart; fein $(<0,2 \mathrm{~mm})$, ohne Dunkelglimmer; sehr feiner Scherben.

Technik: Das Gefäß wurde auf einer gegen den Uhrzeigersinn drehenden Scheibe vom Stock hochgezogen; der enge Hals gewürgt, indem die Wandung an ein Stäbchen gedrückt und von außen mit einem Gegenstück nachgearbeitet wurde; der Standring wurde anschließend mit einer Zentrierhilfe abgedreht (kegelför- 
mige Vertiefung). Der bandförmige Henkel war separat angesetzt und perfekt an die Wandung angarniert. Oberfläche fein geglättet und poliert. Farbe des Tongrundes: hellgrau bis blassgelb (2.5 Y 7/2-8/2, light gray - pale yellow). Der schwarz verfärbte und glänzende Malschlicker dick und homogen aufgetragen. Die zwei Reifen und das breite Band wurden auf der Drehscheibe gezogen. Die Ritzungen sehr fein, exakt und unter Verwendung eines Zirkels gesetzt.

Form: Schlanker Aryballos mit einem nach unten sich stark verjüngenden Gefäßkörper auf einem kaum akzentuierten Standring und mit einem zylindrischen Hals. Auf der Schulter setzt der Vertikalhenkel mit langovalem Querschnitt an.

Dekor: Auf dem Standring ein dünner Reifen. Über dem Standring ein Band aus sehr schmalen langen Zungen. Darüber, von zwei Reifen eingefasst, ein breites Band mit geritzten Schuppen in sieben Reihen, die Schuppen sind doppelt konturiert. Auf der Schulter mittig eine Rosette mit zentraler Kreisfläche und sieben lanzettförmigen Blättern. Auf der Henkelaußenseite eine Reihe

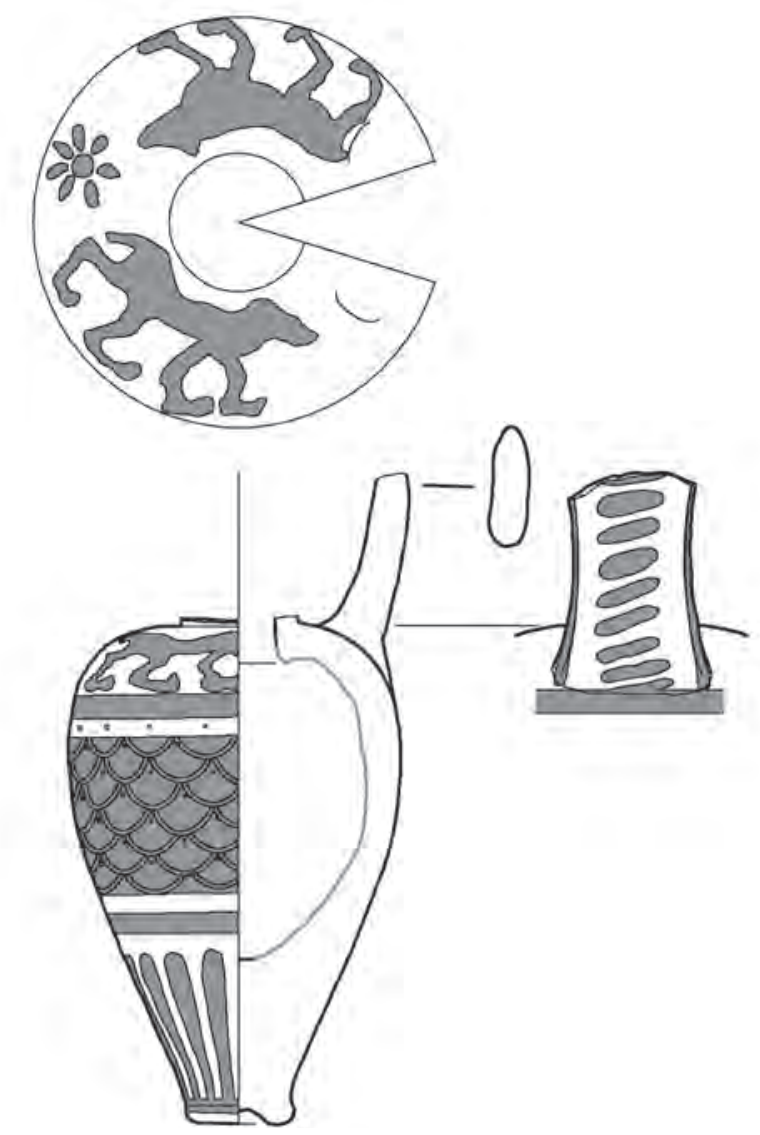

Abb. I 8: Umzeichnung des ovoiden Aryballos G I382 im Maßstab I: I (Zeichnung Karl) von neun Querstrichen zwischen je einem entlang der Henkelkanten führenden Strich.

Darstellung: Hunde - Im Bildfeld auf der Schulter zwei vierbeinig dargestellte, vom Betrachter aus gesehen nach rechts laufende Hunde in Silhouettentechnik. Sie besitzen klobige Köpfe, Ohrenansätze und kurze Schweife.

SPK - TR, um 640-620

Zur Form: Die Gefäßform, ein ovoider Aryballos, auch Spitzaryballos genannt, ist in dieser speziellen Ausprägung im SPK und TR charakteristisch, siehe dazu Neeft, PSA, 272, der solche späten Formen in die Entwicklung der ovoiden Aryballoi integriert (Neeft, PSA, I29-I3I. 260-270). Das schlanke Gefäß mit einem Bodendurchmesser von knapp I,o cm gehört an das Ende dieser Formentwicklung.

Zum Dekor: Zu den mit Schuppenmuster dekorierten Aryballoi siehe Neeft, PSA, 275-289. 356-358.

Zur Darstellung: Die auf der Schulter aufgrund der Negativspuren noch ziemlich gut erkennbaren Hundesilhouetten können als Derivate ähnlicher Darstellungen aus der schwarzfigurigen Technik bezeichnet werden. Zum protokorinthischen schwarzfigurigen Stil siehe Benson, ECW, 35-4I. Auf Ritzungen wurde vollkommen verzichtet. Solche Übergangsstufen zwischen einfach geritzten Hundedarstellungen sowie plumpen Silhouetten zumeist vierbeiniger Hunde finden sich ansonsten an den ovoiden Aryballoi der geometrischen Tradition, wie bei den Gefäßen des Bachofen-Phaleron-Typs (Neeft, PSA, I60 f. Liste LXVIII), des Kopenhagen-Typs (Neeft, PSA, I62 Liste LXIX) bzw. des Kanellopoulos-Malers (Neeft, PSA, I70 Liste LXXII); siehe dazu Neeft, PSA, I 58-I73 Abb. 84. Aufgrund dieser protokorinthischen Stilelemente erscheint trotz der Langlebigkeit der mit Schuppen dekorierten Gefäße eine Datierung des Aryballos G I382 im SPK bis TR plausibel.

Zum Typ: Der Aryballos G I 382 kann den Typen Neeft, PSA, 28 I-288 Liste CXIII-CXIV (entspricht Payne, NC, 286 Nr. 478 A) zugewiesen werden, die nur durch die Dekoration des Mündungstellers zu differieren sind. An den im Durchschnitt ca. 7,6-9,3 cm großen Aryballoi des Typs Neeft, PSA, 28 I-284 Liste CXIII sind soweit bekannt - ausschließlich Zungenbänder statt Hundefriese auf der Schulter charakteristisch. Auch die rekonstruierte Größe des Aryballos (ca. 6,8-7,0 cm) ist nicht für einen dieser beiden Typen entscheidend. In einer Untergruppe (I) des Typs Neeft, PSA, 284 Liste CXIII finden sich Hundefriese auf der Schulter, siehe dazu Neeft, PSA, 286. Diese Gefäße sind allerdings relativ groß. Vgl. den Aryballos mit einer Gesamthöhe von I I, $3 \mathrm{~cm}$ sowie mit „zweibeinig“ dargestellten Hunden: CVA Stockholm I Abb. 9 Taf. I, 9-I 2 (NM ant. 836); Neeft, PSA, 286 Liste CXIV I-2. 


\section{KORINTHISCH}

\section{TAFEL 19}

\section{1-2. Kolonettenkrater}

Tafel 20, 1-3. Tafel 21, 1-4. Beilage 7, 1.

G 238. Fundort unbekannt. Erworben I99I im Schweizer Kunsthandel (Jean-David Cahn AG, Basel), Ankauf.

$\mathrm{H}$ bis zum Rand 33,0 cm. - H mit Henkelplatten 33,2 bzw. 33,7 cm. - Dm Rand 29,4 cm. - Dm Mündung 33,3 cm. - B mit Henkelplatten 40, o cm. - Dm Boden I 8, o cm. - Dm Fuß I 8,6 cm. - H Fuß 3,2 cm. - Dm Henkel 2,0-2,3 cm. - B Henkelplatte ı,,3 bzw. I०, $6 \mathrm{~cm}$. - Volumen 2 I $604 \mathrm{ml}$.

Lehner - Lorenz - Schwarz, Vasen, 20-23 Nr. 9 Abb. I I-I 2 (G. Schwarz). - E. Pochmarski, Streiflichter auf die Geschichte der Archäologischen Sammlung der Universität Graz, NachBlAGStmk 2000-2002, 34 Abb. I2. - E. Pochmarski, Die Anfänge des archäologischen Instituts und der archäologischen Sammlung in Graz, in: M. Novotná (Hrsg.), Probleme und Perspektiven der klassischen und provinzialrömischen Archäologie, Anodos Suppl. 2 (Trnava 2002) 32 Abb. I 2.

Zustand: Das Gefäß aus mehreren größeren Fragmenten zusammengesetzt, kleinere Fehlstellen sowie sämtliche Ausbrüche entlang den Bruchkanten mit Gips ergänzt und retuschiert. Oberfläche gut erhalten; nur wenige Abplatzungen des Malschlickers. Im Inneren einige, bis zu $2 \mathrm{~cm}$ große, kegelförmige Abplatzungen. Reifen in aufgesetzten Farben stark abgerieben und nur mehr in Negativspuren rekonstruierbar.

Technik: Oberfläche der Außenseite und des oberen Mündungsrandes fein geglättet und poliert; Innenseite mit Drehwülsten und feinen Drehrillen. Farbe des Tongrundes: blassgelb (2.5 Y 7/4-8/4, pale yellow). Die flächige Bemalung des Gefäßes erfolgte zum größten Teil auf der Drehscheibe. Der dunkelbraun bis hellbraun verfärbte und glänzende Malschlicker wurde sehr lasierend und nachlässig aufgetragen. Offenbar durch unterschiedliche Hitzeeinwirkung während des Brandes ist der Malschlicker zum Teil fleckig rot verfärbt. Ritzungen sehr präzise und schwungvoll; auch starke Kurvenradien durchgehend und ohne Unterbruch gezogen. Der Reifendekor aus den aufgesetzten Farben Rot und Weiß auf der Drehscheibe gezogen, wobei durch den Anpressdruck schwache Rillen in der ansonsten glatten Oberfläche entstanden. Die rote Ausmalung der Figuren ist nach dem Ritzvorgang besonders nachlässig durchgeführt, zum Teil klecksartig und ohne System auf den Figuren, zumeist füllt sie die Flächen zwischen den Ritzlinien nicht vollständig aus oder reicht darüber hinaus.

Form: Bauchiges Gefäßbecken mit hohem Schwerpunkt auf einem niedrigen kegelförmigen Fuß, mit niedrigem Hals samt einem im rechten Winkel nach außen biegenden, breiten Mündungsrand. Die Oberseite des Mündungsrandes mitsamt den Henkelplatten ist nahezu waagrecht. Unter den Henkelplatten führen bogenförmige Horizontalhenkel mit rundem Querschnitt zur Gefäßschulter. Der Mündungsrand ist leicht unterschnitten. Die Gefäßunterseite hängt so tief herab, dass sie die Standfläche berührt.

Dekor: Die Außenseite ist bis auf die Oberseite des Mündungsrandes samt Henkelplatten sowie den Bildfeldern zwischen den Henkeln durchgehend bemalt. Auf der Fußaußenseite mindestens ein weißer Reifen erkennbar. Unter den Bildfeldern ein Reifendekor mit den aufgesetzten Farben: Weiß und mit etwas Abstand Weiß,
Rot (etwas breiterer Reifen), Weiß. Auf der Oberseite der Mündung ein Strahlenkranz mit nach außen gerichteten Spitzen. Henkelplattenzonen vom Strahlenkranz durch feine Striche getrennt, in den Bildzonen der Henkelplatten wenige Füllornamente wie Kleckse, Vier- und Sechsblatt-Rosetten. Auch in den Bildfeldern am Gefäßbauch ist die Verwendung von Füllornamenten sehr sparsam: Auf Seite A (Sirenen-Seite) sind einige Kleckse bzw. Vier- oder Sechsblatt-Rosetten eingestreut, Seite B (Panther-Seite) besitzt hingegen eine mittig in das Bildfeld gezeichnete Rosette mit zwölf Strahlen und doppelt geritztem Zentrum, der übrige Bildraum ist mit wenigen Klecksen bzw. Vier- oder Sechsblatt-Rosetten versehen. Die Henkel und das Innere des Gefäßbeckens durchgehend bemalt.

Darstellung: Sirene, Panther, Vogel - Die Darstellung beschränkt sich auf die zwei Bildfelder zwischen den Henkeln und auf die Henkelplatten. Seite A: eine stehende Sirene nach rechts mit zurückgewandtem, jedoch stark fragmentiertem Kopf, hier sind gerade noch die Kalotte und das Haarband erhalten. Die Sirene zeigt sich mit ausgebreiteten Sichelflügeln und besonders langen Schwanzfedern. Die Federn und andere Körperdetails der Sirene sind rot dekoriert. Links ein Vogel mit angelegten Flügeln, kurzen Schwanzfedern, einem langen Hals sowie Kopf mit kreisrund geritztem Auge und langem Schnabel. Große unregelmäßige rote Flächen zieren den Flügel und den Hals. Seite B: zwei sich von einander abwendende antithetische Panther mit sehr kleinen Köpfen und langgezogenem Körperbau. Die Schultermuskulatur ist nur mit einer einfachen geschwungenen Ritzlinie gekennzeichnet; über der Bauchlinie mittig am Körperrumpf je vier kurze Rippenlinien. Die Köpfe der Panther besitzen kleine kreisrunde Augen mit kurzen Augapfelstrichen, runde Ohren, eine Nasenlinie aus einem parallelen Doppelstrich und zusätzlich kurze Wangenbackenstriche. Im Bereich der Schulter und des Halses, am linken Panther auch am Hinterteil, überziehen rote Flächen die Malschlickerschicht, ohne besondere Rücksicht auf die Binnenzeichnung. Henkelplatten: je ein Wasservogel mit angelegten Flügeln und kurzen Schwanzfedern, ohne Verwendung von Deckfarben.

\section{FK, um 600/590}

Zur Form: Das Gefäß stellt einen typischen Vertreter eines korinthischen Kolonettenkraters dar. Zur Form siehe Amyx, CVP, 504506. Schwarzfigurig bemalte Kratere sind besonders im Westen, in Sizilien, Süditalien und Etrurien, verbreitet: M. Cristofani - M. Martelli, La distribuzione dei crateri corinzi: il mito e l'immaginario dei simposiasti, in: G. Rizza - F. Giudice (Hrsg.), I vasi attici ed altre ceramiche coeve in Sicilia 2, Atti del Convegno Internazionale Catania, Camarina, Gela, Vittoria, 28 marzo-I aprile I990, CronA 30, I99I [1996], 9-25; C. W. Neeft, Camarina e la sua ceramica corinzia, in: P. Pelagatti - G. di Stefano - L. de Lachenal (Hrsg.), Camarina. 2600 anni dopo la fondazione. Nuovi studi sulla città e sul territorio, Atti del Convegno Internazionale, Ragusa, 7 dicembre 2002/7-9 aprile 2003 (Rom 2006) 9I f.; vgl. die stark fragmentierten Kratere aus den Brandbestattungen der Nekropole Manicalunga von Selinunt: A. Kustermann Graf, Selinunte. Necropoli di Manicalunga. Le tombe della contrada Gaggera, Necropoli della Sicilia antica 2 (Soveria Mannelli 2002) 3I. I $80 \mathrm{Nr}$. I I3/O 204-205 Taf. 57 (Grab II3); 208 Nr. I 52/O 203 Taf. 76 (Grab I 52). Als frühes Zeichen gilt auch die längliche Form der Henkelplatten. Zum Krater als Bestandteil des aristokratischen Banketts und seiner Beliebtheit in Etrurien s. J. de La Genière, Les acheteurs des cratères cointhiens, BCH I I 2, I988, 83-90. 
Zum Dekor: Ein einfacher Strahlenkranz als Ornament am Mündungsrand findet sich vor allem bei Krateren im FK, vgl. Amyx, CVP, 506; vgl. aus dem Demeter-Heiligtum in Bitalemi das Kraterfragment: P. Orsi, Gela. Scavi del I900-I905, MonAnt I7 (Mailand I906) 623 Nr. 2 Abb. 43 I; Payne, NC, 3 I 6 Nr. I I 57; Amyx, CVP, 5 Io Anm. 284. Der Reifendekor in den Farben Weiß und Rot auf der Fußaußenseite, im unteren Gefäßdrittel und unter den Henkelansätzen ist ein Merkmal der frühen Kratere, wie z. B. aus dem um 600 datierten Grab I 35 vom Nordfriedhof (ohne Strahlenkranz im unteren Gefäßdrittel): Payne, NC, 342 (Appendix I); Corinth XIII, I72 Nr. 3 Taf. 89 (T I472); Bakır, Kolonettenkrater, Io Nr. K 2; Amyx, CVP, 506 Anm. 252; 5 10 Anm. 283; bzw. aus Korinth in Athen, NM I 2432 (ohne Strahlenkranz im unteren Gefäßdrittel; Fuß ergänzt): Payne, NC, 30I Nr. 776; Corinth VII I, 55 f. Nr. I 88 Taf. 26; J. L. Benson, Die Geschichte der korinthischen Vasen (Basel I953) 33 Nr. I; Bakır, Kolonettenkrater, ıo Nr. K I Taf. I; Amyx, CVP, 289. 5 Io. Für neues Bildmaterial zum Krater Athen, NM I 2432 ist Alexandra Christopoulou (Athen) zu danken. Die Füllornamente in den Bildfeldern der Henkelplatten, wie Kleckse und sogar Vier- bzw. Sechsblatt-Rosetten, sind ungewöhnlich.

Zur Darstellung: Vögel sind besonders auf den Henkelplatten korinthischer Kratere beliebt, vgl. z. B. aus Megara Hyblaia: G. Vallet - F. Villard, Mégara Hyblaea 2. La céramique archaïque (Paris I964) 64 Taf. 50, I (I/I3877); bzw. aus Korinth: Corinth VII 2, 5 I f. Nr. I74. I76 Taf. 33 (CP-2540. CP-2548; MK). Das Motiv der antithetischen Panther mit zentraler Rosette findet sich in sehr ähnlicher Malweise auf einem Krater aus Grab 2 I Io der Nekropole Rifriscolaro von Camarina: Cristofani - Martelli a. O. I I Abb. 5-6; Neeft a. O. 9I f. Abb. 7 a-c. Antithetisch angeordnete Tiere in den Bildfeldern von Krateren sind sonst relativ selten.

Zum Typ: Der Krater G 238 gehört zur Gruppe I nach der Einteilung korinthischer Kratere durch Tomris Bakır; siehe dazu Bakır, Kolonettenkrater, Io. 23-28; vgl. Payne, NC, 300-302; Amyx, CVP, 504-5II. Nach Humfry Payne zählt der Krater G 238 noch zu den FK-Typen: Payne, NC, 30I f. Nr. 776-780 A. In Form und Bemalung am besten vergleichbar sind die der Phase FK zugewiesenen und erwähnten Kratere aus Korinth in Athen, NM I 2432, und aus Camarina, Grab 2 I IO, sowie das nach Marina Martelli von derselben Hand wie das Exemplar aus Camarina stammende Kraterfragment aus Bitalemi; so Cristofani - Martelli a. O. I I Anm. 3 .

Zum Maler: Eine Malerzuschreibung ist aufgrund des bislang publizierten Materials und der in ihrer figuralen Bemalung inhomogenen Gefäßgattung schwierig. Eine ähnliche Darstellung eines Panthers findet sich auf dem genannten Krater Athen, NM I 2432; dort ist er einem Eber gegenübergestellt. Das Bildfeld ist jedoch trotz identischer Form höher als beim Krater G 238, die Tiere wegen des zusätzlichen Platzes aufrechter gezeichnet. Der Krater Athen, NM I 2432 ist von Jack L. Benson mit drei weiteren Gefäßen zum CEuvre bzw. Umkreis eines Malers zusammengestellt, den er als Eber-Maler bezeichnet: J. L. Benson, Die Geschichte der korinthischen Vasen (Basel I953) 33 f.; eine Malerzuweisung, der Darrell A. Amyx nicht gefolgt ist (Amyx, CVP, 289 Appendix I; sowie Amyx, CVP, 232 Nr. I Taf. IOI, I).

\section{TAFEL 20}

1-3. Siehe Tafel 19, 1-2.
TAFEL 22

\section{1-4. Tafel 24, 1-2. Tafel 25, 1-3. Tafel 80, 1. Alabastron}

Beilage 7, 2.

G 28. Aus Santa Maria Capua Vetere, Tomba principesca dei Quattordici Ponti. Erworben I874 durch Wolfgang Helbig in Rom, Ankauf. Ehemals Slg. Simmaco Doria (Santa Maria Capua Vetere). Alte Inv.-Nr. II 36 (Schenkl) bzw. III 35 (Pichler).

H 24,9 cm. - Dm Mündungsteller rek. 6,4 cm. - H Mündungsteller I, I cm. - Dm Bauch I 2,9 cm. - Dm Vertiefung auf der Unterseite $0,9 \mathrm{~cm}$. - B Ösenhenkel I,8 cm. - Dm Öse licht 0,7 cm. - Gewicht 624 g. - Volumen I393 ml.

W. Helbig, Scavi di Capua, BdI I 874, 246 f. - Lehner - Lorenz - Schwarz, Vasen, 23-25 Nr. Io Abb. I3 (G. Schwarz).

Archäometrie: CT 20I3-380 vom IO. bis I 2. Juli 20I3.

Zustand: Vom Mündungsteller sind drei Viertel weggebrochen; erhalten blieb der Bereich über dem Ansatz des Ösenhenkels. Das Gefäß ist ansonsten ungebrochen und ohne moderne Übermalung. Ein tiefer Kratzer über der rechten Schulter des Typhon. Die Oberfläche ist perfekt erhalten. Im Bereich des Vogels und auf der Unterseite kleinere Abplatzungen des Malschlickers. Zumeist können diese Verluste kleinster Schüppchen des craquelierten Malschlickers auf die Salzbelastung zurückgeführt werden. Minimale Absprengungen durch Kalkeinschlüsse; einige ausgebrannte bzw. ausgewitterte stäbchenartige Vertiefungen. Die rot aufgesetzte Farbe ist besonders gut erhalten. Im Bereich der linken Seite des Typhon (linke Schulter bzw. Schlangenleib) ist die Oberfläche mit einer hellgrauen dünnen (Sinter-)Schicht leicht transparent überdeckt.

Technik: Auf der Unterseite eine kreisrunde Vertiefung (Zentrierhilfe). Oberfläche fein geglättet und poliert. Farbe des Tongrundes: blassgelb (2.5 Y 7/4-8/4, pale yellow). Die verschiedenen Malmittel sind sehr homogen und gleichmäßig aufgetragen. Der Malschlicker dunkelgrau bis schwarz verfärbt; offenbar durch den Brand von feinen netzartigen Haarrissen (Craquelierung) durchzogen. Im Bereich des Vogels ist der Malschlicker durch einen Fehlbrand rötlich verfärbt. Reifen auf der Drehscheibe gezogen. Auf der Unterseite ist der Reifendekor verwischt. Ritzungen sehr fein und exakt; längere Linien mehrmals abgesetzt. Die Malfarben in Rot und Weiß nach dem Ritzvorgang pastos und exakt aufgesetzt; nur an wenigen Stellen reicht die Farbe über die Ritzlinien hinaus. Aufgesetztes Rot dunkelrot bis violettrot verfärbt, zum Teil relativ große Flächen des Malschlickers abdeckend. An vielen Stellen ist die rote Schicht wie der darunterliegende Malschlicker netzartig von feinen Haarrissen durchzogen. Aufgesetztes Weiß z. T. hellgrau verfärbt. Mit dieser Farbe sind zahlreiche Reihen aus feinen bis maximal I mm großen Punkten parallel zu den Ritzlinien ausgeführt; die Kreisflächen im Zentrum der drei Rosetten in der Nähe des Kopfes des Typhon sowie dessen Augapfel sind weiß flächig ausgemalt. Das aufgesetzte Weiß ist bis auf die Punktreihen sehr sparsam verwendet.

Form: Sackförmiger, bauchiger Gefäßkörper mit niedrigem Schwerpunkt und einem flachen, nach außen gezogenen Mündungsteller. Die Unterseite des Gefäßes ist leicht abgeflacht. Der Mündungsteller besitzt eine leicht trichterförmig eingezogene Oberseite und eine etwas unterschnittene Lippe; unter dem Mündungsteller und bündig mit dessen Kante ein Ösenhenkel mit einer abgerundeten Außenseite.

Dekor: Auf der Gefäßunterseite um die zentrale Vertiefung ein breiterer Reifen sowie ein Zungenband, das von zwei Reifen begrenzt ist. Darüber das Bildfeld mit dicht gesetzten Füllornamenten: einfache Rosetten mit vier, sechs oder acht Strahlen, Rosetten mit zwölf und mehr Strahlen sowie kreisförmigen Zentren mit Doppellinien, L-förmige bis dreieckige, zum Teil mit einer einzigen 
gekrümmten Linie versehene Kleckse und spezielle Füllornamente, die in den Zwickel eingepasst den Konturen der Figuren folgen und zumeist eine Ritzung in einem Lotosblütenderivat aufweisen. Einige der genannten Rosetten, aber auch besondere Füllornamente in den Zwickeln sind durch rot aufgesetzte Flächen bereichert. Um den Kopf des Typhon drei Rosetten mit einem weiß aufgesetzten Punkt im Zentrum. Unter dem Mündungsteller zwei Reifen und darüber ein Zungenband. Auf dem Mündungsteller ein Strahlenkranz, am Umbruch zur Mündung ein Reifen. Die Außenseite des Ösenhenkels und der darüber liegende Bereich der Mündungstellerkante bemalt.

Darstellung: Typhon, Vogel - Nahezu die gesamte Oberfläche des Gefäßes wird von der Darstellung eines Typhon mit sichelförmigen Flügeln und einem Schlangenleib in mehreren Windungen eingenommen. Sein bärtiger Kopf mit schulterlangem Haar ist nach rechts gewendet, den Oberkörper richtet er frontal dem Betrachter zu, dabei hat er seinen rechten Arm nach unten abgewinkelt und seinen linken Arm nach rechts ausgestreckt. Im Haar trägt er ein Diadem mit weißen Punkten. Das Auge besitzt einen weißen Augapfel und eine doppelt konturierte große Pupille. Auf Gesicht und Hals ist rot aufgesetzt. Der Typhon trägt ein schulterlanges, bis zum Ansatz des Schlangenleibes reichendes Gewand mit einer T-förmigen Borte über Brust und Schulter. Gewand, Sichelflügel und Schlangenleib sind mit weißen Punktreihen, roten Flächen, Zickzack und gegenständigen Strichgruppen dekoriert. Auf der Gefäßrückseite unter dem Ende des Schlangenleibes - den unteren Reifen der Dekorzone als Standlinie nutzend - ein nach rechts gewandter Vogel. Er besitzt einen langen Hals und einen langen Schnabel, die Flügel sind am Körper angelegt. Auf Hals und Brust verläuft eine Reihe roter Punkte. Der vordere Teil des Flügels rot bemalt, auf der Mittelzone ein rotes Zickzack.

FK, um 600/590. Maler von Brüssel R 224

Zur Erwerbung: Die Akten und die erhaltene Korrespondenz zwischen Wolfgang Helbig, Karl Schenkl und Simmaco Doria des Jahres I 874 am Institut für Archäologie der Karl-Franzens-Universität Graz bzw. im Archiv des DAI Rom zeigen, dass es sich beim Alabastron G 28, aber auch beim zweiten Alabastron G 27 (hier Tafel 23, I-4) sowie beim Granatapfelgefäß G 56 (hier Tafel 30, I-4) um einen Teil der keramischen Ausstattung eines I 873 in der Nähe von Capua (fondo Gennaro, località Quattordici Ponti) entdeckten Grabes, der sog Tomba principesca dei Quattordici Ponti, handelt. Für die Bereitstellung von Briefen an Wolfgang Helbig ist Thomas Fröhlich (Rom) und für Hinweise zum Befund Vincenzo Bellelli (Monterotondo) zu danken. Diese Keramikgefäße werden bereits in W. Helbig, Scavi di Capua, BdI I 874, 246 f. beschrieben. Zum Grab siehe V. Bellelli, La tomba principesca dei Quattordici Ponti nel contesto di Capua arcaica, StA I42 (Rom 2006). Der Verbleib sämtlicher Keramikgefäße aus diesem Grab war bislang der Forschung unbekannt, sie sind jedoch für die Datierung des Grabes sowie für die mitgegebenen Bronzegefäße von Bedeutung.

Zur Form: Grundlegend zur Formgeschichte des korinthischen Alabastrons siehe H. E. Angelmeier, Das Alabastron. Ein Beitrag zur Lekythen-Forschung, Dissertation der Ludwigs-Universität zu Gießen (Gießen I936). Ein direktes Herleiten von ägyptischen Steinalabastra aus dem Material Alabastron wird bereits von Payne, NC, 269 f. Anm. 3 bezweifelt, siehe dazu auch S. Karl, Alabastron oder Bombylios. Zur Frage des ägyptischen Ursprungs. Überlegungen anhand eines Gefäßes aus der Privatsammlung Harald Boesch, in: N. Geworkian (Hrsg.) 30 Jahre Verba et Facta. Burg Strechau. Harald Boesch (Strechau 2009) 43-5I. Das Alabastron G 28 gehört zu den „großen Alabastra“, die eine durchschnittliche Höhe von ca. $30 \mathrm{~cm}$ aufweisen, siehe Payne, NC, 284; hinsichtlich der Terminologie siehe Dehl-von Kaenel, Malophoros, 92-94.
Zum Dekor: Das Dekorsystem mit großen Einzelfiguren, Reihen von weißen Punkten parallel zu den Ritzlinien, einer auf Einansichtigkeit hin orientierten Bildkomposition und zumeist dichten Füllornamenten im Bildfeld kennzeichnen die Gefäße des „whitedot style" nach Payne, NC, 284 f. 290. Zu diesem Stil oder besser Phänomen, von Darrell A. Amyx als Luxus-Gruppe bezeichnet, siehe Amyx, CVP, 87; ausführlicher P. Lawrence, The Luxus Phenomenon I. The Taucheira Painter and Closely Related Hands, Hesperia 67, I998, 303-322. Das Alabastron G 28 besitzt noch FK-Füllornamente, wie Rosetten mit mehrfachen Strahlen und Ornamente in Form von Lotosblüten.

Zur Darstellung: Zu Mischwesen und gefährlichen Raubtieren in der korinthischen Keramik und ihrer psychoanalytischen Deutung hinsichtlich einer menschlichen Strategie zur Bewältigung und Ordnung der wilden und ambivalenten Außenwelt siehe L. Winkler-Horaček, Monster in der frühgriechischen Kunst (im Druck); L. Winkler-Horaček, Mischwesen und Tierfries in der archaischen Vasenmalerei von Korinth, in: T. Hölscher (Hrsg.), Gegenwelten zu den Kulturen Griechenlands und Roms in der Antike (München 2000) 2I7-244.

Zum Typ: Das Alabastron G 28 kann typologisch den TyphonAlabastra Payne, NC, 285 Nr. 389-392 A zugewiesen werden.

Zum Maler: Der Maler ist aufgrund der in den Maßen und in der Darstellung exakten Parallele Eremitage B.I39I gut zu bestimmen: CVA St. Petersburg, State Hermitage Museum 9 Abb. 93 Taf. 39, I-4; 40, I-6; 4I, I-2. Es handelt sich um den Maler von Brüssel R 224. Die Gefäße in Graz und in Sankt Petersburg sind ohne Zweifel von derselben Hand, wohl aber auch derselben Produktionsphase zuzuschreiben. Zum Maler von Brüssel R 224 siehe Amyx, CVP, 9I; Lawrence a. O. 3 I9 f. Als Charakteristika dieses Malers sind das klobige Gesicht, die rot aufgesetzte Gesichts- und Halsfarbe, fachgemäß ausgeführte Überschneidungen und die regelmäßigen Rosetten anzuführen. Mit dem Grazer Alabastron können dem CEuvre dieses Malers nun zusammen mit dem namensgebenden Werk in Brüssel drei Gefäße zugewiesen werden. Die enge Verwandtschaft des Alabastron G 28 mit Brüssel R 224 (Amyx, CVP, 9I Nr. I; CVA Bruxelles, Musées Royaux du Cintquantenaire I, III C Taf. 2, I I) wurde bereits von Helbig erkannt: W. Helbig, Scavi di Capua, BdI I 874, 247 Anm. I im Vergleich zu C. Lenormant - J. de Witte, Élite des Monuments Céramographiques III (Paris I 858) 76. 79 Taf. 3I (damals in der Sammlung von James Alexandre Graf von Pourtalès-Gorgier in Paris). Ein Alabastron in Amsterdam (Allard Pierson Museum 7I5) möchte Patricia Lawrence ebenfalls diesem Maler zuweisen (bei Amyx, CVP, 92 Nr. I 6 unter den nicht weiter zugewiesenen Gefäßen der Luxus-Gruppe). Ein auf dem Flügel eines Hahnes rot aufgesetztes Zickzack findet sich auf einem Alabastron in Syrakus aus dem Grab 7 der Nekropole Camarella von Gela, das ebenfalls der Luxus-Gruppe zugewiesen wird: P. Orsi, Gela. Scavi del I900-I905, MonAnt I7 (Mailand I906) 228 Abb. I80; Amyx, CVP, 92 Nr. 33; Lambrugo, Gela, I 80 Nr. CM 7.I Abb. I2 I Taf. I3 (Syrakus, NM 2I92I; spät FK-früh MK).

\section{TAFEL 23}

\section{1-4. Tafel 24, 3-4. Tafel 26, 1-3. Tafel 80, 2. Alabastron}

Beilage 7, 3.

G 27. Aus Santa Maria Capua Vetere, La Tomba principesca dei Quattordici Ponti. Erworben I874 durch Wolfgang Helbig in Rom, Ankauf. Ehemals Slg. Simmaco Doria (Santa Maria Capua Vetere). Alte Inv.-Nr. II 35 (Schenkl) bzw. III 34 (Pichler). 
H 29,2 cm. - Dm Mündungsteller 6,4 cm. - H Mündungsteller I, I cm. - Dm Bauch I3, I cm. - Dm der Vertiefung auf der Unterseite I,8 cm. - B Ösenhenkel I, I cm. - Dm Öse licht 0,9 cm. Gewicht [6I2] g. - Volumen I $856 \mathrm{ml}$.

W. Helbig, Scavi di Capua, BdI I 874, 246 f. - Lehner - Lorenz - Schwarz, Vasen, 25-27 Nr. I I Abb. I4 (G. Schwarz).

Archäometrie: CT 20I3-380 vom IO. bis I2. Juli 20I3; CT 2013-675 am 20. Nov. 2013.

Zustand: Oberer Teil des Gefäßes in mehrere Fragmente zerbrochen und mit kleineren Verlusten aus insgesamt vier Teilen wieder zusammengesetzt (keine versinterten Bruchflächen; Restaurierung vor I9II/I2); an der Mündungstellerkante mehrere Ausbrüche; ansonsten ist das Gefäß und ohne moderne Übermalung. Das Gefäß ist ohne Spannung, ein senkrechter Riss führt vom Hals über den gesamten Bodenteil bis auf die gegenüberliegende Seite. Keramik in schlechtem Zustand, sie wirkt weich und hat keine Festigkeit; auf der Unterseite ein durch die Wandung gehendes Loch (Absprengung). Große Partien des Malschlickers mitsamt den weißen Punkten, vor allem auf der Rückseite, abgeplatzt. Oberfläche teilweise extrem versintert; vor allem in den Ritzlinien haftet der erhaben vortretende Sinter. Auf der Unterseite eine rezente Kerbe. Auf der gesamten Oberfläche zahlreiche kleine ausgewitterte bzw. ausgebrannte Löcher.

Technik: Einige härtere Einschlüsse im Töpferton hinterließen tiefe Rillen im Zuge des Drehvorganges; auf der Unterseite eine runde, sehr verformte Vertiefung (Zentrierhilfe). Die Öse des Henkels ist sehr ungleichmäßig durchlocht. Im unteren Bereich des Ösenhenkels drei vertikale Kerben. Oberfläche geglättet, ohne jedoch alle äußeren Drehrillen zu entfernen. Farbe des Tongrundes: blassgelb (2.5 Y 7/4-8/4, pale yellow). Der dunkelbraun bis hellbraun verfärbte, leicht glänzende Malschlicker wurde unterschiedlich stark aufgetragen. An wenigen Stellen ist der Malschlicker von netzartigen feinen Haarrissen durchzogen, zum größten Teil glatt. Reifen auf der Drehscheibe gezogen. Die wenigen Ritzungen schwungvoll und präzise. Die Malfarben in Rot und Weiß wurden nach dem Ritzvorgang zum Teil ziemlich pastos aufgetragen, das violett verfärbte Rot gekonnt mit etwas Abstand zu den Ritzlinien aufgesetzt. Aufgesetztes Weiß blassgelb verfärbt.

Form: Unterseite des Gefäßes abgeflacht. Schlauchförmiger, schlanker Gefäßkörper mit mittigem Schwerpunkt und einem flachen, nach außen vorgezogenen Mündungsteller. Dieser besitzt eine trichterförmig eingezogene Oberseite und eine knapp unterschnittene Lippe. Unter dem Mündungsteller und bündig mit dessen Kante ein Ösenhenkel mit einer kantigen Außenseite.

Dekor: Um die zentrale Vertiefung am Boden zwei Reifen und ein Zungenfries. Darüber folgt der figurale Bildfries, der unten und oben von je drei Reifen eingefasst wird. Um den Hals führt ein feines Zungenband. An der Außenseite des Mündungstellers ein einfacher Punktfries. Auf dem Mündungsteller ein Zungenfries zwischen je einem Reifen, ein zusätzlicher Reifen an der Kante zum engen Ausguss. Ösenhenkel und der darüber liegende Bereich der Mündungstellerkante bemalt. Der Bildfries hat kaum Füllornamente; die wenigen konzentrieren sich auf die Hauptansicht. Zwischen den Panthern und dem im Zwischenraum eingeschlossenen Vogel befinden sich Kleckse, ein paar kleine einfache Rosetten mit vier und sechs Blättern und als einzelnes spezielleres Füllornament ein Lotosblütenderivat. Zwischen den Vorderfüßen der Panther je ein kleiner Klecks. Drei große mehrfarbige Rosetten sitzen um die Pantherdarstellungen, zwei davon über dem Rücken zwischen Hals und Schweif, eine unter dem Körper. Dabei handelt es sich um Rosetten mit sichelförmigen Blättern und einem Reifen aus weißen Punkten (sog. Sonnenblumenrosetten); die Rosetten über dem Rücken haben noch zusätzlich ein rot ausgemaltes Zentrum. Die restliche freie Bildfläche ist ohne Füllornamente.
Darstellung: Vogel, Panther - Der Bildfries dieses Gefäßes wird von zwei antithetisch dargestellten, die gesamte Bildhöhe ausfüllenden Panthern eingenommen, die so eng stehen, dass sich ihre Köpfe berühren. Die Schweife dieser Raubkatzen überkreuzen sich auf der Rückseite in einer dekorativen Symmetrie. Trotz der auf Spiegelbildlichkeit angelegten Darstellung gibt es in der Brustmuskulatur der Panther einen auffälligen Unterschied: Der rechte Panther besitzt eine tongrundige Kreisfläche inmitten der Schulterzone. Beide Köpfe der Panther sind identisch gezeichnet, sie haben rote Augen und einen roten Nasen-Stirn-Streifen, große runde Ohren, zwei Stirnfalten und eine Halskrause mit weißen Punkten. Ferner besitzen sie große Augen, die Haare sind nur an den Wangen angedeutet. Der Hals trägt ein charakteristisches Muster aus doppelten Kreisen mit weißen Zentren. Diese Fellzeichnung wird zum Teil von der Schultermuskulatur überlappt. Die Schulter ist flächig rot ausgemalt, zusätzlich betonen gewölbte Bänder aus weißen, aneinander gereihten Punkten die Anatomie des Körpers. Die Beine sind mit denselben weißen Punktreihen eckig konturiert. Die Rippen besitzen alternierend rote Streifen. Das männliche Geschlecht der Panther ist dargestellt. Zwischen diesen Großkatzen steht ein Vogel im Profil nach rechts. Er hat seine Flügel angelegt und wendet seinen Kopf zurück auf seine rechte Seite ins Gefieder. Der Kopf hat ein rundes Auge; ein besonderes Merkmal ist sein weiß und rot bemalter, langer und kräftiger Schnabel. Der Hals ist mit weißen Punkten bedeckt, auf dem Bauchbereich rote Punkte. Auf den Flügeln sitzen rote breite Bänder zwischen weißen Punktreihen.

\section{MK, um 590/580. Erlenmeyer-Maler}

Zur Erwerbung: siehe das Alabastron G 28, hier Tafel 22, I-4.

Zur Form: siehe das Alabastron G 28, hier Tafel 22, I-4.

Zum Dekor: Das Alabastron G 27 gehört zu den Gefäßen des „white-dot style“ nach Payne, NC bzw. der „Luxus-Gruppe“ nach Amyx, CVP; siehe dazu das Alabastron G 28, hier Tafel 22, I-4. Als Datierungselemente finden sich die für MK charakteristischen Sonnenblumen-Rosetten; vgl. Payne, NC, I 57 Abb. 68.

Zur Darstellung: Zoologisch korrekt handelt es sich um Leoparden (panthera pardus) - vgl. die Beschreibung von W. Helbig, Scavi di Capua, BdI I 874, 247 -, da der Begriff Panther die Gattung der Großkatzen, wie Löwen (panthera leo), Leoparden, Jaguare und Tiger umfasst. Zur Darstellung von Panthern siehe J. Schaeffer, Four Corinthian Panthers from Sardis, in: M. A. del Chiaro - W. R. Biers (Hrsg.), Corinthiaca. Studies in Honor of Darrell A. Amyx (Columbia I986) I I7-I23; zu den afrikanischen Großkatzen Löwe, Leopard und Gepard (acinonyx jubatus) siehe W. L. Brown, The Etruscan Lion (Oxford I960) I70-I76. Zur Deutung der Raubtiere siehe das Alabastron G 28, hier Tafel 22, I-4. Zum Motiv des Vogels, der seinen Kopf ins Gefieder gelegt hat, zwischen Panthern vgl. die Darstellung auf einem Alabastron des Malers von Berlin F I008 aus Grab I73 der Nekropole Borgo von Gela: P. Orsi, Gela. Scavi del I900-I905, MonAnt I7 (Mailand I906) Io9 Abb. 77; Payne, NC, 56. 282 Nr. 246; Amyx, CVP, 90 Nr. A-2 Taf. 40, I; Lambrugo, Gela, I I I f. Nr. BSA I73.5 Abb. 43. 49 Taf. 5a (Syrakus, NM 2 I034; spät FK). Der in der Mitte der Großkatzen eingeengte Vogel erinnert wegen der nicht allzu langen Beine und der zwei konzentrischen Halbkreise im Gesichtsbereich am ehesten an eine Eule mit angelegtem Federschleier. Für Informationen ist hier Gerhard Forstenpointner (Wien) zu danken. Das Motiv, Vogel zwischen antithetischen Panthern mit gepunkteten Vorderschenkelrändern (meistens kreisrund wie am rechten Panther des Alabastron G 27), wird auch im etruskischen Bereich imitiert, vgl. z. B. das Alabastron Jena V 486 des Pescia-Romana-Malers: CVA Jena I Taf. 20, 6-7; 2I, I-4 Beil. 7, I.

Zum Typ: Das Alabastron G 27 kann typologisch den PantherAlabastra Payne, NC, 285 Nr. 400-404 zugewiesen werden. 
Zum Maler: Viele Einzelelemente, aber auch Parallelen im Stil und im Dekorsystem zum Alabastron G 27 finden sich im Werk des Erlenmeyer-Malers. Zu diesem siehe J. L. Benson, Die Geschichte der korinthischen Vasen (Basel I953) 4I Liste 64; J. L. Benson, The Erlenmeyer Painter, AntK 7, I964, 72-8 I; B. Rafn, The Corinthian Chimaera Group. Its Chronology and Relations with Protocorinthian and Attic Pottery, ActaArch 49, I978, I60-I62; Amyx, CVP, I60-I62; mit weiteren Zuweisungen: Neeft, Addenda, 48; S. Klinger, A Corinthian Alabastron by the Erlenmeyer Painter in Jerusalem, IEJ 44, I 994, 20I-2 I 5 (IAA V I764) bes. 202 Anm. 4; K. Kilinski, in: H. A. Shapiro (Hrsg.), San Antonio Museum of Art. Greek Vases (San Antonio I995) 57 Nr. I6 Abb. (86.32.I) und das Greifen-Alabastron Tampa Museum of Art I991.I3. Aus Grabungsbefunden stammen ein Hahn-Alabastron aus Sardis: J. S. Schaeffer, The Corinthian Pottery, in: J. S. Schaeffer - N. H. Ramage - C. H. Greenewalt, The Corinthian, Attic, and Lakonian Pottery from Sardis, Archaeological Exploration of Sardis, Monograph ıo (Harvard I997) 43 Nr. Cor 88 (zugehörig Cor 89) Taf. I4 sowie neben dem Fragment eines Panther(vogel)-Alabastrons (Amyx, CVP, I6r Nr. A-24; Dehl-von Kaenel, Malophoros, 95 Nr. 425 Taf. 7) noch weitere Exemplare aus dem Malophoros-Heiligtum von Selinunt: Dehl-von Kaenel, Malophoros, 95-97 Nr. 426. 43 I. 434-435 Taf. 7. Zumeist stellt der Erlenmeyer-Maler jedoch eine einzige Figur dar, die den gesamten Gefäßkörper umspannt. In seinem Werk sind zwei stilistische, wohl chronologisch bedingte Strömungen bemerkbar, worauf bereits J. L. Benson, The Erlenmeyer Painter, AntK 7, I964, 73-77 hingewiesen hat. Einerseits sind es reich dekorierte, kantige Figuren vor einem Hintergrund, der mit Füllornamenten dicht ausgemalt ist, andererseits sind es etwas einfachere, sehr schwungvoll gezeichnete Figuren, wobei auf jegliches Füllornament verzichtet wird. Diese zweite Stilrichtung zeigt zusätzlich noch eine andere Form des Alabastrons mit einem gestauchten oberen Abschluss. Das Alabastron G 27 besitzt Züge der ersten Stilrichtung des Erlenmeyer-Malers, in der Jack L. Benson das frühe CEuvre dieses Malers sieht. Aus derselben Hand wie das Grazer Exemplar stammt das Alabastron Frankfurt am Main, Museum für Vor- und Frühgeschichte $\beta$ 25 I mit der Darstellung eines Greifen: Payne, NC, 303 Nr. 796; CVA Frankfurt I Taf. I4, I-3; Amyx, CVP, I6I Nr. A-9; J. von Freeden, Antikensammlung. Ausgewählte Werke, Museum für Vor- und Frühgeschichte Frankfurt am Main, Archäologische Reihe 5 (Frankfurt am Main I992) 3 I Nr. 2I Abb. Für die Ermöglichung einer Autopsie ist Dagmar Stutzinger (Frankfurt am Main) zu danken. Ein zweites Alabastron, das thematisch eine ähnliche Szene zeigt und von Benson ebenfalls dem Frühwerk des Erlenmeyer-Malers zugewiesen wird, befindet sich in New Haven, Yale University Art Gallery (I9I3.8I): Amyx, CVP, I60 f. Nr. A-8; P. Lawrence, The Chimaera Group at Corinth, in: D. A. Amyx - P. Lawrence (Hrsg.), Studies in Archaic Corinthian Vase Painting, Hesperia Suppl. 28 (Princeton I996) I I I Anm. 225; I 24. Für neues Bildmaterial ist Susan B. Matheson (New Haven) zu danken. Dieses Alabastron ist vom Maler von Louvre E 574 inspiriert und scheint zeitlich vor den Grazer/Frankfurter Alabastra entstanden zu sein; zum Maler siehe die Zusammenstellung von Lawrence a. O. 69-75. I 22-I 24 Liste L. Die tongrundige und leicht nach außen gewölbte Kreisfläche im Schulterbereich des rechten Panthers auf dem Alabastron G 27 ist äußerst ungewöhnlich und harrt einer Erklärung. Gerade im Werk des Erlenmeyer-Malers finden sich dazu noch ähnliche Fälle. Auf dem Alabastron Eremitage B.22 I 2 ist im rechten Flügel des Löwenvogels ein annähernd rechteckiges Feld (, a rectangular opening“) freigelassen: Amyx, CVP, I6I Nr. A-ı 8; CVA St. Petersburg, State Hermitage Museum 9 Taf. 44, I-4; 45, I-6 Abb. 95. Ein dreieckiges Feld ist auch im Flügel des Panthervogels auf dem Alabastron Louvre CA 1796 ausgespart: Payne, NC, 303 Nr. 794; CVA Louvre 6, III C a Taf. 3, 7-II; Amyx, CVP, I6r Nr. A-2I.
TAFEL 24

1-2. Siehe Tafel 22, 1-4.

3-4. Siehe Tafel 23, 1-4.

TAFEL 25

1-3. Siehe Tafel 22, 1-4.

TAFEL 26

1-3. Siehe Tafel 23, 1-4.

TAFEL 27

1-4. Tafel 28, 1-3. Kugelaryballos

Beilage 8, 1.

G 26. Aus Kyme (Kampanien). Erworben I 874 durch Wolfgang Helbig in Rom, Ankauf. Alte Inv.-Nr. II 29 (Schenkl) bzw. III 39 (Pichler).

H max. 9,2 cm. - H Gefäßkörper 7,3 cm. - Dm Mündungsteller 4,2 cm. - H Mündungsteller $0,65 \mathrm{~cm}$. - Dm Bauch 8,8 cm. - Dm Vertiefung auf der Unterseite $0,9 \mathrm{~cm}$. - Querschnitt Henkel 2,2/o,4 cm. - Gewicht I29 g (exkl. Keramiksplitter). - Volumen $244 \mathrm{ml}$.

Lehner - Lorenz - Schwarz, Vasen, 27 f. Nr. I 2 Abb. I 5 (G. Schwarz). - D. Jungblut, Rekonstruktion von Oberflächenmorphologien und Merkmalskeletten aus dreidimensionalen Daten unter Verwendung hochparalleler Rechnerarchitekturen, Dissertation zur Erlangung des Doktorgrades der Naturwissenschaften (Frankfurt am Main 20I2; http://publikationen.ub.uni-frankfurt.de/ frontdoor/index/index/docId/27795 <09.02.20I3>) 2IO-2I4 Abb. I4.I 4 d Tab. I4.I-2. - S. Karl - D. Jungblut - J. Rosc, Berührungsfreie und nicht invasive Untersuchung antiker Keramik mittels industrieller Röntgen-Computertomografie, mit einem Beitrag von R. Erlach, in: E. Trinkl (Hrsg.), Interdisziplinäre Dokumentations- und Visualisierungsmethoden, CVA Österreich Beih. I (Wien 20I3) 77 Tab. I; 80 Abb. 3; 83 Tab. 3; 96 Abb. 2I (d); 99 Abb. 25 Tab. 8; Ior Anm. 62.

Archäometrie: CT 04I36 am I7. Juni 2010.

Zustand: Gefäß ungebrochen; kleine Absplitterungen an der Mündungstellerkante; Oberfläche mit zahlreichen feinen Kratzern überzogen; einzelne ausgebrannte bzw. ausgewitterte Bestandteile. Der Malschlicker partiell abgeplatzt und abgerieben. Durch das Abplatzen des netzartig gerissenen Malschlickers entstanden tiefe Kerben im darunter liegenden Bereich. Auf dem Malschlicker ist das aufgesetzte Rot gut erhalten; zum Teil ist diese rote Schicht mit dem Untergrund abgeplatzt. Eine schleierartige Sinterschicht überzieht partiell den unteren Bereich. Im Inneren des Gefäßkörpers liegen flächig abgeplatzte Keramiksplitter. Auf der Unterseite eine kaum lesbare Bleistiftnummer (vielleicht „I4“).

Technik: Das Gefäß wurde auf einer gegen den Uhrzeigersinn drehenden Scheibe samt Hals und dem nach außen gebogenen 
Mündungsteller in einem Stück - unter Zuhilfenahme eines Werkzeuges für den engen Hals - hochgezogen; Übergänge vom Hals zur Schulter bzw. zum Mündungsteller mit einem scharfkantigen Werkzeug gearbeitet; eine runde Vertiefung auf der Unterseite als Zentrierhilfe. Oberfläche fein geglättet und poliert. Farbe des Tongrundes: hellgelblichbraun bis blassgelb (2.5 Y 6/4-7/4, light yellowish brown - pale yellow). Der schwarz bis dunkelbraun verfärbte und glänzende Malschlicker homogen und zum Rand hin etwas lasierend aufgetragen. Reifen mit Hilfe eines dreifachen Kammpinsels auf der Drehscheibe gezogen. Ritzlinien sehr fein und exakt; es gibt kaum Überschneidungen. Die sparsam verwendete rote Farbe deckt die durch Ritzlinien umschlossenen Flächen bündig ab.

Form: Kugelaryballos mit einem schmalen zylindrischen Halsstück und einem breiten, leicht trichterförmig eingezogenen Mündungsteller. Die leicht schräge Mündungstellerkante bildet eine kurze Lippe aus. An der Mündungstellerkante verläuft der Vertikalhenkel mit langovalem Querschnitt leicht schräg gesetzt zur Schulter des Gefäßes.

Dekor: Die mittige Vertiefung auf der Gefäßunterseite ist ausgemalt. Nach außen folgt ein Kreis, von dem ein sich gegen den Uhrzeigersinn drehender Sichelwirbel ausgeht. Darüber eine Reihe aus sechsstrichigem Gekritzel zwischen je drei Reifen. Im Hauptfries sind die Figuren dicht in die Füllornamentik eingebettet, die kaum einen freien Raum übrig lässt und teilweise parallel den Konturen der Figuren folgt. Neben den geritzten Rosetten, mit oder ohne einfachen oder doppelten Mittelkreis sind zwei charakteristische Füllornamente hervorzuheben. Das erste besitzt eine geritzte Konturlinie und $a b$ einer gewissen Größe eine Binnenzeichnung aus parallelen Wellenlinien einzelner hintereinander gesetzter kurzer Bögen. Das zweite Füllornament besteht aus einer Reihe geritzter Winkel. Alle Füllornamente sind ohne aufgesetzte Farben. Die Abfolge der Füllornamente über den Rücken der drei Löwen folgt demselben Schema. Auf der Schulter ein Dekorband aus einer Reihe von fünfstrichigem Gekritzel zwischen je drei Reifen, darüber ein Zungenband. An der Mündungstelleraußenseite eine Punktreihe. Auf dem Mündungsteller oben zwischen je drei konzentrischen Reifen ein feingliedriger Zungenfries. Auf der Außenseite des Henkels eine Reihe von neun Querstrichen zwischen je zwei entlang der Henkelkanten führenden Vertikalstrichen.

Darstellung: Panthervogel, Löwen - Der Panthervogel ist die zentrale Figur dieses Frieses. Er steht mit ausgebreiteten Flügeln nach links und wendet seinen Kopf frontal dem Beschauer zu. Diese Gestalt hat sehr kleine kreisrunde Augen mit seitlichen Augapfelstrichen, runde Ohren, Stirnfransen, eine halbkreisförmige Linie über der Stirn, breite Wangen und ein kaum akzentuiertes Maul. Zum Panthervogel hin gerichtet stehen zwei Löwen mit aufgerissenen Mäulern und ähnlichen Gesichtsdetails. Sie sind nahezu identisch, nur spiegelverkehrt gezeichnet; dem rechten Löwen fehlen die Stirnfransen. Die Schultern der Löwen sind mit drei parallelen, nicht geschlossenen Linien gezeichnet. Über der Bauchlinie der Löwen eine Reihe von geritzten Rippenlinien. Der dritte nach links gerichtete Löwe besitzt eine andere Beinstellung, bei der die Vorderläufe zusammenstehen. Verschiedene Details an den Tierfiguren, wie die Nasen-Stirn-Linien, die Mähnen, Brust-/Bauchzonen sowie Abschnitte der Schulterzonen und der Flügel, sind rot ausgemalt.

MK, um 590/580. Panthervogel-Gruppe (Schwarz)

Zur Form: Der Kugelaryballos entspricht der Form B I nach Payne, NC, 288-292. Zu den verschiedenen Formen (A, B I und B 2) siehe N. Kunisch, Eine neue Fikellura-Vase, AA I972, 557560 ; C. M. Stibbe, Laconian Oil Flasks and Other Closed Shapes, Allard Pierson Series, Scripta Minora 5 (Amsterdam 2000) 2I. Zur Formentwicklung speziell in der korinthischen Keramik siehe Amyx, CVP, 440-443; Dehl-von Kaenel, Malophoros, 45 f. Zum Ursprung der Form und seinem abrupten Ende H. Parko,
Small Corinthian Oil-Containers: Evidence of the Archaic Perfume Trade, in: C. Scheffer (Hrsg.), Ceramics in Context, Proceedings of the Internordic Colloquium on Ancient Pottery Held at Stockholm, I3-I 5 June I997 (Stockholm 200I) 55-60; S. Karl, Korinthische Kugelaryballoi - Zeugnisse des korinthischen Parfumhandels oder der Spezialisierung in Votivgaben?, Schild von Steier I 8, 2005, I I-25; C. W. Neeft, Camarina e la sua ceramica corinzia, in: P. Pelagatti - G. di Stefano - L. de Lachenal (Hrsg.), Camarina. 2600 anni dopo la fondazione. Nuovi studi sulla città e sul territorio, Atti del Convegno Internazionale, Ragusa, 7 dicembre 2002/7-9 aprile 2003 (Rom 2006) 77 Anm. 5.

Zum Dekor: Der Sichelwirbel auf der Unterseite, die Bemalung der Henkelaußenseite sowie des Mündungstellers und die den Fries rahmenden Ornamentbänder weisen den Aryballos G 26 den FK- bis MK-Dekorationsschemata zu.

Zur Darstellung: Zum Löwenbild siehe T. Bakır, Korinth seramiğinde aslan figürünün gelişimi, Ege Üniversitesi Sosyal Bilimler Fakültesi Yayınları (Izmir I 982). Zur Deutung der Mischwesen und Raubtiere siehe das Alabastron G 28, hier Tafel 22, I-4.

Zum Typ: Der Aryballos G 26 kann dem Typ Payne, NC, 290 Nr. 609-62I A zugewiesen werden, der sog. Panthervogel-Gruppe, siehe dazu J. L. Benson, Die Geschichte der korinthischen Vasen (Basel I953) 48 Liste 78; Amyx, CVP, 93 f.

Zum Maler: In der Panthervogel-Gruppe wird seit J. L. Benson, Some Notes on Corinthian Vase-Painters, AJA 60, I956, $224 \mathrm{f}$. versucht, einzelne Maler herauszugreifen und zu benennen, wie $\mathrm{z}$. B. den Panther-Maler. Dieser Versuch ist in Amyx, CVP, 93 korrigiert worden. Jüngst identifizierte Natalia Sidorova in: CVA Moscow, Pushkin State Museum 7, I9 in dieser Gruppe den Maler der pantherköpfigen Sirene, dem sie die Alabastra Moskau, Pushkin State Museum II Ib 4I, Louvre E 473, Tarent, Museo Nazionale Archeologico 4859, Stockholm, MM I964/Io, Stockholm, NM ant. 837 sowie einen Aryballos im Schweizer Kunsthandel zuweist. Ungewöhnlich und sich von der soweit bekannten PanthervogelGruppe abhebend sind beim Aryballos G 26 die eigenartigen Füllornamente mit den parallelen Wellenlinien bzw. Bogenreihen und der Halbkreis auf der Stirn des Panthers. Zum Halbkreis auf der Stirn vgl. J. L. Benson, Die Geschichte der korinthischen Vasen (Basel I 953) 48 sowie J. L. Benson, Some Notes on Corinthian Vase-Painters, AJA 60, I956, 224. Zu einer ähnlichen Darstellung eines Panthervogels vgl. den Aryballos Gela 9633 der Panthervogel-Gruppe aus Grab 3 I 3 der Nekropole Borgo von Gela: P. Orsi, Gela. Scavi del I900-I905, MonAnt I7 (Mailand I906) I53 f. Abb. II3; Payne, NC, 290 Nr. 609; Amyx, CVP, 94 Nr. A-r 8; Lambrugo, Gela, I 35 Nr. BGR 3 I 3.3 Abb. 72 (spät FK-früh MK). Für die Zuweisung des Aryballos G 26 an einen Maler fehlt es jedoch einerseits an eindeutigen Kriterien, andererseits sind Parallelen zu den geritzten Füllornamenten bislang unbekannt.

\section{TAFEL 28}

1-3. Siehe Tafel 27, 1-4.

\section{TAFEL 29}

\section{1-6. Lekanis}

Beilage 8, 2.

G 4I. Aus Böotien. Erworben I 875 durch Wolfgang Helbig in Athen, Ankauf. Ehemals Slg. Athanasios Rhousopoulos (Athen). Alte Inv.-Nr. II 54 (Schenkl) bzw. III 54 (Pichler). 
Becken: $\mathrm{H}_{4}, 8 \mathrm{~cm}$. - Dm Rand 7,6 cm. - Dm Falz 9,2 cm. - H Falz 0,75 cm. - B mit Henkeln I I,2 cm. - Dm Boden 5, O cm. Querschnitt Henkel o,6/I, I cm. - Gewicht IO2 g. - Volumen I42 ml. - Deckel: H 3,5 cm. - Dm Rand 8,6 cm. - Dm max. 8,9 cm. Dm Knauf I,7 cm. - H Knauf 0,7 cm. - Gewicht 4I g. - Gesamt: $\mathrm{H} 7,5 \mathrm{~cm}$. - Gewicht I $43 \mathrm{~g}$.

Unpubliziert.

Zustand: Bis auf kleine Absplitterungen sind beide Gefäßteile vollständig erhalten. Auf der Unterseite des Beckens geringfügige Verletzungen. Aufgrund der zahlreichen Kalkeinschlüsse in der Keramik mehrere kegelförmige Absprengungen in der Oberfläche. Malschlicker an wenigen Stellen abgeplatzt, zum Teil samt dem darauf aufgesetzten Rot. Auf einer Seite im Inneren des Beckens deutliche Salzausblühungen. Auf der Unterseite des Standringes Reste von weißem Sinter.

Technik: Oberfläche bis auf die Innenseite des Deckels, wo sich deutlich die spiralförmigen Drehrillen zeigen, geglättet und poliert. Farbe des Tongrundes: blassgelb (2.5 Y 8/2-3, pale yellow). Der schwarz verfärbte und glänzende Malschlicker sehr homogen aufgetragen; an den schnell gezogenen Strichen ist der Malschlicker lasierend und braun bis hellbraun verfärbt. Reifen auf der Drehscheibe gezogen. Auf dieses Vorgehen geht auch ein „Ausrutscher“ mit dem Pinsel beim Bemalen des Standringes zurück. Das rot bis hellrotbraun verfärbte Rot ist auf der Malschlickerschicht, zuweilen auch direkt auf dem Tongrund aufgesetzt.

Form: Das Becken der Lekanis entspricht einer tiefen, konischen Schale mit einem Wandungsknick auf einem niedrigen, jedoch sehr breiten, konischen Fuß. Die Wandung bildet im oberen Teil außen einen Randfalz für den Deckel aus. Der Randfalz ist kantig abgesetzt und nach außen abgerundet. Der Rand des Beckens läuft sehr dünn aus. Am Becken zwei gegenständige vertikale Reflexbogenhenkel mit langovalem Querschnitt. Der Deckel hat eine leicht kegelförmige Grundform mit einem nach unten gebogenen, spitz zulaufenden Rand. Mittig ein niedriger, leicht konischer Deckelknauf mit abgeschrägtem Rand.

Dekor: Der Fuß ist bemalt und rot aufgesetzt. Der konische Teil des Beckens ist unverziert, darüber zwei Reifen, wovon der untere mit aufgesetztem Rot überdeckt ist. Zwischen den Henkeln befindet sich ein Bildfeld, das mit je einem Zickzack verziert ist. Henkelaußenseiten und dornartige Fortsätze sind bemalt. Der Falz ist außen durchgehend bemalt und am äußersten Rand mit einem rot aufgesetzten Reifen versehen. Das Becken ist innen durchgehend bemalt und mit drei rot aufgesetzten Reifen dekoriert: der erste am Boden, der zweite auf halber Höhe des Beckens und der dritte knapp unterhalb des Randes. Auch der Deckel ist mit einem linearen Dekor verziert: Um den äußersten Rand des Deckels ein rot aufgesetzter Reifen, darüber ein Band, ein dünner Reifen sowie ein breites Band, das zur Gänze rot aufgesetzt ist. Es folgt ein Band mit Hakenmäander, das beidseitig von je einem dünnen Reifen begrenzt ist. Der obere Teil des Deckels und die Knaufaußenseite sind durchgehend bemalt. Auf der Oberseite des Deckelknaufes eine zentrale Kreisfläche und ein konzentrischer Reifen.

\section{SK II, Ende 6. Jh. bis erste Hälfte 5. Jh.}

Zur Form: Korinthische Lekaniden, die besonders im SK - zumeist mit einfachen Mustern bemalt - beliebt werden, zeichnen sich trotz einheitlicher Grundform durch eine große Dekorationsvielfalt aus; siehe dazu Corinth XIII, I I7. I44-I46; Amyx, CVP, 465-468; Corinth VII 5, 83 f. Im 6. Jh. besitzen diese einfachen Lekaniden zumeist tiefe Becken mit Wandungsknick und Deckel, die sich nach außen kontinuierlich stärker krümmen, vgl. die Lekaniden aus Gräbern des späten 6. Jhs.: Corinth XIII, 2 I 2 Nr. 252 4 Taf. 35 (T 3 IO2); 2 I 4 Nr. $257-8$ Taf. 34 (T I 456 ). Nahezu von identischer Form ist die Lekanis Corinth VII 5, 84 Nr. 297 Taf. I 8 (C-37-I008). Die Form mag noch bis in die Mitte des 5. Jhs. reichen; vgl. die Lekanis aus einem Grab der I. Hälfte des 5. Jhs.: Corinth XIII, 226 Nr. 29I-3 Abb. I 6 Taf. 90 (T I 637).

Zum Dekor: Das Hakenmäander-Band am Deckel findet eine Entsprechung in einem Ornamentband auf der Lekanis Heidelberg, Univ. I4 I aus Phaleron: Payne, NC, 336 Nr. I 530 ; CVA Heidelberg I Taf. I8, I2. Hakenmäander-Bänder sollen nach Corinth VII 5, 28 Tab. I und M. K. Risser, Corinthian, Archaic and Classical Pottery. The Local Style, in: C. K. Williams - N. Bookidis (Hrsg.), Corinth. The Centenary I 896-I996, Corinth XX (Princeton 2003) I 60 für die I. Hälfte des 5. Jhs. typisch sein. Formal und von der Dekorabfolge eng verwandte Deckel stammen aus dem Depot Mauer E von Korinth: Corinth XV 3, 207 Nr. I I09 Taf. 47 (KP 2449; Mitte des 5. Jhs.) und aus Grab C der Nekropole Tor

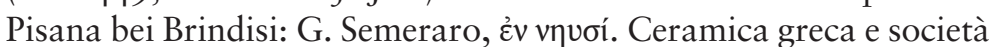
nel Salento arcaico, Beni Archeologici - Conoscenza e Technologie, Quaderno 2 (Bari I997) 47 f. Nr. Io Abb. 7 (um 480/470). Das auf dem Becken der Lekanis G 4I gezeichnete Zickzack ist kaum enger zu datieren. Ein ähnlich regelmäßiges Zickzack besitzt der Beckenrand R. J. Hopper, Corinthian Vases (Excluding Drinking Vessels), in: T. J. Dunbabin (Hrsg.), Perachora. The Sanctuaries of Hera Akraia and Limenia II. Pottery, Ivories, Scarabs, and Other Objects (Oxford I 962) 28 I Nr. 2736 Taf. I I3. Ganz anders die schräg gezeichneten, stark ausschwingenden Zickzackformen wie auf einer Lekanis aus dem um 480/470 datierten Grab 28 I vom Nordfriedhof: Corinth XIII, 223 Nr. 6 Taf. 40 (T I 239).

Zum Typ: Beim Gefäß G 4I handelt es sich um eine Lekanis des Typs Payne, NC, 336 Nr. I 530-I 530 A, der mit linearen und einfachen geometrischen oder floralen Mustern bemalt ist. Vorrangige Dekorflächen sind der äußere Bereich des Deckels und die Zone zwischen den Henkeln. 


\section{OSTGRIECHISCH}

\section{TAFEL 30}

\section{1-4. Granatapfelgefäß}

Beilage 8, 3. Abb. 19.

G 56. Aus Santa Maria Capua Vetere, La Tomba principesca dei Quattordici Ponti. Erworben I874 durch Wolfgang Helbig in Rom, Ankauf. Ehemals Slg. Simmaco Doria (Santa Maria Capua Vetere). Alte Inv.-Nr. II 37 (Schenkl) bzw. III 4I (Pichler).

H 6,8 cm. - H Gefäßkörper 5,2 cm. - Dm Rand 2,2 cm. - Dm Mündungsteller 2,3 cm. - H Mündungsteller o,4 cm. - Innerer Dm Mündung verengend von o,9I auf o,66 cm. - Dm Bauch 6,7 cm. Dm Blüte I, $5 \mathrm{~cm}$; H Blüte $0,8 \mathrm{~cm}$. - Gewicht 73 g. - Volumen $86 \mathrm{ml}$.

S. Karl, Durchleuchtungen griechischer Keramik - Industrielle ${ }_{3}$ D-Röntgen-Computertomografie als archäometrische Methode, in: J. Kiesslich - F. Lang - K. Schaller - C. Uhlir - M. Unterwurzacher (Hrsg.), Primus conventus austriacus archaeometriae. Scientiae naturalis ad historiam hominis antiqui investigandam MMIX, Tagungsband zum Ersten Österreichischen Archäometriekongress, I 5.-I7. Mai 2009, Paris Lodron Universität Salzburg, ArchaeoPlus I (Salzburg 2010) IO2 Abb. 2. - D. Jungblut, Rekonstruktion von Oberflächenmorphologien und Merkmalskeletten aus dreidimensionalen Daten unter Verwendung hochparalleler Rechnerarchitekturen, Dissertation zur Erlangung des Doktorgrades der Naturwissenschaften (Frankfurt am Main 20I2; http://publikationen.ub.uni-frankfurt.de/frontdoor/index/index/ docId/27795<09.02.20I3>) 2IO-2I4 Abb. I4.I3 e Tab. I4.I2. - D. Jungblut - S. Karl - H. Mara - S. Krömker - G. Wittum, Automated GPU-Based Surface Morphology Reconstruction of Volume Data for Archaeology, in: H. G. Bock - W. Jäger - M. J. Winckler (Hrsg.), Scientific Computing and Cultural Heritage. Contributions in Computational Humanities (Heidelberg 2013) 43 Abb. 5.2f. - S. Karl - D. Jungblut - J. Rosc, Berührungsfreie und nicht invasive Untersuchung antiker Keramik mittels industrieller Röntgen-Computertomografie, mit einem Beitrag von R. Erlach, in: E. Trinkl (Hrsg.), Interdisziplinäre Dokumentations- und Visualisierungsmethoden, CVA Österreich Beih. I (Wien 20I3) 77 Tab. I; 83 Tab. 3; 96 Abb. I9. 20 (e); 99 Tab. 8; IOI; I07-I09 Abb. 33; I 10 Abb. 34 (d) - S. Karl - D. Jungblut - H. Mara G. Wittum - S. Krömker, Insights into manufacturing techniques of archaeological pottery: Industrial X-ray computed tomography as a tool in the examination of cultural material, in: M. MartinónTorres (Hrsg.), Craft and science: International perspectives on archaeological ceramics, Ioth European Meeting on Ancient Ceramics (EMAC '09) London, I0.-I3.09.2009, UCL Qatar Series in Archaeology and Cultural Heritage (Doha 20I4) Abb. 4.

Archäometrie: CT 03047 am I7. März 2009.

Zustand: Das Gefäß ist bis auf kleine Absplitterungen vollständig erhalten. Zwei scharfkantige gröbere Verletzungen am Bauch; der Malschlicker zum größten Teil abgeplatzt, mit diesem auch nahezu alle rot aufgesetzten Flächen. Das aufgesetzte Rot ansonsten nur mehr in minimalen Resten erhalten. Ritzungen und Innenseite des Halses stark versintert.

Technik: Der Gefäßkörper entstand nicht auf der Drehscheibe, sondern in einer Negativform. Im Gefäß sind noch deutlich Spuren dieses Herstellungsprozesses zu erkennen. Die vorbereitete Wan- dung wurde in eine Negativform gepresst, wodurch vertikale Risse an der Innenseite hervorgerufen wurden. Nach dem Ansetzen des separat geformten, massiven zylindrischen Halsstückes wurde dieses samt der Gefäßwandung mit einem spitzen Gegenstand durchbohrt, sodass durch diesen Vorgang gratartige Reste weit in den Gefäßkörper hineingedrückt wurden. Zusätzlich auf der Innenseite des Bodens ein unregelmäßiges spitz zulaufendes Einstichloch dieses Werkzeuges, wofür vermutlich ein rundes Holzoder Knochenstäbchen mit einem spitzen Ende verwendet wurde. In der Negativform war aufgrund fehlender Spuren einer eigenen Angarnierungsfläche auch die kegelförmige Blüte des Granatapfels ausgeformt worden, erst danach wurde die Blüte mit den seitlichen Kerben versehen. Oberfläche mit Tuch oder Schwamm geglättet. Farbe des Tongrundes: blassgelb ( 5 Y 8/2, pale yellow). Der dunkelgrau bis schwarz verfärbte, glänzende Malschlicker wurde dick und sehr homogen auf dem oberen Teil des Gefäßes aufgetragen (getaucht?). Trotz der Feinheit der Ritzungen sind diese zum Teil sehr nachlässig ausgeführt, gekennzeichnet durch versetzte bzw. überkreuzte Linienführung und durch ungenaue Anschlüsse. Nach dem Ritzvorgang wurden an bestimmten Stellen des Dekors dunkelviolett verfärbtes Rot aufgesetzt.

Form: Aryballos mit einer annähernd kugeligen Gefäßform in Form eines Granatapfels mit sechs seitlichen schwachen Einbuchtungen, niedrigem Hals und auf seiner Oberseite mit einem leicht trichterförmig eingezogenen, kantigen Mündungsteller. Auf der Unterseite ein kegelförmiger Blütenrest mit sechs radialen Einschnitten und einer mittigen Vertiefung.

Dekor: Die zentrale Vertiefung und die seitlichen Einschnitte im Blütenrest des Granatapfels sind direkt auf Tongrund rot ausgemalt. Auf der Schulter ein eingeritzter Dekor: ein doppelreihiges Band mit Hakenmäander, darüber eine Zone von nach
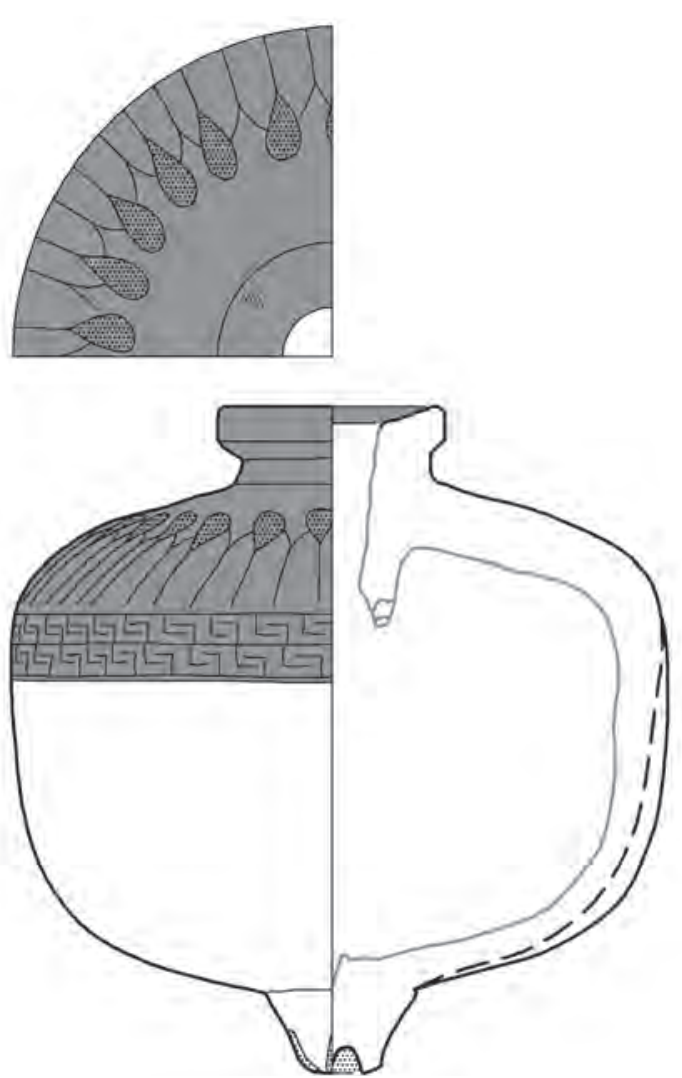

Abb. I9: Umzeichnung des Granatapfelgefäßes G 56 im Maßstab I:I (Zeichnung Karl) 
außen weisenden, tropfenförmigen und spitzen Blättern mit roten Innenflächen. Die Gefäßoberseite ist ab der ritzverzierten Schulter inklusive der Oberseite des Mündungstellers durchgehend bemalt. Auf der Oberseite des Mündungstellers noch rote Farbspuren von Punkten bzw. radialen Zungen.

OA I c-d (ostionisch oder rhodisch), letztes Drittel 7. Jh.

Zur Erwerbung: siehe das Alabastron G 28, hier Tafel 22, I-4.

Zur Technik: Wenig ist über die Herstellungstechnik der Granatapfelgefäße bekannt; konventionell wird davon ausgegangen, dass diese Gattung auf der Drehscheibe hergestellt wurde, siehe Higgins, Terracottas, 9; F. Songu in: CVA Amsterdam 6, 32. An einem fragmentierten, etwas größeren Gefäß aus Naukratis (Dm Bauch $8,5 \mathrm{~cm})$ sind wohl Spuren für diese Annahme vorhanden: Higgins, Terracottas, 3 I Nr. I654 Taf. I9 (GR I888.6-I.752.a). Auf der anderen Seite belegen CT-Untersuchungen am Granatapfelgefäß G 56 eine Herstellung in einer Negativform: S. Karl - D. Jungblut J. Rosc, Berührungsfreie und nicht invasive Untersuchung antiker Keramik mittels industrieller Röntgen-Computertomografie, mit einem Beitrag von R. Erlach, in: E. Trinkl (Hrsg.), Interdisziplinäre Dokumentations- und Visualisierungsmethoden, CVA Österreich, Beih. I (Wien 2013) I07-I09 Abb. 33. Von identischer Herstellungstechnik - soweit dies von außen erkannt werden kann (charakteristisch die tief eingestochene Mündung) - ist ein Granatapfelgefäß aus Grab 45 der Westnekropole von Samos: W. Löwe, Die Kasseler Grabung I 894 in der Nekropole der archaischen Stadt, in: P. Gercke (Hrsg.), Samos - die Kasseler Grabung I894 in der Nekropole der archaischen Stadt von Johannes Boehlau und Edward Habich, Kataloge der Staatlichen Museen Kassel 24 (Kassel I996) 64 Nr. 45,29 Abb. (S I 5). Technisch gesehen - modelgeformt mit anschließender Oberflächenglättung - entspricht das Grazer Exemplar dem Acheloos-Kopfgefäß aus Naukratis: Higgins, Terracottas, 22 Nr. I628 Taf. I2 (GR I888.6-I.752.d).

Zum Dekor: Charakteristisch für eine Gruppe von ostgriechischen Gefäßterrakotten ist eine partielle Bemalung, in die ein Zungenmuster mit zumeist einer Borte in Form von Bändern mit Hakenmäander bzw. Mäanderhaken eingeritzt wird, während der größere Teil des entweder als menschlicher Körperbestandteil oder als Frucht geformten Gefäßes tongrundig bleibt. Zu dieser Gruppe gehören auch die eng verwandten Gefäße in Form eines menschlichen Beines (Gruppe A nach Ducat, Vases plastiques, I34-I36).

Zum Typ: Das Gefäß G 56 gehört zu der von Jean Ducat zusammengestellten Gruppe B der Granatapfelgefäße (ohne Wulst am Übergang der Wandung zum Hals). Derartige Exemplare finden sich vorrangig im ostgriechischen Raum (Ephesos, Samos, Rhodos, Smyrna) bzw. in Etrurien, Kampanien und Sizilien. Mit Zungenband auf der Schulter und einem Hakenmäander- bzw. Mäanderhaken-Band vergleichbar sind - mit oder ohne Wulst Fragmente aus dem Heiligtum von Gravisca: S. Boldrini, Le ceramiche ioniche, Gravisca 4 (Bari I994) 46 Nr. 20 Abb. (Tarquinia 72/I0473-I0474. 72/IO479-IO48I. 72/I0485. 72/IO490) und Nr. 2I Abb. (Tarquinia 72/IO453. 72/IO45 5-I0456 bis), vollständig erhaltene Gefäße aus einem Votivdepot im Demeter-Heiligtum von Catania: A. Pautasso, La ceramica greco-orientale, Stipe votiva del Santuario di Demetra a Catania 2, Studi e Materiali di Archeologia Greca 9 (Catania 2009) 52 Nr. 80-8I Taf. 4. A (K I 264-I 265); aber auch ein Fragment aus einem in das letzte Drittel des 7. Jhs. datierten Kontext im Artemision von Ephesos: Selçuk, Österr. Grabungshaus Depot ART 880966.3. Zur Datierung vgl. auch das Granatapfelgefäß (mit Wulst) aus Grab 77 der Nekropole Borgo von Gela (Syrakus, NM 20896), aus dem ein frühes korinthisches Alabastron (Syrakus, NM, ohne Inv.) der Phase TR-FK stammt: P. Orsi, Gela. Scavi del I900-I905, MonAnt I7 (Mailand I906) 58 Abb. 32; Lambrugo, Gela, 97 f. Nr. BBU 77.I-2 Abb. 27. Weitere vollständige Gefäße stammen aus älteren Sammlungs- beständen wie Berlin I963.I0 angeblich aus Ephesos: A. Greifenhagen, Schmuck und Gerät eines lydischen Mädchens, AntK I965, I 3 Taf. 6, 6; Ducat, Vases plastiques, I42 Nr. 5 Taf. 2I, 3; W.-D. Heilmeyer (Hrsg.), Antikenmuseum Berlin. Die ausgestellten Werke (Berlin I988) 45 Nr. 3 Abb. (L. Giuliani); London, BM GR I 839.II-9.10 aus Italien, GR I861.I0-24.I I aus Kamiros und GR I 888.6-I.752.a aus Naukratis: Higgins, Terracottas, 30 f. Nr. I652-I654 Abb. 6. Io Taf. I9-20; Ducat, Vases plastiques, I43 Nr. 4-6. Zu dieser Produktion gehören auch die von einer Schlange umwundenen Kompositgefäße aus drei bzw. vier Granatäpfeln etwa aus Capua: B. d'Agostino, Un aryballos plastico del Museo Campano, ArchCl I4, I962, 7 I Taf. 46-47; Ducat, Vases plastiques, I 45 Nr. 7 (6630), oder aus Erythrai: M. Akurgal, Korint Seramiği. M. Ö. 750-550 (Istanbul I997) 84 Abb. 59 Taf. I2, 3 (Izmir). Zu den möglichen Inhalten solcher Gefäße siehe N. Massar, Vases à parfum de Grèce de l'Est: raffinement des formes et des couleurs, in: A. Verbanck-Piérard - N. Massar - D. Frère (Hrsg.), Parfums de l'Antiquité. La rose et l'encens en Méditerranée, Ausstellungskatalog Mariemont (Mariemont 2008) 98.

Zur Werkstatt: Zur Gruppe der Granatapfelgefäße vgl. die älteren Arbeiten, die aufgrund des blassgelben Scherbens noch eine korinthische Herkunft vermuteten, K. F. Johansen, Les vases Sicyoniens (Kopenhagen I923) 29. 3 I; M. J. Maximova, Les vases plastiques dans l'Antiquité. Époque archaïque (Paris I927) 89 f. sowie Payne, NC, I76-I 80 und die heute noch grundlegenden Untersuchungen von Reynold A. Higgins und Jean Ducat, die eine rhodische Herkunft annehmen: Higgins, Terracottas, 29 f. zu Nr. I650; bes. Io f. Appendix I; J. Ducat, Les vases plastiques corinthiens, BCH 87, I963, 43 I f.; Ducat, Vases plastiques, I42-I44. I62-I65. Zum Problem der Provenienz siehe die Rez. von E. Paul, Gnomon 42, I970, 79 f. Den möglichen Produktionsort ausschließlich auf die Insel Rhodos einzuengen, erscheint nach den neuesten Erkenntnissen hinsichtlich der ostgriechischen Keramik unsicher, siehe dazu Cook, EGP, passim; M. Akurgal M. Kerschner - H. Mommsen - W.-D. Niemeier, Töpferzentren der Ostägäis. Archäometrische und archäologische Untersuchungen zur mykenischen, geometrischen und archaischen Keramik aus Fundorten in Westkleinasien, ÖJh Ergh. 3 (Wien 2002) 28-36 (M. Kerschner). Zur Frage der Lokalisierung der Werkstatt (bzw. Werkstätten) siehe A. Pautasso, La ceramica greco-orientale, con un contributo di M. Kerschner e H. Mommsen, Stipe votiva del Santuario di Demetra a Catania 2, Studi e Materiali di Archeologia Greca 9 (Catania 2009) 42-44. Zu überlegen wäre auch eine Herstellung in einer der ostionischen Keramikwerkstätten, wobei besonderes Augenmerk auf Terrakotten oder auf nicht auf der Drehscheibe hergestellte Gefäße von figuraler, vegetativer oder anderer Form zu legen wäre. Das erwähnte Granatapfelgefäß London, BM GR I888.6-I.752.a soll in der Keramikart dem Acheloos-Kopfgefäß entsprechen, das naturwissenschaftlich untersucht und einer Gruppe Ionian B zugewiesen wurde, die jedoch Produkte aus mehreren Zentren Ioniens umfasst und somit wenig informativ ist, siehe dazu R. E. Jones - J. Boardman, Provenance Studies of Greek Pottery of the Historic Period, in: R. E. Jones (Hrsg.), Greek and Cypriot Pottery. A Review of Scientific Studies (Athen I986) 667 f. Abb. 8.I3 Tab. 8.8-8.9. Ohne naturwissenschaftliche Untersuchungen wird die Provenienz der Granatapfelgefäße weiterhin spekulativ bleiben. Bemerkenswert ist weiterhin der stilistische und technische Vergleich der Granatapfelgefäße durch Higgins mit einer Gruppe von ostdorischen Trinkschalen, mit hoher Wahrscheinlichkeit rhodischer Provenienz, den sog. Vroulia-Schalen, siehe Higgins, Terracottas, I I zu Nr. I650-I654. $\mathrm{Zu}$ den Vroulia-Schalen und ähnlichen Gefäßen siehe K. F. Kinch, Vroulia, Fouilles de Vroulia (Rhodes) (Berlin I9I4) I68-I88; E. Walter-Karydi, Samische Gefäße des 6. Jhs. v. Chr. Landschaftsstile ostgriechischer Gefäße, Samos 6, I (Bonn I973) 52 f. I34; Cook, EGP, I 4 f.; U. Schlotzhauer, Griechen in der Fremde: Wer 
weihte in die Filialheiligtümer der Samier und Milesier in Naukratis? Mit einem epigraphischen Beitrag von W. Röllig, in: A. Naso (Hrsg.), Stranieri e non cittadini nei santuari greci, Atti del convegno internazionale, Udine, 20-22 novembre 2003, Studi Udinesi sul Mondo Antico 2 (Turin 2006) 302 f. Zu archäometrischen Untersuchungen von Vroulia-Schalen siehe U. Schlotzhauer - A. Villing, East Greek Pottery from Naukratis: The Current State of Research; P. Dupont - A. Thomas, Naukratis: Les Importations Grecques Orientales Archaïques. Classification et détermination d'origine en laboratoire bzw. S. Weber, East Greek ,Situlae' from Egypt, in: A. Villing - U. Schlotzhauer (Hrsg.), Naukratis: Greek
Diversity in Egypt, Studies on East Greek Pottery and Exchange in the Eastern Mediterranean, The British Museum Research Publication I62 (London 2006) 56. 60 Tab. I (Nauk 59); 80 Abb. 5 (NAU 58-59: Duponts Gruppe C2) bzw. I49 f. I 52 Abb. 25 (Nauk 59, London, BM GR I888.6-I.569.a-c: single). Einem möglichen rhodischen Hintergrund schließt sich eine Beobachtung von Richard V. Nicholls an, der aufgrund Ähnlichkeiten in der Keramikart zu Terrakotten aus einem Votivdepot von Ialysos bei der Granatapfelgruppe sogar eine Herkunft aus diesem Ort im Norden von Rhodos vermutet, siehe die Rez. von R. V. Nicholls, AJA 6I, I957, 304 . 


\section{ATTISCH SCHWARZFIGURIG}

\section{TAFEL 31}

1-4. Skyphos

Beilage 9, 1.

G I 8. Aus Athen. Erworben I873 von Franz von Aigner (Graz), Ankauf. Alte Inv.-Nr. II 27 (Schenkl) bzw. III 26 (Pichler).

H 4,3 cm. - Dm Mündung 6,0 cm. - B mit Henkeln Io, I cm. Dm Fuß 3,5 cm. - Dm Henkel o,7 cm. - Gewicht 35 g. - Volumen $68 \mathrm{ml}$.

Lehner - Lorenz - Schwarz, Vasen, 30 Nr. I 5 Abb. 22 (M. Lehner).

Zustand: Vollständig erhalten. Einige kleine oberflächliche Abplatzungen, Bemalung an den Henkeln großflächig abgerieben.

Technik: Oberfläche hellorange, glänzend schwarz bemalt.

Form: Miniaturskyphos (Korinthischer Typus).

Dekor: Auf der Gefäßunterseite im Zentrum ein Punkt, darum eine konzentrische Linie und ein konzentrisches Band in Glanzton. Außenseite des Fußes und unteres Gefäßbecken mit Glanzton bemalt, darüber eine Linie in verdünntem Glanzton vollständig umlaufend. Randzone zwischen den Henkeln mit einer Schrägschraffur in Glanzton markiert, die auf beiden Gefäßseiten beim rechten Henkel als Strichreihe beginnt und links als Tupfenreihe endet. Gefäßinnenseite und Henkelaußenseiten mit Glanzton bemalt.

Um 550

Zur Form: Die Form des Bechers mit horizontalen Henkeln, Ringfuß und nur leicht konvexem Körper ist aus dem korinthischen Formenrepertoire entlehnt. Im 6. Jh. wird er in Attika, nun zum Großteil schwarz überzogen, zum populärsten Trinkgefäß. Der attische Skyphos korinthischen Typs zeichnet sich dabei durch eine dünne, sich nach unten stark verjüngende Wandung und einen konischen Standring aus. Er wurde groß, klein und im Miniaturformat hergestellt. Im Kerameikos kommt der attische Miniaturskyphos korinthischer Form ausschließlich in Kindergräbern vor: Kerameikos IX, 46. Zu Miniaturgefäßen in Kindergräbern vgl. M.-Cl. Crelier, Kinder in Athen im gesellschaftlichen Wandel des 5. Jahrhunderts v. Chr. Eine archäologische Annäherung (Remshalden 2008) 6I-75. Zur Entwicklung der attischen Skyphoi korinthischer Form: Young, Phaleron, 47 f.; Kerameikos VI 2, I 85 f.; Agora XII, 8I-83; Agora XXIII, 58 f.; CVA Athens, National Museum 4, I3 mit weiterer Literatur. Die Miniaturform wurde sowohl als Grabbeigabe, Weihgeschenk, aber auch als Kinderspielzeug hergestellt, vgl. Boardman, ABFV, I79; Boardman, SFVA, I93; I. Scheibler, Griechische Töpferkunst. Herstellung, Handel und Gebrauch der antiken Tongefäße ${ }^{2}$ (München I995) 52 f. Abb. 49. 5 I; L. A. Hammond, Miniature Votive Vessels from the Sanctuary of Athena Alea in Tegea, ungedruckte Diss. Columbia, University of Missouri (Columbia I998); G. Ekroth, Small Pots, Poor People? The Use and Function of Miniature Pottery as Votive Offerings in Archaic Sanctuaries in the Argolid and the Corinthia, in: B. Schmaltz - M. Söldner (Hrsg.), Griechische Keramik im kulturellen Kontext (Münster 2003) 35-37; G. di Stefano, Vasi greci miniaturistici dalle necropoli classiche della Sicilia. Il caso di Camarina. Giocattoli dalle tombe, in: ebd. 38-45. Ein nahezu identisches Stück: Athen, Agora P I7842: Agora XII, 8 I f. Nr. 307 Taf. I4.

\section{5-7. Oinochoe}

Beilage 9, 3.

G 38. Aus Attika. Erworben I 875 durch Wolfgang Helbig in Athen, Ankauf. Ehemals Slg. Athanasios Rhousopoulos (Athen). Alte Inv.-Nr. II 5 I (Schenkl) bzw. III 5 I (Pichler). Der abgebrochene Henkel später irrtümlich unter der Nr. G 87I inventarisiert.

H Gefäßkörper ı , $7 \mathrm{~cm}$. H mit Henkel I I, 3 cm. - B Mündung 4, O cm. - Dm Körper 6, o cm. - Dm Fuß 2,8 cm. - Dm Henkel I, I cm. - Gewicht [96,5 g]. - Volumen I06 ml.

Lehner - Lorenz - Schwarz, Vasen, 32 f. Nr. I7 Abb. 23-24 (M. Lehner). - BAPD 46029.

Zustand: Henkel in zwei Fragmenten abgebrochen und wieder angesetzt, an der Bruchstelle alte Klebespuren (Schellack). Ein kleines Fragment zwischen Mündung und höchster Stelle des Henkels verloren. Einige kleinere Abplatzungen am Fuß und am Rand. Abbruchspuren eines auf der Schulter und überrandständig angesetzten Henkels. Aufgesetztes Weiß sowohl an den Flecken des Rindes als auch am Wasserbecken abgeblättert.

Technik: Oberfläche orangerot. Glänzend schwarze Bemalung, die tief in die Mündung des Gefäßes hineinreicht. Glanzton stellenweise durch den Brand rötlich verfärbt. Aufgesetztes Weiß: Wasserbecken, Flecken am Tierkörper, Früchte am Rankenbaum.

Form: Oinochoe mit leicht aufgewölbtem Scheibenfuß. Ovoider Körper und deutlich eingezogener Hals. In der Schulterzone und überrandständig angesetzter, rundovaler Henkel. Hohe, gerade Halszone, nach außen gezogene, rund abgestrichene Lippe. Kleeblattmündung.

Dekor: An der Oberkante des Fußes ein purpurner Ring. Bildfeld rechts und links von Glanztonlinien sowie unten von zwei um das Gefäß laufende Streifen begrenzt. Ein weiterer, jedoch auf die Breite des Bildfeldes beschränkter Streifen schließt es oben gegen den Hals ab. Darunter sitzt eine Reihe von kurzen Vertikalstrichen (Zungenfries?).

Darstellung: Rinderprotome. - Der Vorderteil eines weißgefleckten Rindes nach rechts, wahrscheinlich ein Stier oder ein Ochse, wird in seiner Körpermitte vom Bildfeldrand überschnitten. Es schreitet nach rechts auf ein Wasserbecken zu, hinter dem ein Rankenbaum sprießt, dessen Früchte mittels paarweise gesetzter, weißer Tupfen angedeutet sind.

Um 500 - nahe dem Maler von Vatikan G 49. Aus der Werkstatt des Athena-Malers (Lehner)

Zur Form: Richter - Milne, Shapes, 20 Abb. I24 (Type V); ABV XI: Shape I. Vgl. Boardman, ABFV, I79; Boardman, SFVA, I93; Kerameikos IX, 44. I33 Taf. 40. 78 Kat. I96, 5 (etwas später); Oinochoe Paris, Cab. Med. 270. 272: CVA Paris, Bibl. Nat. 2, III $\mathrm{H} f$ Taf. 66, I. 3; Oinochoe Compiègne ro30: CVA Compiègne III $\mathrm{H}$ f Taf. I2, 6.

Zur Darstellung: Die Darstellung ist ein Ausschnitt aus einer größeren Szene, wie sie öfters besonders auf Lekythen und Oinochoen erscheint: Zwei einander zugewandte Rinder flankieren ein auf einem Säulchen ruhendes Opferbecken oder einen Altar, hinter dem ein Baum wächst, vgl. C. Bérard - J.-P. Vernant u. a. (Hrsg.), Die Bilderwelt der Griechen. Schlüssel zu einer fremden Kultur, Kulturgeschichte der antiken Welt 3I (Lausanne, Paris I985) $78 \mathrm{f}$. Abb.79, 6-7. 9 (unter den Abb. fehlt 79, 5: Lekythos Athen, Agora 
P 24067, obwohl sie im Verzeichnis aufscheint); L. Durand - F. Lissarrague, Un lieu d'image? L'espace du loutérion, Hephaistos 2, I980, 89-92. Unser Bild zeigt gleichsam die linke Hälfte der Lekythos in Amsterdam: Bérard - Vernant a. O. Abb. 79, 9; J. M. Hemelrijk, The Gela Painter in the Allard Pierson Museum, BABesch 49, I 974, I 20 Abb. 6-9, auf der zwei Rinder ein Louterion flankieren. Das Tier steht für eine rituelle Schlachtung bereit, das Louterion bezeichnet die Kultstätte. Das Opfer findet entweder im Rahmen eines athenischen Festes für Zeus (Ritus der Bouphonia am Fest der Dipoleia), Athena oder Dionysos statt. Auch unsere kleine Oinochoe wird man in den Kontext eines dieser Feste stellen dürfen. Zu den Dipoleia vgl. weiters A. B. Cook, Zeus 3. God of the Dark Sky (Cambridge 1940) 570-605; G. Bakalakis, Das Zeusopfer der Dipolieia auf einer Oinochoe in Saloniki, AntK I2, I 969/2, 56-60; Hemelrijk a. O. I 20-I 58; E. Simon, Festivals of Attica. An Archaeological Commentary (Madison, Wisconsin, I983) 8-I 2; W. C. Parke, Athenische Feste (Mainz I987) 247-256.

Zum Maler: ABV 534-537. 705; Add ${ }^{2}$ I32; ABL, 84 f. (zu StierDarstellungen des Gela-Malers); ebenso Bakalakis a. O. 58-6o. Weitere vergleichbare Rinderdarstellungen: Halsamphora New York, Metr. Mus. GR 529: E. J. Holmberg, The Red-Line Painter and the Workshop of the Acheloos Painter (Jonsered I990) Abb. 26-27; Boardman, ABFV, I 50 Abb. 282; Boardman, SFVA, I63; Oinochoe London, BM B 486: Holmberg a. O. Abb. 54.

\section{TAFEL 32}

\section{1-5. Oinochoe}

Beilage 9, 4.

G I7. Aus Athen. Erworben I 873 von Franz von Aigner (Graz), Ankauf. Alte Inv.-Nr. II 26 (Schenkl) bzw. III 25 (Pichler).

H 8,7 cm. - H mit Henkel ıо,2 cm. - B Mündung 2,8 cm. - Dm Körper 5, O cm. - Dm Boden 3,2 cm. - B Henkel o,9 cm. - Gewicht [47 g]. - Volumen $66 \mathrm{ml}$.

Lehner - Lorenz - Schwarz, Vasen, 33 f. Nr. I 8 Abb. 25 (M. Lehner); BAPD 44IO4.

Zustand: Gebrochener Henkel wieder angesetzt, ansonsten vollständig erhalten. Fuß und Mündung leicht bestoßen. Bemalung stellenweise abgerieben und abgeplatzt.

Technik: Oberfläche hellbraun, Bemalung glänzend schwarzbraun, dünn aufgetragen.

Form: Schlauchförmiges Miniaturkännchen mit Kleeblattmündung ohne Schulterknick.

Dekor: Fuß und unterer Teil des Gefäßkörpers schwarz bemalt, darüber ein Glanztonreifen. Drei horizontale Glanztonstreifen an der Henkelaußenseite, Henkelkanten bemalt. Breiter, unten wellig abgeschlossener Glanztonstreifen an der Außenseite der Mündung. Zwei breite, ursprünglich wahrscheinlich purpurne oder weiße, heute aber nur noch am Tongrund erkennbare Streifen über den Beinen der Vögel.

Darstellung: Wasservögel. - Um die Schulter Fries von drei sich nach rechts bewegenden Vögeln (Gänse, Enten, Schwäne?). Die Vögel sind sehr flüchtig gemalt und weisen keine Ritzungen auf.

Um 490

Zur Form: Boardman, ABFV, I79; Boardman, SFVA, I93. Die Miniaturformen von großformatigen Vasen wurden als Weihgeschenke, Grabbeigaben oder Spielzeug verwendet, vgl. dazu Skyphos G I 8, hier Tafel 3 I, I-4. Diese Gefäßform wurde öfter als Olpe bezeichnet: Richter - Milne, Shapes, I9 Abb. I I 4 Typ I; Boardman, ABFV, I 87; Boardman, SFVA, 202. Formal entsprechende Olpen mit anderer Darstellung: Agora XII, 76 f. Taf. I2; Kerameikos IX, 88 Taf. 44, 5; Wien, Universität 739, I9: CVA Wien I, Universität und Professor Franz v. Matsch (Deutschland 5) Taf. 6, I6 (= ABV 445. 698); Heidelberg, Univ. 259: CVA Heidelberg I Taf. 40, 3.

Zur Darstellung: Ein sehr ähnlicher Schwan findet sich auf einer Pyxis von der Agora P I 5 I I4, vgl. Agora XXIII, I 289 Taf. 9I („Swan- and Palmette-Group“). Zu dieser Gruppe vgl. ABV 660 f.; Para 3 I6; Add ${ }^{2}$ I47. Skyphos (Oxford, Ashmolean Mus. I930.I68) der "Schwan-Gruppe“ mit kopfüber hängenden Schwänen: Boardman, ABFV, I79 Abb. 3 I 5; Boardman, SFVA, I93 Abb. 3 I 5.

\section{Tafel 33, 1-3. 34, 1-5. 81, 1. Lekythos}

Beilage 9, 2.

G 35. Aus Thisbe in Böotien. Erworben I 875 durch Wolfgang Helbig in Athen, Ankauf. Alte Inv.-Nr. II 48 (Schenkl) bzw. III 48 (Pichler).

H 23,5 cm. - Dm Mündung 6,6 cm. - Dm Körper I4,2 cm. Dm Fuß 8,2 cm. - B Henkel 2,2 cm. - D Henkel I, O cm. - Volumen I $329 \mathrm{ml}$.

K. Rakatsanis, Herakles im Löwenkampf, ungedruckte Diss. Innsbruck ( I 977) Kat. I 27 Sk. - E. Pochmarski, Herakles und der nemeische Löwe auf einer Lekythos in Graz, in: F. Krinzinger - B. Otto - E. Walde-Psenner (Hrsg.), Forschungen und Funde, Festschrift Bernhard Neutsch (Innsbruck I980) 34I-348 Taf. 66-67. - Lehner - Lorenz - Schwarz, Vasen, 30-32 Abb. 20-2 I (M. Lehner). - BAPD 4359.

Zustand: Aus Io Fragmenten zusammengesetzt, große Fehlstelle am Bauch und etwas kleinere an der Schulter in Gips ergänzt und orangefarben bzw. mattschwarz bemalt. Glanzton im Fußund Mündungsbereich vielfach abgesplittert. Die Mehrzahl der Absplitterungen scheint erst bei der Abnahme von Versinterungen, wie sie unten am Fuß noch vorhanden sind, entstanden zu sein. Rezente Beschriftung an der Fußunterseite mit Herkunftsangabe.

Technik: Ton hellorange-beige, Glanzton glänzend schwarz, purpurne Höhungen, Ritzungen. Aufgesetztes Purpur: Locken und Bart des Herakles, Mähne des Löwen. Oberschenkel und Brustmuskel des Herakles, Hinterkeule und Rippenbögen des Löwen. Auf dem Schulterbild Haare der Zuschauerfigur links. Rote Streifen an den Himatien aller vier Männer, rote Tupfen am Himation des Mannes rechts außen. Verdünnter Glanzton: Tropfleiste zwischen Schulter und Hals.

Form: Schulterlekythos mit ausladendem Ringfuß und eingezogenem Unterkörper. Ovoider Körper mit gerundeter Schulterkante und abgesetztem, stark eingezogenem kurzen Hals. Stark ausschwingender Mündungskelch mit nach außen gezogener, gerundet abgestrichener Lippe. An Schulter und Halszone angesetzter Bandhenkel mit längsovalem Querschnitt.

Dekor: Untere Hälfte des Gefäßkörpers mit Glanzton überzogen, das darüberliegende Bildfeld unten und oben durch je einen Glanztonstreifen abgegrenzt. Zwischen Schulterzone und Hals Rudiment einer mit verdünntem Glanzton ausgeführten Tropfleiste. Mündungstrichter außen und innen, Henkel nur außen schwarz bemalt.

Darstellung: Im Hauptbildfeld Kampf des Herakles mit dem nemeischen Löwen im Beisein von je zwei Zuschauern links und rechts. Im Schulterbild Boxkampf zweier Athleten, zwei Schiedsrichter - Hauptbild: Die beiden Kontrahenden stehen einander aufrecht gegenüber. Der Löwe aber hat sich in eine missliche Position manövriert, denn sein Kalkül ist nicht aufgegangen. Er ist Herakles angesprungen, wohl in der Meinung, den Helden so zu Fall und den Kampf schnell zu Ende bringen zu können. Doch Herakles, der nackt ist und nur das Schwert in der Scheide trägt, hat der Attakke standgehalten und den Löwen mit der Rechten an seiner linken Vorderpranke gepackt, während er mit der Linken seinen Nacken 
zu umschlingen trachtet. Der Löwe sucht Herakles abzudrängen, indem er seine linke Hintertatze gegen das linke Knie des Helden stemmt, was für ihn einen sehr unsicheren Stand - nur auf dem rechten Hinterbein - ergibt. Eine weitere Abwehrreaktion versucht das Tier mit der rechten Vorderpranke, deren Krallen es in die Schulter des Gegners geschlagen hat. Sein Schwanz peitscht aufgeregt in einem S-förmigen Ornament, das riesige Maul ist mit hervorschnellender Zunge weit aufgerissen, aber es sind keine Zähne zu sehen. Die vier Zuschauer - je zwei rechts und links des Kampfgeschehens - sind mit Chiton und Mantel bekleidet und tragen Speere. Nur der vordere auf der linken Seite, ein bärtiger Mann mit purpurnem, langem Haar, nimmt sichtlich am Geschehen Anteil: Den Speer leicht gesenkt in der Rechten haltend feuert er mit der Linken den Helden an. Der jüngere Mann hinter ihm, bartlos und mit rotem Haar, verharrt regungslos in seinen Mantel gehüllt. Die Zuschauer rechts sind leider durch die große Fehlstelle in Mitleidenschaft gezogen. Der vordere Mann ist schwarzhaarig und bärtig, vom hinteren ist nur der Unterkörper erhalten. Sein Himation ist wie die anderen an den Säumen ritzverziert und rot gestreift, und trägt darüber hinaus rote Tupfen. Das Schulterbild zeigt im Gegensatz zum mythischen Agon auf dem Hauptbild den Boxkampf zweier Athleten. Die schwergewichtigen, gedrungenen Gestalten stehen einander im Ausfallschritt gegenüber, das linke Bein vorgestellt und leicht gebeugt. Bis auf die riemenumwundenen Fäuste sind die Gegner nackt. Beide haben die Rechte hinter dem Kopf zum Schlag erhoben, während sie mit der weit vorgestreckten Linken den Gegner fernzuhalten suchen. Auch hier steht der Ausgang des Kampfes fest, denn der linke Boxer ist deutlich größer und athletischer als der rechte, der noch dazu in der Drei-Viertel-Rückansicht ein rundes Bäuchlein sehen lässt. Der Boxkampf wird zu jeder Seite von einem jugendlichen Schiedsrichter beobachtet. Beide tragen lange, gegabelte Ruten. Der linke Schiedsrichter ist in einen Chiton mit geritzten Bordüren am Hals- und Fußsaum sowie in einen Mantel mit rotem Schrägstreifen und rotem Saum gehüllt, der den rechten Arm freilässt. Vom rechten, ursprünglich rothaarigen Schiedsrichter ist nur mehr der Oberkörper erhalten. Der linke Arm ist in den Mantel gehüllt, der einen roten Streifen und einen gepunkteten Saum aufweist.

Um 540-530 - Sandalen-Maler (Pochmarski)

Zur Form: Zur Schulterlekythos vgl. ABL, I9. 36; CVA Louvre 28, I9; J. de La Genière, Parfumés comme Crésus. De l'origine du lékythe attique, BCH Io8, I984, 9I-Io8; C. Jubier-Galinier, Le lékythe attique, un parfum d'ici et d'au-delà, in: A.Verbanck-Piérard et N. Massar (Hrsg.), Parfums de l'Antiquité. La rose et l'encens en Méditerranée (Morlanwelz-Mariemont 2008) I 47-I 52.

Zur Darstellung: Die Erlegung des nemeischen Löwen ist die erste Tat des Dodekathlos, da man sich die Gestalt des Herakles nicht ohne das Löwenfell denken konnte. Auch wird das Löwenabenteuer von allen Taten, auch jenen außerhalb des Dodekathlos, am häufigsten dargestellt, vgl. R. Flacelière - P. Devambez, Heraclès. Images et récits (Paris I966) 79 f.; F. Brommer, Herakles. Die zwölf Taten des Helden in antiker Kunst und Literatur (Köln, Wien I972) 7-II; ders., Vasenlisten zur griechischen Heldensage $^{3}$ (Marburg I973) Io9 f.; Schefold - Jung, SB IV, I35. Zum Löwenkampfschema vgl. LIMC V (Zürich I990) I9 Nr. I792 f. (Kampfschema I b II mit mehreren Beispielen) s. v. Herakles (J. Boardman). Zur Technik des Boxkampfes: G. Doblhofer - P. Mauritsch, Boxen. Texte, Übersetzungen, Kommentar. Quellendokumentation zur Gymnastik und Agonistik im Altertum 4 (Wien, Köln, Weimar I995) 300-305; Darstellungen von Boxern: E. N. Gardiner, Athletics of the Ancient World ${ }^{2}$ (Oxford I95 5) I 97-206 Abb. I73-1 87; H. A. Harris, Sports in Greece and Rome (London I972) 22; N. Yalouris u. a., Athletics in Ancient Greece. Ancient Olympia and the Olympic Games (Athen 1977) 216-225 Abb. I22-I 25; Sport dans la Grèce antique, I04-I06. Panathen. Am- phora St. Petersburg, Eremitage B I 509: Para I 5 , 5 ; Sport dans la Grèce antique, 353 Abb. 22 I; S. G. Miller, Ancient Greek Athletics (New Haven 2004) 5 I-57 Abb. 83. Die Position mit dem weit vorgestreckten linken Arm wird als effektiver Schutz vor den Schlägen des Gegners auf den Kopf bezeichnet (Gardiner a. O. 204, Yalouris a. O. 22 I), die jedoch den Körper ungeschützt lässt. Der linke Arm konnte aber auch zum Schlag gebraucht werden: Sport dans la Grèce antique, I05. Offensichtlich waren Körperschläge verpönt oder sogar verboten (Dobelhofer - Mauritsch a. O. 302; Gardiner 204 f.; Yalouris a. O. 22I). Dass sie dennoch praktiziert wurden, zeigt die Schale des Sandalenmalers in Baltimore (vgl. unten).

Zum Maler: ABL, I9. 33-39; ABV 70; Para 28; $\mathrm{Add}^{2}$ I8; Boardman, ABFV, 33; Boardman, SFVA, 37. Der Maler profilierte sich auch im Dekorieren von Siana-Schalen (ABV 70, I-3), jedoch sind die Schulterlekythen in der Überzahl (mit dem Grazer Exemplar insgesamt sechs Stück). Auch das namengebende Werk ist eine Schulterlekythos. Es zeigt einen Jüngling, der einen Knaben mit einer Sandale züchtigt, in Bologna, Museo Civico, Coll. Palagi I 269: ABV 70, 7; CVA Bologna 2, III H e Taf. 38, 5; 39, I-2; Boardman, SFVA, Abb. 43. Unter seinen Bildern finden sich Kampf- und Athletendarstellungen, darunter sind die Boxer mit vier Exemplaren (Siana-Schale Baltimore, Robinson: ABV, 70, I; Siana-Schale Theben R 49.26I: ABV 70, 2; CVA Thebes, Archaeological Museum I Taf. 30; Lekythos Athen, Nat. Mus. I056: ABV 70, 4 sowie die Lekythos in Graz) in der Überzahl. Mit den Grazer Boxern vergleichbar sind die Athleten auf der Schale in Baltimore (ABV, 70, I; CVA Baltimore, Robinson Collection I, III H e Taf. 20 b). Sie nehmen eine ähnliche Position ein, doch schlägt der linke Kämpfer, der bärtig ist, gegen die Brust des Gegners. Mythologische Bilder konnten bis jetzt außer dem Grazer Beispiel in seinem Werk nicht nachgewiesen werden, doch im Schulterbild einer Lekythos in Oxford verfolgen Satyrn eine Frau: Oxford 1934.353: ABV 70, 8; ABL, I9 f. Taf. 5, 2; 6, 2. Charakteristisch für den Sandalenmaler ist die hakenförmige Einritzung der Schlüsselbeine bei den nackten Figuren sowie die Vorliebe für rotes Haar.

Zur Verwendung: Die Lekythos diente der Aufbewahrung von Duftölen, welche bei der Toilette, beim Symposion, hauptsächlich aber im Begräbnisritual Verwendung fanden, vgl. CVA Louvre 28, 7. Zur Verwendung schwarzfiguriger Lekythen im Totenkult, z. B. für die bei Marathon Gefallenen: CVA Athènes, Musée National I, III H g. h Taf. Io-I I; in den Gräbern von Rhitsona: Ure, Rhitsona; CVA Thebes, Archaeological Museum I, 9.

TAFEL 33

1-3. Siehe Tafel 32, 6.

TAFEL 34

1-5. Siehe Tafel 32, 6.

\section{TAFEL 35}

\section{1-3. Tafel 37, 3. Lekythos}

Beilage 9, 5.

G I02. Aus Athen. Erworben um I9I2/I3 durch Rudolf Heberdey, Tausch mit dem NM Athen. 
H erh. Io cm. - Dm max. 5,5 cm. - Dm Fuß 3,8 cm. - Wandstärke 0,3 cm. - Gewicht 9I,2 g.

Unpubliziert.

Zustand: Ein Fragment, Hals und ca. 50 \% der oberen Körperhälfte abgebrochen. Körper leicht bestoßen, vor allem in der Fußzone großflächige Abblätterungen. Größere Abplatzungen entlang der Bruchkanten.

Technik: Oberfläche außen mittelbraun, innen hellorange-beige, Bruch mittelbraun bis hellorange-mittelbraun. Dünn aufgetragene, glänzend schwarze Bemalung, selten dunkelbraune Farbwirkung.

Form: Lekythos der Form II oder III/I (nach Kerameikos IX, 34), vgl. auch Agora XXIII, 45 f.; Scheibenfuß mit großer Auflagenfläche, in der Mitte eingezogen. Nach unten konisch einschwingender Körper, leicht eiförmige Wandung, deutlich abgesetzte, leicht abfallende Schulter.

Dekor: Oberseite des Fußes, unterer Teil des Gefäßkörpers schwarz bemalt, unter den Figuren ein schwarzer Streifen.

Darstellung: Kampfszene mit drei Hopliten. - Von links dringt ein Krieger mit Schild und Speer in weitem Schritt nach rechts vor, von einem zweiten, der in dieselbe Richtung eilt, ist nur noch ein Bein, der Schwertknauf sowie ein Mantelzipfel erhalten. Zwischen den beiden Kriegern der Ast einer stilisierten Pflanze. Nach einer großen Fehlstelle sind von dem von rechts anstürmenden Krieger nur noch ein Unterschenkel sowie der erhobene, nach hinten abgewinkelte rechte Arm mit dem Lanzenende erhalten. Auf der Schulter kleiner Rest einer Bemalung in Form eines schwarzen Striches, der zum Schulterknick hin dünner wird, vielleicht die Schwanzfeder eines Hahnes.

Um 500 - Hahnengruppe (?)

Zur Form: Die Lekythenform II unterscheidet sich von Form III, die wiederum in drei Gruppen unterteilt werden kann, im Wesentlichen durch einen breiteren Fußteller, einen schlankeren Körper, einen längeren Hals und eine höhere, zu einem engeren Trichter zusammengezogene Mündung, doch nur III/I besitzt den einteiligen Fußteller, vgl. Kerameikos IX, 34. Lekythen der Gruppe II werden mit der Werkstatt des Phanyllis-Malers, des Sappho- und Diosphos-Malers oder auch der Hahnenklasse in Verbindung gebracht. Da bei unserer Lekythos Hals und Mündung fehlen, ist eine Entscheidung zwischen den Lekythentypen II und III/I schwierig, vgl. Kerameikos IX, 34. 89 Nr. I7, 6 Taf. 77, I: Typ II, Hahnengruppe; Form der Klasse von Athen 58 I, ABV 487-506. Lekythen der Form III wurden zahlreich im Grabhügel von Marathon gefunden, wodurch sie datiert sind. Die Hahnengruppe wird allgemein zwischen 5 Io und 490/80 angesetzt: K. Kathariou, Cocks and Cockfights on Cock Lekythoi, NumAntCl 35, 2006, Io9 f. unterscheidet eine frühere Gruppe mit stärker gerundetem Körper von einer etwas späteren mit strafferem Körperbau.

Zur Darstellung: Die frühen Lekythen der Hahnengruppe zeigen auf der Schulter zwei im Kampf begriffene Hähne, spätere dagegen nur einen nach rechts gerichteten Hahn mit langen Schwanzfedern, meist zwischen zwei Efeublättern, der seinen Kopf, wie um etwas aufzupicken, gesenkt hält (vgl. dagegen das frühe Exemplar Athen, Agora-Museum P I 8006: Agora XXIII, 203 Nr. 793 Taf. 75). Kathariou interpretiert auch den einzelnen Vogel als Kampfhahn, der als Sieger von links kommt (a. O. I I I f.). Die Restbemalung auf der Schulter unserer Lekythos ist vielleicht die Schwanzfeder eines Hahnes, vgl. z. B. Athen, Agora-Museum P I 278: Agora XXIII, Nr. 847 Taf. 78. Da auf dem Gefäßkörper der Lekythen der Hahnengruppe sehr oft Kampfszenen abgebildet sind (vgl. Kathariou a. O. 2 I3), dürfte der Versuch, das Grazer Stück dieser Gruppe zuzuweisen, gerechtfertigt sein. Vgl. Kerameikos VII 2, Nr. 239, I-2 Taf. 35, 7. 9; Nr. 520, 5-7 Taf. 92; Agora XXIII, 208-2 I I Nr. 837-863 Taf. 78; Lekythen Olympia K I0864. K I I 27 I. K I0873. K I IOI4. K I IOI 5: Burow, Attisch schwarzfigurige Keramik, 208 Taf. 76.
Zur Werkstatt: ABV 466-472; Para 208-2 I 2; Add ${ }^{2}$ I I 7 f. Nach ABL, 67 f. gehören manche Exemplare der Hahnen-Gruppe und der Haimon-Gruppe derselben Werkstatt an wie die Klasse von Athen 58I, vgl. auch Kurtz, AWL, I45-I 48.

4-6. Lekythos

Beilage 9, 6.

G 103. Aus Attika. Erworben um I9I2/I3 durch Rudolf Heberdey, Tausch mit dem NM Athen.

H erh. I I,2 cm. - Dm max. 5,3 cm. - Wandstärke 0,7 cm. Gewicht I27,6 g.

Unpubliziert.

Zustand: Ein Fragment, Hals, Schulter und Fuß abgebrochen. Der obere Teil der Wandung der Rückseite fehlt. Gefäßkörper oberflächlich leicht bestoßen, entlang der Bruchkanten einige größere Abplatzungen. Die alte Ergänzung der Standfläche mit Gips wurde entfernt.

Technik: Oberfläche außen orangefarben, innen und Bruch rötlich mittelbraun. Bemalung glänzend schwarz, bei dünnem Auftrag dunkelbraune Farbwirkung. Durchscheinend aufgetragenes Weiß.

Form: Lekythos Form IV/I. Schlanker, zylindrischer, nach unten konisch einschwingender Körper.

Dekor: Unterer Bereich des Körpers schwarz bemalt. Die schwarze Zone wird zweimal von je zwei tongrundigen Streifen unterbrochen. Über der Figurenzone zweireihiges schwarz-weißes Punktmuster zwischen zwei Streifen, vom Bildfeld wiederum durch einen Streifen abgesetzt. Zusätzliche Farben: Aufgesetztes Weiß: Außer für die Punkte am oberen Abschluss für das Wagenlenkergewand sowie für Gesicht, Hals, Füße, Helmbusch und Ägis der Athena und einen Pferdeschwanz (?). Aufgesetztes Rot: Zaumzeug und Mähnen der Pferde. Ritzungen: Wagenräder, Gesicht und rechter Arm des Wagenlenkers, Zügel, Konturen der Pferde, Zaumzeug, Falten am Gewand der Athena.

Darstellung: Wagenrennen. - Der bärtige Wagenlenker in langem weißen Chiton steht auf dem Wagen seines nach rechts galoppierenden Dreigespannes. Neben den Zügeln hält er auch ein Kentron. Unter dem in sehr schlampiger Ritzung angegebenen Wagenrad ist eine Bodenlinie angedeutet, die anzeigt, dass das Gespann abwärts jagt. Tatsächlich befindet sich das Rad auf einer höheren Ebene als die Hinterbeine der Pferde. Hinter dem Rücken der Pferde stürmt die Göttin Athena mit Peplos, Helm, Ägis und Lanze nach links.

Erstes Viertel 5. Jh. - Werkstatt des Haimon-Malers (Christidis)

Zur Form: vgl. Kerameikos IX, 36 Taf. 77.

Zur Darstellung: ABV 545, I84-I94; Para 275 f.; - Zu Dreigespannen allgemein: RE VII A I Sp. I25-I 27 s. v. Triga $(\mathrm{H}$. Miltner); G. Schwarz, Die Triga im antiken Griechenland, in: P. Mauritsch - Chr. Ulf (Hrsg.), Kultur(en). Formen des Alltäglichen in der Antike. Festschrift für I. Weiler zum 75. Geburtstag Bd. I (Graz 20I3) I6I-I75. Trigen finden sich auf geometrischen Vasen, vgl. J. Wiesner, Fahren und Reiten, ArchHom I F (Göttingen I968) 20-22. 64-67; Krater New York, Metr. Mus. I4.I30.I4: CVA Metr. Mus. 5, I 3 zu Taf. 8; auf pontischen Amphoren: Heidelberg, Univ. 59/5: R. Hampe - E. Simon, Griechische Sagen in der frühen etruskischen Kunst (Mainz I964) 2 zu Taf. 3-4; München J I 5 I: Hampe - Simon a. O. I 9 f. zu Taf. 7; auf einer frühlukanischen Pelike in Policoro, Museo della Siritide 35.304: L. Weidauer, Poseidon und Eumolpos auf einer Pelike aus Policoro, AntK I2, I969, Taf. 4I, 2, und schließlich wohl auch auf einer unserem Fragment verwandten Lekythos von der Athener Agora: Agora XXIII, 2 I 8 Nr. 922 Taf. 8I (P 24368). E. Manakidou 
dagegen hält die Möglichkeit, dass es sich bei den Darstellungen auf spätschwarzfigurigen Lekythen tatsächlich um Dreigespanne handelt, für unwahrscheinlich und macht die Massenproduktion dafür verantwortlich, vgl. E. Manakidou, П $\alpha \rho \alpha \sigma \tau \alpha ́ \alpha \varepsilon 1 \varsigma ~ \mu \varepsilon \alpha ́ \alpha \mu \alpha \tau \alpha$.

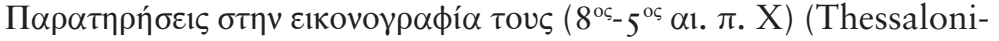
ki I 994) 90 f. Zu ähnlichen Darstellungen, die auf Lekythen der Formen III und IV aufscheinen, vgl. Kerameikos IX, 40. Allerdings ist dort auch oft die Wendesäule (nyssa), die das Gespann umrunden muss, zu sehen. Diese Wendemarke fehlt auf unserer Lekythos. Vergleichbar sind z. B. Kerameikos IX, Nr. 6I, 2 Taf. 26, 2; Nr. I I I, 2 Taf. 28, 4; Nr. I I7, 2-3 Taf. I6, 3; Nr. I 8 I, 6 Taf. 35, 6; Nr. 2 I 5, 3 Taf. 58, 5; Nr. 257 F Taf. 37, I. Eine Verbindung der Darstellung mit dem Tod ist hier schwerlich herzustellen. Am ehesten wird man wegen der Anwesenheit der Athena an ein Wagenrennen anlässlich der Panathenäen denken, wofür sich zahlreiche Beispiele auf Gefäßen des 6. Jhs., besonders auf Panathenäischen Amphoren, anführen lassen, vgl. z. B. Würzburg I7I: E. Langlotz, Griechische Vasen in Würzburg (München I932) 26 f. Nr. I7I Taf. 3I. Zu Panathenäischen Preisamphoren vgl. J. Frel, Panathenaic Prize Amphoras, Kerameikos Book 2 (Athen I973); M. Bentz - N. Eschbach (Hrsg.), Panathenaika. Symposion zu den Panathenäischen Preisamphoren (Mainz 200I). Eine ansprechende Erklärung für die Anwesenheit der Athena wird im Zusammenhang mit der Oinochoe Kopenhagen, Nationalmuseum VIII 340 (CVA Copenhague, Musée National 3, III H Taf. I 22, 2 a-b) versucht, wo Athena in gleicher Richtung mit dem Gespann läuft: Die Anwesenheit der Göttin, deren Stärke bekanntlich in ihrer Geschicklichkeit liegt, gibt dem Wagenlenker die richtige Taktik ein, das schwierige Wendemanöver geschickt zu lösen und so zum Sieg zu gelangen, vgl. La cité des images, Io9 f. Abb. I 56. So kann das Wagenrennen im Beisein der Athena auch als Metapher für ein geglücktes Leben unter den Augen der Göttin aufgefasst werden.

Zur Werkstatt: vgl. dazu die Lekythos G Io4, hier Tafel 36, $\mathrm{I}-3$.

\section{TAFEL 36}

\section{1-3. Tafel 37, 4. Lekythos}

Beilage 9, 10.

G I04. Aus Attika. Erworben um I9I2/I3 durch Rudolf Heberdey, Tausch mit dem NM Athen.

H erh. I I, $3 \mathrm{~cm}$. - Dm Schulter 5, I cm. - B Henkel I, $3 \mathrm{~cm}$. Wandstärke 0,5 cm. - Gewicht I 2 I,3 g.

Unpubliziert.

Zustand: Ein Fragment. Am Schulterknick stark bestoßen, am Körper einige kleinere Abplatzungen. Henkel, Hals und Fuß abgebrochen.

Technik: Oberfläche orangefarben, Bruch hellorange-mittelbraun. Glänzend schwarz bemalt. Details in durchscheinend dünn aufgetragenem Cremeweiß und Purpurrot.

Form: Lekythos der Form IV/I. Schlanker, leicht konkaver Körper, zum Schulterknick leicht ausschwingend. Deutlich abgesetzte Schulter. Auf der Schulter ansetzender Bandhenkel mit längsovalem Querschnitt.

Dekor: Unterer Teil des Gefäßkörpers mit schwarzem Glanzton überzogen, am oberen Ende von einmal zwei sowie einem tongrundigen Band unterbrochen, das oberste schlampig gemalte Band geht in die Standlinie der Figuren über. Über den Figuren wieder zwei schmale schwarze Streifen, darüber auf der Vorderseite eine doppelte, schwarz-weiße Punktreihe (Weiß nahezu vollständig verloren) bis zum Schulterknick. Auf der Schulter ein doppelter Strahlenkranz, die kleinen Strahlen der zweiten Reihe sind fast zu Punkten verkommen. Henkel auf der Außenseite schwarz bemalt.

Darstellung: Frau auf Klappstuhl sitzend zwischen zwei reitenden Mänaden. - Die Frau im Zentrum sitzt in ein langes Gewand gehüllt auf einem Klappstuhl nach rechts. Ihr Haar, in dem ein eingeritztes und mit aufgesetztem Rot gehöhtes Band liegt, hat sie zu einem Knoten aufgenommen. Auch die Falten ihres Mantels, der sie ganz einhüllt, sind sowohl geritzt als auch mit Rot gehöht. Gesicht und Hals der Frau sind mit Deckweiß übermalt. Auf ihren Knien stützt sie eine große Leier auf, deren Saiten schwach eingeritzt sind; Reste der weißen Übermalung sind im oberen Teil erhalten. Außen jeweils ein nach innen gewandtes, ithyphallisches Maultier, darauf je eine mit einem kurzen Gewand bekleidete Mänade reitend, deren Beine weiß übermalt sind. Zweige mit weißbemalten Früchten hinter den Gestalten.

\section{0-450 - Werkstatt des Haimon-Malers}

Zur Form: Zu Lekythen der Form IV/I vgl. ABL, 267; Kerameikos IX, 36 f. Die Frühform der Lekythen mit leicht konkavem Körper verjüngt sich nicht gleichmäßig, sondern zieht sich über dem Standring abrupt zusammen, vgl. Kerameikos IX, Taf. I6, 3.4 mit den Beispielen aus Grab I I7, die fast ausschließlich aus der Werkstatt des Haimon-Malers stammen.

Zur Darstellung: Die Szene ist eine Kompilation von Versatzstücken aus dem dionysischen Kreis und Symposionsszenen. Zu dem Versuch, die figürlichen Darstellungen auf den schwarzfigurigen Lekythen systematisch zu ordnen, vgl. Kerameikos IX, 38-43. Dabei ergeben sich für bestimmte Lekythen-Formen charakteristische Themen. So sind etwa für die Form III/I dionysische Bilder typisch, die jedoch um 480/460 wieder seltener werden. Dennoch erscheinen Maultierreiterinnen wie auf unserer Lekythos sowie tanzende Mänaden zusammen mit Dionysos auch auf Lekythen des Typus IV. U. Knigge (Kerameikos IX, 39) erklärt die starke Verbreitung der Bilder des dionysischen Thiasos auf Vasen nach der Mitte des 6. Jhs. mit der Einführung des orphischen Dionysoskultes in Athen zur Zeit des Peisistratos sowie mit dem Erlösungsgedanken, der dieser Religion innewohnt. Auch der sitzenden Leierspielerin, die aus dem Schema der Symposionsszenen mit gelagertem Mann und leierspielender Frau auf dem Typus IV entnommen scheint, dürfte die Vorstellung vom glücklichen Leben im Jenseits zugrunde liegen. Der Gelagerte, zu dessen Füßen eine Leierspielerin sitzt, wurde allerdings auch als Dionysos mit Ariadne (?) interpretiert, zumal wenn das Paar von Maultierreiterinnen flankiert wird, vgl. M.-Chr. Villanueva Puig, La ménade montée sur un animal, in: B. Schmalz - M. Söldner (Hrsg.), Griechische Keramik im kulturellen Kontext (Münster 2003) I 5 I. Zu Mänaden allgemein vgl. M.-Chr. Villanueva-Puig, Ménades (Paris 2009). Vergleichbare Darstellungen auf Lekythen der Form IV aus der Werkstatt des Haimon-Malers: Kopenhagen Chr.VIII 897: ABV 549, 305; CVA Copenhague, Mus. Nat. 3, Taf. I I I, 6; Berkeley, University of California 8.33 I9: ABV 550, 309; Para 28I f.; Kerameikos IX, Nr. I I7, 9 Taf. I6, 3; Nr. I87, I Taf. I7, 2; Nr. 250, 2 Taf. 37, 3. 7; Kerameikos VII 2, Nr. 82, 2 Taf. 22, I. 3 (Haimon-Werkstatt, späte Haimon-Gruppe. Weiß-Maler); Nr. 29 Taf. I I, I. 3 (Leierspielerin neben gelagertem Mann).

Zur Werkstatt des Haimon-Malers: ABL, I30-I4I; ABV 539583; Para 269-286; Add $^{2}$ I 34-I 37; Kurtz, AWL, I 50-I 52 ; Burow, Attisch schwarzfigurige Keramik, 209 Nr. 209-249 Taf. 8I-284; Nr. 250 Taf. 284 stammt wohl vom Haimon-Maler selbst. Zur Lokalisierung der Haimon-Werkstatt in Athen (Lenormant- Konstantinoupoleos-Str.), zusammen mit anderen spätschwarzfigurigen Vasenmalern und -gruppen, vgl. M.-C. Monaco, Ergasteria. Impianti artigianali ceramici ad Atene ed in Attica dal Protogeometrico alle soglie dell'ellenismo (Rom 2000) 88 f. I40. 2 I 5 f. 
Zum Maler: ABV 538 f.; Para 269; Add ${ }^{2}$ I 33 f. Nach ABL, I39 sind die Lekythen der Pholosgruppe möglicherweise das Spätwerk des Haimon-Malers (ABV 57 I f.; Para 287; Add² I37: PholosMaler); Boardman, ABFV, I49; Boardman, SFVA, I62. Zur Verbindung des Haimon-Malers mit der Beldam-Werkstatt vgl. Kurtz, AWL, I $52 \mathrm{f}$.

\section{4-7. Lekythos}

Beilage 9, 9.

G 105. Aus Attika. Erworben um I9I2/I3 durch Rudolf Heberdey, Tausch mit dem NM Athen.

H erh. 5,2 cm. - Dm max. 4,3 cm. - Wandstärke 0,7 cm. - Gewicht $35,2 \mathrm{~g}$.

Unpubliziert.

Zustand: Ein Fragment, oberes Drittel des Gefäßkörpers einer Lekythos, ein kleiner Rest des scharfen Schulterknicks erhalten. Zwei tiefe Kerben am Körper, ansonsten kaum bestoßen.

Technik: Oberfläche innen hellbraun, außen streifig mittelbraun, Bruch hell mittelbraun. Bemalung in dünn aufgetragenem, glänzendem Schwarz, selten durchscheinend dünn aufgetragenes Cremeweiß und Rot. Weiß: Gegenstand in den Händen der Frau links, Gesicht der Frau rechts, undefinierbarer Gegenstand in ihren Händen, zwei Tupfen zwischen ihr und dem Mann rechts, Früchte an den Zweigen. Rot: Bänder im Haar und Falten am Gewand der Männer.

Form: Gefäßwand leicht geschwungen wie bei G I०4 (hier Tafel 36, I-3). Lekythos der Form IV/I (?)

Dekor: Über dem Bildfeld ein dreireihiger, von Horizontallinien getrennter Punktfries, der mit einem schwarzen Streifen nach oben hin begrenzt ist. Zum Teil überschneiden die Köpfe der Figuren die obere Bildfeldbegrenzung.

Darstellung: Vier Figuren. - Ganz links nach rechts sitzende Frau, die einen nicht mehr erkennbaren Gegenstand, möglicherweise eine in Weiß angegebene Leier, hält. Rechts neben ihr ein stehender, nach rechts blickender, bärtiger Mann mit einem roten Band im Haar. Es folgt eine nach links sitzende Frau, die ebenso einen undefinierbaren Gegenstand in Händen hält. Hinter ihr ein Mann, der von rechts ein Podium betritt. Er trägt einen gegabelten Ast und hat ein rotes Band im Haar. Alle vier Gestalten sind in Mäntel gehüllt, deren Falten geritzt sind, die Mäntel der Männer zeigen teilweise rote Falten. Hinter den Figuren Zweige mit Früchten, die nur noch teilweise als weiße Kugeln erhalten geblieben sind.

Um 470-450 - Werkstatt des Haimon-Malers (Christidis)

Zur Form: Der leicht konkave Gefäßkörper entspricht der Lekythen-Form IV/I, vgl. Kerameikos IX, 36. Vgl. auch die Lekythos G I04, hier Tafel 36, I-3 Beilage 9, Io.

Zum Dekor: Die gleiche, durch Streifen getrennte dreifache Punktreihe findet sich etwa auf Kerameikos IX, Nr. 97, 4 Taf. 30, 2 oder Nr. I09, I Taf. 29, 2-3 (Haimon-Gruppe).

Zur Darstellung: Man würde die Szene gerne als Dionysos zwischen zwei sitzenden Mänaden deuten, wie sie auf Lekythen dieser Form häufig erscheint (vgl. Kerameikos IX, 38), jedoch die von rechts ein Podium besteigende männliche Figur schließt eine solche Interpretation wohl aus. Der Mann führt einen langen Stab mit sich, wie er Schiedsrichtern zukommt, vgl. etwa E. N. Gardiner, Athletics of the Ancient World ${ }^{3}$ (Oxford I955) Taf. 52 a. b, Taf. I 24. I 57. I 58 usw. Auch bei musischen Agonen sind Preisrichter zugegen, vgl. H. Kotsidu, Die musischen Agone der Panathenäen in archaischer und klassischer Zeit (München I99I) 30I: Katalog der schwarz- und rotfigurigen attischen Vasenbilder mit Darstellungen von musischen Agonen Nr. 7-9. 23. 25. 28; E. Böhr, Der Schaukelmaler, Kerameus 4 (Mainz I982) Taf. I78 A (Seite A der Bauchamphora Philadelphia 4832). I83 B (Seite B der Bauchamphora München, Staatl. Antikensammlungen I4 I I). Die Musizierenden sind häufig auf einem Bema dargestellt, vgl. etwa Kotsidu a. O. Nr. 49. I7. 20. 22. 23. 27. 28. 29. 32 sowie S. G. Miller, Ancient Greek Athletics (New Haven 2004) Abb. I 58-I6I. Aber auch die Juroren dürften gelegentlich eine Tribüne benutzt haben, vgl. Kotsidu a. O. I 53 mit Anm. 83. Auf einer pseudo-panathenäischen Preisamphora, Paris, Cab. Med. 243, sieht man enthusiasmierte Zuschauer auf einem Podium, die einem Waffenakrobaten zujubeln. Die Tribüne war vielleicht für den Preisrichter gedacht, vgl. La cité des images, I09 Abb. I 55 b. Möglicherweise hat also der Mann, der mit seinem Stab eben das Podium betritt, über eine Darbietung des anderen Mannes zu urteilen. Zur Tribüne für die Hellanodiken in Olympia vgl. L. Drees, Olympia. Götter, Künstler und Athleten (Stuttgart I967) Io9 Abb. 22.

\section{TAFEL 37}

\section{1-2. Weißgrundige Efeulekythos}

Beilage 9, 8 .

G 54. Aus Athen. Erworben I 866/67 von Maximilian Theodor von Karajan (Graz), Schenkung. Alte Inv.-Nr. II ıo (Schenkl) bzw. III ro (Pichler).

H erh. I3,2 cm. - Dm Schulter 5, O cm. - Dm Fuß 3,7 cm. Wandstärke $0,3 \mathrm{~cm}$. - Gewicht [I 28,8 g].

Unpubliziert.

Zustand: Ein Fragment. Gefäßkörper bis etwa zur Mitte des Halses erhalten, Rand und Henkel abgebrochen. Entlang der Schulterkante Absplitterungen, der Ansatz des Henkels an der Oberseite der Schulter ist modern verstrichen. Die schwarze Bemalung über der weißen Grundierung ist großteils abgeplatzt. Die schwarzen Zungen auf der Schulter sind nur noch im Ansatz erhalten. An der Unterseite des Bodens „G 54“ mit schwarzer Tinte.

Technik: Oberfläche hellorange. Oberseite des Fußes mit schwarzem Glanzton versehen. Drei Viertel des Körpers, Schulter und Halsansatz cremeweiß grundiert (dünner Farbauftrag), Bemalung in dünn aufgetragenem, glänzendem Schwarz. Miltos: Außen- und Unterseite des Fußes.

Form: Lekythos der Form VI: Hoher, konkaver Standteller, an der Unterseite spitz hochgewölbt. Konischer, nach unten einschwingender Körper, scharfe Schulterkante, stark eingezogener Hals.

Dekor: Um den Standteller ein schwarzer Streifen. Oberseite des Fußes und unteres Viertel des Gefäßkörpers mit schwarzem Glanzton überzogen, am oberen Ende zwei Mal mit zwei tongrundigen Streifen unterbrochen. Der Dekor im Bauchbereich ist nur mehr ansatzweise erhalten: Horizontaler Efeuzweig zwischen Gitterbändern. Auf der Schulter ein doppelter Zungenfries, Glanzton auf weißer Grundierung.

Drittes Viertel 5. Jh. - Werkstatt des Beldam-Malers

Zur Form: siehe ABL, I87. Der Typus gehört nach Haspels, ABL, I70-I9I bes. I8I der Werkstatt des Beldam-Malers an (Datierung: um 470-450). Zu Lekythen der Form VI vgl. Kerameikos IX, 37 Taf. 77; ABV 586 f.; Para 292 f.; Add² I 39. Diese rein ornamental verzierten Lekythen wurden in großer Zahl produziert. Sie waren in der Herstellung einfacher und daher wohl billiger als die 
figürlich bemalten und fanden sich auch außerhalb Attikas, vgl. z. B Corinth XIII, I64. 247. 249 Taf. 55. Aus derselben Werkstatt stammen auch die Lekythen Kerameikos IX, I 52 Nr. 295, 3-4 Taf. 4 I sowie Kerameikos IX, I 54 Nr. 300, I; Nr. 30I, I und Nr. 302, I Taf. 66, weiters I95 Pr I4, I-3 Taf. Io0, 5. Eine Lekythos dieser Form fand sich im Grab eines Gesandten aus Kerkyra aus dem Jahre 433/432 im Kerameikos: Kerameikos IX, 37 Anm. 36 Taf. I I2. II3; U. Knigge, Untersuchungen bei den Gesandtenstelen im Kerameikos zu Athen, AA I972, 602. Weitere zahlreiche Vergleichsbeispiele aus dem Kerameikos erweisen die große Beliebtheit dieses Typus: Kerameikos VII 2, 82 f. Nr. 282, I-8 Taf. 55, I. 3 (nach 460); 94 Nr. 35 I, I-2 Taf. 63, 2 (um 440); 97 Nr. 372 Taf. 64, 2 (Mitte 5. Jh.); 97 Nr. 382,2 Taf. 63, 7 (2. Viertel 5. Jh.); 90 Nr. 322 Taf. 59, I (Mitte bis 3. Viertel 5. Jh.); 9I Nr. 327, 2 Taf. 6I, I (3. Viertel 5. Jh.); I 29 Nr. 489, I-5 Taf. 88, I (3. Viertel 5. Jh.); I 50 Nr. 493 , 3-8 Taf. 88 , 3; I 50 f. Nr. 495 , I-8 Taf. 88, 4 . Vgl. weiters CVA Stuttgart I Taf. 25, I-2. 5; CVA Heidelberg 4 Taf. I77, I3 (L 5); CVA Harrow School Taf. I2, 9-Io (I 864.48); CVA Jena I Taf. 59, I 2-I3. I 8 (V 229); I4-I 5. I7 (V 228).

Zum Dekor: Die weiße Grundierung auch von Schulter und Hals gehört der Spätzeit der Beldam-Werkstatt an (Kerameikos VII 2, zu Nr. 327). Es gibt auch eine Variante mit Efeu am Hals und anderen geometrischen oder pflanzlichen Motiven am Körper; vgl. Boardman, SFVA, Abb. 280 (freundl. Hinweis E. P. Manakidou). Zum Export der attischen Ornament-Lekythen nach Korinth und Sizilien vgl. Kurtz, AWL, I38-I4I. Der Efeu als immergrüne Pflanze gibt eine passende Dekoration auch für Gefäße sepulkraler Verwendung ab. Dem Gott Dionysos zugeordnet ist er das Zeichen der Dionysosmysterien, vgl. DNP 3 (Stuttgart I997) 886 f. s. v. Efeu (F. Graf); T. Thie, Unteritalische Vasen aus Kärntner Sammlungen, ungedruckte Diss. Wien (2005) I40-I43.

Zum Maler: ABV 57 I f., 586 f.; Kurtz, AWL, passim, bes. 9. I 5. I 8 f. 84-87 Taf. 70, 6-8 (Oxford, Ashmolean Mus. I940.I 49 und I879.210; Korinth, Museum T 566-I I 8: Efeu-Lekythen des Beldam-Malers). $\mathrm{Zu}$ den letzten schwarzfigurigen Malern vgl. Boardman, ABFV, I 46-I 50, zum Beldam-Maler I 49 f; Boardman, SFVA, I62. In seinen früheren Werken erweist sich der Maler geschickter als etwa der Haimon-Maler und auch origineller, vgl. z. B. die namengebende Lekythos in Athen, NM I I 29 (Boardman, SFVA, Abb. 277). Auch zwei der frühesten weißgrundigen Lekythen mit Umrisszeichnung gehen auf ihn zurück, Athen, NM I982: ABL, I75 Taf. 5I, 4; 52, I; $\mathrm{ARV}^{2} 75 \mathrm{I}$, I; $\mathrm{Add}^{2} 285$, sowie Athen, NM I983: ABL, I75 Taf. 52, 2; $\mathrm{ARV}^{2} 75$ I, 2; $\mathrm{Add}^{2} 285$, und ebenso eine rotfigurige Lekythos in Kopenhagen I94I: ARV 2 75I, 3; CVA Copenhague, Musée National 4, III I Taf. I64, I; Kurtz, AWL, I9 Anm. Io. Seine kleineren Lekythen zeigen häufig weißen Grund mit floralem Dekor wie Efeuranken, aber auch die beliebten Palmetten-Lekythen werden hergestellt.

Zur Werkstatt: ABL, I70-I9I. 266-269; Kurtz, AWL, I 52I 55, wo betont wird, dass nicht alle der zahlreichen weißgrundigen Lekythen mit Efeuranken, die bis an das Ende des 5. Jhs. populär waren, aus der Werkstatt des Beldam-Malers stammen können. Unter allen Ornamenten war die Efeuranke in der 2. Hälfte des 5. Jhs. das beliebteste. Von Blattwerk gerahmt und mit roter Farbe gehöht war es nicht unattraktiv.
3. Siehe Tafel 35, 1-3.

4. Siehe Tafel 36, 1-3.

\section{5-7. Weißgrundige Palmettenlekythos}

Beilage 9, 7.

G 106. Aus Attika. Erworben um I9I2/I3 durch Rudolf Heberdey, Tausch mit dem NM Athen.

H erh. 9,0 cm. - Dm Schulter 5,3 cm. - Wandstärke o,8 cm. Gewicht 96,2 g.

Unpubliziert.

Zustand: Ein Fragment. Ansatz des Wulstes über Fußscheibe sowie Schulterknick nur partiell erhalten, hier auch einige größere Abplatzungen. Kleinere Bestoßungen in der Ornamentzone. Im Inneren des Gefäßes mit Kugelschreiber „4“.

Technik: Oberfläche und Bruch hellorange-mittelbraun. Gefäßkörper im unteren Teil schwarz bemalt, im oberen cremeweiß grundiert. Bemalung glänzend schwarz, über der weißen Zone ist der Farbeindruck dunkelbraun. Miltos: zwei dünne Streifen am unteren, schwarzen Gefäßkörper.

Form: Lekythos der Form VI.

Dekor: Im unteren Teil Streifenverzierung mit zwei dünnen roten Streifen, darüber zwei Mal zwei tongrundige. Auf cremeweißem Grund drei nach rechts liegende Palmetten, darüber ein schwarzer Streifen. Unter dem Schulterknick ein zweireihiger Punktfries mit schwarzen, versetzten Punkten, unten und oben von je einem schwarzen Streifen eingefasst.

\section{Zweites Viertel 5. Jh. - Werkstatt des Beldam-Malers}

Zur Form: vgl. Kerameikos IX, 37 f.: Der Typus gehört nach ABL, I 85 der Beldam-Werkstatt an, vgl. dazu die Lekythos G 54, hier Tafel 37, I-2.

Zum Dekor: Der Schmuck dieser Lekythen besteht bis auf wenige Ausnahmen in drei aufrechtstehenden, einfachen oder hängenden, doppelten Palmetten oder liegenden Palmetten auf weißem Grund (wie G I06), in der späteren Phase aus Gittermuster oder umlaufender Efeuranke (wie G 54). Lekythen mit vergleichbarem Dekor aus der Werkstatt des Beldam-Malers finden sich u. a.: Kerameikos IX, Nr. I 52, 4 Taf. 4I, 2; Nr. 224, I Taf. 36, 5; Nr. 262, 2 Taf. 36, IO; Kerameikos VII 2, Nr. I I I, I-2 Taf. 25, 6; Nr. 495, I Taf. 88, 4 (frühe, sorgfältige Arbeit); Corinth XIII, 242 f. Taf. 49, 6; Heidelberg, Univ. L I 3: CVA Heidelberg 4 Taf. I77, 4; Athen, Kerameikos-Museum: Kurtz, AWL, Taf. 7I, I; Olympia K I0802: Burow, Attisch schwarzfigurige Keramik, Nr. 57 I Taf. 87.

Zur Datierung: vgl. Burow, Attisch schwarzfigurige Keramik, 283, der mehrere Gruppen von Palmettenlekythen unterscheidet. Das unserer Lekythos eng verwandte Stück wird in das 2. Viertel des 5. Jhs. datiert.

Zur Werkstatt: vgl. dazu die Lekythos G 54, hier Tafel 37, I-2. 


\section{ATTISCH ROTFIGURIG}

\section{TAFEL 38}

\section{1-2. Tafel 39. 1-4. Halsamphora}

Beilage 10, 1.

G 29. Aus Capua. Erworben 1874 durch Wolfgang Helbig in Rom, Ankauf. Ehemals Slg. Simmaco Doria (Santa Maria Capua Vetere). Alte Inv.-Nr. II 3 I (Schenkl) bzw. III 36 (Pichler).

H 33,3 cm. - Dm Mündung I4,4 cm. - Dm Körper I9, I cm. Dm Fuß 8, I cm. - B Henkel 2,6 cm. - D Henkel I, 2 cm. - Gewicht I 428 g. - Volumen 39I $2 \mathrm{ml}$.

G. Schwarz, Ein unbekanntes Werk des Yale-Lekythos-Malers, AA I974, 240-247 Abb. 5-7. - Lorenz - Lehner - Schwarz, Vasen, 47-49 Nr. 25 Abb. 36-37 (G. Schwarz). - BAPD 4I.

Zustand: Vollständig erhalten. Randoberseite leicht bestoßen, eine Absplitterung (Dm ca. I cm) über einem Kalksteinchen. Bemalung in der Halszone und an der Oberseite eines Henkels stellenweise abgerieben. Leicht verzogene Mündung

Technik: Schwarzer, glänzender Glanzton. Hals innen gefirnisst. Relieflinien: auf A Auge, Ohr, Buckellocken, Korkzieherlocke und Bart, rechter Arm, Dreizack und Mantelfalten des Poseidon, und B Mantelfalten und rechte Hand des Mannes. Ausgesparte Kopfkontur auf A und B, auf B auch Bartkontur ausgespart. Umrisszeichnung: Lippen der Figuren. Vorzeichnungen: Auf A Körper des Poseidon unter dem Gewand. Auf B Beine des Mannes. Verdünnter Glanzton: Auf A Mantelsaum, auf B Bartspitzen, Ärmelbausch und Saum des Mantels.

Form: Nolanische Amphora mit dreiteiligen Henkeln. An der Unterseite stark eingezogener Scheibenfuß, durch einen breiten Wulst vom Gefäßkörper getrennt. Bauchiger Gefäßkörper, vom Fuß aufsteigend konisch ausschwingend. Deutlich ausgeformte Schulter, starke, durch einen Grat abgesetzte Halseinziehung. Hoher Hals, weit ausgreifende, durch einen Grat abgesetzte Mündung. Randzone innen stark gekehlt, fast horizontal abgestrichene Lippe. Zwei gegenständige, unterrandständige, aus drei Wülsten geformte Bandhenkel.

Dekor: Unter den Figuren auf A und B je ein kurzes Mäanderband.

Darstellung: A Poseidon, B älterer Mann. - Auf A Poseidon, nach rechts eilend, in Ärmelchiton und Mantel, die Linke mit geöffneter Hand vorgestreckt, mit der Rechten den Dreizack schulternd. Er hat das Haar zu einem Schopf aufgebunden, darüber liegt eine Tänie. Über der Stirn Buckellöckchen, hinter dem Ohr eine weit herabfallende Korkenzieherlocke. Der lange, mit geraden Strichen angegebene Bart wirkt eigentümlich unnatürlich, wie aufgeklebt. Dünner Schnurrbart. Lippen in Umrisszeichnung. Ein Zinken des Dreizacks, der schon auf den Gefäßhals reichen müsste, fehlt. B: ein bärtiger Mann mit Stirnglatze in Chiton und Mantel nach links stehend, die rechte Hand stützt sich auf einen Stock. Durch den Mantel, dessen oberer Saum ihm über die Schulter fällt, zeichnet sich das Standbein ab. Die Konturen des Bartes sind voll ausgemalt, nur die Enden mit einzelnen Pinselstrichen angesetzt. Der dünne Schnurrbart ähnelt dem des Poseidon auf A. Augenbraue stark geschwungen.

Um 470 - Maler der Yale-Lekythos

Zur Form: Zur Entwicklung der „nolanischen“ Amphora vgl. H. Bloesch, Antike Kunst in der Schweiz (Erlenbach-Zürich I943)
66; weitere Lit. vgl. Boardman, ARFV I, 239; zu der Annahme, die „nolanische“ Amphora sei in der Werkstatt des Berliner Malers entstanden, vgl. J. D. Beazley, The Berlin Painter (Nachdruck Mainz 1974) $3 \mathrm{f}$.

Zur Darstellung: U. Heimberg, Das Bild des Poseidon in der griechischen Vasenmalerei (Freiburg/Br. I968) 74 f.; LIMC VII (Zürich I994) 462 Nr. I44 s. v. Poseidon; 467 f. (E. Simon). Der eilige Poseidon ist, wie man aus analogen Bildern schließen kann, in einer Verfolgungsjagd begriffen, doch kann der bärtige Mann auf B nicht der Grund seines Bemühens sein. Es ist vielmehr ein geliebtes Wesen, Mädchen oder Knabe, das er mit weitem Schritt verfolgt, den Arm bereits nach dem Gegenstand seiner Sehnsucht ausgestreckt. Der glatzköpfige Mann auf B ist wohl als Begleitperson der verfolgten Person aufzufassen, vielleicht ihr Pädagoge. Zum Bild des Pädagogen vgl. H. Schulze, Ammen und Pädagogen. Sklavinnen und Sklaven als Erzieher in der antiken Kunst und Gesellschaft (Mainz I998), sowie Th. Harten, Paidagogos. Der Pädagoge in der griechischen Kunst (Kiel I999). Zu Liebesverfolgungen des Poseidon vgl. S. Kaempf-Dimitriadou, Die Liebe der Götter in der attischen Kunst des 5. und 4. Jhs., AntK II. Beih. (Bern I979) I 2. 26-30. 97-IOO, sowie Schefold, SB III, 248-258. Verfolgung der Aithra: F. Brommer, AM 63/64, I938/I939, I72 f.; Heimberg a. O. 4I mit Anm. 4; LIMC I (Zürich I98I) 420 f. Nr. I-I 2; 428 f. s. v. Aithra (U. Kron); Verfolgung der Amymone: J. D. Beazley in: L. D. Caskey - J. D. Beazley, Attic Vase Paintings in the Museum of Fine Arts Boston 2 (Boston I954) 89-93; Brommer a. O. I7I-I76; E. Diehl, Die Hydria (Mainz I 964) 204-206; LIMC I (Zürich I98I) 744 Nr. I7-24 s. v. Amymone (E. Simon); Verfolgung des Pelops: LIMC VII (Zürich I994) 283 Nr. I s. v. Pelops (I. Triantis). Man möchte sich zu dieser Halsamphora gerne ein Pendant als Ergänzung denken, das die Darstellung erst sinnvoll erscheinen lässt, wie etwa die unten erwähnte Amphora in New York, auf der zwar ein zu ihrem königlichen Vater eilendes Mädchen auf A sowie eine Fliehende auf B gezeigt werden, nicht aber der Verfolger. Als Ergänzung zu unserer Halsamphora kämen als Verfolgte Amymone, Amphitrite und Aithra, aber auch Pelops mit ihren Begleitpersonen in Betracht. Besonders häufig ergänzen die Bilder auf Lekythen einander paarweise, vgl. dazu die Lekythos G 37, hier Tafel 48, 5-7; 50, 2, sowie CVA Erlangen 2, 94 zu Taf. 40, 8-9; 4I, 2. 4 .

Zum Maler: ARV 2 657-662 (benannt nach der Lekythos ARV ${ }^{2}$ 658, 30). I664; Para 403 f. 52 I; Add $^{2}$ 277; EAA V (Rom I963) 303. 305 f.; A. Rumpf, Malerei und Zeichnung, HdArch IV (München I953) I02; G. M. A. Richter, Attic Red-Figured Vases ${ }^{2}$ (New Haven/London I967) 93. I09. Der Maler verwendete einmal den Lieblingsnamen Charmides (auf der Halsamphora London BM E 29I: ARV² 662; CVA Brit. Mus. 5, III I c Taf. 48, 3) und nannte einmal einen Agyrrios (auf der Schale in London BM E 90: ARV² 662, 96; I664). Der Grazer Amphora stilistisch vergleichbar ist etwa die Amphora in New York, Metropolitan Museum 4I.I62.I 56: $\mathrm{ARV}^{2}$ 657, 4 („Extract from a pursuit - sisters of the ravished hearing the alarm, leaving their parent, and rushing to her side"); Gallatin: CVA Hoppin and Gallatin Collections I Taf. I3, I-3. Vgl. weiters die Halsamphora in London E 309: $\mathrm{ARV}^{2}$ 657, 7; CVA Brit. Mus. 5, III I c Taf. 55, 3 a. b, sowie die Stamnoi Würzburg L 5 I 8: ARV² 657, 2; G. Schwarz, Ein unbekanntes Werk des Yale-Lekythos-Malers, AA I974, 24I Abb. I. 2, und Wien, KHM ANSA IV 3730: ARV 257,3 , CVA Wien, Kunsthistorisches Museum 2 Taf. 67; Schwarz a. O. 242 f. Abb. 3-4. Der Maler der Yale-Lekythos zählt zu den „flüchtigen, wenn auch 
nicht ungeschulten Lekythenmalern" (Zitat Rumpf a. O.), dem rund soo Gefäße zugeschrieben werden, außer Lekythen vor allem die kleinen „nolanischen“ Amphoren, Hydrien und Peliken, aber auch große Gefäße wie Stamnoi. Bei den Frisuren seiner Gestalten liebt er besonders die lange, steif hinter dem Ohr herabfallende Korkzieherlocke, bei den Bärten die starr aus der Haarmasse abstehenden Bartenden. Die Falten der Gewänder gibt er in großzügigen, meist geraden Linien an, denen es ein wenig an Schwung fehlt. Liebesverfolgungen gehören zu seinen bevorzugten Themen, und unter den Göttern scheint Poseidon sein Favorit gewesen zu sein. Der Yale-Lekythos-Maler liefert im allgemeinen Massenware, doch finden sich auch einige gut gelungene und sorgfältig gemalte Bilder darunter, die Gestalten des Berliner Malers oder des Hermonax in Erinnerung rufen. Sein Verharren in der Tradition des Strengen Stils stellt ihn dem Providence-Maler an die Seite.

\section{TAFEL 39}

1-4. Siehe Tafel 38, 1-2.

\section{TAFEL 40}

\section{1-2. Tafel 41, 1-4. Halsamphora}

Beilage 11, 1.

G 20. Aus Capua. Erworben I 873 durch Wolfgang Helbig in Rom, Ankauf. Alte Inv.-Nr. II I9 (Schenkl) bzw. III 27 (Pichler).

H 35,6 cm. - Dm Mündung I 5,6 cm. - Dm Körper I9,5 cm. - Dm Fuß 9,3 cm. - B Henkel 2,6 cm. - Dm Henkel I,4 cm. - Volumen $4247 \mathrm{ml}$.

G. Schwarz, Der Alkimachos-Maler in Graz, AntK I7, I974, 36-38 Taf. 7, I-2. 4. - Lehner - Lorenz - Schwarz, Vasen, 49 f. Nr. 26 Abb. 38. 40 (G. Schwarz). - BAPD I 285.

Zustand: Die Vase wurde im Jahre 20 I I einer umfassenden Restaurierung unterzogen. Dabei stellte sich heraus, dass sie bei ihrer Erstrestaurierung aus Io Teilen zusammengesetzt wurde. Der Unterteil besteht aus einem großen Fragment, das nahezu die Hälfte der Vase ausmacht, der Oberteil aus 9 kleineren Fragmenten. Die Fugen wurden an der Außenwand derart perfekt retuschiert, dass der Eindruck eines intakten Gefäßes entstand. Im unteren Gefäßbereich ist die Oberfläche unbehandelt, im oberen, besonders im Bereich der Schulter, überfasst und fast flächig mit einem Lack überzogen, wodurch sie besonders stark glänzt. Die Binnenlinien wurden an den Bruchstellen sehr exakt nachgezeichnet. Das Gefäß zerbrach offenbar ein zweites Mal in zwei große Teile und wurde mit einer gipsartigen Masse wieder zusammengesetzt. Beim Entfernen dieser Masse zeigte sich eine kleine Fehlstelle im Bereich der Bruchfuge am Oberkörper der Frau. Ansonsten vollständig erhalten.

Technik: Ton hellorange, Bemalung glänzend schwarz. Miltos: Fußunterseite. Relieflinien: Profillinie, Auge, Haarband, Gewandfalten, Fackel der Flügelfrau auf A; Auge, Kinn und Schulter des Jünglings auf B. Verdünnter Glanzton: Hauptsächlich im oberen Bereich des Gefäßes (Muster des Chitons der Frau, Flaumfedern der Flügel), doch durch die starke Übermalung nur teilweise original. Ausgesparte Kopfkontur auf A und B. Vorzeichnungen: Umfangreiche Vorzeichnungen am Unterkörper der Flügelfrau sowie am Faltenzipfel ihres Mäntelchens. Die Vorzeichnungen am Oberteil der Frau wurden bis auf geringe Reste im Bereich des Flügels im Zuge der ersten Restaurierung übermalt. Aufgesetzte Farbe:
Dunkelrot für Flammen der Fackeln auf A, Rot für den Reif im Haar des Jünglings auf B. Graffiti: Auf A im Rücken der Flügelfrau und B vor dem Kopf des Jünglings einige unleserliche Buchstaben.

Form: Halsamphora nolanischer Form. An der Unterseite stark eingezogener Scheibenfuß. Bauchiger Gefäßkörper, zur Fußzone hin konisch eingezogen. Deutlich ausgeformte Schulter, starke, durch einen Grat abgesetzte Halseinziehung. Hoher, annähernd zylindrischer Hals, weit ausgreifende, durch eine Rille abgesetzte Mündung. Randzone innen stark gekehlt, fast horizontal abgestrichene Lippe. Zwei gegenständige, unterrandständige Bandhenkel mit längsovalem Querschnitt.

Dekor: Je ein Mäanderstreifen unter den Figuren auf A und B.

Darstellung: Nike, junger Athener. - Auf A: Nach links eilende Flügelfrau in Ärmelchiton und Mantel, das Haar, um das ein Band gelegt ist, zu einem Knoten aufgenommen. In beiden Händen trägt sie brennende Fackeln. Ihr linker Fuß berührt im Lauf nur flüchtig mit den Zehen den Boden, während der rechte frei schwebt. Sie wendet den Kopf zurück. Auf B steht ein Jüngling ruhig auf seinen Stock gestützt, den er mit der weit vorgestreckten Rechten am gebogenen Griff umfasst, während er die Linke in die Seite stemmt. Unbärtiges Gesicht mit schwerem Kinn, kurzes, dichtes Haar, auf dem ein Reif liegt. Er ist ganz in ein Himation gehüllt, das nur die rechte Schulter und den rechten Arm freilässt.

Um 470-46o - Alkimachos-Maler

Zur Form: Zur nolanischen Amphora vgl. G 29, hier Tafel 38, I-2.

Zur Darstellung: Die fackeltragende Flügelfrau findet sich zumeist auf kleinen Halsamphoren und Lekythen, also Gefäßen, die primär im Totenkult Verwendung fanden. Überhaupt „erscheint die Flügelfrau häufig auf nolanischen Amphoren, wobei auf der Rückseite Manteljünglinge zu stehen pflegen“: C. Isler-Kerényi, Nike. Der Typus der laufenden Flügelfrau in archaischer Zeit (Erlenbach-Zürich, Stuttgart I969) 44. Zu Nike vgl. weiters Thomsen, Wirkung I 68-235; Zu Flügelfrauen vgl. H. Kenner, Flügelfrau und Flügeldämon, ÖJh 3 I, I938/I939, 8I-95; C. Isler-Kerényi, Ein Spätwerk des Berliner Malers, AntK I4, I97I, 27. 30 f., wo auf die Rolle der fackeltragenden Nike als Begleiterin in die Unterwelt verwiesen wird. Das Flüchtige ihrer Erscheinung wird wie hier so auch auf vielen anderen Darstellungen durch das Zurückwenden des Kopfes zum Ausdruck gebracht: Isler-Kerényi a. O. 3 I. Zum sepulkralen Charakter der Flügelfrauen vgl. Kenner a. O. 90-95, ebenso A. Gulaki, Klassische und klassizistische Nikedarstellungen (Bonn I98I) I40 f. Allgemein zu Nike-Darstellungen vgl. C. Thöne, Ikonographische Studien zu Nike im 5. Jh. v. Chr. Untersuchungen zur Wirkweise und Wesensart (Heidelberg I999) passim. Der Manteljüngling erscheint, wie oben erwähnt, sehr häufig im Zusammenhang mit einer Flügelfrau. Seine Ausstattung mit Mantel und Stock weist ihn als Athener Bürger aus, vgl. H.-G. Hollein, Bürgerbild und Bildwelt der attischen Demokratie auf den rotfigurigen Vasen des 6.-4. Jhs. v. Chr. (Frankfurt am Main I988) 25, der Mantelfiguren dieser Art dem „dynamis-Typus“ zuweist. Ruhig betrachtet er das Erscheinen der Todesbotin, die an ihm vorübereilt.

Zum Maler: ARV 2 529-533. I658; Para 383 f.; Add $^{2} 254$ f.; Boardman, RFVA II, 39 Abb. 46. 47. Das erhaltene Oeuvre des Malers umfasst rund 75 Werke. Benannt ist er nach dem Lieblingsnamen Alkimachos, den er auf zwei Gefäße setzte: die nolanischen Amphoren München, Staatl. Antikensammlungen 2325: $\mathrm{ARV}^{2}$ 530, I9; Para 383, $\mathrm{Add}^{2}$ 254; CVA München 2, Taf. 58, I; K. Schefold, Sophokles 'Aias auf einer Lekythos, AntK I9, I976, 7I-78 Taf. I6, 2 und London, BM E 3I8: ARV 2 530, 20; Para 383 , Add 254 ; G. M. A. Richter, Perspective in Greek and Roman Art (London I 970) Abb. 96. Auch andere Vasenmaler priesen diesen Jüngling, dessen Name sich zumindest noch auf fünf weiteren 
Vasen findet, vgl. ARV ${ }^{2}$ I 56I f. Es handelt sich um Alkimachos, Sohn des Epichares, von dem ein anderer Alkimachos (Alkimachos II) unterschieden werden muss, der auf späteren Vasen genannt wird, vgl. ARV ${ }^{2}$ I 562. I698. Möglicherweise ist sogar noch ein Alkimachos III auszumachen (ARV ${ }^{2}$ I 562). Die Gefäße, die den Sohn des Epichares nennen, gehören alle dem Zeitraum von 470460 an. Der Alkimachos-Maler dekorierte in erster Linie Amphoren - unter ihnen scheint er die nolanische Form mit dreiteiligen Henkeln bevorzugt zu haben - und Kolonettenkratere, aber auch Peliken, Loutrophoren, Lekythen und Schalen. Zeitweilig scheint er vom Pan-Maler beeinflusst (vgl. ARV ${ }^{2}$ 529; Boardman, ARFV II, 39): Der „Daphnis“ auf dem namengebenden Glockenkrater des Pan-Malers in Boston, Mus. of Fine Arts IO.I85, zeigt ähnlich kurvige Faltenkringel an seiner Exomis: ARV 25 , I.I659; Para 386; Add $^{2} 256$ f.; E. Simon, Die griechischen Vasen ${ }^{2}$ (München I98I) I22 f. Taf. I70; vgl. auch Simon a. O. I 24 Taf. I73; ARV $^{2}$ 55I, I 5.I 659; Add $^{2} 257$ zum Kolonettenkrater in Neapel, NM I 27929. Der Maler setzte noch auf zwei weitere nolanische Amphoren jeweils eine Flügelfrau und eine Jünglingsgestalt, vgl. Palermo V 745: $\mathrm{ARV}^{2}$ 530, I4; Para 254; CVA Palermo Taf. 26, 2; 28, I-2, sowie Paris, Rothschild: $\mathrm{ARV}^{2}$ 530, I 5 . Doch ist sein Repertoire erstaunlich groß und umfasst Darstellungen aus geläufigen Mythen über den trojanischen Sagenkreis (Nolan. Amphora Madrid I I IOI: $\mathrm{ARV}^{2}$ 530, 23; $\mathrm{Add}^{2}$ 254; CVA Madrid 2, Taf. 20, 4 ) bis zu dem originellen Bild der Geburt des Dionysos aus dem Schenkel des Zeus (Lekythos Boston 95.39; ARV $^{2}$ 533, 58; Para 384 Add $^{2}$ 255; K. Schefold, Sophokles`Aias auf einer Lekythos, AntK 19, I976, Taf. I6, 3). Vergleichsstücke für den Jüngling auf der Grazer nolanischen Amphora sind beispielsweise Seite B einer Halsamphora in London, BM GR I928. I-I7.57: ARV² 529, I2 („Unusually pleasant for this painter“); Add $^{2} 254$; CVA Brit. Mus. 5 Taf. 46, 2 b; G. Schwarz, Der Alkimachos-Maler in Graz, AntK I 7, I974, 36-38 Taf. 7, 3, sowie für die Flügelfrau die Halsamphora mit Boreas und Oreithyia in Neapel, Museo Nazionale 3 I25: ARV² 530, 2I; G. Patroni, Vasi Dipinti del Museo Vivenzio disegnati da Costanzo Angelini nel I798 (Rom I900) Taf. 9.

\section{TAFEL 41}

1-4. Siehe Tafel 40, 1-2.

\section{TAFEL 42}

\section{1-2. Tafel 43, 1-5. Halsamphora}

Beilage 12, 1.

G 2I. Aus Capua. Erworben I 873 durch Wolfgang Helbig in Rom, Ankauf. Alte Inv.-Nr. II 20 (Schenkl) bzw. III 27 (Pichler).

H 34,9 cm. - Dm Mündung I 5,8 cm. - Dm Körper I 8,8 cm. - Dm Fuß 8,4 cm. - B Henkel 2,4 cm. - Dm Henkel I, 5 cm. - Volumen $3930 \mathrm{ml}$.

G. Schwarz, Eine neue Amphora des Sabouroff-Malers, AA I972, 4I-46 Abb. I-2. 4. - Lehner - Lorenz - Schwarz, Vasen, 50-52 Nr. 27 Abb. 39. 4I (G. Schwarz). - G. G. Kavvadias, O

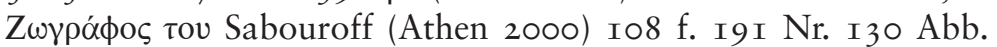
94. - BAPD 50.

Zustand: Aus über 20 Fragmenten zusammengesetzt, einige kleinere Fehlstellen und Absplitterungen in Gips ergänzt und schwarz übermalt. Stark verzogene Mündung.
Technik: Glänzend schwarze Bemalung auf hellorangefarbenem Ton. Relieflinien: Schulter des Mannes auf A, einzelne Gewandfalten auf A und B. Verdünnter Glanzton: Faltenbausch unter linkem Arm der Figur auf B. Vorzeichnungen auf A: Rechtes Bein des Mannes. Aufgesetztes Rot: Kranz des Mannes und Haarband der Frau auf A.

Form: Halsamphora nolanischer Form. An der Unterseite stark eingezogener Scheibenfuß. Bauchiger Gefäßkörper, zur Fußzone hin konisch eingezogen. Deutlich ausgeformte Schulter, starke, durch einen Grat abgesetzte Halseinziehung. Hoher, annähernd zylindrischer Hals, weit ausgreifende, durch einen Grat abgesetzte Mündung. Hals innen mit Glanzton versehen. Randzone innen stark gekehlt, fast horizontal abgestrichene Lippe. Zwei gegenständige, unterrandständige Bandhenkel mit längsovalem Querschnitt.

Dekor: Unter den Figuren auf A Band mit Kreuzplattenschlüsselmäander, auf B einfacher rechtsläufiger Mäander.

Darstellung: Abschiedsszene. - A: Eine Frau steht rechts und wendet sich nach links. Sie hält in der gesenkten Rechten eine Oinochoe und blickt nach links zu einem Mann, sodass ihr Kopf im Profil erscheint. Sie ist in Chiton und Mantel gehüllt und hat das Haar mit einem Band aufgebunden. Auf dem unteren Ende ihres Chitons sitzt eine wellenförmige Punktverzierung. Mit der Linken greift sie in den Saum ihres faltenreichen Mantels, der über ihre linke Schulter gelegt ist. Der Mann ihr gegenüber streckt ihr mit der Rechten eine Phiale entgegen. Er ist bärtig, trägt einen Mantel, der die rechte Schulter freilässt und hat einen Kranz im Haar. Neben ihm ist ein Stock sichtbar. B: Nach links laufende Frau in Chiton und Mantel, die Rechte vorgestreckt, die Linke gänzlich unter dem Mantel verborgen. Auf dem unteren Ende ihres Chitons eine wellenförmige Punktverzierung.

Um 450 - Sabouroff-Maler

Zur Form: Zur nolanischen Amphora vgl. G 29, hier Tafel 38, I-2.

Zur Darstellung: Die beiden Gestalten auf Seite A haben sich zu einer Abschiedslibation zusammengefunden, wie sie vor Antritt einer Reise üblich war. Denn dass eine solche bevorsteht, bezeugt der Stock, der neben der männlichen Figur steht und sie als Wanderer ausweist. Auch ist das Gefäß in seiner Hand eine OpferPhiale und keine Trinkschale (Kylix). Zur Abschiedslibation vgl. E. Simon, Opfernde Götter (Berlin I953) 7I; H. Gericke, Gefäßdarstellungen auf griechischen Vasen (Berlin I970) 27. 33; G. G.

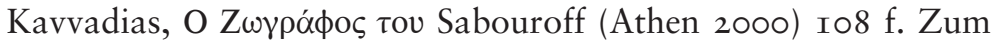
Kranz im Haar des Mannes, der dem Auszug einen festlichen Charakter verleiht, vgl. M. Blech, Studien zum Kranz bei den Griechen (Berlin I982) 23. I74. 433. 447. Zum Stock, der auch Abzeichen des athenischen Bürgertums ist, vgl. G 24, hier Tafel 57, 4-5; 58 , I-3. Die laufende Frau auf B, die ohne Attribut dargestellt ist, könnte als Teilnehmerin an dem Opfer aufgefasst werden. Diesen „friedlichen“ Auszugsbildern stellte der Maler gelegentlich auch „Kriegers Abschied“ gegenüber (Kavvadias a. O. Io9 f.).

Zum Maler: ARV² 837-85I; I672. I695. I707; Para 423 f.; $\operatorname{Add}^{2}$ 295-297; K. F. Felten, Thanatos- und Kleophonmaler. Weißgrundige und rotfigurige Vasenmalerei der Parthenonzeit (München I97I) 32; Kurtz, AWL, 34-37; Wehgartner, AWK, 26-29; 70 Nr. 76; 73 Nr. 86. 90 f.; Boardman, RFVA II 39. I 36; Kavvadias a. O.; DNP Io (Stuttgart 200I) I I 92 s. v. Sabouroff-Maler (J. Oakley). Im Schaffen des Sabouroff-Malers lassen sich drei Perioden unterscheiden, die sich durch die Zusammenarbeit mit verschiedenen Werkstätten ergeben und von der Vorliebe für bestimmte Gefäßtypen geprägt sind. In der mittleren Periode, der unsere Amphora angehört (455-440), arbeitete der Künstler in der Werkstatt des Achilles-Malers. Die Maler arbeiteten an manchen Stücken gemeinsam und der stilistische und ikonographische Einfluss des Achilles-Malers ist an fast allen Werken dieser Epoche sichtbar. Der Sabouroff-Maler dekorierte zu dieser Zeit nahezu alle Gefäß- 
formen, die in dieser Werkstatt hergestellt wurden, d. h. Halsamphoren, Peliken, besonders aber rotfigurige und weißgrundige Lekythen, zusätzlich aber auch zwei Kolonettenkratere sowie andere Gefäßtypen. Durch seine Übernahme der reinen Mattfarbenbemalung vom Schulterornament auf das Figurenbild, die bei ihm das erste Mal nachzuweisen ist, hat der Sabouroff-Maler einen wichtigen Beitrag zur Entwicklung der weißgrundigen Technik geleistet. Aus seiner mittleren Schaffensperiode finden sich mehrere nolanische Amphoren, die mit dem Grazer Gefäß eng verwandt sind, besonders die Rückseitenfiguren ähneln einander stark. Das gilt speziell für die laufende Frau mit Fackel auf einer Amphora in Brüssel, Musées Royaux d'Art et d'Histoire A 3094 (ARV² 842, I22; Add ${ }^{2}$ 296; G. Schwarz, Eine neue Amphora des Sabouroff-Malers, AA I972, 43 Abb. 3; Kavvadias a. O. I90 Nr. I22 Taf. 88), die im locker-flüchtigen Pinselstrich ein typisches Geschöpf des SabouroffMalers ist, an denen sich seine Werke leicht identifizieren lassen. Sie zeigt dieselbe Frisur, dieselbe Kleidung mit derselben Faltengebung wie das Grazer Mädchen, wobei vor allem die Andeutung des linken Beines unter dem Gewand sowie der mit einem dicken Pinselstrich akzentuierte Gewandbausch über dem linken Arm charakteristisch sind. Den Chiton beider Gestalten, der unter dem Mantel sichtbar ist, schmückt eine Punktreihe. Sorgfältiger sind die Gestalten auf der Vorderseite gearbeitet. Ihr ruhiges Nebeneinander, die sanfte Neigung ihrer Köpfe und ihre gemessenen Gebärden rufen andere Spendeszenen der Klassik wach, wie z. B. den Kriegerabschied auf dem Stamnos des Kleophon-Malers in München, Staatl. Antikensammlungen 24 I 5: ARV ${ }^{2}$ I I43, 2; I 684; Para 455; $\operatorname{Add}^{2} 334$; E. Simon, Die griechischen Vasen ${ }^{2}$ (München I98I) Taf. 205-207. Der Körper der Frau ist in Frontalansicht gedreht, ihr Kopf mit dem roten Band im Haar erscheint im Profil. Ihre rechte Brust ist unter dem dünnen, faltenreichen Chiton sichtbar, die linke ist vom Mantel bedeckt, in dessen Saum die Frau mit ihrer linken Hand greift. Die gesenkte Rechte hält eine Oinochoe. Der Mantel der Frau hängt in einem dichten Faltengeschiebe von der linken Schulter und dem Unterarm, am Vorderteil sind die Falten sparsamer. Ihr Chiton trägt am unteren Rand ein Punktmuster. Der Mann ist ganz im Profil gezeigt. Er ist bärtig und hat sich einen Kranz ins Haar gedrückt, das in Lockensträhnen auf die Schulter fällt. Sein Mantel lässt die rechte Schulter frei und ist in einem Bausch um den linken Unterarm gewickelt. Mit der Rechten streckt er der Frau eine Phiale entgegen. Der Stock, der neben ihm lehnt, weist ihn als Wanderer aus. Auch dieses Bild hat eine enge Parallele im Oeuvre des Sabouroff-Malers, nämlich die nolanische Amphora in Kopenhagen, Nationalmuseum 4: $\mathrm{ARV}^{2}$ 842, I20; $\mathrm{Add}^{2}$ 296; Schwarz a. O. 45 Abb. 5; Kavvadias a. O. I90 Nr. I 20 Abb. 87). Sie zeigt gleichfalls eine Abschiedslibation, in der besonders der ausziehende Wanderer dem Grazer Pendant verblüffend ähnlich ist. Auch die Rückseitenfigur, obwohl hier ein Jüngling, entspricht dem Grazer Mädchen in der Wiedergabe des Mantels bis ins Detail. Sowohl auf der Amphora in Kopenhagen als auch auf der zuvor erwähnten in Brüssel finden sich auf A und B dieselben Mäanderbänder wie auf dem Grazer Exemplar (Kavvadias a. O. 58 f. $\Gamma$ I9 und $\Gamma$ 27).

Zum Dekor: Das Schmuckband auf A, das aus drei abwechselnd nach rechts und nach links laufenden Mäandergliedern besteht, unterbrochen von einem Viereck mit Andreaskreuz in der Mitte, kommt bei fast allen nolanischen Amphoren der mittleren Schaffensperiode des Sabouroff-Malers zur Anwendung. Die Kreuzplatte steht dabei abwechselnd über oder hängt unter der Begrenzungslinie. Dieses Schmuckelement wurde in der Werkstatt des Berliner Malers entwickelt, wo es auf vielen großformatigen Gefäßen aufscheint, und vom Achilleus-Maler übernommen, der es wieder an Werkstattgenossen weitergab (Kavvadias a. O. 63). Das Schmuckband auf B, der einfache fortlaufende rechtsläufige Mäander, ist das häufigste Schmuckelement der mittleren Schaffensperiode des Sabouroff-Malers und eines der häufigsten in der attischen Vasenmalerei überhaupt (Kavvadias a. O. 64).
TAFEL 43

1-5. Siehe Tafel 42, 1-2.

TAFEL 44

1-2. Tafel 45, 1-2. Tafel 46, 1-6. Tafel 82, 1. Hydria

Beilage 13, 1.

G 30. Aus Capua. Erworben I 874 durch Wolfgang Helbig in Rom, Ankauf. Ehemals Slg. Simmaco Doria (Santa Maria Capua Vetere). Alte Inv.-Nr. II 30 (Schenkl) bzw. III 37 (Pichler).

H 28,7 cm. - Dm Mündung I I,2 cm. - Dm Fuß 9, O cm. - H Vertikalhenkel 8,2 cm. - Dm Henkel I,7/I,3 cm. - Volumen 3873 ml.

$\mathrm{ARV}^{2}$ I634, I 83 bis. - Add $^{2}$ I96. - A. Peschlow-Bindokat, Demeter und Persephone in der attischen Kunst des 6. bis 4. Jhs. v. Chr., JdI 87, I972, I 46 V 62. - G. Schwarz, Eine Hydria des Berliner Malers in Graz, ÖJh 50, I972-I975, I 25-I33 Abb. I-4. 6-7. - MuM, Kunstwerke der Antike, Auktion 5 I, I975, 68. M. Robertson, The Berlin Painter at the Getty Museum and Some Others, in: Greek Vases in the J. Paul Getty Museum I (Malibu 1983) 66 f. - G. Schwarz, Triptolemos. Ikonographie einer Agrar- und Mysteriengottheit, Grazer Beiträge Suppl. II (Graz I987) 36. 86. 90. $92 \mathrm{~V} 44$ Abb. 5. - T. Hayashi, Bedeutung und Wandel des Triptolemosbildes vom 6.-4. Jh., Beiträge zur Archäologie 20 (Würzburg I992) I36 f. Nr. 40. - Lehner - Lorenz - Schwarz, Vasen, 44-47 Nr. 24 Abb. 34-35 (G. Schwarz). - BAPD 275094.

Zustand: Die Hydria wurde durch die Restauratoren R. Fürhakker und G. Klatz im Jahre 20I I einer eingehenden Prüfung und Restaurierung unterzogen. Dabei ergab sich folgender Zustand: Der rechte Henkel war in drei Fragmenten abgebrochen, die bei einer Restaurierung im I9. Jh. zusammengesetzt und in Gips wieder angesetzt wurden, dabei wurde der mittlere Teil um $2 \mathrm{~mm}$ verdickt. Aufgrund der passgenauen Bruchkanten handelt es sich jedoch um den originalen Henkel. Ansonsten vollständig erhalten. Bei dieser ersten Restaurierung wurde der gesamte, außerhalb des Bildes liegende Bereich übermalt bzw. überfasst, so dass auch die durch Fehlbrand rot gefärbten Zonen am Fuß und dem darüberliegenden Bereich teilweise schwarz wirken. Gänzlich schwarz erscheint nur der Fuß, an anderen Stellen wurde die Rotfärbung des Fehlbrandes in abgeschwächter Form übernommen. An der bildlichen Darstellung wurden bis auf das Haar der sitzenden Figur keine Übermalungen vorgenommen. Die Originaloberfläche bzw. Glanztonschicht ist durch Salzsprengungen so sehr in Mitleidenschaft gezogen, dass eine Abnahme der modernen Überfassung nur mit großen Verlusten an Originaloberfläche, die in weiten Bereichen nur noch durch die Übermalung an Ort und Stelle gehalten wird, verbunden gewesen wäre. Keine Beschädigung findet sich an der figuralen Darstellung.

Technik: Oberfläche hellorange, glänzend schwarz bemalt. Stellenweise Fehlbrand. Ausgesparte Kopfkontur: Triptolemos, Kore. Relieflinien: Falten der Mäntel und der Chitonunterteile, Fackel, Wagengestell, oberer Teil des Rades. Verdünnter Glanzton: Löckchen und Halsmuskel des Triptolemos, Falten der Chitonoberteile, Halsschmuck der Kore. Vorzeichnungen: Im Gesicht und an den Armen der Kore. Ritzungen: Das Wagenrad ist in doppelter Kontur eingeritzt.

Form: Kalpis-Hydria. Profilierter Ringfuß, bauchiger Gefäßkörper, zur Fußzone hin konisch eingezogen. Deutlich ausgeformte Schulter, starke Halseinziehung. Hoher Hals, leicht nach außen 
gezogene Mündung. Randzone innen stark gekehlt, fast horizontal ausbiegende Lippe. Zwei gegenständige, unterhalb der Schulter angesetzte, nach oben gebogene Horizontalhenkel mit rundem Querschnitt. Ein unterrandständiger Vertikalhenkel mit rundem Querschnitt.

Dekor: Unter den Figuren ein Kreuzplattenschlüsselmäander, „ULFA“.

Darstellung: Triptolemos empfängt von Kore die Abschiedslibation. - Triptolemos thront nach rechts hin auf dem Flügelwagen. Er hält ein Szepter in der Linken, mit der Rechten streckt er eine Spendeschale vor. Er ist mit einem langen Ärmelchiton und einem über die linke Schulter gelegten Mantel bekleidet. Das Haar bildet Löckchen über Stirn und Schläfen und fällt ihm lang auf den Rücken. Ihm gegenüber steht - an ihrer jugendlichen Schopffrisur kenntlich - Kore, die Tochter der Demeter, um ihm die Abschiedsspende aus einer Oinochoe einzugießen. Sie ist in derselben Tracht gekleidet wie der Jüngling, trägt Halsschmuck sowie ein Diadem im Haar und hält eine lange Fackel in der Linken.

\section{Um 470 - Berliner Maler (Beazley)}

Zur Form: E. Diehl, Die Hydria. Formgeschichte und Verwendung im Kult des Altertums (Mainz I964) 6I. Während der Berliner Maler in seiner frühen Periode die Figuren nur auf die Schulter der Kalpis setzt, zieht er sie ab der Mitte seiner Schaffenszeit von der Schulter über den Gefäßbauch hinab, was stark gelängte Gestalten ergibt: vgl. z. B. MuM, Kunstwerke der Antike, Auktion 5 I, I 975 , 68 Nr. 55; M. Robertson, The Berlin Painter at the Getty Museum and Some Others, in: Greek Vases in the J. Paul Getty Museum I (Malibu I983) 65-67 Abb. I7; Die Komposition besteht meist wie auf der Grazer Kalpis - aus einer Zweiergruppe, der ein Mäanderband als Standfläche dient.

Zum Dekor: Die Abkürzung ULFA wurde von Beazley für ein symmetrisches Mäanderband kreiert, das eng mit dem Werk des Berliner Malers und seiner Nachfolger verbunden ist. Sie steht für „upper, lower, facing alternatively“, vgl. J. D. Beazley, The Berlin Painter (Melbourne I964) 7; Robertson a. O. 66.

Zur Darstellung: Die Aussendung des eleusinischen Heros Triptolemos mit dem Ährengeschenk der Demeter an die Menschen stellte einen der Höhepunkte der Mysterien von Eleusis dar. Besonders die Vasenmaler des beginnenden 5. Jhs. wurden nicht müde, von der Aussendung des jugendlichen Königssohnes, der mit Demeter und Kore eine Trias bildete, zu erzählen. Sie wurde auch zu einem Lieblingsthema des Berliner Malers, das auf I I weiteren von seiner Hand bemalten Gefäßen begegnet, vgl. G. Schwarz, Triptolemos. Ikonographie einer Agrar- und Mysteriengottheit, Grazer Beiträge Suppl. II (Graz I987) 86-98 V 36-47 Abb. 3-6; T. Hayashi, Bedeutung und Wandel des Triptolemosbildes vom 6.-4. Jh. Beiträge zur Archäologie 20 (Würzburg I992) I33-I37. Zumeist thront Triptolemos bereits auf seinem Flügelwagen, der ihn über die Welt bringen soll, oder er ist im Begriff, ihn zu besteigen. Die beiden eleusinischen Göttinnen Demeter und Kore oder eine der beiden geben ihm den Abschied, wobei ihm häufig ein Ährenbündel überreicht oder wie hier die Abschiedslibation eingegossen wird. Diese Libation wurde auch nicht nur als die übliche Abschiedsspende, wie sie vor einem Aufbruch mit der Bitte um glückliche Heimkehr libiert wird, sondern als Versinnbildlichung des heiligen Waffenstillstandes gedeutet, der alljährlich vor der Mysterienfeier ausgerufen worden ist, vgl. Hayashi a. O. 84. 86. Das Ährengeschenk der Demeter, das Triptolemos den Menschen bringt und sie den Ackerbau lehrt, spielte nicht nur im eleusinischen Kult eine zentrale Rolle. Der Eleusinier wird damit zum Kulturheros und zum Bringer der Zivilisation schlechthin, eine Rolle, die Athen, das sich Eleusis längst einverleibt hatte, nur allzu gern für sich reklamierte. Doch Triptolemos ist nicht nur der eleusinische Ährenspender, der mit dem Geschenk der Demeter über die Welt fährt, vielmehr veranlasst er als echter Kulturbringer auch Stadtgründungen (vgl. Schwarz a. O. 5). Daher konnte er sowohl für hellenistische Herrscher als auch für römische Kaiser als Identifikationsfigur dienen. Vgl. dazu E. La Rocca, L'età d'oro di Cleopatra. Indagine sulla Tazza Farnese, Documenti e ricerche d'arte alessandrina 5 (Rom I984), und H. P. Laubscher, Triptolemos und die Ptolemäer, JbMusKGHamb 6/7, I988, I I-40, sowie A. Alföldi, Redeunt Saturnia Regna 7: Frugifer Triptolemos im ptolemäisch-römischen Herrscherkult, Chiron 9, I979, 553-606. Zur Ausfahrt des Triptolemos: C. Dugas, La mission de Triptolème d'après l'imagerie athénienne, MEFRA 62, I950, 9-3I = Recueil Ch. Dugas, Publications de la Bibliothèque S. Reinach I (Paris I960) I23-I39; E. Simon, Opfernde Götter (Berlin I953) 68 f.; A. Peschlow-Bindokat, Demeter und Persephone in der attischen Kunst des 6. bis 4. Jhs. v. Chr., JdI 87, I972, 60-I 57; H. Metzger, L'imagerie éleusinienne des VIième et Vième siècle, in: Recherches sur l'imagerie athénienne (Paris I965) 7-32; J. Thimme, JbBadWürt 6, I969, 7-I6; G. Schwarz, Zwei eleusinische Szenen des Berliner Malers auf einem Kelchkrater in Athen, AA I97I, I 79-I 82; J. K. Raubitschek - A. E. Raubitschek, The Mission of Triptolemos, in: Studies in Athenian Architecture, Sculpture and Topography Presented to H. A. Thompson, Hesperia Suppl. 20 (Princeton, NJ I982) I09-II7; G. Schwarz, Triptolemos am Nil, in: E. Böhr - W. Martini (Hrsg.), Studien zur Mythologie und Vasenmalerei. Konrad Schauenburg zum 65. Geburtstag (Mainz I986) I75-I79; M. Robertson, Two Pelikai by the Pan Painter, in: Greek Vases in the J. Paul Getty Museum 3 (Malibu I986) 73-89; G. Schwarz, Triptolemos. Ikonographie einer Agrar- und Mysteriengottheit, Grazer Beiträge Suppl. II (Graz I987) 73-I44; M. Prange, Der Niobidenmaler und seine Werkstatt (Frankfurt am Main 1989) 78; H. A. Shapiro, Art and Cult under the Tyrants in Athens (Mainz I989) 76 f.; E. Simon, Triptolemos in Syrien, Orientalia 59, I990, 265-270; K. Clinton, Myth and Cult: The Iconography of the Eleusinian Mysteries (Stockholm I992); ders., The Eleusinian Mysteries and Pan-Hellenism in Democratic Athens, in: W. Coulson et al. (Hrsg.), The Archaeology of Athens and Attica under the Democracy, Oxbow Monographs 37 (London I994) I6I-I72; S. Matheson, The Mission of Triptolemos and the Politics of Athens, GrRomByzSt 35, I 994, 345-372; H. A. Shapiro, Art and Cult under the Tyrants in Athens, Suppl. (Mainz I995) I 8 f.; LIMC VIII (Zürich I997) 57-65 s. v. Triptolemos (G. Schwarz); H. Pierre, Le voyage de Triptolème en Etrurie et en Grande Grèce, Pallas 77, 2008, III-I32. Zu den eleusinischen Mysterien: L. Deubner, Attische Feste (Berlin I932) 69-9I; G. E. Mylonas, Eleusis and the Eleusinian Mysteries (Princeton, NJ I96I); K. Kerényi, Die Mysterien von Eleusis (Zürich I962); M. P. Nilsson, Die Geschichte der griechischen Religion I 3 (München I967) 469-477; F. Graf, Eleusis und die orphische Dichtung Athens in vorhellenistischer Zeit (Berlin I974); K. Clinton, The Sacred Officials of the Eleusinian Mysteries, TransactAmPhilosSoc 64.3, I974; U. Bianchi, The Greek Mysteries. Iconography of Religions XVII, 3 (Leiden I976) 8-I I Abb. I-52; K. Clinton, IG ${ }^{2}$ 5, The Eleusinia and the Eleusinians, AJPh I00, I979, I-I2; K. Clinton, A Law in the City Eleusinion Concerning the Mysteries, Hesperia 49, I980, 258-288; E. Simon, Festivals of Attica. An Archaeological Commentary (Madison, Wisc. I983) 24-35; G. Sfameni Gasparro, Misteri e culti mistici di Demetra, Storia delle Religioni 3 (Rom I986); H. W. Parke, Athenische Feste (Mainz I987) 79-I09.

Zum Maler: $\mathrm{ARV}^{2}$ I96-219. I633-I636. I700-I70I; Para 34I-345. 5 I0. 520; Add² I06. I90-I97; J. D. Beazley, Der Berliner Maler (Berlin I930); ders., The Berlin Painter (Nachdr. Mainz I974); ders., The Berlin Painter (Melbourne I964); Boardman, ARFV I, 9I-I I I; Boardman, RFVA I, Io0-I 23; C. Isler-Kerényi, Ein Spätwerk des Berliner Malers, AntK I4, I97I, 25-3 I; R. Lullies, Der Dinos des Berliner Malers, AntK I4, I97I, 44-55; E. 
Simon, Die griechischen Vasen ${ }^{2}$ (München I98I) Io8-ı I I Taf. I36-I44 Farbtaf. 35; D. C. Kurtz, The Berlin Painter (Oxford I983); Robertson a. O. 55-72; G. Schwarz, Triptolemos. Ikonographie einer Agrar- und Mysteriengottheit, Grazer Beiträge Suppl. II (Graz I987) 86-98.

\section{TAFEL 45}

1-2. Siehe Tafel 44, 1-2.

\section{TAFEL 46}

1-6. Siehe Tafel 44, 1-2.

\section{TAFEL 47}

\section{1-2. Oinochoe}

Beilage 13, 2.

G 200. Fundort unbekannt. Erworben vor 1937. Später irrtümlich unter der Nr. G 237 ein zweites Mal inventarisiert.

H erh. 8,6 cm. - Dm Körper 8,3 cm. - Dm Bauch 5,8 cm. - B Henkel I, 5 cm. - Dm Henkel o,7 cm. - Gewicht 79,6 g.

G. van Hoorn, Choes and Anthestheria (Leiden I95I) I3 I Nr. 547 ter Abb. 388 j. - J. Leichtfried, Der Hase in der antiken Kunst, ungedruckte Diss. Graz (I979) 43 Abb. 32. - BAPD I 6256.

Zustand: Ein Fragment. Gefäßkontur vom Boden bis zum Anfang der Halseinziehung erhalten. Rechter Teil von Gefäß und Bildfeld fehlt. Einige kleine Absplitterungen.

Technik: Glänzend schwarzer Glanzton, an der Innenseite sehr dünn aufgetragen, sodass die hellorangefarbene Oberfläche durchscheint. Aufgesetztes Weiß: Zwei Striche über dem Hasen.

Form: Ausgestellter, niedriger Ringfuß mit flachem Boden.

Dekor: Den unteren Abschluss des Bildfeldes bildet ein Eierstab, der zwischen zwei horizontale Schlickerlinien gesetzt ist. Über dem unteren Streifen, in den Zwickeln der Eierschalen, Einzelpunkte. Das Bildfeld ist links mit einem schmalen Strich gerahmt.

Darstellung: Hase. - Das Häschen sitzt nach rechts auf seinen Hinterläufen und streckt seine Vorderläufe hoch. Von der Bruchstelle oberhalb des Hasen führen zwei rote Streifen zu ihm herab. Einer davon könnte zu einer Leine gehören, an der das Tier geführt wird, es kann sich aber auch um Elemente von Spielzeug handeln.

Um 420

Zur Form: Richter - Milne, Shapes, I9 f. Typ III (Chous). Choenkannen weisen häufig einen ausgestellten Fuß auf, flache oder nahezu flache Böden sind jedoch selten, vgl. J. R. Green, Choes of the Later Fifth Century, BSA 66, I97I, 204. 215; CVA Wien, Kunsthistorisches Museum 5, 34 zu Taf. 88, 4.

Zur Darstellung: Die kleinen Choenkännchen, die als Geschenke an die dreijährigen Kinder zum Choentag gedeutet werden, zeigen sowohl Szenen, die sich auf das Fest beziehen, als auch solche aus dem Alltag der Kleinen. Für die große Gruppe der Kännchen, die am Boden kriechende Kinder beim Spiel zeigen, wurde vermutet, dass sie nicht beim Choenfest, sondern im Totenkult Verwendung fanden, da es sich bei den Dargestellten nicht um Dreijährige handeln könne. Denkbar wäre auch, dass nicht erst Dreijährige, sondern bereits Kriechkinder am Choenfest mit Weinkännchen bedacht worden sind, oder dass es sich um Geschenke ohne Bezug zu den Anthesterien handelt, vgl. Green a. O. I89-228; J. Bažant, Iconography of Choes Reconsidered, LF 98, I975, 72-78; E. M. Stern, Kinderkännchen zum Choenfest, Castrum Peregrini I32/I33 (Amsterdam I978) 28-33; H. Rühfel, Kinderleben im klassischen Athen (Mainz I984) I64 f.; H. W. Parke, Athenische Feste (Mainz I987) I63 f.; R. Hamilton, Choes and Anthesteria. Athenian Iconography and Ritual (Ann Arbor I992) 63-67. I 2 I. $\mathrm{Da}$ der Hase als Spieltier bei den Kindern beliebt war, erscheint er auch öfter auf den Choenkännchen, vgl. Rühfel a. O. I39 Abb. 77; München, Staatl. Antikensammlungen, Slg. v. Schoen 69: Rühfel a. O. I44 Abb. 8I; Parke a. O. I65 Abb. 47. Abgesehen von den vielfältigen Funktionen, die der Hase als Liebesgeschenk des Erastes an seinen Eromenos oder als Fruchtbarkeitssymbol im Zusammenhang mit Dionysos und Aphrodite ausübt, diente er auch häufig als Geschenk für die Toten, vgl. CVA Wien, Kunsthistorisches Museum 5, I 66 zu Taf. 72, sodass sein Auftauchen auch im Falle einer sepulkralen Verwendung der Choenkännchen sinnvoll wäre. In unserem Zusammenhang wird man eher an ein Spieltier für Kinder denken, das sie auch auf anderen Darstellungen begleitet und zu dem sie eine enge Beziehung aufbauen konnten, vgl. etwa das Schaleninnenbild des Douris, auf dem ein Knabe sein Häschen, das er aus dem Käfig genommen hat, auf dem Schoß hält und zärtlich mit ihm Zwiesprache zu pflegen scheint, Slg. Hirschmann 33 I: H. Bloesch, Griechische Vasen in der Sammlung Hirschmann (Zürich I982) 68 Nr. 33 Abb. S. 69; Buitron-Oliver, Douris, 24. 78 Nr. 89 Taf. 59. Auch auf der Grazer Oinochoe ist mit einem kindlichen Gegenüber zu rechnen. Zur Darstellung von Hasen als Spieltiere vgl. M. Bouvier, Le lièvre dans l'antiquité (Lyon 2000) I32-138.

\section{3-8. Pyxis mit Deckel}

Beilage 13, 3.

G 40. Aus Attika. Erworben I 875 durch Wolfgang Helbig in Athen, Ankauf. Ehemals Slg. Athanasios Rhousopoulos (Athen). Alte Inv.-Nr. II 53 (Schenkl) bzw. III 53 (Pichler).

Pyxis: H 4,I cm. - Dm Mündung 6,0 cm. - Dm Bauch 6,4 cm. - Dm max. 6,6 cm. - Deckel: H I,o cm. - Dm max. 7,0 cm. - Dm Mündung 6,4 cm. - Gewicht (Pyxis) 70 g. - Volumen (Pyxis) $76 \mathrm{ml}$.

Lehner - Lorenz - Schwarz, Vasen, 56 f. Nr. 3 I Abb. 48 (G. Schwarz). - BAPD 44IOI.

Zustand: Gefäßkörper vollständig erhalten, einige kleinere Absplitterungen. Deckel entlang der Vertikalkante gebrochen, aus 4 Fragmenten zusammengesetzt. Zwei größere Fehlstellen am Deckelrand mit Gips ergänzt, außen mattschwarz übermalt. Bemalung großflächig bestoßen und abgesplittert.

Graffiti: Buchstabe Pi (П) sowohl auf der Standfläche als auch auf der Innenseite des Deckels eingeritzt.

Technik: Bemalung innen und außen glänzend schwarz, auch auf der Innen- und Außenseite des Deckels mit Glanzton überzogen, durch den Brand vor allem außen großflächig orangefarben bis orangebraun verfärbt. Verdünnter Glanzton: Löckchen über Stirn und Schläfen der Frau. Ausgesparte Kopfkontur.

Form: Pyxis vom Typus D mit leicht aufgewölbtem Standboden. Bodenzone durch einen breiten Außenwulst betont. Zylindrischer Körper, verkröpfte Lippe. Flacher Deckel mit randnah umlaufendem Grat an der Oberseite. Lippe an der Unterseite stark ausgezipfelt.

Dekor: Um die Darstellung auf der Deckeloberseite läuft ein konzentrisches, tongrundiges Band um. Mit Glanzton überzogen ist das gesamte Gefäß mit Ausnahme der Standfläche, der Oberkante des Gefäßrandes, der Innenseite des Deckelrandes sowie des umlaufenden Grates an der Deckeloberseite. 
Darstellung: Frauenkopf. - Die Frauenbüste, die knapp unter dem Hals endet, erhebt sich direkt aus einem schmalen Bodenstreifen und blickt vom Betrachter nach rechts. Die Frau hat ihr Haar im Nacken zu einem Schopf aufgenommen und um den Kopf ein breites, ursprünglich gemustertes Band geschlungen, das aus Kreisen und Dreiecken bestanden zu haben scheint. Unter dem Kekryphalos quillt das Haar hervor, das sich in Löckchen an den Schläfen, im Nacken und am Haarschopf kräuselt. Im Ohr trägt die Frau eine Schmuckscheibe, in deren Mitte ein Stein sitzt. Ihr Profil weist eine gerade Stirn- und Nasenlinie mit einem winzigen Buckel am Nasenansatz und einer leicht gebogenen Nasenspitze auf. Auffallend ist die kleine Querfalte in der Stirn. Die leicht geschürzten Lippen sind geschlossen, das Kinn ist sehr voll. Am Hals tritt der Kehlkopf deutlich hervor.

Um 4 IO

Zur Form: Zur Pyxis allgemein: S. Rutherford-Roberts, The Attic Pyxis (Chicago I978) vgl. bes. I36 Taf. 82, 2 zu einer der Grazer ähnlichen Pyxis des Typus D; Richter - Milne, Shapes, 20 f., Abb. I43-I45; Agora XII, I77 f. Nr. I306-I3I7 Taf. 43 Abb. II, darunter bes. Nr. I3 I3; CVA Oxford, Ashmolean Museum I, III I Taf. 4, 6; 47, I2 (334); J. H. Oakley, Attic Red-figured Type D Pyxides, in: A. Tsingarida (Hrsg.), Shapes and Uses of Greek Vases (7th-4th centuries B.C), Proceedings of the Symposium held at the Université libre de Bruxelles 27-29 April 2006 (Brüssel 2009) 59-76; CVA Copenhague, Musée National 4, III I Taf. I62, 2-3; CVA München 2 Taf. 99, 2; 100, 3 (2726 a); CVA Wien, Kunsthistorisches Museum I, III I Taf. 48, 2. 5 (IV I97I); CVA Berlin 3 Taf. I 50, 6-7 (45 I 7); CVA Tübingen 4 Taf. 44, 4-8; CVA Berlin, Antikensammlung Pergamonmuseum (DDR 3 ) Taf. 46, I. Viele Pyxiden des Typus D zeigen im Medaillon nur einen Kopf oder eine Büste, vgl. Chr. J. Karouzos, An Early Classical Disk Relief from Melos, JHS 7 I, I95 I, I00 Anm. I 3 sowie die Addenda in: CVA Tübingen 4 zu Taf. 44 und CVA Berlin, Antikensammlung Pergamonmuseum (DDR 3) zu Taf. 46; Agora XXX, Nr. I055 Taf. ıо ; E. Simon (Hrsg.), Die Sammlung Kiseleff im Martin-von-Wagner-Museum der Universität Würzburg II (Mainz I989) I05 Nr. I74 Taf. 75 mit weiteren Beispielen.

$\mathrm{Zu}$ den Graffiti: Agora XII, I78 Anm. 38; Kerameikos VII 2, I39 Nr. 54 I Taf. 93, 3. 7 und A. W. Johnston, Trademarks on Greek Vases (Warminster I979) 38. I80 f. zu Pyxiden der Form D mit übereinstimmenden Einzelbuchstaben auf Deckel und Dose. Die eingeritzten Buchstaben auf Gefäß und Deckel bezeichnen die Zusammengehörigkeit der beiden Teile, die so nach dem Brennen im Töpferofen leicht wieder zusammengesetzt werden konnten. Graffiti sind daher auf Pyxiden besonders häufig zu finden.

Zur Verwendung: S. Schmidt, Rhetorische Bilder auf attischen Vasen. Visuelle Kommunikation im 5. Jh. v. Chr. (Berlin 2005) 86-I 5 I bes. 93-IOI (Pyxiden als typische Gefäße für Frauen).

Zur Darstellung: Eine Frauenbüste auf einer Bauchlekythos in Würzburg, die wie unsere aus einem Bodenstreifen aufsteigt, lässt Simon a. O. 99 Nr. I67 Taf. 74 an die Anodos einer Göttin denken, die als Aphrodite, Persephone oder eine Nymphe gedeutet werden kann. Götterköpfe und -büsten stellen einen beliebten Medaillonschmuck klassischer und spätklassischer Pyxiden der Form D dar, vgl. z. B. CVA Wien, Kunsthistorisches Museum I, III I Taf. 48, 3 . 6 (IV 37 I 8): gelockter, behelmter Jünglingskopf (Ares? Er wäre als Geliebter der Aphrodite ein passendes Motiv) oder auch den vermenschlichten Panskopf auf der Pyxis der Sammlung Kiseleff K I 84I: Simon a. O. Taf. 75. Der Apollo mit Schmollmund auf der Pyxis im Ashmolean Museum 334: CVA Oxford, Ashmolean Museum I, III I Taf. 4, 6 könnte ein jüngerer „Bruder“ unserer schönen Dame sein; vgl. auch Oakley a. O. 62 f.

Zum Maler: Verwandte Frauenköpfe findet man im Umkreis des Meidias-Malers, aber auch von seiner Hand selbst gezeichnet, häufig, vgl. L. Burn, The Meidias Painter (Oxford I987) I I I MM
73 Abb. 48; Ioo M 33 Abb. 46; 97 M 2 Abb. 28 sowie passim; zum Meidias-Maler vgl. weiters Boardman, RFVA II, I38. I 52 f.; I74. 230.235 .

\section{TAFEL 48}

\section{1-4. Tafel 50, 1. Tafel 81, 2. Schulterlekythos}

Beilage 14, 1.

G 36. Aus Tanagra. Erworben I 875 durch Wolfgang Helbig in Athen, Ankauf. Ehemals Slg. Athanasios Rhousopoulos (Athen). Alte Inv.-Nr. II 49 (Schenkl) bzw. III 49 (Pichler).

H I9,2 cm. - Dm Mündung 4,3 cm. - Dm Schulter 7,3 cm. Dm Fuß 4,8 cm. - B Henkel I, 4 cm. - D Henkel 6,7 cm. - Gewicht [255 g]. - Volumen $297 \mathrm{ml}$.

Lehner - Lorenz - Schwarz, Vasen, 52 f. Nr. 28 Abb. 42 (G. Schwarz). - BAPD 44I06.

Zustand: Aus 3 Fragmenten zusammengesetzt, ansonsten vollständig erhalten. Mündung leicht bestoßen, einige kleinere Absplitterungen am Körper.

Form: Schulterlekythos, Nebenform (BL). Scheibenfuß, an der Unterseite flach hochgezogen, Außenseite des Fußes leicht konkav eingezogen. Zylindrischer, nach unten konisch einschwingender Körper, scharfe Schulterkante, stark eingezogener kurzer Hals. Vorspringender Mündungskelch mit schräger, konvexer Wandung und gerade abgestrichener Lippe. Auf der Schulter angesetzter Bandhenkel mit längsovalem Querschnitt.

Technik: Oberfläche hellorange, die glänzend schwarze Bemalung stellenweise so dünn aufgetragen, dass die Oberfläche durchscheint. Verdünnter Glanzton: Wollfaden, Wollknäuel, Aufhängung für das Alabastron. Relieflinien: Gewandfalten, Haarband, Teile des Stuhls.

Dekor: Das Bildfeld wird unten und oben von je einem Band mit rechtsläufigem Schlüsselmäander begrenzt. 5 Palmetten in schwarzem Glanzton auf der Schulter. Aus einer hängenden Mittelpalmette entwickelt sich nach rechts und links je eine schräg liegende Palmette. Neben dem Mittelblatt dieser Palmette entspringt beidseitig der Stängel der abschließenden, stehenden Randpalmette. Um den Hals ein Zungenfries.

Darstellung: Frauengemachszene. - Auf einem Stuhl mit geschwungener Lehne sitzt eine Frau in fein plissiertem Chiton und Mantel nach rechts hin, das Haar mit einem Band zu einem Krobylos aufgebunden. Die Sitzfläche ihres Stuhles ist seitlich mit Punkten verziert, die Rückenlehne endet oben in einer Nackenstütze. Rechts vor der Frau hängt ein Alabastron von einem Pflock an der Wand herab, am Boden vor ihr steht ein Wollkorb (Kalathos). Die Frau wickelt wohl einen Wollfaden aus dem Korb auf.

\section{Um 470/460 - Bowdoin-Maler (Schwarz)}

Zur Form: Die Form der Lekythos und ihr Dekor sind charakteristisch für den Bowdoin-Maler, die nach ihm BL (Bowdoin-Lekythos) genannt wird, vgl. ARV ${ }^{2}$ 675. 678. Sie ist von der Standardform oft kaum zu unterscheiden, vgl. Kurtz, AWL, I 6 f.; CVA Berlin I2, I3.

Zur Darstellung: Zum Thema vgl. E. Götte, Frauengemachdarstellungen in der Vasenmalerei des 5. Jhs. v. Chr. (München I96I). Zum Alabastron, das im Frauengemach über dem Sitz der Hausfrau aufgehängt ist, vgl. H. Gericke, Gefäßdarstellungen auf griechischen Vasen (Berlin I970) 73. Vgl. P. Badinou, La laine et le parfum: épinetra et alabastres. Forme, iconographie et fonction, Recherche de céramique attique féminine, Monographs on Antiquity 2 (Leuven 2003) 65-67. 
Zum Maler: Allgemein vgl. ARV² 677-695. I665 f. I706; Para 405-407; Add $^{2} 279$ f. Nach ABL, I 57-I 60 ist der Bowdoin-Maler sehr wahrscheinlich identisch mit dem Athena-Maler, der zu Beginn des 5. Jhs. als Maler schwarzfiguriger Lekythen reüssierte. Beazley (ARV2 677) ist geneigt, dem Vorschlag zuzustimmen. Vgl. auch Boardman, RFVA II, 39 f. I34; Kurtz, AWL, I6. 79 f.; Der Grazer Lekythos vergleichbar etwa die Lekythos in Genf, Musée d'art et d'histoire I8043: ARV² 682, I04 bis; Para 406; CVA Genève, Musée d'Art et d'Histoire I Taf. 22, I-2; I. Rácz, Antikes Erbe. Meisterwerke aus Schweizer Sammlungen mit einer Einleitung von K. Kerényi (Zürich I965) Taf. 57; vgl. auch die weißgrundige Lekythos desselben Themas in Houston, Museum of Fine Arts, Annette Finnigan Collection: H. Hoffmann, Ten Centuries that Shaped the West. Greek and Roman Art in Texas Collections (Mainz I97I) 409 f. Nr. I 84. Zum Stil des Malers vgl. S. Matheson Burke - J. J. Pollitt, Greek Vases at Yale (New Haven I975) 56 f. Nr. 49 sowie CVA Wien, Kunsthistorisches Museum 5, 25 f. zu Taf. 9, I-4. Der Maler stellte mit Vorliebe Bilder aus dem Leben der Frauen dar, wobei die fleißige Hausfrau am Wollkorb eines seiner Lieblingsthemen gewesen zu sein scheint. Er war vorwiegend als Lekythen-Maler tätig, die er im rotfigurigen, aber auch im weißgrundigen Stil bemalte. Sein äußerst umfangreiches Oeuvre von fast 300 auf uns gekommenen, meist kleinen Gefäßen lässt darauf schließen, dass der Maler sein eigenes Atelier betrieb.

\section{5-7. Tafel 50, 2. Schulterlekythos}

Beilage 14, 2.

G 37. Aus Tanagra. Erworben I 875 durch Wolfgang Helbig in Athen, Ankauf. Ehemals Slg. Athanasios Rhousopulos (Athen). Alte Inv.-Nr. II 50 (Schenkl) bzw. III 50 (Pichler).

H I7,7 cm. - Dm Mündung 3,7 cm. - Dm Schulter 5,8 cm. Dm Fuß 3,7 cm. - B Henkel I, 4 cm. - D Henkel o, 6 cm. - Gewicht 220 g. - Volumen I $44 \mathrm{ml}$.

Lehner - Lorenz - Schwarz, Vasen, 54 f. Nr. 29 Abb. 43 (G. Schwarz). - BAPD 44107.

Zustand: Vollständig erhalten. Stellenweise größere Absplitterungen, die wieder angesetzt wurden. Oberfläche zonal abgerieben.

Technik: Bemalung glänzend schwarz, durch den dünnen Auftrag scheint stellenweise die Oberfläche durch. Mit Glanzton überzogen sind die Oberseite des Fußes, der Gefäßbauch, die Außenseite der Mündung und die Henkelaußenseite. Relieflinien: Auge, Innenseite des Petasos, teilweise Konturen des rechten Armes und Beines, Gewandsaum, Schwertspitze. Verdünnter Glanzton: Lokken, Kinn und Mantelsaum des Jünglings. Vorzeichnung: An den Unterschenkeln des Jünglings.

Form: Nebenform in der Ausprägung ATL (den Lekythen des Aischines- und des Tymbos-Malers nahestehend, vgl. ARV ${ }^{2} 728$ f. I668. I706; Para 4II; Add $^{2}$ 283; vgl. auch G I, hier Tafel 49, I-3). Scheibenfuß mit breiter Standzone. Zylindrischer, nach unten konisch einschwingender Körper, scharfe Schulterkante, stark eingezogener Hals. Der vorspringende Mündungskelch ist durch eine Doppelgratung von der Halszone abgesetzt. Gerade abgestrichene, deutlich verdickte Lippe. An der Schulter und der Halszone angesetzter Bandhenkel mit längsovalem Querschnitt.

Dekor: Das Bildfeld ist unten und oben von einem tongrundigen Reifen begrenzt. Über dem Bild nur auf der Vorderseite des Gefäßes einSchlüsselmäander. Auf der Schulter 2 Strahlenreihen, wobei von der oberen Strahlenreihe nur noch die Ansätze in Form von Punkten erhalten sind.

Darstellung: Jüngling mit Schwert. - Der Jüngling stürmt mit weitausholendem Schritt, das linke Bein vorgesetzt, nach rechts. Er trägt nackenlange Locken, sein Mantel ist an der rechten Schulter genestelt und lässt den rechten Arm frei, ein Petasos hängt ihm im Nacken. Der rechte Arm mit dem gezückten Schwert ist nach unten zurückgenommen, der linke unter dem Mantel vorgestreckt. Die Haarkalotte durch eine tongrundige Linie vom Hintergrund abgesetzt, das Auge im Profil.

\section{Um 460 - Karlsruhe-Maler (Schwarz)}

Zur Form: Eine große Klasse von rotfigurigen und weißgrundigen Lekythen gehören dem „Secondary Type“ an, vgl. ARV² 675: Der Hals dieser Gefäße ist nahezu immer tongrundig und die Schulterdekoration besteht entweder - wie in unserem Fall - aus einer schwarzen Strahlenreihe oder aus kleinen, altmodischen Palmetten. Einer eigenen Klasse gehören die CL-Lekythen an, die Beazley nach der Lieblingsform des Karlsruhe-Malers benannte, vgl. ARV ${ }^{2}$ 676 f.; Kurtz, AWL, 84; Agora XXX, 46. Der Karlsruhe-Maler dekorierte jedoch auch einige Stücke vom BL-Typus: ARV ${ }^{2} 730$; CVA Athens, Museum of Cycladic Art I, I09 zu Taf. 80, I-4.

Zur Darstellung: Der Jüngling ist im sogenannten „Tyrannenmördertypus" dargestellt, das den Angreifer wie Harmodios in der Tyrannenmördergruppe mit gezücktem Schwert vorwärtsstürmend zeigt. Allerdings führt Harmodios das Schwert in der erhobenen Rechten, während er in der zurückgenommenen Linken die Schwertscheide hält. Zur Tyrannenmördergruppe des Kritios und Nesiotes vgl. S. Brunnsåker, The Tyrant-Slayers of Kritios and Nesiotes ${ }^{2}$ (Stockholm I97I); C. Rolley, La sculpture grecque I (Paris I994) $330 \mathrm{f}$. Abb. 338-339; Die griechische Klassik. Idee oder Wirklichkeit, Ausst.-Kat. (Mainz 2002) 237-240 Kat. I32 (mit Bibliographie). Besonders Theseus wurde häufig im „Tyrannenmördertypus“ dargestellt, vgl. E. Hudeczek, Theseus und die Tyrannenmörder, ÖJh 50, I972/I973, I34-I49. Nach Ausweis zahlreicher Vasenbilder verfolgt er eine Frau, die erschreckt vor ihm flieht. Auf der Grazer Lekythos erscheint nur der Angreifer allein, sodass man sich die Verfolgte wohl auf einem Gegenstück vorzustellen hat, das jedoch nicht erhalten oder nicht erkannt ist. Es sind mehrere solcher Gefäßpaare bekannt, die nur zusammen einen Sinn ergeben, vgl. Antiken aus rheinischem Privatbesitz, Ausst.-Kat. Bonn (Köln I973) 47 Nr. 63, I-2 Taf. 28; G. Hornbostel, Aus Gräbern und Heiligtümern (Mainz I980) I 48 f. Nr. 86; ders. (Hrsg.), Kunst der Antike. Schätze aus norddeutschen Privatbesitz (Mainz I977) 336 f. Nr. 287; zu Pendant-Gefäßen im Allgemeinen vgl. O. Dräger in: CVA Erlangen 2, 98 zu Taf. 4I, 2. 4. Da die Verfolgung mit gezücktem Schwert stets eine ernste Bedrohung bedeutet - während die Liebesverfolgung durch einen Jüngling mit zwei Speeren gekennzeichnet ist (vgl. dazu C. Sourvinou-Inwood, Menace and Pursuit, in: Images et socitété en Grèce ancienne. L iconographie comme méthode d'analyse, Actes du Colloque International, Lausanne I984 [Lausanne I987] 4I-55 Abb. I-6, sowie dies., A Series of Erotic Pursuits. Images and Meanings, JHS 107, I987, I3 I-I 53), ergeben sich für den angreifenden Jüngling, der nicht als Krieger gerüstet ist, außer Theseus, der seine Mutter bedroht (siehe unten), nur wenige Interpretationsmöglichkeiten: ist es Orestes bei seinem Angriff auf Klytämnestra und/oder Aigisthos, oder ist es Alkmaion, der seine Mutter Eriphyle mit dem Tode bedroht? Auch die Rache des Telemachos an einer der treulosen Mägde wurde genannt: O. Touchfeu-Meynier, Thèmes odysséens dans l’art antique (Paris I968) 94 Nr. I83. Für einen Angriff des Theseus auf seine Mutter Aithra gibt es zwar keinen literarischen Beleg, wohl aber die inschriftlich gesicherte Darstellung auf einer Schale des Makron in St. Petersburg B I 543: ARV² 460, I 3 ; Para 5 I 2; Add ${ }^{2}$ 244; CVA St. Petersburg, State Hermitage Museum 5 Taf. 44. 45; C. SourvinouInwood, Theseus as Son and Stepson. A Tentative Illustration of Greek Mythological Mentality, BICS Suppl. 40 (London I 979) Taf. I; LIMC I (Zürich I98I) 422 f. Nr. 25 s. v. Aithra I (U. Kron). Theseus will seine Mutter wohl mit dem Schwert zwingen, den Namen seines Vaters preiszugeben (LIMC I [Zürich I 98I] 429 Nr. 25 s. v. Aithra I [U. Kron]). Die literarische Vorlage dazu könnte in dem 
verlorenen Theseus-Epos zu suchen sein (LIMC I [Zürich I98I] 429 Nr. 25 s. v. Aithra I [U. Kron]). Eine andere Vermutung äußert H. W. R. Smith, Der Lewis-Maler (Leipzig I939) 24, der an eine Verwechslung von Aithra mit seiner „Stiefmutter“ Medea denkt, die Theseus aus Attika verjagen will, vgl. ebenso Sourvinou-Inwood a. O. passim; dies., Reading Greek Culture (Oxford I99I) 58-65. Auch Schefold - Jung, SB IV, 236 denkt an die Möglichkeit einer Verwechslung mit Medea. Dagegen: J. Neils, The Youthful Deeds of Theseus, Archaeologica 76 (Rom I987) I03 Nr. 68 und LIMC VII (Zürich I994) 925 Nr. 30 s. v. Theseus. Die Vertreibung der Medea wird bei Apollod. Epit. I 48 (Mythogr. Gr. I p. I74 ed. Wagner) und dem Mythographus Vaticanus I 48 überliefert. Eine ganze Reihe von Vasenbildern (LIMC I [Zürich I98I] 422 f. Nr. 25-43; 428 f.; vgl. besonders die Schale des Makron in St. Petersburg [siehe oben]: C. Sourvinou-Inwood, Theseus as Son and Stepson. A Tentative Illustration of Greek Mythological Mentality, BICS Suppl. 40 [London I979] Taf. I) zeigt einen Jüngling mit gezücktem Schwert eine Frau verfolgend. Häufig tritt er dabei in Reisekleidung (mit Petasos, Stiefeln und Chlamys) auf, die verfolgte Frau trägt allerdings griechische und nicht, wie man es bei Medea erwarten würde, orientalische Tracht. Wie U. Kron, Die zehn attischen Phylenheroen. AM 5. Beih. (Berlin I976) I3 I jedoch anmerkt, erscheint Medea erst im letzten Drittel des 5. Jhs. in orientalischer Kleidung, was wohl durch die 43 I aufgeführte Tragödie „Medea“ des Euripides bewirkt wurde, wie schon D. L. Page, Medea (Oxford I938) LXII Anm.I vermutete. Der Angriff könnte daher sowohl Aithra als auch Medea gelten. Eine vor Theseus fliehende Frau, die mit Sicherheit Medea darstellt, erscheint im Zusammenhang mit dem marathonischen Stier auf einer Pelike in Athen, NM I3026, vgl. M. Meyer, Zur Relevanz bildlicher Darstellungen mythischer Figuren, in: CVA Deutschland Beih. 4 (München 2009) 29 Abb. 4; LIMC VII (Zürich I994) 937 f. Nr. I93. 203-208 s. v. Theseus (J. Neils).

Zum Maler: vgl. ARV ${ }^{2}$ 730-739. 740. 74I. I668; Para 4II f.; $\mathrm{Add}^{2}$ 283; Wehgartner, AWK, 25. 50. I02. I48. I64 f.; G. Neumann - I. Wehgartner, „Man leaning on his stick“. Zu Bild und Inschrift eines attischen Salbgefäßes, WürzJbAltWiss I 5 , I989, 22323 I; Boardman, RFVA II, 40, wo dem Karlsruhe-Maler ein eleganterer Stil als dem Bowdoin-Maler zugesprochen wird; ders. I34; C. Weiss, CVA Karlsruhe 3, 8I f. zu Taf. 4I, 5-9; 42, I-2; Robertson, Vase-Painting, I73. I78; S. I. Rotroff - J. H. Oakley, Debris from a Public Dining Place in the Athenian Agora, Hesperia Suppl. 25 (Princeton I992) 88 Taf. 33 Nr. 97-98; CVA Athens, Museum of Cycladic Art I, I09 zu Taf. 80, I-4. Vergleichsstücke: die Lekythos im Ashmolean Museum i9 16.I 5: ARV² 733, 7I; CVA Oxford, Ashmolean Museum I, III I Taf. 38, I, sowie zwei Lekythen, die ein Paar bilden (angreifender Jüngling - fliehendes Mädchen): Antiken aus rheinischem Privatbesitz, Ausst.-Kat. Bonn (Köln I973) 47 Taf. 28 Nr. 63, I-2. Der Maler scheint Gefallen an dem Thema gefunden zu haben, denn es sind sechs von seiner Hand bemalte Schalen erhalten, die das Paar angreifender Jüngling - fliehende Frau zeigen: $\mathrm{ARV}^{2} 737, \mathrm{I} 34-\mathrm{I} 38 ; 738$, I43, sowie mit dem Grazer Exemplar insgesamt drei Lekythen mit dem Bild des Angreifers allein (Oxford I9I6.I 5 und Athen, NM E I842: $\mathrm{ARV}^{2}$ 733, 7I-72), wobei das Pendant mit der Figur der fliehenden Frau bislang nicht gefunden ist. Es könnte unter den zahlreichen Lekythen mit Darstellungen laufender Frauen zu suchen sein: $\mathrm{ARV}^{2}$ 73 I, 26-732, 4I.

\section{TAFEL 49}

\section{1-3. Schulterlekythos}

Beilage 14, 3.

G I. Aus Athen. Erworben I 866 durch Josef von Zahn (Graz), Ankauf. Ehemals Slg. Theodor von Heldreich (Athen). Alte Inv.-Nr. II I (Schenkl) bzw. III I (Pichler).
H I 7,5 cm. - Dm Mündung 3,9 cm. - Dm Schulter 6, I cm. Dm Fuß 3,4 cm. - B Henkel I, 2 cm. - Volumen I 34 ml.

Lehner - Lorenz - Schwarz, Vasen, 55 f. Nr. 30 Abb. 44 (G. Schwarz). - BAPD 44I03.

Zustand: Aus I4 Fragmenten zusammengesetzt. Eine große Fehlstelle an der Hinterseite modern geschlossen und mattschwarz übermalt, eine weitere Fehlstelle an der Schulter ebenfalls geschlossen und in annähernd der Oberflächenfarbe übermalt. Einige Absplitterungen, Bemalung zonal abgerieben und abgesplittert.

Technik: Glänzend schwarze Bemalung, dünn aufgetragen, sodass stellenweise die Oberfläche durchschimmert. Tongrundig: Lippenoberseite, Hals, Torusrand und Standfläche. Aussparung über dem Haarschopf der Flügelfrau.

Form: Nebenform in der Ausprägung ATL. Scheibenfuß, an der Unterseite spitz hochgezogen. Zylindrischer, nach unten konisch einschwingender Körper, scharfe Schulterkante, stark eingezogener Hals. Vorspringender Mündungskelch mit steilschräger Wandung, gerade abgestrichene Lippe. An Schulter und Halszone angesetzter Bandhenkel mit längsovalem Querschnitt.

Dekor: Als Standlinie ein tongrundiger Streifen. Über dem Bildfeld Schlüsselmäander. Auf der Schulter Strahlenreihe, darüber eine Reihe mit kleineren Strahlen, von denen vielfach nur mehr der Ansatz als Punkt erhalten ist.

Darstellung: Flügelfrau. - Die geflügelte Frau ist ruhig nach rechts stehend dargestellt und hält in beiden vorgestreckten Händen eine Tänie. Sie trägt Chiton und Mäntelchen. Ihre Frisur wird bis auf das Haar an Schläfen und Stirn von einer Haube umhüllt, deren Rand ebenso wie der Chitonsaum mit einer gepunkteten Borte verziert ist. Eine ebensolche Punktleiste trennt auch die Flaum- von den Schwungfedern des sichtbaren vorderen Flügels. Flüchtige Malerei.

\section{Um 460/450 - Beth-Pelet-Maler}

Zur Form: ARV2 675; Kurtz, AWL, 82 f.; CVA Erlangen 2, 99 zu Taf. 4I, I. 7. IO. I I Beil. 8, 2; CVA Athens, Museum of Cycladic Art I, I07 zu Taf. 79, I-4; I08 zu Taf. 79, 5-8.

Zur Darstellung: Eine Flügelfrau ohne eindeutige Attribute ist in archaisch-klassischer Zeit nicht mit Sicherheit als Nike zu identifizieren, vgl. C. Weiß in: E. Simon (Hrsg.), Die Sammlung Kiseleff im Martin-von-Wagner-Museum der Universität Würzburg II (Mainz I989) I I 3 zu Nr. I86. So bringen etwa Flügelgöttinnen Gaben für die Braut herbei auf dem Lebes Gamikos des Frauenbadmalers in New York, Metropolitan Museum 07.286.35: ARV ${ }^{2}$ I I 26, I; Para 453; Add $^{2} 332$; LIMC VI (Zürich I 992) 880 Nr. 36 I s. v. Nike (A. Goulaki-Voutira); ebenso auf einem Lebes Gamikos desselben Malers in Athen, Benaki-Museum 3 I I I 7: CVA Athens, Benaki Museum I, 38 f. Taf. 3 I. 32 (3 I I I7). Zur sepulkralen Bedeutung der Nike vgl. H. Kenner, Flügelfrau und Flügeldämon, ÖJh 3I, I938/I939, 8I-95; C. Isler-Kérenyi, Ein Spätwerk des Berliner Malers, AntK I4, I97I, 27. 30 f.; LIMC VI (Zürich I992) 880 f. Nr. 36I s. v. Nike (A. Goulaki-Voutira); A. Gulaki, Klassische und klassizistische Nikedarstellungen. Untersuchungen zur Typologie und zum Bedeutungswandel (Bonn I98I) I 40 f.; C. Thöne, Ikonographische Studien zu Nike im 5. Jh. v. Chr. Untersuchungen zur Wirkweise und Wesensart (Heidelberg I999) 94-96. I 48 f. sieht Einzelbilder von Niken mit Tänien nicht ausschließlich als agonale Siegesbilder, sondern als Verkünderinnen einer herausragenden Tüchtigkeit im Allgemeinen. Nur selten sind diese Darstellungen unmissverständlich agonal zu deuten. Dem sakralen Bereich ist Nike mit einer Tänie in Händen zuzurechnen, wenn sie auf einen Altar zuschwebt (Thomsen, Wirkung, I70 f. Abb. 70).

Zum Maler: Der Maler, von Schwarz a. O. 56 als „Nahe dem Werk des Seireniske-Malers“ angesprochen, steht dem Aischinesund dem Tymbos-Maler nahe, die den ATL-Lekythen ihren Namen gaben, vgl. auch G 37, hier Tafel 48, 5-7. Der Maler hat seine Bezeichnung nach der Herkunft einer Lekythos aus Beth Pelet in Is- 
rael, heute in Oxford, Ashmolean Museum I930.550: ARV² 729, 4. Er hat hauptsächlich Lekythen bemalt, die alle der ATL-Klasse angehören, ansonsten nur wenige kleine Vasen von anderer Form. Charakteristisch für seine grobe Zeichnung ist die Beschränkung auf wenige parallele Striche zur Angabe von Gewandfalten und Gefieder. In etwas verfeinerter Form findet sich diese Reduzierung auch beim Aischines-Maler (vgl. unten). Die Wiedergabe der Flügel erfolgt immer in derselben Art, indem die Flaumfedern mit einem gepunkteten Streifen von den Schwungfedern, die durch einen Strich geteilt werden, abgesetzt sind, vgl. etwa die schwebenden Niken mit Tänien in Händen auf einer Lekythos in Erlangen I 243: CVA Erlangen 2, 96 f. Taf. 40, 6. IO-I I; 4I, 6 Beil. 8, I; Athen,

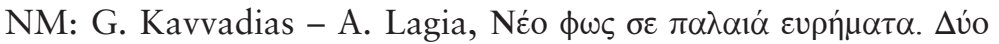

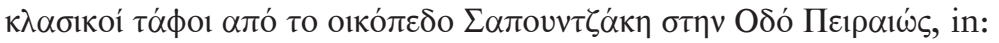
J. H. Oakley - O. Palagia (Hrsg.), Athenian Potters and Painters II (Oxford 2009) 76 Abb. 6 Farbtaf. 2 A („Art des Aischines-Malers”); Athen, Agora-Museum P 2 I 266: Agora XXX, 260 Nr. 865 Taf. 88; Athen, Benaki Museum 40309: Sabetai, Vases, 83; Kerameikos VII 2, Io8 Taf. 72, 5 Nr. 424, 6 (KER 2 I262, „Art des Aischines-Malers“). Eine schwebende Flügelfrau, die einen Spiegel in der Linken und eine Frucht in der Rechten hält, zeigt dieselbe Stilisierung von Gewand und Flügeln wie das Grazer Exemplar: Kerameikos VII 2, 9I Taf. 6I Nr. 324, I („Aischines-Maler“), ebenso die schwebende Nike mit Tänie: Kerameikos VII 2, I 52 Taf. 98 Nr. 630, 5. Zu Altar laufende Flügelfrau des Beth-PeletMalers in Athen, NM: Kavvadias - Lagia a. O. 776 f. Abb. 8 Farbtaf. 2 B ("Werkstatt des Aischines-Malers"); in Washington: S. J. Schwarz, Greek Vases in the National Museum of Natural History Smithsonian Institution Washington, D. C. (Rom I996) 37 Taf. 5 I; in Athen, Kerameikos: Kerameikos IX, I 48 Nr. 269, I Taf. 42, 3-4 („Art des Aischinesmalers“); zu Altar laufende Frau in Athen, Benaki-Museum 30893: Sabetai, Vases, 76-78 Nr. 9 Abb. 28-3 I (mit ausführlicher Bibliographie). Zum Maler allgemein, besonders zum dümmlichen Ausdruck seiner weiblichen Physiognomien mit vorgeschobener, hängender Unterlippe vgl. P. Armandry et al., Collection de l'École Française d’Athènes, BCH 96, I972, 56 f. (J.J. Maffre). Darin unterscheidet er sich vom Aischines-Maler, vgl. etwa die doch qualitätvollere Zeichnung der ansonsten fast identen laufenden Flügelfrau mit Tänie in Händen auf der Lekythos aus dem Kerameikos: Kerameikos IX, I46 Taf. 36, 7 Nr. 262, I.

\section{4-9. Tafel 50, 3-5. Aryballos}

Beilage 14, 4.

G 39. Aus Attika. Erworben 1875 durch Wolfgang Helbig in Athen, Ankauf. Ehemals Slg. Athanasios Rhousopulos (Athen). Alte Inv.-Nr. II 52 (Schenkl) bzw. III 52 (Pichler).

H 8,5 cm. - Dm Mündung 3, O cm. - Dm Körper 7,4 cm. - Dm Boden 3,2 cm. - Gewicht [9I g]. - Volumen I I 4 ml.

G. Schwarz, Addenda zu Beazley's Aryballoi, ÖJh 54, I983, 27-32 Abb. I-3. - Lehner - Lorenz - Schwarz, Vasen, 58 Nr. 32 Abb. 45-47 (G. Schwarz). - BAPD 8347.

Zustand: Aus vier Fragmenten zusammengesetzt, vollständig erhalten. Oberfläche stellenweise bestoßen, am Körper (unterhalb der Figur des Eros) ein die Wandung vollständig durchbrechendes Loch.

Technik: Ton an der Oberfläche hellorange. Glänzend schwarz bemalt, in der Halszone sehr dünner Auftrag, durch den die Oberfläche durchscheint. Mündung innen mit Glanzton überzogen. Relieflinien: Gewandfalten, Flügel und Körperkonturen des Eros. Ausgesparte Kopfkontur: Alle Figuren.

Form: Aus der Masse gearbeiteter, niedriger Standring, kugeliger Körper, stark eingezogener Hals. Ausschwingender Mündungskelch mit rund abgestrichener Lippe.

Dekor: Unter den Beinen des Eros ist der Rest einer tongrundigen Standlinie erhalten, hinter ihm eine stilisierte Pflanze. Die
Bodenlinie, auf der sich die Figuren bewegen sollten, ist fast durchwegs übermalt, nur unter dem Eros ist ein kleines Stück von ihr stehengeblieben.

Darstellung: Eros verfolgt Mädchen. - Ein nackter Eros mit großen Rückenflügeln verfolgt in weitem Schritt nach rechts ein Mädchen, das nach rechts enteilt und im Laufen zu ihm zurückblickt. Sie trägt einen Peplos und hat ihr Haar zu einem Knoten am Hinterkopf geschlungen. Im linken Arm hält sie ein Kästchen. Von ihrer Rechten, die sie zu Eros ausstreckt, flattert eine breite Binde, die mit Fransen und einem zweireihigen Zackenmuster versehen ist. Links von Eros läuft eine zweite junge Frau nach links. Sie trägt ebenfalls einen Peplos mit Überschlag und eine Knotenfrisur. In ihrer Rechten schwenkt sie ein schmaleres Fransenband mit Querstreifen. Auch sie sieht sich im Laufen nach Eros um, von dem sie eine kleine stilisierte Pflanze am Boden trennt.

Um 400

Zur Form: Richter - Milne, Shapes, I6 Type II (Attisch). Es sind auffallend wenige attisch-rotfigurige Aryballoi auf uns gekommen, vgl. J. D. Beazley, Aryballoi, BSA 29, I927/I928, I87-2 I 5. Seine durch mehrere neu hinzugekommene Exemplare in $\mathrm{ARV}^{2}$ und Para ergänzte Liste bei G. Schwarz, Addenda zu Beazley's Aryballoi, ÖJh 54, I983, 27 f. umfasst 32 Exemplare. A. Heinemann, Bild, Gefäß, Praxis. Überlegungen zu attischen Salbgefäßen, in: CVA Deutschland Beih. 4 (München 2009) I 64 betont die Seltenheit realer Aryballoi im archäologischen Befund im Vergleich zu bildlich wiedergegebenen und erstellt neuerlich eine Liste von rotfigurigen, spätschwarzfigurigen und weißgrundigen Aryballoi aus Athen: Heinemann a. O. I70 f. Appendix A. Sie zählt nunmehr 34 Stück, von denen die Hälfte spätarchaisch bis frühklassisch zu datieren ist, die andere Hälfte dem späten 5. bis frühen 4. Jh. angehört. Die Diskrepanz zwischen der Anzahl der tatsächlich erhaltenen und der Vielzahl der abgebildeten Aryballoi wird unter Hinweis auf die These H. Hommels, die Gefäßform sei aus den steif gegerbten Hodensäcken von Schafsböcken entstanden (Bocksbeutel und Aryballos. AbhHeidelberg [Heidelberg 1978]), mit der Vergänglichkeit des Materials erklärt (Heinemann a. O. I64 f.). Ihrer verschiedenen Entstehungszeit entsprechend differieren die keramischen Aryballoi auch in der Form: Wenn diese auch nicht bei allen Exemplaren zu ermitteln war, so lässt sich doch von den publizierten Stücken ablesen, dass die frühe Gruppe stets mit einer oder zwei Ösen zum Aufhängen des Gefäßes mittels eines Lederriemens ausgestattet war. Vor allem für die kugelige Form des Aryballos, die von der Mitte des 6. Jhs. an, dem korinthischen Typus nachgestaltet, in Attika gebräuchlich wurde (vgl. Richter - Milne, Shapes, I6 Abb. I03. I04), war die Möglichkeit einer Aufhängung wichtig. Die enge Einziehung des Gefäßhalses gewährleistet allerdings auch ohne Öse(n) eine sichere Aufhängung, vgl. C. H. E. Haspels, How the Aryballos was Suspended, BSA 29, I927/I928, 2 I 6 Abb. I. Vom Ende des 6. Jhs. an gibt es Aryballoi mit flachem Boden oder Standring, die sich auch zum Hinstellen eignen, aber trotzdem noch mit Ösen für eine Aufhängung versehen sind, wie den Aryballos des Douris in Athen, NM T. E. 556: Buitron-Oliver, Douris, 62 f. 73 Nr. I3 Taf. 8. Eine Schale des Peithinos in Berlin, ehem. Antiquarium F 2279, zeigt beide Formen, die kugelige und die abgeflachte, nebeneinander: $\mathrm{ARV}^{2}$ I I 5, 2; I 626; Para 332; Add $^{2}$ I74; CVA Berlin 2 Taf. 60-6I; H. Gericke, Gefäßdarstellungen auf griechischen Vasen (Berlin I970) 76. I I 2 Liste Aryballos Io. Seit der Zeit des Berliner Malers scheinen nur noch Aryballoi mit flachem Boden gebräuchlich gewesen zu sein, die man sowohl aufhängen als auch hinstellen konnte: Gericke a. O. 77. Die Aryballoi der späteren Gruppe sind fast ausnahmslos henkellos. Mit der Veränderung der Form geht auch ein Wechsel in den Bildthemen einher: Waren sie zunächst ganz in der männlichen Sphäre angesiedelt, bevorzugen die späteren Exemplare Themen aus dem Lebensbereich der Frau. 
Zur Darstellung: Die Darstellung - das neckische Spiel zweier Mädchen mit Eros - gehört zweifellos in die weibliche Sphäre und scheint auf hochzeitliche Bräuche anzuspielen. Auffallend an dem nackten Eros ist die Arm- bzw. Handhaltung: Er hat beide Arme vorgestreckt, die Fingerspitzen seiner rechten Hand sind über einem kleinen, unsichtbaren Gegenstand zusammengeführt. Die Linke hält er mit offener Handfläche darunter, so als wollte er den Gegenstand, wenn er seinen Fingern entglitten ist, auffangen und in Richtung auf das fliehende Mädchen hin weiterschnippen. Die zweite junge Frau, die links von Eros in entgegengesetzte Richtung läuft, hat mit der Linken, wie die offene Handfläche zeigt, einen kleinen, rundlichen Gegenstand in Richtung auf die Gruppe Eros - fliehendes Mädchen geworfen. Von diesem Paar trennt sie eine kleine, stilisierte Pflanze. Zur sicheren Deutung der Szene müsste der kleine Gegenstand, den das Mädchen wirft - und einen ebensolchen hält gewiss auch Eros mit seinen Fingerspitzen -, geklärt werden. Am ehesten handelt es sich um eine Feige oder Nuss, die beide im Hochzeitszeremoniell Verwendung fanden: Beim Eintritt in das Haus ihres Gatten wurde die Braut mit Feigen, Nüssen und auch Münzen überschüttet, Gaben, die ihr selbst Fruchtbarkeit, dem ganzen Hause jedoch Wohlstand und Gedeihen bescheren sollten, vgl. R. Flacelière, Griechenland. Leben und Kultur in klassischer Zeit (Stuttgart I 977) 92; H. J. Oakley, The Anakalypteria, AA I982, I I3-I I 8; G. Schwarz, Hochzeitsszenen der Parthenonzeit, in: W. Alzinger (Hrsg.), Pro Arte Antiqua, Festschrift H. Kenner 2, ÖAI Sonderschr. I 8 (Wien I985) 322 f.; J. H. Oakley - R. H. Sinos, The Wedding in Ancient Athens (Madison, Wisc. I993) 26. 34 f.; Auf Hochzeitsbräuche weisen aber auch die Bänder und das Kästchen im Arm der von Eros Verfolgten hin: Es enthält wohl die Geschenke, die die Braut am Tag nach ihrer Hochzeit, den Epaulien, erhielt: Flacelière a. O. 93; Oakley - Sinos a. O. 7. Iо. I 8. 24. 38-42. 45 f. Vgl. weiters zu Kästchen: E. Brümmer, Griechische Truhenbehälter, JdI Ioo, I985, I38-I5I (III D 2); F. Lissarrague, Frauen, Kästchen, Gefäße. Einige Zeichen und Metaphern, in: Pandora, 99-Iо . Zu den Bändern: Krug, Binden, 25-28. 87 f. Liste 7 D. Ein laufendes Mädchen, das eine sitzende Frau mit einer Feige (oder ähnlichem) bewirft, findet sich auf einer Pyxis in Heidelberg, Univ. 58/2 I: R. Hampe und Mitarbeiter, Neuerwerbungen I957-1970, Katalog der Sammlung antiker Kleinkunst des Archäologischen Instituts der Universität Heidelberg II (Mainz I97I) 55 f. Nr. 85 Taf. 62.

Zum Maler: Stilistische Parallelen zu den ausladenden Rückenflügeln des Eros bietet etwa die Nike auf einer Bauchlekythos des Well-Malers in Athen, Agora P 5265: ARV² I 220, 3; Agora XXX, 265 Nr. 922 Taf. 9I.

\section{TAFEL 50}

1. Siehe Tafel 48, 1-4.

2. Siehe Tafel 48, 5-7.

3-5. Siehe Tafel 49, 4-9.

\section{TAFEL 51}

\section{1-3. Tafel 52, 1-4. Skyphos}

Beilage 14, 5.

G 23. Aus Capua. Erworben 1873 durch Wolfgang Helbig in Rom, Ankauf. Alte Inv.-Nr. II 22 (Schenkl) bzw. III 30 (Pichler).
H I6,4 cm. - Dm Mündung I9, I cm. - B mit Henkeln 28,5 cm. - Dm Fuß I 2, I cm. - Dm Henkel I,8 cm. - Gewicht 92 I g. Volumen 298 I ml.

Lehner - Lorenz - Schwarz, Vasen, 42-44 Nr. 23 Abb. 32-33 (G. Schwarz). - BAPD 44IO2.

Zustand: Vollständig erhalten. Einige kleine Absplitterungen.

Form: Niedriger, außen abgerundeter Ringfuß. Tiefer, nach unten hin leicht verjüngter Schalenkörper. Randzone vertikal, Lippe spitz gerundet abgestrichen. Zwei gegenständige Horizontalhenkel mit rundem Querschnitt.

Technik: Ton an der Oberfläche hellorange, Bemalung glänzend schwarz, Boden orangerot bemalt. Verdünnter Glanzton für die drei konzentrischen Kreise am Gefäßboden. Relieflinie: Auf A Lyra, Mantelfalten auf A und B. Ausgesparte Kopfkontur beim Jüngling auf A. Vorzeichnung: Linkes Bein der Frau auf B.

Dekor: Auf der Gefäßunterseite im Zentrum ein Punkt, darum drei konzentrische Kreise. Feiner tongrundiger Streifen zwischen Fuß und Gefäßkörper. Zwei schmale tongrundige Streifen, deren oberer den Figuren als Standlinie dient.

Darstellung: Manteljüngling mit Lyra, laufende Frau. - A: Der Jüngling, der in einen Mantel gehüllt ist, welcher die rechte Schulter frei lässt, steht ruhig nach rechts und hält in der vorgestreckten Rechten eine Lyra, deren Corpus mit einer herabfallenden Tänie geschmückt ist. In seinem Haar liegt ein Reif, Löckchen fallen vor dem Ohr auf seine Wange herab. Rechts über der Figur horizontal die Inschrift „kalos“. Durch die zahlreich verwendeten Relieflinien ist diese Gefäßseite als Hauptseite deklariert. B: Die Rückseite zeigt eine nach links laufende Frauengestalt, die mit Chiton und Mantel bekleidet ist und die mit der Rechten ihr Himation unten leicht anhebt. Auf dem Kopf trägt sie eine turbanartig gewundene Haube, den Sakkos. Ein Bausch ihres dunklen Haares wird vor dem Ohr sichtbar, das durch einen Kreis gebildet ist. Links vor ihr ist die Inschrift „kale“ vertikal angebracht, hinter ihr hängt ein Band mit Fransen an der Wand.

Inschrift: Auf A „KA $\Lambda \mathrm{O} \Sigma$ “, auf B „КА $\Lambda \mathrm{H}^{\prime}$ als Dipinti.

460/455 - Maler von Brüssel R 330

Zur Form: Richter - Milne, Shapes, 28 (Typ II). Die Form des Skyphos oder der Kotyle leitet sich vom protokorinthischen Skyphos des 7. Jhs. her, ohne jedoch dessen Eleganz zu bewahren. Das Fassungsvermögen eines solchen Trinkbechers konnte bis zu 8 Liter betragen. Da beim Trinken auch die Unterseite des Gefäßes sichtbar wurde, haben die meisten Skyphoi verzierte Böden. Seiner etwas unglücklichen Form wegen - das nach oben ausladende Gefäß wird durch seine Horizontalhenkel gleichsam belastet und auseinandergedrückt - findet sich der Skyphos in der figürlich verzierten Feinkeramik wesentlich seltener als in der Schwarzfirniskeramik. Allerdings gab es Maler, die sich gerade auf die Dekoration von Skyphoi spezialisiert hatten, wie der sogenannte Lewis-Maler: Er bemalte im 2. Viertel des 5. Jhs. ausschließlich Skyphoi, rund 40 davon sind erhalten, vgl. H. R. W. Smith, Der Lewis-Maler (Berlin 1939). Ansonsten waren es vor allem Schalenmaler, die auch Skyphoi dekorierten, darunter große Meister wie Douris, der Brygos-Maler oder Makron, vgl. E. Buschor, Griechische Vasen (München I969) I70.

Zur Darstellung: Die Figuren auf der Vorder- und Rückseite stehen in inhaltlichem Zusammenhang und bilden ein Paar: Der leiertragende Jüngling erwartet das Mädchen, das heraneilt, um ihn zum Symposion zu begleiten. Durch den turbanartig gebundenen Sakkos ist die junge Frau als Hetäre gekennzeichnet, vgl. H. Hoffmann, Sexual and Asexual Pursuit. A Structuralist Approach to Greek Vase Painting (London I977) 4 zu Taf. 5, 5-6.

Zum Maler: siehe ARV2 925-93 I. I 674 f.; Para 43 I; Add 306. Der Maler von Brüssel R 330 ist ein anonymer Schalenmaler, der wie der Lewis-Maler der großen Penthesileia-Werkstatt angehörte, 
die von frühklassischer Zeit bis in das 3. Viertel des 5. Jhs. florierte. In seinem Oeuvre finden sich rund i so erhaltene Gefäße, darunter meist Schalen, aber auch I 3 Skyphoi. Benannt ist er nach einer Trinkschale in Brüssel, Musées Royaux d'art et d'histoire R 330, die er - wie viele Maler dieser Werkstatt - mit einem Kollegen gemeinsam dekorierte: CVA Bruxelles, Musées Royaux du Cinquantenaire I, III, I d Taf. 3, 2. Die Zuschreibung ergab sich durch den Vergleich mit folgenden Werken: Skyphos in Mainz, Univ. I I : ARV² 930, 97; R. Hampe - E. Simon, Griechisches Leben im Spiegel der Kunst (Mainz I959) Taf. 3 I; Skyphosfragment Florenz Museo Archeologico Etrusco I9 B 29: ARV² 929, 98; CVA Florenz 2, III I Taf. I9, 29; Skyphosfragment Athen, Akropolis-Museum 524: ARV $^{2}$ 929, 9I; B. Graef - E. Langlotz, Die antiken Vasen von der Akropolis zu Athen II (Berlin I93I) Taf. 4I; Schale Oxford 2I I 256: ARV2 925, 3; Para 43 I; Select Exhibition of Sir John and Lady Beazley`s Gifts to the Ashmolean Museum I91 2-I966 (Oxford 1967) Taf. 37; Schale Santa Barbara, Museum of Art C I9 WL 55: $\mathrm{ARV}^{2}$ 926, 24; Para 43 I; M. A. Del Chiaro, Classical Vases in the Santa Barbara Museum of Art, AJA 68, I964, Taf. 35 (Innenbild vom Maler von Orvieto I9I A); Schale Adolphseck, Schloss Fasanerie 33: ARV² 926, 25; CVA Adolphseck, Schloß Fasanerie I Taf. 25, 3; 27 (Innenbild vom Maler von Orvieto I9I A). Zum Hauptseitenbild vgl. auch die Schale des Penthesileia-Malers in Hamburg, Museum für Kunst und Gewerbe I900.I64: ARV² 880, 4; I673; Para 428; Add $^{2} 30$ I; H. Diepolder, Der PenthesileiaMaler (Leipzig I936) Taf. I I, I.

\section{TAFEL 52}

\section{1-4. Siehe Tafel 51, 1-3.}

5-6. Tafel 53, 1-4. Schale

Beilage 15, 1.

$G$ 22. Aus Capua. Erworben 1873 durch Wolfgang Helbig in Rom, Ankauf. Alte Inv.-Nr. II 2I (Schenkl) bzw. III 29 (Pichler).

H I 2,0 cm. - Dm Mündung 30,0 cm. - Dm Schulter 28,4 cm. - Dm Fuß I I,9 cm. - Dm Henkel I, 2 cm. - Gewicht IO2 I g. - Volumen $2803 \mathrm{ml}$.

$\mathrm{ARV}^{2}$ I 52, 8. - E. Diez, Junger Athlet, in: Festschrift des Instituts für Leibeserziehung der Universität Graz (Graz I954) I3 f. Taf. I. - Lehner - Lorenz - Schwarz, Vasen, 35-38 Nr. 20 Abb. 27-28 (G. Schwarz). - BAPD 201394.

Zustand: Vollständig erhalten. Einige kleine Absplitterungen und zwei tiefe Kerben an der Innenseite. Eine größere Absplitterung (Dm ca. I, $2 \mathrm{~cm}$ ) im Medaillon.

Form: Hohlfuß mit stark ausschwingender Standfläche, über dem außen gerundeten Fuß außen ein breiter Wulst. Flacher Schalenkörper. Scharf abgesetzte Randkante, ausschwingende gerundete Lippe. Im Gefäßinneren eine tiefe Rille unterhalb der geknickten Wand. Zwei gegenständige, nach oben gebogene Horizontalhenkel mit rundem Querschnitt.

Technik: Ton an der Oberfläche hellorange, glänzend schwarz bemalt. Vorzeichnungen: An beiden Füßen, die ursprünglich näher beieinander standen. Relieflinien: Profil, Auge, Braue, Arme und Hände, rechte Schulter und rechter Oberschenkel des Athleten. Zusätzliche Farben: Aufgesetztes Rot für den Kranz. Weiß für das Dipinto. Ausgesparte Kopfkontur.

Dekor: Gefäßaußenseite vollständig bemalt, mit Ausnahme des gekehlten Randes der Fußscheibe, der trichterförmigen Einziehung des Fußes, zwei schmalen Streifen unter- und oberhalb des Wulstes am Fuß, der Henkelfelder und Henkelinnenseiten, sowie auf der Gefäßinnenseite der Kreislinie um den Tondo.
Darstellung: Weitspringer. - Der junge, nackte Athlet nach rechts befindet sich vor seinem Sprung, er hat die Halteren eben vom Boden aufgehoben. Dabei neigt er sich vor, führt beide Arme nach vorne und beugt in Schrittstellung die Knie. Der rechte Fuß berührt nur mit dem Ballen den Boden. Die Haltung, die sich dabei ergibt, fügt sich ideal in das Rund des Medaillons ein. So geschickt sich der Vasenmaler in der Anlage der Figur erweist, so wenig Mühe ist für ihre Ausführung verwendet: Keine Binnenzeichnung für den Körper, verkümmerte Arme, die rechte Hand zu klein, Unterschenkel zu dünn und eckig, die Füße nur summarisch angegeben. Frisch und lebendig dagegen das Gesicht mit dem in archaischer Manier noch rein frontal gesehenen, schräg gestellten Auge unter der kräftigen, hohen Braue. Die stumpfe Nase, die kurze Oberlippe mit dem kleinen Mund und das spitze Kinn wirken individuell. Im kurzen, schwarzen Haar liegt ein rot aufgemalter Blattkranz.

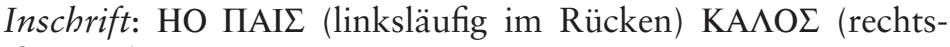
läufig vor den Armen).

Um 5 Io - Verwandt mit dem Epeleios-Maler (Beazley)

Zur Form: Zur Knickwandschale vgl. Richter - Milne, Shapes, 24 f. Abb. I 56 (Typ I); H. Bloesch, Formen attischer Schalen von Exekias bis zum Ende des Strengen Stils (Bern I940) I I9-I3 I Nr. I 2 Taf. 35, 2; Kunst der Schale, 46-49. I79-I 8 I (B. Kaeser).

Zur Darstellung: Das Springen war eine Disziplin des Pentathlon, des Fünfkampfes, der bei den Olympischen Spielen in der Reihenfolge Diskoswerfen, Springen, Speerwerfen, Laufen und Ringen ausgetragen wurde. Der Weitsprung setzte sich aus fünf Einzelsprüngen zusammen und erfolgte aus dem Stand. Die Technik, sich mit Hilfe von Sprunggewichten (halteres) Schwung beim Absprung und zugleich Balance beim Aufkommen zu verschaffen, war in der Antike üblich und wird in der einschlägigen Literatur gelegentlich beschrieben, vgl. G. Doblhofer - M. Laurencic - P. Mauritsch, Weitsprung. Text, Übersetzung und Kommentar, Quellendokumentation zur Gymnastik und Agonistik 2 (Wien, Köln, Weimar I992); J. Mouratidis, On the Jump of the Ancient Pentathon, Nikephoros, Beih. 20 (Hildesheim 20I2) IO3-I I4; E. N. Gardiner, Athletics of the Ancient World (Oxford I955) I44I 53; J. Ebert, Zum Pentathlon der Antike. Untersuchungen über das System der Siegerermittlung und die Ausführung des Halterensprunges AbhLeipzig 56/I (Berlin 1963); L. Drees, Olympia. Götter, Künstler und Athleten (Stuttgart I967) 86-88; J. Jüthner - F. Brein, Die athletischen Leibesübungen der Griechen II: Einzelne Sportarten, I: Lauf-, Sprung- und Wurfbewerbe (Wien I968) I 59-22 I; N. Yalouris, Athletics in Ancient Greece (Athens I977) I76-I 87; Sport dans la Grèce antique, I06-I09. 2I 2. 269-275. Die Antike kannte verschiedene Formen von Halteren, die auch einer Entwicklung unterworfen waren (Jüthner - Brein a. O. I62I82). Auf unserer Schale sieht man in den Händen des Athleten kolbenförmige Sprunggewichte, deren Vorderkolben größer, die rückwärtigen Teile dagegen kleiner und abgerundet gebildet sind, um so die gewünschte Vorverlegung des Schwerpunktes zu erreichen (Jüthner - Brein a. O. I 66). Eine unserem Springer verwandte Haltung mit schräg nach unten vorgestreckten Armen zeigt z. B. ein Schaleninnenbild in der Art des Epeleios-Malers in Kopenhagen, Thorvaldsen-Museum I07: ARV² I49, 20; Jüthner - Brein a. O. Abb. 47; das Innenbild der namensgebenden Schale des Malers von Berlin 2268 aus Tarquinia in Berlin F 2268: ARV ${ }^{2}$ I 53, 2; $\mathrm{Add}^{2}$ I 80; CVA Berlin 2 Taf. 65, 6; La cité des images, 34 Abb. 49; Jüthner - Brein a. O. Taf. 48, 2; weiters das Medaillon einer Schale des Oltos aus Vulci ehem. Des Vergers I37: $\mathrm{ARV}^{2}$ 62, 84; I622; $\operatorname{Add}^{2}$ I 65; Jüthner - Brein a. O. Abb. 46 (mit bauchigen Halteren).

Zum Maler: Zum Epeleios-Maler und Verwandten: ARV² I46I 48 (Epeleios-Maler). I48-I5 I ( "manner of the Epeleios-Painter"). I 52 ("related to the Epeleios-Painter"). I 700; Para 335 f.; 
Add² I 79 f.; Boardman, ARFV I, 6I f.; Boardman, RFVA I, 68. 70: Zur Verwendung von Beazleys Gebrauch des Terminus „related“ vgl. M. Robertson in $\mathrm{Add}^{2}$ XIII. Beazley rechnet den Epeleios-Maler, dessen Werke oftmals schwache Kopien des Euergides-Malers sind, zum "coarser wing" der frührotfigurigen Schalenkunst, doch sind einige seiner Bilder durchaus originell, vgl. z. B. CVA Basel 2 Taf. 7, 4; 8, I-3 (BS 463); W. Hornbostel, Aus der Glanzzeit Athens. Meisterwerke griechischer Vasenkunst in Privatbesitz (Hamburg I986) 88 f. zu Nr. 40. Vergleichbare Schalen in der Art des Epeleios-Malers mit dem Bild eines Weitspringers im Medaillon in Neapel, Museo Archeologico Nazionale H 26I6: ARV 2 I 49, 2 I; Add $^{2}$ I79; J. T. Cummings, The Michigan State University Kylix and its Painter, AJA 73, I969, 70 Taf. 30, 7; ARV² I 50, 39; Add $^{2}$ I79; Jüthner - Brein a. O. Taf. 58 e.

\section{TAFEL 53}

1-4. Siehe Tafel 52, 5-6.

\section{Tafel 54, 1-3. Tafel 55, 1. Schale}

Beilage 15, 2.

G I94. Fundort unbekannt. Erworben vor 1937. Später irrtümlich unter der Nr. G 236 ein zweites Mal inventarisiert.

H erh. 6,8 cm. - Dm Rand rek. 27,2 cm. - Wandstärke o,6 cm.

$\mathrm{ARV}^{2}$ 4I6, 5: Once Vienna Univ. (perhaps only for restauration). I: „Winged woman pursuing a boy (Eos and Tithonos, one would have sad, but she holds a caduceus: Iris?)". - $\operatorname{Add}^{2} 234$. CVA Wien I, Universität und Professor Franz v. Matsch (Deutschland 5) 23 f. zu Taf. I I, 5; I 2, I-2. - CVA Oxford, Ashmolean Museum I, III I, 4 f. zu Taf. 2, 3; 7, I-2 (305). - G. Schwarz, Iris und Ganymed auf attischen Vasenbildern, ÖJh 5I, I976/I977, I-IO. - S. Kaempf-Dimitriadou, Die Liebe der Götter in der attischen Kunst des 5. Jhs. v. Chr., AntK I I. Beih. (Bern I979) 59 Anm. I9. - Schefold, SB III, 2 I 2 Anm. 438. 44 I. - LIMC III (Zürich I986) 77I Nr. 23I s. v. Eos (C. Weiß). - LIMC IV (Zürich I988) I 59 Nr. 83 a, s. v. Ganymedes (H. Sichtermann). - LIMC V (Zürich I990) 757 Nr. I62 s. v. Iris (A. Kossatz-Deissmann). Lehner - Lorenz - Schwarz, Vasen, 38-40 Nr. 2I Abb. 30-3 I (G. Schwarz). - BAPD 204536.

Zustand: Von den sechs erhaltenen Fragmenten des Schalenbeckens (Rand- und Wandzone) konnten fünf wieder zusammengesetzt werden, zwei Fehlstellen in Gips ergänzt, eine davon im Zentrum der Schale. Innerhalb der Bildfelder orangefarben, an der Unterseite schwarz bemalt. Das sechste, nicht anpassende, aber sicher zugehörige Fragment ist heute verloren und zeigte Reste zweier nach rechts gewandter Figuren.

Technik: Schwarzer, glänzender Glanzton, dicke Pinselstriche an den Flügeln der Frau im Innenbild. Verdünnter Glanzton auf I: Löckchen am Kopf des Knaben, Maschen des Astragalnetzes, Chitonfalten an rechter Schulter und rechtem Oberarm der Flügelfrau.

Relieflinien auf I: Profil, Sakkos, oberer Flügelrand, Daumen der Flügelfrau, Kontur und Gewandfalten des Knaben außer der Haarkalotte, Kontur des Astragalnetzes. Relieflinien auf A und B: Sämtliche Konturen der erhaltenen Figuren sowie Gesamtkontur des Sitzenden auf B. Vorzeichnungen: Füße des Sitzenden auf B.

Form: Schale Typus B. Flacher Schalenkörper, schräg aufgestellter Rand mit abgestrichener Lippe.

Dekor: Auf der Außenseite eine durchgehende konzentrische tongrundige Linie unter den Figuren auf A und B. I: Tondorahmen mit linksläufigem Mäander.

Darstellung: I Flügelfrau und Knabe. A, B Fünf Frauen eilen zu einem sitzenden Greis.
Innenbild: Die Flügelfrau im Medaillon trägt einen dünnen, durchsichtigen, an den Ärmeln geknöpften Chiton. Ihr Haar hat sie mit einem gemusterten Sakkos mit Quaste umhüllt. Mit der (verlorenen) Rechten umfasst sie ein Kerykeion, dessen oberes Ende vor ihrem linken Flügel sichtbar ist. Die Flügel sind in gepunktete Flaumfedern und zwei Reihen von Schwungfedern unterteilt. Die Schwungfedern sind mit einer dünnen Linie von den Flaumfedern abgesetzt, unter der Punkte aufscheinen und die von einem dicken Pinselstrich betont wird. Eine zweite dünne Linie, die wieder von dicken Strichen betont wird, teilt die Schwungfedern in zwei Zonen. Die rechte Brust der Flügelfrau wird im Profil unter dem Chiton sichtbar, von der linken nur der Ansatz. Die Gewandfalten sind irrtümlich über den rechten Unterarm weitergeführt. Der Knabe, den die Flügelfrau an seiner rechten Schulter ergriffen hat, wo ihr großer linker Daumen sichtbar wird, trägt eine Kurzhaarfrisur mit Tänie, aus der sich einzelne Löckchen in Wangen und Nacken kräuseln. Er hat einen schweren, sorgfältig drapierten Mantel über die linke Schulter geführt, wo er breit umgeschlagen ist und einen abgetreppten Saum bildet. Die Mantelfalten, die schwer und steif herabfallen, stehen im Gegensatz zum dünnen Gewand der Frau. In seiner linken Hand hält der Knabe ein Netz mit Quaste hoch, dessen Inhalt als schwarze Masse angegeben ist. Sein Kopf ist im Profil der Frau zugewandt, er eilt aber, wie ein Rest seines linken Beines zeigt, von ihr weg.

Außenbilder: Durch den Rest einer Henkelpalmette lässt sich die Darstellung auf der Außenseite in zwei Szenen unterteilen: In der Bildmitte von B thront ein bärtiger Mann mit Stirnglatze in Chiton und Mantel nach links auf einem Lehnsessel, im Arm einen mit einem Band umwundenen Stab, dessen oberes Ende nicht erhalten ist, wohl ein Szepter. Sein Haar hat er mit Hilfe einer Binde zu einem Schopf hochgebunden. Zu ihm eilen von links und rechts bittflehend je zwei Frauengestalten: Die beiden von rechts kommenden sind mit einem Chiton bekleidet, die vordere streckt einen Arm nach dem Greis aus. Von den beiden sich von links nähernden Frauen streckt ihm die vordere beide Hände entgegen. Sie trägt einen Chiton, während die hintere mit Chiton und Mantel bekleidet ist. Ihr folgt jenseits der Henkelpalmette auf A eine weitere Frau in Chiton und Mantel. Nach einer großen Fehlstelle ist von der Figur, die für die Deutung den Ausschlag gibt, nur ganz wenig erhalten geblieben: Ein Fuß und ein Stück des von einem Schlangenschwanz überschnittenen Chitons, neben ihr ein größerer Fuß. Doch diese Reste genügen, um den gesamten Bildschmuck von A und B deuten zu können: Es handelt sich auf A um den Ringkampf der Thetis mit Peleus, in dessen Verlauf sie sich hier in eine Schlange verwandelt. Der größere Fuß könnte zu Peleus gehören. Ihre Schwestern, die Nereiden, flüchten indessen angstvoll zu ihrem Vater Nereus im Zentrum von B. Wo das heute verlorene Fragment mit zwei Gewandfiguren - eine in Chiton, die andere im Mantel - zu positionieren ist, muss ungewiss bleiben; zu diesem siehe G. Schwarz, Iris und Ganymed auf attischen Vasenbildern, ÖJh 5 I, I976/I977, 7 f. Abb. 6.

Um 480-470 - Maler der Schale Louvre G 265 (Beazley)

Zur Form: Richter - Milne, Shapes, 25; Kunst der Schale, 78 f.

Zur Darstellung: Medaillon: Beazley denkt bei dem verfolgten Knaben an Tithonos, bei der Flügelfrau an Eos, doch das Kerykeion bereitet ihm Zweifel, sodass er Iris vorschlägt. Doch wen verfolgt Iris und für wen ist ihre Beute gedacht? Tatsächlich gibt es außer der Grazer Schale eine kleine Gruppe von Bildern, auf denen eine geflügelte Frauengestalt mit Kerykeion einen Knaben oder Jüngling verfolgt: I) Schale Bryn Mawr, Fragmente P 95 I-953: CVA Bryn Mawr College I, I 5 f. Taf. I I, I-4; 2) Kolonettenkrater des Agrigent-Malers in Bologna, Museo Civico Archeologico I 83: $\mathrm{ARV}^{2}$ 575, I4; CVA Bologna, Museo Civico I, III I c Taf. 32, 3; H. Kenner, Flügelfrau und Flügeldämon, ÖJh 3 I, I939, 93; G. 
Schwarz, Iris und Ganymed auf attischen Vasenbildern, ÖJh 5I, I976/I977, 3 Abb. 3; 3) Kolonettenkrater des Agrigent-Malers in Syrakus, Museo Nazionale 53237: ARV ${ }^{2}$ 575, I 5; G. Vinicio Gentili, Megara, Hyblaea (Siracusa), NSc I954, I03 Nr. I Abb. 26 B; 4) Strickhenkelamphora der Gruppe des Polygnot in Neapel, $\mathrm{Mu}$ seo Capodimonte M 6746: $\mathrm{ARV}^{2}$ I058, I I7; $\mathrm{Add}^{2}$ 323. Zu diesen vier Exemplaren gesellt sich nun die Grazer Schale als fünftes hinzu. Für die Flügelfrau mit Kerykeion bietet sich eine Benennung auf Iris zwingend an. Kenner (a. O. 93) betont die Verwandtschaft von Iris mit den Harpyien, deren Schwester sie nach Hesiod ist (Theog. 266 f.). Auch Eos ist nicht allzu weit von ihnen entfernt, als Flügelfrau verkörpert sie einen raffenden Dämon (Kenner a. O. 89) mit jenseitsbezogenem Charakter. Doch ergibt die Darstellung auf dem Kolonettenkrater in Bologna (oben Nr. 2) einen anderen, auf eine konkrete mythologische Situation bezogenen Deutungsansatz: Dort verfolgt eine Flügelfrau mit Kerykeion, also Iris, einen Knaben mit Lagobolon, der geradewegs auf einen Mann zuläuft, der am linken Bildrand stehend auf sein Szepter gestützt auf ihn zu warten scheint. Der Mann ist in Vorderansicht wiedergegeben, bärtig mit am Hinterkopf zu einem Knoten aufgebundenem Haar, und wendet den Kopf nach rechts dem Knaben zu. Sein Auftreten ist würdevoll und selbstsicher, sodass man in ihm den Göttervater Zeus selbst erkennen möchte. Der Knabe, den Iris ihm in die Arme treibt, kann demnach nur Ganymed sein. Iris ist zwar als Räuberin des Ganymed im Auftrag des Zeus nicht direkt überliefert, doch bezeichnet ein Scholion zu Apollonios Rhodios unter Berufung auf den Lyriker Ibykos des 6. Jhs. Eos als Entführerin des trojanischen Prinzen (Schol. Apoll. Rh. 3, I I 4-I I 7 b Wendel). Eos jedoch raubte schöne Knaben stets ausschließlich im eigenen Interesse und hätte Ganymed wohl kaum dem Zeus überlassen, sodass die Vermutung einer Verwechslung von Eos mit Iris naheliegt. Schließlich tritt auch Hermes, der Iris als Götterbote ablöst, als Entführer des Ganymed auf, wie einige attisch-rotfigurige Vasenbilder zeigen, vgl. die Beispiele bei H. Sichtermann, Ganymed (Berlin I953) 78 Kat. 52 (= 372); 96 Kat. 367-368 oder war zumindest an dem Knabenraub beteiligt (Schwarz a. O. 4 f.). Auch er handelt im Auftrag des Zeus und nicht etwa in eigener Sache (Sichtermann a. O. 26). An verschiedenen anderen Beispielen lässt sich zeigen, dass die beiden Götterboten „austauschbar“ waren und literarische und bildliche Zeugnisse für dieselbe Szene durchaus zwischen ihnen wählen konnten (Schwarz a. O. 5). Doch was lässt in dem Knaben auf der Grazer Schale tatsächlich Ganymed erkennen und nicht einfach einen Sterblichen, der von einem raffenden Dämon verfolgt wird? Er hält ein Netz mit nicht näher definiertem Inhalt mit der Linken hoch. In solchen Netzen bewahrten Kinder in der Antike besonders gern Astragale auf, ein Spielzeug, das von ihnen hoch geschätzt wurde, vgl. RE II I793-I795 s. v. Astragalos (Mau); E. Schmidt, Spielzeug und Spiele der Kinder im klassischen Altertum, Südthüringische Forschungen 7 (Meiningen I97I) 55 f. 85 ; M. Fittà, Spiele und Spielzeug in der Antike (Stuttgart I998) I4-г 8. Besonders Ganymed war ein leidenschaftlicher Knöchelspieler (Hom. Il. 20, 233), musste doch Zeus ihm, um ihm den Aufenthalt im Olymp schmackhaft zu machen, Eros als Spielgefährten und sehr viele Astragale versprechen (Lukian. dial. deor. IV 3 Jacobitz). Und auch er selbst fand es nicht unter seiner Würde, mit dem Knaben der Knöchelspielleidenschaft zu frönen, was den eifersüchtigen Spott der Hera hervorrief (Lukian. dial. deor. V 2). Bei Apollonios Rhodios treffen wir denn auch Eros und Ganymed in ihr Knöchelspiel versunken an (III I I4-II7 b), und monumentale Darstellungen astragalspielender Knaben lassen sich häufig auf Eros und Ganymed deuten, vgl. B. Neutsch, Spiel mit dem Astragal, in: Ganymed, Heidelberger Beiträge zur antiken Kunstgeschichte (Heidelberg I949) I 8 f. 27 Anm. 30 Abb. I3. Auch die "pueri astragalizontes“ des Polyklet (Plin. nat. hist. 34, 55) wollte man daraufhin auf Eros und Ganymed benennen, freilich ohne wirklichen Anhaltspunkt, Neutsch a. O. I 8 f.; vgl. dage- gen RE XXI, 2 (München I952) I7I I Nr. I6 s. v. Polykleitos (G. Lippold). Das Netz mit den Astragalen dürfte demnach die Benennung des Grazer Knaben auf Ganymed nicht unerheblich stützen. Die fragmentierte Schale scheint also der bisher einzige Beleg für eine Sagenversion zu sein, nach welcher der Raub des Ganymed durch Iris ausgeführt wird.

Außenseiten: Zur Darstellung allgemein vgl. X. Krieger, Der Kampf zwischen Peleus und Thetis in der griechischen Vasenmalerei (Münster I975). Zu Nereiden: J. Barringer, Divine escorts: Nereids in archaic and classical Greek art (Ann Arbor 1995). Ob sich auf unserer Schale Thetis in mehrere Tiere verwandelt oder nur in eine (oder mehrere?) Schlange, lässt sich wegen des Erhaltungszustandes nicht mehr ausmachen. Die eindrucksvollste Darstellung des Ringkampfes bietet wohl das Innenbild der Schale des Peithinos aus Vulci in Berlin, Antikensammlung F 2279, wo sie sich in einen Löwen und drei Schlangen verwandelt, die Peleus bedrohen: ARV ${ }^{2}$ I I 5, 2; I 626; Para 332; Add $^{2}$ I74; CVA Berlin 2 Taf. 6I, I; LIMC VIII (Zürich I997) 8 Nr. I3 s. v. Thetis (R. Vollkommer); Krieger a. O. 47; Schefold, SB II, I90 f. Abb. 257. Auf zahlreichen attisch-rotfigurigen Vasen verschiedener Formen vom Ende des 6. Jhs. an findet sich der Ringkampf wie auf der Grazer Schale mit den zu ihrem Vater Nereus fliehenden Nereiden vergesellschaftet, vgl. LIMC VI (Zürich I992) 830 f. Nr. 69-86 s. v. Nereus (M. Pipili). Besonders gut eignen sich jedoch Schalenaußenseiten für diese vielfigurige Szene, vgl. etwa die Schale aus Vulci in München, Staatl. Antikensammlungen 2648 (um 480), die Beazley dem Douris oder seiner Schule zuschreibt: ARV 244 I, I 85 (school-piece?); Para 52 I; Add $^{2}$ 240; FR I Taf. 24; R. Lullies - M. Hirmer, Griechische Vasen (München I953) Taf. 80 unten; 88-9I; P. E. Arias - B. Shefton - M. Hirmer, A History of Greek Vase-Painting (London I963) Taf. I43; Buitron-Oliver, Douris, 88 Kat. O,8 Taf. I34: Ödipus-Maler; LIMC VI (Zürich I992) 83 I Nr. 78 s. v. Nereus (M. Pipili); LIMC VIII (Zürich I997) 9 Nr. 20; Schefold, SB II, I90 Abb. 256 (Epeleios-Maler) = LIMC VI (Zürich I992) 805 Nr. 284 s. v. Nereides (N. Icard-Gianolio - A.V. Szabados). Auf der Schale in München 2648 verwandelt sich Thetis in einen Löwen. Ein ähnliches Ensemble, bei dem ebenfalls die Verwandlung in einen Löwen angedeutet wird, auch auf den beiden Schalen des Douris im Louvre G I I6: ARV ${ }^{2}$ 43 I, 44; Add ${ }^{2}$ 236; Buitron-Oliver, Douris, 77 Nr. 64 Taf. 47; LIMC VI (Zürich I992) 830 f. Nr. 77 s. v. Nereus (M. Pipili), sowie Louvre G I26: $\mathrm{ARV}^{2}$ 438, I 29; Para 375; Add $^{2}$ 239; Buitron-Oliver, Douris, 83 Kat. I74 Taf. 97; LIMC VI (Zürich I992) 830 Nr. 76 s. v. Nereus (M. Pipili); möglicherweise auch auf dem Fragment einer DourisSchale in Bryn Mawr, The Ella Riegel Memorial Museum P 942: $\mathrm{ARV}^{2}$ 44I, I 82; Para 375; $\mathrm{Add}^{2}$ 240; CVA Bryn Mawr I Taf. I7, I-2; Buitron-Oliver, Douris, 84 f. Nr. 2 I 6 Taf. Io8.

Zum Maler: Der Maler der Pariser Schale Louvre G 265, dem Beazley die Fragmente zuwies, gilt als ein Nachahmer des BrygosMalers, der innerhalb der „Mild-Brygan Group“ als „weak“ geführt wird $\left(\mathrm{ARV}^{2}\right.$ 405. 4I6). Tatsächlich zeigt sich der Maler der Grazer Schale dem Brygos-Maler in manchen Details stark verpflichtet: So ähnelt der Kopf der Flügelfrau mit dem schweren Kinn und dem vom Sakkos verhüllten Haar der Selene auf ihrem von zwei geflügelten Rossen gezogenen Gespann in Berlin, sogar die Dekoration des Sakkos mit einem Punktmuster ist vergleichbar. Auch das Gefieder der Flügel ist an der Flügelfrau ähnlich wiedergegeben wie an den Rossen auf dem Innenbild der Schale des Brygosmalers in Berlin, Antikensammlung F 2293: ARV² 370, Io; Para 365. 367; Add $^{2} 224$; CVA Berlin 2 Taf. 70, 3; A. Cambitoglou, The Brygos-Painter (Sydney I968) Taf. I0, I. Diese Art von Kopfbedeckung findet sich beim Brygos-Maler häufig, etwa auf Seite B der Schale London, BM E 65: ARV² 370, I3; I649; Para 365. 367; Add $^{2}$ 224; M. Wegner, Brygosmaler (Berlin I973) Taf. 7; weiters auf dem Innenbild der Schale in Wien, Univ. 502: $\mathrm{ARV}^{2}$ 377, I09; CVA Wien I, Universität und Professor Franz v. 
Matsch (Deutschland 5) Taf. I I, I; sowie auf der Schale in Bowdoin I9I3.2I: $\mathrm{ARV}^{2}$ 378, I36; $\mathrm{Add}^{2}$ 226; D. M. Buitron, Attic Vase Painting in New England Collections (Cambridge, Mass. I972) 89 Nr. 44; ebenso auf dem Tondo der Schale in Florenz, Museo Archeologico Etrusco 76I03: $\mathrm{ARV}^{2}$ 379, I42; $\mathrm{Add}^{2} 226$; Wegner a. O. Taf. $40 \mathrm{~h}$; und der Schale in Bryn Mawr P I86: $\mathrm{ARV}^{2}$ 379, I43; $\mathrm{Add}^{2}$ 226: CVA Bryn Mawr College I Taf. II, 7; sowie auf der Kylix in München, Staatl. Antikensammlungen 2675: ARV $^{2}$ 379, I 5I; Add $^{2}$ 227; Wegner, a. O. Taf. 40 f.; CVA München I6 Taf. 22, 3 .

Verwandtschaft besteht auch zwischen dem Knabenkopf mit der spitzen Nase und dem hinter der Unterlippe zurücktretenden Kinn und der Zeuxo des Brygosmalers auf dem Innenbild der Schale in London, BM E 65: ARV ${ }^{2}$ 370, I3; I649; Para 365. 367; Add $^{2}$ 224; Cambitoglou a. O. Taf. 8, I; Wegner a. O. Taf. I6 b; 40 g. Das Netz in der Hand des Knaben findet sich auch bei dem jungen Eromenos im Innenbild einer Schale des Brygosmalers in Oxford, Ashmolean Museum I967.304: ARV² 378, I37; Boardman ARFV I, Abb. 260; Sport dans la Grèce antique, 238 Nr. IO2.

\section{TAFEL 54}

1-3. Siehe Tafel 53, 5.

\section{TAFEL 55}

1. Siehe Tafel 53, 5.

2-3. Tafel 56, 1-2. Schale

Beilage 15, 3.

G I98. Fundort unbekannt. Erworben vor 1937.

H erh. 4,2 cm. - Dm Rand rek. 24,2 cm. - Wandstärke 0,7 cm. ARV2 809, I4 („Vienna, Univ.“, ohne Fragment B). - Schwarz, Komostänzer, I25-I28 Abb. 68-7I. - BAPD 209993.

Zustand: Sechs Scherben einer Schale. Vier anpassende Scherben zusammengesetzt, eine größere Fehlstelle in Gips ergänzt und schwarz bemalt (das Motiv auf der Außenseite orangefarben ergänzt): Fragment A. Zwei weitere Scherben zusammengesetzt: Fragment B (bei Beazley nicht erwähnt). Fragmente A und B nicht anpassend. Entlang der Bruchkanten einige kleinere Absplitterungen.

Malmittel: Glänzend schwarzer Tonschlicker. Relieflinie: Binnenzeichnung des Jünglingskörpers, Gewandfalten. Aufgesetzte Farbe: Rot für die Blätter des Kranzes. Ausgesparte Kopfkontur.

Form: Schale Form B. Flacher, nur leicht gewölbter Schalenkörper, Ansatz eines runden Stielfußes.

Dekor: I: Um das Mittelbild rechtsläufiger Mäander. A und B: Dünner tongrundiger Streifen als Standlinie für die Figuren. Henkelpalmetten: Auf A ist etwa die Hälfte erhalten von einer ursprünglich elfblättrigen Palmette (fünf Blätter erhalten), von einer Ranke umschrieben, welche unter der Palmette in Voluten endigt (die linke noch sichtbar). Aus der Ranke wächst ein langer Trieb empor, aus dem abermals eine Volute sprießt. B: Erhalten nur der lange Rankentrieb, aus dem eine Volute entspringt. Innen und außen unterhalb der Lippe eine tongrundige Linie.

Darstellung: A junger Tänzer. - I: Oberes Ende eines Knotenstocks. A: Nackter Jüngling, der einen zusammengefalteten Mantel von vorne über Brust und Oberarme geworfen hat, in einem Tanzschritt nach links, wohin auch sein bekränzter Kopf gewendet ist. Der Jüngling ist links neben einem Henkelornament positioniert, von dem sich etwa die Hälfte erhalten hat. B: Rechter Unterarm und Hand einer Figur, die mit nach links ausgestrecktem Arm einen gefalteten Mantel hält. Die Figur befindet sich rechts neben der Henkelpalmette, von der sich nur mehr der Trieb samt Volute erhalten hat.

Um 460 - Nahe dem Klinik-Maler (Beazley)

Zur Form: Richter - Milne, Shapes, 25. Wie alle vom Klinik-Maler selbst oder in seiner Art bemalten Schalen besaß auch diese einen Fuß, der im Ansatz zu erkennen ist (mit Ausnahme der „stemless cup" London, BM E I24: ARV2 8 I3, 94).

Zur Darstellung: Symposion- und Komos-Szenen nehmen im Werk des Klinik-Malers und der ihm nahestehenden Maler, das hauptsächlich aus Schalen besteht, naturgemäß einen großen Raum ein. Wie der Rest des Innenbildes zeigt, bewegte sich auch dieses in derselben Sphäre, nämlich der Welt der attischen Bürger, wurde doch der Stock als „Symbol und Ausweis des freien Atheners“ angesehen: Zitat G. Koch-Harnack, Knabenliebe und Tiergeschenke. Ihre Bedeutung im päderastischen Erziehungssystem (Berlin I983) 208, vgl. auch H.-G. Hollein, Bürgerbild und Bildwelt der attischen Demokratie auf rotfigurigen Vasen des 6.-4. Jhs. v. Chr. (Frankfurt am Main I988) I7 f. Anm. 30. 33. A: Der tanzende Jüngling hat seinen Mantel zu einer Schärpe zusammengelegt und sie von vorne über Brust und Oberarme geworfen, sodass sein Rücken nackt bleibt. Der jugendliche Tänzer ist in Frontalansicht gezeichnet, nur der Kopf ist ins Profil gedreht. Im Haar trägt er einen Kranz, dessen Blätter in aufgesetztem Rot wiedergegeben sind. Die Kopfkontur ist ausgespart. Das Profil zeigt eine niedere Stirn, einen langen, leicht konkav gebogenen Nasenrücken mit spitzer Nase und geschürzte Lippen. Die Schädelform weist einen flachen Oberkopf mit ausladendem Hinterhaupt auf. Der Kranz sitzt tief in der Stirn. Wenige einzelne Härchen schieben sich abgesondert von der Haarkappe, die eng anliegt, vor dem hochsitzenden Ohr in die Wange. Die Binnenzeichnung des Körpers ist in feinen Relieflinien ausgeführt, im Becken sind die Leistenwülste stark betont. Besonders signifikant ist die Wiedergabe des Schamhaares in Form eines auf den Kopf gestellten T, das mit zwei dicken Pinselstrichen gezogen ist. Der Jüngling führt vor unseren Augen eine präzise Tanzfigur aus: Er bewegt seine Hände in graziösen Gesten, die linke weist im Verlauf des gestreckten Armes mit geöffneter Handfläche nach unten, der Daumen ist abgespreizt. Die rechte Hand ist bei gestrecktem Arm mit der Handfläche nach außen nahezu in rechtem Winkel aufgebogen. Beide Füße stehen mit ganzer Sohle und nach außen gedrehten Fußspitzen fest am Boden. Beide Knie sind gebeugt, das rechte etwas mehr als das linke. In der Terminologie des klassischen Balletts handelt es sich bei diesem Tanzschritt um ein „plié inégal à la seconde aux pieds en dehors“, vgl. G. Prudhommeau, La danse grecque antique (Paris I965) 37, 4I; 94, 273; I 20, 389 Abb. 27I. Die Position dient als Vorbereitung für einen Sprung (échappé), mit dem die Beine wieder zusammengeführt werden.

B: Die verlorene Figur, die mit ausgestrecktem Arm einen gefalteten Mantel hält, ist ebenfalls als tanzender Jüngling oder Mann zu ergänzen.

Zum Maler: ARV2 808-8I 4; Para 420; Add $^{2}$ 29I f.; Boardman, ARFV I, I95; Boardman, RFVA I, 2I3. Die originelle Darstellung auf einem Aryballos im Louvre CA 2183, die eine Klinik zeigt (ARV2 8I 3 f., 96; Boardman, RFVA I, Abb. 377), gab dem Maler, der in der Makron-Nachfolge neben dem Telephos-Maler die Hauptrolle spielte, seinen Namen (CVA Berkeley Io, 4I). In ARV² 807 spricht Beazley von der Schwierigkeit, Vasen, die er definitiv dem Klinik-Maler zuschreibt, von denen, die ihm nahestehen, $\mathrm{zu}$ trennen und vereinigt die beiden Listen. Boardman, ARFV I, I 95 und Boardman, RFVA I, 2 I 3 bezeichnet den Klinik-Maler als überdurchschnittlich und würdigt seinen Sinn für Humor. Der Ma- 
ler dekorierte hauptsächlich Schalen, auf die er mit Vorliebe tanzende und musizierende Komasten setzte. Seine anspruchsvollsten Bilder jedoch, die erwähnte Szene in der „Klinik“ und die deutlich in der Makron-Nachfolge stehende Gesandtschaft zu Achill in Berlin, Antikensammlung F 2326 (ARV² 8 I 4, 97; Add ${ }^{2}$ 292) setzte er auf Aryballoi, während Makron seine Presbeia auf einen Skyphos malte, heute im Louvre G I 46 (ARV² 458 f., 2; 48 I [Töpfer Hieron]; I654; Para 377; Add $^{2}$ 243). In den Komos-Szenen liebt der Maler den zu einer Schärpe zusammengefalteten Mantel, den die Tänzer von vorne über Brust und Schultern geworfen haben, vgl. die Außenseite einer Schale in Orvieto, Museo Civico Io3 8: ARV ${ }^{2}$ 809, 9; CVA Musei Comunale Umbria I, III I c Taf. 5, I. Weitere Beispiele für dieses Gewandmotiv bei Komasten, das nicht häufig anzutreffen ist, sind die Seite B der Schale des Epiktetos in London, BM E 37: ARV $^{2}$ 72, I7; I 623; Para 328; Add $^{2}$ I 67; Prudhommeau a. O. Abb. 847 f.; F. Lissarrague, Around the Krater: An Aspect of Banquet Imagery, in: O. Murray (Hrsg.), Sympotica. A Symposium on the Symposium (Oxford I994) I99 Abb. I 8 b; und Seite A der Pelike des Geras-Malers in Basel, Antikenmuseum BS 06.30I: $\mathrm{ARV}^{2}$ 285, 2; CVA Basel 2 Taf. 5 I, I. Auch eine Mänade auf einer Kylix des Epiktetos in Paris zeigt dieselbe Gewanddrapierung, Louvre G 6: ARV $^{2}$ 72, 2I; CVA Louvre Io, III I b Taf. Io, 6-7. Allen diesen Figuren ist gemeinsam, dass sie tanzen. Dem Grazer Tänzer brüderlich verwandt erscheint der Diaulosbläser auf einem Skyphosfragment in Adria B 49: ARV² 813, 95; CVA Adria, Museo Civico I, III, I Taf. 38, 7; Schwarz, Komostänzer, I 27 Abb. 72. Er zeigt dieselbe Schädelform und dasselbe Profil mit der niederen Stirn und der langen, vorne etwas aufgebogenen Nase. Auch die knappe Haarangabe mit den in Stirn und Schläfen gekämmten Fransen und dem tief in die Stirn gedrückten Kranz sind identisch. Vielleicht gehörte auch der Flötenspieler aus Adria zu einer Komos-Darstellung, wo er zum Tanz aufspielte. Das Fragment wird bei Beazley (ARV2 809, I4) mit einer Schale in St. Petersburg B.2638 verglichen, auf der sich auch die schlanken, stark gelängten Körper der Figuren erhalten haben: ARV ${ }^{2} 8$ IO, 20; G. Q. Giglioli, Phyllobolia, ArchCl 2, I950, 32 Taf. XII I. 2 (A und B); A. A. Peredolskaja, Attisch-rotfigurige Vasen in der Eremitage, Katalog (КРАСНОФИГУРНЫЕ АТТИЧЕСКИЕ ВАЗЫ В ЭРМИТАЖЕ ЛЕНИНГ, Leningrad І967) 8I f. Taf. 58, І-3; 44, 7; CVA St. Petersburg, State Hermitage Museum 5 Taf. 53-55. Dargestellt ist auf I ein Knabe mit Spielwagen, von dem besonders das Profil, aber auch der zusammengerollte Mantel vergleichbar ist. Die Außenseiten zeigen jeweils einen Knabensieger mit zwei Schiedsrichtern. Bei einem der Jünglinge (Schwarz a. O. Abb. 74) springt die Ähnlichkeit mit dem Grazer Fragment in der Wiedergabe des Rumpfes ins Auge: Schlüsselbeine und Brustmuskulatur, die fast eckigen Leistenwülste, von denen sich die Weichteile in einem langgezogenen U-förmigen Bogen absetzen, sowie die Wiedergabe des Genitals und des Schamhaares in Form eines umgekehrten T sind ident. Ebenso überzeugend wie die Körperbildung weisen die Henkelornamente auf dieselbe Malerhand.

\section{TAFEL 56}

\section{1-2. Siehe Tafel 55, 2-3.}

3-5. Schale

Beilage 15, 4.

G I96. Fundort unbekannt. Erworben vor 1937.

H erh. 3,6 cm. - Dm Stiel I,7 cm. - Wandstärke o,4 cm. - Gewicht $[46,4 \mathrm{~g}]$.

Unpubliziert.
Zustand: Zwei Fragmente, zusammengesetzt. Drei Viertel des Schalenkörpers, Rand und Fuß abgebrochen. Oberfläche entlang der Bruchkanten abgerieben, ansonsten nur wenige winzige Bestoßungen. Ansatz eines runden Stielfußes und eines Horizontalhenkels erhalten.

Malmittel: Glänzend olivschwarzer Tonschlicker. Relieflinien: Mantelfalten der Frau im Medaillon. Verdünnter Glanzton: Haarband der Frau mit flatternden Enden.

Form: Schale Typ B mit flachem, nur leicht gewölbtem Schalenkörper.

Dekor: Um das Medaillon ein Band aus jeweils drei linksläufigen Mäandergliedern, dazwischen eine quadratische Platte mit zentralem Kreuz und vier schwarzen Würfeln in den Ecken. Außenseite: Henkelpalmette und Palmettenherz nur zur Hälfte erhalten, zwei Voluten, aus der größeren entspringt ein langer Trieb, der sich (offenbar) biegt und wieder zu einer Volute einrollt, aus der abermals ein Trieb hervorgeht. Aus den Ansatzstellen der Triebe sprießen Blätter. Zwei konzentrische, tongrundige Kreise als Standlinien für die Figuren auf der Außenseite.

Darstellung: I zwei Personen, A Satyr verfolgt Mänade. - Im Medaillon rechts eine Frau in Mantel gehüllt in Vorderansicht, im zum Knoten hochgesteckten Haar ein Band mit wegflatternden Enden, den Kopf nach links gewandt. Links neben ihr oben die rechte Hand und Unterarm, unten der Rest der linken Hand einer zweiten Figur. Außenseite: links ein Satyr nach rechts springend, von dem die Beine, Hüfte, Schwanz und rechte Hand erhalten sind. Rechts von ihm eine Frau (Mänade?) in Chiton und Mantel, die nach rechts flieht (nur Unterteil erhalten).

Um 450

Zur Form: Kleine Schale Typus B. Flacher, nur leicht gewölbter Schalenkörper, Ansatz eines runden Stielfußes und eines Horizontalhenkels.

Zum Dekor: vgl. CVA St. Petersburg, State Hermitage Museum 5 Taf. 66 f. 73 f. (Schale des Sotades- und Karlsruhe-Malers) sowie CVA Benaki-Museum I Taf. 55-58 mit ähnlichem HenkelOrnament.

Zur Darstellung: Die Szene im Tondo lässt sich wegen des Erhaltungszustandes nicht mehr interpretieren, doch scheint die Frauengestalt, die ihren Mantel eng um den Körper geschlungen hat, sodass er auch die Hände verdeckt, vor einer sich von links nähernden Gestalt, die beide Arme mit geöffneten Händen nach ihr ausstreckt, zurückzuweichen.

Zum Maler: Der Maler ist im weiteren Umkreis des PenthesileaMalers zu suchen, vgl. etwa die Schale in Karlsruhe (mit umschriebenen Henkelpalmetten), wo im Innenbild ein Jüngling mit Speer eine Frau verfolgt, während auf den Außenseiten Satyrn Mänaden hinterher jagen, Badisches Landesmuseum 59/72: $\mathrm{ARV}^{2}$ 883, 60; I673; Add $^{2} 301$; CVA Karlsruhe 3 Taf. 35, I-2; 36, I-3; J. Thimme, Neuerwerbungen des Badischen Landesmuseums Karlsruhe, AA I960, 59-65 Nr. 5 Abb. I3-I6; J. Thimme, Griechische Vasen. Eine Auswahl aus den Sammlungen des Badischen Landesmuseums (Karlsruhe I975) Abb. 45-47; V.-M. Strocka, Alltag und Fest in Athen. Griechische Vasen zur Ausstellung (Freiburg I987).

\section{TAFEL 57}

\section{1-3. Schale}

Beilage 15, 5 .

G I97. Aus Orvieto. Erworben vor 1937.

H erh. 3,5 cm. - Dm Stiel I, 6 cm. - Wandstärke o,8 cm. - Gewicht $69, \mathrm{I}$. 
Unpubliziert.

Zustand: Ein Fragment. Fuß, Rand und große Teile des Schalenkörpers abgebrochen. Einige kleinere Bestoßungen auf der Innenund Außenseite.

Technik: Tonschlicker glänzend schwarz, bei dünnem Auftrag dunkelgraue Farbwirkung. Figuren mit dickem Pinselstrich umfangen. Dicke Pinselspur für Mantelsäume auf I. Relieflinien an Körpern und Himatia der Jünglinge auf I sowie an Füßen und Gewändern der Figuren auf A und B. Vorzeichnungen für die Körper beider Jünglinge auf I.

Form: Kleine Schale Typus B. Flacher, nur leicht gewölber Schalenkörper, Ansatz eines runden Stielfußes.

Dekor: Der Tondo ist mit einem Kreuzplattenmäanderband gerahmt: Bis zu fünf rechtsläufige Mäanderglieder alternieren mit einem Quadrat, in dessen Zentrum ein schwarzes Kreuz und in den Ecken schwarze Punkte. Verschluss linksläufig. Henkelpalmette: Zwölfblättrige Palmette mit Punkt im Kern. Unter ihr zwei Doppelvoluten, aus denen Triebe hervorsprießen; in den leeren Flächen Keile.

Darstellung: I und A Manteljünglinge. - I: Auf einer tongrundig belassenen Standfläche zwei Jünglinge im Himation frontal stehend. Der linke hat die rechte Schulter frei und den rechten Arm gesenkt. Er wendet den Kopf nach rechts seinem Partner zu. Dieser hat den Kopf nach links gedreht und den rechten Arm erhoben, die Hand im Redegestus. Seine rechte Schulter ist ebenfalls nackt. A: Untere Hälfte einer männlichen Figur im Himation, rechts neben ihr Stock und Fuß einer weiteren Figur. B: Unterteil einer männlichen Figur im Himation, links neben ihr Fuß einer weiteren Gestalt.

Um 420 - Montlaurès-Maler (Beazley)

Zur Form: Zu kleinen Schalen des Typus B vgl. Agora XXX, 687 I (mit Bibliographie).

Zur Darstellung: I: Die Unterhaltung der beiden Jünglinge ist im Vergleich zu der doch eher bescheidenen Malerei ausgesprochen lebhaft, der rechte hat den Kopf zu eindringlicher Rede gesenkt und gestikuliert heftig mit der rechten Hand, während der Gesprächspartner, der sich zum Weggehen nach links anschickt, abweisend wirkt, da er ihm die "geschlossene“ Körperseite zuwendet. Auch die abwärts deutende Geste seiner rechten Hand drückt Ablehnung aus. ARV ${ }^{2}$ I 295, 24 („Vienna, Univ., frr., from Orvieto. One fragment, CV. pl. 23, 8. I, two youths [in himatia, frontal, one with head to right, the other with head to left and right arm extended. A, [on the left, lower half of a male, then a stick and a foot]; B, [on the right, a foot, and a male]. The published fragment cannot be placed exactly.”). Das in CVA Wien I, Universität und Professor Franz v. Matsch (Deutschland 5) Taf. 23, 8 abgebildete Fragment, welches Kopf und Oberkörper eines Jünglings in schwarz gesäumtem Himation und mit weißem zweizackigen Diadem im Haar bewahrt hat, stimmt nicht mit Beazleys Beschreibung überein, welche sich auf den größeren Teil der Schale in Graz bezieht. Es gehört jedoch zu derselben Schale, wahrscheinlich auf eine Außenseite, auch wenn es nicht direkt platziert werden kann (ARV' I 296, 24).

Zum Maler: ARV² I 294-I 296; Para 474; Add $^{2}$ 359; Beazley zählt diesen Maler unter den klassischen Schalenmalern zu den „minor painters of cups and stemlesses“. Den Namen gab er ihm nach einem Gefäß (Skyphos oder Schale) aus Montlaurès in Narbonne ohne Inv. (ARV² I 295, IO). Der Maler dekorierte zumindest eine Schale gemeinsam mit dem Maler von Heidelberg 2 I I, in Todi, Museo Civico I94.568 (475): ARV² I295, I8; Add ${ }^{2} 359$; CVA Umbria, Musei Communali I, III I d Taf. 8, 3. 7. Sein Repertoire ist nicht besonders reichhaltig. Auf den Schalen figurieren ausschließlich Athleten, Jünglinge und reife Männer. Nur auf einem Skyphos und zwei Pyxiden erscheinen auch Frauengestalten und Eroten, vielleicht sogar das mythische Paar Paris und Helena, so auf der Pyxis in München, Staatl. Antikensammlungen 2722: ARV $^{2}$ I 296, 26; Add $^{2}$ 359; CVA München 2 Taf. 97, 2. 5-6. Der Maler geht in der Wiedergabe aller Details sehr sorglos vor: Die Kopfkontur ist ausgespart und ein dicker Farbklecks bildet die Haarkappe, aus der sich einzelne Härchen stehlen, so wie auf dem Tondo der Grazer Kylix sich bei dem linken Jüngling eine lange Locke hinterm Ohr auf die Wange ringelt. Die Gesichter zeigen eine lange Nasenlinie und ein kurzes Untergesicht. Die Muskelpartien sind mit wenigen Linien skizziert, ebenso die Gewandfalten. Auffallend ist der mit dicken Pinselstrichen akzentuierte Saum der Himatia. Die fragmentierten Schalen in Todi, die Beazley derselben Malerhand zuweist (ARV2 I 295, I I. I2. I 8. I9; $\mathrm{Add}^{2}$ 359; CVA Umbria, Musei Comunali I, III I d Taf. 9, I-2; 8, 3. 6-7) sind wegen des schlechten Erhaltungszustandes nicht sehr aussagekräftig. Sie zeigen auf Innen- und Außenseiten ebenfalls Jünglinge und Männer im Gespräch. Der linke Jüngling auf Taf. 9, I zeigt dieselbe Haargestaltung samt langem Lockenkringel sowie denselben nach unten weisenden Gestus der rechten Hand wie der Grazer Jüngling. Die Mäanderbänder sind gröber gemalt, während die Henkelpalmetten auf Taf. 8, 7 der unseren entsprechen.

\section{4-5. Tafel 58, 1-3. Schale}

\section{Beilage 16, 1.}

G 24. Aus Capua. Erworben I873 durch Wolfgang Helbig in Rom, Ankauf. Alte Inv.-Nr. II 23 (Schenkl) bzw. III 3 I (Pichler).

$\mathrm{H}_{4,7} \mathrm{~cm}$. - Dm Mündung I $5,4 \mathrm{~cm}$. - B mit Henkeln 22, I cm. - Dm Fuß 7,2 cm. - Dm Henkel o,8 cm. - Gewicht 2 I 6 g. - Volumen $409 \mathrm{ml}$.

Lehner - Lorenz - Schwarz, Vasen, 4I f. Nr. 22 Abb. 29 (G. Schwarz). - BAPD 44I05.

Zustand: Vollständig erhalten, vor allem außen zahlreiche kleinere oberflächliche Absplitterungen, tiefere Absplitterungen an den Henkelansätzen.

Technik: Tonoberfläche orangefarben, Bemalung glänzend schwarz. Vorzeichnungen: Beine. Relieflinien am linken Fuß und für die Binnenzeichnung der Figur. Zusätzliche Farbe: Weiß für den Kranz. Ausgesparte Kopfkontur.

Form: Fußlose Schale mit hohem, doppelt profiliertem Standring. Flacher, konkaver Schalenkörper mit steilschräg aufgestellter Randzone. Rund abgestrichene Lippe. Gegenständige, nach oben gebogene Horizontalhenkel mit rundovalem Querschnitt.

Dekor: Auf der Gefäßunterseite im Zentrum ein tongrundiger Punkt inmitten eines kleinen Kreises in Glanzton. Fußring innen und außen mit Glanzton überzogen, mit Ausnahme eines tongrundigen Streifens an der Kante der Standfläche. Das linksläufige Mäanderband um das Medaillon wird nach jeweils vier Mäandergliedern von einzelnen Quadraten je mit vier tongrundigen und fünf Glanztonfeldern (Schachbrettmäander) unterbrochen. Mäanderverschluss oben.

Darstellung: Manteljüngling. - Im Tondo ein Manteljüngling nach links mit langem Stock. Der Jüngling steht mit um die linke Schulter geworfenem Mantel in Dreiviertelansicht vor uns, wobei er den Kopf im Profil leicht zur rechten Schulter neigt und den rechten Arm weit von sich gestreckt auf einen hohen Stock stützt, dessen Griff er mit der Hand umfasst. Die Linke hat er unter dem Mantel verborgen in die Hüfte gestemmt. Im gelockten Kurzhaar trägt er einen in Weiß aufgemalten Blattkranz. Der Jüngling steht auf dem rechten Bein, der Fuß des Standbeines, über dem sich die Hüfte etwas ausbiegt, ist nach links gedreht. Der linke Fuß ist in Verkürzung frontal gesehen. Trotz des ruhigen Standes wird so die Tendenz einer Bewegung vom Betrachter aus nach links vermittelt, zumal der Jüngling auch nicht in der Vertikalachse des Kreisrundes steht, sondern der größere Teil seines Körpers sich in der rechten Medaillonhälfte befindet. 
Um 430 - Kalliope-Maler (Schwarz)

Zur Form: Schalen auf niedrigem Ringfuß sind im 5. Jh. sehr selten. Dem Kalliope-Maler war bis jetzt erst eine Schale dieser Form zugewiesen worden, das Fragment in Berlin Sa 48I x: ARV ${ }^{2}$ I 262 , 58 bis; Para 47I; CVA Berlin 3 Taf. Io8, 3. 6; A. Lezzi-Hafter, Der Eretria-Maler. Werke und Weggefährten, Kerameus 6 (Mainz I 988$) 302$ f. Kat. 300 Taf. I 88 a. b Abb. I04. Zu dieser Schalenform vgl. auch Wehgartner, AWK, 49-5 I.

Zur Darstellung: Manteljünglinge wie dieser bevölkern vom beginnenden 5. Jh. an ohne Zahl die Bildflächen griechischer Vasen. Sie sind als Selbstdarstellung des athenischen Bürgers gedacht, also desjenigen, der diese Vasen bestellte, kaufte und verwendete. So ist es naheliegend, dass sich die athenische Bürgerschaft auch selbst verkörpert sehen wollte, als Idealbild ihrer Gesellschaft, vgl. H.-G. Hollein, Bürgerbild und Bildwelt der attischen Demokratie auf den rotfigurigen Vasen des 6. bis 4. Jhs. v. Chr. (Frankfurt am Main I988): Unser Jüngling verkörpert den „dynamis-Typus“, vgl. Hollein a. O. 25 f. 3 I f. 36. 86. 88. 99. II3. I 30 f. I40. I48. I62 f. I 80 f. I92 f. 2 IO. Zum Stock siehe auch G 2 I bzw. G I98, hier Tafel 42, I-2; 43, I-5 bzw. Tafel 55, 2-3; 56, I-2.

Zum Maler: Zum Eretria-Maler und seinen Werkstattgenossen in der EKDN-Werkstatt (Eretria-, Kalliope-, Disney-Maler und Maler der Neapler Hydriskai), vgl. Lezzi-Hafter a. O.; zum Kalliope-Maler speziell Lezzi-Hafter a. O. 48-57.302-307. 322327; vgl. weiters ARV2 I 259-I 264. I 688. I707; Para 470 f.; Add $^{2}$ 355. Die Jünglingsfigur weist stilistische Besonderheiten auf, die sie in die Nähe des Eretria-Malers rücken und wohl einem seiner Werkstattgefährten, dem Kalliope-Maler, zuzuschreiben sind. Der Kalliope-Maler, ein Schalenmaler, der produktivste Mitarbeiter der EKDN-Werkstatt (Lezzi-Hafter a. O. 48), erhielt seinen Namen von Beazley nach der Muse Kalliope, die er auf zwei seiner Schalen malte und auch inschriftlich bezeichnete (ARV ${ }^{2}$ I 259, 4. 3; Lezzi-Hafter a. O. 326 f. Kat. I23. I26 Taf. 84. 85 g. h). Er besaß eine besondere Fähigkeit, das Gewand mit wenigen Pinselstrichen gekonnt zu stilisieren. Charakteristisch sind vor allem das enge Faltengeschiebe, das sich von der linken Schulter quer über die Brust zieht, die lappenartigen Falten darunter sowie der von der linken Schulter fallende getreppte Mantelsaum, aber auch die Tendenz, unter dem Mantel möglichst viel von der Figur und ihrem Standmotiv erahnen zu lassen. Auch sind die Haken seiner Mäanderbänder stets offen, während sie sich auf der Grazer Schale schließen. Doch auch bei ihr bleibt die äußere Beckenwand mit Glanzton überzogen. Vergleichbare Manteljünglinge gibt es etwa auf der Schale in Boston 21.4: Lezzi-Hafter a. O. 322 Kat. 84 Taf. 63, und auf den beiden Schalen aus Spina in Ferrara T $30 \mathrm{I} \mathrm{B:}$ Lezzi-Hafter a. O. 322 Kat. 83 Taf. 62, und Ferrara T 617: LezziHafter a. O. 324 Kat. 98 Taf. 79. Eine Frauengestalt, deren Körper unter dem Gewand in ähnlicher Weise durchscheint, zeigt auch die Pyxis in Athen, Ephorie Athinon A I 877: Lezzi-Hafter a. O. 347 Kat. 256 Taf. I67 c. d. Wie es den späteren Gewohnheiten des Kalliope-Malers entspricht, sind auf der Grazer Schale nur sehr wenige Relieflinien verwendet, vgl. Lezzi-Hafter a. O. 303.

\section{TAFEL 58}

1-3. Siehe Tafel 57, 4-5.

4-6. Schale

Beilage 15, 6.

G I99. Fundort unbekannt. Erworben vor I937.

H erh. 2,o cm. - Dm Fuß rek. 6,9 cm. - Wandstärke o,6 cm. Gewicht 44,3 g.
Unpubliziert.

Zustand: Ein Fragment. Zwei größere Absplitterungen an der Unterseite des Fußes, zahlreiche kleine Absplitterungen im Tondo. Bruchflächen und abgesplitterte Stellen versintert.

Technik: Schwarzer bis olivschwarzer Glanzton. Relieflinie: Auge und linke Vorderpranke der Sphinx, rechte Tatze, Kontur des linken Flügels, Schwungfedern. Zusätzliche Farbe: Weiß für das Haarband.

Form: Fußlose Schale mit profiliertem Standring. Wulstiger Ringfuß mit Ansatz eines flachen Schalenkörpers.

Dekor: Gefäßunterseite tongrundig bis auf zwei konzentrische Kreise mit Punkt in der Mitte und umlaufendes Band in Glanzton. Tondorahmen mit rechtsläufigem Mäander. Im Inneren des Medaillons ein mit dem Reißzirkel gezogener Kreis, der die Vordertatzen der Sphinx überschneidet.

Darstellung: Sphinx. - Vorderteil einer Sphinx im Profil nach links. Kopf, Brust, Vorderpranken, Flügel und ein Teil des Rückens erhalten. Der Kopf der Sphinx ist leicht gehoben. In ihrem Haar liegt ein dreifaches weißes Band, das auch um den tiefen Haarknoten geschlungen ist. Ausgesparte Kopfkontur. Der große, eckige vordere Flügel verdeckt den Ansatz des linken Vorderbeines. Die Schwungfedern sind im oberen Teil der Flügel geradlinig und nur im Schulterbereich leicht geschwungen gebildet. Da für die Vorderpranken der Sphinx keine Unterlage sichtbar ist, auf die sie sich stützen könnten, ist wohl anzunehmen, dass sie erhoben waren und die Sphinx im Sprung dargestellt ist, was auch die Kopfhaltung nahelegt.

Drittes Viertel 5. Jh.

Zur Form: Zu Schalen auf niedrigem Ringfuß vgl. hier zu Tafel 57, $4-5 ; 58, \mathrm{I}-3$; Niedrige Schalen mit einfachem oder profiliertem Standring wurden erst ab der Frühklassik vermehrt hergestellt. Wegen ihrer kompakten und weniger eleganten Form eignen sie sich besser für den täglichen Gebrauch als ihre hochstieligen, vornehmen Schwestern. Besonders beliebt waren sie in der GlanztonKeramik, vgl. G 9 und G Io, hier Tafel 74, 5-7; 75, I-3 (apulisch). Ihre Bemalung ist daher auch selten wirklich qualitätvoll, vielmehr sind ihre Innenseiten häufig mit Stempeldekor oder eingeritzten Mustern verziert, vgl. Wehgartner, AWK, 50.

Zur Darstellung: Sphingen dienen selten als Motiv für Schalentondi, vgl. S. Pfisterer - Haas in: CVA Leipzig 3, 48 zu Taf. 2I, wo außer dem Leipziger Exemplar nur zwei frühere genannt werden. Ausführlich zur Darstellung der Sphinx: J.-M. Moret, Oedipe, la sphinx et les Thébains. Essai de mythologie iconographique (Genf I984) passim; V. Sabetai, in: J. H. Oakley (Hrsg.), Athenian Potters and Painters, Catalogue of the Exhibit, December I, I994-March I, I995, Gennadius Library, American School of Classical Studies (Athen I 994) 4I f. (mit weiterer Literatur); LIMC VIII Suppl. (Zürich I997) I I 49-I I 65 s. v. Sphinx (N. Kourou). Sphingen haben ihren Platz sowohl im eschatologischen Bereich, wo sie als Grabwächter fungieren, sind jedoch auch den olympischen Göttern zugeordnet, vgl. E. Simon, Die Sammlung Kiseleff im Martin-vonWagner-Museum der Universität Würzburg II (Mainz I989) 97 Nr. I63 Taf. 73, wo den häufigen Darstellungen von Sphingen auf Lekythen ein eschatologischer Charakter zugesprochen wird, wie er ihnen auch auf den Grabstelen zukommt. Vorsichtig bezüglich einer sepulkralen oder eschatologischen Symbolik der Sphinx in der Vasenmalerei äußern sich Moret a. O. 29 Anm. 2; N. Kourou, LIMC VIII Suppl. (Zürich I997) II64 f. sowie A. Heinemann, Bild, Gefäß, Praxis. Attische Salbgefäße zwischen Betrachtung und Benutzung, in: S. Schmidt - J. H. Oakley (Hrsg.), Hermeneutik der Bilder. Beiträge zur Ikonographie und Interpretation griechischer Vasenmalerei, CVA Deutschland Beih. 4 (München 2009) I 66-I70. Besonders beliebt ist die Wiedergabe einzelner Sphingen auf Bauchlekythen: W. Rudolph, Die Bauchlekythos. Ein Beitrag 
zur Formgeschichte der attischen Keramik des 5. Jhs. v. Chr. (Bloomington I97I) 57 f., I02 f.; Heinemann a. O. I 67 f., vgl. bes. die Tabellen 2 und 3. Für die Sphinx auf Bauchlekythen sucht Heinemann a. O. I66-I70 eine außerhalb der Todessymbolik gelegene Bedeutung und findet sie im sirenenhaft-verlockenden Wesen des Ungeheuers. Damit fügt sie sich zwanglos in das überwiegend aphrodisisch geprägte Repertoire der Bauchlekythen ein. Auch auf einer Schale erscheint die Sphinx als sexuell agressives Wesen passender als ein Todesdämon.

Zum Maler: An der Grazer Sphinx fällt das Bewegungsmotiv auf, das am ehesten als Sprung gedeutet werden kann, sowie das volle Kinn und die ausladenden, steil aufgerichteten Flügel. Die Schwungfedern sind in langen feinen Strichen angegeben. Eine zum Sprung ansetzende Sphinx findet sich auf der Lekythos in Würz- burg, Martin-von-Wagner-Museum K I 826: Simon a. O. $97 \mathrm{Nr}$. I63 Taf. 73. Eine wie auf dem Grazer Fragment in ein Kreisrund eingepasste, aber nach rechts gerichtete Sphinx zeigt eine fragmentierte Schale gleichen Typs in der Sammlung Mouret: CVA Ensérune Taf. 8, 4. Die Schale wird von Beazley, ARV ${ }^{2}$ I 527, 2 in die Nähe der Gruppe Wien I I6 gerückt (vgl. auch ARV² I484. I 522 ), die jedoch bereits ins 4 . Jh. datiert. Leider fehlt der Vorderteil des Mischwesens, jedoch die Art, wie der Körper frei schwebend ohne feste Grundlinie in den Tondo gesetzt ist, entspricht der Grazer Darstellung. Auch die Rückenflügel scheinen ähnlich gebildet zu sein. In der Physiognomie, die ein auffallend volles Kinn zeigt, sind die Flügelfrauen des Washing-Malers auf einem Lebes Gamikos in Athen, Benaki-Museum 3 I I 7 unserer Sphinx nahe, vgl. CVA Athen, Benaki Museum I Taf. 3 I-32. 


\section{ATTISCH WEISSGRUNDIG}

\section{TAFEL 59}

\section{1-2. 5-6. Schulterlekythos}

Beilage 16, 2.

G 34. Aus Attika. Erworben I 875 durch Wolfgang Helbig in Athen, Ankauf. Ehemals Slg. Athanasios Rhousopoulos (Athen). Alte Inv.-Nr. II 47 (Schenkl) bzw. III 47 (Pichler).

H 33,4 cm. - Dm Mündung 6,0 cm. - Dm Schulter ıо, o cm. - Dm Fuß 6,4 cm. - B Henkel I,6 cm. - Dm Henkel I, 2 cm. - Volumen IO6I ml.

Unpubliziert.

Zustand: Aus mindestens 24 Fragmenten zusammengesetzt, drei größere Fehlstellen an der Schulter und am Körper wurden mit Gips ergänzt. Die Lippe ist an zwei Stellen stark bestoßen, entlang der Bruchflächen kleinere Absplitterungen. Die weiße Grundierung ist großflächig abgerieben, die schwarze Bemalung stellenweise abgeblättert. Der Erhaltungszustand aller zeichnerischen Details ist sehr schlecht. An Unterseite des Fußes mit Bleistift „60“ und „A I “.

Technik: Tonoberfläche hellorange, glänzend schwarze Bemalung, dünn aufgetragen und an einigen Stellen durch Fehlbrand dunkelbraun verfärbt. Körper, Schulter und Halsansatz matt cremeweiß grundiert. Aufgesetzte Farbe: Bräunlich Gelb.

Form: Standardform. Scheibenfuß mit abgeschrägt konvexem Außenprofil und abgesetzter Kehlung unter der Oberkante. An der Unterseite eingezogen, in der Mitte Zapfen mit umlaufender Vertiefung. Verbindungswulst zwischen Fuß und Körper durch je eine Rille abgesetzt. Zylindrischer, nach unten konisch einschwingender Körper, scharfe Schulterkante, schwache Kehlung zum stark eingezogenen Hals. Vorspringender Mündungskelch mit steilschräger Wandung, durch eine Rille von der Halszone abgesetzt. Flachschräg nach innen abgestrichene, nach oben deutlich verdickte Lippe. An Schulter und Halszone angesetzter Bandhenkel mit rundovalem Querschnitt.

Dekor: Oberseite des Fußes, unterer Teil des Gefäßkörpers, größter Teil des Halses sowie Mündung innen und außen mit Glanzton überzogen. Größter Teil des Gefäßkörpers, Schulter und unterer Teil des Halses mit weißem Überzug versehen. Über der Glanztonzone im unteren Gefäßteil ein brauner umlaufender Streifen als untere Begrenzung. Als oberer Abschluss der Darstellung unter dem Schulterknick ein Mäanderband. Auf der Schulter drei mit Ranken verbundene Palmetten, darüber, am Übergang zwischen Schulter und Hals, ein Eierstab.

Darstellung: Szene am Grab. - In der Mitte des Gefäßkörpers Blätterkranz über den Resten einer Truhe (?). Rechts davon Reste des gelockten Oberkopfes einer Figur mit Band im Haar.

$460-450$

Zur Form und ihrer Entwicklung: I. Wehgartner, CVA Berlin 8, 24 f.; J. H. Oakley, Picturing Death in Classical Athens. The Evidence of the White Lekythoi (Cambridge 2004) 4 f.; N. ZimmermannElseify, CVA Berlin I2, I3 f., zur Verwendung vgl. ebd. I 5, die betont, dass weißgrundige Lekythen zunächst nicht primär dem Totenkult dienten, was aus ihrer vielfach diesseitigen Ikonographie hervorgeht. Sie stellten vielmehr mit duftendem Salböl gefüllt auch repräsentative Geschenke für weibliche Empfänger dar und fanden so Eingang in das Bestattungsritual, zumal die Pflege der Toten und der Familiengräber in den Händen der Frauen lag. Die Form unserer Lekythos ist vergleichbar mit CVA Berlin I 2 Taf. I4 Beil. 2, 3 (F 2445), um 460-450, Sunion-Gruppe (Wehgartner). Die Form der Lippe entspricht allerdings eher der Lekythos in Berlin, Antikensammlung V.I. 3292: CVA Berlin I 2 Taf. 7 Beil. 2, 2; siehe hier zu Tafel 59, 3-4 Beilage I6, 2.

Zur Darstellung: Die bekränzte Truhe kann Teil der Darstellung eines Begräbnisrituals sein, vgl. etwa die Lekythen in Athen, NM I929 und Madison (Wisconsin), Elvehjem Art Center EAC 70.2: Kurtz, AWL, 27. 45 Taf. 25, 2-3; CVA Berlin I 2 Taf. 30, 3; 3 I, 4 (F $245 \mathrm{I})$. Wie der Eintragung im älteren Inventarbuch zu entnehmen ist, waren zur Zeit des Ankaufs noch Reste der Bemalung erkennbar: „Bildfeld n. oben abgeschlossen durch e. Mäander, n. unten durch e. breiteren Streifen. Darstellung: in d. Mitte hohe, schlanke Stele auf drei Stufen, mit Kyma, Leiste u. Giebel mit Mittel- u. Eckakroteren. Links v. d. Stele steht e. Mädchen n. rechts, auf der Linken e. Korb, dem sie mit d. Rechten e. Kranz entnimmt. Vom Korb hängt e. breite Binde herab. Auf d. anderen Seite steht e. n. links gewandte Gestalt, die die Rechte gegen d. Mädchen ausstreckt. Von d. Figur nur Kopf, Schulterkontur u. Hände erhalten; ob Jüngling oder Mädchen, ist nicht zu entscheiden. Das in flotten kurzen Strichen wiedergegebene Haar spricht eher für ersteren. “

\section{3-4. 7. Schulterlekythos}

Beilage 16, 3.

G 33. Aus Attika. Erworben I 875 durch Wolfgang Helbig in Athen, Ankauf. Ehemals Slg. Athanasios Rhousopoulos (Athen). Alte Inv.-Nr. II 46 (Schenkl) bzw. III 46 (Pichler).

H $35,8 \mathrm{~cm}$. - Dm Mündung 6,4 cm. - Dm Schulter 9,5 cm. Dm Fuß 6,3 cm. - B Henkel I,6 cm. - Dm Henkel I, 3 cm. - Volumen $887 \mathrm{ml}$.

Unpubliziert.

Zustand: Aus mindestens 29 Fragmenten zusammengesetzt, 7 größere Fehlstellen (an Halsansatz, Schulter, Körper und in der Einziehung oberhalb des Fußes) mit Gips ergänzt. Weiße Grundierung großflächig abgerieben, schwarze Bemalung stellenweise abgeblättert. Auf der Gefäßunterseite mit Bleistift: „80“.

Technik: Oberfläche hellorange, glänzend schwarz bemalt, zum Teil durch den Brand dunkelbraun verfärbt. Körper und Halsansatz weiß grundiert. Aufgesetzte Farben: Rot, Gelb.

Form: Standardform. Scheibenfuß mit annähernd vertikalem Außenprofil, an der Unterseite trichterförmig hochgezogen mit leichtem Zapfen im Zentrum. Nicht abgesetzte Kehlung zwischen Fuß und Körper. Zylindrischer, nach unten konisch einschwingender Körper, zur Schulter sich geringfügig verjüngend. Scharfe Schulterkante, Schulter geht nahtlos in den stark eingezogenen Hals über. Deutlich abgesetzter, vorspringender Mündungskelch mit steilschräger Wandung, gerade abgestrichene, leicht nach innen ausgezipfelte Lippe. Auf Schulter und Halszone angesetzter Bandhenkel mit rundovalem Querschnitt.

Dekor: Oberseite des Fußes, unterer Teil des Gefäßkörpers sowie größter Teil des Halses und Mündung (innen und außen) mit Glanzton überzogen. Größter Teil des Gefäßkörpers, Schulter und unterer Teil des Halses mit weißem Überzug versehen. 
Zwei gelbliche Linien im unteren und oberen Bereich der weißgrundigen Zone des Körpers, die wohl die bildliche Darstellung begrenzten.

Darstellung: Szene am Grab. - Die schräge Linie ist wohl mit dem Stock des Jünglings zu identifizieren. Außer ein paar roten Linien ist ansonsten nichts mehr zu erkennen.

Zweites Viertel 5. Jh.

Zur Form: vgl. etwa die Lekythos in Berlin, Antikensammlung V.I. 3292: CVA Berlin I 2 Taf. 7 Beil. 2, 2 (Leto-Maler, 470-460); ARV $^{2} 729$ f.; Para 4I I, Add ${ }^{2}$ 283. Zu Form und Verwendung der weißgrundigen Lekythen allgemein siehe zu G 34, hier Tafel 59, I-2. 5-6.
Zur Darstellung: Auch die Darstellung auf dieser Lekythos war laut älterem Inventarbuch zur Zeit des Ankaufs noch zu erkennen: „Das Bildfeld n. oben abgeschlossen durch zwei Paare schmaler Parallelstreifen in Ockergelb, n. unten durch e. breiteren Streifen in Ockergelb. Darstellung mit roter Deckfarbe in Umrisszeichnung: In d. Mitte Grabstele auf zwei Stufen, mit schwarzem Kyma, das mit eingeritzten Vertikalstrichen verziert ist; sie ist mit e. Akanthus bekrönt u. umwunden v. einer Binde m. herabhängenden Enden, in demselben Grauschwarz aufgemalt wie das Kyma. Rechts v. d. Stele e. Tumulus u. dahinter e. auf e. Stuhle n. links sitzendes Mädchen. Rechts v. d. Grabstele e. nach rechts stehender Jüngling m. gekreuzten Beinen, auf e. Stock gestützt; er streckt d. Mädchen sie begrüßend die Hand entgegen. Hinter d. Stele kommt eine zweite, breitere u. niederere zum Vorschein“. 


\section{ATTISCHE GLANZTON-WARE}

\section{TAFEL 60}

\section{1-2. Halsamphora}

Beilage 17, 1.

G 5I. Aus Capua. Erworben 1874 durch Wolfgang Helbig in Rom, Ankauf. Ehemals Slg. Simmaco Doria (Santa Maria Capua Vetere). Alte Inv.-Nr. II 32 (Schenkl) bzw. III 40 (Pichler).

H 2 I, 4 cm. - Dm Mündung Io,3 cm. - Dm Körper I3,3 cm. Dm Fuß 7,8 cm. - B Henkel I, 9 cm. - D Henkel o,7 cm. - Gewicht 548 g. - Volumen I I97 $\mathrm{ml}$.

Lehner - Lorenz - Schwarz, Vasen, 69 f. Nr. 4I Abb. 60 (G. Schwarz).

Zustand: Vollständig erhalten, einige kleinere Absplitterungen.

Technik: Auf dem orangefarben-mittelbraunen Ton ist die Bemalung in glänzendem Schwarz dünn aufgetragen. Der Glanzton bedeckt auch das Innere des Halses. Gefäßunterseite orangebraun überzogen.

Form: Scheibenfuß, an der äußeren Oberkante eine Rille. Am Übergang zum bauchig ausschwingenden Gefäßkörper ein breiter Wulst. Deutlich ausgeformte Schulter. Starke, durch einen Grat abgesetzte Halseinziehung. Hoher Hals, weit ausgreifende, durch eine Rille abgesetzte Mündung. Randzone leicht verdickt, minimal nach außen fallende abgestrichene Lippe. Zwei gegenständige, auf der Schulter angesetzte, unterrandständige Bandhenkel, aus drei Wülsten zusammengesetzt.

Dekor: Auf der Standfläche orangefarbener Überzug. Der Wulst, der den Fuß vom Gefäßkörper trennt, ist oben und unten durch einen tongrundigen Streifen akzentuiert. Das restliche Gefäß ist an seiner Außenseite vollständig mit Glanzton überzogen.

Um 450

Zum Typ: Gefäße, die ausschließlich mit Glanzton überzogen sind, erreichen die Wirkung von Metallgefäßen, was wohl auch intendiert war. Auch im Falle unserer Amphora täuscht der tiefschwarze Glanz des Überzuges Metallcharakter vor. Doch während zahlreiche andere Gefäßformen wie Kannen, Hydrien, Kratere, Schalen, Skyphoi und andere (vgl. G 47-49, hier Tafel 60, 3-4; 6I, I-6) häufig als Glanztonkeramik anzutreffen sind, finden sich unter den Amphoren weitaus weniger Beispiele dafür. Zur attischen Glanztonkeramik allgemein: Agora XII, 47-I 86; zu Glanztonamphoren, die auch in Zentren außerhalb Attikas produziert werden, vgl. Agora XII, $47 \mathrm{f}$.

Zur Form: Die kleine Halsamphora schließt sich eng an die nolanische Form an. $\mathrm{Zu}$ dieser vgl. G 29, hier Tafel 38, I-2 sowie Agora XII, 47 Anm. 4. Die kleine Amphora von der Athener Agora (Agora XII, Taf. I, 3) zeigt ein ähnlich straffes Profil, aber mit Ringfuß (um 500). Weitere Beispiele von Glanztonamphoren attischer Provenienz: Agora XII, 48. Besonders gut vergleichbar ist das Exemplar in Altenburg, Lindenau-Museum 33: CVA Altenburg 2 Taf. 80, I (Mitte 5. Jh.).

\section{3-4. Oinochoe}

Beilage 17, 2.

G 49. Fundort unbekannt. Erworben vor I9I I/I 2 .
H 8,3 cm. - Dm Rand 8, o cm. - B mit Henkel Io, 5 cm. - Dm Körper 8,6 cm. - Dm Boden 6,3 cm. - B Henkel 2,2 cm. - Dm Henkel o,6 cm. - Gewicht [I44 g]. - Volumen $288 \mathrm{ml}$.

Lehner - Lorenz - Schwarz, Vasen, 70 Nr. 42 Abb. 62 rechts (Th. Lorenz).

Zustand: Vollständig erhalten. Henkel in zwei Fragmenten abgebrochen und wieder angesetzt. Henkel, Bauch im Bereich des Henkelansatzes, Mündung innen und außen sowie Teil des Fußes wurden übermalt, so dass der ursprüngliche Glanz der originalen Oberfläche überdeckt ist und dieser Bereich mattschwarz wirkt. Einige Absplitterungen an der Oberfläche ebenfalls übermalt. An der Gefäßinnenseite Absplitterungen.

Technik: Innen und außen glänzend schwarzer Malschlicker, deckend aufgetragen. Farbe des Malschlickers (Bauch): schwarz ( 5 Y 2.5/I, black). Am Boden ist der Malschlicker zum Teil verwischt. Ein Fingerabdruck in diesem Bereich sowie an der Innenseite des Henkels. Farbe des Tongrundes: rötlichbraun (5 YR 5/4, reddish brown).

Form: Kleine Oinochoe der Form 8 B, Typ Phidias. Flacher Standboden. Niedriger Körper mit vertikaler Rippung. Leichte Halseinziehung, durch einen Grat von der Schulter abgesetzt. Ausschwingender Mündungskelch, rund abgestrichene Lippe. An der Schulter und am Gefäßrand angesetzter Bandhenkel mit längsovalem Querschnitt.

Dekor: Auf der Gefäßunterseite in der Mitte ein schwarzer Kreis. Am Bauch senkrechte Riefelung vom Fuß bis zum Hals, am Henkelansatz unterbrochen. Grat zwischen Körper und Hals durch reliefierte Punktreihe dekoriert.

Mitte 5. Jh.

Zur Form: Zu den Riefelkännchen, auch „Pheidias shape“ genannt: A. Mallwitz, Die Werkstatt des Phidias in Olympia, OF 5 (Berlin I965) I69-I 82 Taf. 64-65; Agora XII, 72-74. Die Grazer Kanne ähnelt sehr dem Riefelkännchen Athen, Agora-Museum P 21870: Agora XII, 250 Nr. 20I Abb. 3 Taf. I I.

Zum Dekor: Zur Riefelung auf Oinochoen dieses Typs siehe Agora XII, 74 .

Zum Typ: Allgemein zum Typ siehe Agora XII, 72-74. Der flache Boden und sein Kreis in der Mitte, die Riefelung ohne Verbindungsbogen am oberen Teil und der Bandhenkel weisen darauf hin, dass das Grazer Exemplar eines der früheren Kännchen ist.

\section{5-6. Kantharos}

Beilage 17, 3.

G 45. Fundort unbekannt. Erworben vor I9II/I 2.

H I 2,8 cm. - Dm Rand II, $8 \mathrm{~cm}$. - B mit Henkeln 2I, I cm. - Dm Boden 5,7 cm. - Dm Fuß 6,I cm. - B Henkel I,6 cm. - D Henkel I, $2 \mathrm{~cm}$. - Volumen $565 \mathrm{ml}$.

Lehner - Lorenz - Schwarz, Vasen, 7I f. Nr. 45 Abb. 63 links (Th. Lorenz).

Zustand: Am konkaven oberen und am konvexen unteren Teil ist ein großes Wandstück herausgebrochen, das wieder eingesetzt und mit Gips ergänzt wurde. Nur auf der Außenseite ist die Ergänzung mattschwarz koloriert. An der Innenseite des Mündungsrandes wurde eine kleine Fehlstelle mit Gips ergänzt und mattschwarz 
bemalt. An der Gefäßinnenseite sind der gesamte Unterteil und obere Teil auf einer Seite, außerdem die Gefäßunterseite und an der Außenseite der obere Teil des Fußes massiv verwittert. Der Überzug an der größten Ausdehnung des Randes, an einem Henkel, am Grat des Fußes und der Standfläche stark abgerieben, so dass der Tongrund zum Vorschein kommt. Ansonsten punktuelle Abreibungen.

Technik: Glänzender Malschlicker deckend und homogen aufgetragen. Farbe des Malschlickers (Bauch): schwarz (5 Y 2.5/I, black). Farbe des Tongrundes: rötlichbraun (5 YR 5/4, reddish brown).

Form: Kantharos. Hoher, leicht nach außen gezogener und durch einen deutlichen Grat profilierter Ringfuß, auf seiner Unterseite konkav eingezogen. Nach oben konisch erweiterter Körper, gerundete Schulter. Deutliche Halseinziehung, der hohe, steilschräg nach außen gezogene Hals ist durch eine Rille von der Schulter abgesetzt. Nach außen rundlich verdickte Lippe, spitz abgestrichener Mundsaum. Zwei gegenständige Vertikalhenkel mit rundovalem Querschnitt, an der Schulter und am Rand angesetzt und an der Oberseite oberhalb der Henkel weit ausgezipfelt.

Dekor: Nahezu die gesamte Oberfläche ist mit glänzendem Malschlicker überzogen, mit Ausnahme eines Teils der Standfläche und einer feinen Rille am Außenprofil des Fußes.

Um 320

Zur Form: Allgemein zur Form siehe Agora XII, I 22 Nr. 696-704 (Kantharos with moulded rim). Die Form des Grazer Kantharos ist mit dem Kantharos Athen, Agora-Museum P 2552 identisch: Agora XII, 286 Nr. 703 Taf. 29.

Zum Typ: Kantharoi der Glanztonware existierten in Athen seit dem 6. Jh. Im 4. Jh. erscheint der sog. cup-kantharos, aus dem die Kantharoi dieses Jahrhunderts abgeleitet sind, vgl. Agora XII, I I 3 f. I22.

\section{7-8. Tafel 61, 7. Kantharos}

Beilage 17, 4.

G 46. Fundort unbekannt. Erworben vor I9II/I2.

H I 4,7 cm. - Dm Rand I3,2 cm. - B mit Henkel 2I, 8 cm. - Dm Boden 7,I cm. - Dm Fuß 7,2 cm. - B Henkel I, 5 cm. - D Henkel I, I cm. - Gewicht 65 I g. - Volumen 8 I 9 ml.

Lehner - Lorenz - Schwarz, Vasen, 72 Nr. 46 Abb. 63 rechts (Th. Lorenz).

Zustand: Vollständig erhalten. Absplitterungen am Fuß, an der Mündung und an den Auszipfelungen der Henkel. Überzug teilweise abgesplittert. Auf der Innenseite des Gefäßbodens ein Riss.

Technik: Malschlicker seidig, glänzend, deckend und sehr sorgfältig aufgetragen. Farbe des Malschlickers (Bauch): schwarz (2.5 Y 2.5/I, black). Miltos: auf der Standfläche, in der Rille zwischen unterem und oberem Teil des Fußes sowie zwischen Körper und Fuß.

Form: Kantharos. Hoher, leicht nach außen gezogener und verkröpfter Ringfuß, auf seiner Außenseite konkav eingezogen. Die Standfläche ist durch eine Rille zweigeteilt. Nach oben konisch erweiterter, vertikal gerippter Körper, gerundete Schulter. Hoher, konkaver Hals. Nach außen gezogene Lippe, spitz abgestrichener Mundsaum. Kurz unterhalb des Mundsaumes nach außen vorspringender Wulst. Zwei gegenständige Vertikalhenkel mit rundovalem Querschnitt, an der Schulter und am Rand angesetzt und an der Oberseite oberhalb der Henkel weit ausgezipfelt.

Dekor: Bauch vom Fuß bis zum Halsansatz vertikal geriefelt, an den Henkelansätzen unterbrochen. Unter den Henkelansätzen je ein stehendes Dreieck durch tiefe Rillen gestaltet. Am Boden der Gefäßinnenseite Rollrädchendekor aus doppelten Kreislinien. In der Mitte Teil einer Spirallinie mit Querstrichen.

Ende 4 . Jh.

Zur Form: Allgemein zur Form siehe Agora XII, I 22 Nr. 696-704 (Kantharos with moulded rim). Der Grazer Kantharos zeigt große Ähnlichkeiten mit dem Kantharos Athen, Agora-Museum P 33778: Agora XII, 286 Nr. 704 Taf. 29.

Zum Dekor: Im 4. Jh. ist die Riefelung als Dekor sorgfältig und akkurat ausgeführt und ähnelt der Reliefkeramik. Die Bögen am oberen Teil sind miteinander verbunden, vgl. Agora XII, 2 I f. Zum Rollrädchendekor siehe Agora XII, $3 \circ$ f. (standard type of rouletting).

Zum Typ: siehe G 45, hier Tafel 6o, 5-6.

\section{TAFEL 61}

\section{1-2. 6. Kantharos}

Beilage 18, 1.

G 47. Fundort unbekannt. Erworben vor I9I I/I 2.

H I I, I cm. - Dm Rand Io, $8 \mathrm{~cm}$. - B mit Henkeln I $8,7 \mathrm{~cm}$. - Dm Boden 6,2 cm. - Dm Fuß 6,5 cm. - B Henkel I, 3 cm. - D

Henkel I, o cm. - Gewicht 365 g. - Volumen $522 \mathrm{ml}$.

Lehner - Lorenz - Schwarz, Vasen, 7I Nr. 44 Abb. 63 Mitte (Th. Lorenz).

Zustand: Vollständig erhalten, einige winzige Absplitterungen, vereinzelt brüchige Oberfläche. Eine größere oberflächliche Fehlstelle an der äußeren Randzone wurde schwarz übermalt. Riss am Henkel.

Technik: Schwarzer, glänzender Malschlicker deckend und sorgfältig aufgetragen. Farbe des Malschlickers (Bauch): schwarz (2.5 Y 2.5/I, black). Miltos: Rille zwischen oberem und unterem Teil des Fußes, zwischen Körper und Fuß und an der Standfläche.

Form: Kantharos. Hoher, nach außen gezogener und durch einen massiven Grat betonter Ringfuß. Nach oben konisch erweiterter, vertikal gerippter Körper, gerundete Schulter. Hoher, konkaver Hals, durch einen Knick von der Schulter abgesetzt. Nach außen gezogene Lippe, spitz abgestrichener Mundsaum. Kurz unterhalb des Mundsaumes mächtiger, nach außen vorspringender Wulst. Zwei gegenständige Vertikalhenkel mit rundovalem Querschnitt, am Rand und an der Schulter angesetzt und an der Oberseite weit ausgezipfelt.

Dekor: Am Bauch senkrechte Riefelung vom Fuß bis zum Hals, an den Henkelansätzen unterbrochen (I 5 auf Seite A und I 3 Riefen auf Seite B). Unter den Henkelansätzen stehende Dreiecke durch tiefe Rillen gestaltet, in der Mitte senkrechte Rille. An einer Seite der oberen Ecke des Dreiecks Querstrich. Am Boden der Schale Stempeldekor mit vier gegenseitigen Palmetten. Darüber Rollrädchendekor aus vier bzw. fünf Kreislinien in einer Spirale ausgeführt.

Zweite Hälfte 4. Jh.

Zur Form: Allgemein zur Form siehe Agora XII, I22 Nr. 696704 (Kantharos with moulded rim). Der Grazer Kantharos zeigt große Ähnlichkeiten mit dem Kantharos Athen, Agora-Museum P I269I: Agora XII, 286 Nr. 70I Abb. 7. Die Zipfel des Grazer Exemplars sind länger als die des Kantharos aus der athenischen Agora. Große Ähnlichkeiten zeigt der Kantharos Capua, Museo 
Campano 230 aus Capua: CVA Capua 3, IV E g Taf. 4, 6 (Abweichung am Fuß).

Zum Dekor: siehe Kantharos G 46, hier Tafel 60, 7-8.

Zum Typ: siehe Kantharos G 46, hier Tafel 60, 7-8.

\section{3-5. Kantharos}

Beilage 18, 2.

G 48. Fundort unbekannt. Erworben vor I9I I/I 2.

H Io,2 cm. - H mit Henkel I I, 2 cm. - Dm Rand 8,9 cm. - Dm Boden 5,3 cm. - Dm Fuß 5, O cm. - Dm Henkel o,8 cm. - Gewicht [293 g]. - Volumen $324 \mathrm{ml}$.

Lehner - Lorenz - Schwarz, Vasen, 7 I Nr. 43 Abb. 62 links (Th. Lorenz).

Zustand: Ein Henkel fehlt vom Henkelansatz aufwärts. Um die Henkelansätze rezente schwarze Übermalung, die Bruchkante eines Henkelansatzes auch schwarz übermalt. Fuß, Bauch und Rand beschädigt und abgesplittert. Zweiter Henkel gebrochen und wieder zusammengesetzt, der Bruch wurde mit klarem Lack (Schellack?) überzogen. Auf der Gefäßinnenseite bestoßen und insgesamt stark verwittert. Am Boden im Gefäßinnern Rückstände von organischem Material. Die tongrundige Rille am Fuß teilweise verwischt.

Technik: Glänzender Malschlicker schwarz, deckend und sorgfältig aufgetragen. Farbe des Malschlickers (Bauch): schwarz (2.5 Y 2.5/I, black). Farbe der Tongrundes: rötlichbraun (7.5 YR 5/6, strong brown).

Form: Hoher Ringfuß, an seiner Außenseite durch einen Grat profiliert. Niedriger, breiter Körper mit deutlich ausgeformter Schulter. Leicht eingezogener, nach oben ausschwingender Hals. Außen kurz unterhalb des Mundsaumes breiter, weit vorspringender, horizontal umlaufender Wulst. Leicht nach außen gezogene, rund abgestrichene Lippe. Am Körper unten angesetzte gegenständige Bandhenkel mit rundem Querschnitt, ausschweifend nach oben und anschließend nach innen gebogen.

Dekor: Vollständig mit Glanzton überzogen, mit Ausnahme eines Teils der Standfläche und der Rille am Außenprofil des Fußes. Auf dem Boden der Gefäßinnenseite Rollrädchendekor aus zwei Kreislinien.

Zweite Hälfte 4. Jh.

Zur Form: Allgemein zur Form siehe Agora XII, I I 8 f. (cup-kantharos). Diese Form ist der Vorläufer der Kantharoi des 4. Jhs. Der Grazer Kantharos lässt sich besonders gut vergleichen mit Kantharoi von der Agora, wie: Agora XII, 283 Nr. 66I Abb. 7 Taf. 28 (P I 2690); dem Kantharos Capua, Museo Campano ohne Inv.: CVA Capua 3, IV E g Taf. 4, 7 (gleiche Höhe); dem Kantharos Gotha Ahv. I 6 : CVA Gotha 2 Taf. 77, I (wurde von Helbig im Jahr I873 erworben); und einem Kantharos aus Olynthos: D. M. Robinson, Excavations at Olynthus XIII (Baltimore I950) $285 \mathrm{Nr}$. 50 I Taf. I 87.

Zum Dekor: Zum Rollrädchendekor siehe Agora XII, $30 \mathrm{f}$.

Zum Typ: Agora XII, I 8 f. Abb. 7 Taf. 28.
7. Siehe Tafel 60, 7-8.

8. Näpfchen

Beilage 18, 3.

G I95. Aus Athen; möglicherweise aus den Grabungen des Jahres I 895 am Westabhang der Akropolis. Erworben I908/Io durch Hans Schrader. Ehemals Slg. Hans von Prott (Athen).

$\mathrm{H}_{3,3} \mathrm{~cm}$. - Dm Rand 5,6 cm. - Dm Boden 5,4 cm. - Gewicht [70 g]. - Volumen $22 \mathrm{ml}$.

Unpubliziert.

Zustand: Vollständig erhalten. Größere Abplatzungen außen entlang des Randes. Oberfläche außen bestoßen und stellenweise versintert. Im Inneren des Gefäßes starke Ablagerungen von Kalk. An der Gefäßunterseite mit schwarzer Tusche „Athen“ und „Prott“ (leicht verblasst).

Technik: Außen schwarzer, glänzender Malschlicker, deckend aufgetragen. Farbe des Malschlickers: schwarz ( 5 Y 2.5/I, black). Innen dunkelbrauner bis rotbrauner Malschlicker. Farbe des Tongrundes: hellbraun (7.5 YR 6/3, light brown).

Form: Flacher Boden, minimal konkav eingezogen. Der zylindrische Körper besitzt eine leicht konkave Wandung. Im Gefäßinnern halbrunde Gefäßmulde.

Dekor: Bis auf die Gefäßunterseite und den horizontalen Mündungsrand vollständig mit Glanzton überzogen.

\section{Um $475-460$}

Zur Erwerbung: Das Näpfchen könnte aus den Grabungen am Westabhang der Akropolis stammen. $\mathrm{Zu}$ weiteren Funden aus der Slg. Hans von Prott in der Originalsammlung des Instituts für Archäologie der Karl-Franzens-Universität Graz siehe die flache Pyxis G 730, hier Tafel 9, 2 oder die Kanne mit runder Mündung G I038, hier Tafel I7, 7-8. Hans von Prott, der an den Grabungen am Westabhang der Akropolis unter der Leitung von Wilhelm Dörpfeld im Jahre I 895 teilnahm, stand in enger Verbindung zu Hans Schrader. Das keramische Fundmaterial aus diesen Grabungen wurde von Hans Schrader vorgelegt: H. Schrader, Die Ausgrabungen am Westabhange der Akropolis. Funde im Gebiete des Dionysion, AM 2I, I896, 265-286; zur Grabung siehe W. Dörpfeld, Die Ausgrabungen am Westabhange der Akropolis. Das Lenaion oder Dionysion in den Limnai, AM 20, I895, I6I-206.

Zur Form: Allgemein zur Form siehe Agora XII, I 36 f. (saltcellar: concave wall); Kerameikos IX, 5 I-53. Das Grazer Näpfchen lässt sich mit dem Näpfchen Athen, Agora-Museum P 5 I48: Agora XII, 30I Nr. 927 Abb. 9, und mit dem Näpfchen: Kerameikos IX, I39 Nr. 216, 2 Abb. 20 Taf. 82, I, gut vergleichen.

Zum Typ: Die Funktion der Näpfchen ist nicht mit Sicherheit bezeugt. Kleine Näpfchen solcher Art wurden in erster Linie in Kindergräbern gefunden. Sie als Salzgefäße zu betrachten, ist aus diesem Grund eher unwahrscheinlich. Eventuell waren sie als Trinkgefäße oder als Behälter von Honig gedacht, vgl. Kerameikos IX, 5 I. Da die Mündung von fast allen Näpfchen tongrundig blieb, nimmt man an, dass eventuell Deckel aufgelegt wurden, wie bei den Pyxiden, vgl. Agora XII, I36. 


\section{BÖOTISCH SCHWARZFIGURIG}

\section{TAFEL 62}

\section{1-4. Tafel 63, 1-2. Palmettenschale}

Beilage 18, 4.

G 52. Fundort unbekannt. Erworben vor I9II/I 2.

H Iо, O cm. - Dm Mündung 25,4 cm. - B mit Henkel 33,5 cm. - Dm Fuß 8, I cm. - Dm Henkel o,9 cm. - Gewicht 687 g. - Volumen I $563 \mathrm{ml}$.

Lehner - Lorenz - Schwarz, Vasen, 34 f. Abb. 26 (M. Lehner).

Zustand: Vollständig erhalten. Einige winzige Absplitterungen und Sinterspuren.

Technik: Oberfläche beige, im Bruch beige mit hellorangefarbenem Kern. Glänzend schwarzbraun bemalt.

Form: Schale mit niedrigem, ausladendem Schalenfuß, an seiner Außenseite durch eine horizontale Rille profiliert. Fußunterseite stark konkav eingezogen. Tiefer, kegelförmiger Körper, verlaufende Randkante, nach außen gezogener Rand. An der tiefsten Stelle im Gefäßinneren ein kleiner Buckel. Zwei gegenständige, nach oben gebogene Horizontalhenkel.

Dekor: Breiter Glanztonstreifen auf der Unterseite des Fußes, Rille an der Fußaußenseite tongrundig belassen, Oberseite des Fußes und Beckenansatz mit Glanzton überzogen. Über einem konzentrischen Streifen ein Lotos-Palmettenfries aus vier I7-strahligen Palmetten und zwei Lotosblüten. Die Palmblätter entsprießen einem Volutenpaar, das durch einen Strich verbunden ist. Unterhalb der Henkel befindet sich je eine kleinere, einfache Palmette ohne unteres Volutenpaar. Konkave Randzone mit Glanzton überzogen, ebenso die Henkel vollständig schwarz bemalt. Das Gefäßinnere vollständig schwarz bemalt, im Zentrum ist ein Kreis von $4 \mathrm{~cm}$ Dm ausgespart.

Letztes Viertel 5. Jh.

Zur Form: Zur Gattung allgemein: P. N. Ure, Boeotian Pottery of the Geometric and Archaic Styles, in: Union académique internationale, Classification des céramiques antiques I2 (Macon I927) 20 f.; K. Kilinski II, Boeotian Black Figure Vase Painting of the Archaic Period (Mainz I990) 67; A. D. und P. N. Ure, Boeotian Vases in the Akademisches Kunstmuseum Bonn, AA I933, 28 Abb. 28; P. N. Ure, Ring Aryballoi, Hesperia I 5, I946, 27-37; A. D. Ure, Floral Black-figured Cups in Reading and Freiburg, AntK Beih. 9 (Bern I973) II2 f. Taf. 40, I-4; J. J. Maffre, Collection Paul Canellopoulos VIII: Vases béotiens I, BCH 99, I975, 506-509 Abb. 48-4I; ders., Collection P. Canellopoulos X: Vases béotiens 2, BCH I02, I978, 272-278 Abb. 5-7; I. R. Metzger, Gefäße mit Palmetten-Lotos-Dekor, in: J.-P. Decoeudres et al. (Hrsg.), Euboeans in Australia, Eretria VI (Bern I978) 63-67; CVA Theben I Taf. I3, 2-4 (Th. P. 696).

Zum Dekor: A. D. Ure, Ares in Coronea, JHS 55, I935, 79 f. („last quarter of the fifth century“). Vgl. auch A. D. Ure, Floral Black-Figured Cups at Schimatari, JHS 46, I 926, 57 mit Taf. 2, 2 (ausgesparte Mulde in der Mitte des Gefäßinnern); 56 Abb. 2 (Palmetten und Schalenform in Athen, NM); CVA Bruxelles, Musées Royaux du Cinquantenaire 3, III G Taf. 4, 5; G. Touchais, Chroniques des Fouilles, BCH II3, I989, 63 I; Walker, Floral Ware, $263 \mathrm{f}$.
Zum Typ: Floral verzierte Schalen wurden in böotischen und euböischen Werkstätten in der 2. Hälfte des 5. Jhs. in großer Zahl hergestellt. Zwar steht der Produktionsbeginn nicht fest, doch existiert in dem thespischen Polyandrion, wo die 424 in der Schlacht von Delion gefallenen Krieger beigesetzt waren und in dem sich einige frühe Palmettenschalen fanden, ein gesicherter terminus ante quem, vgl. A. D. Ure, Floral Black-figured Cups in Reading and Freiburg, AntK Beih. 9 (Bern I973) I I 2; Schilardi, Polyandrion I, 240-246; V. Sabetai, CVA Thebes I zu Taf. I3, 2-4. Das Inventar eines Grabes in Rhitsona (Nr. I 23) entspricht genau dem des Polyandrions und ist daher etwa gleichzeitig zu datieren: Ure, Rhitsona, 75. Auch in diesem Grab befand sich eine Palmettenschale: Ure, Rhitsona, Taf. 24 Nr. I23.32. Diese frühe Gruppe unterscheidet sich allerdings von der Grazer Schale, aber auch ein späteres Exemplar in Reading, das A. D. Ure, Floral Blackfigured Cups in Reading and Freiburg, AntK Beih. 9 (Bern I973) I I 3 Taf. 40, I. 3 bereits in das 4. Jh. datiert, zeigt Abweichungen sowohl in der Form als auch in der Ausgestaltung der Palmetten. Als Produktionsstätte kommt am ehesten Tanagra in Frage. Eine große Vielfalt solcher Lotus-Palmettenschalen ist in den klassischen Gräbern von Tanagra gefunden worden, vgl. A. Andreiomenou, Tavó $\gamma \rho \alpha$.

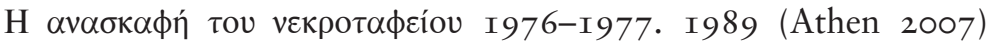
232-236 und passim. Auch in Chaironea trat eine Vielzahl von Palmettenschalen zutage.

\section{TAFEL 63}

1-2. Siehe Tafel 62, 1-4.

3-4. Deckel

Beilage 19, 1.

G 107. Fundort unbekannt. Erworben um I912/I3 durch Rudolf Heberdey, Tausch mit dem NM Athen.

H 3,9 cm. - H Knauf I, O cm. - Dm Knauf 3,5 cm. - Dm max. 9,6 cm. - Wandstärke o,8 cm. - Gewicht 94 g.

Unpubliziert.

Zustand: Vom Rand des Deckelknaufes etwa $40 \%$ abgesplittert, unterer Rand des Deckels umlaufend bestoßen. Einige Versinterungen und kleinere Absplitterungen. Am Bruch in schwarzer Tusche „Mus. Ath.“.

Technik: Oberfläche hellorange-mittelbraun, orangebraun bemalt. An der Innenseite des Deckels mit schwarzbraunem Malschlicker bemalt, etwas flüchtig aufgetragen. Farbe des Malschlickers: schwarz - schwarzdunkelbraun (IO YR 2/I-3/I, black - very dark gray). Der Malschlicker nahezu an der ganzen Oberfläche der Außenseite durch Fehlbrand rot verfärbt. In einem Bereich der konischen Hauptzone hinuntergelaufen, dadurch Teil des Hauptmotivs verschmiert (zwei obere Blätter und eine Beere). Farbe des Tongrundes (am Bruch): rötlichgelb ( 5 YR 6/6-7/6, reddish yellow). Miltos: Auf der gesamten Oberfläche der Außenseite orangebraun aufgebracht. Der Zweig besteht aus acht wiederholten Einheiten, von denen fünf größer sind, da sie zuerst gemalt wurden. Anschließend wurden in die Zwischenräume kleinere Motive eingefügt.

Form: Hohldeckel mit steilschräger Mündungszone. An seiner Oberseite gekehlter, niedriger Knauf. 
Dekor: Auf der Randzone vertikale Winkel, nach rechts offen. In der Hauptzone ein Kranz nach rechts, 8 mal Muster mit abwechselnd Blättern und Beeren. An der Oberseite des Knaufes konzentrisch ein Wellenband (laufender Hund) nach rechts.

Ende 5./Anfang 4. Jh.

Zur Form: Der Rand des Deckels ist gerade, die Lippe schließt horizontal ab. Solche flachen Deckel kommen auf böotischen Pyxiden, Stamnospyxiden oder Lekaniden vor, siehe Walker, Floral Ware, 239-244. 248-25I. Die meisten Deckel dieser Art sind auf Stamnospyxiden erhalten, z. B. die Stamnospyxis in Heidelberg I 8 I: CVA Heidelberg I Taf. 28, 3-4; Walker, Floral Ware, I $50 \mathrm{Nr}$. 204 Abb. I3i Taf. I07, 2-I08, I; auf Pyxiden, z. B. Pyxis Nauplion, Arch. Mus. 97: Walker, Floral Ware, I74 f. Nr. 248 Abb. I 5 ix Taf. I30, 6-I3 I, 2 und auf Lekaniden z. B. Lekanis Reading 26.xii.24: CVA Reading I Taf. 20, 6; Walker, Floral Ware, I37 f. Nr. I 8 I Abb. I Iv Taf. 93, 6. Lekaniden sind sehr selten im floralen Stil bemalt, siehe Walker, Floral Ware, 249-25I. Die meisten Pyxiden und Stamnospyxiden stammen aus Museumssammlungen, wobei die Provenienz unbekannt ist: Walker, Floral Ware, 239. 243. Der Grazer Knauf ist sehr ähnlich den Deckelknäufen der erwähnten Pyxis Nauplion, Arch. Mus. 97 und der erwähnten Lekanis Reading 26.xii.24.

Zum Dekor: Der Deckel zeigt drei Dekorationsmotive: vertikale Winkel, Kranz und Wellenband. Alle drei Motive gehören zu einer Dekorationsart, die auf Vasen des floralen Stils untergeordnet verwendet wird. Solche Motive treten auf Näpfen, Pyxiden und Lebetes Gamikoi auf, vgl. Walker, Floral Ware, 272 Tab. I 2. Das Wellenband erscheint öfters an Vasen des floralen Stils als einfaches, sich wiederholendes Motiv, siehe Walker, Floral Ware, 273. Vertikale Winkel als Dekor finden sich selten auf böotischen Vasen des floralen Stils, vgl. eine Pyxis in einer Sammlung in Chicago: F. P. Johnson, Eight Pieces of Pottery, AJA 53, I949, 244 f. Nr. 6 Taf. 34. 35 a (R 25I); an der Schulter von zwei Exaleiptra aus dem Polyandrion: Schilardi, Polyandrion II, I 69 f. Nr. 4I4-4I 5. Im Gegensatz dazu ist das Muster auf dem Grazer Deckel nicht spitz und geometrisch, sondern eher rundlich. Ein ähnliches Ornament findet sich in Blattkränzen, die Pyxiden dekorieren, z. B. auf der Pyxis Bukarest 0492: CVA Bucarest, Musée National des Antiquités I Taf. 2I, 2; oder auf einer Pyxis der Sammlung Kanellopoulos: J. J. Maffre, Collection Paul Canellopoulos X: Vases Béotiens 2, BCH I02, I978, 278-280 Nr. 6 Abb. 8 (BT 268). Die meisten böotischen Vasen des floralen Stils sind nur mit Palmetten oder Palmetten, die mit Lotosblüten abwechseln, geschmückt. Andere Motive, wie Efeuzweige oder Kränze bzw. Zweige mit Myrten- oder Lorbeerblättern, sind als Hauptmotiv nicht so geläufig wie Palmetten, aber durchaus gebräuchlich. Die Blätter der Zweige können entweder rundlich oder spitz sein. Allgemein zu der Hauptdekoration der Vasen des floralen Stils siehe Walker, Floral Ware, 253-27I. Der Zweig als florales Nebenmotiv ist auf Pyxiden sowohl am Körper des Beckens als auch auf Deckeln zu sehen, z. B. ein Lorbeerkranz oberhalb des Hauptdekors auf der Pyxis München, Staatl. Antikensammlungen 7408: A. D. Ure, Some Provincial Black-Figure Workshops, BSA 6I, I940-I945, 2 I Nr. 4; Walker, Floral Ware, I 56 Nr. 2 I 4 Taf. I I3, 3, oder auf der Pyxis Nauplion, Arch. Mus. 97: Ure a. O. 2 I Nr. 3 Taf. 6, 2; Walker, Floral Ware, I74 f. Nr. 248 Taf. I30, 6. Zu Lorbeerzweigen als Nebendekor auf Deckeln siehe CVA Bruxelles, Musées Royaux du Cinquantenaire 3, III G Taf. 5, 6 (A 78); am Rand des Deckels Bonn, Akad. Kunstmuseum 855: A. D. Ure - P. N. Ure, Boetian Vases in the Akademisches Kunstmuseum in Bonn, AA I933, 30. 33 Abb. 22; Walker, Floral Ware, I 45 f. Nr. I95 Abb. I 2vi. Zweige bzw. -Kränze auf Deckeln umrunden üblicherweise den Knauf, nicht nur um ihn vom Körper abzusetzen, sondern auch um den eingeschränkten Platz, der sich nur für schlichte Dekorationen eignet, auszufüllen, siehe Walker, Floral Ware, 272. In den Funden aus dem Kabirion ist florales Dekor häufig entdeckt worden. Neben dem Efeuzweig kommt auch der Myrtenzweig und etwas weniger häufig der Ölzweig vor, vgl. Wolters - Bruns, Kabirenheiligtum, I I9. Die Kabirenkantharoi sind auch mit pflanzlichen Ornamenten, Efeuranken, Myrten- und Olivenzweigen vor allem in den zwei letzten Jahrzehnten des 4. Jhs. dekoriert: Braun - Haevernick, Kabirenheiligtum, 33 .

Allgemein können - allein durch ihre Bemalung - solche untergeordneten Dekormotive keinen Werkstätten zugeordnet werden, vgl. Walker, Floral Ware, 272 f. Das gilt auch für das Grazer Exemplar, besonders da sich die Art der Bemalung von anderen Exemplaren mit Zweigdekor unterscheidet.

Myrten-, Oliven- und Lorbeerzweige besitzen ähnliche Blätter. Bezüglich der Form der Blätter sind botanologische Differenzen vorhanden. Unterschiedlich sind diese Blätter auch auf den Vasenbildern abgebildet. E. Kunze-Götte hat die Abweichung der Blätter bemerkt und alle drei verglichen, vgl. E. Kunze-Götte, Myrte. Als Attribut und Ornament auf attischen Vasen (Kilchberg 2006) 7-I3. Die Blätter des Grazer Zweiges sind rundlich und haben ihre größte Breite im mittleren Bereich. Blätter solcher Art sind Lorbeerblätter. Die Blätter eines Myrtenzweiges sind dagegen spitz, was beim Grazer Deckel nicht zutrifft, z. B. der Myrtenzweig auf einem Deckel in Tübingen, siehe CVA Tübingen I Taf. 50, 4 (56I8). Anders aber als bei einem Lorbeerzweig besitzen die Früchte des Grazer Deckels relativ lange Stiele. Ähnliche Blätter, wie von dem Grazer Deckel, sind auf dem Kabirion als Olivenblätter bezeichnet, z. B. Kantharos K 52I, Braun - Haevernick, Kabirenheiligtum, 55 Nr. 2 I 8 Taf. ıо, 6. Die Blätter des Grazer Deckels sind jedoch eher als Lorbeerblätter anzusehen und weniger als Olivenblätter, da sie lang und relativ stark sind.

Zum Typ: Allgemein zur schwarzfigurigen böotischen Keramik des floralen Stils siehe Ure, Black Glaze Pottery; Ure, Rhitsona; Schilardi, Polyandrion I-III; Wolters - Bruns, Kabirenheiligtum; Braun - Haevernick, Kabirenheiligtum; Walker, Floral Ware; J. J. Maffre, Collection Paul Canellopoulos VIII: Vases Béotiens, BCH 99 I975, 409-520. Die Farbe des böotischen Tongrundes variiert stark. Es gibt sowohl orangefarbene als auch blasse, gelbliche Beispiele, die attische und korinthische Gefäße nachahmen. Gefäße mit orangefarben-gelblicher Tonfarbe wie bei dem Grazer Deckel wurden im thespischen Polyandrion gefunden, siehe V. Sabetai, Marriage Boiotian Style, Hesperia 67 I998, 324 Anm. 5; Schilardi, Polyandrion I, 92; Walker, Floral Ware, 53-59 Nr. 32-37. 39-42. Anhand der Form, der Bemalung und den Ähnlichkeiten mit den böotischen Beispielen kann angenommen werden, dass der Deckel aus Böotien stammt. Typische Merkmale von böotischen Werkstätten sind unter anderem der laufender Hund sowie die sich wiederholenden Motive (laut brieflicher Mitteilung von V. Sabetai). Da weder die Provenienz bekannt noch das ehemals dazugehörige Gefäßbecken vorhanden ist und auch keine exakte Parallele vorliegt, kann allein aus der Form und dem Dekor des Deckels keine exakte Zuweisung vorgenommen werden. 


\section{ELISCH}

\section{5-7. Lekythos}

Beilage 19, 2.

G 75. Fundort unbekannt. Erworben I9I I.

H 29,4 cm. - Dm Mündung 6,6 cm. - Dm Körper 7,6 cm. - Dm Fuß 5,5. - B Henkel 2, I cm. - D Henkel o,6 cm.

Lehner - Lorenz - Schwarz, Vasen, 72-74 Nr. 47 Abb. 6I (M. Lehner).

Zustand: Randzone oberhalb des Henkelansatzes gebrochen und wieder zusammengesetzt, ansonsten vollständig erhalten. Fehlstellen: am Fuß eine, an der Lippe zwei. An der Lippe bestoßen. Die Oberfläche ist massiv abgerieben, so dass der Tongrund zum Vorschein kommt. Im Inneren des Gefäßkörpers befinden sich lose Reste einer ehemaligen Vorrichtung zur Stabilisierung des Halses.

Technik: Schwarzer Malschlicker auf der gesamten Oberfläche, an der Innenseite der Mündung und an der Fußunterseite. Der Ton ist sehr fein, trocken und pulvrig, so dass der Malschlicker auf der Oberfläche nicht hält. Farbe des Malschlickers (Schulter/Körper): schwarz (2.5 Y 2.5/I, black). Malschlicker auf der Oberfläche nicht gleichmäßig aufgetragen. Am Hals, an der Schulter, an einem Teil des Henkels und vor allem auf der A Seite (links vom Henkel) ist der Malschlicker dick aufgetragen. Fehlbrand, großflächige rote und braune Verfärbungen. Am Fuß horizontale Farbstriche, durch das Ausdünnen des Schlickerauftrages entstanden. Stempeldekor auf Körper und Schulter. Die Riefen des plastischen Dekors sind freihändig eingezogen. Pinselspuren am Henkel. Farbe des Tongrundes: rötlichgelb (7.5 YR 7/6, reddish yellow).

Form: Hochovale Lekythos des Typus Ig. Hoher Ringfuß, Fußzone durch einen Grat deutlich nach oben hin abgesetzt. Ovaler, nach unten einschwingender Körper. Gerundete Schulter, stark eingezogener, hoher Hals, trichterförmige Mündung. Schräg nach innen abgestrichene, nach oben deutlich verdickte Lippe. Auf der Schulter und der oberen Halszone angesetzter Bandhenkel mit längsovalem Querschnitt.

Dekor: Vollständig mit Malschlicker überzogen, mit Ausnahme eines Teils des Fußes (wegen des schlechten Erhaltungszustandes nicht feststellbar) sowie des Gefäßinneren. Der Gefäßbauch ist durch horizontale Rillen in drei Zonen gegliedert. Die untere Zone ist vertikal geriefelt, die beiden Rillen unter dem Henkel laufen Vförmig aufeinander zu. Jedes 2. oder 4. Riefenpaar ist durch eine Linie von Doppelkreisen voneinander getrennt. Den oberen Abschluss der Dreiecke bilden zwei aneinander liegende Bögen, der Abschluss der vertikalen Streifen ist rund. Die Spitzen der Dreiecke sind unten nicht verbunden. Die Stempelkreise besitzen einen Dm von ca. $0,3 \mathrm{~cm}$ und sind zum Teil übereinander gelegt. Die breite, mittlere Zone zeigt hängende Dreiecke, die mit Doppelkreisen gefüllt sind. Diese Dreiecke wechseln bis auf ein einziges Mal mit vertikalen Streifen ab. Im Bereich unter dem Henkel Schlussmotiv durch einen breiten, vertikalen Streifen mit Stempelkreisen. Die stehenden Dreiecke bleiben undekoriert. Die obere Zone zeigt zwei vollständige und eine unvollständige Doppelkreisreihe. Auf der Schulter eine Reihe von Stempelkreisen, darüber eine Reihe von 23 gestempelten, nach unten weisenden Palmetten.

Erste Hälfte 4. Jh.

Zur Form: Allgemein zur Form siehe U. Sinn, Das Heiligtum der Artemis Limnatis bei Komothekra, AM 93, I978, 59-63. Die Gra- zer Lekythos gehört zu der hochovalen Form des Typus Ig mit zugespitztem Gefäßkörper. Sehr ähnliche Form zeigen die Lekythen P 2335 und aus dem Grab I4 (FN I46G-XVID, 2.5.I968) aus der W-Nekropole in Elis: Georgiadou, Totenkult, 80. I I 4 Nr. I, I

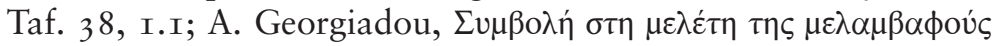

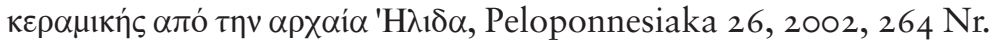
I Abb. I Taf. I; I I 5 Taf. 38, I4.I.

Zum Dekor: Die Verzierung der „elischen“ Lekythoi besteht aus senkrechten Riefelungen, die paarweise schräg angeordnet sind, so dass dadurch zungenförmige Ornamente entstehen. Als Füllornamente dienen gestempelte kleine Kreise, die abwechselnd auftreten. Zur Dekoration der „elischen“ Keramik siehe Georgiadou a. O. 26I; Georgiadou, Totenkult, 47; Sinn a. O. 7I-76. Die Dekoration der Grazer Lekythos entspricht keiner der von U. Sinn zusammengefassten Kategorien. Anders als die Gefäße der attischen Glanztonware sind die „elischen“ Exemplare nicht so qualitätvoll gearbeitet. Sowohl das Auftragen des Tonschlickers als auch die Ausführung der Riefen und des Stempeldekors sind sehr flüchtig, vgl. Sinn a. O. 76-78.

Zum Typ: Allgemein zur Gattung siehe Georgiadou a. O. 26I-269; Georgiadou, Totenkult, 78-80; A. Georgiadou, „Elische" Lekythen aus der Nekropole von Lithovouni in Aitolien. Aspekte der Datierung und Lokalisierung der Gattung, in: R. Einicke u. a. (Hrsg.), Zurück zum Gegenstand, Festschrift für A. E. Furtwängler (Langenweißbach 2009) 283; A. Georgia-

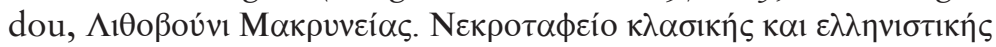

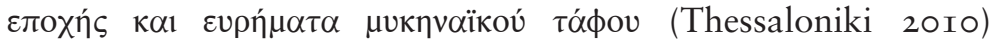
88-93; Sinn a. O. 50-63. Lekythen dieser Gattung werden als „elisch“ bezeichnet. Ursprünglich wurden sie als Lekythen der „Galaxidi“-Klasse benannt. Laut Sinn a. O. 79 f. gilt als Herkunft der Gattung die Landschaft Elis. Vorbilder dieser Gattung waren Gefäße aus Metall. Anhand der großen Anzahl „elischer“ Lekythen an anderen Fundorten, in Patras, in Ätolien und in Akarnanien wurde nachgewiesen, dass außerhalb von Elis auch andere Produktionsstätten existierten. Der elische Ton ist fein und weich, weshalb der Malschlicker nicht hält. Die Farbe des elischen Tons unterscheidet sich von dem Ton anderen Werkstätten und ist entweder rosa oder rötlich gelb, vgl. Georgiadou a. O. 262; Georgiadou, Totenkult, 46. 79 f.; A. Georgiadou, $\Lambda$ 1 $\theta$ oßoúvı

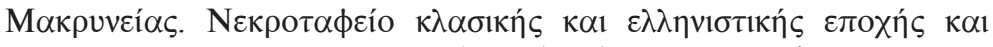

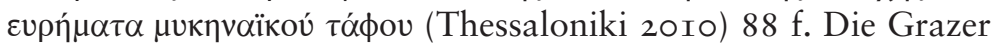
Lekythos ist aufgrund der Form, der Tonfarbe, der Konsistenz und der Art der Dekoration einer elischen Werkstatt zuzuordnen, vgl. Georgiadou a. O. 9I. I 2I. I 26; Georgiadou, Totenkult 46 f. A. Georgiadou, „Elische“ Lekythen aus der Nekropole von Lithovouni in Aitolien. Aspekte der Datierung und Lokalisierung der Gattung, in: R. Einicke u. a. (Hrsg.), Zurück zum Gegenstand, Festschrift für A. E. Furtwängler (Langenweißbach 2009) 285; D.

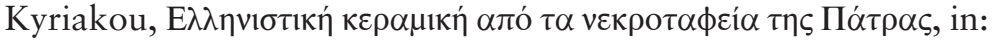

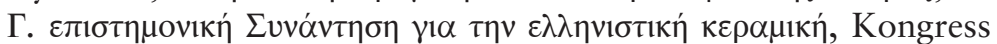
Thessaloniki 24.-27. September (Athen I994) I88-I90. I93 f.; Sinn a. O. 76-78. Die Art und Stelle des Bruches am Hals der Grazer Lekythos ist auch bei anderen elischen Lekythen gleich, z. B. bei den Lekythen aus der W-Nekropole in Elis, Georgiadou a. O. 264-269 Nr. I-7. I I-I3 Taf. I, 2. Es handelt sich hier um eine empfindliche Stelle. 


\section{ITALISCH}

\section{ETRUSKISCH}

\section{TAFEL 64}

\section{1-3. Knickrandschale}

Beilage 19, 4. Abb. 20.

G 32. Aus Grotte di Castro bei Bolsena. Erworben I 874 durch Wolfgang Helbig in Rom, Ankauf. Alte Inv.-Nr. II 34 (Schenkl) bzw. III 44 (Pichler).

H Io, 5 cm. - Dm Mündung I7,0 cm. - Dm Körper I6,0 cm. - Dm Fuß 7,4 cm. - Dm Henkel I, 2 cm. - Gewicht [548 g]. - Volumen I033 ml.

G. Camporeale, La caccia in Etruria, Archaeologica 50 (Rom I984) 93 Nr. 9; 95. 97. - Lehner - Lorenz - Schwarz, Vasen, 29 Nr. I3 Abb. I6-I7 (Th. Lorenz).

Zustand: Beide Henkel zum Teil abgebrochen. Einige großflächige Absplitterungen am Fuß und an der Lippe. Zwei horizontale Risse von der Lippe bis zur Schulter.

Technik: Bucchero. Oberfläche außen und innen dunkelbraun bis schwarzgrau, Bruch dunkelbraun. Magerung stark, Körnchengröße fein, vereinzelt schwarze Partikel, einige weiße Partikel. Oberfläche innen und außen geglättet, außen jedoch sorgfältiger. Das eingetiefte Reliefband ist wohl mit Hilfe eines trapezförmigen Rollsiegels (cilindretto) vor dem Brand in den noch weichen Ton eingedrückt worden.

Form: Hoher konischer Fuß. Tiefer Schalenkörper mit deutlich ausgeprägter Schulter und Halseinziehung. Steilschräg ausgestellte Randzone mit gerundeter Lippe. Zwei gegenständige Horizontalhenkel mit rundem Querschnitt, am maximalen Umfang der Schulter angesetzt.

Darstellung: Jagdfries - Unterhalb der Henkel umlaufendes Reliefband mit gestempelten Tier- und Menschendarstellungen. Die Abfolge der von links nach rechts schreitenden Tiere wiederholt sich sechsmal, wobei nur der Hirsch, dem ein Jäger seine Lanze von rückwärts in den Rücken stößt, und ein Steinbock eindeutig zu benennen sind. Bei den anderen könnte es sich um Hunde und einen sich umblickenden Löwen handeln.

Um $580-570$

Zur Form: T. B. Rasmussen, Bucchero Pottery from Southern Etruria, Cambridge Classical Studies ${ }^{2}$ (Cambridge 2006) II9 f. Taf. 38 Nr. 22 I Typ 3 b; CVA Brit. Mus. 7, IV B a Taf. I 5, I I (H I93): Die Kylix ist gestreckter und besitzt einen höheren Fuß, der zwar angesetzt, aber wahrscheinlich zugehörig ist. Statt der

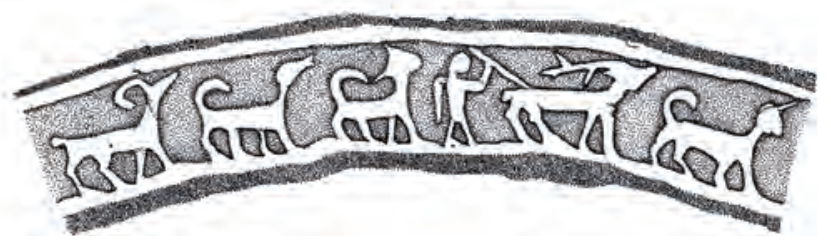

Abb. 20: Umzeichnung des Reliefbandes G 32 im Maßstab I:I (Zeichnung Kraschitzer)
Henkel sind horizontale Lotosblüten angebracht. Der gestempelte Fries zeigt zwei Wiederholungen: Ph. Perkins, Etruscan Bucchero in the British Museum, Research Publication I 65 (London 2007) 36 Nr. II 8.

Zum Dekor: Zu etruskischer Bucchero-Ware mit Reliefs, die mit Hilfe von zylindrischen Rollsiegeln („a cilindretto“) aufgebracht wurden, vgl. H. B. Walters, Cypriote, Italian und Etruscan Pottery, Catalogue of the Greek and Etruscan Vases in the British Museum I, 2 (London I9I 2) 243-247; CVA Brit. Mus. Io, I I. Zu etruskischer Bucchero-Ware "a cilindretto" aus Tarquinia vgl. G. Camporeale, Buccheri a cilindretto di fabbrica tarquiniese, StEtr 40, I972, I I 5-I 49; G. Gualtiero in: M. Bonghi Jovino (Hrsg.), Produzione artigianale de esportazione nel mondo antico. Il bucchero etrusco, Atti del Colloquio Internazionale, Milano Io-I I Maggio I990 (Mailand I993) I40-I 44 Abb. I6.

Zur Darstellung: Der Jäger, der den Hirsch attackiert, bringt ein erzählendes Element in den ansonsten rein dekorativ angelegten Fries. Eine menschliche Figur erscheint auch bei G. Gualtiero a. O. Abb. I6 Nr. VII auf einem Fries 2A ,a cilindretto“ aus Tarquinia.

Zur Werkstatt: Als Herstellungsort dieser mit Relieffriesen verzierten Buccheroware wird Orvieto, das antike Volsinii, angesehen: G. Camporeale, Buccheri a cilindretto di fabrica orvietana (Firenze I972); P. Tamburini, Dai primi studi sul bucchero etrusco al riconoscimento di bucchero di Orvieto, in: A. Naso (Hrsg.), Appunti sul bucchero, Atti della giornate di studio, Archeologia Atti di Convegni e Seminari (Firenze 2004) I 79-222 bes. 200-202 mit Taf. 7 a. Die Form der Kylix Typ I a entspricht der Form Rasmussen $3 \mathrm{~b}$ (siehe oben).

\section{TAFEL 65}

\section{1-6. Kleeblattkanne}

Beilage 19, 3.

G 3 I. Aus Chiusi. Erworben I 874 durch Wolfgang Helbig in Rom, Ankauf. Alte Inv.-Nr. II 28 (Schenkl) bzw. III 43 (Pichler).

H I 8,3 cm. - Dm Mündung 9,4 cm. - Dm Fuß 6,7 cm. - Dm Bauch I I,2 cm. - Gewicht $[454,3] \mathrm{g}$.

Lorenz - Lehner - Schwarz, Vasen, 29 f. Nr. I4 Abb. I8-I9 (Th. Lorenz).

Zustand: Aus mehreren Fragmenten zusammengesetzt. Eine größere Fehlstelle am Rand. Henkel abgebrochen und verloren, unterer Henkelansatz mit einem Stück der Wandung aus dem Bauch herausgebrochen.

Technik: Dunkelgrauer Ton. Oberfläche dunkelgrau bis schwarz glänzend, außen sorgfältig poliert. Einkerbungen.

Form: Schräg nach außen gezogener Ringfuß. Kugeliger Körper. Halsansatz durch gekerbten Grat von der Schulter abgesetzt. Kurzer Hals, schräg nach außen gezogener Mündungskelch, rund abgestrichene Lippe. Lanzettförmiger Henkelansatz am Bauch. Kleeblattmündung. Ausbruchspuren eines randständigen Henkels. Beidseitig des oberen Henkelansatzes je eine senkrecht gestellte Rotelle. 
Dekor: Bandhenkel am Henkelansatz am Bauch und am oberen Ansatz mit feinem Kerbmuster versehen.

Darstellung: Je ein Löwenkopf auf den Henkelrotellen.

Zweite Hälfte 6. Jh.

Zur Form: Die Form ist zuerst von S. Gsell, Fouilles dans la nécropole de Vulci (Paris I89I) Taf. B kategorisiert worden: T. B. Rasmussen, Bucchero Pottery from Southern Etruria. Cambridge Classical Studies ${ }^{2}$ (Cambridge 2006) Typ 3d (Gsell 63); B. Belelli Marchesini, Appunti sul bucchero vulcente, in: A. Naso (Hrsg.) Appunti sul Bucchero. Atti delle Giornate del studio, Archeologia - Atti di Convegni e Seminari (Firenze 2004) 9I-I 47 bes. IOO-IO4 Taf. 9, 2. Vgl. die Oinochoen mit Reliefverzierung in CVA Brit. Mus. 7, IV B a Taf. I9, I2. I4 mit Henkelrotellen: Ph. Perkins, Etruscan Bucchero in the British Museum, Research Publication I 65 (London 2007) 65 f. Nr. 257 (aus Vulci); CVA Tübingen 6 Taf. I 5, I-2. 7 (S./I 2 2453). Die Form weist Ähnlichkeiten mit Kannen der bemalten sog. Pontischen Keramik auf, vgl. z. B. Oxford, Ashmolean Museum L i76: C. M. Stibbe, Neue Fragmente lakonischer Schalen aus Cerveteri, MededRom 38, I976, Taf. 5 mit gemaltem Pantherkopf auf den Rotellen. Oinochoen in ähnlicher, bauchiger Form mit Henkelrotellen und Reliefverzierung am
Bauch: CVA Malibu 6 Taf. 305-309, I-3 („Vulcian“). Mit Pantherköpfen verzierte Rotellen auf einer schlankeren, vermutlich chiusinischen Oinochoe: CVA Malibu 6 Taf. 304.

Zur Werkstatt: Die Oinochoe gehört zu der weit verbreiteten Bucchero-Pesante-Produktion aus einer Vulcenter Werkstatt, von wo die meisten nicht reliefverzierten und auch die ältesten Exemplare stammen. Daher gilt Vulci als Herstellungszentrum dieser Gattung. Zu Herkunft und Verbreitung vgl. J. M. J. Gran Aymerich, CVA Louvre 23 Text zu Taf. 37, I (mit weiterführender Literatur) und B. Rückert, CVA Tübingen 6 Text zu Taf. I 5 , I-2. 7. Aber auch im Chiusiner und Orvietaner Gebiet ist diese Oinochoenform verbreitet, die häufig mit sparsamem Reliefdekor versehen ist. Es liegen jedoch keine eindeutigen Kriterien für die Zuweisung an eine bestimmte Produktionsstätte vor, vgl. G. Batignani, Le oinochoai di bucchero pesante di tipo „chiusino“, StEtr 33, I965, 3 Iо f. In der Bucchero-Keramik von Vulci gibt es in der zweiten Hälfte des 6. Jhs. Formen, die man auch in der pontischen Keramik findet, vgl. L. Hannestad, The Followers of the Paris Painter (Kopenhagen I976) Taf. 32-34; M. A. Rizzo, La ceramica a figure nere, in: M. Martelli (Hrsg.), La ceramica degli Etruschi (Novara I987) 3 I-35. Als Vorbild für diese Formen gelten Metallgefäße, vgl. J. M. J. Gran Aymerich, Le bucchero et les vases métalliques, REA 79, I995, 45 f. 


\section{APULISCH ROTFIGURIG}

\section{TAFEL 66}

\author{
1-4. Lekythos
}

Beilage 20, 1.

G 6. Aus Süditalien. Erworben I 868 von Richard Knabl, Schenkung. Ehemals Slg. Richard Knabl (Graz). Alte Inv.-Nr. IV 2 (Schenkl) bzw. III I 2 (Pichler).

H 9,8 cm. - Dm Mündung 3,3 cm. - Dm Körper 4,o cm. - Dm Boden 3,2 cm. - Dm Fuß 3,3 cm. - B Henkel o,7 cm. - Gewicht 62 g. - Volumen $24 \mathrm{ml}$.

Essenwein, Katalog, 27 Nr. 213. - S. Karl, HOKUS POKUS FIDIBUS. Eine Spurensuche zum so genannten unteritalischen Grabfund im Institut für Archäologie der Karl-Franzens-Universität Graz, RÖ 28, 2005, I77-I 84. - Karl, Richard Knabl, 30I Nr. 2. - Karl, Knabl, 82 Kat. 2 Taf. I. - Lehner - Lorenz - Schwarz, Vasen, 67 f. Nr. 38 Abb. 50 (Th. Lorenz).

Zustand: Eine kleine Partie am Mündungsrand fehlt, ansonsten vollständig erhalten. Kleine Fehlstelle am Standring und Bestoßungen der Oberfläche vor allem am Mündungskelch. Malschlicker stellenweise abgeplatzt. Im Inneren des Gefäßes zwei zugeschnittene, gefaltete und an einer Seite angebrannte Papierstreifen (Fidibus). Auf einem von den beiden: „...mer in Wien“.

Technik: Schwarzer glänzender Malschlicker, zum größten Teil deckend aufgetragen. Farbe des Malschlickers (Bauch): schwarz ( 5 Y 2.5/2, black). Die Zeichnung und die Bemalung sind flüchtig. Der verdünnte Tonschlicker für die Konturenzeichnung ist am Hals, am Sakkos, an der Grundlinie und an der Ranke sichtbar. Die Bemalung des Hintergrundes ist ebenfalls flüchtig aufgetragen, so dass an einigen Stellen die Konturen sichtbar oder übermalt sind. Unterseite des Fußes, Rückseite und Henkel zu einem Viertel durch Eintauchen dick mit Tonschlicker versehen. Tropfspuren des Malschlickers im Mündungsinneren und auf der Gefäßunterseite. An den Henkelansätzen sind Pinselspuren zu erkennen. Miltos: Überzogen sind die tongrundigen Partien des Bildfeldes und die Unterseite. Verdünnter Tonschlicker: eine Locke im Haar der Frau. Relieflinie: Auge mit Pupille, Augenbraue, Nase, Mund, Ohr, Sakkosfalten, Kinn- und Kehllinie.

Form: Bauchlekythos auf ausladendem Standring. Langovaler Körper mit leicht betonter Bauchzone und durch einen Grat vom Hals abgesetzter Schulter. Mittelhoher, enger Hals. Die sanft ausschwingende Glockenmündung ist durch eine breite Rille abgesetzt. Lippe deutlich nach innen herabgezogen und leicht gerundet abgestrichen. Unterhalb der Schulter und in der Halszone angesetzter Bandhenkel mit längsovalem Querschnitt.

Dekor: An den Seiten des Hauptfeldes wächst jeweils eine Ranke mit zwei sich einrollenden Voluten, mit unten einem kleinen tropfenförmigen und mittig einem größeren lanzettförmigen Ornament empor. Auf der unteren Hälfte des Halses ein umlaufendes Stabband.

Darstellung: Frauenprotome. - Frauenkopf im Profil nach links. Die Frau trägt einen unverzierten Sakkos, die Haube endet in der Mitte des Hinterkopfs in zwei Zipfeln. Aus der Haube quillt ein Teil des lockigen, dichten Haares von der Stirn bis zum Ohr hervor; das Ohr ist durch einen Bogen wiedergegeben. Das Auge wird von einer geraden Unter- und einer schrägen Oberlinie, die sich nicht berühren, gebildet. Knapp darüber befinden sich je eine wei- tere Linie für die Augenhöhle und darüber eine lange gebogene für die Augenbraue. Die Pupille grenzt an die obere Augenlinie, der Blick ist gerade nach vorn gerichtet. Die abgeflachte Nase ist unordentlich ausgeführt. Geschlossener Mund mit betonter Unterlippe. Rundes Kinn, um den Hals ein Ring.

Drittes Drittel 4. Jh. - Umkreis der Chevron-Gruppe (Karl)

Zur Erwerbung: Aus dem älteren Inventarbuch ist bekannt, dass diese Lekythos zusammen mit acht weiteren Gefäßen zu einem „unteritalischer Grabfund“ gehört. Das Ensemble der neun Vasen wurde der Universität Graz am I5. April i 868 vom Pfarrer Richard Knabl zu St. Andrä in Graz geschenkt, vgl. Karl, Grabfund, I77-I 84. Das Originalverzeichnis der Antikensammlung von Knabl, eigenhändig von ihm am I2. Mai I 865 geschrieben, nennt nur bei den Lekythen G 5-7, hier Tafel 66, I-8; 78, 5-7 eine Herkunft aus „Gräbern“ ohne weitere Angabe einer Region oder eines Fundortes. Dieses Verzeichnis konnte vor kurzem im Nachlass Knabl am Universalmuseum Joanneum, Abteilung Archäologie \& Münzkabinett aufgefunden werden. Es besteht demnach kein zwingender Grund, alle neun Gefäße einem einzigen Grabkontext zuzuschreiben.

Zur Technik: Über das Tauchen der Gefäße in verdünnten Tonschlicker als Bemalungstechnik der Antike siehe Agora XII, I7; TonArt, 75 Anm. 3; T. Schreiber, Dipping as a Glazing Technique in Antiquity, in: Occasional Papers on Antiquities 2, Greek Vases in the J. Paul Getty Museum 3 (Malibu I986) I43-I48.

Zur Form: Ähnlichkeiten zu der Form der Grazer Lekythos zeigen die von Hoffmann kategorisierten Lekythoi der Gruppe 8: Bauchlekythen mit langovalem Körper und unprofiliertem Fuß. Besondere Affinitäten zeigt sie zu dem Typ I I I/94, vgl. Hoffmann, Grabritual, 30. Lekythoi sind die am häufigsten gefundenen Ölund Parfümbehältnisse in Tarent. Die Rolle der Lekythoi dieser Gruppe im Totenkult scheint sehr wahrscheinlich, siehe Hoffmann, Grabritual, Io4 f. Eine ähnliche Lekythos befindet sich in Nantes: CVA Nantes, Musée Dobrée I Taf. 44, 4-6 (985.2-4). $\mathrm{Zu}$ rotfigurigen attischen Lekythoi siehe W. Rudolf, Die Bauchlekythos (Bloomington I97I); Agora XXX, 47 f. (squat lekythoi). Von den zwei Haupttypen der attischen Lekythoi, die im großen Ausmaß in der klassischen und nachklassischen Zeit in Gebrauch waren, war die Bauchlekythos in Unteritalien weit verbreitet, vgl. Schauenburg, Studien III, 9.

Zum Dekor: Sehr ähnliche Ranken wie auf der Grazer Lekythos befinden sich auf dem Glockenkrater der Archidamos-Untergruppe New York 96.I 8.22: RVAp II, 654 Nr. 48 Taf. 24I, 5-6, und dem Glockenkrater Bari Cavalcanti 9: RVAp II, 653 Nr. 43 Taf. $242,2-3$.

Zur Darstellung: Frauenkopfdarstellungen sind erst ab dem 2. Viertel des 4. Jhs. auf Vasen des Ilioupersis-Malers und seines Umkreises zu sehen. Dieses Motiv ist entweder ein Teil der Dekoration großer Vasen, oder Hauptthema auf der Rückseite von Gefäßen, oder auch Hauptthema kleinerer Vasen. Über ihre Deutung gibt es viele Meinungen. Frauenköpfe mit charakteristischen Attributen - wie z. B. phrygische Mütze - mit Amazone oder Artemis Bendis in Verbindung zu setzen, ist wahrscheinlich. Für Frauenköpfe ohne Attribute bleibt die Frage nach der Identifizierung offen. Allgemein zu Frauenkopfdarstellungen, sog. Head Vases, in der unteritalischen Vasenmalerei siehe Trendall, RFVSIS, 92 f.; RVAp II, 646-650; CVA Dresden I, I7; CVA Göttingen I, I 5 f.; Splitter, Vasenbilder, 59-6I; Schauenburg, Studien II, 59 f. Frauenkopf- 
bilder auf Gefäßen aus tarentinischen Gräbern waren ein sehr beliebtes Motiv. Dieses Motiv ist weder ausschließlich auf Frauen konnotierten Gefäßen noch exklusiv bei Frauenbestattungen zu sehen. Außerdem wurden Vasen mit Frauenkopfbildern auch bei Siedlungen gefunden. Die Deutung der Figuren ohne Attribute ist sehr schwierig. Konnotationen dieser Bilder zum Idealbild von Weiblichkeit scheinen jedoch sehr wahrscheinlich, vgl. Hoffmann, Grabritual, I 58-160.

Zum Maler bzw. zur Gruppe: Die Lekythos gehört in die spätapulischen Werkstätten der Chevron-Gruppe, speziell der Archidamos- und Magnini-Untergruppe, sowie des Malibu-Malers. Die Zuweisung zu dieser Gruppe ergibt sich aus der Zeichnung der Augenpartie, bei der die Augenbraue ziemlich lang ist und die Oberlidlinien eng beieinander liegen, aus dem undekorierten Sakkos, aus der Anordnung der Haare, die aus der Kopfbedeckung nur an Stirn und Schläfe hervortreten, aus der Existenz und Wiedergabe der Lippen, der Kinn- und Kehllinie, die nicht weit voneinander und gerade gezeichnet sind, sowie aus den Palmetten. Allgemein zur Chevron-Gruppe: RVAp II, 650-66o; RVAp Suppl. I, I I 2-I I 4; RVAp Suppl. II, 200-207. Die Augenpartie findet Parallelen bei Frauenköpfen der Magnini-Untergruppe, vgl. den Glokkenkrater Matera II334: RVAp II, 655 Nr. 56 Taf. 243, I, aber auch Ähnlichkeiten zum Malibu-Maler, vgl. den Glockenkrater Malibu 7I AE 302: RVAp II, 657 Nr. 78 Taf. 243, 9. Der undekorierte Sakkos zeigt Ähnlichkeiten mit einigen Kekryphaloi der Archidamos- und Magnini-Untergruppe, vgl. den Teller ehemals im Londoner Handel, Christie's 35: RVAp II, 654 Nr. 54 Taf. 242, 8; den Teller ehemals im Londoner Handel, Sotheby I 45 : RVAp II, 655 Nr. 55 Taf. 242, 9; den Glockenkrater ehemals im Londoner Handel, Sotheby I 88: RVAp II, 655 Nr. 6I Taf. 243, 4. Eventuell gab es zusätzlich weiße Deckfarbe, die heute nicht mehr erhalten ist. Zur soliden und lockigen Haartracht vgl. den Teller ehemals im Londoner Handel, Sotheby I 45: RVAp II, 655 Nr. 55 Taf. 242, 9; den Teller La Louvière 9IT: RVAp Suppl. II, 204 Nr. 53 d Taf. 55, 2; die Lekythos Nantes 985-2-4: CVA Nantes, Musée Dobrée I Taf. 44, 4-6. Zur Existenz der Kinn- und Kehllinie vgl. die erwähnten Teller ehemals im Londoner Handel, Christie's 35 und Sotheby I 45. Zur waagrechten Kinnlinie vgl. die Lekythos Nantes 985-2-4: CVA Nantes, Musée Dobrée I Taf. 44, 4-6, sowie die Glockenkratere ehemals im New Yorker Handel: RVAp Suppl. II, 203 Nr. 48 a. c Taf. 54, 6-7.

\section{5-8. Lekythos}

Beilage 20, 2.

G 7. Aus Süditalien. Erworben I 868 von Richard Knabl, Schenkung. Ehemals Slg. Richard Knabl (Graz). Alte Inv.-Nr. IV 3 (Schenkl) bzw. III I3 (Pichler).

H I I,2 cm. - Dm Mündung 3,4 cm. - Dm Körper 4,5 cm. - Dm Fuß 3,9 cm. - B Henkel I, 3 cm. - Gewicht 88 g. - Volumen 4I ml.

Essenwein, Katalog, 27 Nr. 2 I 2. - S. Karl, HOKUS POKUS FIDIBUS. Eine Spurensuche zum so genannten unteritalischen Grabfund im Institut für Archäologie der Karl-Franzens-Universität Graz, RÖ 28, 2005, I77-I84. - Karl, Richard Knabl, 30I Nr. 3. - Karl, Knabl, 82 f. Kat. 3 Taf. I. - Lehner - Lorenz - Schwarz, Vasen, 66 f. Nr. 37 Abb. 49 (Th. Lorenz).

Zustand: Henkel abgebrochen und verloren. Schwarzer Malschlicker am Hals und an der Mündung stellenweise abgeblättert. Pinselspuren am unteren Henkelabsatz und unterhalb des Henkels. Mündung bis zur Halsmitte in verdünntem Tonschlicker eingetaucht, Rinnspur des schwarzen Tonschlickers in das Mündungsinnere. Sinterreste am oberen Teil des Fußes und am Übergang zum Körper. Zwei Fidibuszettel mit Resten des Aufdrucks: „[...]er in Wien“ und „[...]n Wien“. Ein auf einer Seite abgerisse- ner und auf der anderen Seite angebrannter Zettel mit dem Inhaltsverzeichnis eines Teiles des katholischen Katechismus. Im Inneren des Gefäßes befand sich ein so genanntes Palmkätzchen.

Technik: Schwarzer Tonschlicker. Farbe des Malschlickers (Bauch): schwarz (2.5 Y 2.5/I, black). Standfläche, Außenkante und Übergang zum Körper schwarz bemalt. Innenkante stellenweise mit schwarzer Farbe verwischt. Mündungstrichter außen und innen schwarz bemalt. Miltos: Auf der Gefäßunterseite sowie allen nicht mit Tonschlicker überzogenen Flächen. Verdünnter Tonschlicker: Augen, Locken am Ohr, Striche und Falten des Kekryphalos. Bemalung sehr flüchtig ausgeführt. Zuerst wurden die Konturen der Figuren mit verdünntem Tonschlicker gezeichnet und dann die schwarzen Teile noch einmal bemalt. Der Maler hielt sich nicht an seine Konturen, so dass an einigen Stellen der verdünnte Tonschlicker sichtbar ist oder Konturen übermalt sind; nur die Gesichtskontur ist ziemlich präzis ausgeführt. Erst anschließend wurden die tongrundigen Flächen mit roter Farbe bemalt. Der Miltos ist im Bereich des Henkels etwas dichter, so dass er rötlicher wirkt.

Form: Bauchlekythos auf niedrigem Ringfuß. Langovaler Körper, durch einen Grat vom Hals abgesetzte Schulter. Mittelhoher, enger Hals und ausladende Glockenmündung. Lippe deutlich nach innen herabgezogen und gerundet abgestrichen. Unterhalb der Schulter und in der Halszone angesetzter Bandhenkel mit längsovalem Querschnitt.

Dekor: Auf der Rückseite eine Palmette mit I 2 Blättern, die aus einem Segmentkreis aufwächst; ihre Spitze führt über den unteren Henkelansatz. Seitlich je eine Ranke mit zwei Volutenblättern und einem Zwickelblatt. Hinter dem Frauenkopf im Bereich des Halses ein tongrundiger Kreis mit dunklem, tropfenförmigem Zentrum. Auf der unteren Hälfte des Halses ein umlaufendes Stabband.

Darstellung: Frauenprotome. - Frauenkopf mit Schulteransatz im Profil nach rechts. Sie trägt einen mit Strichen und einer Reihe relativ weit auseinander liegender Punke dekorierten Kekryphalos. Die solide Haarmasse quillt von der Stirn bis zum Ohr hervor. Aus der homogenen Haarmasse zeichnet sich nur vereinzelt eine kurze Locke in der Höhe des Auges und eine längere im Ohrbereich ab. Am Hinterkopf kommt das Haar als Knoten aus dem Kekryphalos, einige Haarsträhnen lösen sich heraus. Gerades Nasenprofil mit Punkt für den Nasenflügel. Mund geöffnet, runde Unterlippe. Das Auge ist durch zwei lange Linien, die einen spitzen Winkel bilden, wiedergegeben. Eine weitere Linie für die Augenhöhle berührt das Auge, darüber eine dicke Augenbraue. Der Blick ist nach oben gerichtet. Die Kehle ist durch eine Wölbung wiedergegeben, auf dem Hals ein kräftiger Punkt.

Drittes Drittel 4. Jh. - Winterthur-Gruppe (Lorenz). Zürich2660-Gruppe (Karl)

\section{Zur Erwerbung: siehe G 6, hier Tafel 66, I-4.}

Zur Form: siehe G 6, hier Tafel 66, I-4. Ähnlichkeiten zeigt die Lekythos zu dem Typ I I I/92 und I I I/94, vgl. Hoffmann, Grabritual, 30 .

Zum Dekor: Frauenköpfe sind gewöhnlich von Ranken flankiert; vgl. den Glockenkrater Malibu 7I AE 30I: RVAp II, 656 Nr. 76 Taf. $243,8$.

Zur Darstellung: Über Frauenkopfdarstellungen siehe G 6, hier Tafel 66, I-4.

Zum Maler bzw. zur Gruppe: Die Zürich-266o- und die Winterthur-Gruppe dekorierten Vasen mit Frauenköpfen, beide Gruppen gehören zum Umkreis des Dareios- und des Unterwelt-Malers. Allgemein zur Zürich-266o-Gruppe siehe RVAp II, 677-682; RVAp Suppl. I, I I 8-I 20; RVAp Suppl. II, 2I 2-2I4; zur Winterthur-Gruppe siehe RVAp II, 694 f.; RVAp Suppl. I, I 22 f.; RVAp Suppl. II, 2 I 7 f. Die Wiedergabe des Auges, bei dem das Oberlid eine weitere Linie berührt und das Ober- und Unterlid einen spit- 
zen Winkel bilden sowie der nach oben gerichtete Blick sind sehr ähnlich mit der Malweise der Zürich-2660-Gruppe, vgl. Skyphos Bari Stimola 2: RVAp II, 679 Nr. 373 Taf. 252, 3; Glockenkrater Armidale, University of New England 73/3: RVAp II, 678 Nr. 368 Taf. 252, 5; Teller Zagreb 389: RVAp II, 680 Nr. 393 Taf. 252, 7; Teller Zagreb 379: RVAp II, 680 Nr. 394 Taf. 252, 8; Skyphos Triest, Civico Museo S. 500: CVA Trieste, Civico Museo I, IV D Taf. 32, 7-8. Der Haarschopf am Hinterkopf des Frauenkopfes auf der Grazer Lekythos zeigt große Ähnlichkeiten mit einem auf dem Skyphos Armidale, University of New England 73/3: RVAp II, 678 Nr. 368 Taf. 252, 5. Zu parallelen Haarschöpfen siehe den Teller: RVAp Suppl. I, I I 8 Nr. 400 Taf. 2 I, Io (Londoner Handel, Faustus Gallery). Der Haarschopf hat aber auch Ähnlichkeiten mit solchen in der Winterthur-Gruppe, vgl. Pelike Winterthur 322: RVAp II, 696 Nr. 569 Taf. 258, 5; CVA Ostschweiz Ticino Taf. 26, I-3; Pelike Bassano del Grappa, Chini ro4: RVAp II, 697 Nr. 598 Taf. 259, 3; Teller Kopenhagen 40: RVAp II, 698 Nr. 607 Taf. 259, 5. Kekryphaloi mit Strichen und Punkten sind von der Gruppe-Zürich-2660 ähnlich gezeichnet. Siehe den Glockenkrater Armidale, University of New England 73/3: RVAp II, 678 Nr. 368 Taf. 252, 5 und den Teller Zagreb 379: RVAp II, 680 Nr. 394 Taf. 252, 8. Für die Dekorierung des Kekryphalos wird gewöhnlich weiße Farbe verwendet, die bei der Grazer Lekythos aber nicht zu sehen ist.

\section{TAFEL 67}

\section{Lekanisschale}

Beilage 20, 3.

G I4. Aus Süditalien. Erworben I 868 von Richard Knabl, Schenkung. Ehemals Slg. Richard Knabl (Graz). Alte Inv.-Nr. IV 7 (Schenkl) bzw. III I 8 (Pichler).

H 4,4 cm. - Dm Rand 7,I cm. - Dm Boden 3,6 cm. - Dm Fuß 3,7 cm. - Dm Henkel o,6 cm. - B mit Henkel I I,4 cm. - Gewicht [85 g]. - Volumen $56 \mathrm{ml}$.

Essenwein, Katalog, 26 Nr. 203. - Karl, Richard Knabl, 30I Nr. 9. - Karl, Knabl, 83 Kat. 8 Taf. I.

Zustand: Vollständig erhaltenes, ungebrochenes Gefäß. Massive Sinterreste an der gesamten Oberfläche, der Außen- und Unterseite des Fußes. Im Inneren nur winzige Versinterungen. Abrieb des Tonschlickers am Auflager. Bestoßungen vor allem im Bereich des Auflagers.

Technik: Schwarzer Tonschlicker, gleichmäßig und deckend aufgetragen. Farbe des Malschlickers (Bauch): schwarz (5 Y 2.5/I, black). Das Gefäß wurde in Tonschlicker getaucht. Am unteren Teil des Fußringes an drei Stellen Rinnspur des Tonschlickers und Fingerabdrücke. Miltos: Fußunterseite, Standfläche, Fußinnenseite.

Form: Hoher Fuß, flacher, weit trichterförmig auskragender Schalenkörper, vertikale Randzone mit spitz gerundeter Lippe und massivem Deckelfalz außen. Zwei Horizontalhenkel mit rundem Querschnitt.

Dekor: Auf der Innen- und Außenseite mit Tonschlicker schwarz überzogen.

$340-320$

Zur Erwerbung: siehe G 6, hier Tafel 66, I-4.

Zur Form: Allgemein zur Form der Lekanis siehe Agora XXX, 54 f.; A. Lioutas, Attische schwarzfigurige Lekanai und Lekanides (Würzburg I 987); E. D. Breitfeld-von Eickstedt, Die Lekanis vom 6.-4. Jh. v. Chr. Beobachtungen zur Form und Entwicklung einer
Vasengattung, in: J. H. Oakley - W. D. E. Coulson - O. Palagia (Hrsg.), Athenian Potters and Painters. The Conference Proceedings (Athen I997) 55-6I. Das Becken der Lekanides wird im Laufe der Zeit immer flacher und ab der 2. Hälfte des 4. Jhs. kantiger. Die attischen besitzen im Gegensatz zu den unteritalischen Exemplaren einen niedrigen Fuß: Schauenburg, Studien II, 57-6I. Die Lekanides als Gefäße für Schminkutensilien und kosmetische Gegenstände finden sich in der Nekropole von Tarent sehr oft, vgl. Hoffmann, Grabritual, I00-I02. Die Grazer Lekanisschale zeigt Ähnlichkeiten mit dem Typ 427/II und 427/I3, vgl. Hoffmann, Grabritual, 45 Taf. 87. Im älteren Inventarbuch wird vermutet, dass das Becken zum Deckel G I 5 (hier Tafel 67, 2-4) gehört. Typologisch würden sie zusammenpassen, allerdings ist der Durchmesser des Deckels etwas größer als der des Auflagers, so dass der Deckel nicht richtig auf der Schale sitzt. Dass ursprünglich die Schale G I 4 für den Deckel G I 5 bzw. vice versa geschaffen wurde, ist fraglich.

\section{2-4. Lekanisdeckel}

\section{Beilage 20, 5.}

G I 5. Aus Süditalien. Erworben I 868 von Richard Knabl, Schenkung. Ehemals Slg. Richard Knabl (Graz). Alte Inv.-Nr. IV 6 (Schenkl) bzw. III 23 (Pichler).

H 4,6 cm. - Dm Rand 8,o cm. - Dm max. 8,2 cm. - H Knauf 2,9 cm. - Dm Knauf 4,4 cm. - Gewicht 72 g.

Essenwein, Katalog, 27 Nr. 208. - Karl, Richard Knabl, 30 I Nr. 5. - Karl, Knabl, 83 Kat. 8 Abb. 3 Taf. I. - Lehner - Lorenz - Schwarz, Vasen, 64 f. Nr. 35 Abb. 53 (Th. Lorenz). - RVAp II, 780 Nr. I9.

Zustand: Ungebrochen. Kleine Bestoßungen an Mündung und Körper, stellenweise Absplitterungen des Tonschlickers, besonders am Knauf. Riss um den Stiel am Übergang zum Knauf. Links der Figur auf Seite A bis zum Hinterkopf der Frau auf Seite B sowie am unteren Teil des Körpers und am Rand durch Fehlbrand rotbraun verfärbt.

Technik: Dunkelbrauner bis schwarzer Tonschlicker. Farbe des Malschlickers (Knauf): schwarzdunkelgrau ( 5 Y 3/I, very dark gray). Tonschlicker teilweise ungenau und sehr flüchtig aufgebracht, ein diagonaler Strich auf dem Mittel- und seitlichen Blatt der Palmette. Farbe des Tongrundes: rosafarben (7.5 YR 8/4, pink). Miltos: Auf der gesamten Gefäßoberseite, besonders intensiv am Rand und an der Knaufoberseite; an der Innenseite des Deckels sehr dünn und flüchtig aufgetragen. Zwei Flecken sind vom Rand getropft. Aufgesetzte Farbe: Weiß: Gerade Stirnstreifen, gewellte Nackenstreifen und Zipfel des Sakkos. Gelb: Diadem, Ohrringe, Halskette, Kerne in der Palmette. Verdünnter Tonschlicker: zum Teil an den Gesichtskonturen, Auge, Haar, Sakkosverzierung, Begrenzungslinie.

Form: Auf der Außenseite leicht trichterförmige Randzone, scharf abgeknickter Rand. Flaches konisches Deckelbecken, zylindrischer Hals. Außen profilierter Griffknauf, an seiner Oberseite eingezogen. Auf der Innenseite vertikale Randzone, darüber gleichmäßige, recht flache Höhlung.

Dekor: Am Rand der Außenseite hängendes Wellenband nach links. Auf der Bildzone wechseln sich zwei Frauenköpfe mit zwei eckig gerahmten Fächerpalmetten ab, in den Zwickeln der Köpfe kleine Palmetten. Stiel in der Mitte schwarz bemalt, unten und oben je ein tongrundiger Streifen. Unterseite der Knaufscheibe tongrundig, Außenkante schwarz. Profilierter Rand tongrundig, Übergang zur Scheibe schwarz. Auf der Oberseite des Knaufs außen flache Randzone tongrundig, trichterförmige Zone schwarz. Rot lasierte Rille mit Strahlen umfasst das geschmückte Mittelfeld: In der Vertiefung ein Strahlenmotiv, in dessen Zentrum eine kleine Eintiefung, umgeben von einem schwarzen und einem roten Kreis. 
Darstellung: Zwei Frauenköpfe. - Auf der Hauptzone der Außenseite je ein nach links gerichteter Frauenkopf zwischen Palmetten. Rechts und links unter und rechts über der Frau jeweils kleine Fächerpalmetten. Die Frauen tragen jeweils einen verzierten Sakkos, Diadem, Ohrringe, ebenso eine gepunktete Halskette und haben den Blick nach oben gerichtet. Unterhalb der Kopfbedeckung Haarbausch im Ohrbereich sichtbar.

\section{0-320 - Amphorae-Gruppe (Trendall - Cambitoglou)}

Zur Erwerbung: siehe die Lekythos G 6, hier Tafel 66, I-4.

Zur Form: zur fraglichen ursprünglichen Zusammengehörigkeit von Deckel (G I 5) und Schale (G I4) siehe die Lekanisschale G I4, hier Tafel 67, I. Die Form des Grazer Lekanisdeckels zeigt Ähnlichkeiten zu dem Typ 427/I3, vgl. Hoffmann, Grabritual, 45 Taf. 87 .

Zum Dekor: Palmetten in eckigem Rahmen zwischen Frauenköpfen kommen auf apulischen Lekanisdeckeln dieser Zeit häufig vor, vgl. CVA Göttingen I Taf. 24, 4-6 (Hu 575 b); IO-I 2 (Hu 575 d); 25, I-3 (Hu 575 c); CVA Malibu 3 Taf. I65, I-3 (77 AE I9). 4-6 (78 AE 278); CVA Kassel 2 Taf. 8I, 2 (T 706), vor allem bei der Amphorae-Gruppe, vgl. CVA Como I Taf. I4, 3 (C. 79); CVA Moscow, Pushkin State Museum 2 Taf. 38,4 (II Ib 47I).

Zur Darstellung: Zu Frauenköpfen als Hauptdekoration von kleinen Vasen sowie ihrer Interpretation siehe G 6, hier Tafel 66, I-4.

Zum Maler bzw. zur Gruppe: Von der Amphorae-Gruppe existiert eine Reihe von Vasen mit Kopfbildern. In dieser Werkstatt ist für die Verzierung des Sakkos die Verwendung dicker weißer und schmaler sowie schwarzer Streifen und Striche typisch, vgl. RVAp II, 766-774; RVAp Suppl. I, I34-I36; RVAp Suppl. II, 238-242. Der Grazer Deckel ist von Trendall zusammen mit anderen Deckeln in der Kategorie kleiner Vasen des Amphorae-Malers aufgelistet, die aber von Lehrlingen seiner Werkstatt angefertigt wurden. Ein markantes Charakteristikum dieses Malers sind die miteinander verbundenen zwei oberen Augenlinien. Der Frauenkopf der Seite A zeigt große Ähnlichkeit zu einem auf dem Lekanisdeckel Manchester IV C I3, vor allem im Blick des Kopfes nach oben sowie in der Zeichnung der Nase und des Kinns: RVAp II, 773 Nr. IO4 Taf. 286, 4 .

\section{TAFEL 68}

\section{1-8. Schale}

Beilage 20, 4.

G I I. Aus Süditalien. Erworben I 868 von Richard Knabl, Schenkung. Ehemals Slg. Richard Knabl (Graz). Alte Inv.-Nr. IV 5 (Schenkl) bzw. III I7 (Pichler).

H 4,6 cm. - Dm Rand I 4,4 cm. - Dm Fuß 7, I cm. - Dm Henkel 0,6 cm. - Volumen $339 \mathrm{ml}$.

Essenwein, Katalog, 27 Nr. 207. - Karl, Richard Knabl, 30 I Nr. 4 Abb. 8. - Karl, Knabl, 83 Kat. 7 Taf. 2. - Lehner - Lorenz - Schwarz, Vasen, 65 f. Nr. 36 Abb. 56-57 (Th. Lorenz). - E. Pochmarski, Streiflichter auf die Geschichte der Archäologischen Sammlung der Universität Graz, Archäologische Gesellschaft Steiermark, Nachrichtenblatt 2000-2002, 32 Abb. I. - E. Pochmarski, Die Anfänge des archäologischen Instituts und der archäologischen Sammlung in Graz, in: M. Novotná (Hrsg.), Probleme und Perspektiven der Klassischen und Provinzialrömischen Archäologie, Anodos Suppl. 2 (Trnava 2002) 25 Abb. I. - RVAp II, 629 Nr. 260.
Zustand: Ein großes Fragment der Seite A und ein kleineres am Henkelansatz gebrochen und zusammengesetzt. An der AuBenseite Bruch am Henkelansatz, zum Teil geflickt und übermalt. Der Henkel rechts und ein kleines Randstück davor in Gips ergänzt und übermalt. Durch die Flickung ist ein kleiner Teil der Palmette verdeckt. Aufgesetzte Farbe stellenweise abgeblättert. Kleine Absplitterungen auf der Oberfläche und vor allem an den Brüchen. Kleine Bestoßungen am Mündungsrand. Versinterungen an der Profilierung des Fußes und am Übergang zum Körper. An der Wandung rund um den erhaltenen Henkelansatz Pinselspuren.

Technik: Schwarzer Malschlicker glänzend. Farbe des Malschlickers (Bauch): schwarz (2.5 Y 2.5/I, black). Eierstab der Seite B ca. in der Mitte verwischt. Miltos: Überzogen sind die tongrundigen Partien des Bildfeldes. Aufgesetzte Farbe: Weiß: Tuchfransen, Korymben und Blätter der Efeuranke. Gelb: Diadem, Haarbändchen, Ohrringe, Halskette, Armreifen, Schuhwerk, Schale, Eier, Punkte des Kranzes, Rosette, Stiel des Zweiges, Unterteilung des Felsens, Blüten und Punktgruppen der Efeuranke, Flügelunterteilung, Beinkette, Spiralschmuck, Verzierung des Kästchens, Fenster, Palmette, Fächerpalmette. Ritzung: Efeuranke (I). Verdünnter Malschlicker: I: Eierstab. Körper der Frau: Haar, Brust, Gürtel, linker Oberschenkel, Saum des Chitons. A: Haar, Gewandsaum des Chitons. B: Haar, Flügel. Die ausgesparten Partien mit verdünntem Tonschlicker konturiert. Mit dickem Tonschlicker abgedeckt. In einigen Bereichen verdünnter Tonschlicker sichtbar: auf I Wellenband, Zweig, Felsen, auf der Außenseite Grundlinie, obere Linie, Wellenband, Palmetten, Fächerpalmetten und Fenster. Relieflinie: I: Binnenzeichnung: Auge mit Pupille, Augenbraue, Ohr, Kekryphalos, Lippe, Venusring, Finger, Handgelenk, innere Ellenbogen, Gewandfalten, Schuhwerk, Kranzreif. Eierstab: Begrenzungslinien, äußerer Bogen und Punkt. Unterhalb des Eierstabes über der schwarzen Abdeckung horizontale Linie (wahrscheinlich ein Versehen). Außen: Eierstab: Begrenzungslinien, äußerer Bogen und Punkt. A: Auge mit Pupille, Augenbraue, Ohr, Kekryphalos, Lippe, Schulter, Finger, Handgelenk, innerer Ellenbogen, Gewandfalten, Schuhwerk. B: Binnenzeichnung: Auge mit Pupille, Augenbraue, Ohr, Kekryphalos, Lippe, Venusring, Schulter, Finger, Körperkonturen, Schuhwerk, Andreaskreuz an der Kiste und Flügelunterteilung.

Form: Schale auf niedrigem, profiliertem Fuß mit Knickhenkeln (,stemless cup“).

Dekor: Bodenunterseite tongrundig mit einem breiten und einem dünnen, schwarzen Streifen. An der Innenwandung des Fußes ist im oberen Teil ein dünner Streifen tongrundig belassen, darunter schwarze Bemalung. Standfläche tongrundig. Profilierte Außenkante schwarz bemalt, oberer Teil des Fußes tongrundig. Wellenband nach rechts als untere Begrenzung der Bildzone. Unter den Henkeln je eine Palmette über einem Halbkreis, jeweils umrahmt von einer liegenden, eingefassten Palmette sowie von tropfenförmigen Blättern. Hinter der Figuren je eine Fächerpalmette. An der Mündung der Außenseite Eierstab mit Zwickelpunkten, begrenzt unten und oben von je einem schwarzen Streifen; auf der den Henkeln gegenüberliegende Zone ist das Motiv übermalt. Im Schaleninnern an der breiten schwarzen Randzone eine konzentrische, geritzte Efeuranke mit durch aufgesetzte Farbe wiedergegebenen Blüten und eingestreuten kleinen Dreipunktgruppen. Bildtondo von leicht profiliertem, tongrundigem Streifen und einem Wellenband (laufender Hund) nach rechts begrenzt. Standlinie: Eierstab mit Punkten zwischen zwei Horizontallinien auf tongrundigem Band.

Darstellung: I sitzende Frau, A sitzende Frau, B sitzender Eros. I: Auf einem Felsen mit gelben Plattenschichten und weißen Punktreihen sitzt eine Frau nach links, sie trägt einen Chiton, goldgelbe Schuhe und Schmuck (Halskette aus zwei Punktreifen, zwei Armreifen, Ohrringe), ein goldgelbes Strahlendiadem, einen Kekryphalos sowie eine Lampadionfrisur mit goldgelben Raffbändchen. 
Die Frau hält in der vorgestreckten Rechten eine Schale mit gelben Punktreihen und gelbem Rand, darauf vier weiße Kugeln, und in der hinter sich gesenkten Linken einen Kranz (auf tongrundigem Kreis schwarzer Kreis und Punkte mit Zusatzfarbe). Als Füllornamente steht vor ihr ein Zweig mit gelbem Stiel und Korymben, hinter ihr hängt ein Mantelschal und über der Schale schwebt eine Rosette.

A: Frau mit Kekryphalos, gegürtetem Chiton, Halsketten, Armreifen und Ohrringen (in Gelb) sitzt auf einem Felsen (gelbe Plattenschichten) nach links. Sie hält in der vorgestreckten Rechten eine Schale mit gelben Punktreihen und gelbem Rand, darauf drei weißen Kugeln, und in der gesenkten Linken einen Kranz (auf tongrundigem Kreis Punkte mit schwarzer und gelber Farbe). Vor der Frau „Fenster“, darunter eine Rosette.

B: Nackter Eros mit Kekryphalos, gepunkteter Hals- und Beinkette, zwei Armreifen und Schuhe mit Spiralschmuck sitzt auf einem Felsen (gelbe Plattenschichten) nach links. In der vorgestreckten Rechten hält er einen Korb und in der gesenkten Linken einen Kranz. Der Korb ist mit Diagonalkreuz, parallelen Linien an den Schmalseiten und Dreipunktgruppen an den Langseiten verziert, am oberen Rand links eine Kugel (Frucht oder Ei). Am linken und oberen Rand weiße Kanten. Vor dem Kopf des Eros „Fenster“. Vor ihm am Boden ein stehender Zweig mit Früchten.

Drittes Viertel 4. Jh. - Gruppe des Kentauren im Britischen $\mathrm{Mu}-$ seum (Trendall - Cambitoglou)

\section{Zur Erwerbung: siehe G 6, hier Tafel 66, I-4.}

Zur Form: Der Begriff „stemless cup“ wurde für die attischen Schalen der Glanztonware zum ersten Mal verwendet, vgl. Agora XII, 98-I05. Die Produktion rotfiguriger, kleinformatiger Vasen in Apulien hat ab Mitte des 4. Jhs. zugenommen. Schalen mit niedrigem Fuß kommen nicht so oft vor. Stattdessen wurden eher Teller bevorzugt, vgl. RVAp II, 602. In den anderen Zentren Unteritaliens spielten sie dagegen keine Rolle, vgl. Schauenburg, Studien I, 30.

Zum Dekor: Zum Eierstab am Rand der Außenseite vgl. die Schale Karlsruhe B I I: CVA Karlsruhe 2 Taf. 72, I-2; Schale Triest, Civico Museo S. 462: CVA Trieste I, IV D Taf. 28, I-3; RVAp II, 850 Nr. 487 Taf. 3 I 7, 4 (Menzies-Gruppe); Schale Moskau, Pushkin State Museum of Fine Arts II rb I83: CVA Moscow, Pushkin State Museum 2 Taf. 37, I-3 (Gruppe des Kentauren im Britischen Museum). Zum Eierstab im Innenbild als Segment vgl. die Schale Karlsruhe B I33: CVA Karlsruhe 2 Taf. 7 I, 2-4; den Teller Altenburg 243: CVA Altenburg 3 Taf. I07, 6; RVAp II, 628 Nr. 243; Teller Triest, Civico Museo 5470: CVA Trieste I, IV D Taf. 27, 3 ; RVAp II, 628 Nr. 257. Die Efeuranke mit geritztem Rankentrieb sowie Blätter und Dreipunktmotiv mit aufgesetzter Farbe zeigen Einfluss der zeitgenössischen Gnathia-Ware. Die Kombination von Efeuranke im Gnathia-Stil und rotfiguriger Darstellung ist auch auf Epichysis-Gefäßkörpern zu sehen, vgl. RVAp II, 602. Am Anfang des Gnathia-Stils wird die neue Technik in Kombination mit rotfigurigen Darstellungen verwendet, vgl. Green, Bonn, 2. Im Gnathia-Stil wird das Efeuzweigmotiv dieser Art von der KonakisGruppe $(\mathrm{Kb})$ verwendet, vgl. Webster, Classification, 6. Dieser Dekor entspricht, nach Alexandropoulous Klassifikation, der Efeuvariante Ez Ia, vgl. Alexandropoulou, Gnathia, Io-I4 Abb. I. Zum gleichen Ornament als Rahmung von Innenbildern vgl. die Schale Karlsruhe B I I: CVA Karlsruhe 2 Taf. 72, I-2; Schale Triest, Civico Museo S. 462: CVA Trieste I, IV D Taf. 28, I-3; RVAp II, 850 Nr. 487 Taf. 3 I 7, 4; Schale Bonn I 30 : CVA Bonn 3 Taf. 43, I-2; Schale Reading 22.iii.24: CVA Reading I Taf. 32, 7 a-b; oder auf Innenbildern von Tellern, wie der Teller St. Petersburg, Univ. I687: RVAp II, 607, 29 Taf. 233, 5. Die eingeritzte Efeuranke ist eher in der Theano-Gattung als in der apulischen Vasenmalerei beliebt, vgl. Schauenburg, Studien I, 32 Anm. 370 f. Efeuranke durch doppelte, geritzte Stange und antithetisch angelegte Efeublätter, ebenfalls ohne Korymben, vgl. die Schale Ruvo, Museo Jatta 779: RVAp II, 822 Nr. 36 Taf. 307, 6; Teller Prag, NM 2038/o: RVAp II, 493 Nr. 85 I Taf. 3I7, 5. Zur Symbolik des Efeus und zur Verbindung des Motivs zur aphroditisch-dionysischen Welt siehe T. Thie, Unteritalische Vasen aus Kärntner Sammlungen, ungedruckte Diss. Wien (2005) I40-I43.

Zur Darstellung: Zu Kompositionen auf Innenbildern vgl. K. Stähler (Hrsg.), Apulien. Kulturberührungen in griechischer Zeit (Münster I985) 48-60; K. Schauenburg, Tondokompositionen aus Großgriechenland, JdI Io I, I986, I 59-183. Zu Einfigurenbildern siehe CVA Hamburg 2, I3-I 5. Sitzende Frauen sind ein weit verbreitetes Motiv in der apulischen Vasenmalerei. Solche Frauen sind mit rein weiblichen Attributen, mit dionysischen Attributen oder als Spendende dargestellt, vgl. A. Hoffmann, Die Verwendung der unteritalisch-rotfigurigen Keramik und die Funktion der Bilder, in: Hurschmann - Hoffmann - Knoll, Skulpturensammlung, 63 f. Die Felsen weisen auf die freie Natur hin, entfernen sich von der realen und nähern sich der Welt der Nymphen an. $\mathrm{Zu}$ der Bedeutung sitzender Frauen siehe Hoffmann, Grabritual, I 66 Taf. 25, 4. Nackter Eros mit Schmuck, Schuhen, Lampadionfrisur und nahezu weiblichem Körper erscheint seit dem 2. Viertel des 4. Jhs. als sehr häufiges Motiv auf unteritalischen Vasen, vgl. RVAp II, 8I9; R. Hurschmann, Die Macht der himmlischen Kraft: Eros, in: Hurschmann - Hoffmann - Knoll, Skulpturensammlung, 77. Allgemein zum Eros auf den unteritalischen Vasen, seiner weiblichen Erscheinung und Bedeutung vgl. W. D. Albert, Darstellungen des Eros in Unteritalien (Amsterdam I979); Hoffmann, Grabritual, I63 f.; R. Hurschmann, Die Macht der himmlischen Kraft: Eros, in: Hurschmann - Hoffmann - Knoll, Skulpturensammlung, 77-90; CVA Göttingen I, I 7 f. (mit älterer Literatur); K. Schauenburg, Flügelgestalten auf Grabvasen, JdI I02, I987, 208-232; G. Schneider-Herrmann, Eros auf einer Tonschale mit anthropomorphem Handgriff, BABesch 38, I963, 92-97; G. Schneider-Herrmann, Spuren eines Eroskultes in der italischen Vasenmalerei, BABesch 45, I970, 86-I I7. Die Deutung der Kugeln auf den Schalen ist unklar. Sie werden als Eier oder als Früchte interpretiert und gelten als Opfergaben, vgl. CVA Australia I Taf. 42 (NM 98.56; eggs?). 62-63 (NM 46.47; egglike objects). Eier bzw. Eierschalen gehören zum typischen apulischen Bildrepertoire. Sie sind mit der dionysischen Welt verbunden, vgl. H. Frielinghaus, Einheimische in der apulischen Vasenmalerei. Ikonographie im Spannungsfeld zwischen Produzenten und Rezipienten (Berlin I995) I32 f.; R. Hurschmann, Symposienszenen auf unteritalischen Vasen (Würzburg I985) 97; K. Schauenburg, Dionysiaka, in: ders. (Hrsg.), Charites. Studien zur Altertumswissenschaft, für Ernst Langlotz (Bonn I957) I7 I-I73. Dagegen Hoffmann, Grabritual, I65 Anm. 994: die Konnotation der Eierschalen a priori mit Dionysos ist unsicher. Eier in Schalen sind auch als Opfergabe für den Verstorbenen bei Naiskosdarstellungen zu sehen, vgl. Lohmann, Grabmäler, 88. Eier stehen ebenfalls auf Basen oder Stufen von Grabstelen und besitzen eine grabsymbolische Bedeutung, vgl. Schauenburg, Studien II, 4I f. Abb. I 59-I6I. Zum Fenster vgl. H. Cassimatis, Fenêtre de l'au-delà dans l'iconographie italiote, MEFRA I07, I995, I06I-I092; B. Brandes-Druba, Architekturdarstellungen in der unteritalischen Keramik (Frankfurt am Main I994) I 58-I70; K. Schauenburg, Frauen im Fenster, RM 79, I972, I-I 5 . Im Gegensatz zu Türen, die bereits in der attischen Vasenmalerei beliebt waren, sind Fenster erst in der italischen und besonders in der spätapulischen Vasenmalerei dargestellt, vgl. Schauenburg a. O. 4; ders., Frauen im Fenster, Nachtrag, RM 80, I973, 27 I-273. Im Unterschied zu den großen Fenstern mit Ladenflügeln besitzen die „Schlitzfenster" einen rein dekorativen Charakter, eventuell handelt es sich hier um schmale Luftschächte, vgl. Brandes-Druba a. O. I66. Kästchen gelten als weibliche Attribute und sind wie auch Kränze hochzeitlichem Ambiente zuzuweisen, vgl. Hoffmann, Grabritual, r65. Allgemein zu Truhen und Kästchen vgl. E. Brüm- 
mer, Griechische Truhenbehälter, JdI Ioo, I 985 , I35-I 5 I; Lissarrague, Frauen, 9I-IOI; Lohmann, Grabmäler, 75-77; Stähler a. O. 54. Bei dem Kästchen auf der Grazer Schale handelt es sich um einen Behälter mit Stülpdeckel (Kiste). Diese sind geflochtene, runde Objekte und in der Regel ohne Fuß. Auf der Grazer Schale wird die runde Form des Behälters durch die Zeichnung des Bodens angedeutet, vgl. Brümmer a. O. I8-22. 62 Abb. I9 b. Das hängende Tuch mit Fransen zeigt Ähnlichkeiten mit den Binden der von Krug erfassten ersten Kategorie. Solche Binden tauchen in der attischen rotfigurigen Vasenmalerei auf und wurden als Kopfbedeckung verwendet. Auf den weißgrundigen Lekythoi sind sie in Szenen des Grabkultes zu finden, vgl. Krug, Binden, 3-9 Taf. I, I; 2, I a. Solche Gestalten, wie die sitzende Frau auf der Seite A und der Innenseite, sowie andere jugendlichen Figuren sind als Teil von Grabszenen oder in einem dionysischen Kontext auf zahlreichen apulischen Vasen dargestellt. Diese Rahmenfiguren stehen entweder im Zusammenhang mit den Zeremonien zur Trauerlösung, nachdem sich die Seele des Verstorbenen in Jenseits befindet, oder mit dem seligen Jenseits selbst, das von der dionysischen Gelassenheit geprägt ist, siehe L. Giuliani, Tragik, Trauer und Trost. Bildvasen für eine apulische Totenfeier (Berlin I995) I43-I 5 I.

Zum Maler bzw. zur Gruppe: Allgemein zur Werkstatt der Gruppe des Kentauren im Britischen Museum: RVAp II, 62 I-63 I; RVAp Suppl. I, I05 f.; RVAp Suppl. II, I90-I93. Vasen dieser Gruppe sind in der Regel kleinformatig und mit einer, maximal zwei Figuren versehen. Diese Gruppe beinhaltet eine große Zahl von Tellern mit Frauen, Jünglingen und Eroten, vgl. Schauenburg, Studien I, 30-32 Abb. I I9-I 20; RVAp II, 628 f. Nr. 243-259. Die Schale Boston, Museum of Fine Arts I9.309, die Trendall nach der Grazer Schale aufgelistet hat (vgl. RVAp II, 629 Nr. 26I), gehört nach näherer Untersuchung zu der paestanischen Werkstatt des Aphrodite-Malers, der nach Trendall in Apulien gearbeitet hat, bevor er nach Paestum ausgewandert ist, vgl. RVP, 237 f. $250 \mathrm{Nr}$. 985 Taf. I 55 e: Boston, Museum of Fine Arts, http://www.mfa. org/collections/object/drinking-cup-kylix-with-seated-womanwith-phiale-I 54198<09.02.2013>. Die sitzenden Frauen im Innen- und Außenbild der Grazer Schale nähern sich stilistisch den Frauen im Innenbild des Tellers Altenburg 243 an: CVA Altenburg 3 Taf. I07, 6; RVAp II, 628 Nr. 243. Vgl. auch die Oinochoe Reading 87.35/4: CVA Reading I Taf. 3 I, 3; RVAp II, 622 Nr. I 50 , eine weitere in Lecce: CVA Lecce 2 IV Dr Taf. 38, I (697), sowie eine Pelike in Matera: RVAp II, 630 Nr. 27I Taf. 237, 5-6 (I003 I). Der Körperbau, die Zeichnung der Brustpartie, der Füße, der Wellenlinie am untersten Teil des Chitons zeigen Ähnlichkeiten mit der Oinochoe Lecce 697: RVAp II, 622 Nr. I47 Taf. 236, 2. Die Zeichnung der Flügel des Eros und die Verwendung der weißen Farbe für die doppelte Punktreihe, die vertikalen Striche und die obere Außenkante ist ähnlich mit jenen auf dem Deckel der Lekanis Turin 4524+45 I9: CVA Torino, Museo di Antichitá I Taf. I6, 2; RVAp II, 627 Nr. 238; und auf der Oinochoe Karlsruhe, Badisches Landesmuseum B 216: CVA Karlruhe 2 Taf. 70, 4; RVAp II, 624 Nr. I79. 


\section{KAMPANISCH ROTFIGURIG}

\section{TAFEL 69}

\author{
1-6. Tafel 70, 1-10. Tafel 83, 1-2. Amphora
}

Beilage 20, 6.

G I6. Fundort unbekannt. Erworben I 87 I von „Principe F. de Liguory“, Ankauf. Alte Inv.-Nr. II I 8 (Schenkl) bzw. III 22 (Pichler).

H 62,0 cm. - Dm Rand I 5,8 cm. - Dm Körper 2I,4 cm. - Dm Fuß I 5,8 cm. - Dm Henkel I,9 cm. - H Personen auf Seite A: Krieger I 2,7 cm. - Frau mit Zweig I I,9 cm. - Flügelfrau $8,8 \mathrm{~cm}$. - Frauenkopf (auf dem Hals) 9,8 cm. - H Personen auf Seite B: sitzende Frau I 6,4 cm. - stehende Frau I9, I cm. - Frauenkopf (auf dem Hals) IO, I cm. - Gewicht [2750 g].

C. Albizzati, Saggio di esegesi sperimentale sulle pitture funerarie dei vasi italogreci, Dissertazioni della Pontificia Accademia Romana di Archeologia I4, I920, I92 Abb. 4I. - J. D. Beazley, Groups of Campanian Red-Figure, JHS 63, I943, 86 Nr. I3. - M. Dewailly, Les Femmes des guerriers indigènes dans les scenes de libation représentées sur les vases à figures rouges d'Italie du Sud au IVe siècle, MEFRA 94, I982, 6I8. - S. Karl, Der „oskische“ Krieger in der kampanisch-rotfigurigen Vasenmalerei, ungedruckte Diplomarbeit Graz (200I). - Lehner - Lorenz - Schwarz, Vasen, 60-62 Nr. 33 Abb. 5 I-52 (Th. Lorenz). - C. Saulnier, L'armée et la guerre chez les peuples samnites (VIIe-IVe s.) (Paris I983) I49 Nr. 3.322. - LCS, 457 Nr. 4I.

Zustand: Gebrochen und wieder zusammengesetzt. Die Fragmente sind unsauber zusammengesetzt und verzogen, deshalb passen einige Bruchkanten nicht zueinander. Stellenweise Bemalung oberflächlich abgeplatzt oder abgerieben, kleinere Absplitterungen entlang der Bruchkanten. An der Unterseite des Fußes ein Riss. Fuß an der oberen Kante des Stieles gebrochen, wieder angesetzt und retuschiert. Rote Verfärbungen des schwarzen Tonschlickers wegen Fehlbrand: linke Hälfte der gesamten Seite B, Mündungsteller, Innenseite des Halses, Henkel. An Seite A helle Verfärbung: hinter der stehenden Frau, unter dem Flügel der Flügelfrau, im Hintergrund, sowie auf der Halszone am Haar des Frauenkopfes. Striche an der Schulter. Pinselspuren an den Henkeln und Henkelansätzen. Seite B: Schwarze Flecken zwischen den Verfärbungen abgeplatzt.

Technik: Farbe des Tongrundes: hellgelblichbraun ( IO YR 6/4, light yellowish brown). Schwarzer Tonschlicker ungleichmäßig, flüchtig sowie nicht homogen aufgetragen. Farbe des schwarzen Malschlickers im homogenen Bereich: schwarz ( 5 Y 2.5/I, black). Umriss der Figuren durch Konturenstrich ausgespart. Dieser ist bei den Gesichtern ziemlich genau und sorgfältig ausgeführt, dagegen ist der Strich bei den Gewändern flüchtig und ungenau. Der Malschlickerstrich der Konturen ist zum Teil sichtbar, vor allem am Kopf der Flügelfrau, bei der die Hintergrundfarbe nicht dekkend aufgetragen ist. Schwarzer Malschlicker an vielen Stellen abgeplatzt. Am Hals ist der schwarze Tonschlicker sehr flüchtig aufgetragen, nicht homogen, Striche teilweise sichtbar.

Miltos: sehr flüchtig auf den tongrundigen Partien des Bildfeldes aufgetragen.

Aufgesetzte Farbe: Weiß: Seite A: Fenster, Punktreihe der Phiale, Dekor am blütenähnlichen Gebilde, hängende Bänder, Wellenlinie am Boden. Flügelfrau: Kekryphalos, Flügel, Schuhwerk. Obst auf dem Korb. Krieger: Lanzenstiel, Schwert, Schwertgurt, Schild, Feder, Busch. Felsen: Umrahmung und Punkte. Frau: Haut. Grabstele. Seite B: Fenster, Kettenbänder, Tympanonbänder. Sitzende Frau:
Klismos, Schuhwerk, Kekryphalos. Schalenrand, Band. Stehende Frau: Schuhwerk. Frauenkopf auf dem Hals der Seite A: Phiale, Punkt in der Mitte, Diademstrahlen. Frauenkopf auf dem Hals der Seite B: Punktreihe der Phiale, Diademstrahlen. Ornament: Seite A: Punkte in der Mitte der Volute, Bänder am Volutenstamm, Linie an der Blüte, Schattierung an den Blättern am unteren Ansatz. Gelb: Seite A: Punkt in der Mitte der Phiale. Flügelfrau: Schmuck, Kranz. Schattierungen an Flügeln und Obst. Krieger: Lanzenspitze, Schwertscheide, Dekor des Schildes, Helm und Helmbusch. Felsen: Schattierung an Umrahmung und Punkte. Frau: Haar, Kekryphalos, Gesichtszüge, anatomische Details, Zweig. Dekor der Grabstele, Obst. Seite B: Diadem, Schmuck. Zweig. Schattierungen am Klismos. Frauenkopf Hals Seite A: Ohrschmuck, Halskette, Diademreifen. Frauenkopf Hals Seite B: Ohrschmuck, Halskette, Diademreifen, Punkt in der Mitte der Phiale. Ornament: Seite B: Punkte in der Mitte der Volute, Schattierung am unteren Ansatz des Blattes.

Verdünnter Malschlicker: Seite A: Gewand beider weiblicher Figuren. Seite B: Gewand beider weiblicher Figuren. Relieflinie: Seite A: Flügelfrau: Kekryphalos, Augenpartie, Lippe, Körper- und Gewandzeichnung, Flügel. Krieger: Augenpartie, Lippe, Körperzeichnung. Stehende Frau: Gewandzeichnung. Ciste und Felsen. Seite B: Tympanon, Augenpartie, Mund, Kekryphalos, Gewand beider Frauen.

Fingerabdruck: Fingerabdrücke an der Innenseite beider Henkel. Fingerabdruck am unteren Teil des Kekryphalos des Frauenkopfes der Seite B. Auf dem Fußstiel Tonkleckse.

Form: Halsamphora. Auf der Gefäßunterseite außen horizontale flache Auflagerzone, im Zentrum stark ausgehöhlt. Scheibenfuß außen unten in der vertikalen Zone einfach gerillt, darüber hochgezogener Stiel, durch eine deutliche Rille vom Gefäßkörper getrennt. Langgezogener bauchiger Körper, zur Fußzone hin konisch eingezogen. Deutlich ausgeformte Schulter, starke, durch einen leichten Grat abgesetzte Halseinziehung. Hoher Hals, weit ausgreifende, durch einen Grat abgesetzte Mündung. Randzone der Mündung auf der Unterseite stark gekehlt, Lippe nach unten geknickt und rund abgestrichen.

Dekor: Fußaußenseite und Bauchansatz mit Glanzton überzogen. Unter der Bildzone ein tongrundiger Streifen, darauf mittig ein dünner dunkelbrauner Streifen, darüber ein Wellenband nach rechts (laufender Hund), darüber auf der tongrundigen Zone wieder eine Glanztonlinie. Auf der Schulter eine tongrundige Zone, darauf eine Glanztonlinie und ein Stabband, unterbrochen an den Henkelansätzen. Unter den Henkeln je eine aufsteigende Ranke, die aus der Bodenleiste herauswächst und bis zum oberen Feldabschluss reicht. Aus dem Hauptstamm wachsen eingerollte Seitentriebe, Kammblätter, Palmetten und eine Zwickelblüte. Weiß gepunktete Spitzen. Unter dem rechten Henkel sind in einer Ranke und am Stamm drei bis vier dünne Streifen als Verzierung angebracht. Bereich über den Frauenköpfen bis zur Unterseite der Mündung tongrundig belassen. Henkel außen und teilweise innen mit Glanzton überzogen.

Darstellung: A Szene an einem Grab, B Frauengemachszene Seite A: Links sitzt ein Krieger auf einem Felsen, Kopf und Körper im Profil nach rechts. Er stützt sich mit der rechten Hand auf den Felsen, während er mit der Linken seine auf den Boden gestützten Waffen, Schild und Lanze, hält. Auf dem Kopf trägt er einen Helm mit Busch und zwei langen Federn. Über seiner rechten Schulter und diagonal um den Körper hängt ein Gurt, an dem das Schwert befestigt ist, dessen Griff hinter seiner linken Hüfte zu sehen ist. 
Vor ihm steht eine Frau im Kontrapost (linkes Spielbein), den Kopf im Profil, den Körper in Dreiviertelansicht nach links. Die Frau trägt einen Kekryphalos, der wenig Haar am Ohr und einen Schopf am Hinterkopf frei lässt. Sie blickt auf den Krieger und hält mit der vorgestreckten rechten Hand einen Palmzweig empor. Sie trägt Chiton und ein Himation, das über ihre linke Schulter herabfällt, quer über die Hüfte gelegt ist und mit ihrem verdeckten linken Arm an der Taille zusammengehalten wird. Dahinter steht rechts am Bildrand eine mittelhohe Stele, ein einfacher Pfeiler mit zweifachen doppelten horizontalen Linien geschmückt auf einer flachen Stufe. Oben auf der Grabstele liegt ein Granatapfel. Über den Figuren und in der Mitte des Bildfeldes schwebt von links eine Flügelfrau heran. Kopf und Körper sind im Profil nach rechts wiedergegeben, das rechte Bein ist stark abgewinkelt, während das linke Bein eine große Schrittstellung in Laufrichtung nach rechts zeigt. Ihr Oberkörper ist nackt, während ihr Unterkörper mit einem Himation verhüllt ist. In ihrer linken Hand hält sie vor sich einen Opferkorb, während sich in ihrer rechten Hand ein aus zwei Palmzweigen gebildeter Halbkranz befindet, von dem zwei Bänder herabhängen. Die großen offenen Flügel der Nike sind mit drei Reihen vertikaler Linien verziert. Sie trägt einen Kekryphalos und ein Diadem, im Ohrbereich sind eine bis zur Schulter reichende lange Haarsträhne und am Hinterkopf ein kurzer Haarzopf sichtbar. Die Nike trägt als Schmuck eine Perlenkette um den Hals und eine quer über dem Oberkörper, Spiralreifen an beiden Handgelenken und Ohrschmuck. Der Korb ist mit horizontalen Reihen von Querstrichen, Zickzack- und parallelen horizontalen Linien geschmückt. Auf dem Opferkorb sind Zweige, zwei Granatäpfel und zwei Kugeln zu sehen. Vor ihrer Fußspitze befindet sich eine stehende Blüte. In der linken oberen Bildfeldecke ist ein mit Punkten verziertes scheibenförmiges Objekt (Phiale), in der rechten oberen Ecke ein schießschartenförmiges Fenster zu sehen. Hinter dem Fenster und zwischen der Frau und dem Grabmal scheinen kettenförmige Bänder, hinter dem sitzenden Krieger ein stehender Zweig auf.

Seite B: Links sitzt eine Frau auf einem Klismos mit breiter Lehne nach rechts, Kopf und Körper im Profil. Sie ist leicht nach vorne gebeugt. Der Körper der Frau ist mit einem Mantel umhüllt. Sie hält mit ihrer linken Hand ein herabhängendes Band und darüber eine Schale. Auf dem Kopf trägt sie einen Kekryphalos und als Schmuck ein Diadem, Ohrgehänge und eine Halskette. Ihr gegenüber steht eine weitere Frau, in einen Mantel eingehüllt, Kopf und Körper im Profil nach links. Ein Knie ist leicht gebeugt. Sie trägt einen Kekryphalos, aus dem am Ohr und Schopf Locken herausquellen, und als Schmuck ein Strahlendiadem, Ohrgehänge und eine Halskette. Zwischen den beiden Figuren hängt in der Höhe des Kopfes der stehenden Frau ein Tympanon mit Bändern. In der linken oberen Ecke sind ein Fenster und ein kettenförmiges Band, hinter der stehenden Frau ein stehender Zweig sichtbar.

Halsbild A: Frauenkopf und Schulteransatz nach links. Die Frau trägt einen Sakkos, aus dem wenig Haar im Ohrbereich herausragt. Die Haube ist zweifach unterteilt und mit senkrechten Punktreihen geschmückt. Die Frau trägt eine Perlenkette um den Hals, Ohrgehänge und ein Strahlendiadem. Vor dem Hals der Frau ist ein scheibenförmiges Objekt (Phiale) zu sehen.

Halsbild B: Frauenkopf und Schulteransatz nach links. Die Frau trägt einen Kekryphalos, der nur eine Haarlocke im Ohrbereich und einen kurzen Haarschopf am Hinterkopf frei lässt. Der Kekryphalos ist zweifach geteilt und mit zwei senkrechten Punktreihen sowie einigen Kreuzchen verziert. Vor dem Hals der Frau ist ein scheibenförmiges Objekt (Phiale) sichtbar.

350-330 - CA-Maler (Beazley - Trendall). Walters-Untergruppe (Karl)

Zur Form: Amphoren, Halsamphoren sowie Bügelamphoren gehören zu den beliebtesten Formen des Malers, vgl. LCS, 45 I. Die
Halsamphoren mit langem Stiel sind eine spezifische Eigenart des Malers und seiner Manufaktur.

Zum Dekor: Der Dekor der großen Vasen ist ziemlich sorgfältig. Lange sowie reichlich dekorierte Ranken sind unter den Henkelansätzen der Halsamphoren üblich. Ähnliche Ranken sind auf der Amphora Capua, Museo Campano ohne Inv., aus Caivano: LCS, 457 Nr. 39 Taf. I77, I; CVA Capua I, IV E r Taf. I8, 3 (breitere Ranke als diejenige in Graz) und auf der Halsamphora Warschau, NM I98545: LCS, 463 Nr. 99 Taf. I8 I, 3-4; CVA Warsaw, Musée National 5 Taf. 22, 2 (allerdings ohne Kammblätter) zu sehen. Auf dem Bildfeld verteilte Elemente wie Phiale, Tänie oder Kränze sind häufig in der Werkstatt Cumae I, siehe LCS, 45I. Zweige sind ebenfalls sehr beliebt, siehe Schauenburg, Studien IV/V, 73 Anm. 762. Tänien sind bei dem Maler häufig im Bildfeld verstreut, zu ähnlichen kettenförmigen Tänien siehe Schauenburg, Studien IV/V, 73 f. Nr. I60 a-b; I65 b. Anders als auf dem Grazer Exemplar hängen sie öfters vom Fenster herab. Zu Punkttänien auf Vasen des CA-Malers siehe Schauenburg, Studien IV/V, 7423 Anm. 216; Schauenburg, Studien IX/X, 2I Anm. I48. Zur Darstellung: Allgemein zu Grabszenen siehe CVA Dresden I Taf. 42; A. Hoffmann, Die Verwendung der unteritalisch-rotfigurigen Keramik und die Funktion der Bilder, in: K. Knoll (Hrsg.), Die Lebenden und die Seligen. Unteritalisch-rotfigurige Vasen der Dresdner Skulpturensammlung (Mainz 2003) 63; Lohmann, Grabmäler, 2-8; Splitter, Vasenbilder, 7 I-77. Szenen im Grabkult mit „oskischem Krieger" siehe G. Schneider-Herrmann, The Samnites of the Fourth Century B. C. as Depicted on Campanian Vases and in Other Sources, BICS Suppl. 6I (London I996) I I9-I23. Der „oskische“ Krieger ist gewöhnlich stehend oder sitzend, mit kurzem Chiton, Helm mit Busch und Federn, Dreischeibenpanzer, Gürtel und Beinschienen dargestellt. Seine üblichen Waffen sind Lanze und Schild. Zu Tracht und Ausrüstung des „oskischen“ Kriegers siehe Schneider-Herrmann a. O. 3-88; S. Karl, Der „oskische" Krieger in der kampanisch-rotfigurigen Vasenmalerei, ungedruckte Diplomarbeit Graz (200I) I4-I6; Mayo - Hamma, Magna Graecia, 2 I 5; LCS, I92 f.; A. D. Trendall, Gli indigeni nella pittura italiota (Tarent I97I) Io f. I7-I9 (mit älterer Literatur). Zu Federn auf Helmen siehe Schauenburg, Studien IX/X, I 5 Anm. 58; Schneider-Herrmann a. O. 39-45. Helme wurden in Unteritalien gewöhnlich mit zwei oder drei Federn geschmückt. Es gibt aber auch Helme mit sechs Federn, z. B. auf einem Skyphos im Kunsthandel, vgl. Schauenburg, Studien IX/X, I9 Abb. 33. Für sehr seltene apulische Beispiele siehe K. Schauenburg, Zu einem Krater mit Maskenfries, ÖJh 66, I997, 89. Zu der Tracht der Frauen siehe M. Dewailly, Les femmes des guerriers indigènes, MEFRA 94, I 982, 58 I-623; Schneider-Herrmann a. O. 95-IO2. Im Gegensatz zu der Werkstatt in Capua, bei welcher die oskische Tracht für Frauen bevorzugt wurde, sind die Frauen auf den Vasen der Werkstatt in Cumae in griechischer Tracht gezeigt, jedoch mit Merkmalen des lokalen Geschmacks, was Farben und Dekor betrifft, vgl. Dewailly a. O. 583-593. Palmenzweige kommen häufig in der unteritalischen Vasenmalerei vor. Allgemein zur Palme siehe H. F. Miller, The Iconography of the Palm in Greek Art (ungedruckte Diss. Berkeley 1979). Mit Palmenzweigen werden auch Grabmäler geschmückt, siehe Lohmann, Grabmäler, 29 f. Zur Darstellung der Nike auf unteritalischen Vasen und ihre Verbindung mit der Unsterblichkeit siehe K. Schauenburg, Flügelgestalten auf Grabvasen, JdI I02, I987, 228. Allgemein zum Klismos siehe G 25, hier Tafel 7I, I-3. Zum Opferkorb siehe G I I, hier Tafel 68, I-8. Allgemein zum Fenster siehe G I I, hier Tafel 68, I-8. Schlitzfenster scheinen nicht nur in der apulischen Vasenmalerei beliebt, es gibt auch Darstellungen aus anderen unteritalischen Werkstätten, vgl. B. Brandes-Druba, Architekturdarstellungen in der unteritalischen Keramik (Frankfurt am Main I994) I65. Mantelfiguren sind oft auf der Rückseite unteritalischer Vasen nachzuweisen. Es wurde eine sepulkrale Funktion, aber auch eine Verbindung zur Palästra 
vorgeschlagen, vgl. Trendall, RFVSIS, I3; CVA Bonn 3, I3 f. Auf der Grazer Amphora handelt es sich um zwei weibliche Mantelfiguren. In diesem Fall haben die Mantelfiguren mit Totenkult zu tun, da auch eine Grabstele dargestellt ist, vgl. Trendall, RFVSIS, I68; LCS, 453 Nr. 9 Taf. I75, 4 (85804).

Zum Maler: Allgemein zum Maler als Hauptvertreter der Gruppe Cumae I A siehe Mayo - Hamma, Magna Graecia, I98. 2I3, Nr. 94. Schauenburg IV/V, 72-74; LCS, 447-452. Darstellungen mit oskischen Kriegern sind ein sehr beliebtes Thema des CA-Malers und seiner Werkstatt, siehe LCS, 452. Die Manufaktur in Cumae zeigt einen hohen Anteil von Kriegervasen. Die Werkstatt des CA-Malers weist zusammen mit der der Libation-Gruppe und des Malers von New York GR rooo die höchsten Produktionszahlen von Kriegervasen auf, siehe Karl a. O. 66-7 I Abb. 2-5. „Oskische Krieger" erscheinen in Gesellschaft einer oder mehrerer Frauen sitzend oder stehend. Sie sitzen auf Felsen oder auf einem Stoffballen, vgl. den Skyphos in Athen, NM I423: LCS, 463 Nr. 98 Taf. I 8 I, 5 (Krieger auf Tuch). Die Felsen sind mit weißer und schwarzer Farbe getupft und mit weißer Umrahmung gezeichnet, vgl. Halsamphora Warschau, NM I98545: LCS, 463 Nr. 99 Taf. I8 I, 3. Der Krieger auf der Grazer Amphora ist nackt dargestellt. Die Zeichnung seines Körpers mit der typischen Wiedergabe der Brust, die rechte Hälfte frontal und die linke in Seitenansicht, sowie die Zeichnung der Bauchmuskulatur sind sehr ähnlich dem Krieger auf einem Glockenkrater in Wien, KHM ANSA IV 752: LCS, 463 Nr. 92 Taf. I80, 4. Die Frau gegenüber dem Krieger besitzt weiße Haut, ein Charakteristikum des kampanischen Malers, vgl. den Glockenkrater University of California in Berkeley 8/38I4: LCS, 462 Nr. 89 Taf. I 80 , I bzw. den erwähnten Glockenkrater Wien, KHM ANSA IV 752. Eine schwarze mittige Bordüre auf dem Chiton der Frauen lässt sich sehr oft beim CA-Maler und vor allem bei der Walters-Untergruppe nachweisen, vgl. LCS, 462-464. Ein um die Hüfte gelegter Mantel, meist in Weiß, ist typisch für den CAMaler, vgl. Schauenburg, Studien IV/V, 73. Das Himation der Frau auf dem erwähnten Glockenkrater Wien, KHM ANSA IV 752 fällt über die Schulter herab; sowie auf einem Glockenkrater in Privatbesitz: Schauenburg, Studien IV/V, Abb. I59 a. Rituelle Szenen mit einer oder mehreren Frauen vor einer Stele und gelegentlich in Anwesenheit eines oskischen Kriegers sind ein beliebtes Motiv der Werkstatt des CA-Malers, siehe LCS, 450; Mayo - Hamma, Magna Graecia, 2 I3, Nr. 94. Eine Flügelfrau über der zentralen Szene ist auf einer Hydria in Basel zu sehen: LCS, 463 Nr. 96 Taf. I 8 I, 7 (I906.3 Io). Eine Flügelfrau im Knielaufschema und in der Grazer Figur ähnlichen Gestalt ist auf dem Deckel gezeigt in Graz, Universalmuseum Joanneum 8643: LCS, 465 Nr. I I 7 Taf. I 82, 4. Auf beiden Grazer Gefäßen befindet sich vor den Füßen der Flügelfrau ein blütenähnliches Gebilde. Eine sitzende in Kombination mit einer stehenden Mantelfigur ist auf der Rückseite der meisten Vasen des Malers abgebildet, siehe Schauenburg, Studien IV/V, 74 Anm. 770. Sie sind in zwei Darstellungstypen gegliedert, siehe LCS, 450. Das Grazer Exemplar gehört zum zweiten Typus mit einer sitzenden Frau und einer gegenüber stehenden weiblichen Mantelfigur. Eine ähnliche Abbildung einer sitzenden Frau mit Mantel findet sich auf einem Skyphos im Privatbesitz: Schauenburg, Studien IV/V, 74 Nr. I63 b. I64 b. Voll bekleidete sitzende Frauenfiguren sind Standardtypen des Malers: Schauenburg, Studien IV/V, 74 Nr. I 62 a-b Anm. 769; Schauenburg, Studien XI/XII, Abb. 8I. Die Szene der Grazer Amphora zeigt sehr große Ähnlichkeiten mit jener Szene auf einer Bügelamphora in New York, Columbia Universität: LCS, 464 Nr. I02 Taf. I8I, 2 (ohne Inv.); weiters auf der Amphora Warschau, NM I98545: LCS, 463 Nr. 99 Taf. I 82, 4. Frauenköpfe solcher Art hat die Werkstatt des CA-Malers in großer Zahl auf verschiedenen Vasentypen hinterlassen, sowohl als Halsdekoration auf Halsamphoren als auch als Hauptdekoration auf Glockenkrateren, Bügelamphoren, Deckeln oder Askoi, siehe LCS, 472-475. Sowohl Beazley als auch Trendall haben die Grazer
Amphora dem CA-Maler zugewiesen. Der Vergleich des Kriegers der Grazer Sammlung mit dem auf dem erwähnten Glockenkrater Wien, KHM ANSA IV 752 zeigt, dass die Gestalt beider Krieger identisch ist. Große Ähnlichkeit besitzt die Gestalt des Kriegers der Grazer Amphora mit der auf dem Glockenkrater Berkeley, Phoebe Apperson Hearst Museum of Anthropology: LCS, 462 Nr. 89 Taf. I 80, I-2. Die Zeichnung der Brustwarzen, die durch zwei parallele Striche wiedergegeben sind, sind typische Merkmale der WaltersUntergruppe. Ein anderes Charakteristikum ist das schwere kräftige Kinn bei den Figuren. Diese Besonderheit ist sowohl bei dem Krieger als auch bei den anderen Figuren der Grazer Halsamphora zu sehen. Die Walters-Untergruppe gehört zu den Werken aus der späten Schaffensperiode des CA-Malers, vgl. Karl a. O. 84 f.

\section{TAFEL 70}

1-10. Siehe Tafel 69, 1-6.

\section{TAFEL 71}

\section{1-3. Tafel 72, 1-2. Tafel 73, 1-5. Tafel 84, 1-2. Lekanisdeckel}

Beilage 21, 1.

G 25. Fundort unbekannt. Erworben I 874 durch Wolfgang Helbig in Rom, Ankauf. Alte Inv.-Nr. II 39 (Schenkl) bzw. III 33 (Pichler).

H I0,7 cm. - Dm Rand 28, I cm. - H Deckelrand I, 5 cm. - H Deckelknauf mit Stiel 4,75 cm. - H Deckelknauf 2,05 cm. - Dm Deckelknauf Io,6 cm. - B Randoberseite Deckelknauf Io, 3 cm. Dm Medaillon Deckelknauf 5,9 cm. - Dm Vertiefung Deckelknauf $8,0 \mathrm{~cm}$. - Gewicht [977 g].

LCS, 243 Nr. I 27 Taf. 97, 2. - LCS Suppl. III, I I 6. - C. Aellen, A la recherche de l'ordre cosmique. Forme et fonction des personnifications dans le céramique italiote (Kirchberg/Zürich I994) 2 I 3 Nr. 9I Taf. I I 2. - G. Beckel, Götterbeistand in der Bildüberlieferung griechischer Heldensagen (Waldsassen I96I) 68 f. Nr. 72. - F. Brommer, Vasenlisten zur griechischen Heldensage ${ }^{3}$ (Marburg I973) 242 Nr. DI. - Brommer, Theseus, 37. 42. 44. 46 f. I 45 Taf. 29 b. - F. Brommer, Theseus-Deutungen II, AA I982, 85 f. Abb. 8. - E. Diez, Der Kampf des Theseus mit Minotaurus auf einem Schalendeckel in Graz, ÖJh 38, I950, 5 5-65. - Lehner - Lorenz Schwarz, Vasen, 62-64 Nr. 34 Abb. 54-55 (Th. Lorenz). - LIMC II (Zürich I 984) I006 Nr. 539 s. v. Athena (P. Demargne). - LIMC III (Zürich I986) I054 Nr. 26 s. v. Ariadne (M. L. Bernhard - W. A. Daszewski). - LIMC VI (Zürich I992) I 33 Nr. 3 s. v. Krete Taf. 60 (M. Andreadakis-Vlasakis). - LIMC VI (Zürich I992) $572 \mathrm{Nr}$. 26 s. v. Minos I (J. Bažant). - LIMC VII (Zürich I994) 94I Nr. 243 s. v. Theseus (S. Woodford). - J. M. Moret, L' Ilioupersis dans la céramique italiote. Les mythes et leur expression figurée au IV siècle (Genf I975) I 23, 82.

Zustand: Aus acht Fragmenten zusammengesetzt, wobei eines fast die Hälfte des Deckels umfasst. Versinterungen durch Ablagerungen. Am Rand Absplitterungen. Um I990 restauriert. An der Außenseite viele Übermalungen, sowohl auf dem Tongrund als auch auf der schwarzen Engobe. Rezent sind die Zusatzfarben sowie die Körper- und Gewandkonturen im Bereich der Brüche. Innenseite: Die Brüche wurden mit einer Verbindungsmasse nachgebessert, mit braun-gelber und darüber rosa Farbe übermalt und anschließend lackiert. Von der rezenten Restaurierung stammen ebenfalls einige Flecken und Kleckse (Lack, rosa und schwarz). Rand: Am Rand innen und außen unterhalb der liegenden Palmette, hinter Athena und bis zu dem Felsen, auf dem sie sitzt (ca. 
5,5 cm), abgeplatzte Oberfläche. Dieser Bereich wurde zum Teil mit Gips befestigt, anschließend rosafarben koloriert, das Wellenband schwarz gefärbt. Die schwarze Engobe des Wellenbandes ist zusätzlich in folgenden Bereichen übermalt: Unterhalb des Zwickelblattes der Palmette (vor dem sitzenden Minos) bis unterhalb der Fußspitze des Minos, unterhalb der Fußspitze der Athena und bis zur Fußspitze des rechten Beines des Minotaurus. Der Tongrund am Wellenband ist in vielen Bereichen rosafarben übermalt. Etwa die Hälfte des Randes der Innenseite ist flüchtig rosafarben versehen. Knauf am Stiel gebrochen, zusammengesetzt, ergänzt und schwarz übermalt. Palmetten auf dem Knauf übermalt. Außenseite: Die Brüche wurden ergänzt und übermalt. Athena: Ein Bruch verläuft über dem Kranz, den sie hält, an der Stirn, durch das Gesicht und entlang des Körpers und des Felsens. Dieser Bruch wurde ergänzt und übermalt. Einige Innenkonturen des Gewandes und Körpers sind nachgezogen. Ein zweiter Bruch beginnt am Gesicht der Göttin und läuft über ihren linken Arm, ihr linkes Knie, entlang des Schildes, zum Teil ist dieser ergänzt, besonders am unteren Teil, so dass der Bruch unsichtbar ist. Theseus: Ein Bruch beginnt am Rücken des Minotaurus über dem rechten Arm des Theseus und geht quer über seinen Körper bis zum Oberschenkel. Ein zweiter Bruch läuft quer über seinen Oberschenkel und zurückgestellten Fuß bis zur Bodenerhebung. Beide Brüche sind retuschiert. Einige Innenkonturen des Körpers sind nachgezogen oder zusätzlich aufgetragen. Die schwarzen Tupfen sowie der Tongrund der Erhebung sind ebenfalls retuschiert. Minotaurus: Ein Bruch läuft quer über Rücken und Brust, sowie über die Palmette. Dieser wurde retuschiert, so dass er unterhalb der Palmette nicht sichtbar ist. Ein zweiter Bruch läuft quer über seinen rechten Oberschenkel. Dieser ist ebenfalls retuschiert. Ariadne: Ein Bruch läuft von dem rechten Arm quer über den Oberkörper. Ein zweiter beginnt an der Brust und läuft entlang des Körpers bis zum Knie. An dieser Stelle findet sich ein weiterer Bruch, der quer über die Unterschenkel und bis zu der Palmette läuft. Innenkonturen nachgezogen. Im Bereich des rechten Knies existieren einige senkrechte Kerbungen. Innenkonturen des Körpers sind nachgezogen oder zusätzlich aufgetragen, vor allem am Gewand im Bereich des Oberkörpers. Minos: Der Bruch verläuft am Szepter, Ellenbogen des rechten Armes, Oberschenkel und vor den hinteren Stuhlbeinen. Die Innenkonturen von Gewand, Körper und Szepter sind am Bruch nachgezogen. Kreta: An der Fußspitze und am Blatt der Palmette sind rosafarbene deckende Tupfen sichtbar.

Technik: Schwarzer Tonschlicker deckend aufgetragen. Zum Teil ist der Auftrag des Tonschlickers flüchtig, da einige Konturen überdeckt oder nicht vollständig abgedeckt sind. Farbe des Tongrundes: hellblassbraun ( Io YR 7/4, very pale brown). Miltos: Figuren und Palmetten. Relieflinie: Gesicht- sowie Körperdetails und Gewänder der Figuren (zum Teil auch rezent). Aufgesetzte Farbe: Weiß: Die Haut aller weiblichen Figuren. Außerdem Athena: Helm, Federn, Punkte und Schlangen der Ägis, Sandale. Theseus: rechtes Schuhwerk (linker Fuß ist übermalt). Minotaurus: Schuhwerk. Ariadne: Haarbänder und Schuhwerk. Minos: Schuhwerk und Stuhl. Kreta: Punkte des Gürtels, Schuhwerk, sowie Gras am Felsen. Gelb: Athena: Helm, anatomische Details an der Hand, Armreifen, Blätter des Kranzes, Lanzenspitze, Schild, Tupfen am Felsen. Ariadne: Augenpartie, Lippe, Ohrringe, Diadem, Armreifen. Minos: Diadem, Perlenkette, Verzierung des Szepters, Stuhl. Kreta: Augenpartie, Lippe, Ohrringe, Diadem, anatomische Details an Hand und Ellenbogen, Halskette, Armreifen. Verdünnter Tonschlicker: zum Teil auf den Konturen der Figuren. Vorzeichnung: Theseus: Kopf. Athena: Falten des Gewandes zwischen den Beinen. Kreta: Unterkörper und Beine. Farbe des Malschlickers: 2.5 Y 2.5/I (black). Fingerabdruck: Am Außenrand des Knaufes in drei Bereichen.

Form: Flach-konischer Deckel mit senkrechter Randzone. Lippe leicht nach außen gezogen und rund abgestrichen. Großer, profi- lierter und fußscheibenartiger Griffknauf mit einer Vertiefung in der Mitte der Oberseite und einem zentralen Loch. Knauf verzogen.

Dekor: Auf dem Außenrand des Deckels Wellenband (laufender Hund) nach links. Auf dem Bildfeld sind alle Personen voneinander mit je einer Ranke getrennt, so z. B. vor Minos eine niedrige Ranke mit eingedrehtem Blatt und Spirale sowie zwei Zwickelblättern, oder rechts von Kreta eine doppelte Ranke mit zwei antithetisch angeordneten Blättern mit je einem Voluten- und tropfenförmigen Blatt. Links Zwickelblatt, rechts Palmette mit zehn Blättern aus einer rautenförmigen Basis wachsend. In der Mitte Palmette mit sechs Blättern aus einem tropfenförmigen Gebilde wachsend (diamond-shaped floral). Über der Bildzone ein tongrundiger Reifen, Stiel mit Glanzton überzogen, Außenkante des profilierten Knauffalzes tongrundig belassen, Knaufrand und Oberseite auf dem horizontalen Rand mit Glanzton überzogen. Auf der Oberseite des Knaufs drei gesprengte Palmetten von außen zum Zentrum, jeweils mit einem Mittelblatt und drei Blättern an jeder Seite. Deckelunterseite nicht bemalt.

Darstellung: Figürliche Darstellung umlaufend: Kampf des Theseus mit Minotaurus unter Schutz der Athena und unter Beobachtung von zwei weiblichen sowie einer männlichen Figur. - Links nimmt Theseus Minotaurus in den „Schwitzkasten“ und drückt dessen Stierkopf nach unten. Er stützt sich mit seinem rechten Knie auf eine mit Punkten dekorierte halbrunde Erhebung (Felsen?), während sein ausgestrecktes linkes Bein von dem Ungeheuer gefasst wird. Kopf und Bauch in Dreiviertelansicht, Oberkörper bzw. Schulter im Profil, rechtes Bein frontal, linkes Bein und Becken im Profil; kurzes, lockiges, festes Haar, ein großes Auge mit langer Augenbraue und runder Pupille, spitze Nase, runde Lippe und schweres Kinn. Blick des Theseus über den Minotaurus hinweg. Geschlossenes Schuhwerk, kurz über dem Knöchel gebunden.

Minotaurus ist mit Stierkopf und menschlichem Körper, der kräftiger ist als der seines Gegners, dargestellt. Er ist ins Knie gesunken, Kopf, Oberkörper und rechtes Bein im Profil, Unterkörper und linker Oberschenkel in Dreiviertelansicht. Stierkopf mit großem Auge, langer, starker Schnauze und Hörnern. Blick auf Bein des Theseus. Das Ungeheuer trägt gleiches Schuhwerk wie Theseus. Den leeren Platz zwischen linkem Arm und Bein füllt eine Ranke mit eingedrehtem Blatt, einer Spirale, sowie einem Zwickelblatt. Diese Szene ist von je einer größeren Ranke mit eingedrehtem Blatt und Spirale, einem zwickel- und tropfenförmigen Blatt flankiert. Die Ranke hinter Minotaurus besitzt zusätzlich zwei Zwickelblätter.

Links des Geschehens sitzt Athena auf einem mit Punkten verzierten Felsen. Kopf im Profil, Oberkörper in Dreiviertel- und Unterkörper in Seitenansicht. Ihre rechte Hand mit der Lanze liegt auf dem Felsen auf. Ihre linke Hand ist vorgestreckt und hält einen Kranz hinter Theseus. Ihr Rundschild lehnt an ihrem linken Knie. Sie trägt einen ärmellosen Chiton, in der Taille mit einem schwarzen Band gegürtet, und Schuhe.Die schwarze Ägis ist mit einer Scheibe in der Mitte und Punkten gemustert. Auf dem Kopf hat sie einen Helm mit Busch und Federn. An beiden Handgelenken trägt sie Spiralarmreifen.

Rechts der zentralen Szene steht Ariadne im Kontrapost nach links, Kopf im Profil und Körper in Dreiviertelansicht, dem Geschehen zugewandt. Mit ihrer linken Hand hielt sie eventuell ein Wollknäuel vor die Brust (aufgrund der Restaurierung um I990 nicht feststellbar), mit ihrer rechten Hand greift sie einen Zipfel des Chitons und hebt ihn in einem brauthaften Entschleierungsgestus an. Zusätzlich zu dem ärmellosen Chiton trägt sie um ihre Hüften ein Himation, das über ihrer linken Schulter herabfällt und ihren linken Unterarm umhüllt, sowie Schuhe. Ihr lockiges Haar ist mit einem breiten Band in einer Lampadionfrisur zusammengebunden, aus dem Knoten fallen zwei schmale Zierbänder herab. Zusätzlich trägt sie ein Diadem. An ihren Ohren ist Ohrschmuck 
zu erkennen, an ihrem rechten Handgelenk befindet sich ein Armreif. Hinter Ariadne sitzt Minos auf einem Klismos nach links und richtet seinen Blick auf den Kampf. Kopf und Beine sind in Seiten-, sein Körper in Dreiviertelansicht angegeben. Er trägt einen lockigen Bart und hat eine runde Nase sowie ein großes Auge mit langer Augenbraue, darüber horizontale Falten auf der Stirn. Minos hat leicht gelocktes, kräftiges Haar, wobei sein Ohr sichtbar ist, und trägt ein Diadem. Sein linker Arm liegt hinter die Rückenlehne und stützt sich am Stuhl ab, in seiner vorgestreckten Rechten hält er ein auf dem Boden stehendes Szepter fest. Sein Oberkörper ist etwas nach vorne gebeugt und nackt, während sein Unterkörper in ein Himation gehüllt ist. An seinem unbekleideten Oberkörper lässt sich von seiner rechten Schulter quer über die Brust eine Perlenkette erkennen. Der lange Stiel des Szepters ist mit Punkten und der Abschluss mit einem Zapfen verziert. Rechts von Minos sitzt auf einer der beiden Erhebungen des wellenförmigen Felsens eine Frau mit überkreuzten Beinen, die die Personifikation der Insel Kreta darstellt, nach rechts, die ihren Kopf im Profil nach links zurückwendet, der Körper ist in Dreiviertelansicht wiedergegeben. Als Kopfbedeckung trägt sie einen Sakkos, wobei nur ein kleines lockiges Haarbüschel sowie das linke Ohr mit Ohrring ausgespart sind, sowie ein Diadem. Mit der rechten Hand stützt sie sich auf eine Felserhebung, während sie ihren linken Arm nach rechts erhoben hat. Sie trägt einen ärmellosen, langen Chiton, quer über ihre Beine ist ein Mantel gewickelt. Als Schmuck trägt sie eine Halskette, Ohrringe, Spiralarmreifen an beiden Handgelenken und in der Taille einen Perlengürtel. Den Abschluss der Szene bildet eine doppelte Ranke mit zwei antithetisch angeordneten Blättern mit je einem Voluten- und tropfenförmigen Blatt. Links Zwickelblatt, rechts Palmette mit zehn Blättern aus einer rautenförmigen Basis wachsend. In der Mitte Palmette mit sechs Blättern aus einem tropfenförmigen Gebilde wachsend (diamond-shaped floral).

340-330 - Aigisthos-Gruppe (Trendall)

Zur Form: Allgemein zur Entwicklung der Form der attischschwarzfigurigen Lekanides siehe A. Lioutas, Attische schwarzfigurige Lekanai und Lekanides (Würzburg I987), und zu rotfigurigen Lekanides siehe E. D. Breitfeld-von Eickstedt, Die Lekanis vom 6.-4. Jh. v. Chr. Beobachtungen zur Form und Entwicklung einer Vasengattung, in: J. H. Oakley - W. D. E. Coulson - O. Palagia (Hrsg.), Athenian Potters and Painters. The Conference Proceedings (Athen I997) 55-6I. Rotfigurige Lekanides sind in Süditalien sehr populär, siehe F. P. Porten-Palange, Lekanis campana a figure rosse del Pittore CA in una collezione privata ticinese, NumAntCl 8, I979, 85. Zur Form der Lekanis und ihrer Funktion als Gefäß zur Aufbewahrung kosmetischer Gegenstände und Schminkutensilien siehe Hoffmann, Grabritual, IOO-IO2; zum Unterschied zwischen Lekanis (Schale mit Deckel) und Lekane (nur Schalenbecken) siehe Schauenburg, Studien II, 57. Der Dekkel in Graz gehört zu den seltenen größeren Vertretern der Gattung. Zu großformatigen, kampanischen Deckeln siehe den Deckel Mannheim Cg 443 (Dm 24 cm): CVA Mannheim 2 Taf. 44; sowie den Deckel Portland 26.289 (Dm 28, I cm): LCS, 240 Nr. Io8, Taf. 97, I. Die größte Lekanis mit einem Durchmesser von $49 \mathrm{~cm}$ (mit Henkeln) ist apulisch und stammt vom Ilioupersis-Maler: St. Petersburg I776: RVAp I, I98 Nr. 49; Schauenburg, Studien IX/X, 57 Anm. 6I 2 f.

Zum Dekor: Die Abschlusspalmette nennt Trendall diamantförmige Blume (diamond shaped floral), siehe LCS, 243. Solche Palmetten befinden sich auf der Rückseite von zwei Lekythoi in Neapel, NM 82799 und 82802: LSC, 24I Nr. II4-II 5 Taf. 95, 3-4 (Rückseite nicht abgebildet). Die Deckelgriffe besitzen auf der Oberseite eine Vertiefung, die in der Regel dekoriert ist, vgl. Schauenburg, Studien IX/X, 57. Palmetten auf der Oberseite des Deckelknaufs kommen sehr oft vor, vgl. die Lekanis Bochum S I 57: CVA
Bochum 3 Taf. 36, 3-5. Drei Palmetten im ähnlichen Schema wie auf dem Grazer Deckelknauf sind auch auf dem Deckel Portland 26.289 zu sehen (Dm 28, I cm): LCS, 240 Nr. I08 Taf. 97, I.

Zur Darstellung: Die Darstellung ist von links nach rechts zu lesen. Damit ist Athena die erste und Kreta die letzte Figur. Der Maler hat das Ende der Szene durch die größere Palmette genau abgegrenzt. Alle Figuren schauen auf das zentrale Thema. Darstellungen auf Deckeln zeigen in der Regel vereinzelte Figuren - Köpfe, Frauen, Satyrn, Eroten - umgeben von floralen Motiven. Eine spezielle Episode aus der Mythologie, die auch ausführlich illustriert wird, bleibt eine von wenigen Ausnahmen, siehe Porten-Palange a. O. 86 Anm. 2. Der Kampf des Theseus gegen Minotaurus ist ein sehr beliebtes Thema in der Vasenmalerei. Dieser Abschnitt aus der Theseussage ist das älteste und am häufigsten dargestellte Motiv. Das Thema erfreute sich besonders in der attischen Vasenmalerei großer Beliebtheit. Allgemein zum Thema und zu den Darstellungen in der Kunst siehe Brommer, Theseus, 35-64; Servadei, Theseus, Iо०-I07; K. Schefold, Götter- und Heldensagen der Griechen in der früh- und hocharchaischen Kunst (München I993) I I4-I 22. 255-260; Schefold, SB II, I 50-I 54; Schefold Jung, SB IV, 253-258. In Unteritalien ist die Tötung des Minotaurus durch Theseus als Vasendekoration nicht zeitgemäß. Auf dem kampanischen Deckel wird nicht die Tötung des Ungeheuers, sondern der Kampf mit ihm gezeigt. Theseus ist ohne Schwert abgebildet. Im Ringkampf wie hier sind gewöhnlich junge Männer nackt in der Palästra gezeigt, siehe W. Decker, Sport in der griechischen Antike (München I995) 66; und eine Palästradarstellung auf der Schale des Onesimos in München, Staatl. Antikensammlungen J 795: $\mathrm{ARV}^{2}$ 322, 28; I604. I645; Para 359; $\mathrm{Add}^{2}$ 21 5; CVA München I 6 Taf. 4-5. Bei den sonstigen Heldentaten ist Theseus gegen den Räuber Kerkyon im Ringkampf zu sehen, vgl. Brommer, Theseus, I9-2I. Theseus ist kniend („agenouillé“) dargestellt. Das zeigt den Unterschied in der Gestaltung der Episode zwischen attischen und italischen Malern, vgl. Moret a. O. I 23. Minos tritt seit den frühesten Darstellungen als Betrachter des Geschehens auf. Auf den attischen Beispielen der Jahre 480-450 steht er immer neben dem Geschehen und nimmt sogar auch am Kampf teil, vgl. LIMC VI (Zürich I992) 57I f. Nr. I6-24 s. v. Minos Taf. 3 I I-3 I 3 (J. Bažant). Ansonsten erscheint er sitzend als Zuschauer, vgl. Servadei, Theseus, I05 Abb. 42. 43. Allgemein zum Klismos siehe C. Ehrl, Vom Hocker zum Thron, in: B. Otto - F. Ehrl (Hrsg.), Echo. Beiträge zur Archäologie des mediterranen und alpinen Raumes, Johannes B. Trentini zum 80. Geburtstag (Innsbruck I990) I 2 I f. Abb. 8; G. M. A. Richter, The Furniture of the Greeks, Etruscans and Romans (London I966) 33-37. Minos trägt eine gepunktete Kette quer über seinem Körper. Solche Ketten tragen gewöhnlich Eroten, Satyrn oder der Gott Dionysos, vgl. Vasen aus der gleichen Gruppe, wie die Bauchlekythos Newark 50.3 I4: LCS, 240 Nr. I09 Taf. 95, 2 (sitzender Eros); der Deckel Portland 26.289: LCS, 240 Nr. I08 Taf. 97, I (Satyrn); die Bauchlekythos Montpellier, Société archéologique I 28: LCS, 244 Nr. I3 I Taf. 97, 3 (Dionysos). Die Punktkette ist ein in der unteritalischen Vasenmalerei sehr verbreitetes Motiv. Vor allem auf den paestanischen Vasen wird es sehr gern verwendet. Es kann rein dekorativ, als Hinweis auf bestimmte mythische Bereiche oder als Zeichen für festliche Anlässe gemeint sein, vgl. Schauenburg, Studien IX/X, I 8 f. Anm. I09. Ariadne hebt in der Höhe der rechten Schulter ihr Gewand in einem Hochzeitgestus an (Anakalypteria). Zu dem Gestus und seiner Bedeutung siehe J. H. Oakley - R. H. Sinos, The Wedding in Ancient Athens (Madison I993) 25; E. Reeder, Frauenbilder, in: Pandora, I24-I27. I 54-I60 Nr. I 8-20. Ariadne tritt seit den frühen Darstellungen im Kampf gegen Minotaurus auf; in der attischen Vasenmalerei besitzt sie jedoch keine protagonistische Rolle. Das Bild, dass Ariadne ihr Knäuel in der Hand hält, findet sich bis in die letzten Jahrzehnte des 7. Jhs. Das Motiv erscheint erst wieder auf unteritalischen Vasenbildern, z. B. auf dem lukanischen 
Glockenkrater des Pisticci-Malers in einer Privatsammlung: LIMC VI (Zürich I992) 576 Nr. 25 s. v. Minos Taf. 320 (J. Bažant); Brommer, Theseus, 47 Taf. 27; vgl. Schefold - Jung, SB IV, 256; LIMC III (Zürich I986) I053-I056 Nr. I6-4I s. v. Ariadne; I066 Taf. 727-729 (M.-L. Bernhard - W. A. Daszewski). Sitzende Ortspersonifikationen entstammen dem Typus der sitzenden Gottheit in der Natur, der in der attischen Vasenmalerei der zweiten Hälfte des 5. Jhs. auftaucht. Ortspersonifikationen treten häufiger auf italischen als auf attischen Vasen auf. Der Ort, den sie verkörpern, ist ein wesentliches Element der Darstellung. Kreta sitzt auf einem Felsen, der „ihre“ Insel symbolisiert, vgl. Aellen a. O. Io3 f. Kreta hat ihre linke Hand in einem Gestus erhoben, der Verwunderung, aber auch Erschrecken und Angst zeigt; vgl. LIMC VI (Zürich I992) I 33 s. v. Krete Nr. 3 Taf. 60 (M. Andreadakis-Vlasakis); G. Neumann, Gesten und Gebärden in der griechischen Kunst (Berlin I 965) 4I-48. IO2-I05. Auf einem Mosaik in Nea Paphos, Villa of Theseus (R. 36), hat Kreta ihre Hand an ihre Wange gelegt, so dass ihre Angst stärker ausgedrückt wird, siehe LIMC VI (Zürich I992) I33 s. v. Krete Nr. 4 (M. Andreadakis-Vlasakis). Der Gestus der Kreta bezieht sich auf den gegenwärtigen Zeitpunkt, in dem sich das Ereignis vor ihren Augen entfaltet, siehe Aellen a. O. I36. Auf diese Art und Weise nimmt Kreta nicht aktiv am Kampf teil, hofft jedoch auf die Befreiung der Insel von Minotaurus und begrüßt sowie unterstützt die Bemühungen des Theseus, siehe Aellen a. O. I45. Athena ist bei dem Kampf oder nach der Tötung des Minotaurus in wenigen Abbildungen dargestellt, siehe Servadei, Theseus, I04. II I. Bei den üblichen Darstellungen hält gewöhnlich Ariadne den Siegeskranz und nicht Athena, vgl. Brommer, Theseus, 47. Bei diesen Darstellungen gilt der Kranz als Siegessymbol und drückt zusätzlich die romantischen Gefühle der Ariadne zu dem Heros aus, siehe LIMC III (Zürich I986) I066 s. v. Ariadne (W. A. Daszewski).

Zum Maler: Zur Aigisthos-Gruppe siehe LCS, 243-245. Die Aigisthos-Gruppe ist eine Untergruppe der Getupften-Felsen-Gruppe (spotted rock group), die zu dem Kreis des Kassandra-Malers gehört. Zum Kassandra-Maler und seinem Kreis: LCS, 222-245; LCS
Suppl. I, 4I-43; LCS Suppl. II, I87-I90; LCS Suppl. III, I I 5-I I 8; Mayo - Hamma, Magna Graecia, I98. Charakteristika der Aigisthos-Gruppe sind die bärtigen Figuren und die Verwendung der weißen Farbe für die nackten Teile des weiblichen Körpers. Die auf einem Klismos sitzende Gestalt des Minos zeigt große Ähnlichkeiten zu der bärtigen Figur auf der Hydria London, BM F 228: LCS, 243 Nr. I26 Taf. 96, 4. Die Vasen der Aigisthos-Gruppe zeigen enge Verwandtschaft zu den anderen Untergruppen der GetupftenFelsen-Gruppe. Stilistische Ähnlichkeiten lassen sich vor allem in der Zeichnung der spitzen Nasen und der floralen Dekoration sehen. Bezüglich der Wiedergabe der Gewänder erwähnt Trendall Ähnlichkeiten zum Sitzenden-Nike-Maler. Die Gestalt der sitzenden Kreta ist in überkreuzten Beinen, der Haltung sowie dem ihre Beine umhüllenden Mantel und der Kopfbedeckung mit der Frau auf der Hydria Neapel, NM 82733 sehr verwandt: LCS, 24I Nr. I 6 Taf. 97, 5. Ariadne erinnert in der Kontraposthaltung, dem Griff in das Gewand, der Zeichnung des Chitons und des quer liegenden Mantels an die weibliche Figur auf der Bauchlekythos in Montpellier, Société archéologique I 28: LCS, 244 Nr. I3 I Taf. 97, 3. Das Thema des Grazer Deckels, seine friesartige Anordnung, die Anzahl sowie die Vielfalt der Figuren machen das Objekt zu einer der Meisterarbeiten der Aigisthos-Gruppe.

TAFEL 72

1-2. Siehe Tafel 71, 1-3.

TAFEL 73

1-5. Siehe Tafel 71, 1-3. 


\section{GLANZTON-WARE}

\section{TAFEL 74}

\section{1-4. Oinochoe}

Beilage 21, 2.

G 8. Aus Süditalien. Erworben I 868 von Richard Knabl, Schenkung. Ehemals Slg. Richard Knabl (Graz). Alte Inv.-Nr. IV 4 (Schenkl) bzw. III I4 (Pichler).

H 7,o cm. - Dm Mündung 4,6 cm. - Dm Körper 5,3 cm. - Dm Boden 3,2 cm. - Dm Fuß 3,4 cm. - B Henkel I,2 cm. - Gewicht 55 g. - Volumen $64 \mathrm{ml}$.

Essenwein, Katalog, 27 Nr. 204. - Karl, Richard Knabl, 30I Nr. Io. - Karl, Knabl, 82 Kat. 4 Abb. 2 Taf. I.

Zustand: Gefäß vollständig erhalten. Kleines Fragment am Fuß abgebrochen und wieder angesetzt. Innen und außen Absplitterungen und Bestoßungen. Vereinzelt kleine Risse. Sinterreste an der gesamten Oberfläche. Dichte Versinterungen im Bereich des Henkels sowie an der Gefäßunter- und der Fußaußenseite.

Technik: Grün-schwarzer, dicker, wenig glänzender Malschlicker. Farbe des Malschlickers (Bauch): schwarz ( 5 Y 2.5/I, black). Malschlicker deckend aufgetragen. Das Gefäß wurde eingetaucht, da der Tonschlicker im Gefäßinneren viel und an der Bodenunterseite wenig verlaufen ist. An der Außenkante des Henkels Pinselspuren. Farbe des Tongrundes: 5 YR 7/6 (reddish yellow).

Form: Kleine Oinochoe der Form 8M auf niedrigem Ringfuß mit kugeligem Körper und trichterförmiger Mündung. Vertikaler Bandhenkel mit längsovalem Querschnitt.

Dekor: Gefäßaußenseite vollständig mit Tonschlicker überzogen. Auf der Bauchzone vertikale Riefel. Unterhalb des unteren Henkelansatzes sternförmige Riefen.

Zweite Hälfte 4. Jh. - Apulisch

Zur Erwerbung: siehe G 6, hier Tafel 66, I-4.

Zur Form: Ähnlichkeit zur Grazer Oinochoe zeigt Morels Form Nr. 53 I 4: Morel, Céramique, 350 , besonders Nr. 53 I 4 b. d: Morel, Céramique, 350 Taf. I62 (als „gobelet" bezeichnet). Ähnliche Beispiele finden sich in Timmari auf der Terrasse „Camposanto“, Tomba I 2: Lo Porto, Timmari, 42 Nr. I 8, Taf. I7, 3, I; in Locarno: CVA Ostschweiz Ticino Taf. 54, I (Slg. Rossi 28); aus Rudiae in Lecce, Museo Provinciale „S. Castromediano“: Bernardini, Lecce, Taf. 68, 20 f. (I973-I974; als Kyathoi benannt). Nach Cambitoglou war der Subtyp M der Form 8 eine italische Schöpfung, siehe A. Cambitoglou, The Lampas Painter, BSR I9, I95 I, 40 Anm. 4; Schauenburg, Studien III, 29 Anm. 306 f. Allgemein zu Oinochoen der Form 8 siehe K. Schauenburg, A Dionysiac Procession on a Monumental Shape 8 Oinochoe, in: W. G. Moon (Hrsg.) Ancient Greek Art and Iconography (London I983) 258-268.

Zum Dekor: Senkrechte Riefelung ist eine beliebte Art der Verzierung bei Oinochoen mit schwarzem Malschlicker nach dem Vorbild von Metallgefäßen. In Athen waren geriefelte Oinochoen (mug, Pheidias-shape) äußerst populär, vgl. Agora XII, 73; sowie G 49, hier Tafel 60, 3-4. Die Oinochoen dieses Typs im GnathiaStil sind die ersten, die den Dekor der Riefelung im letzten Viertel des 4. Jhs. adoptiert haben, vgl. Green, Bonn, Io; Lanza, Puglia, 47. Sternförmiges Motiv unter dem Henkel ist üblich, vgl. die Oinochoe Locarno 4I: CVA Ostschweiz Ticino Taf. 54, 2. 4. Dieses Motiv ist auch im Gnathia-Stil üblich, Beispiele dazu wären:
Lanza, Puglia, 89 Nr. 24 (368 Io); 95 Nr. 30 (35368); für attische Exemplare vgl. Agora XII, 74 .

Zum Typ: Oinochoen dieses Typus sind auch im rotfigurigen Stil ausgeführt worden, vgl. CVA Copenhague, Musée National 6, IV D Taf. 265, I (Chr. VIII 792); CVA Bologna 3, IV D r Taf. 32, 8 (Slg. Palagi 900). Im rotfigurigen Stil erscheinen sie nicht so häufig, vgl. K. Schauenburg, Gruppe polychromer apulischer Vasen in Kiel, JdI Ioo, I98 5, 433 f.; K. Schauenburg, A Dionysiac Procession on a Monumental Shape 8 Oinochoe, in: W. G. Moon (Hrsg.) Ancient Greek Art and Iconography (London I983) 263 Abb. I7.I I a-b. Oinochoen dieser Form sind im Gnathia-Stil verbreitet, vgl. CVA Bologna 3, IV D s Taf. I, I7-23 (Slg. Palagi 763765, 770, 777, 877, I3 I7; als Kyathoi bezeichnet); CVA Napoli, Museo Nazionale 3, IV E Taf. 64, 7; Io-I3 (Sant. I209-I2 I0, I2I 5-I216; 80932; als bicchieri benannt); CVA Ostschweiz Ticino Taf. 53, 9-I9 (Slg. Lombardi 22, 27, 29-30, 32-33); CVA St. Petersburg, State Hermitage Museum 6 Taf. 26, I-2; 29, 3-4; 30 (B. I977; als mug bzw. Oinochoe $8 \mathrm{M}$ bezeichnet); CVA Tübingen 7 Taf. 28, 8-9 (742I, 7427; mit weiteren Vergleichsbeispielen). Die meisten gehören zur Knudsen-Gruppe. Oinochoen der „Laurel Spray"-Gruppe finden sich in Ruvo di Puglia, Museum Jatta, vgl. Lanza, Puglia, 88-95 Nr. 23-30 (als Boccaletto Tipo M benannt).

\section{5-7. Schale}

Beilage 21, 3.

G 9. Aus Süditalien. Erworben I 868 von Richard Knabl, Schenkung. Ehemals Slg. Richard Knabl (Graz). Alte Inv.-Nr. IV 9 (Schenkl) bzw. III I 5 (Pichler).

H 4,7 cm. - Dm Rand I7, I cm. - B mit Henkeln 23,9 cm. - Dm Boden 7,7 cm. - Dm Fuß 7,9 cm. - Dm Henkel o,9 cm. - Gewicht 245 g. - Volumen $490 \mathrm{ml}$.

Essenwein, Katalog, 26 Nr. 205. - Karl, Richard Knabl, 30 I Nr. 6. - Karl, Knabl, 83 Kat. 5 Taf. 2. - Lehner - Lorenz - Schwarz, Vasen, 74-75 Nr. 48 Abb. 64 (Th. Lorenz).

Zustand: Vollständig erhalten. Ungebrochen. Starke Versinterungen an der Gefäßunterseite, außen am Körper und an der Innenseite. Kleine Absplitterungen. Auf der Gefäßinnenseite um den Stempeldekor ein braun verfärbter „Diskus“, von der Stapelung im Brennofen.

Technik: Glänzender, schwarzer Malschlicker, sorgfältig und deckend aufgetragen. Farbe des Malschlickers (Bauch): schwarz ( Iо YR 2/I, black). Am Henkelansatz Pinselspuren. An der Unterseite des Fußes ist an einer Stelle der schwarze Malschlicker leicht verlaufen. Miltos: auf der ganzen Unterseite des Gefäßes. Am Fuß unterhalb der schwarzen Oberfläche Miltos, heute sichtbar unter der Absplitterung bzw. Abreibung des schwarzen Malschlickers. Stempelverzierung: im Zentrum der Innenseite Dekor durch Stempelung und Einritzung.

Form: Schale auf weitem, niedrigem, profiliertem Ringfuß (stemless cup). Die Wandung ist außen konvex gewölbt, innen am Übergang vom Schalenkörper zum Rand ein deutlich abgesetzter Grat. Zwei gegenständige, nach oben gebogene Horizontalhenkel mit rundovalem Querschnitt.

Dekor: Die Schale ist abgesehen vom Zentrum der Gefäßunterseite vollständig mit schwarzem Malschlicker überzogen. Am Innenboden ein negativer Stempeldekor mit vier durch gebogene Linien verbundenen Palmetten (palmette cross). 
Mitte 4. Jh. - Apulisch

Zur Erwerbung: siehe G 6, hier Tafel 66, I-4.

Zur Technik: Allgemein zur Übereinanderlagerung in einem Brennofen siehe B. Geißler in: TonArt, 93 Abb. 22; IOI f. Nr. 72; N. Cuomo di Caprio, La ceramica in archeologia 2. Antiche tecniche di lavorazione e moderni metodi d'indagine, StA I44 (Rom 2007) 325. Bei Stapelung im Brennofen wurde ein Gefäß mit dem Durchmesser der Standfläche von $6,8 \mathrm{~cm}$ auf unsere Schale gestellt. Der Abdruck des darüberliegenden Gefäßes ist an zwei Stellen sichtbar, nach innen folgt eine ca. $0,55 \mathrm{~cm}$ breite braune Verfärbung, der Kern bleibt schwarz.

Zur Form: Schalen mit schwarzem Tonschlicker (stemless cup, delicate class), die eine dünne Wandung und einen Grat an der Innenseite besitzen, wurden in Athen vom 3. Viertel des 5. Jhs. bis zum 2. Viertel des 4. Jhs. hergestellt, siehe Agora XII, IO2-I05. Der Typus der süditalischen Schalen wurde von den attischen übernommen. Ähnliche Form zeigen fünf Schalen aus der Nekropole in Ordona; siehe R. Iker, La tomba LX, Ordona 3 (Brüssel I97I) 65 f. 72 . Nr. 9. 30. 34. 38. 39 Abb. 20-2 I Taf. 35. Zu Schalen mit relativ tiefem Becken ähnlich wie das Grazer Exemplar siehe CVA Fiesole 2 Taf. 37 Nr. 3-4 (ohne Inv.); CVA Ostschweiz Ticino Taf. 54, I I. I 2 (Locarno 60); G. Andreassi - F. Radina, Archeologia di una città. Bari dalle origini al X secolo (Bari I988) 259 Nr. 3 I6; 355 f. Nr. 723; Hayes, Ontario, 62 f. Nr. I03 Abb. ıо (968.r I.I); S. K. Rihl, Die Keramik der Sammlung Nowak aus dem Höbarthmuseum der Stadt Horn (Wien I992) 55 Nr. 39; CVA Prague, Université Charles 2 Taf. 9I, I-2 Abb. 34, 3 (58.739); L. Merzagora, I vasi a vernice nera della collezione H. A. di Milano (Mailand I97I) 2 Nr. 5 Taf. 2. 40.

Zum Dekor: Allgemein zum Stempeldekor auf Vasen mit schwarzem Tonschlicker: Agora XII, 22-30; Cuomo di Caprio a. O. 449 f.; TonArt, 7 I-75. Stempelverzierung mit Palmetten werden bei attischen Schalen im 4. Jh. stereotyp. Diese zeigen als Dekoration des Innenbeckens untereinander Ähnlichkeiten, vgl. Agora XII, IO4 Nr. 5I3-5I7 Taf. 52 Nr. 5I7. Dieses Motiv wird von den unteritalischen Werkstätten übernommen. Vergleiche zum Palmettendekor: CVA Copenhague, Musée National 7, IV Taf. 288, 3 a-b (Chr. VIII 20I; sechs Palmetten); CVA Prague, Université Charles 2 Taf. 9I, I-2 Abb. 34, 3 (58.739); CVA Reading I Taf. 34, I3 (87.35/29); 34, I4 (22.iii.7); R. Iker, Description d’un matérial funéraire préromain, Ordona I (Brüssel I965) 60 Nr. Io Abb. I9 Taf. 4I b. Über die Entwicklung des Stempeldekors siehe A. Balland, Céramique étrusco-campanienne à vernis noir, Fouilles de l'École Française de Rome à Bolsena 3 (Paris I969). Schalen dieser Art wurden zum Teil mit aufgesetzter Farbe dekoriert, vgl. Hayes, Ontario, I I 6-I I 9 Nr. I99-200; Schauenburg, Studien III, 38 Nr. I 86-I 87.

Zum Typ: Solche Schalen waren in apulischen und lukanischen Gräbern seit Ende des 5. Jhs. und während des gesamten 4. Jhs. weitgehend verbreitet. Die älteren besaßen einen kräftigeren Aufbau, sie wurden im Laufe des 4. Jhs. schlanker; Andreassi - Radina a. O. 335 . Die dünne Wandung und der Miltos der Unterseite ohne zusätzliche Dekoration sind üblich für die süditalische Ware des 4 . Jhs., vgl. Hayes, Ontario, 57. Schalen gleicher Art wurden auch in kampanischen Werkstätten produziert, siehe Morel, Céramique, 295 Nr. 422 I Taf. I 20, sowie in Sizilien, siehe Meligunìs - Lipára II, 2 I I-226.

\section{TAFEL 75}

\section{1-3. Schale}

Beilage 21, 4.

G Io. Aus Süditalien. Erworben I 868 von Richard Knabl, Schenkung. Ehemals Slg. Richard Knabl (Graz). Alte Inv.-Nr. IV Io (Schenkl) bzw. III I6 (Pichler).
H 4,2 cm. - B mit Henkeln 2I,7 cm. - Dm Mündung I6,0 cm. - Dm Fuß 7,3 cm. - Dm Henkel o,7 cm. - Gewicht 2 I I g. - Volumen $4 \mathrm{I} 5 \mathrm{ml}$.

Essenwein, Katalog, 26 Nr. 205. - Karl, Richard Knabl, 301 Nr. 7. - Karl, Knabl, 83 Kat. 6 Taf. 2. - Lehner - Lorenz - Schwarz, Vasen, 74 f. Nr. 49 Abb. 65 (Th. Lorenz).

Zustand: Vollständig erhalten. Ungebrochen. Vereinzelt kleine Absplitterungen, vor allem an den Henkeln und an der Lippe. Standfläche durch Abnutzung abgerieben. Sinterspuren an der Unterseite des Fußes. Nahezu die gesamte Fläche der Innenseite versintert. Riss am Ansatz des Ringfußes und des Henkels. Im Zentrum des Gefäßinneren ein dezentraler Abdruck von der Stapelung im Brennofen.

Technik: Glänzender schwarzer, irisierender Malschlicker, deckend und sorgfältig aufgetragen. Farbe des Malschlickers (Bauch): schwarz (Io YR 2/I, black). Miltos: partiell an der Bodenunterseite, flüchtig aufgetragen.

Form: Schale auf weitem, niedrigem, doppelt profiliertem Ringfuß (stemless cup). Wandung außen konvex gewölbt, innen am Übergang vom Schalenkörper zum Rand ein deutlich abgesetzter Grat. Zwei gegenständige, nach oben gebogene Horizontalhenkel mit rundovalem Querschnitt.

Dekor: Die Schale ist mit Ausnahme des Zentrums der Gefäßunterseite mit schwarzem Malschlicker versehen. Am Innenboden ein negativer Stempeldekor mit vier durch gebogene Linien verbundene Palmetten (palmette cross).

Mitte 4. Jh. - Apulisch

Zur Erwerbung: siehe G 6, hier Tafel 66, I-4.

Zur Technik: Der Abdruck im Zentrum der Innenseite besitzt einen Durchmesser von 6,3 cm durch Aufsetzen eines weiteren Gefäßes während des Brandes. Der Abdruck zeigt sich in einer konzentrischen Kerbung und im Zentrum in einer hellen verfärbten Fläche. An der Außenseite auf Höhe des Grates und darüber ein

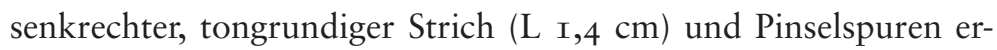
kennbar. Zur Übereinanderlagerung in einem Brennofen siehe $G 9$, hier Tafel 74, 5-7.

Zur Form: siehe G 9, hier Tafel 74, 5-7.

Zum Dekor: siehe G 9, hier Tafel 74, 5-7.

Zum Typ: siehe G 9, hier Tafel 74, 5-7.

\section{Tafel 76, 1-6. Guttus}

Beilage 22, 1.

G 2. Aus Capua. Erworben I876, Ankauf. Alte Inv.-Nr. IVc 60 (Pichler).

$\mathrm{H}_{4}, 8 \mathrm{~cm}$. - H mit Ausguss 7,6 cm. - H Fuß I,7 cm. - Dm Körper Io,6 cm. - Dm Boden 7,0 cm. - Dm Medaillon 4,7 cm. - Dm Mündung 3,4 cm. - L mit Ausguss I3,I cm. - Gewicht [236 g].

Lehner - Lorenz - Schwarz, Vasen, 75-77 Nr. 50 Abb. 66-67 (Th. Lorenz). - M. Christidis, Ein Guttus aus der Originalsammlung des Instituts für Archäologie der Universität Graz, in: E. Trinkl (Hrsg.), Interdisziplinäre Dokumentations- und Visualisierungsmethoden, CVA Österreich Beih. I (Wien 20I3) I6I-I70 Abb. I-I 2.

Archäometrie: Röntgenaufnahmen am 7. Sept. 20Iо; CT 04345 am I I. Nov. 20IO; CT 20I I-053 am I. Febr. 20 II.

Zustand: Tülle gebrochen und wieder angesetzt, Bruchkante sichtbar. Ringhenkel gebrochen und verloren, Henkelstumpf erhalten. Kleine Bestoßungen, Absplitterungen und Abreibungen an der Oberfläche. Wenige Versinterungen an der Gefäßunterseite und dort am Tubus. Abplatzungen an der Kante der abfallenden Lippe 
der Tülle und am Übergang des Fußes zum Körper. Abnutzungsspuren an der Standfläche. Eine Delle läuft vom eingetieften Ring um das Medaillon bis zum Rand unterhalb des Pferdeschweifs. Eine zweite Delle sitzt unterhalb der Vorderbeine des Pferdes am Rand des Medaillons und an der Profilierung. Dieser „Unfall“ passierte im lederharten Zustand vor dem Brand eventuell durch ein spitzes Objekt während der Verbesserung der Oberfläche nach der Platzierung des Medaillons. Der Rand des Medaillons unterhalb des Pferdeschweifes ist durch den Druck verrutscht. Durch Abnutzung des Gefäßes ist die Oberfläche an einigen Stellen des Medaillons abgerieben, darunter ist ziegelroter Tongrund sichtbar. Standfläche am inneren und äußeren Rand zum Teil von der schwarzen Übermalung verwischt.

Technik: Die gesamte Oberfläche der Außenseite ist durch eine historische Restaurierung schwarz übermalt. Standfläche, Bodenplatte und Standringinnenseite teilweise mit originaler Bemalung. Der Tongrund an Bodenplatte und Standfläche ist rötlichbraun (7.5 YR 5/6, strong brown). Die Schräge zwischen Bodenplatte und innerem Tubus und ein weiterer in kleinem Abstand umlaufender Ring sowie die Innenseite des Standringes sind mit schwarzem Tonschlicker versehen. Schräge und Ring flüchtig gemalt, zum Teil verwischt. Die authentische Engobe, die an abgeplatzten Stellen erkannt werden kann, ist heller und matter als die Oberfläche: schwarzdunkelgrau ( 5 YR $3 / \mathrm{I}$, very dark gray). An einigen kleinen abgeplatzten Stellen der Engobe ist der ziegelfarbene Ton erkennbar. Durch Abplatzung der rezenten Übermalung im konkaven Oberteil des Fußes ist ein sehr kleiner Teil roter Farbe (Miltos) sichtbar.

Form: Im Zentrum der Gefäßunterseite sitzt ein Tubus, der zylindrisch nach oben führt. Der Übergang zum Tubus ist abgeschrägt. Ringfuß, der auf seiner Außenseite durch doppelte Rillen dreigeteilt ist. Der Übergang zum Körper ist konkav eingezogen, darüber ein feiner Grat. Der elliptische Gefäßkörper hat seine maximale Ausdehnung in der Mitte des Bauches. Der röhrenförmige Ausguss ist schräg nach oben gezogen, die gerundete Lippe stark nach außen gezogen. Ungefähr im Winkel von $90^{\circ}$ zum Ausguss sitzt der Ringhenkel. Im Zentrum der Gefäßoberseite sitzt ein Medaillon mit flachem Relief, von zwei Rillen eingefasst.

Dekor: Auf der Gefäßunterseite um die Tubusöffnung ein schmaler, außen ein breiter schwarzer Ring. Die Gefäßaußenseite ist vollständig schwarz bemalt. Die untere Hälfte des Körpers ist glatt, die obere Hälfte mit einer senkrechten feinen Riefelung versehen, die oben durch eine umlaufende Rille abgeschlossen ist. Die Zone unterhalb der Tülle ist glatt belassen. Am Henkelansatz flachere Riefelung.

Darstellung: Amazonomachie (im Relief) - Medaillon: Ein Reiter sprengt von links gegen eine halb kniende, gefallene Amazone und richtet die Lanze, die er in seiner rechten, erhobenen Hand hält, gegen sie. Er trägt einen kurzen Chiton, eine Chlamys und auf dem Kopf einen attischen Helm. Die Amazone stützt sich mit ihrem linken Knie und Ellenbogen am Boden ab und schwingt mit der Rechten ein Beil, mit dem sie den Gegner abwehren will. Ihr rechtes Bein ist zwischen den Hinterbeinen des Pferdes ausgestreckt. Sie trägt einen kurzen Chiton, eine Chlamys und Stiefel.

\section{Zweite Hälfte 4. Jh. - Kampanisch}

Zum Zustand: Das Gefäß wurde nach seiner Auffindung und vor seiner Erwerbung restauriert. Bei den Restaurierungen wurde die Oberfläche und ca. ein Viertel der Standringinnenseite übermalt. Unterhalb der rezenten Übermalung wurde eine weiße Masse sichtbar. Diese Masse ist an der Mündung, am Fußring und an der Bruchkante des Ringhenkels zu sehen. Durch naturwissenschaftliche Untersuchungen wurde festgestellt, dass diese einen großen Teil des Körpers umfasst und dass die Unter- und Innenseite des Fußes, der Tubus und das Medaillon ausgespart sind. An der Schulter ist gegenüber dem Ausguss ein Fragment abgesplittert, ergänzt und anschließend schwarz übermalt worden. Die weiße Ausgleichsmasse ist besonders stark im Bereich des Ausgusses, des Henkels, des Bruches zwischen Fuß und Körper sowie an der gerippten Schulter im Bereich der abgeplatzten Oberfläche verstrichen. Die Ausgleichsmasse wurde auf der originalen Oberfläche aufgetragen und war eine Art Grundierung für die schwarze Übermalung. Weiße Stellen wurden auch am Medaillon entdeckt, weisen aber im Gegensatz zu den übrigen Stellen eine wachsartige Substanz auf (evt. Paraffin). Der Ausguss gehört nicht zu dem Gefäß. Die Mündung war gebrochen und wurde durch eine neue ersetzt. Die neue Mündung ist später noch einmal gebrochen, erneut zusammengesetzt, aber nicht retuschiert worden. Der Fuß war ebenfalls gebrochen, wurde wieder angesetzt und retuschiert. Heute ist der Bruch, der in dem Ansatzbereich des Fußes glatt und durchgehend verläuft, nur in den CT- und Röntgenbildern sichtbar.

Zur Form: Allgemein zu den Gutti und Askoi vgl. CVA Göttingen I, 63; F. Gilotta, Rez. zu: „Les gutti et les askoi à reliefs étrusques et apuliens. Essai de classification et de typologie“, StEtr 47, I 979, 5 52-5 57; J. P. H. Herdejürgen, Zur Funktion der sogenannten calenischen Gutti, in: H. A. G. Brijder (Hrsg.), Ancient Greek and Related Pottery, Proceedings of the International Vase Symposium Amsterdam I984 (Amsterdam I 984) 285-287; M. O. Jentel, Les gutti et les askoi à reliefs étrusques et apuliens (Leiden 1976) 27. 95-446; L. Merzagora, I vasi a vernice nera della collezione $\mathrm{H}$. A. di Milano (Mailand I97I) I9-24 Taf. 3 I-38. 64-70; Morel, Céramique, 42 I-426 Nr. 8 Ioo Taf. 208-2 I I; R. Pagenstecher, Die calenische Reliefkeramik, JdI Ergh. 8 (Berlin I909) I 26-I 35. Der Grazer Guttus gehört in die Kategorie der Gutti mit mittelgroßem Fuß, vgl. Jentel a. O. 27 und der von Morel erfassten Gruppen Nr. 8I40 bzw. 8I4I. Der Guttus besitzt zusätzlich einen inneren Tubus. Die Form ähnelt dem Exemplar Nr. 8I 4 I d 2 und Nr. 8 I 4 I $\mathrm{f}$ I. Bei dem ersten Beispiel sind Körper und Fuß sehr ähnlich dem Grazer Gefäß, nur besitzt es keinen inneren Tubus wie das zweite Beispiel, vgl. Morel, Céramique, 423 Nr. 8I 4I d 2 und Nr. 8I4I f Taf. $208 \mathrm{f}$

Zum Dekor: Gutti sind mit wenigen Ausnahmen immer geriefelt. Der Grazer Guttus besitzt Riefen mittlerer Größe, vgl. Jentel a. O. $276 \mathrm{Nr}$. AP II 4a Abb. I4 I („moyennes“).

Zur Darstellung: Szenen mit Amazonomachie sind auf Medaillons von Gutti oft vertreten, vgl. P. G. P. Meyboom, Amazonomachies on „Calenian“ Gutti, in: H. A. G. Brijder - A. A. Drukker C. W. Neeft (Hrsg.), Enthousiasmos, Essays on Greek and Related Pottery, Presented to J. M. Hemelrijk, Allard Series 6 (Amsterdam I986) I93-202. Zum Motiv auf dem Medaillon mit einem Reiter (nach rechts) gegen eine kniende Amazone: Pagenstecher a. O. IO2 Nr. 21 3 a-c Taf. 22; CVA Genève, Musée d'Art et d'Histoire I, IV E Taf. 38, 5 (MF 207); CVA Zürich I Taf. 55, 7-8 (2829); Amsterdam, Allard Pierson Museum 8594: Meyboom a. O. 200 Abb. 8-9. Mit einem Reiter nach links: Pagenstecher a. O. IO2 Nr. 2 I 2 a-c; CVA Capua 3, IV E g Taf. I I, 5 (7973). Das Motiv ist auch in vertauschten Rollen auf Reliefmedaillons zu sehen: Pagenstecher a. O. IOI f. Nr. 210 a-1 Taf. 22; CVA Louvre I 5, IV E Taf. I7, IO-I 2 (H 308, N 3704, S I784); CVA Göttingen I Taf. 47, 7 (Hu I382 a; nicht sicher). 8; CVA Tübingen 7 Taf. 43, I (S./IO I377; mit Fragezeichen).

Zur Datierung: Jentel a. O. 30-33 datiert die apulischen Gutti mit Relief in die 2. Hälfte des 4. Jhs. Morel datiert die zwei Exemplare Nr. 8I4I d 2 und Nr. 8I4I f I, die dem Grazer Guttus ähneln, in die zweite Hälfte des 4. Jhs. oder ins 3. Jh. Die apulischen Gutti sind aufgrund der Publikation ihrer Grabkomplexe in die 2. Hälfte des 4. Jhs. datiert. Eine Replik des Medaillons mit der Amazone als Reiterin stammt aus einem Grab in Arpi (F. Tiné Bertocchi, Le necropoli daunie di Ascoli Satriano e Arpi [Genova I985] 252 Nr. 38 Abb. 42I Taf. I9 c Grab 6), das in die zweite Hälfte des 4. Jhs. gehört, vgl. CVA Göttingen I, 63 Taf. 47, 7-8 
(Hu I382 a-b); CVA Tübingen 7 Taf. 42, 5; 43, I (S./IO I377). $\mathrm{Da}$ die apulischen und kampanischen Gutti in Form und Reliefdekor keine großen Unterschiede zeigen, können beide Typen gleich datiert werden: in die 2. Hälfte des 4. Jhs., vgl. M. Bentz, CVA Göttingen I, 63 zu Taf. 47, 7-8.

Zur Werkstatt: Die apulischen Gutti mit Relief wurden von Jentel a. O. 27. 95-446 untersucht. Die kampanischen Exemplare sind dagegen nicht erforscht. Modelle des Medaillons wurden sowohl in Apulien als auch in Kampanien verwendet. Die Darstellung auf dem Medaillon, die Ähnlichkeit mit anderen kampanischen Exemplaren, vor allem mit den Gutti Zürich 2829 (CVA
Zürich I Taf. 5 5, 7-8), Genf MF 207 (CVA Genève, Musée d'Art et d'Histoire I Taf. 38, 5) und Capua, Museo Campano 7973 (CVA Capua 3, IV E g Taf. I I, 5) sowie der Fundort in Capua führen zu der Annahme, das der Grazer Guttus ein kampanisches Erzeugnis ist.

\section{TAFEL 76}

1-6. Siehe Tafel 75, 4. 


\section{GNATHIA-WARE}

\section{TAFEL 77}

\section{1-3. Schalenskyphos}

Beilage 22, 2.

G I2. Aus Süditalien. Erworben I 868 von Richard Knabl, Schenkung. Ehemals Slg. Richard Knabl (Graz). Alte Inv.-Nr. IV 8 (Schenkl) bzw. III I9 (Pichler).

H 6,9 cm. - Dm Fuß 5,5 cm. - Dm Rand Io, 4 cm. - Dm Henkel 0,6 cm. - Gewicht [I 24 g]. - Volumen $373 \mathrm{ml}$.

Essenwein, Katalog, 26 Nr. 206. - Karl, Richard Knabl, 30I Nr. 8. - Karl, Knabl, 83 f. Kat. 9 Taf. I. - Lehner - Lorenz - Schwarz, Vasen, 68 f. Nr. 39 Abb. 58 (Th. Lorenz).

Zustand: Gefäß vollständig erhalten. Wandansatz und Henkel gebrochen und wieder eingefügt. Kleine Bestoßungen. An Seite B die Deckfarbe teilweise abgerieben. An der Unterseite der Henkel kleine Kerbungen vor dem Auftragen des Malschlickers entstanden. An Henkeln, Henkelansätzen und Fuß Pinselspuren.

Technik: An der Außenseite bis zum Unterkörper und an der Mündung der Innenseite schwarzer Malschlicker. Farbe des Malschlickers (Bauch): schwarz (7.5 Y 2/o, black). An der Unterseite des Fußes sehr flüchtig aufgetragen. Malschlicker insgesamt dünn aufgetragen, nur ein Streifen ca. 3, $9 \mathrm{~cm}$ unterhalb des Randes ist mit dickem Malschlicker bemalt. Der Tonschlicker auf der Gefäßinnenseite wurde ebenfalls dünn aufgetragen, so dass Flekken zu erkennen sind. Pinselspuren an Rand und Henkeln. Ritzung: Am Rand unterhalb zwei, oberhalb eine horizontale Ritzlinie, ebenso die Schalen des Eierstabes und die Stämme der Efeuzweige geritzt. Miltos, nachlässig aufgetragen: auf der vollständigen Fußunterseite, obere Hälfte der Fußaußenseite, unterster Teil des Körpers. Aufgesetzte weiße Farbe: Rosetten, Blätter und Beeren des Efeus, Eier und Punkte am Eierstab.

Form: Gefäßunterseite konvex gewölbt. Profilierter Ringfuß mit umlaufendem Grat. Tiefer Schalenkörper mit vertikaler Mündung und spitz gerundeter Lippe. Zwei gegenständige, horizontal verlaufende Knickhenkel mit rundem Querschnitt.

Dekor: Auf beiden Seiten identisch: Von einer horizontalen Ritzlinie hängen je drei wellenartige Efeuzweige mit Blättern und Früchten herab. Die Efeufrüchte (Korymben) sind als Dreipunktmuster wiedergegeben. In den Feldern zwischen den Efeuzweigen je eine weiße Rosette mit fünf Blumenblättern. Unterhalb der Mündung, zwischen zwei geritzten Horizontallinien, ein Eierstab mit Punkten zwischen den Zungen.

\section{0-330- Konnakis-Gruppe}

Zur Erwerbung: siehe G 6, hier Tafel 66, I-4.

Zur Form: Der Schalenskyphos (cup-skyphos) mit dem tiefen Schalenkörper und den Knickhenkeln ist wie auch der einfache Skyphos eine typische und beliebte Form für den Gnathia-Stil (standard Gnathia cup), siehe Green, Bonn, 4 Nr. I8-I9 Taf. I9 (I728. I62). Sie existieren beide über einen langen Zeitraum, vgl. J. R. Green, More Gnathia in Bonn, AA I977, 5 56. Aus dem Standard-Typus (cup-skyphos oder auch footed cup benannt) wird noch am Ende der frühen Gnathia-Phase ein neuer Skyphos mit halbkugeligem Körper, hohem Fuß und Ring- oder geknotetem Henkel entwickelt, der bis zur letzten Phase des Gnathia-Stils exi- stiert, vgl. Webster, Classification, 2. Die Form des Schalenskyphos Bassano del Grappa 46I ist mit der des Grazer Exemplars identisch: A. D’Amicis, La ceramica di Gnathia, in: G. Andreassi u. a. (Hrsg.), Ceramica sovraddipinta. Ori, Bronzi, Monete della collezione Chini nel Museo Civico di Bassano del Grappa (Rom I995) 84 Nr. I.3.32. Große Ähnlichkeiten zeigt das Grazer Exemplar mit folgenden Schalenskyphoi: Schalenskyphos in Göttingen: CVA Göttingen I Taf. 42, 9-I I (F 52; „Kylix“); zwei Schalenskyphoi in Neapel: CVA Napoli, Museo Nazionale 3 Taf. 63, 4. 7 (ohne Inv.; Sant. I367); Schalenskyphos aus der Tomba 2 in Gioia della Colle: B. M. Scarfi, Gioia del Colle. Scavi nella zona di Monte Sannace, MonAnt 45 (Rom I96I) I63-I66 Nr. I7 Abb. I 8 (ohne Inv.); Schalenskyphos aus der Tomba I di via G. Giovane, Tarent: Forti, Gnathia, 38 f. Taf. 6 e. Solche Gefäße, hier unter dem Begriff Napfschalen, wurden auch in der Nekropole von Tarent gefunden. Sie tauchen in der Phase AI (375-350) auf, und in der nächsten Phase A2 (350-325) gehören sie zum Standardrepertoire der Grabbeigaben: Hoffmann, Grabritual, 65-67 Anm. 2I4. Zum Typ: Hoffmann, Grabritual, 4I f. Typ 422/I Taf. 8I (Form 422: „Napf-Skyphos“).

Zum Dekor: Der Eierstab mit Punkten zwischen eingeritzten Linien, die herabhängenden Efeuzweige sowie die Rosetten mit fünf Blumenblättern sind gleich wie auf dem Schalenskyphos 46I in Bassano del Grappa: D’Amicis a. O. I995, 84 f. Nr. I.3.32. Ein sehr ähnliches Motiv zeigt Seite A eines Schalenskyphos, die Rosette hier besitzt jedoch vier Blätter: CVA St. Petersburg, State Hermitage Museum 6 Taf. 5, I (B.593). Eierstab an der Mündung von kleinen offenen Gefäßen ist eine sehr beliebte Verzierung, vgl. Bernardini, Lecce, Taf. I 8-I9; sowie auf dem erwähnten Skyphos Eremitage B.593; der Kotyle Göttingen Univ. F 52: CVA Göttingen I Taf. 42, 9-II; den beiden Skyphoi Neapel, NM 80899 und 80894: CVA Napoli, Museo Nazionale 3, IV E Taf. 63, 2; I I. Alexandropoulou hat anhand der Gestaltung der Efeuzweige einige Gruppen zusammengestellt. Der Grazer Skyphos entspricht am ehesten der Variante Ez Ia, im Unterschied dazu sind aber beim Grazer Gefäß die Efeublätter und die Dreipunktmuster ohne Blattstängel angesetzt, vgl. Alexandropoulou, Gnathia, IO-I 2 Abb. I, I, I. Die Efeuvariante Ez Ia ist ein Leitmotiv der frühen GnathiaKeramik und wird in den süditalischen Werkstätten bis zum Ende des 4. Jhs. verwendet, vgl. Alexandropoulou, Gnathia, I4. Seit der Mitte und im letzten Viertel des 4. Jhs. gelten Efeuzweige mit geritzten Stielen in Tarent als altmodisch, vgl. Green I982, 257. Über Efeu als Ornament und seine Symbolik siehe T. Thie, Unteritalische Vasen aus Kärntner Sammlungen, ungedruckte Diss. Wien (2005) I40-I 43. Rosetten zwischen hängenden Efeuzweigen sind öfters auf meist kleinen Gefäße der Gnathia-Keramik zu sehen, siehe CVA Göttingen I Taf. 42, 9 (F 52); CVA Napoli, Museo Nazionale 3, IV E Taf. 59, 5 (827I4); 63, 2 (80899); 63, 7 (Sant. I367); 73, 7 (8073 I). Dieser Dekor schmückt auch die Rückseite von Skyphoi, vgl. Alexandropoulou, Gnathia, I7 Anm. 93 mit Beispielen.

Zum Maler: Allgemein zum Konnakis-Maler und seiner Gruppe siehe Forti, Gnathia, I 5-I7; Green, Bonn, 2; Webster, Classification, 4-I3. Die Art der Bemalung der Efeuzweige mit der runden Endung der Efeublätter, den wellenartigen Stielen und dem Dreipunktmuster sind Charakteristika des Konnakis-Malers und seines Umkreises, daher wird diese Efeuzeichnung Konnakis-Efeu genannt (Konnakis ivy). Der Grazer Skyphos gehört anhand seiner Bemalung der Konnakis-Gruppe $(\mathrm{Kb})$ an, vgl. Webster, Classification, 6 Taf. I a. In dieser Gruppe bilden solche Efeuzweige die Hauptdekoration von Gefäßen. 


\section{TAFEL 78}

1-4. Olpe

Beilage 22, 3.

G 50. Fundort unbekannt. Erworben vor I9II/I 2.

H 23,3 cm. - Dm Fuß 7,8 cm. - Dm Körper I2,3 cm. - Dm Mündung rek. 8,6 cm. - B Henkel 2,7 cm. - Gewicht [6oI g]. Volumen ror $9 \mathrm{ml}$.

Lanza, Torino, 96 Nr. 34 Abb. 35 a. - Lehner - Lorenz Schwarz, Vasen, 69 Nr. 40 Abb. 59 (Th. Lorenz).

Zustand: Größter Teil der Mündung und des Henkels fehlt. Kleines Fragment des Mündungsrandes war abgebrochen und wurde wieder angesetzt. Versinterungen auf der gesamten Oberfläche, vor allem an der Standfläche und am Hals. Kleine Bestoßungen. Absplitterungen der Engobe, markant am Henkelansatz, am unteren und oberen Teil des Halses im Bereich des Henkels und an der Gefäßunterseite. Die weiße aufgesetzte Farbe fehlt fast völlig, die rote ist teilweise abgerieben. Im unteren Teil des Körpers teilweise Flecken von einer Klebemasse. An der Standfläche Abnutzungsspuren.

Technik: Malschlicker matt wirkend, schwarz und deckend aufgetragen. Inneres der Mündung und oberer Teil des Halses mit schwarzem Malschlicker versehen. Farbe des Malschlickers: schwarz (2.5 YR 2.5/I, black). Farbe des Tones am Bruch: rot bis dunkelgrau (2.5 YR 4/6- 5 YR 4/I, red - dark gray). Auf halber Höhe des Halses Fingerabdrücke. Am Henkelansatz Pinselspuren. Zwei Verfärbungen: eine (max. H 3,5 cm; max. L 6,3 cm) beginnt als Strich an der Schulter neben dem Henkel und verbreitert sich zu einem halbkreisförmigen Fleck (ca. $2 \mathrm{~cm}$ ) unterhalb des Henkelansatzes. Eine zweite Verfärbung ist direkt unterhalb der ersten zu sehen. Diese ist eher eiförmig (L 5,4 cm) und reicht bis zur Standfläche. Im unteren, glatten Bereich verbreitert sie sich wellenförmig in eine Richtung (ca. L $3 \mathrm{~cm}$ ). Ritzung: Am glatten Streifen zwischen Fußring und Rippendekor ein geritztes Wellenmotiv. Da der Dekor nur auf einer Seite erscheint und nicht durchgehend ist, kann das auf Nachlässigkeit oder einen Fehler des Töpfers hinweisen. Am Hals Stamm eines Efeuzweiges. Zusatzfarbe: Weiß: Efeublätter. Rot: Dreipunktmuster. Am geriefelten Körper sind an einigen Stellen Ritzungen zu sehen, ein Zeichen für die flüchtige Fertigstellung des Dekors.

Form: Gefäßunterseite geringfügig eingezogen. Niedriger Fußring, schlanker konischer Körper und runde Schulter. Hoher, deutlich eingezogener Hals mit ausschwingender, nach unten gezogener und an der Oberseite konkav abgestrichener Lippe.

Dekor: Das Gefäß ist an seiner Außenseite vollständig mit Malschlicker überzogen. Der Ringfuß ist durch eine Rille vom Körper getrennt. Die Zone zwischen Ringfuß und geriefeltem Bauch ist nur an einer Seite (rechts des Henkels) dekoriert. Der Dekor besteht aus einer eingeritzten durchgehenden, wellenförmigen Linie. In den Kurven jeweils Verdoppelung durch zusätzlichen Bogen. Auf dem Bauch führt eine senkrechte Riefelung um, unten und oben an der Schulter durch eine doppelte horizontale Rille gerahmt. Die Riefelung ist von oben nach unten und von links nach rechts geführt. Die Rillen sind aus diesem Grund nicht gerade, sondern neigen sich etwas nach rechts. Am Oberkörper ist die Riefelung tiefer und am Unterkörper flacher geführt. Am Hals eine horizontale Efeuranke mit eingeritztem, durchgehend wellenförmigem Hauptzweig. Im Inneren der Wellenlinie beginnt ein eingeritzter, bogenförmiger Stängel mit herzförmigen Efeublättern. Auf der gegenüberliegenden Seite der Welle sind Efeufrüchte (Korymben) als Dreipunktmuster wiedergegeben.

Ende 4. Jh. bis Anfang 3. Jh. - Sizilisch

Zur Technik: Die Verfärbungen sind aufgrund der Stapelung des Gefäßes im Brennofen entstanden. Durch direkten Kontakt mit anderen Gefäßen oder den engen Platz, der eine gute Luftströmung verringert, wurden beide Verfärbungen verursacht. Allgemein zu Verfärbungen im Brennofen siehe G 9, hier Tafel 74, 5-7.

Zur Form: Die Form der Olpe mit dem niedrigen Fußring, dem ovalen und schlanken Körper sowie der überkippten Lippe kommt nur in sizilischen Werkstätten vor, vgl. Lanza-Catti, Puglia, 267 Taf. I, Olpe Oinochoe V A (Beazley). Diese Form findet sich nicht in der apulischen Gnathia-Keramik. Die apulischen Oinochoen mit glattem Körper besitzen einen breiten ovalen Bauch und eine Kleeblattmündung, vgl. Bernardini, Lecce, Taf. 37-44; LanzaCatti, Puglia, 268 Taf. 2 („oinochoe a corpo globulare“). In der Nekropole von Lipari wurde eine Reihe von Olpen dieser Form aufgefunden. Sie wurden in einer sizilischen Werkstatt produziert. Sie sind entweder mit schwarzem Malschlicker versehen oder im Gnathia-Stil bemalt und besitzen konische Körper, die glatt oder seltener geriefelt sind, vgl. mit schwarzem Malschlicker und glattem Körper: Meligunìs - Lipára II, 234 Taf. I 30 , 2c. 3 b; I 3 I, 5 d; I35, Ia. 2a; geriefelt: Taf. I27, Ib; I32, 2a; I34, 2b; im GnathiaStil, glatter Körper: Taf. I28, Ia. 2a; I29, Ia. 3a; I36, 6a; I39, 3c. Olpen im gleichen Typ: CVA Aberdeen I Taf. 49, 4-5 (64I44); CVA Brit. Mus. I, IV D c Taf. 5, 9. I I (F 567); CVA Karlsruhe 2 Taf. 82, 9 (B 23); 82, IO (B 3025). Zu sizilischen Olpen mit geriefeltem Körper (Olpai baccellate) vgl. Lanza, Torino, 94-I03. Als bester Vergleich mit der Grazer Stück kann die Olpe Turin 4I45 gelten: Lanza, Torino, 96 Nr. 34 Abb. 35 .

Zum Dekor: Die Riefelung als Dekor auf apulischen Vasen des Gnathia-Stils ist ein typischer Dekor für die letzte Phase der Gnathia-Vasen (325 bis Ende des 3. Jhs.), vgl. Green, Bonn, IO-I3; Webster, Classification, 23-33. Die apulischen Oinochoen sind am Bauch geriefelt. Die sizilischen Olpen können sowohl glatt als auch geriefelt sein. Die meisten Olpen aus Lipari besitzen glatte Körper. Geriefelt sind dagegen sechzehn Olpen im Museum in Turin, wobei die senkrechte Riefelung nicht bis zum Ringfuß reicht, sondern die Gefäße einige Zentimeter über dem Fuß glatt belassen sind. Es gibt jedoch zwei Ausnahmen (Nr. 37-38), vgl. Lanza, Torino, 94. Das an dieser Stelle eingeritzte Wellenmotiv der Grazer Olpe ist dabei singulär. Riefelung als Dekor von Gefäßen war kein neues Dekorationsschema. Seit dem 5. Jh. wurde sie in Athen als Nachahmung der beliebten, zeitgenössischen Metallgefäße angewendet, vgl. Green, Bonn, Io f. und Anm. 45. Senkrechte Riefelung ist populär in Athen im 5. und 4. Jh., in späterer Zeit wird sie ein wesentliches Element, siehe Agora XII, 2 I f. Das Motiv der Efeuranke ist sehr beliebt in der Keramik des Gnathia-Stils. Dekor durch Ritzung ist in der späten Phase der apulischen Vasen nicht mehr in Mode. Stattdessen werden die Motive bis Ende des 4. Jhs. zunehmend aufgemalt, vgl. P. Baumeister, Neue Gnathia-Vasen im Akademischen Kunstmuseum Bonn, BJb 20I, 200I, 232. Der Dekor am Hals von Oinochoen im Gnathia-Stil aus der Nekropole in Lipari besteht öfters aus einem eingeritzten Efeuzweig, gerade oder wellig, und aufgemalten Korymben: Meligunìs - Lipára II, 234 Taf. I 28, гa. 2a; I 34, 2b; I3 8, 2c. Eingeritzte Efeuranken sind auch auf Olpen in Turin, Museo di Antiquità zu sehen: Lanza, Torino, 96-I03, Nr. 37. 39-47. 49 (Slg. Moschini 4I 45, 4 I 48, 4273, $4275,4276-4277,4279,428 \mathrm{I}-4283,37930-3793 \mathrm{I}, 37933$, 37934); gleichen Dekor wie auf der Grazer Olpe mit eingeritzten Wellenlinien und gemalten herzförmigen Blättern und Korymben besitzen die Olpen Lanza, Torino, 95-IO3, Nr. 34-35. 44. 47. Die Efeuranke der Grazer Oinochoe zeigt Ähnlichkeiten mit den von Alexandropoulou zusammengefassten Typen Ez Ia, Ib und Ic, ist aber mit keiner von diesen identisch, siehe Alexandropoulou, Gnathia, Iо-16 Abb. I-3. Efeu und Efeuranken sind Kultpflanzen, hauptsächlich mit Dionysos und Aphrodite verbunden, die auch als Unterweltsgottheiten bekannt sind. Efeuornament und die Verwendung von Olpen als Grabbeigaben sind belegt, vgl. T. M. Schmidt, Studien zur Vasenkunst des Hellenismus III: GnathiaVasen in der archäologischen Lehrsammlung des Winckelmann- 
Institutes der Humboldt-Universität zu Berlin, FuB 3 I, I99 I, I I 5. Allgemein zum Efeu als Ornament und seine Bedeutung siehe T. Thie, Unteritalische Vasen aus Kärntner Sammlungen, ungedruckte Diss. Wien (2005) I40-I 43.

Zum Typ bzw. zur Werkstatt: Aus stilistischen Gründen kann die Olpe einer sizilischen Werkstatt zugewiesen werden und gehört wie die Olpen aus der Nekropole in Lipari der ersten Phase (Fase initiale) an, vgl. Meligunìs - Lipára II, 234-236. 239-24I.
Zur Produktion der Gnathia-Keramik in Sizilien siehe Forti, Gnathia, I37-I40. Lanza meint, dass es schwierig sei, die Olpen aus dem Museum in Turin einer speziellen Werkstatt zuzuordnen. Olpen mit glattem Körper sind in Lipari anzutreffen, während solche mit Riefelung selten sind. Da die Exemplare im Museum in Turin Ähnlichkeiten mit den Olpen aus Centuripe zeigen, nimmt die Autorin für beide Gruppen dieselbe Werkstatt an, vgl. Lanza, Torino, 94 . 


\section{VARIA}

\section{5-7. Lekythos}

Beilage 22, 4.

G 5. Aus Süditalien. Erworben I 868 von Richard Knabl, Schenkung. Ehemals Slg. Richard Knabl (Graz). Alte Inv.-Nr. IV I (Schenkl) bzw. III I I (Pichler).

H 7,7 cm. - Dm Körper 3,4 cm. - Dm Boden 2,6 cm. - Dm Henkel o,7 cm. - Wandstärke 0,2 cm. - Gewicht 49 g.

Essenwein, Katalog, 27 Nr. 2 I 4. - Karl, Richard Knabl, 30 I Nr. I. - Karl, Knabl, 8 I f. Kat. I Taf. I.

Zustand: Ein Teil des Halses und die Mündung fehlen. Sinterreste an der Unterseite des Fußes sowie an einer Seite am Fuß, Körper, Hals und Henkel. An der Unterseite des Fußes Reste von Klebelack. Die Klebemarke ist abgelöst, ein Zettel mit Schnur war um den Henkel gehängt. Pinselspuren an der Außenkante des Henkels, unter dem Henkelansatz sowie am Körper.

Technik: Bemalung sehr flüchtig ausgeführt. Schwarzer Tonschlicker flüchtig und teilweise nicht deckend aufgetragen. Farbe des Malschlickers (Bauch): schwarz (5 Y 2.5/I, black). Unterer Teil des Stieles teilweise mit schwarzem Schlicker verwischt. Keine Deckfarben. Die Bemalung wirkt durch den dünnen Auftrag und den Brand stellenweise dunkelbraun bis dunkelorange. An der zylindrischen Fußzone Tonkleckse. Der Henkel wurde in den Tonschlicker eingetaucht. Rote Lasur: auf der ganzen Fläche, damit der Tongrund braun-rötlich wirkt.

Form: Flacher Scheibenfuß, auf der Gefäßunterseite eine konzentrische Rille, auf der Außenseite eine kräftige Rille. Über dem Fuß eine hohe, annähernd zylindrische Zone. Ovaler Körper mit abgesetzter Schulter, eingezogene Halszone. Unterhalb der Schulter und am Hals angesetzter Bandhenkel mit langovalem Querschnitt.

Dekor: Fuß auf der Außenseite mit schwarzem Tonschlicker versehen. Stiel und unterster Bauchansatz tongrundig. Auf dem Körper rautenförmiges Netzmuster, unten von einem breiten Band und oben von einer dünnen Linie und einem breiteren Band, das über den Schulterknick führt, begrenzt. Um den unteren Henkelansatz schwarz bemalt. Um den Hals Stabband. Obere Hälfte des Henkels innen und außen schwarz bemalt.

\section{Zweite Hälfte 4. Jh. - Apulisch-lukanisch}

Zur Erwerbung: siehe G 6, hier Tafel 66, I-4.

Zur Form: Allgemein zu den unteritalischen Netzlekythoi siehe R. Hurschmann, Unteritalische Netzlekythoi, AA I 995, 667-69I. - E. Lanza, Vasi a reticolo della collezione Moschini al museo di antiquità di Torino: Riflessioni sulla storia del collezionismo e su une classe ceramica. Quaderni soprintendenza Archeologica del Piemonte 20, 2004, 2I-52. Anhand der Gattung gehört die Grazer Lekythos zu der apulisch-lukanischen Hauptgruppe der Formvariante c (IVc), vgl. Hurschmann a. O. 684-686. Lekythoi dieser Kategorie besitzen einen Standring mit hohem Vasenstiel, gerundetem Körper und Mündungstrichter. Die Grazer Lekythos besitzt einen ovalen Körper, ähnlich wie die Beispiele bei Hurschmann a. O. 684 Nr. 25-29 (Parma C I46; Rennes 32.8.I Io; Genua 3534; Münster, Privatbesitz; Bari, aus Goia del Colle, Grab 3). Die Form des Körpers mit dem verhältnismäßig hohen Stiel ähnelt vor allem der Lekythos in St. Gallen, 450/I.9: CVA Ostschweiz Ticino Taf. I3, I6; Hurschmann a. O. 684 Nr. 20. Aus der Nekropole von Tarent stammen auch eine Reihe von Netzlekythoi mit langovalen Körpern und Füßen mit hoher Einziehung, vgl. Hoffmann, Grab- ritual, 3 I f. Typen I I I/I 30-I 35. Das Grazer Exemplar zeigt Ähnlichkeiten zum Typ I I I/I32 Taf. 48.

Zum Dekor: Der Dekor der Grazer Lekythos ist flüchtig ausgeführt, ähnlich wie die Netzlekythos im Museo Civico di Bassano del Grappa: S. Fozzer, La ceramica attica e italiota sovraddipinta, i vasi a reticolo; in: G. Andreassi u. a. (Hrsg.), Ceramica sovraddipinta. Ori, Bronzi, Monete della collezione Chini nel Museo Civico di Bassano del Grappa (Rom I995) 27 Nr. I.I.I I (476). Die Entstehung des Motivs ist nicht mit Sicherheit bezeugt. Der Netzdekor stammt eventuell von den Netzen, die Athleten in der Palästra verwendeten, um ihre Lekythoi zu transportieren oder aufzuhängen. Oder das Netz ist ein Muster, das den Bast, um Gefäße aus Glas zu schützen, imitierte. Bemerkenswert ist, dass diese Dekoration nur Gefäße für Öl bzw. Parfum betrifft, vgl. J. R. Green, Gnathia and Other Overpainted Wares of Italy and Sicily: a Survey, in: P. Lévêque - J. P. Morel (Hrsg.), Céramiques hellénistiques et romaines (Paris 200I) 60; vgl. Lanza, Torino, 77; G. Pianu, La necropoli meridionale di Eraclea. Le tombe di secolo IV e III a. C. (Rom I990) 72. Mündung und Henkel der Netzlekythoi sind durchwegs getaucht, siehe J. D. Beazley, Miniature Panathenaics, BSA 4I, I940-I945, I7. In der Nekropole von Policoro ist außer der Lekythos die Flasche die einzige Form, auf der Netzdekor vorkommt (Unguentario di bottiglia), vgl. Pianu a. O. 73 Anm. 9. Mit Netzdekor werden auch Lekythoi, Flaschen und etwas seltener Alabastra im Gnathia-Stil versehen, inspiriert wahrscheinlich von dieser Gattung, vgl. Lanza, Torino, 77-84, sowie die Beispiele dazu: CVA Napoli, Museo Nazionale 3, IV E Taf. 69, IO-I2 (80968; Sant. I389); 69, I 5 (80969); Fozzer a. O. 29-3 I: Bernardini, Lecce, Taf. 46, 5-6; 50, I-5.

Zum Typ: Bauchlekythoi sowie Alabastra und seltener Amphoriskoi mit Netzdekor wurden ursprünglich in Athen produziert. Die Gefäße dieser Gattung, auch Bulas-Gruppe benannt, wurden im 4. Jh. hergestellt. Allgemein zu den attischen Exemplaren siehe Beazley a. O. I7-2 I; C. Bulas, Étude sur une classe de vases a décor, $\mathrm{BCH}$ 56, I932, 388-398; CVA Erlangen 2 Taf. 45, 4; ABL, I67-169 Anm. 3; D. M. Robinson, Excavations at Olynthus V (Baltimore I933) I 8 I-I 85 Nr. 474-504 Taf. I46-I47; D. M. Robinson, Excavations at Olynthus XIII (Baltimore I950) I60-I67 Nr. I64-I94 Taf. I02. I07-I08. Der Dekor bei den attischen Netzlekythoi umfasst den ganzen Körper des Gefäßes. Netzlekythoi sind im gesamten Raum Süditaliens verbreitet. Der Typ unserer Netzlekythos wurde am meisten in Apulien gefunden, vor allem in Tarent und Umgebung, aber auch in Lukanien und Kampanien, vgl. Hurschmann a. O. 667 f. 684. Netzlekythoi gehören hauptsächlich zum Grabinventar, in Siedlungen bzw. Heiligtümern wurden sie dagegen nur vereinzelt gefunden. Netzlekythoi der apulischlukanischen Hauptgruppe (Kategorie IV), zu der das Grazer Exemplar gehört, finden sich in Ostlukanien und Apulien. Gefäße dieser Gruppe sind zusammen mit dem apulisch-unteritalischen Haupttyp (Kategorie II) die größten Vertreter der Gattung. Bei den qualitativ hochwertigsten Beispielen dieser Gruppe wurden auch weiße Punkte aufgebracht, vgl. Hurschmann a. O. 690. Zu unterschiedlichen Produktionsstätten in Süditalien siehe CVA Ostschweiz Ticino I6.

TAFEL 79 
TAFEL 80

1. Siebe Tafel 22, 1-4.

2. Siehe Tafel 23, 1-4.

\section{TAFEL 81}

1-2. Siehe Tafel 71, 1-3.

1-2. Siehe Tafel 69, 1-6.
TAFEL 83

\section{TAFEL 84}

1. Siehe Tafel 32, 6.

2. Siehe Tafel 48, 1-4.

\section{TAFEL 82}

1. Siebe Tafel 44, 1-2. 


\section{VERLUSTE}

\section{ZYPRISCH BRONZEZEITLICH}

\author{
Kugelschale \\ G 2I I. Aus „Cypern“. Erworben I940. \\ Dm I I, $8 \mathrm{~cm}$. \\ Unpubliziert. \\ Älteres Inventarbuch: „Kugelschale, außen roter Überzug, D \\ I I 8 . “
}

Wahrscheinlich Red Polished Ware, Frühzyprisch II - Mittelzyprisch II, 2075-I725

$\mathrm{Zu}$ Technik und Form: Vermutlich eine halbkugelige Schale der Red Polished Ware, wie G 2 I 2, Tafel I, I-4, Beilage I, I. Bei diesem Stück aber nicht, wie bei G 2 I2, „pol.“ (poliert?) angegeben.

\section{ATTISCH SCHWARZFIGURIG}

\section{Halsamphora}

Beilage 22, 5 .

G I 3 a. Fundort unbekannt. Erworben I 872 von Adolf Wünsch (Triest), Ankauf. Alte Inv.-Nr. II I7 (Schenkl) bzw. III 2I (Pichler). $\mathrm{H}$ I $7 \mathrm{~cm}$.

Unpubliziert.

Älteres Inventarbuch: „Schwarzfig. Amphora, o, I7 m h. Mündung innen und außen schwarz gefirnißt, ebenso die zweigeteilten
Henkel u. Fuß. Lippe rot. Hals, gegenständige Palmette, Schulter, Stabornament. Auf d. unteren Teil d. Gefäßkörpers Strahlen. Bauch geschmückt mit umlaufender bakchischer Szene: in d. Mitte Dionysos n. r. schreitend mit zurückgewandtem Kopf, in langem Chiton und Mantel, Füllhörner in d. Händen. Rechts u. links je e. ihm zugewandte Mänade auf ithyphall. Maultier, dann je ein ithyph. Satyr u. hierauf wieder e. Mänade auf ithyph. Maultier. Innenzeichnung geritzt, vereinzelt auch Konturen. Aufgesetztes Weiß. Spätes, schlechtes Stück.“

\section{ATTISCHE GLANZTON-WARE}

\section{Näpfchen}

\section{Beilage 22, 6.}

G I9 a. Fundort unbekannt. Erworben kurz vor I $875 / 76$. Alte Inv.-Nr. III 26 (Pichler).

$\mathrm{H} 2,4 \mathrm{~cm}$. - Dm Mündung $6 \mathrm{~cm}$.

Unpubliziert.

Älteres Inventarbuch: „Kleiner, schwarzgefirnißter, fuß- und henkelloser Napf. Höhe o,024 m. Durchm. 0,06 m.“
Form: Henkelloses Näpfchen der „Schüsselform“ mit konvexer Wandung und ohne Standring.

Mitte 5. Jh.

Zur Form: vgl. die Näpfchen von der Agora und vom Kerameikos: Agora XII, I 36 Nr. 899-920 Abb. 9 Taf. 34 (saltcellar, echinus wall); Kerameikos IX, 5I f. Abb. 20 (= Nr. 99, 2). Ähnlichkeiten zeigt das Grazer Exemplar mit den Näpfchen Kerameikos IX, I I I Nr. 94, 3; I I 3 Nr. 99, 2; I 20 Nr. I 28, 7; I 28 Nr. I62, 6; I 33 Nr. I94, 3 Taf. 82, I-2. 
VERZEICHNISSE

\section{KONKORDANZ: INVENTARNUMMERN - TAFELN - BEILAGEN - ABBILDUNGEN}

\begin{tabular}{|c|c|}
\hline G 1 & Tafel 49, 1-3 \\
\hline G 2 & Tafel 75,$4 ; 76,1-6$ \\
\hline G 5 & Tafel 78, 5-7 \\
\hline G 6 & Tafel $66,1-4$ \\
\hline G 7 & Tafel $66,5-8$ \\
\hline G 8 & Tafel 74, 1-4 \\
\hline G 9 & Tafel 74, 5-7 \\
\hline G 10 & Tafel 75, 1-3 \\
\hline G 11 & Tafel $68,1-8$ \\
\hline G 12 & Tafel $77,1-3$ \\
\hline G $13 \mathrm{a}$ & \\
\hline G 14 & Tafel 67,1 \\
\hline G 15 & Tafel $67,2-4$ \\
\hline G 16 & $\begin{array}{l}\text { Tafel } 69,1-6 ; 70,1-10 ; \\
\quad 83,1-2\end{array}$ \\
\hline G 17 & Tafel $32,1-5$ \\
\hline G 18 & Tafel 31, 1-4 \\
\hline G 19 a & \\
\hline G 20 & Tafel $40,1-2 ; 41,1-4$ \\
\hline G 21 & Tafel $42,1-2 ; 43,1-5$ \\
\hline G 22 & Tafel $52,5-6 ; 53,1-4$ \\
\hline G 23 & Tafel $51,1-3 ; 52,1-4$ \\
\hline G 24 & Tafel $57,4-5 ; 58,1-3$ \\
\hline G 25 & $\begin{array}{c}\text { Tafel } 71,1-3 ; 72,1-2 ; \\
73,1-5 ; 84,1-2\end{array}$ \\
\hline G 26 & Tafel $27,1-4 ; 28,1-3$ \\
\hline G 27 & $\begin{array}{c}\text { Tafel } 23,1-4 ; 24,3-4 ; \\
26,1-3 ; 80,2\end{array}$ \\
\hline G 28 & $\begin{array}{c}\text { Tafel } 22,1-4 ; 24,1-2 ; \\
25,1-3 ; 80,1\end{array}$ \\
\hline G 29 & Tafel 38, 1-2; 39, 1-4 \\
\hline G 30 & $\begin{array}{c}\text { Tafel } 44,1-2 ; 45,1-2 ; \\
46,1-6 ; 82,1\end{array}$ \\
\hline G 31 & Tafel $65,1-6$ \\
\hline G 32 & Tafel 64, 1-3 \\
\hline G 33 & Tafel 59, 3-4. 7 \\
\hline G 34 & Tafel 59, 1-2. 5-6 \\
\hline G 35 & $\begin{array}{l}\text { Tafel } 32,6 ; 33,1-3 ; \\
\qquad 34,1-5 ; 81,1\end{array}$ \\
\hline G 36 & Tafel $48,1-4 ; 50,1 ; 81,2$ \\
\hline G 37 & Tafel 48, 5-7; 50, 2 \\
\hline G 38 & Tafel 31, 5-7 \\
\hline G 39 & Tafel 49, 4-9; 50, 3-5 \\
\hline G 40 & Tafel 47, 3-8 \\
\hline G 41 & Tafel 29, 1-6 \\
\hline $\mathrm{G} 42.42 \mathrm{a}$ & Tafel 12, 1-7 \\
\hline G 43 & Tafel 13, 5-8 \\
\hline G 44 & Tafel 10, 1-5 \\
\hline G 45 & Tafel 60, 5-6 \\
\hline G 46 & Tafel $60,7-8 ; 61,7$ \\
\hline
\end{tabular}

\begin{tabular}{|c|c|c|c|}
\hline Beilage 14, 3 & & G 47 & Tafel 61, 1-2. 6 \\
\hline Beilage 22, 1 & & G 48 & Tafel 61, 3-5 \\
\hline Beilage 22, 4 & & G 49 & Tafel 60, 3-4 \\
\hline Beilage 20,1 & & G 50 & Tafel 78, 1-4 \\
\hline Beilage 20, 2 & & G 51 & Tafel $60,1-2$ \\
\hline Beilage 21,2 & & G 52 & Tafel $62,1-4 ; 63,1-2$ \\
\hline Beilage 21, 3 & & G 53 & Tafel 17, 4-6 \\
\hline Beilage 21,4 & & G 54 & Tafel 37, 1-2 \\
\hline Beilage 20, 4 & & G 56 & Tafel 30, 1-4 \\
\hline Beilage 22, 2 & & G 57 & Tafel 6, 1-6 \\
\hline Beilage 22, 5 & & G 75 & Tafel $63,5-7$ \\
\hline Beilage 20, 3 & & G 90 & Tafel 15, 1-4 \\
\hline Beilage 20, 5 & & G 91 & Tafel $11,1-4$ \\
\hline Beilage 20, 6 & & G 95 & Tafel $14,3-4$ \\
\hline & & G 96 & Tafel 7, 4-5 \\
\hline Beilage 9, 4 & & G 97 & Tafel 9, 3-6 \\
\hline Beilage 9,1 & & G 98 & Tafel $17,1-3$ \\
\hline Beilage 22, 6 & & G 99 & Tafel 7, 1-3 \\
\hline Beilage 11,1 & & G 100 & Tafel $8,1-3$ \\
\hline Beilage 12,1 & & G 102 & Tafel $35,1-3 ; 37,3$ \\
\hline Beilage 15,1 & & G 103 & Tafel 35, 4-6 \\
\hline Beilage 14,5 & & G 104 & Tafel 36, 1-3; 37, 4 \\
\hline Beilage 16,1 & & G 105 & Tafel 36, 4-7 \\
\hline Beilage 21,1 & & G 106 & Tafel $37,5-7$ \\
\hline & & G 107 & Tafel $63,3-4$ \\
\hline Beilage 8,1 & & G 194 & Tafel 53,$5 ; 54,1-3 ; 55,1$ \\
\hline Beilage 7,3 & & G 195 & Tafel 61,8 \\
\hline & & G 196 & Tafel 56, 3-5 \\
\hline Beilage 7,2 & & G 197 & Tafel $57,1-3$ \\
\hline & & G 198 & Tafel $55,2-3 ; 56,1-2$ \\
\hline Beilage 10,1 & & G 199 & Tafel 58, 4-6 \\
\hline Beilage 13,1 & & G 200 & Tafel 47, 1-2 \\
\hline & & G 208 & Tafel 4, 1-5 \\
\hline Beilage 19,3 & & G 209 & Tafel 5, 1-5 \\
\hline Beilage 19,4 & Abb. 20 & G 210 & Tafel 3, 1-6 \\
\hline Beilage 16,3 & & G 212 & Tafel $1,1-4$ \\
\hline Beilage 16,2 & & G 238 & Tafel 19, 1-2; 20, 1-3; \\
\hline Beilage 9, 2 & & & $21,1-4$ \\
\hline & & G 718 & Tafel 9, 1 \\
\hline Beilage 14,1 & & G 719 & Tafel $13,1-2$ \\
\hline Beilage 14,2 & & G 726 & Tafel 16, 1 \\
\hline Beilage 9, 3 & & G 729 & Tafel 13, 3-4 \\
\hline Beilage 14,4 & & G 730 & Tafel 9, 2 \\
\hline Beilage 13, 3 & & G 733 & Tafel 14, 1-2 \\
\hline Beilage 8,2 & & G 741 & Tafel 11, 5-6; 79, 1-2 \\
\hline Beilage 4, 2 & & G 749 & Tafel 16, 2-3 \\
\hline Beilage 5,1 & & G 766 & Tafel 18, 1-2 \\
\hline Beilage 3, 4 & Abb. 6 & G 1038 & Tafel 17, 7-8 \\
\hline Beilage 17,3 & & G 1382 & Tafel $18,3-8$ \\
\hline Beilage 17,4 & & G 2046 & Tafel 2, 1-5 \\
\hline
\end{tabular}

Beilage 18, 1 Beilage 18, 2 Beilage 17, 2 Beilage 22, 3 Beilage 17, 1 Beilage 18, 4 Beilage 6, 4 Beilage 9, 8 Beilage 8, 3 Beilage 1, 6 Beilage 19, 2 Beilage 5, 4 Beilage 3, 5 Beilage 5, 3 Beilage 2, 2 Beilage 3, 2 Beilage 6, 3 Beilage 2, 1 Beilage 2, 3 Beilage 9, 5 Beilage 9, 6 Beilage 9, 10 Beilage 9, 9 Beilage 9, 7 Beilage 19, 1 Beilage 15, 2 Beilage 18, 3 Beilage 15, 4 Beilage 15, 5 Beilage 15, 3 Beilage 15, 6 Beilage 13, 2 Beilage 1, 4 Beilage 1, 5 Beilage 1, 3 Beilage 1, 1 Beilage 7, 1

Beilage 3, 1 Beilage 4, 3 Beilage 6, 1 Beilage 4, 4 Beilage 3, 3 Beilage 5, 2 Beilage 4, 1 Beilage 6, 2 Beilage 6, 6 Beilage 6, 5 Beilage 6, 7 Beilage 1, 2
Abb. 19

Abb. 12

Abb. 2

Abb. 5

Abb. 1

Abb. 3 Abb. 9 Abb. 13 Abb. 10 Abb. 4 Abb. 11 Abb. 7-8 Abb. 14 Abb. 17 Abb. 15-16 Abb. 18 


\section{KONKORDANZ: ALTE UND AKTUELLE INVENTARNUMMERN}

\begin{tabular}{|c|c|c|}
\hline Schenkl (1866-1875) & Pichler (1875/76) & Inventar G (1911/12) \\
\hline \multicolumn{3}{|l|}{$1865 / 66$} \\
\hline II 1 & III 1 & G 1 \\
\hline II 3 & \multicolumn{2}{|c|}{ Verlust: „Große Schüssel mit Verzierungen (Athen)“ } \\
\hline II 4 & \multicolumn{2}{|c|}{ Verlust: „Kleineres Töpfchen mit Deckel (Athen)“ } \\
\hline II 5 & \multicolumn{2}{|c|}{ Verlust: „Kleines Alabastron“ } \\
\hline \multicolumn{3}{|l|}{$1866 / 67$} \\
\hline II 10 & III 10 & G 54 \\
\hline \multicolumn{3}{|l|}{$1867 / 68$} \\
\hline IV 1 & III 11 & G 5 \\
\hline IV 2 & III 12 & G 6 \\
\hline IV 3 & III 13 & G 7 \\
\hline IV 4 & III 14 & G 8 \\
\hline IV 5 & III 17 & G 11 \\
\hline IV 6 & III 23 & G 15 \\
\hline IV 7 & III 18 & G 14 \\
\hline IV 8 & III 19 & G 12 \\
\hline IV 9 & III 15 & G 9 \\
\hline IV 10 & III 16 & G 10 \\
\hline \multicolumn{3}{|l|}{$1868 / 69$} \\
\hline II 11 & III 20 & G 53 \\
\hline \multicolumn{3}{|l|}{$1871 / 72$} \\
\hline II 17 & III 21 & G 13 a (Verlust) \\
\hline II 18 & III 22 & G 16 \\
\hline \multicolumn{3}{|l|}{$1872 / 73-1873$} \\
\hline II 19 & III 27 & G 20 \\
\hline II 20 & III 28 & G 21 \\
\hline II 21 & III 29 & G 22 \\
\hline II 22 & III 30 & G 23 \\
\hline II 23 & III 31 & G 24 \\
\hline II 24 & \multicolumn{2}{|c|}{ Verlust: „Kantharos in Calvi gekauft“ } \\
\hline
\end{tabular}

\begin{tabular}{|c|c|c|c|}
\hline Schen & $1(1866-1875$ & Pichler (1875/76) & Inventar G (1911/12) \\
\hline & II 25 & Verlust: „Kleine Lekyt & aus Athen“ \\
\hline & II 26 & III 24 & G 17 \\
\hline & II 27 & III 25 & G 18 \\
\hline 1874 & & & \\
\hline & II 28 & III 43 & G 31 \\
\hline & II 29 & III 39 & G 26 \\
\hline & II 30 & III 37 & G 30 \\
\hline & II 31 & III 36 & G 29 \\
\hline & II 32 & III 40 & G 51 \\
\hline
\end{tabular}
bei Bolsena"

\begin{tabular}{|c|c|c|}
\hline II 34 & III 44 & G 32 \\
\hline II 35 & III 34 & G 27 \\
\hline II 36 & III 35 & G 28 \\
\hline II 37 & III 41 & G 56 \\
\hline II 38 & Verlust: „Ganz kleine Lekythos“ & \\
\hline II 39 & III 33 & G 25 \\
\hline \multicolumn{3}{|l|}{1875} \\
\hline II 46 & III 46 & G 33 \\
\hline II 47 & III 47 & G 34 \\
\hline II 48 & III 48 & G 35 \\
\hline II 49 & III 49 & G 36 \\
\hline II 50 & III 50 & G 37 \\
\hline II 51 & III 51 & G 38 \\
\hline II 52 & III 52 & G 39 \\
\hline II 53 & III 53 & G 40 \\
\hline II 54 & III 54 & G 41 \\
\hline II 55 & III 55 & G 42/42 a \\
\hline II 56 & III 56 & G 43 \\
\hline II 57 & III 57 & G 44 \\
\hline
\end{tabular}

\section{MALER, WERKSTÄTTEN, GRUPPEN, KLASSEN}

$\begin{array}{ll}\text { Aigisthos-Gruppe } & \text { G } 25 \\ \text { Alkimachos-Maler } & \text { G } 20 \\ \text { Amphorae-Gruppe } & \text { G } 15 \\ \text { Athena-Malers, Werkstatt des } & \text { G } 38 \\ \text { Base-Ring Ware } & \text { G } 57 \\ \text { Beldam-Malers, Werkstatt des } & \text { G 54, G } 106 \\ \text { Berliner Maler } & \text { G 30 } \\ \text { Beth-Pelet-Maler } & \text { G } 1 \\ \text { Bowdoin-Maler } & \text { G 36 } \\ \text { Brüssel R 224, Maler von } & \text { G 28 } \\ \text { Brüssel R 330, Maler von } & \text { G 23 } \\ \text { CA-Maler/Walters-Untergruppe } & \text { G 16 } \\ \text { Chevron-Gruppe, Umkreis der } & \text { G } 6 \\ \text { Dipylon-Meisters, Werkstatt des } & \text { G 741 } \\ \text { Epeleios-Maler, verwandt mit dem } & \text { G 22 } \\ \text { Erlenmeyer-Maler } & \text { G 27 } \\ \text { Kentauren im Britischen Museum, Gruppe des } & \text { G } 11 \\ \text { Hahnengruppe } & \text { G } 102\end{array}$

Haimon-Malers, Werkstatt des

Kalliope-Maler

Karlsruhe-Maler

Klinik-Maler, nahe dem

Konnakis-Gruppe

Louvre G 265, Maler von

Montlaurès-Maler

Panthervogel-Gruppe

Red Polished Ware

Red Polished Black-Topped Ware

Sabouroff-Maler

Sandalen-Maler

Vatikan G 49, Gruppe des Malers von

White Painted Ware

White Slip Ware

Widderkanne, Maler der

Yale Lekythos, Maler der

Winterthur-Gruppe/Zürich-2660-Gruppe

G 103, G 104, G 105
G 24
G 198
G 12
G 194
G 197
G 26
G 212, G 2046
G 212
G 21
G 35
G 38
G 208, G 210
G 209
G 1038
G 29
G 7




\section{FUNDORTE, SAMMLUNGEN, VORBESITZER}

$\begin{array}{ll}\text { Aigina } & \text { G } 1038 \\ \text { Athen } & \text { G 1, G 17, G 18, G 42/42 a, G 43, } \\ & \text { G 44, G 53, G 54, G 195, G 729, } \\ & \text { G 730, G 741 } \\ \text { Attika } & \text { G 33, G 34, G 38, G 39, G 40, G 96, } \\ & \text { G 98, G 100 } \\ \text { Böotien } & \text { G 41 } \\ \text { Capua } & \text { G 2, G 20, G 21, G 22, G 23, G 24, } \\ & \text { G 27, G 28, G 29, G 30, G 51, G 56 } \\ \text { Chiusi } & \text { G 31 } \\ \text { Grotta di Castro bei Bolsena } & \text { G 32 } \\ \text { Kalyvia Kouvara (Ostattika) } & \text { G 90, G 97 } \\ \text { Kyme (Kampanien) } & \text { G 26 } \\ \text { Orvieto } & \text { G 197 } \\ \text { Tanagra } & \text { G 36, G 37 } \\ \text { Thesbe (Böotien) } & \text { G 35 } \\ \text { Süditalien } & \text { G 5, G 6, G 7, G 8, G 9, G 10, G 11, } \\ \text { Zypern } & \text { G 12, G 14, G 15 } \\ \text { Scherbensammlung des NM } & \text { G 208, G 209, G 210, G 212 } \\ \text { Athen } & \text { G 99, G 718, G 719, G 726, G 749, } \\ & \end{array}$

Tausch mit dem NM Athen

Slg. Simmaco Doria (Santa Maria Capua Vetere) Slg. Theodor von Heldreich (Athen)

Slg. Richard Knabl (Graz)

Slg. Hans von Prott (Athen)

Slg. Athanasios Rhousopoulos (Athen)

Franz von Aigner (Graz)

Karin Gether (Graz)

Maximilian Theodor von

Karajan (Graz)

Principe F. de Liguori

Friedrich Pichler (Graz)

Fritz Schachermeyr (Graz)

Adolf Wünsch (Triest)

Josef von Zahn (Graz)

\author{
G 90, G 91, G 95, G 96, G 97, G 98, \\ G 100, G 102, G 103, G 104, G 105, \\ G 106, G 107 \\ G 27, G 28, G 29, G 30, G 51, G 6 \\ G 1, G 53 \\ G 5, G 6, G 7, G 8, G 9, G 10, G 11, \\ G 12, G 14, G 15 \\ G 195, G 729, G 730, G 1038 \\ G 33, G 34, G 36, G 37, G 38, G 39, \\ G 40, G 41, G 42/42 a, G 43, G 44 \\ G $17, \mathrm{G} 18$ \\ G 2046 \\ G 54 \\ G 16 \\ G 53 \\ G 1382 \\ G 13 a \\ G 1
}

\section{INSCHRIFTEN: DIPINTI UND GRAFITTI}

$\mathrm{KA} \Lambda \mathrm{O} \Sigma$

$\mathrm{KA} \Lambda \mathrm{H}$

\author{
G 22, G 23 \\ G 23
}

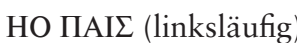

ПI (zwei Mal)
G 22

G 40

\section{DARSTELLUNG}

\begin{tabular}{ll} 
Abschiedsspende & G 30 \\
Ägis & G 25 \\
Alabastron & G 36 \\
Ast, gegabelt & G 105 \\
Athlet(en) & G 105, G 194 \\
Amazone & G 2 \\
Andreaskreuz & G 11 \\
Ariadne & G 25 \\
Athena & G 25, G 38, G 103 \\
Ärmelchiton & G 20, G 29, G 30, G 194 \\
Band, Binde & G 11, G 16, G 22, G 25, G 39 \\
Bart Backen-/Kinnbart & G 25, G 28, G 29 \\
\multicolumn{1}{c}{ Schnurrbart } & G 29 \\
Blattkranz & G 22, G 24, G 198 \\
Bouphonia & G 38 \\
Boxer & G 35 \\
Chiton & G 1, G 2, G 11, G 16, G 21, G 23, G 25, \\
& G 29, G 35, G 36, G 104, G 194 \\
Demeter & G 30 \\
Diadem & G 11, G 15, G 16, G 25, G 28, G 30 \\
Dionysos & G 38 \\
Dipoleia & G 38 \\
Dipylonschild, siehe Schild & \\
Dreigespann & G 103 \\
Dreizack & G 29 \\
Efeu, -zweig, -blätter, -früchte & G 11, G 12, G 50 \\
Ente(n), siehe Vogel & G 11, G 39 \\
Eros & \\
&
\end{tabular}

\begin{tabular}{|c|c|}
\hline Fackel(n) & G 20, G 30 \\
\hline Felsen & G 11, G 16, G 25 \\
\hline Fenster & G 11, G 16 \\
\hline Flügel & $\begin{array}{l}\text { G 1, G 11, G 16, G 26, G 28, G 39, } \\
\text { G 194, G 199, G } 238\end{array}$ \\
\hline Flügelfrau & G 1, G 16, G 20, G 194 \\
\hline Flügelrad, -wagen & G 30 \\
\hline Fransen & G 23, G 39 \\
\hline Frau & G 196 \\
\hline leierspielend & G 104 \\
\hline laufend & G 21, G 23, G 194 \\
\hline sitzend & G 11, G 105 \\
\hline stehend & G 16, G 21 \\
\hline Frauenbüste & G 40 \\
\hline Frauengemach & G 36 \\
\hline Frauenkopf & G 6, G 7, G 15, G 16 \\
\hline Früchte & G 16, G 38, G 104, G 105 \\
\hline Gans, siehe Vogel & \\
\hline Grabstele & G 16 \\
\hline Granatapfel & G 16 \\
\hline Griff & G 20 \\
\hline Haarband & $\begin{array}{l}\text { G 20, G 21, G 40, G 104, G 105, G 196, } \\
199\end{array}$ \\
\hline Haarknoten & G 20, G 39, G 104, G 199 \\
\hline Haarreif & G 23, G 29, G 194 \\
\hline Haarschopf & G 20, G 40, G 194 \\
\hline Halsschmuck & G 30 \\
\hline
\end{tabular}




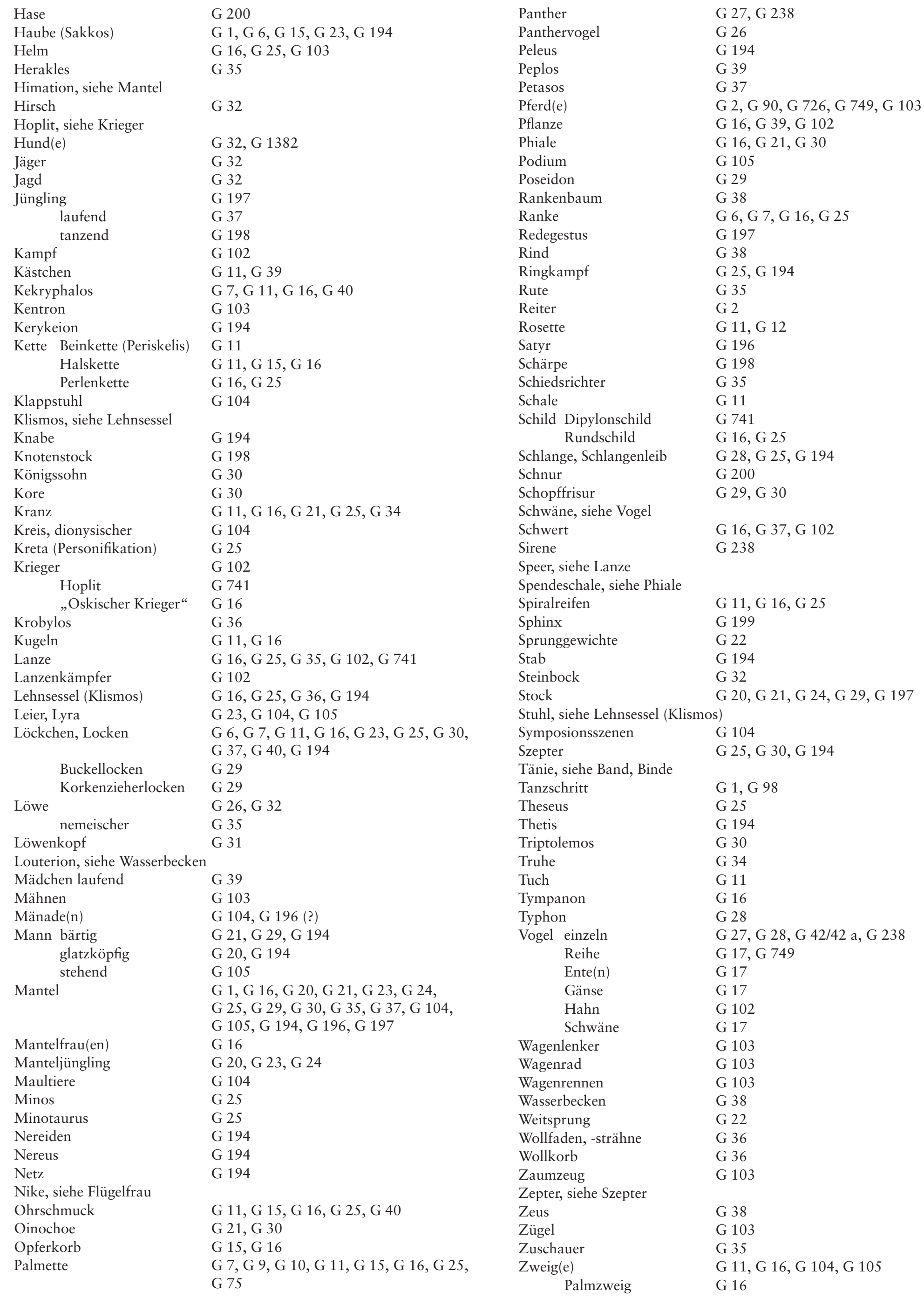




\section{DEKOR}

Band

Blatt, lanzettförmig

Blattrosette (Metope)

Doppelaxt (Füllornament)

Doppelaxt-Strichgruppen-Fries

Efeuzweige

Gekritzel fünf- und mehrstrichig

Gitterband

Hakenmäander

Henkelpalmette

Hundszahn

Halbkreise konzentrisch

Keile

Kerbmuster

Kreis(e) Unterseite

Kymation/Eierstab

Leitermuster

Linie horizontal

vertikal

einfach,

im rechten Winkel kreuzend

parallel, mehrfach,

im rechten Winkel kreuzend

Lotosblüten

-Derivat

Löwenkopfrelief(s)

Mäander

\section{schraffiert}

Medaillon

Netzdekor

Palmetten

Parallel-Zickzack

Punkt Unterseite weiß aufgesetzt

Punktmuster

Punktreihe

Punktrosette einzeln mit Punktkette

Ranken

Rautenband, einfach
G 40, G 104, G 200

G 1038

G 42/42 a

G 719, G 741

G 100

G 105

G 26

G 105

G 41, G 56

G 196, G 197, G 198

G 100, G 718

G 99

G 197

G 31, G 2046

G 2, G 18, G 23, G 24, G 196, G 199

G 11, G 12, G 34, G 200

G 209

G 208, G 209, G 210

G 208, G 209

G 209

G 208, G 210

G 52

G 27

G 31

G 1, G 20, G 21, G 24, G 29,

G 30, G 34, G 36, G 37, G 194,

G 196, G 197, G 198, G 199

G 44, G 730

G 2

G 5

G 34, G 36, G 52, G 106

G 718

G 18, G 23, G 24, G 199

G 27, G 28

G 103, G 104, G 105, G 200

G 26, G 27, G 43, G 49, G 719,

G 729, G 741

G 42/42 a, G 44, G 91, G 1382

G $42 / 42$ a

G 34

G 209 gegittert

Rautenkette mit Innenpunkten

Riefelung

Rollrädchendekor

Rosette

zwölf und mehr Strahlen mit Innenkreis

Sanduhr

mit Sichelstrahlen

Schachbrettmuster

Schuppenmuster

Sichelwirbel

Speichenrad

Stabband

Stempeldekor

Stempelkreise

Stern achtzackig 16-zackig

Strahlenkranz

Streifen, wellig

Strichmuster

Strichgruppen diagonal vertikal am Rand

Swastika Füllornament schraffiert schraffiert, mit zusätzlichen Haken

Tangentenkreiskette

Tangentenkleckskette

Tropfleiste

Tupfen

Vogelaugen (?)

Voluten

Wellenband

Winkel M-förmig vertikal

Wolfszahn, siehe Hundszahn

Zickzack einfach gegittert mehrfach schraffiert

Zungenband, -muster
G 209

G 719, G 729

G 2, G 8, G 46, G 47, G 49, G 50

G 46, G 47, G 48

G 12

G 26, G 28, G 238

G 27

G 91, G 99

G 719, G 729

G 1382

G 26

G 95

G 6, G 7

G 47

G 75

G 42/42 a, G 97

G 43

G 1, G 37, G 104, G 238

G 17

G 6, G 7, G 16, G 18, G 36, G 38

G 209, G 210

G 209

G 43, G 44, G 1038

G $42 / 42$ a

G 733

G 729

G 42/42 a

G 42/42 a

G 35

G 18

G 208

G 52, G 196, G 197

G 11, G 15, G 16, G 98, G 107

G 44, G 733

G 97, G 107

G 208

G 208

G 208, G 210

G 719

G 26, G 27, G 28, G 105, G 1382

\section{TECHNISCHE BESONDERHEITEN}

$\begin{array}{ll}\text { Abdruck (Vertiefung) } & \text { G 9, G } 10 \\ \text { Ansatzstelle eines zweiten Gefäßes } & \text { G } 57 \\ \text { Blasen in der Gefäßwand } & \text { G } 57 \\ \text { Delle } & \text { D 2, D 718 } \\ \text { Eintauchen } & \text { G 6, G 7, G 8, G 14 } \\ \text { Fehlbrand } & \text { G 15, G 28, G 30, G 33, G 34, G 43, } \\ & \text { G 50, G 75, G 90, G 107, G 238 } \\ \text { Fingerabdruck } & \text { G 25, G 50 } \\ \text { Form Granatapfel } & \text { G 56 } \\ \quad \text { Stierkopf } & \text { G 44 } \\ \text { Hornartige Fortsätze } & \text { G 2046 } \\ \text { Kammpinsel } & \text { G 44, G 766 } \\ \text { Negativer Stempeldekor } & \text { G 9, G } 10 \\ \text { Negativform } & \text { G 56 }\end{array}$

Pinselspuren

Politur

Reliefband

Rinnspur

Rippen

Sekundär verbrannt

Verfärbung

Verwischung

Vorzeichnung

Zirkel geritzt zentrierter Kammpinsel
G 6, G 7, G 8, G 10, G 12, G 50, G 75

G 57, G 209, G 210, G 212 , G 2046

G 32

G 6, G 7, G 14

G 57

G 730

G 9, G 10, G 38, G 40

G 11

G 20, G 21, G 22, G 24, G 29,

G 30, G 37, G 194, G 197

G 30, G 199, G 1382

G 99 


\section{BEILAGEN UND TEXTABBILDUNGEN}

Beilagen

1, 1-22, 4 Profilzeichnungen

22, $5 \quad$ G 13 a, Foto aus dem älteren Inventarbuch

22, 6 G 19 a, Foto aus dem älteren Inventarbuch
Textabbildungen

$1 \quad$ Foto (Vergleich der Fragmente G 99 und Prag 22. 31)

2-7 Umzeichnungen

$8 \quad$ Fotomontage (Fragmente G 741 und Göttingen Hu 533 s mit Athen, NM 802)

9-15 Umzeichnungen

$16 \quad$ Fotomontage (Einpassung des Fragmentes G 1038 in das Gesamtgefäß Aigina K 566)

$17-20$ Umzeichnungen

\section{TECHNISCHE PARAMETER DER COMPUTERTOMOGRAFIE-UNTERSUCHUNGEN}

Zur Methode siehe S. Karl - D. Jungblut - J. Rosc, Berührungsfreie und nicht invasive Untersuchung antiker Keramik mittels industrieller Röntgen-Computertomografie, mit einem Beitrag von
R. Erlach, in: E. Trinkl (Hrsg.), Interdisziplinäre Dokumentations- und Visualisierungsmethoden, CVA Österreich Beih. I (Wien 20I3) 73-II4

\begin{tabular}{|c|c|c|c|c|c|c|c|c|c|c|c|c|c|c|c|}
\hline $\begin{array}{l}\text { Inventar- } \\
\text { nummer }\end{array}$ & ÖGI-ID & CT-Anlage & Datum & $\begin{array}{l}\text { Voxelsize } \\
{[\mu \mathrm{m}]}\end{array}$ & $\begin{array}{l}\text { FOD } \\
{[\mathrm{mm}]}\end{array}$ & $\begin{array}{l}\text { Number } \\
\text { Images }\end{array}$ & $\begin{array}{l}\text { Total } \\
\text { Rotation }\end{array}$ & $\begin{array}{l}\text { Volume } \\
\text { Size Z } \\
\text { [voxel] }\end{array}$ & $\begin{array}{l}\text { Timing } \\
\text { Val [ms] }\end{array}$ & Averaging & STime $[\mathrm{s}]$ & $\begin{array}{l}\text { Voltage } \\
{[\mathrm{kV}]}\end{array}$ & $\begin{array}{l}\text { Current } \\
{[\mu \mathrm{A}]}\end{array}$ & $\begin{array}{l}\text { XRay } \\
\text { Filter }\end{array}$ & $\begin{array}{l}\text { XRay } \\
\text { Filter } \\
\text { Thickness } \\
{[\mathrm{mm}]}\end{array}$ \\
\hline \multirow[t]{3}{*}{ G 2} & $\begin{array}{l}\text { Röntgen- } \\
\text { aufnahmen }\end{array}$ & vltomelx C 240 D & 07.09 .2010 & - & & 7 & - & & & - & & & & & \\
\hline & CT 04345 & $\mathrm{x}$ |argoslcompact & 11.11 .2010 & $\begin{array}{l}64,8 \\
(X, Y) ; \\
259,1(Z)\end{array}$ & 812,7 & 2160 & 360 & 1 & 55 & 1 & 118,8 & 266 & 3200 & $\mathrm{Al}+\mathrm{Zn}$ & $1,5+0,5$ \\
\hline & CT 2011-053 & vltomelx C 240 D & 01.02 .2011 & $\begin{array}{l}299,3 \\
(X, Y, Z)\end{array}$ & 891,3 & 600 & 360 & & 400 & 3 & $\begin{array}{l}3851 \\
(=64,2 \mathrm{~min})\end{array}$ & 160 & 210 & $\mathrm{Al}$ & 2,5 \\
\hline G 26 & CT 04136 & vltomelx C $240 \mathrm{D}$ & 17.06.2010 & $\begin{array}{l}240,8 \\
(X, Y, Z)\end{array}$ & 479,5 & 600 & 360 & & 400 & 2 & 719 & 93 & 450 & none & 0 \\
\hline \multirow[t]{2}{*}{ G 27} & $\begin{array}{l}\text { CT 2013- } \\
380 *\end{array}$ & xlargoslcompact & $\begin{array}{l}10 .- \\
12.07 .2013\end{array}$ & $\begin{array}{l}259,1 \\
(\mathrm{X}, \mathrm{Y}) ; \\
64,8(\mathrm{Z})\end{array}$ & 812,5 & 1800 & 360 & 2230 & 50 & 1 & $\begin{array}{l}200700000 \\
(=55,8 \mathrm{~h})\end{array}$ & 320 & 2800 & none & 0 \\
\hline & CT 2013-675 & vltomelx C $240 \mathrm{D}$ & 20.11.2013 & $\begin{array}{l}143,7 \\
(X, Y, Z)\end{array}$ & 931,9 & 1500 & 360 & & 333 & 2 & $\begin{array}{l}1500 \\
(=25 \mathrm{~min})\end{array}$ & 155 & 220 & $\mathrm{Al}$ & 2,0 \\
\hline G 28 & CT 2013-380* & xlargoslcompact & $\begin{array}{l}10 .- \\
12.07 .2013\end{array}$ & $\begin{array}{l}259,1 \\
(\mathrm{X}, \mathrm{Y}) ; \\
64,8(\mathrm{Z})\end{array}$ & 812,5 & 1800 & 360 & 2230 & 50 & 1 & $\begin{array}{l}200700000 \\
(=55,8 \mathrm{~h})\end{array}$ & 320 & 2800 & none & 0 \\
\hline G 56 & CT 03047 & vltomelx C 240 D & 17.03.2009 & $\begin{array}{l}189,6 \\
(X, Y, Z)\end{array}$ & 336,6 & 600 & 360 & & 400 & 2 & 720 & 85 & 225 & $\mathrm{Al}$ & 1,0 \\
\hline G 1382 & CT 2011-267 & vltomelx C 240 D & 08.09 .2011 & $\begin{array}{l}175,1 \\
(X, Y, Z)\end{array}$ & 310,7 & 600 & 360 & & 400 & 2 & 720 & 100 & 200 & $\mathrm{Al}$ & 1,0 \\
\hline
\end{tabular}

* zusammen

Parameter

Voxelsize

FOD

Number Images

Total Rotation

Volume Size Z

Timing $\mathrm{Val}$

Averaging

STime

Voltage

Current

XRay Filter

XRay Filter Thickness

\section{Erklärung}

Voxelgröße, Kantenlänge eines Volumenelements [ $\mu \mathrm{m}]$

Fokus-Objekt-Abstand [mm]

Anzahl der aufgenommenen Bilder

Bei der Aufnahme abgedeckter Rotationswinkel

Höhe des Volumens [voxel]

Belichtungszeit des Detektors [ms]

Anzahl der Bilder, über die ein Mittelwert gebildet wird (Rauschreduktion)

Scan-Dauer [s]

Beschleunigungsspannung [kV]

Röhrenstrom $[\mu \mathrm{A}]$

Art des Vorfilters

Dicke des Vorfilters [mm] 



\section{BEILAGEN}



BEILAGE 1
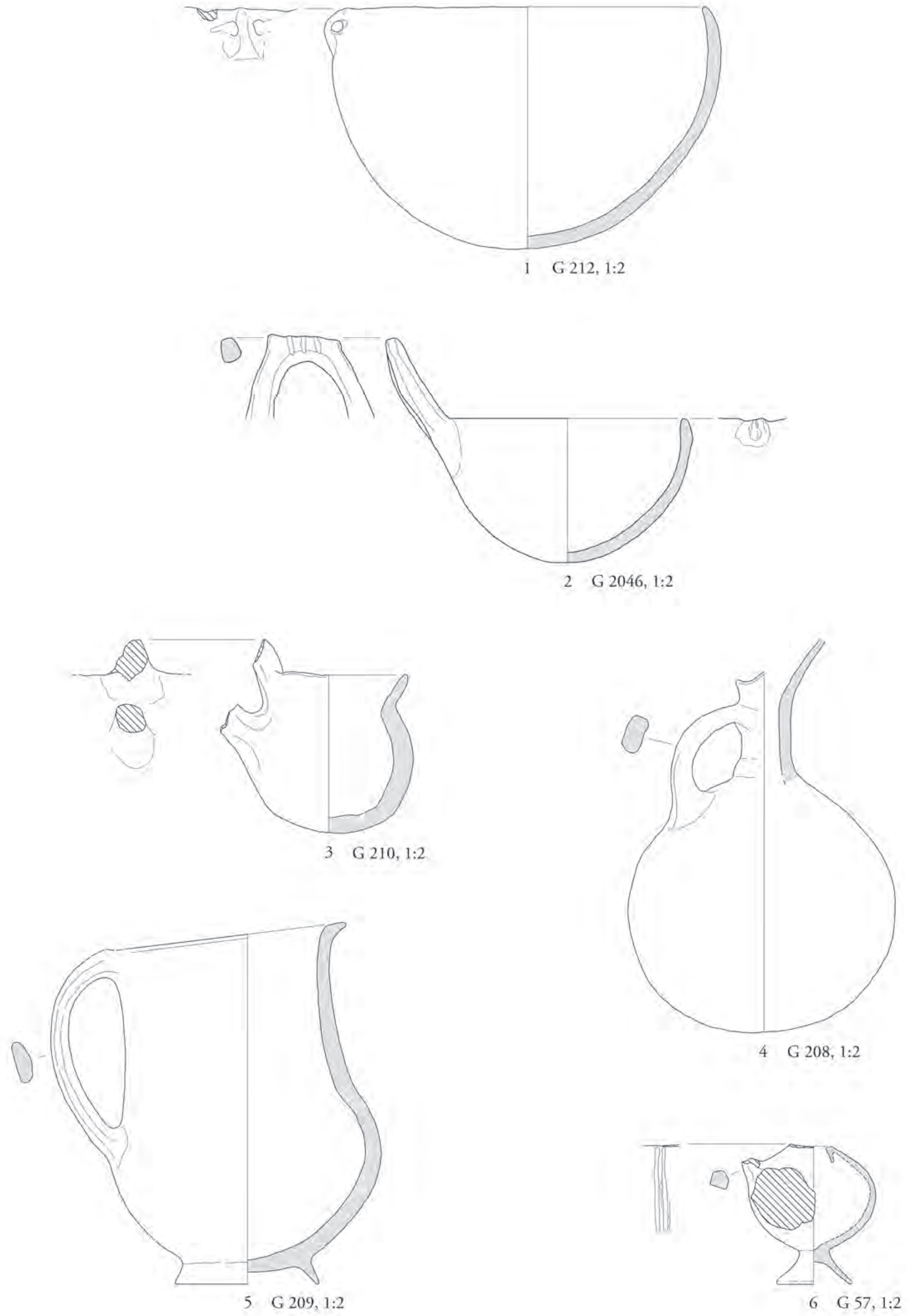
BEILAGE 2

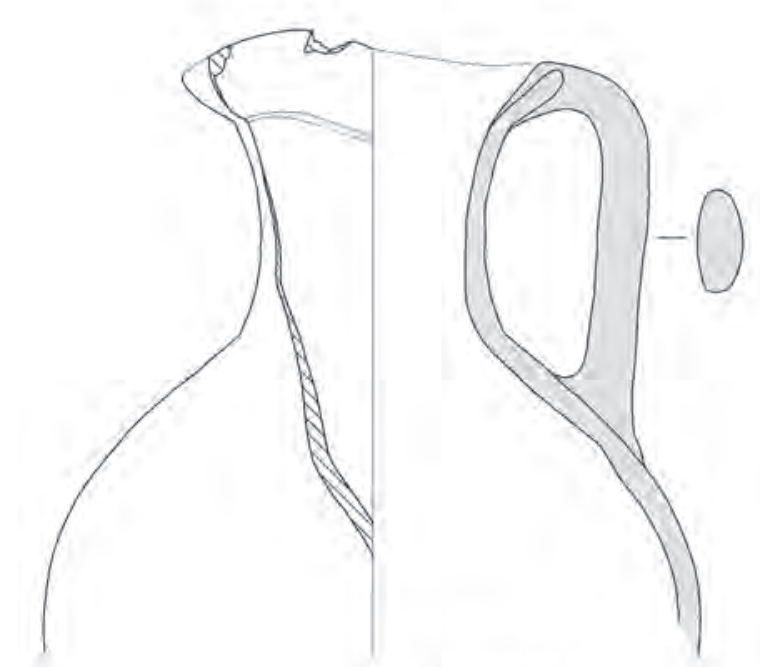

1 G 99, 1:2
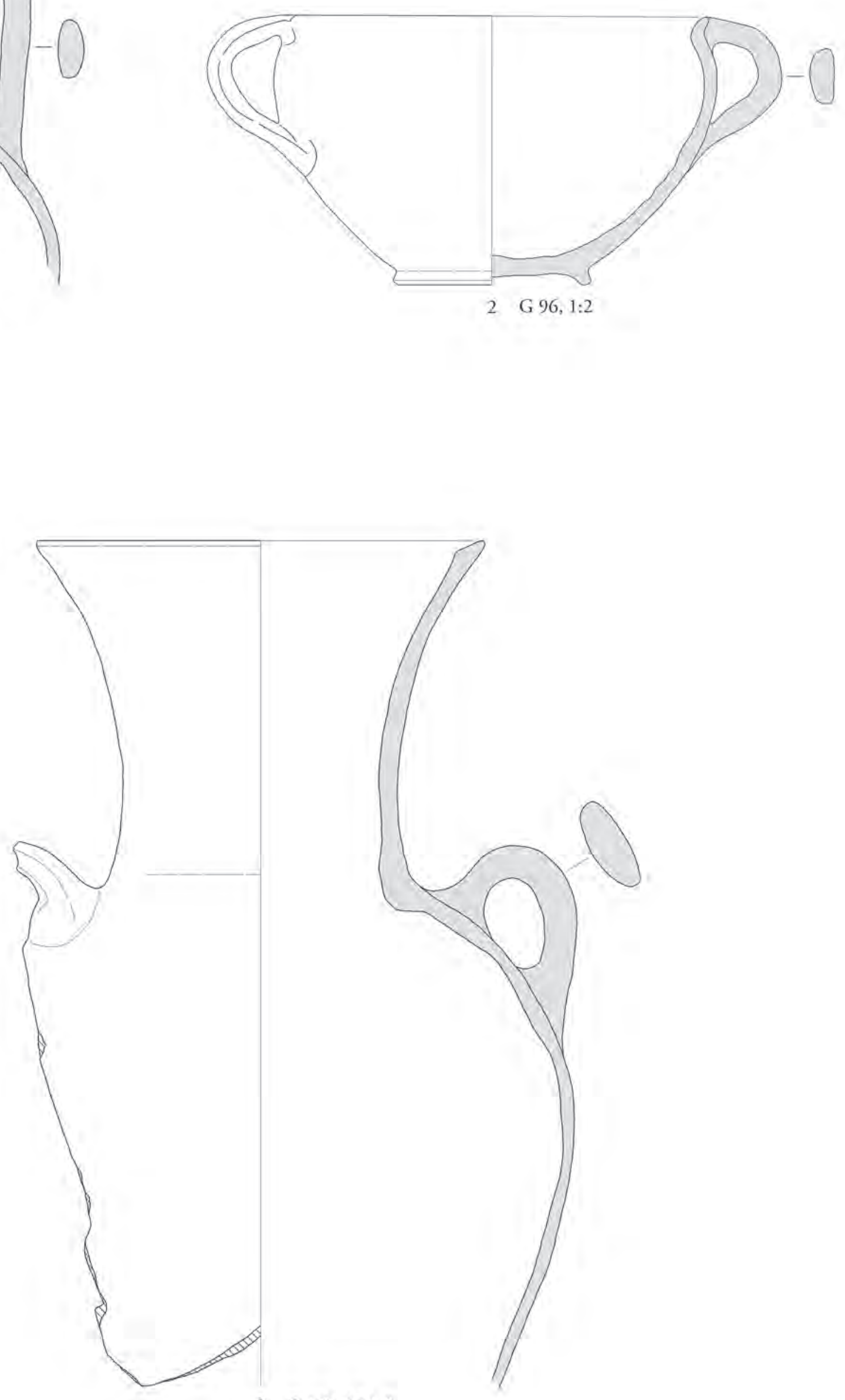

3 G 100, M 1:2 
BEILAGE 3
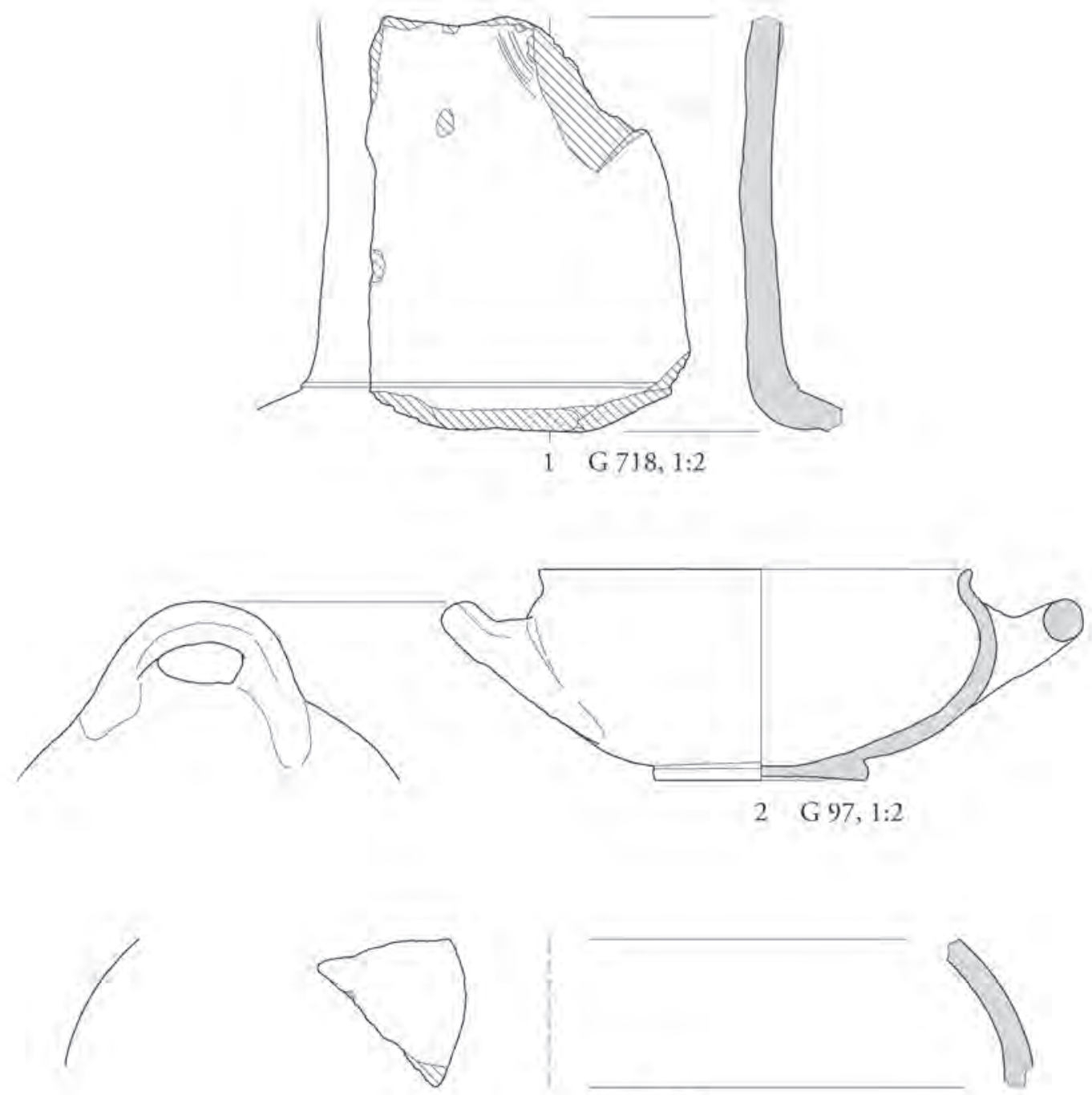

3 G 730, 1:2
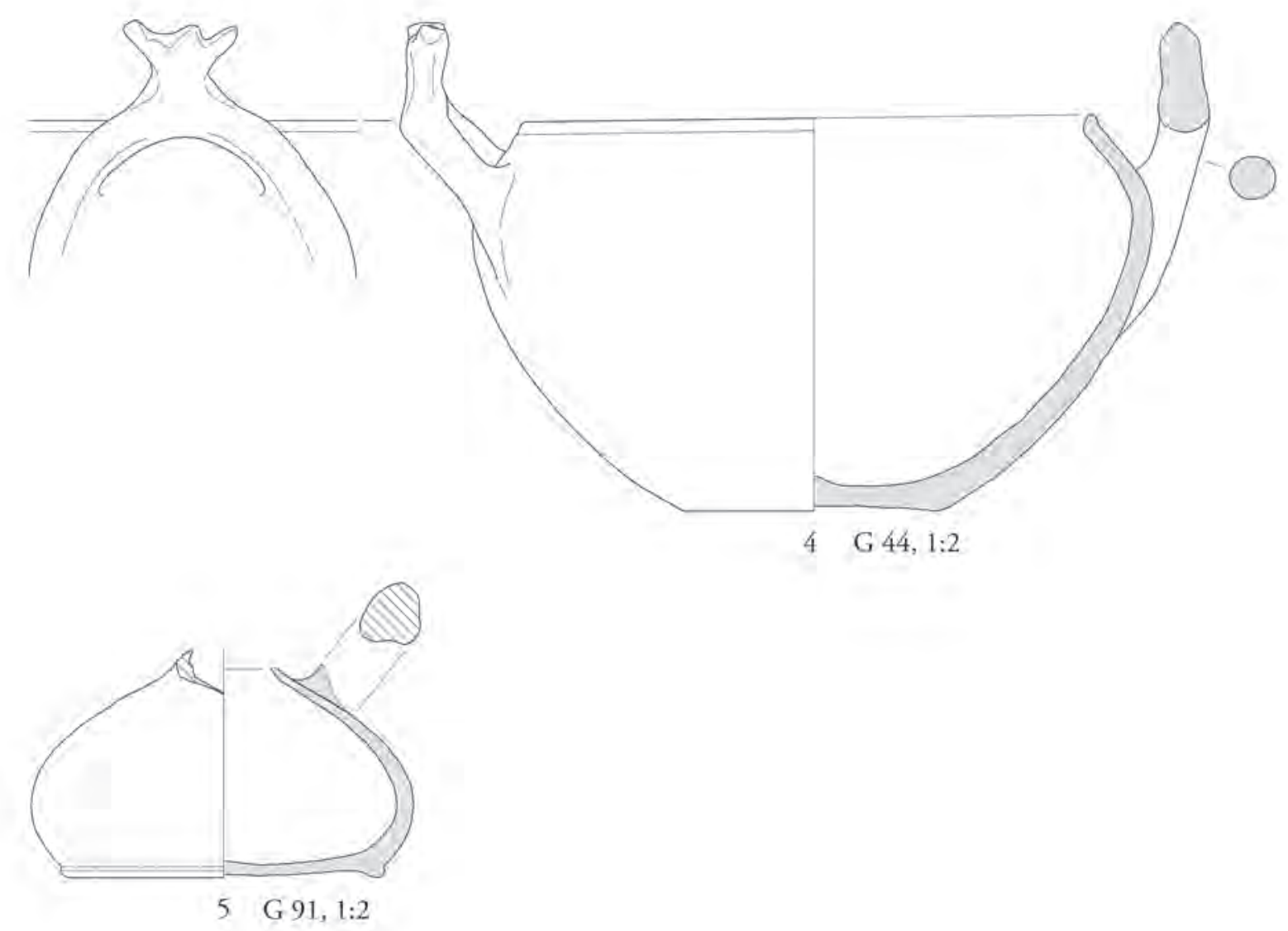
BEILAGE 4
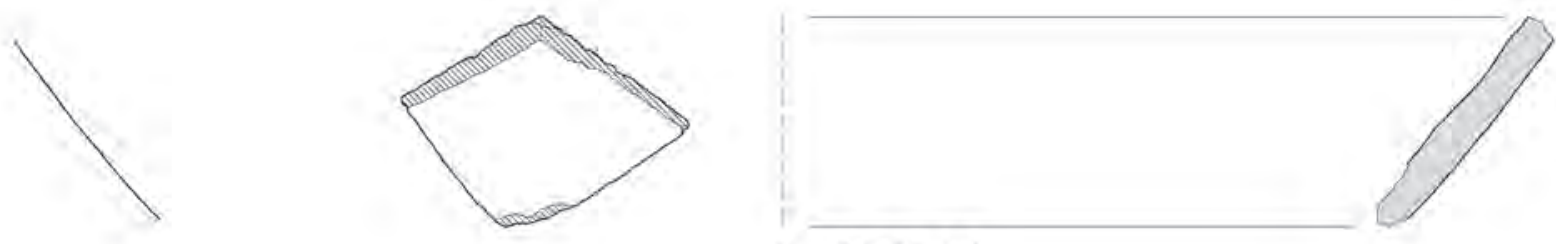

$1 \mathrm{G} 741,1: 4$
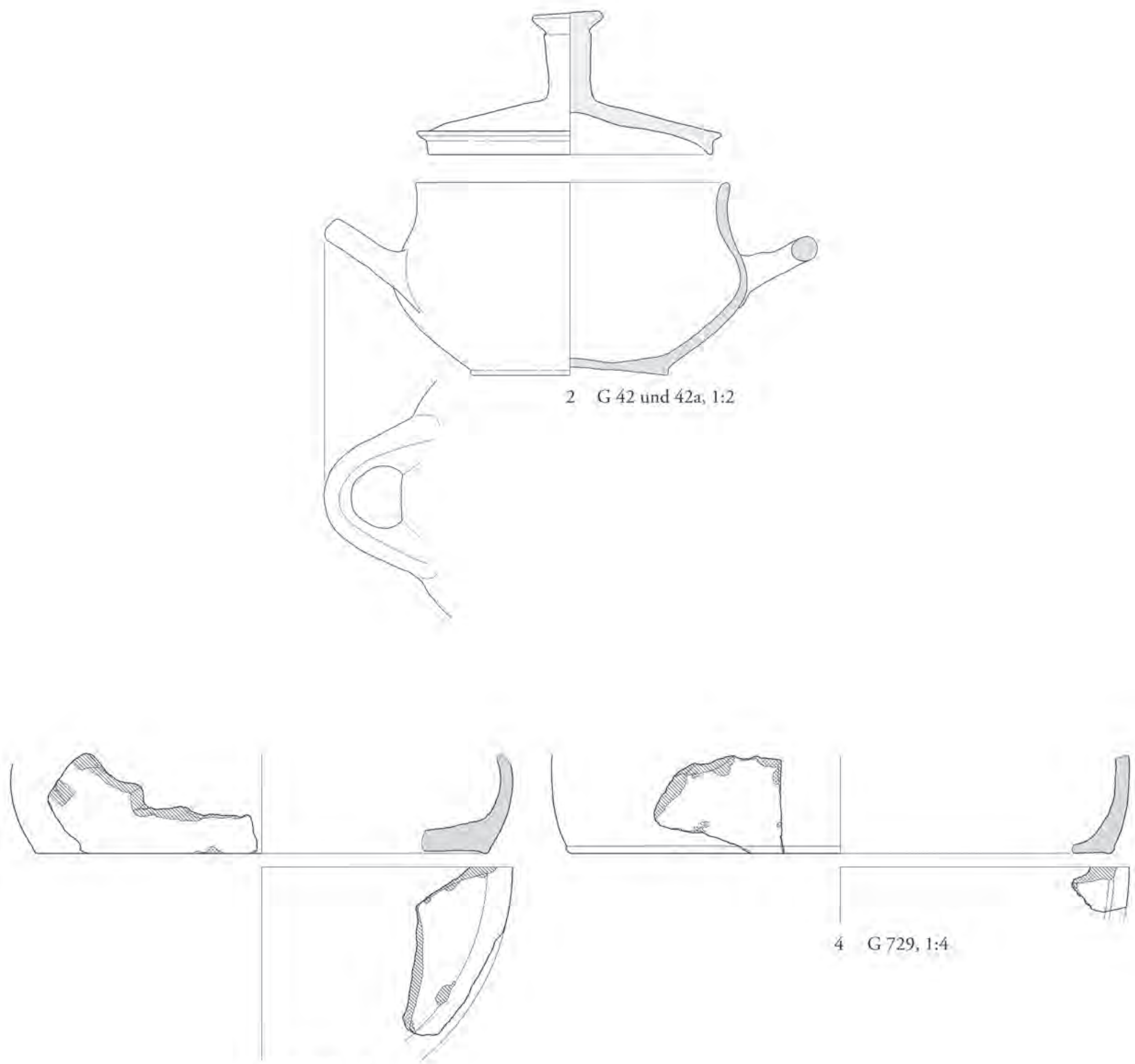

4 G 729, 1:4

$3 \mathrm{G} 719,1: 4$ 
BEILAGE 5
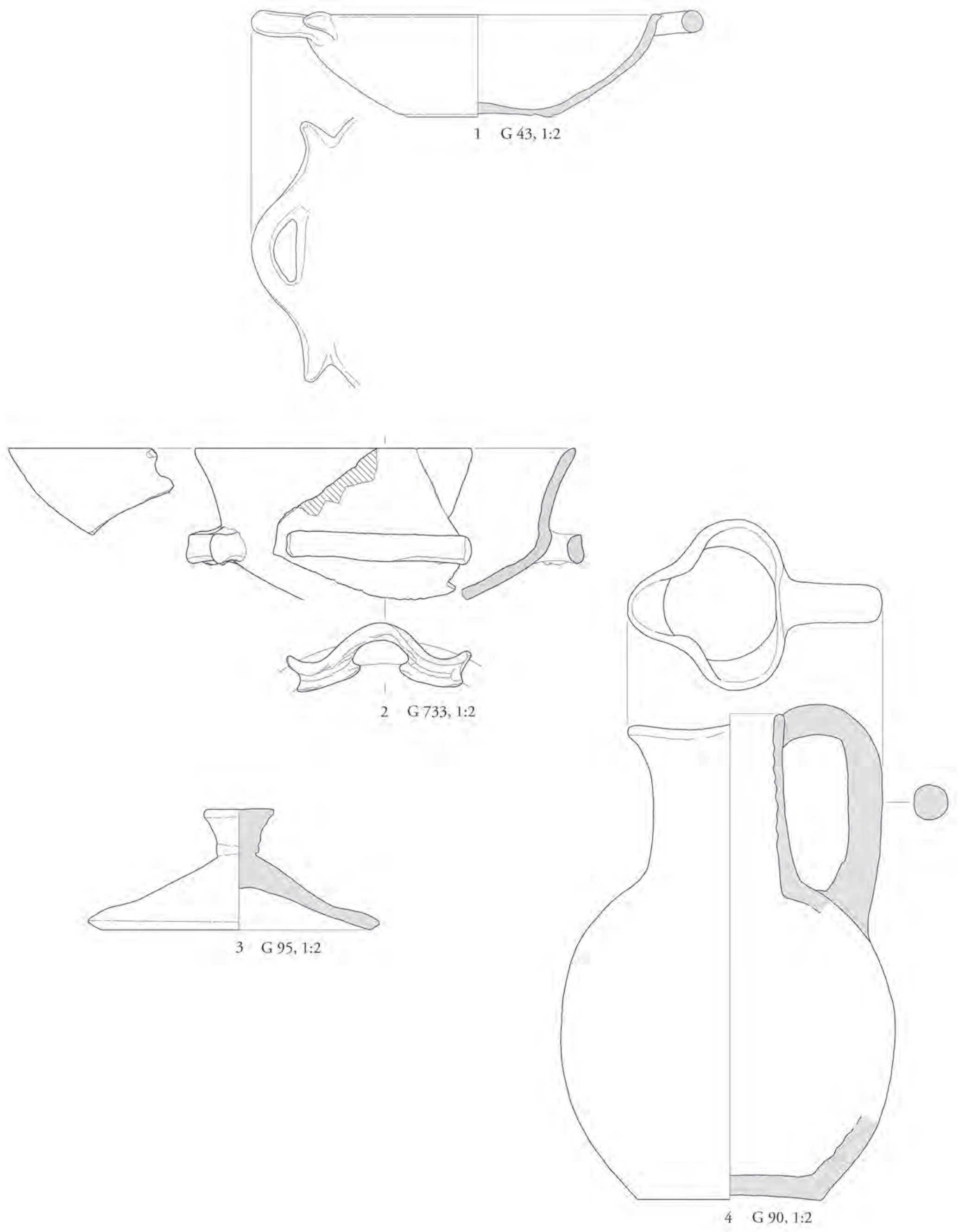
BEILAGE 6
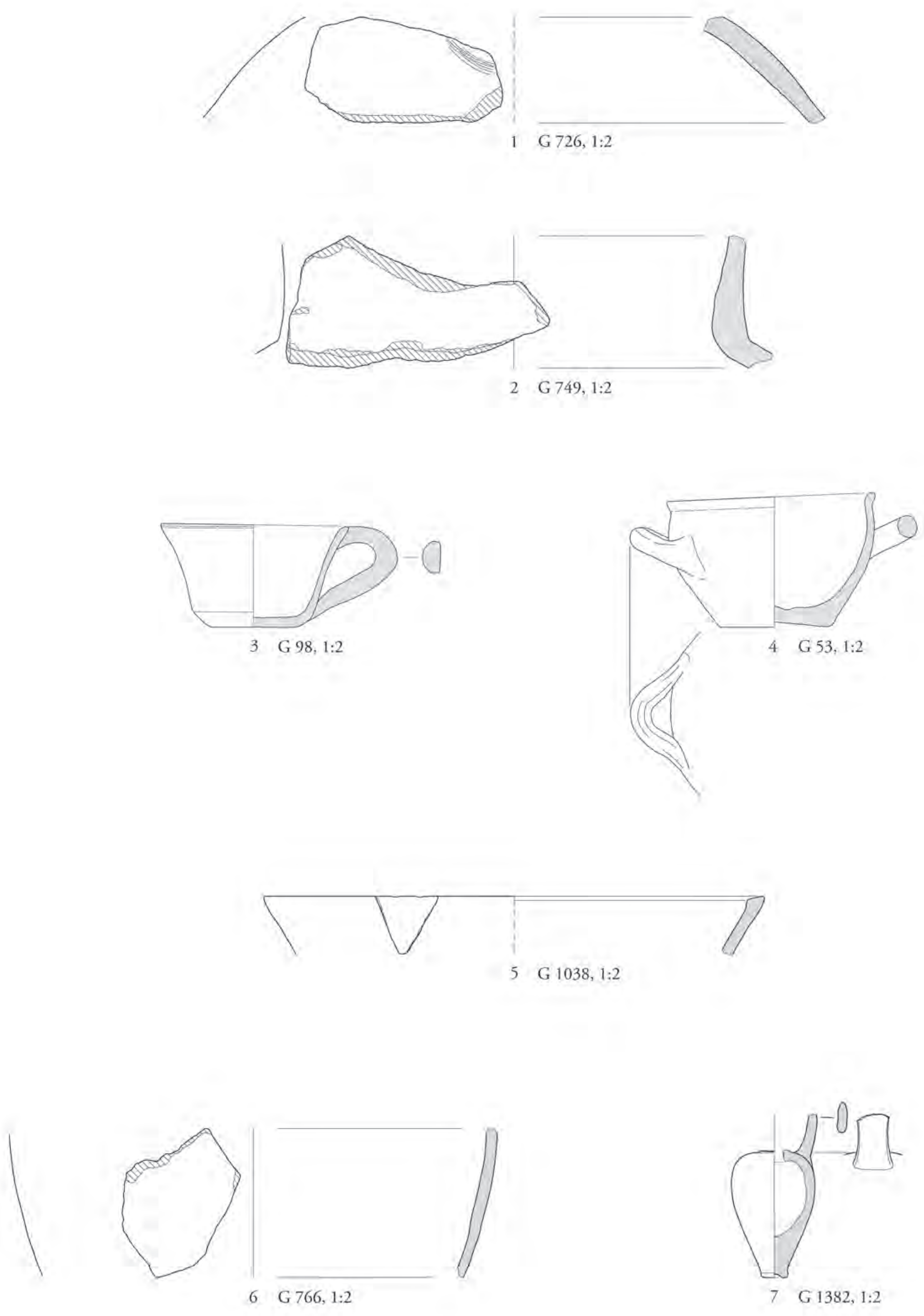
BEILAGE 7
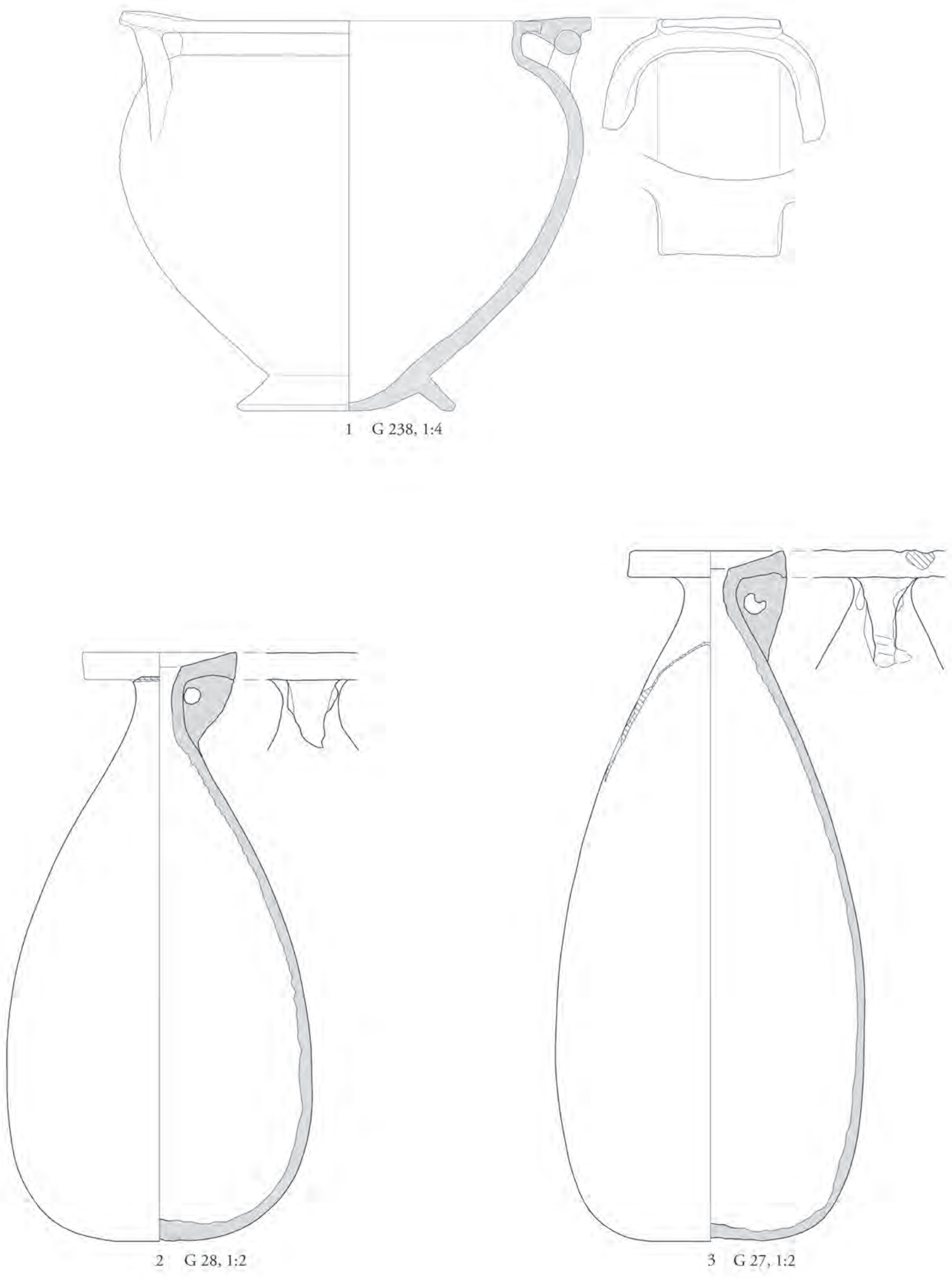
BEILAGE 8
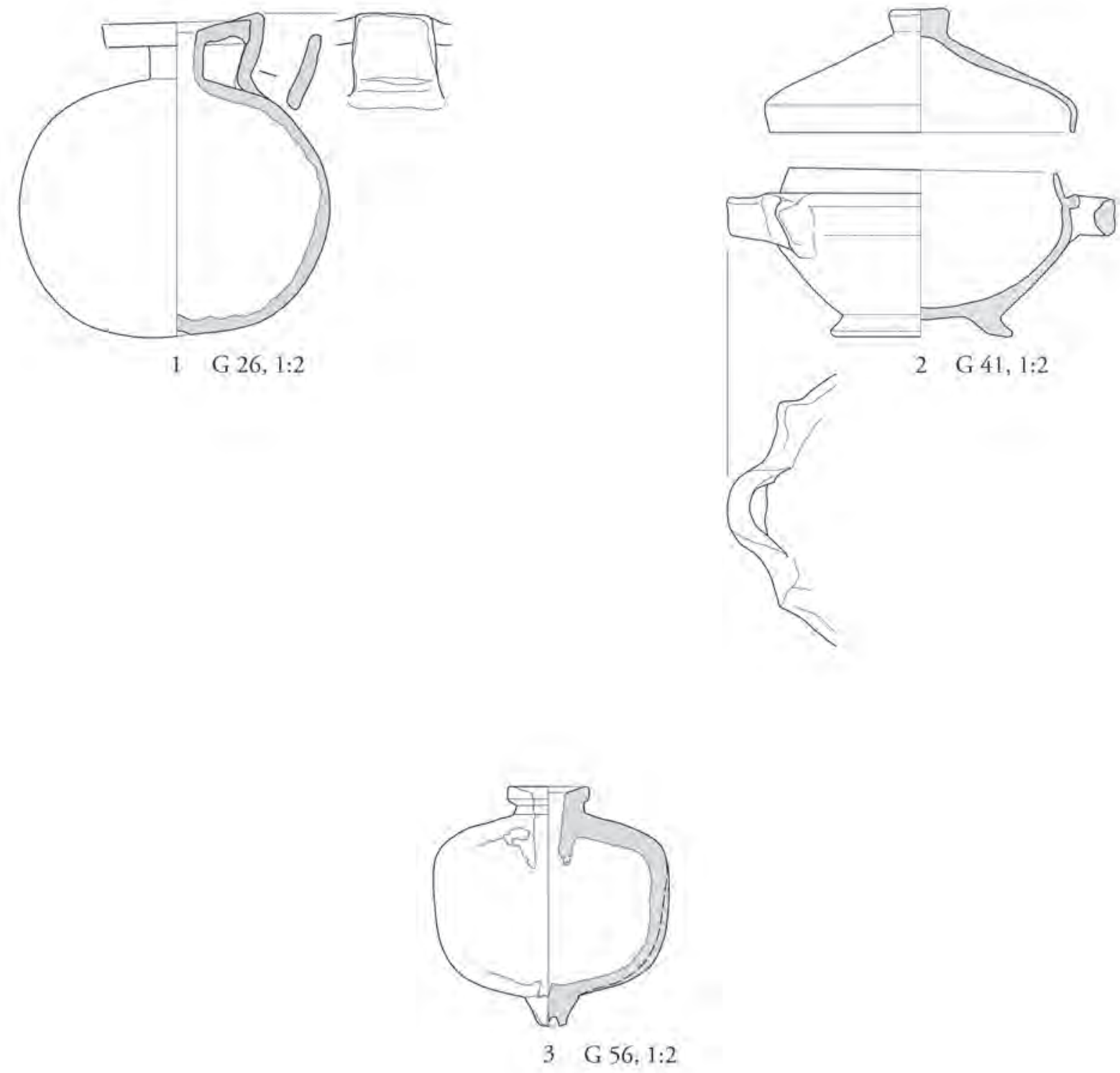

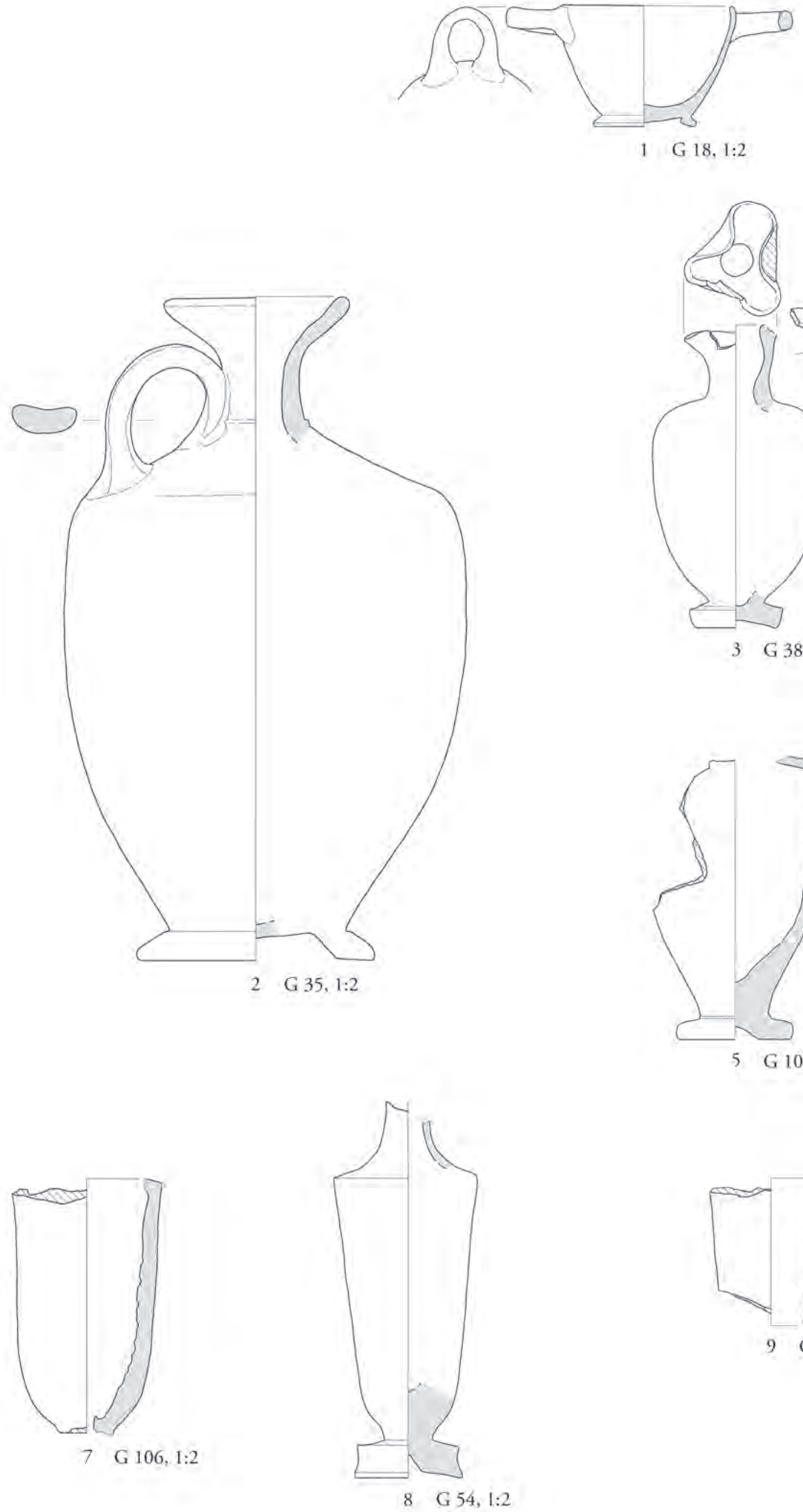
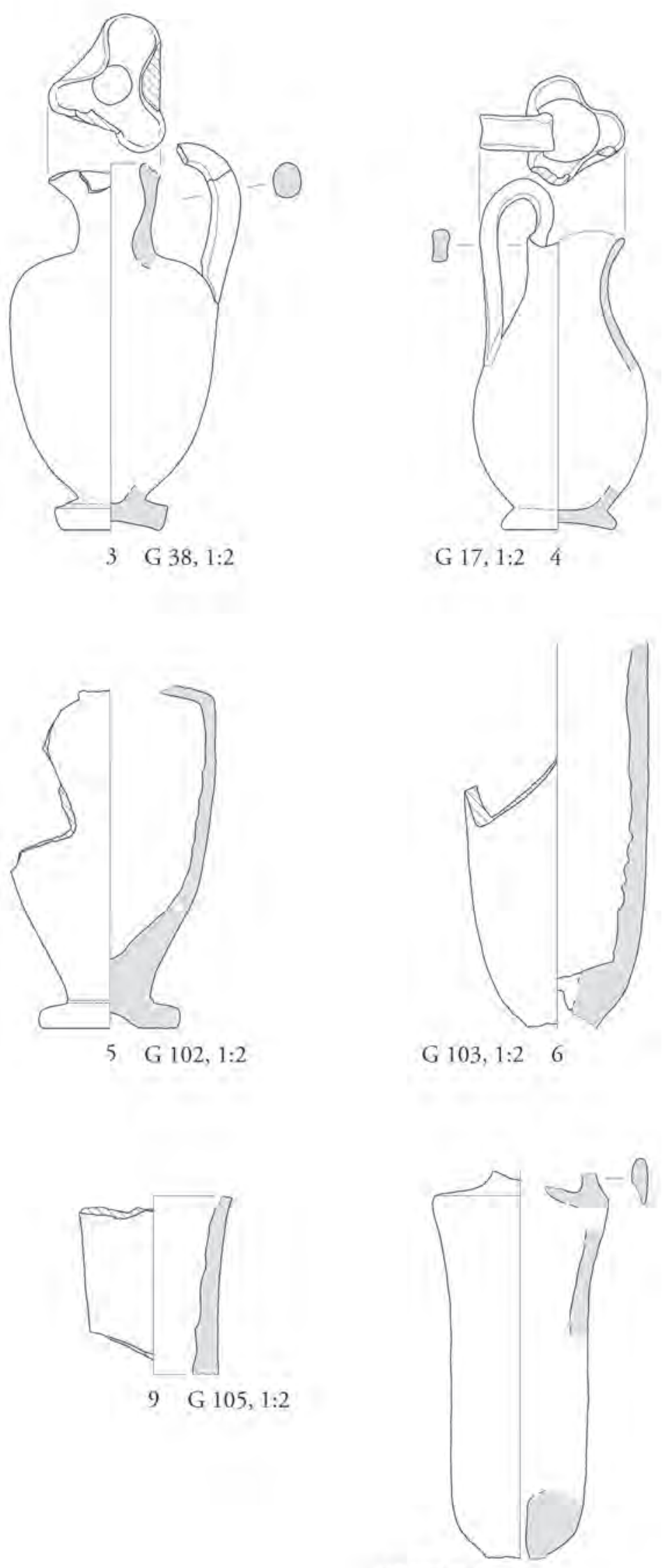

G $104,1: 2 \quad 10$ 
BEILAGE 10

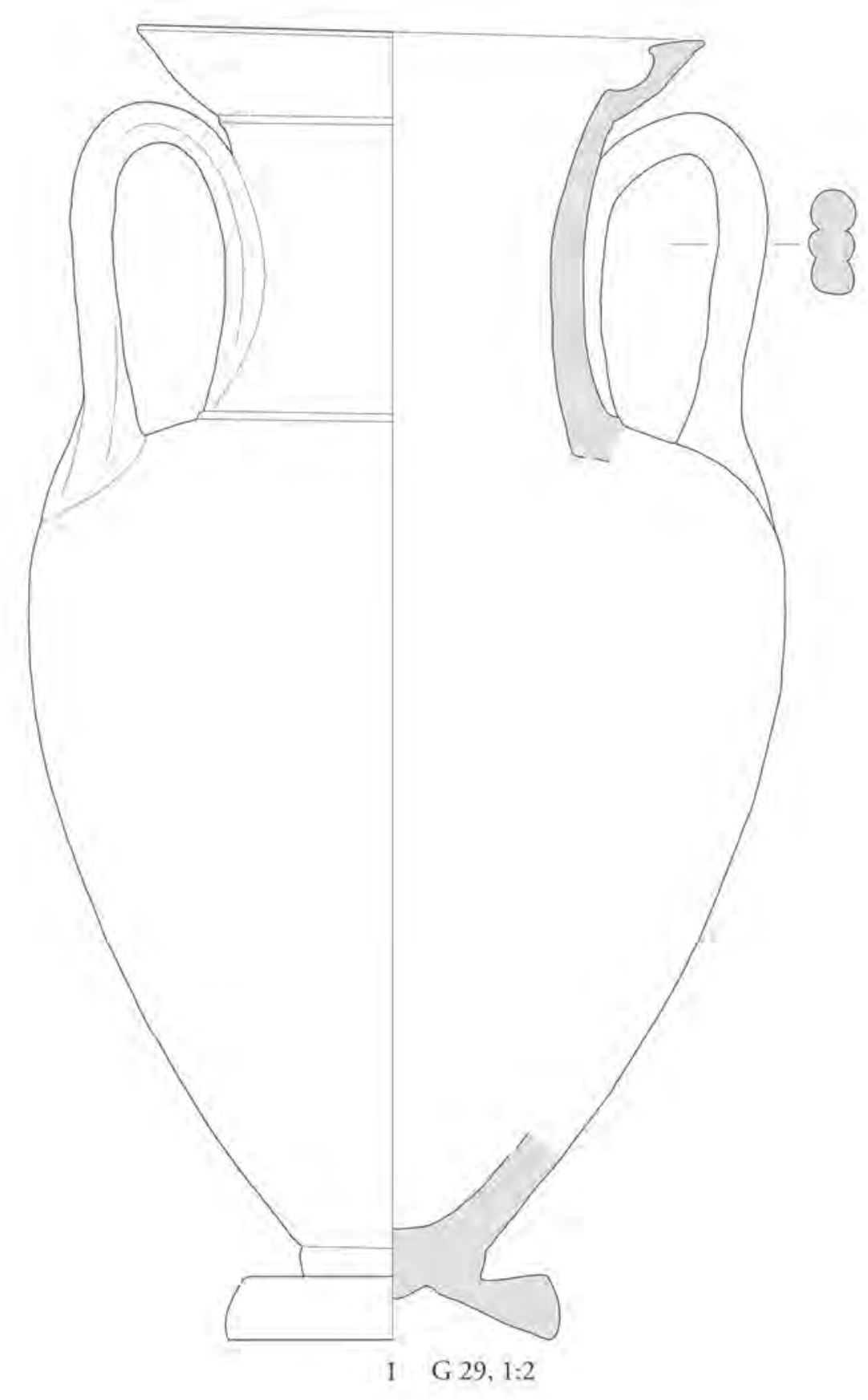


BEILAGE 11

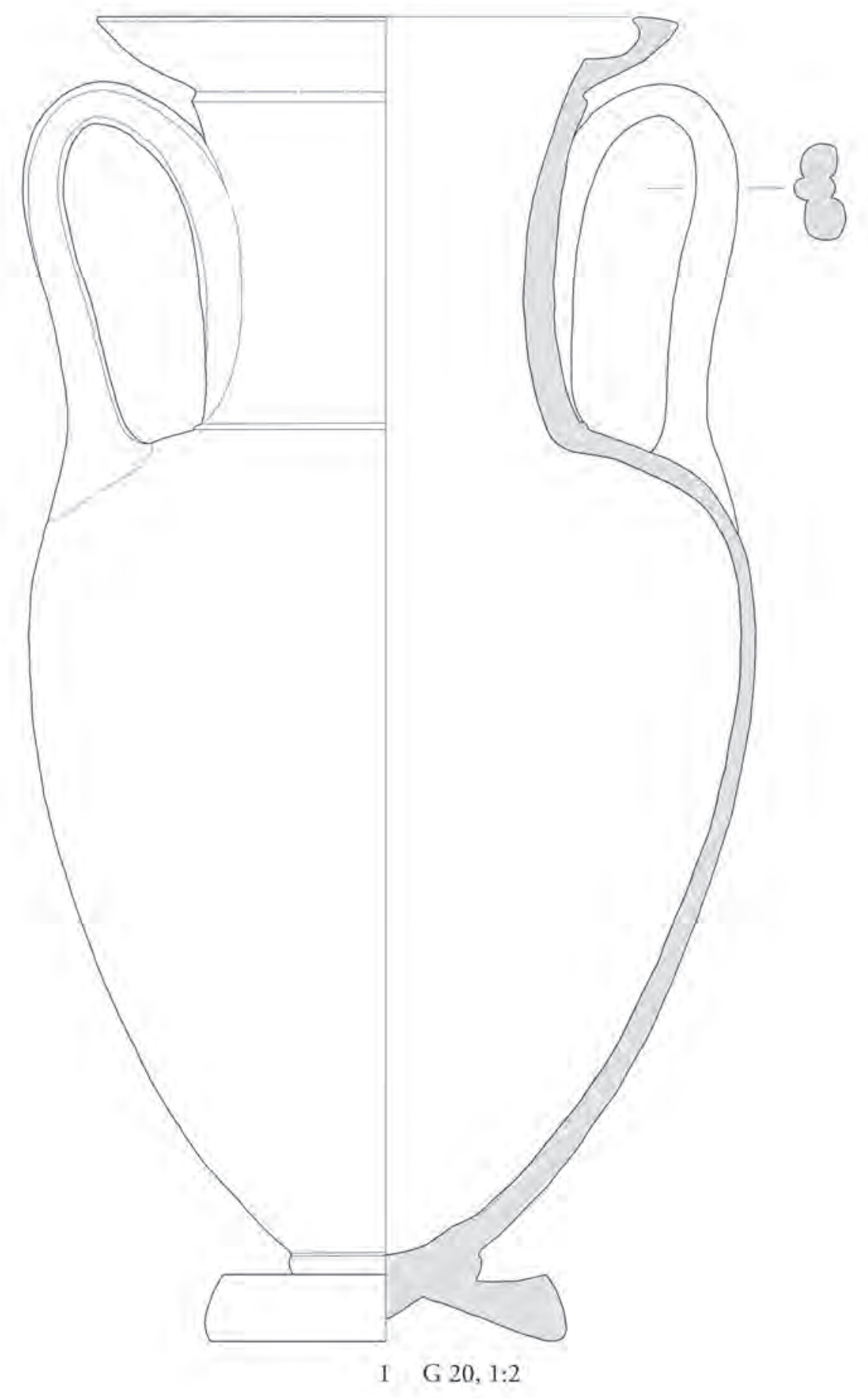


BEILAGE 12

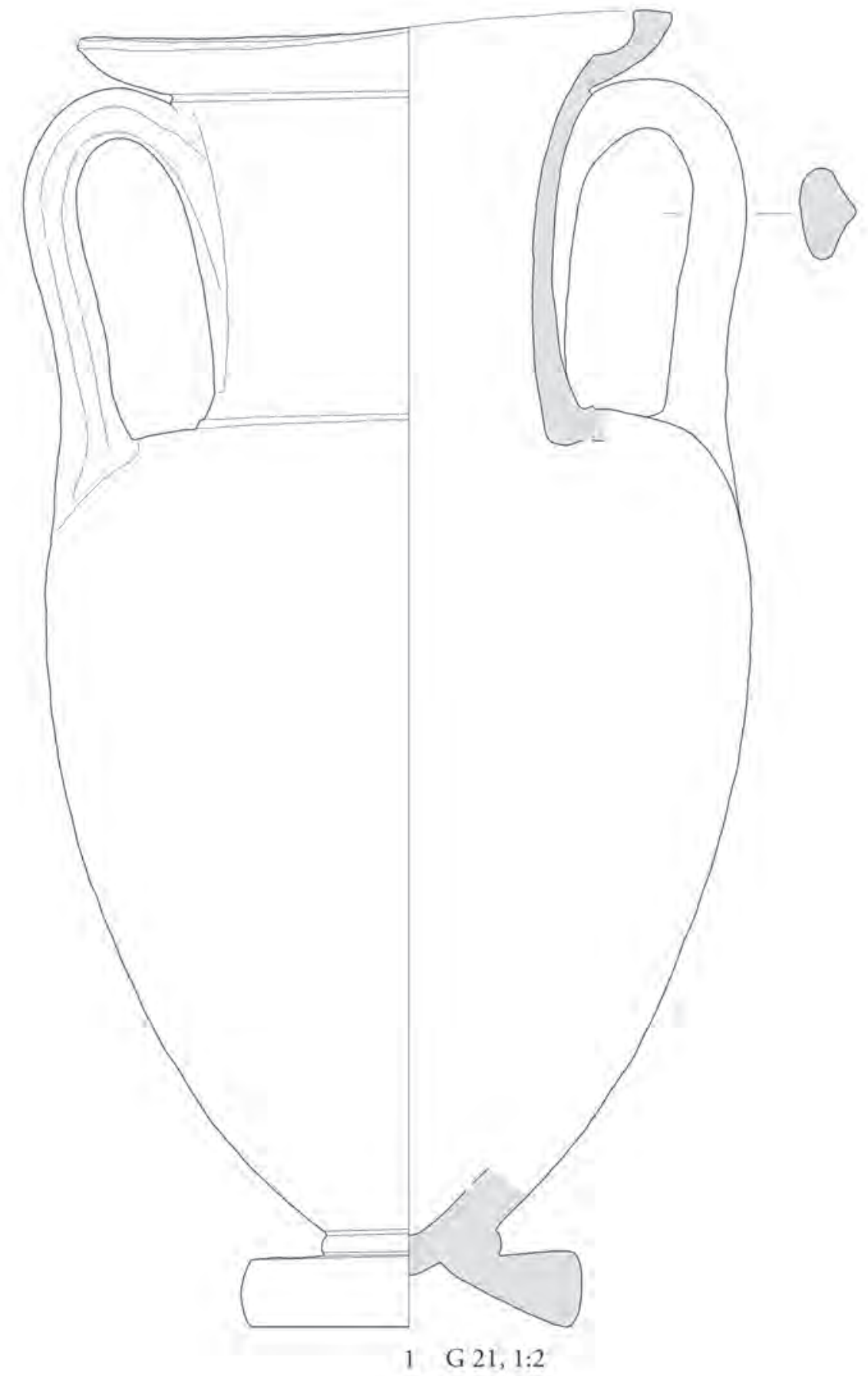


BEILAGE 13
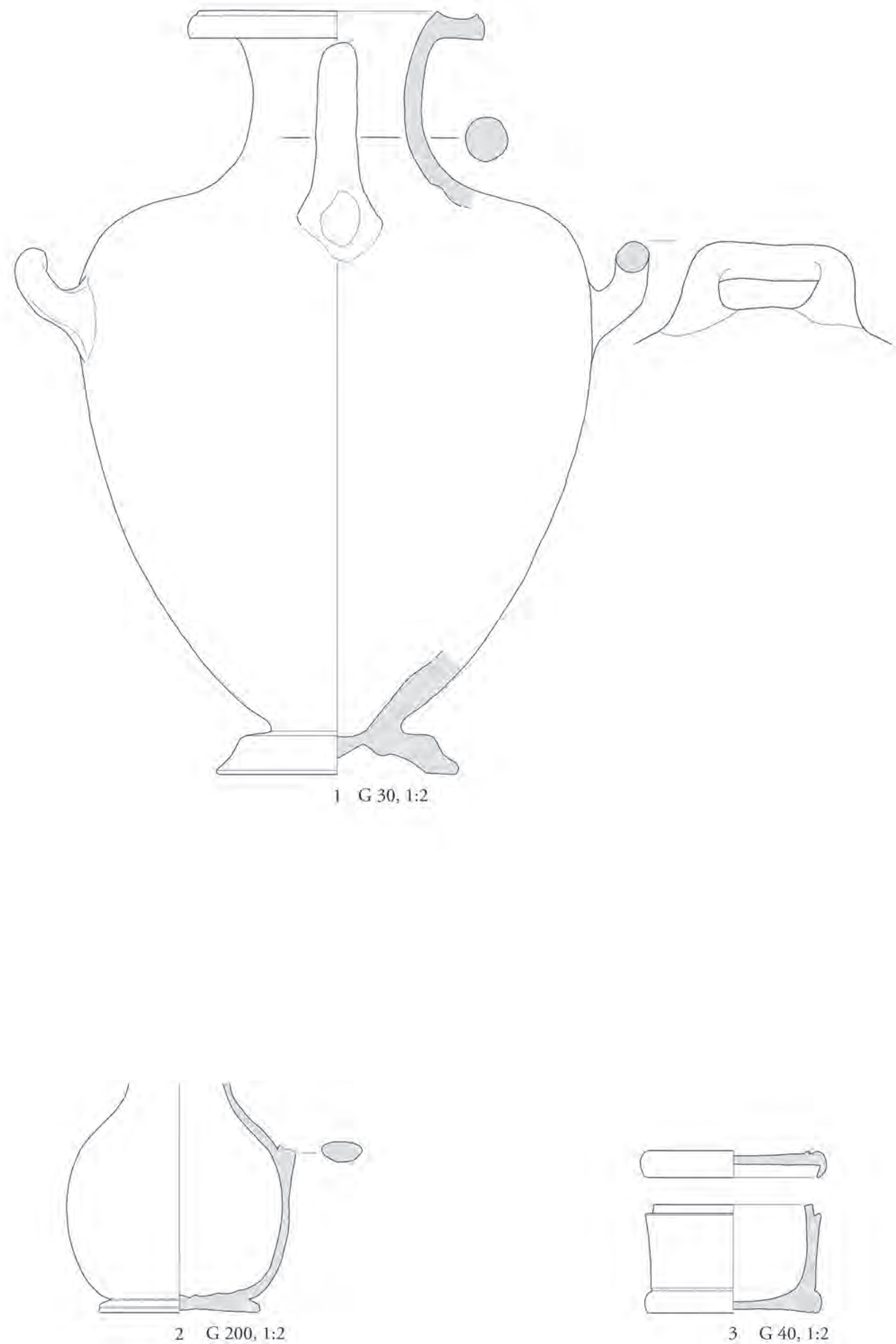
BEILAGE 14

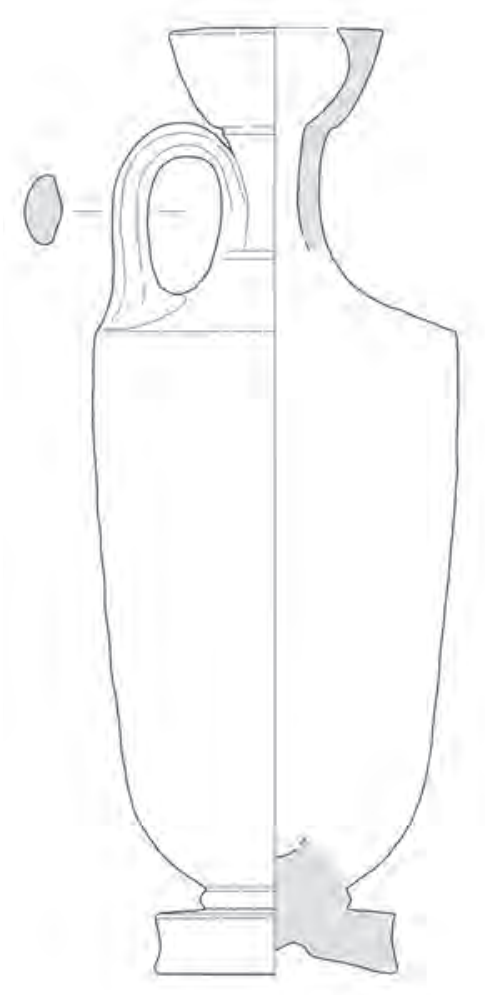

I G 36, I:2
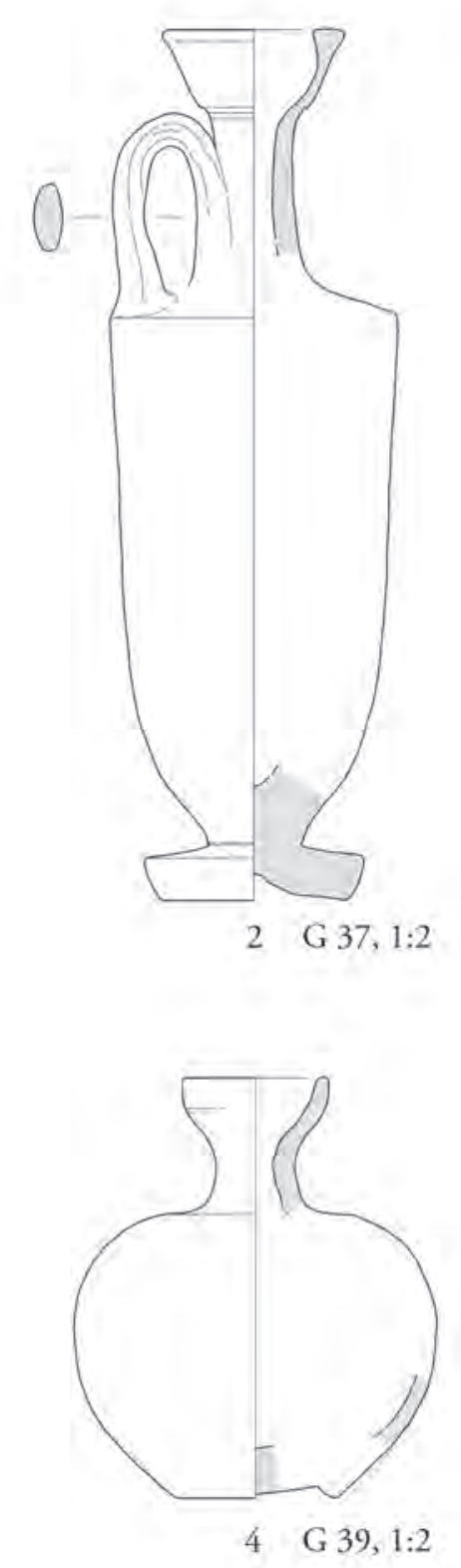

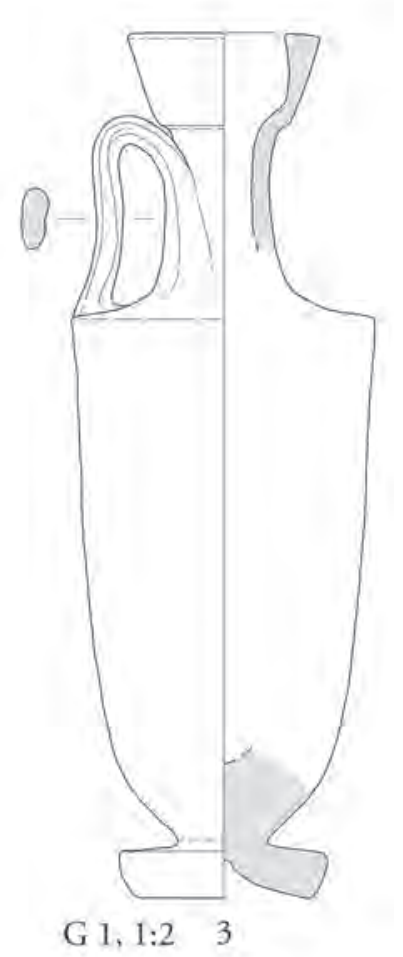

G 1, 1:2 3

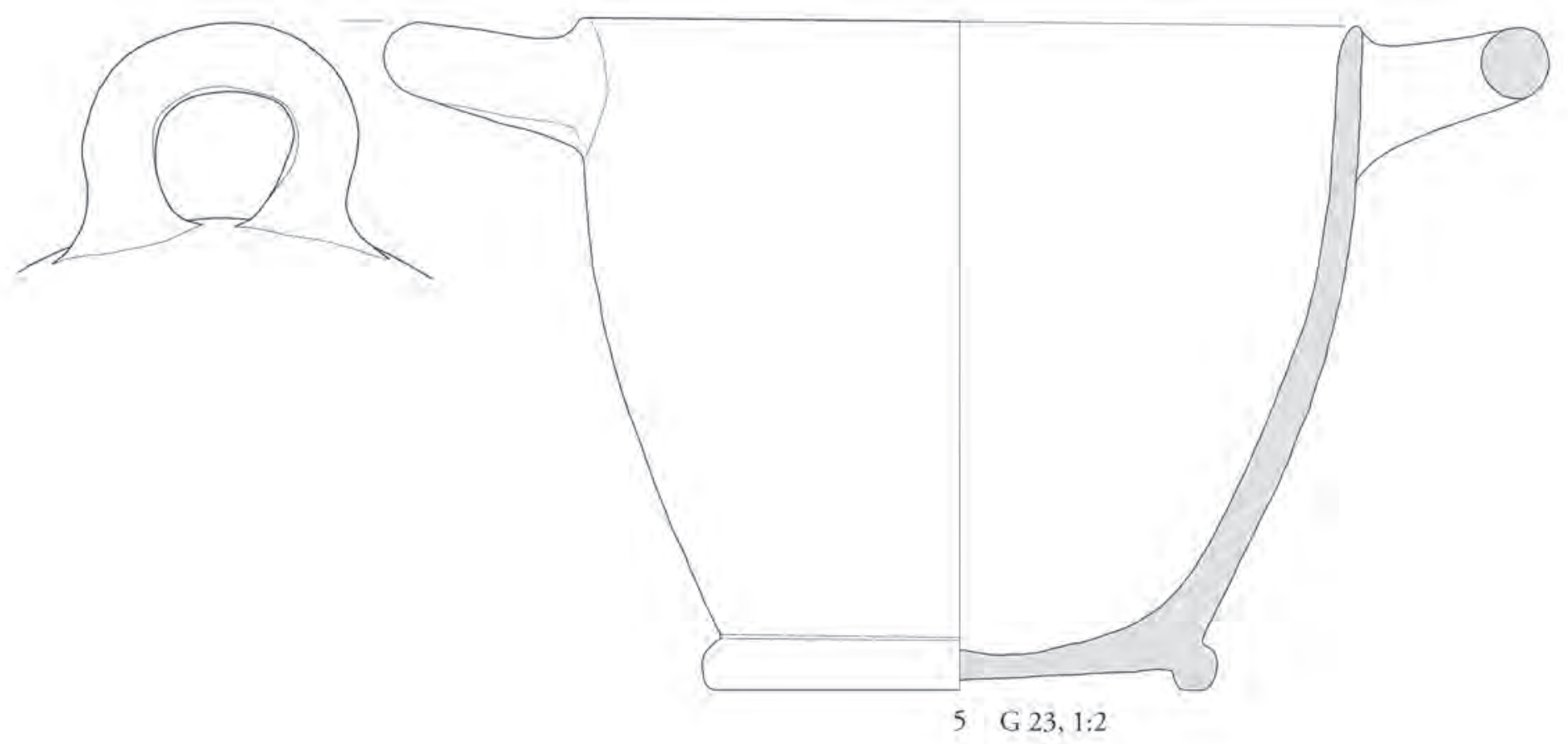



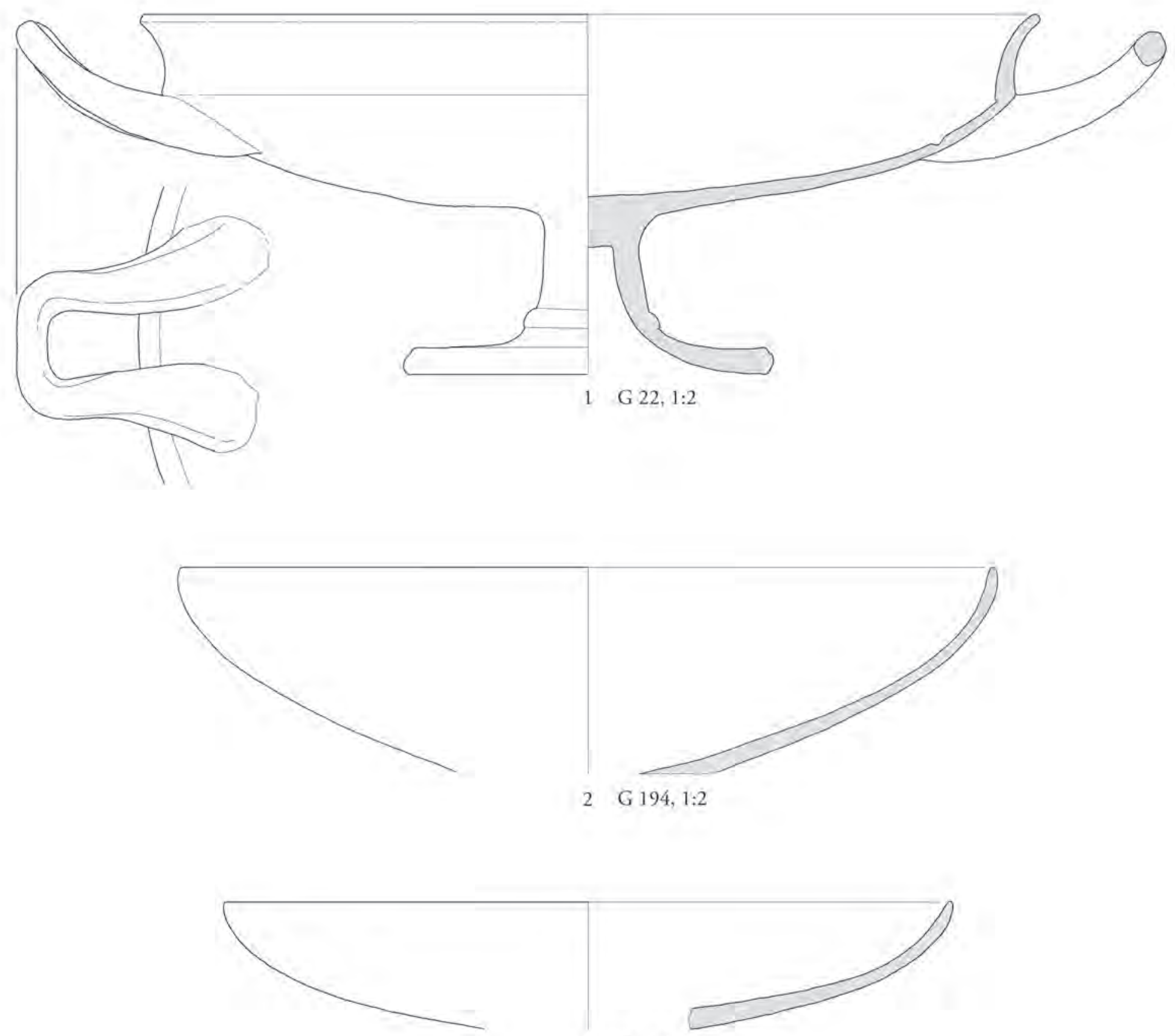

$3 \mathrm{G} 198,1: 2$

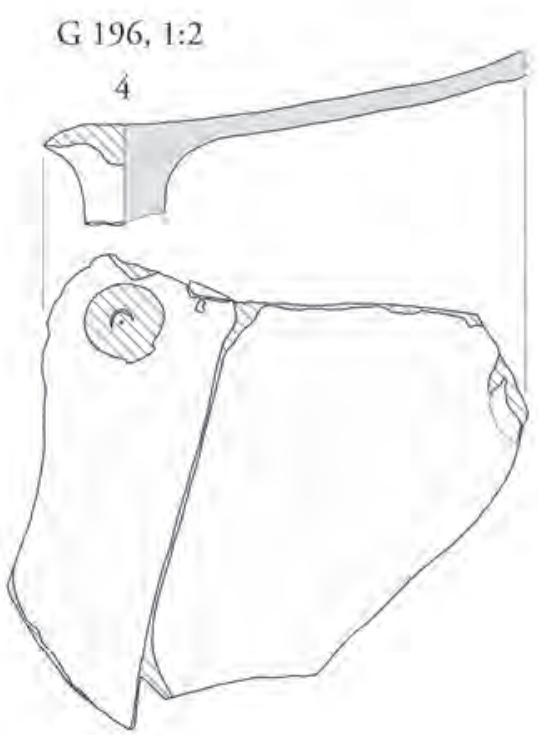

G 197, 1:2

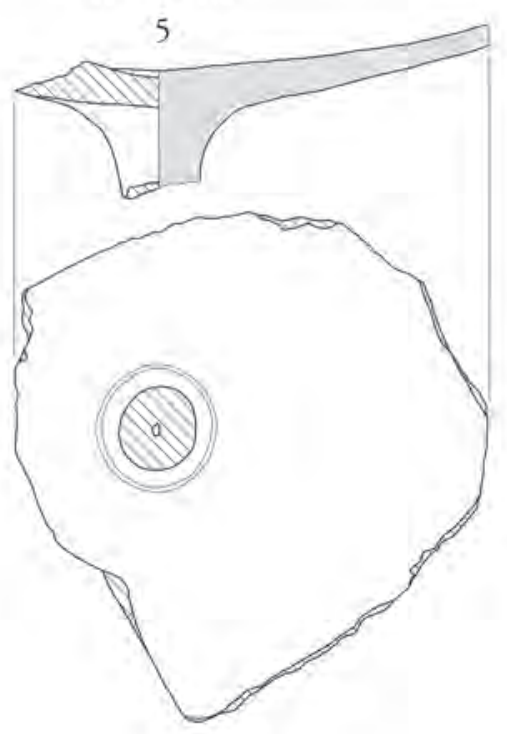

G 199, 1:2

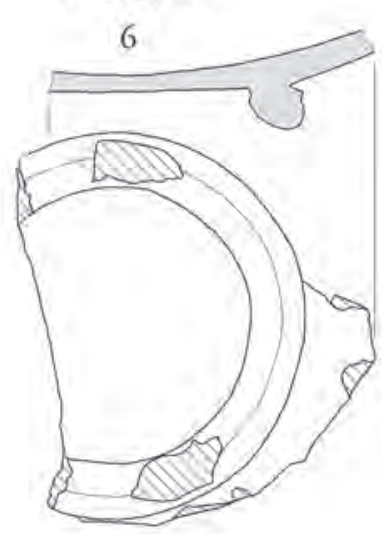



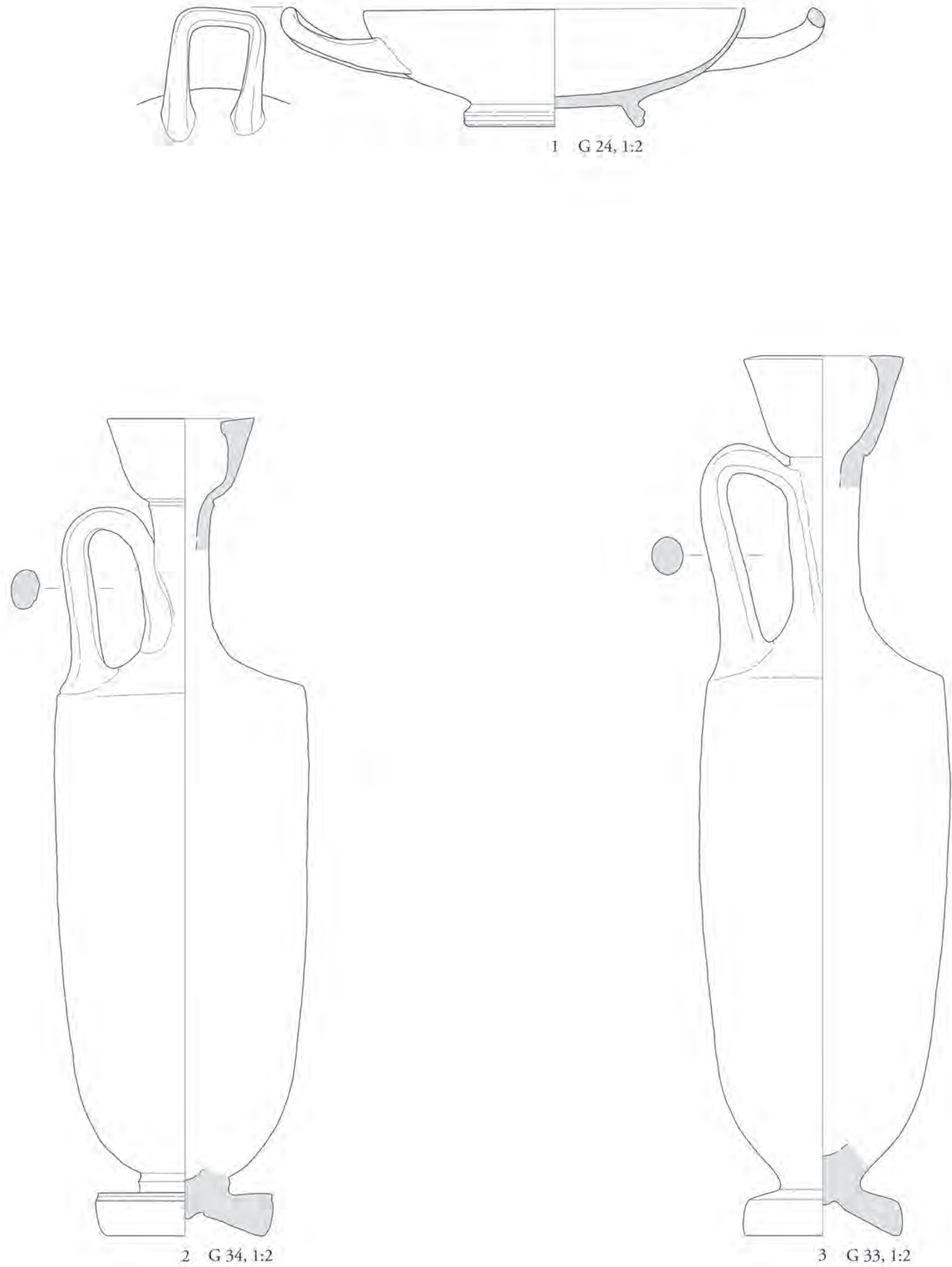
BEILAGE 17
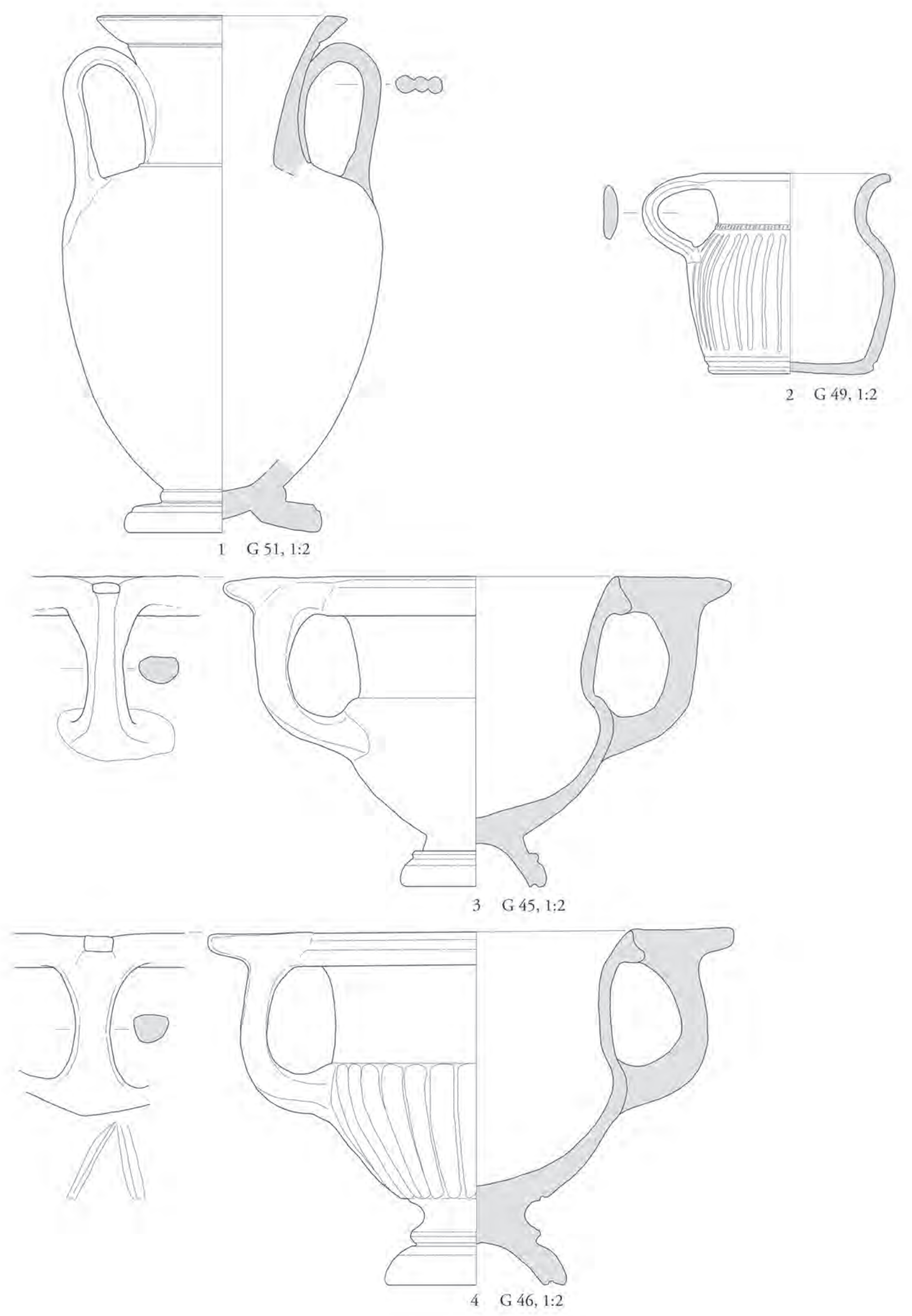
BEILAGE 18
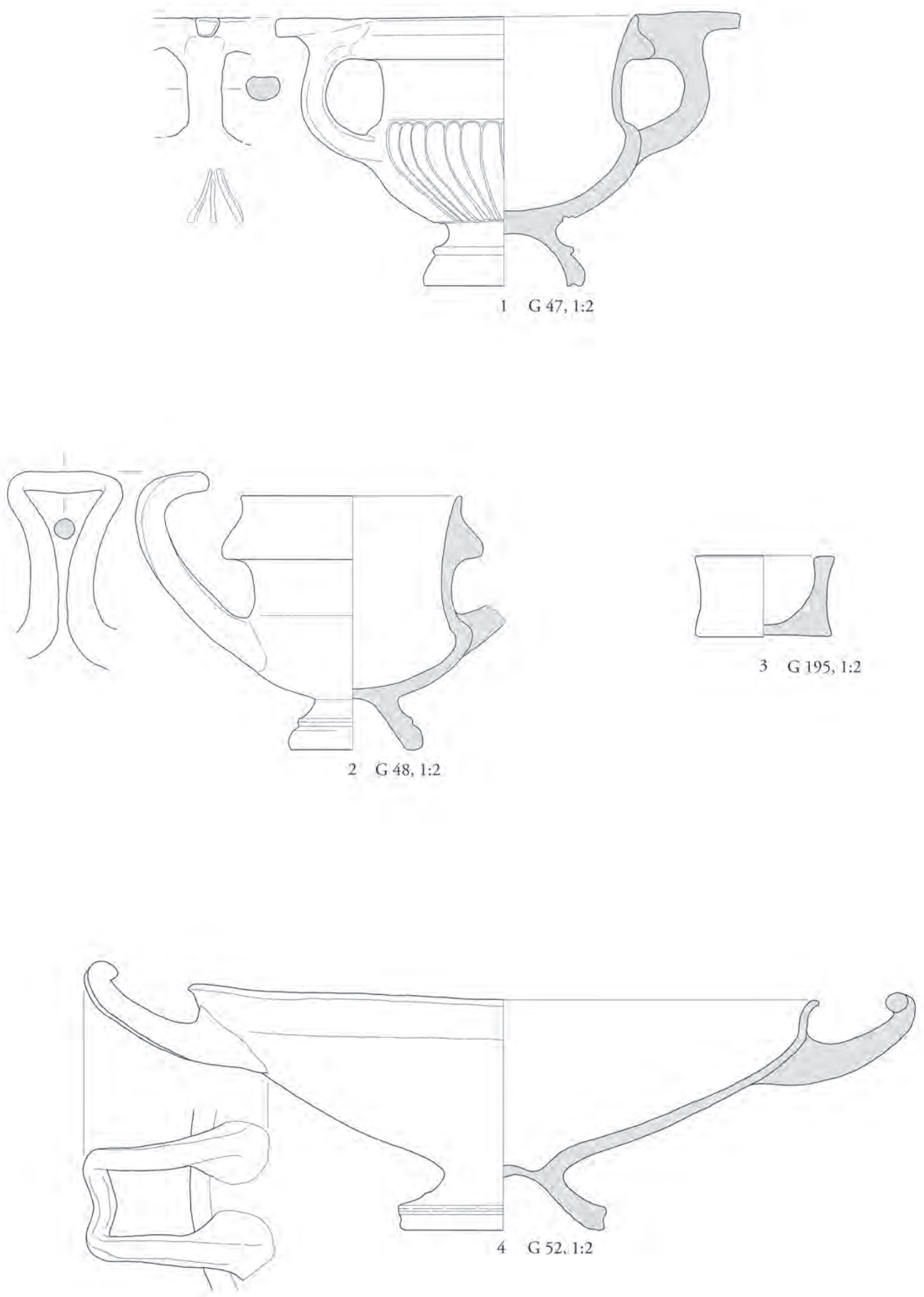


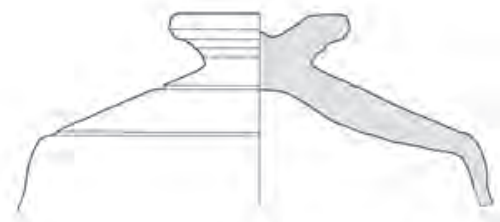

1 G 107, 1:2
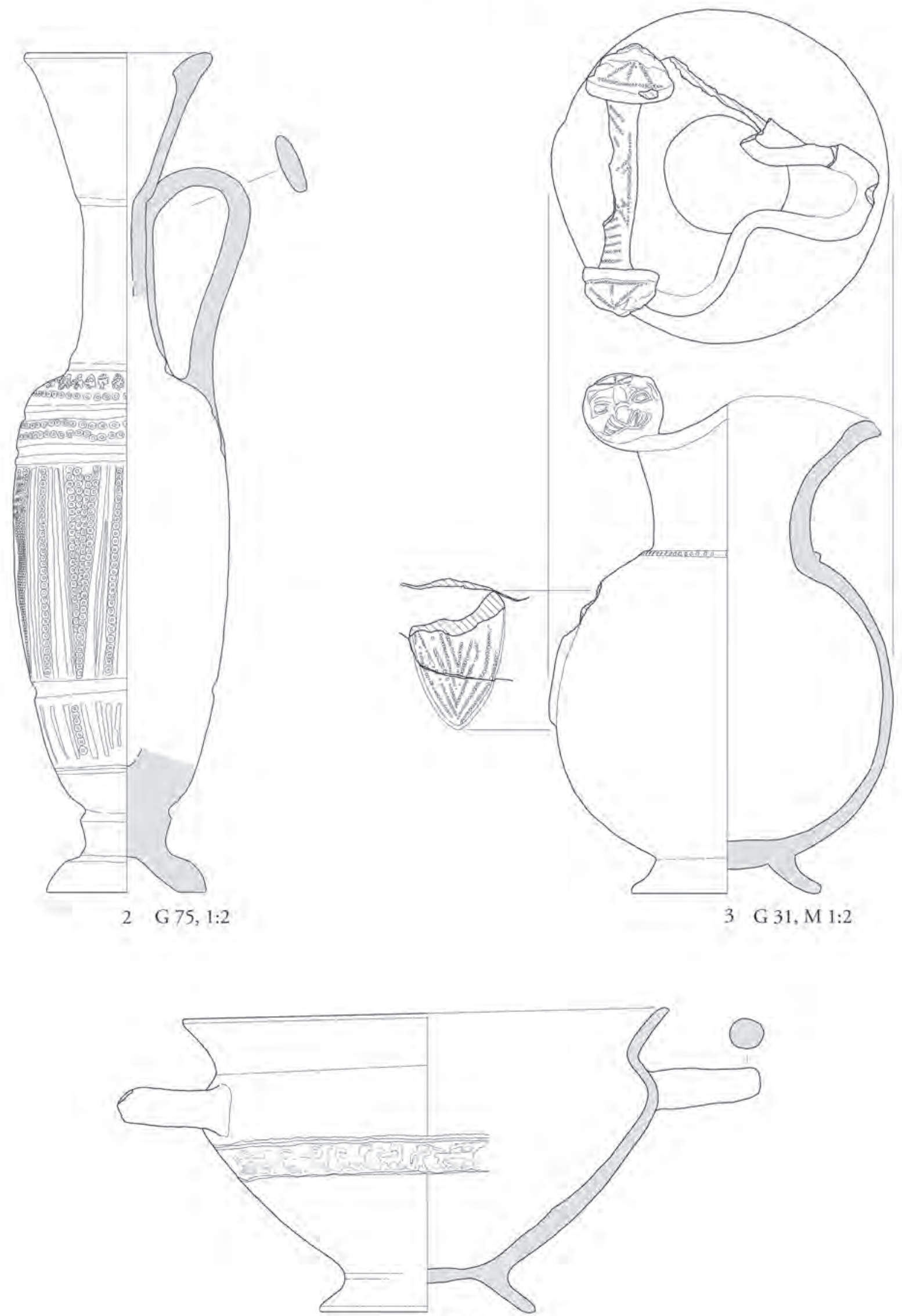

4 G 32, 1:2 
BEILAGE 20
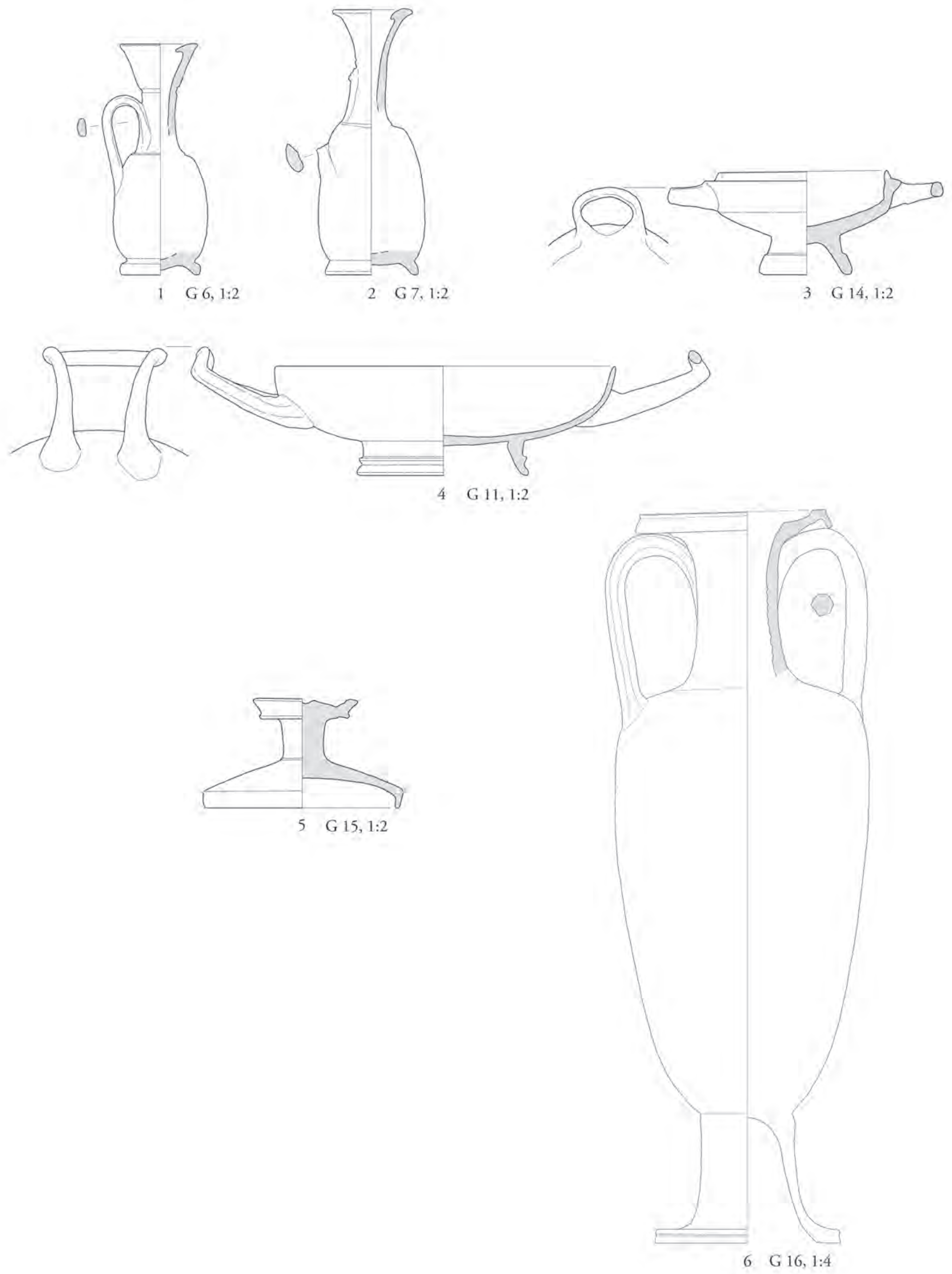
BEILAGE 21
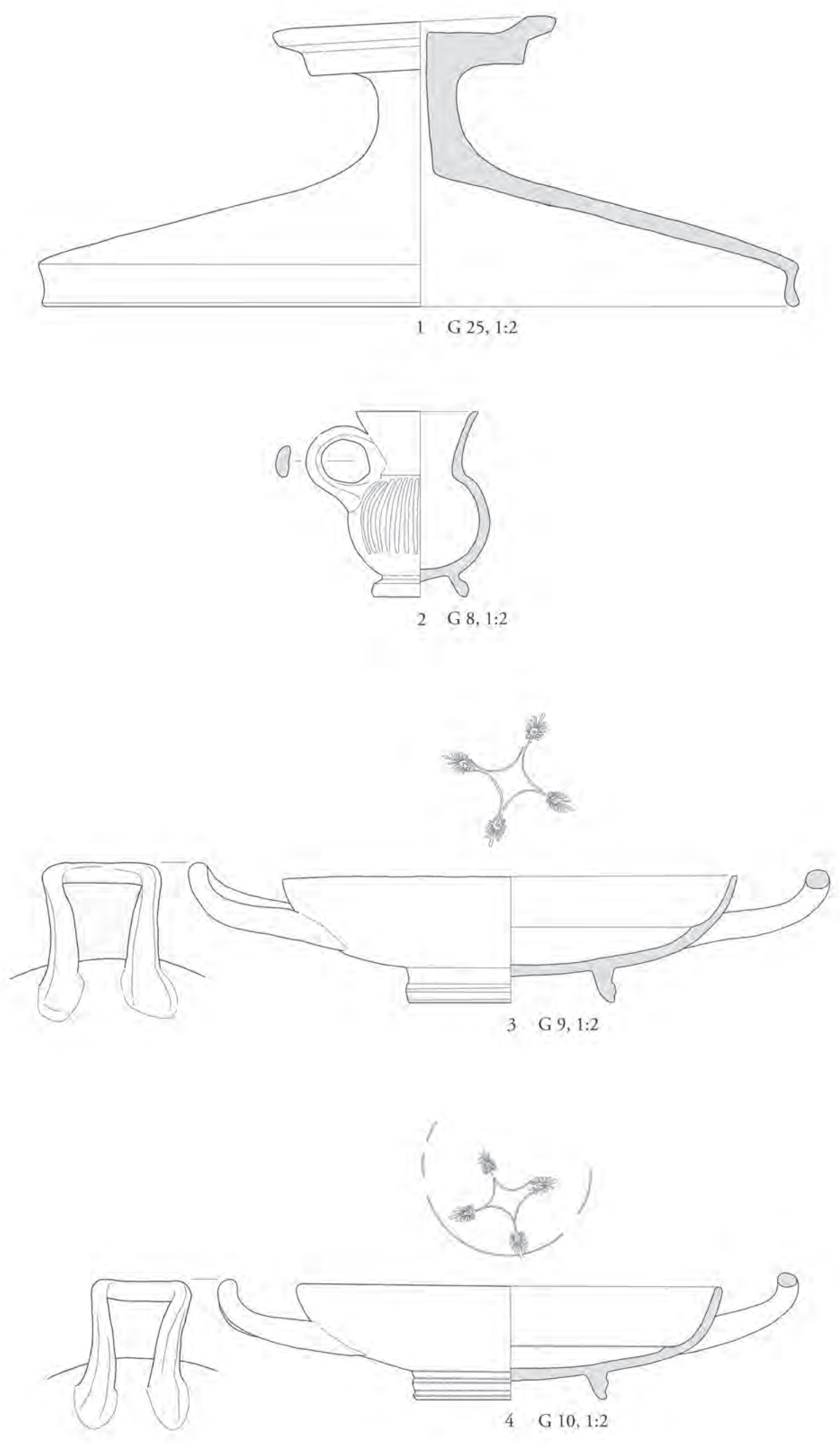

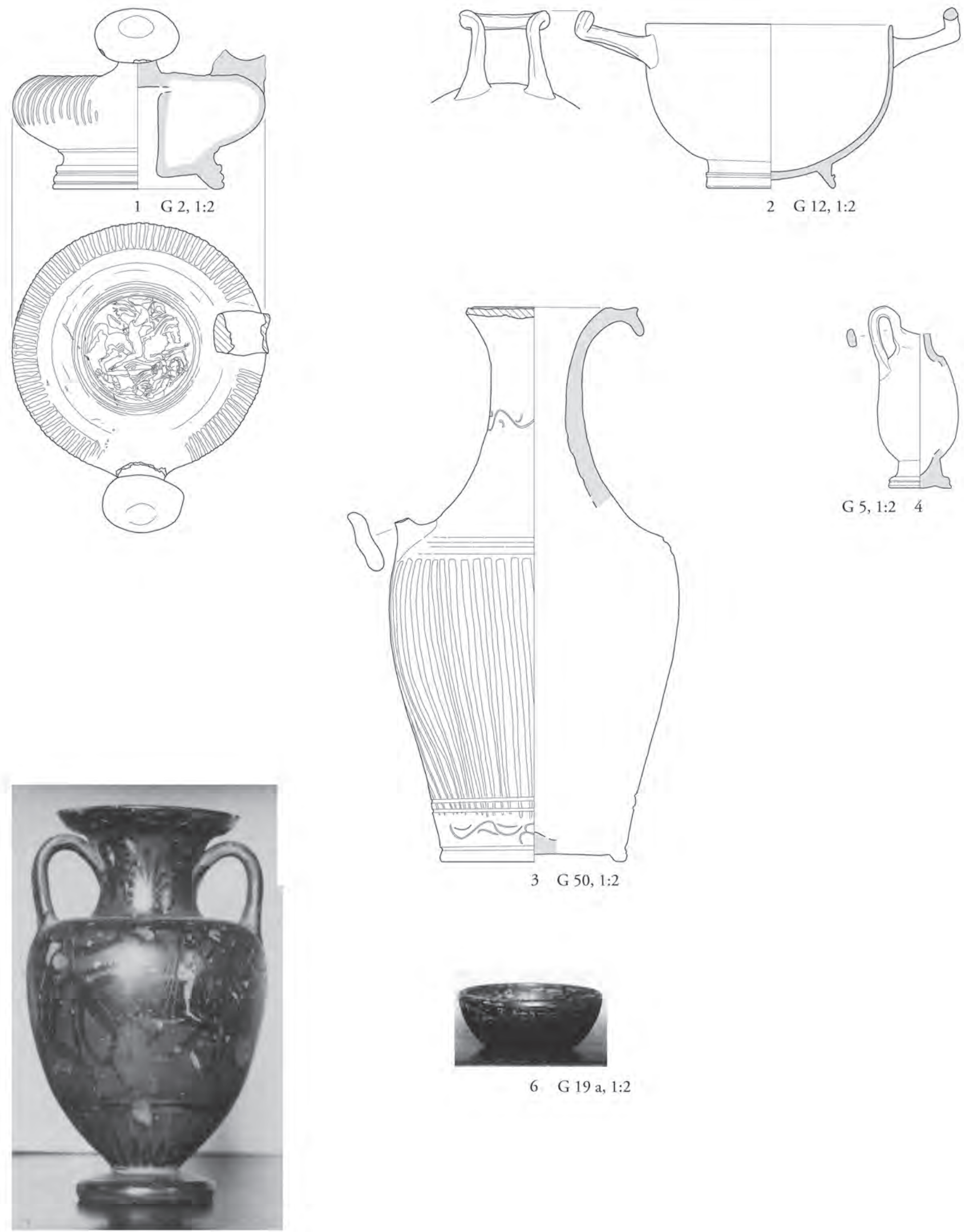

3 G 50, 1:2

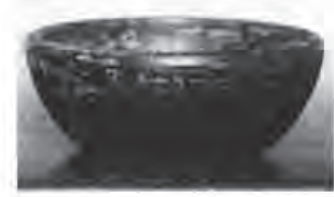

6 G 19 a, 1:2

5 G 13 a, 1:2 
TAFELN 



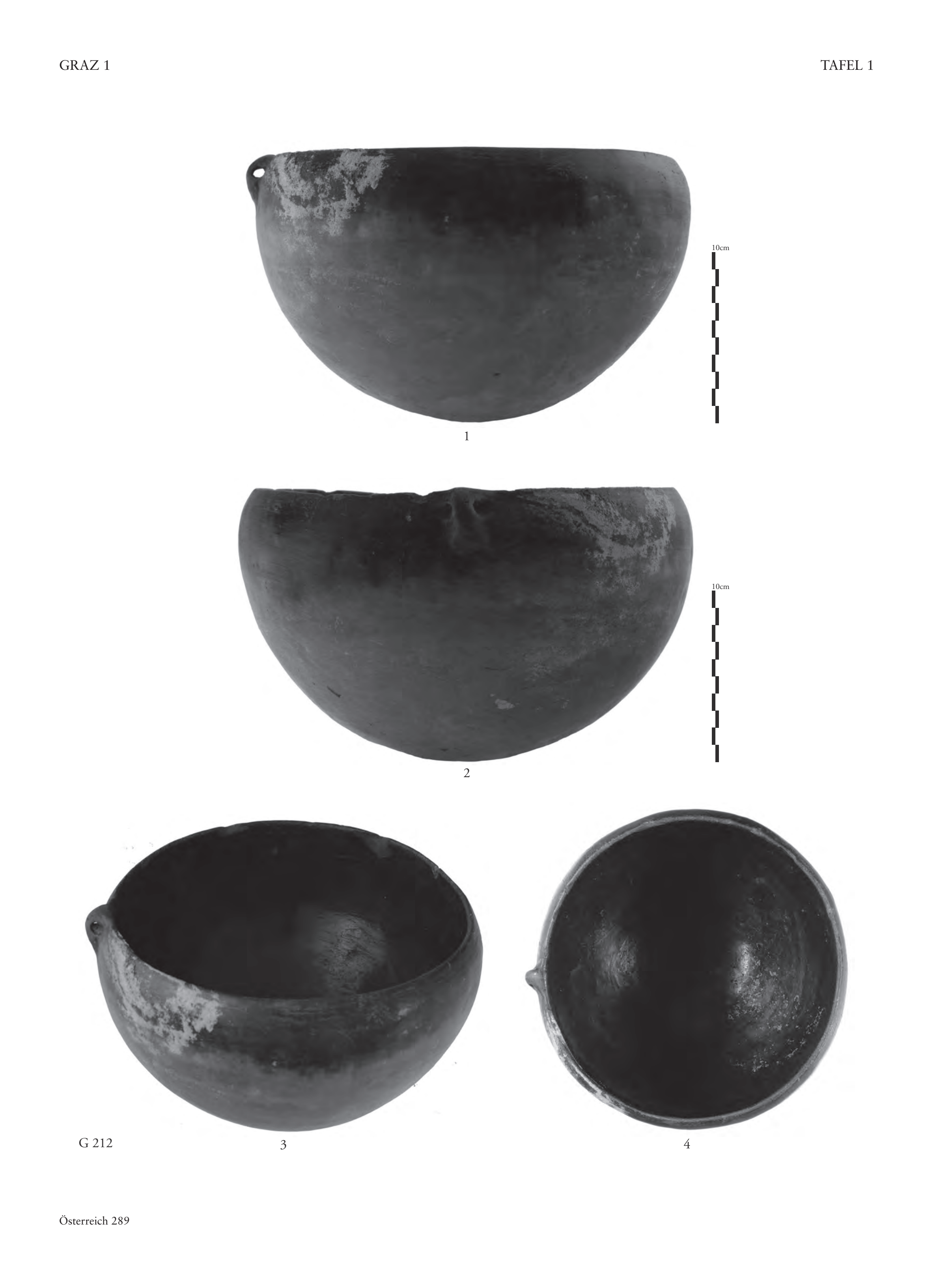



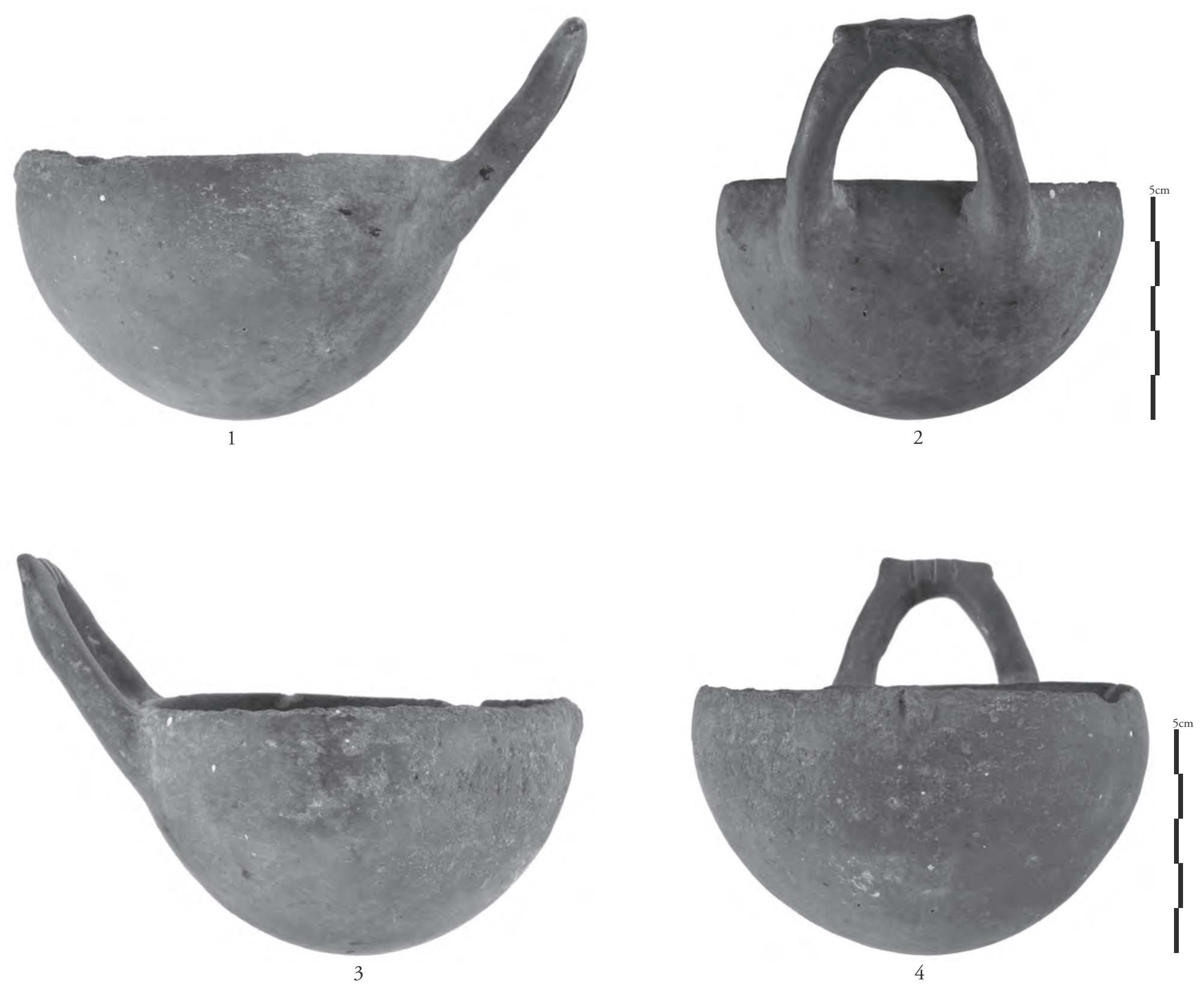

G 2046

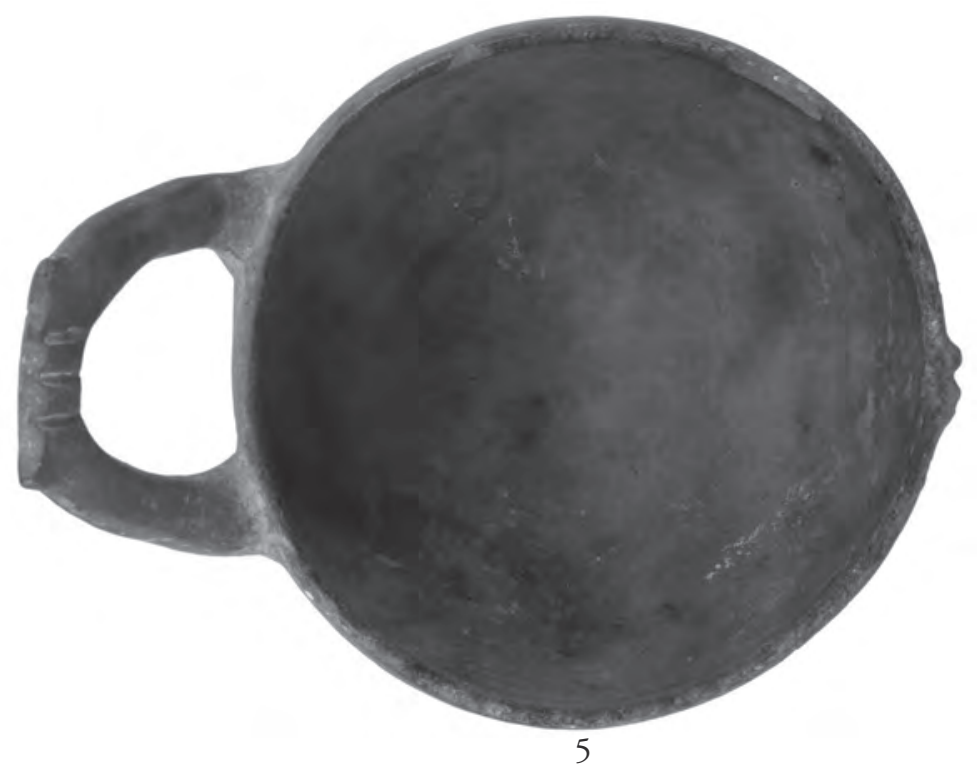



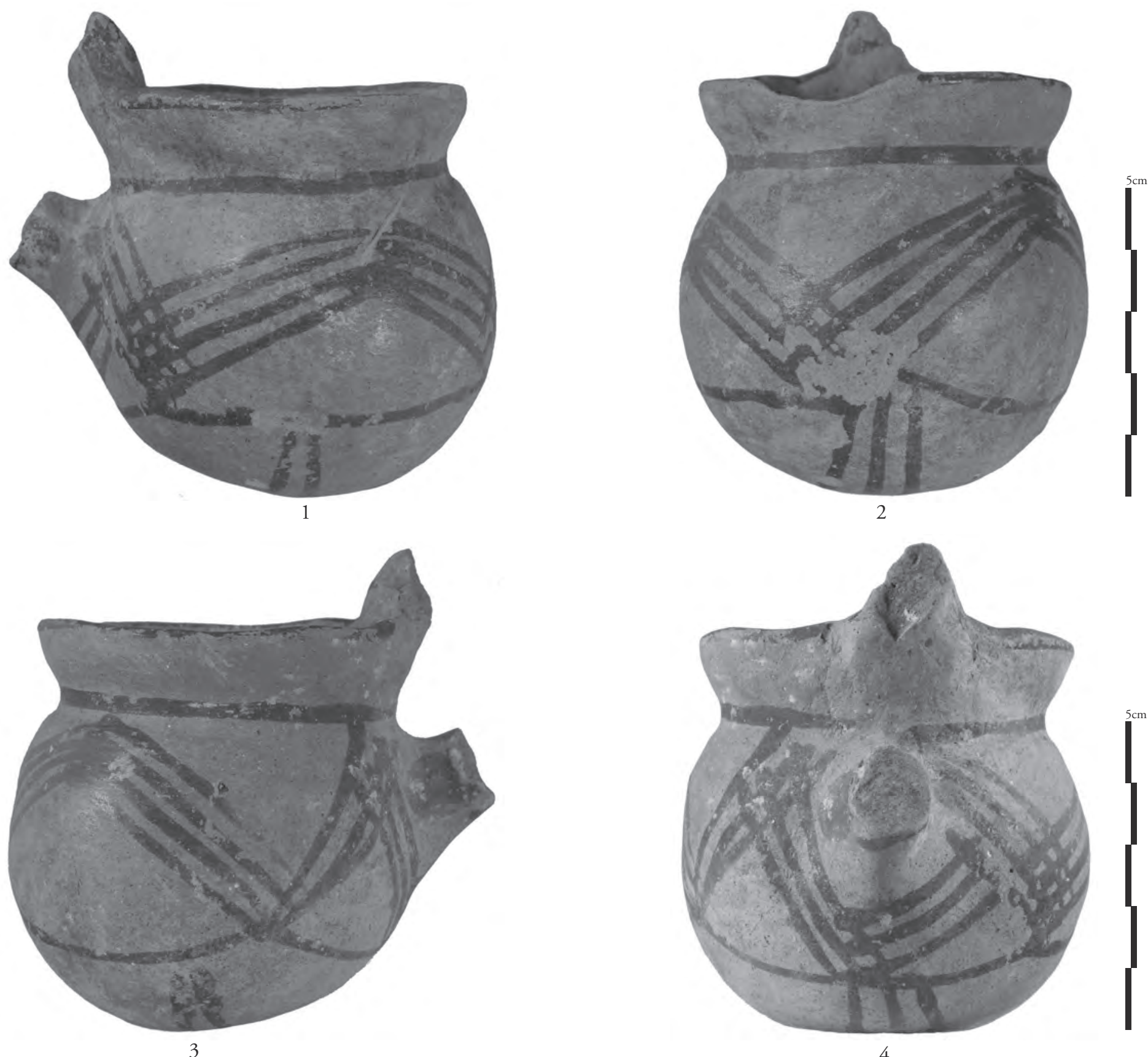

4
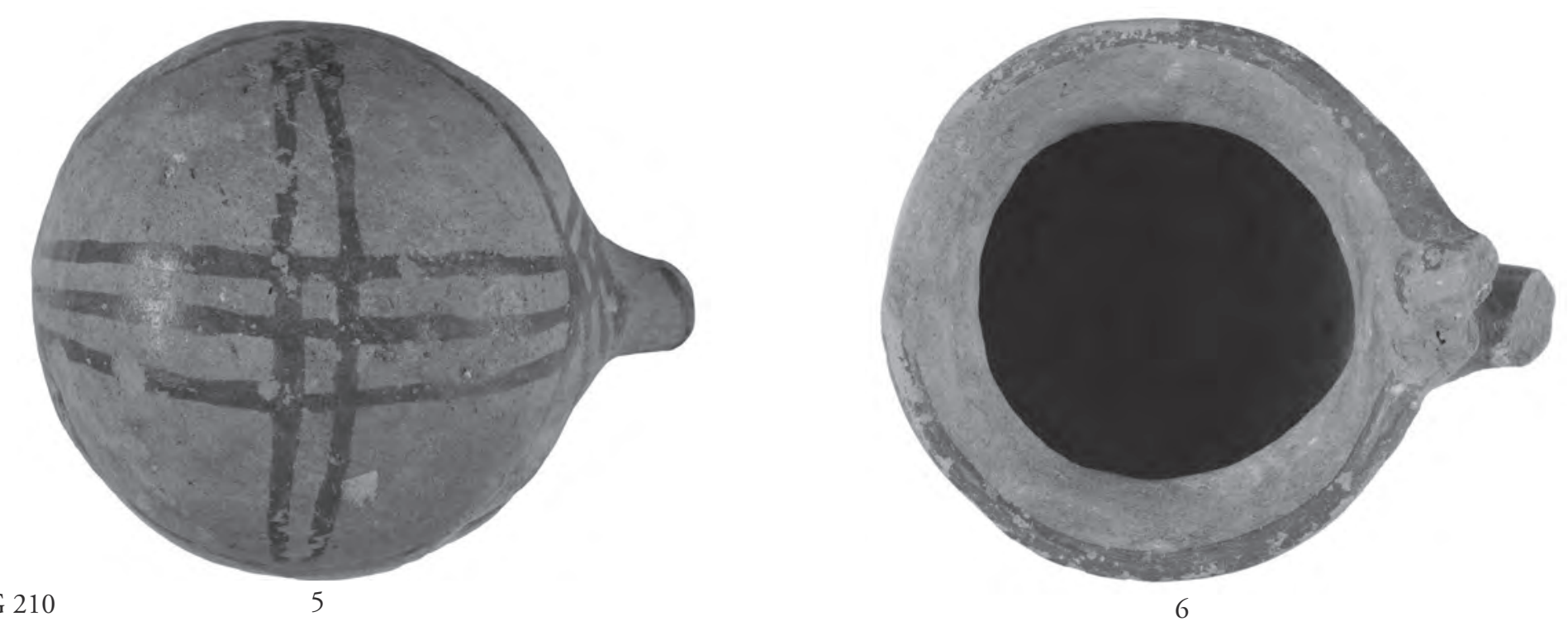

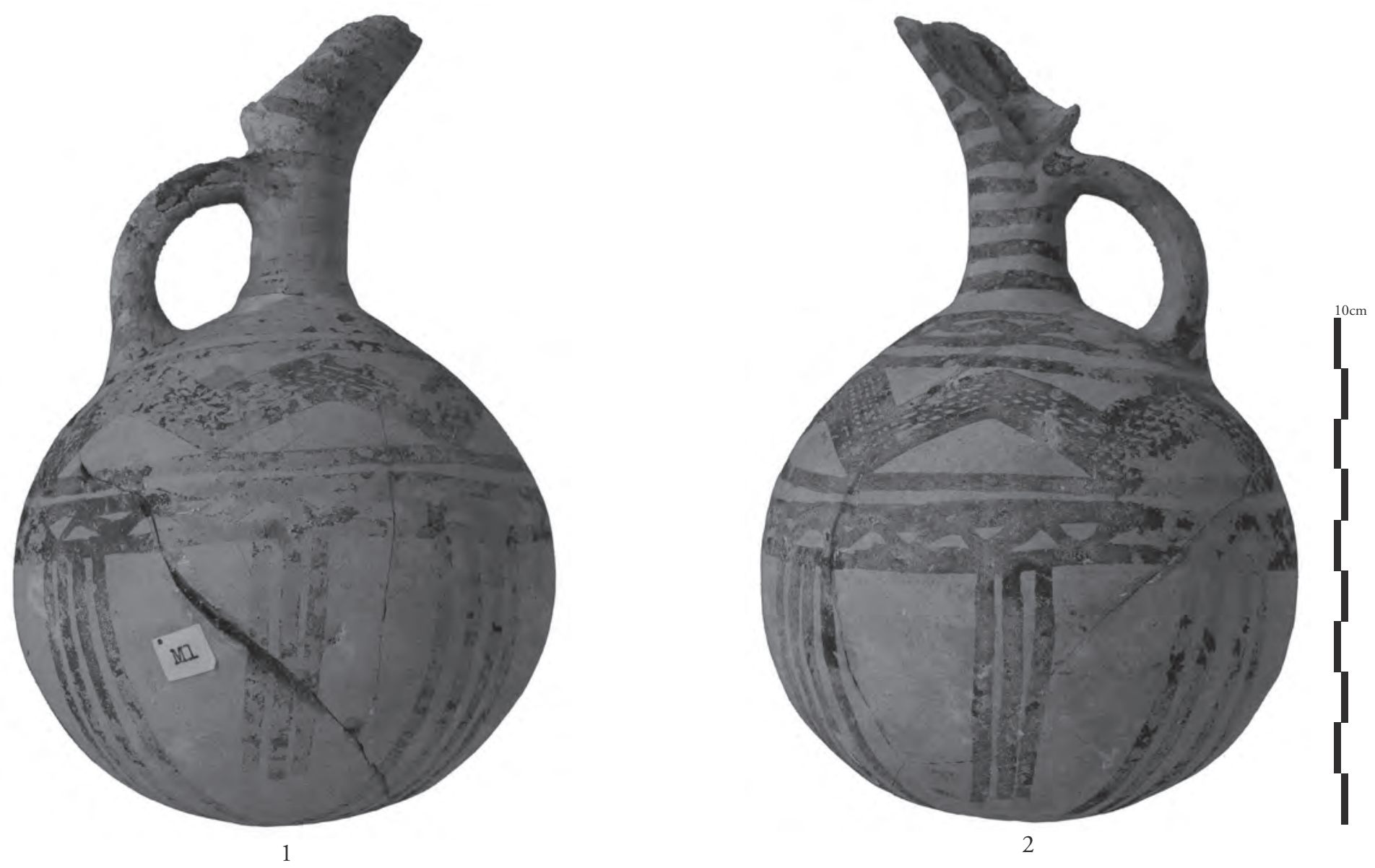

G 208
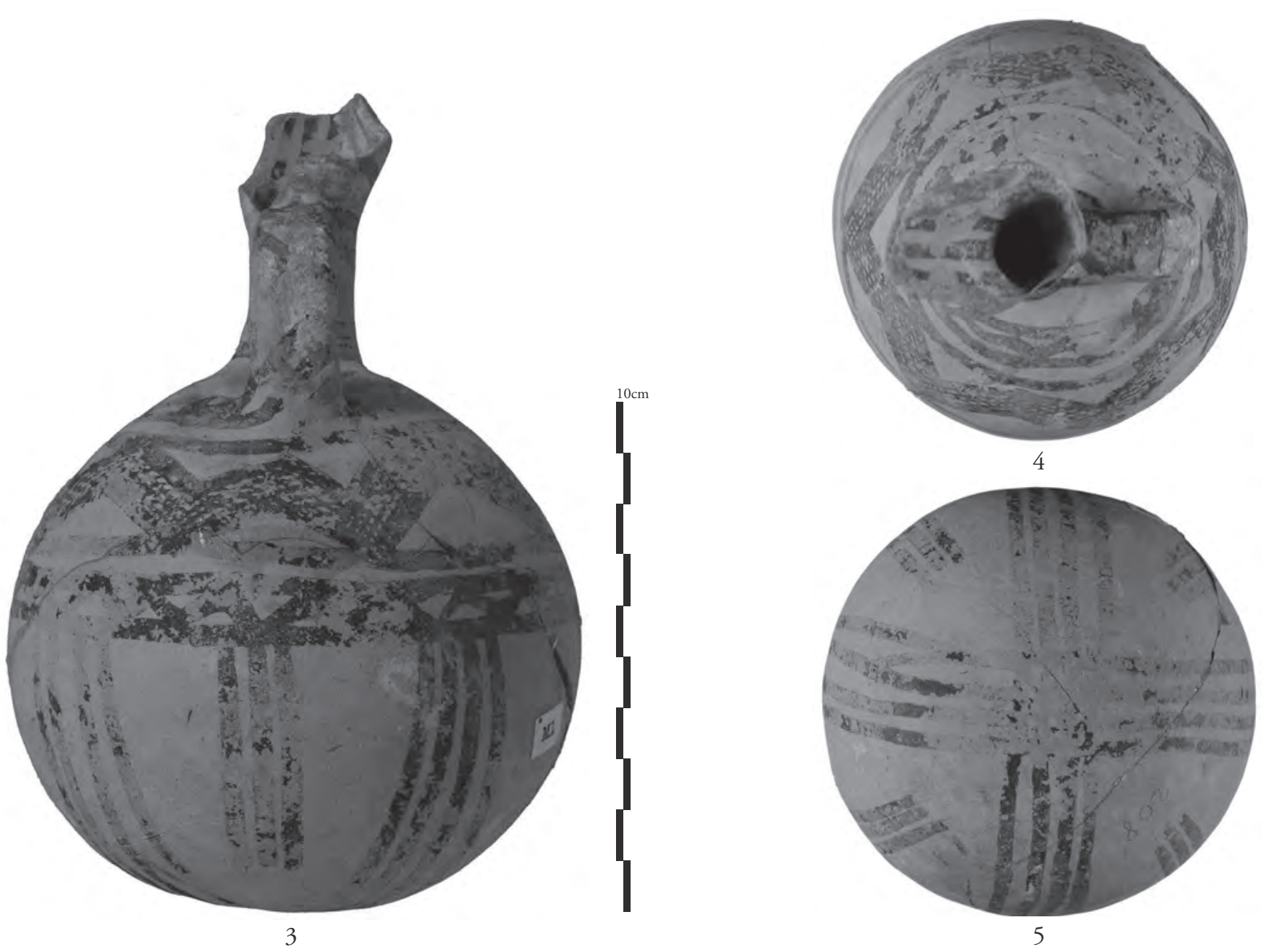

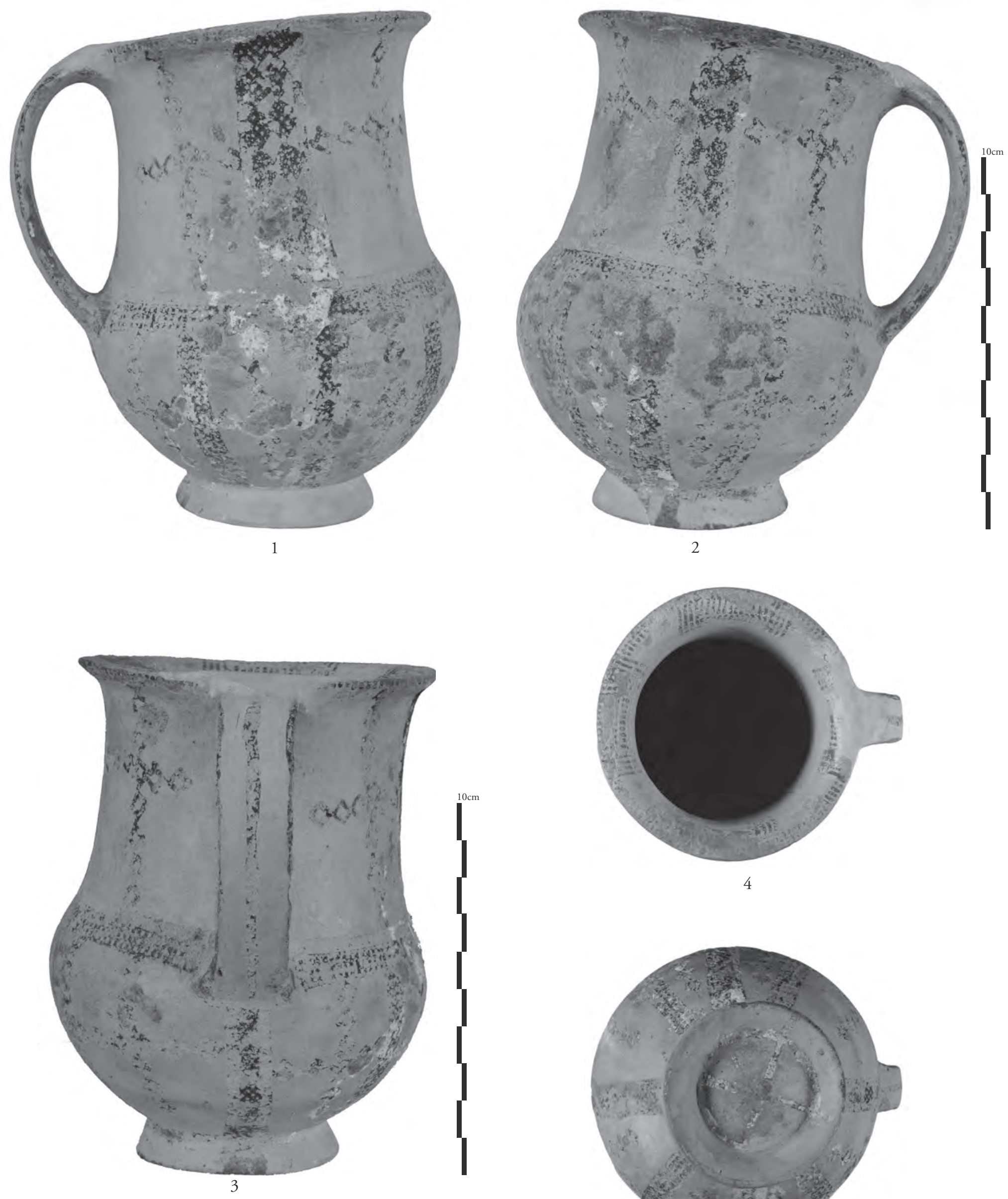

G 209

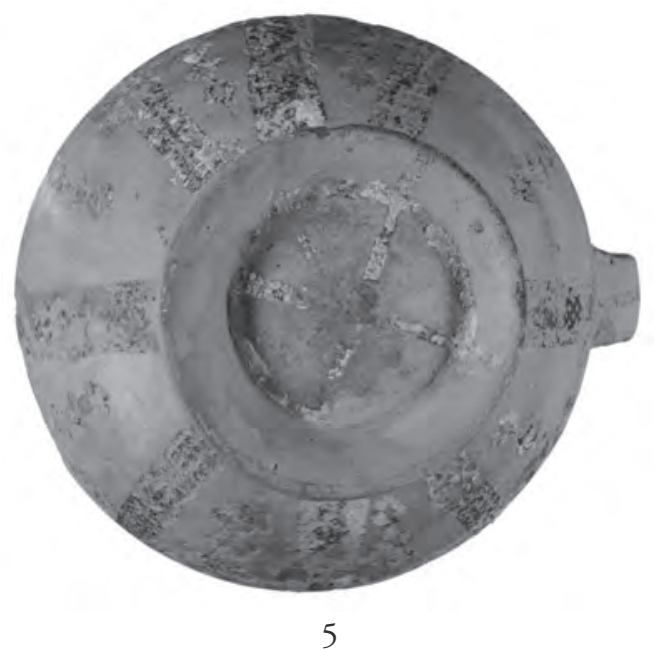



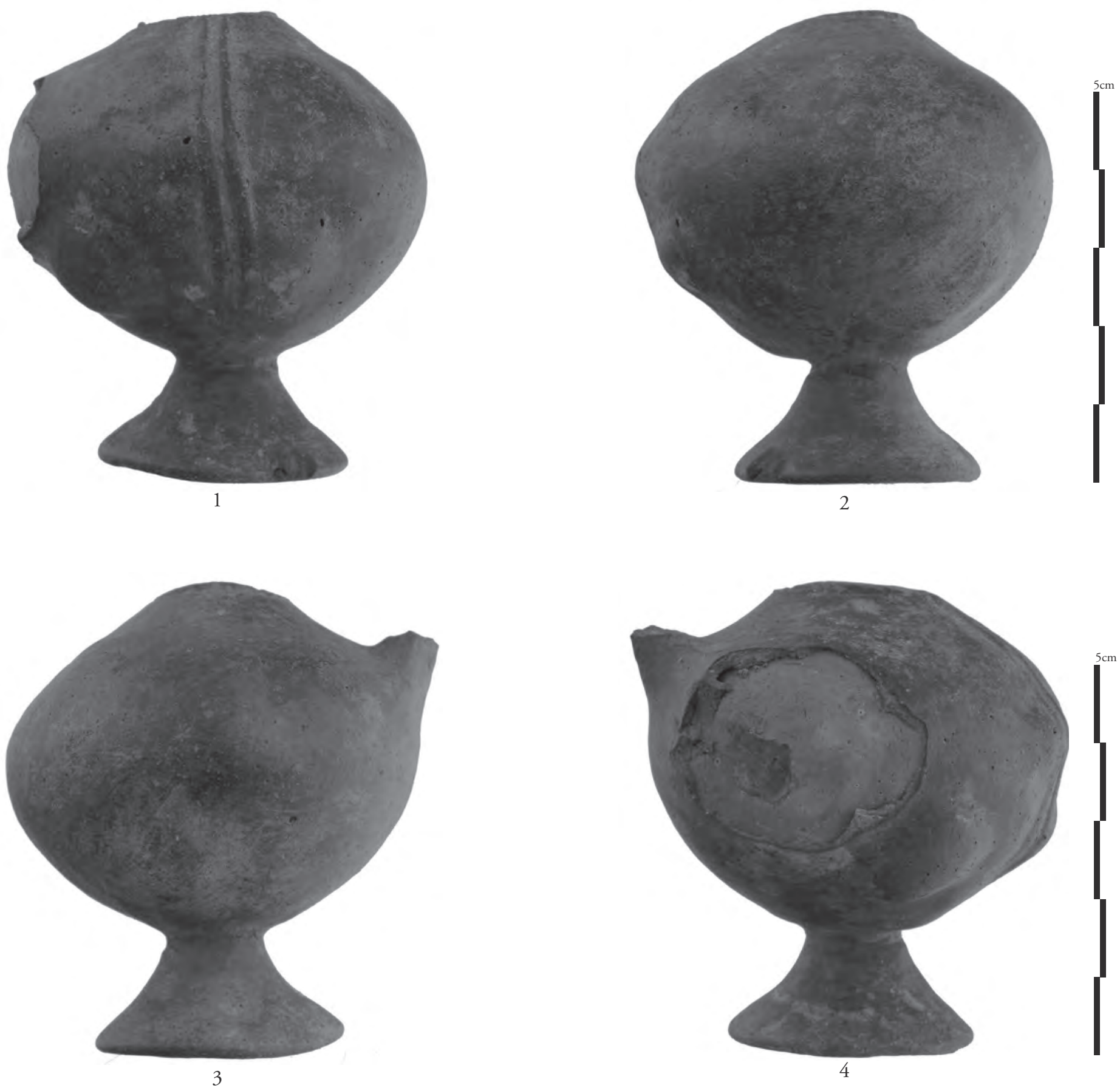

G 57
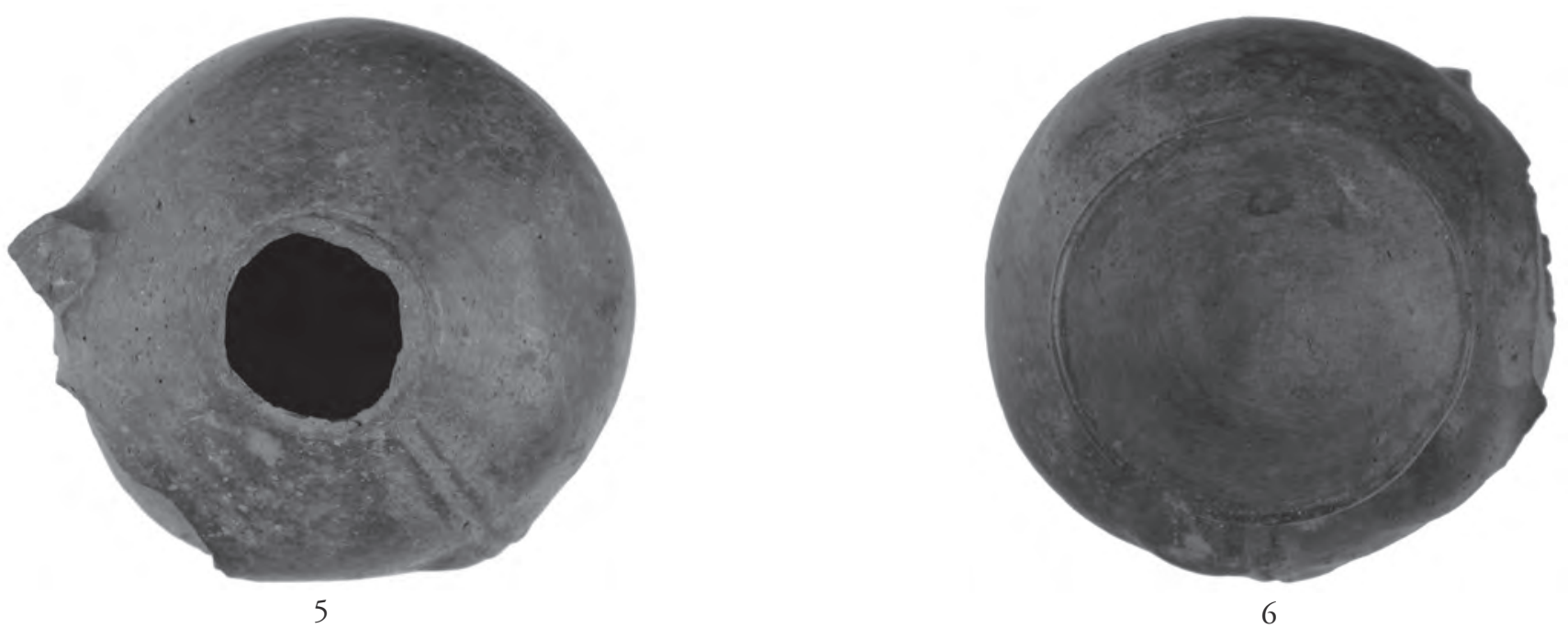

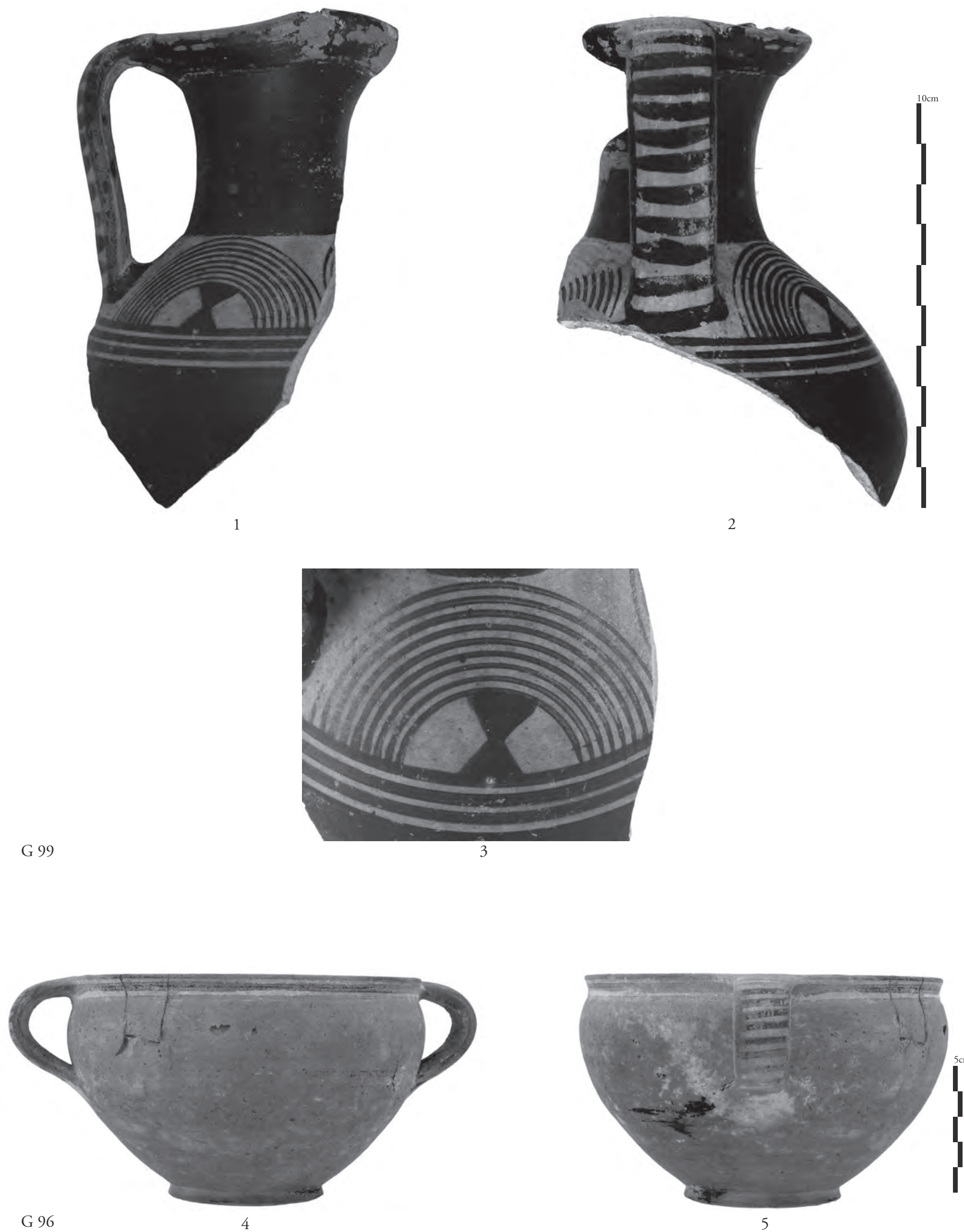

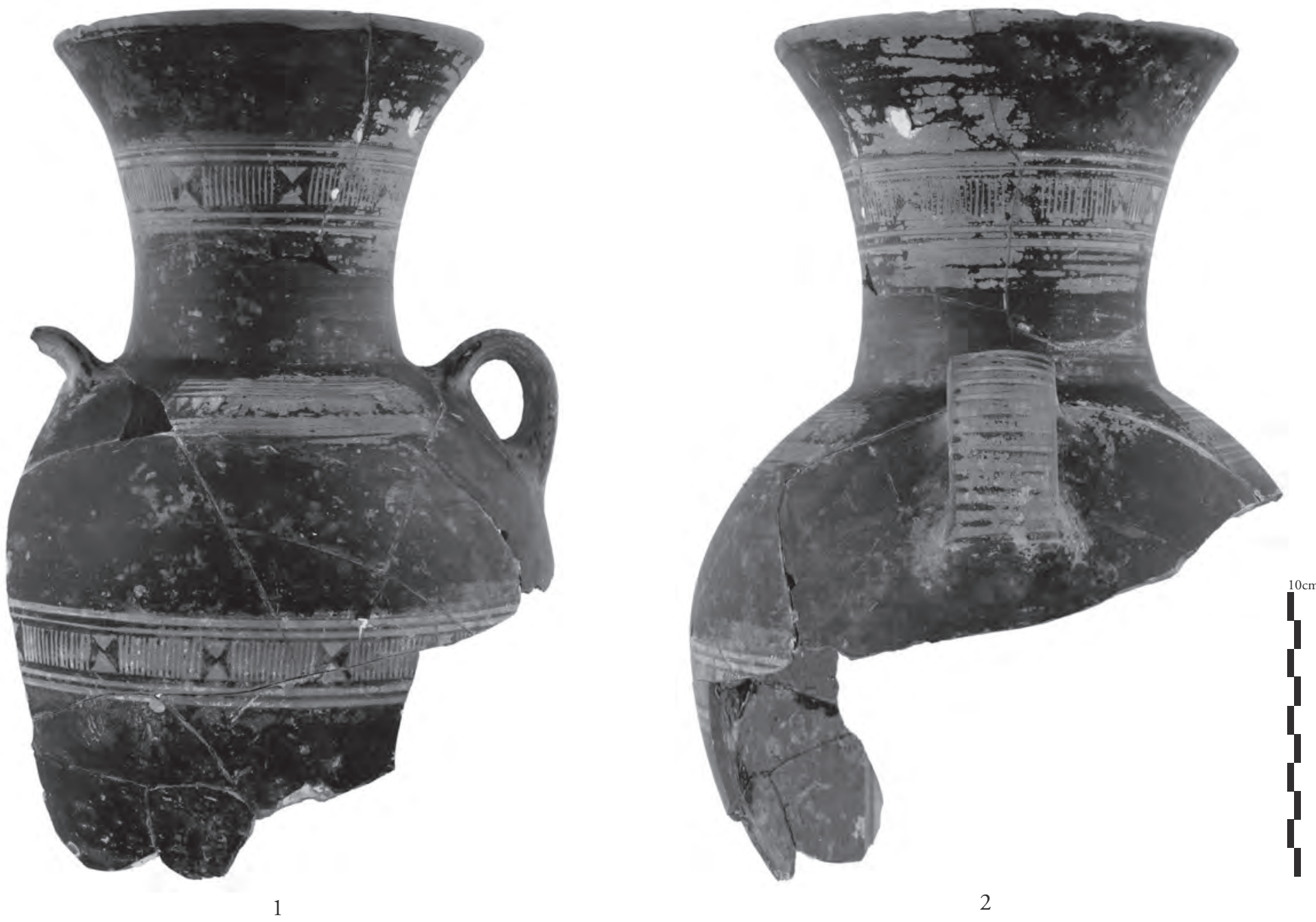

G 100

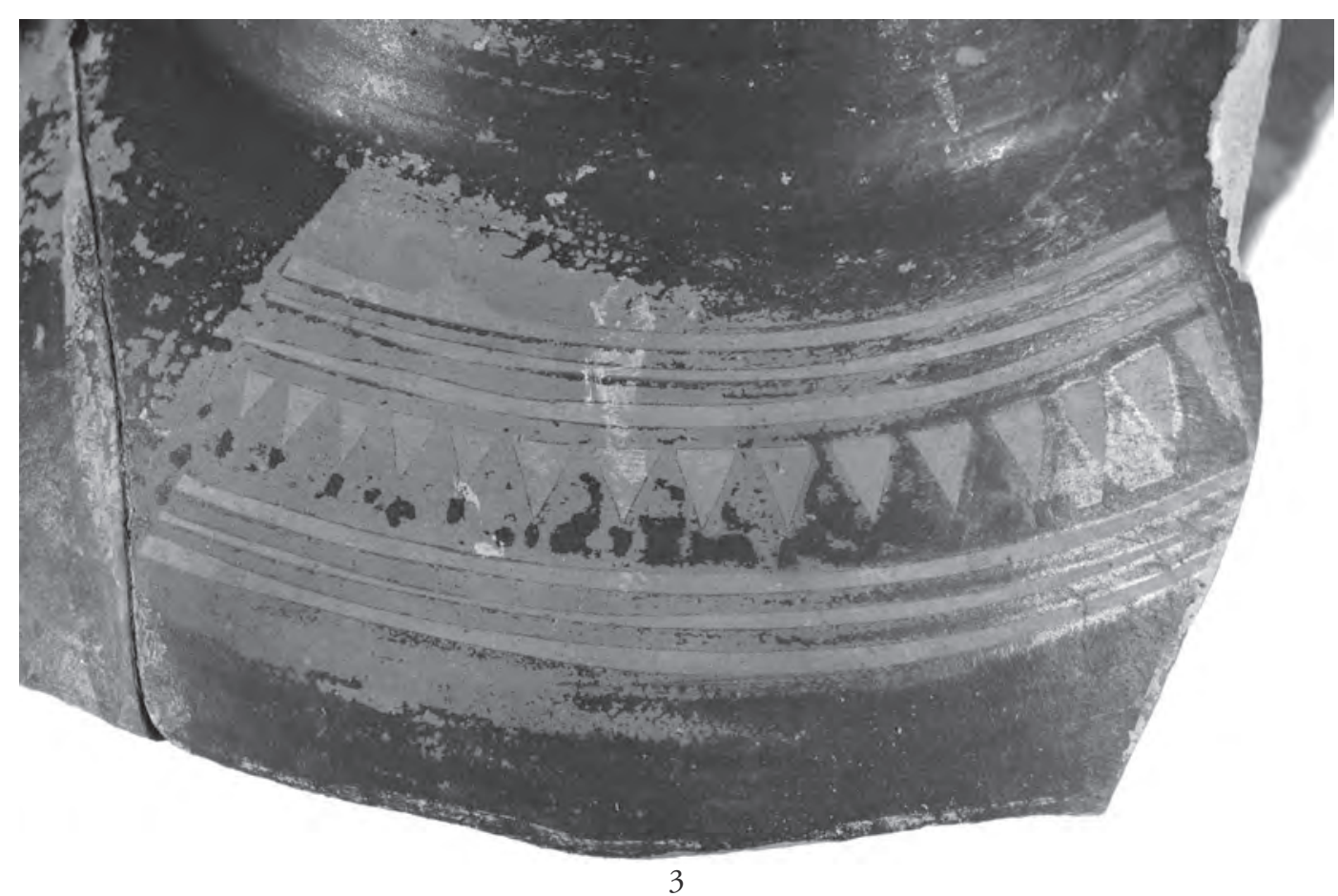



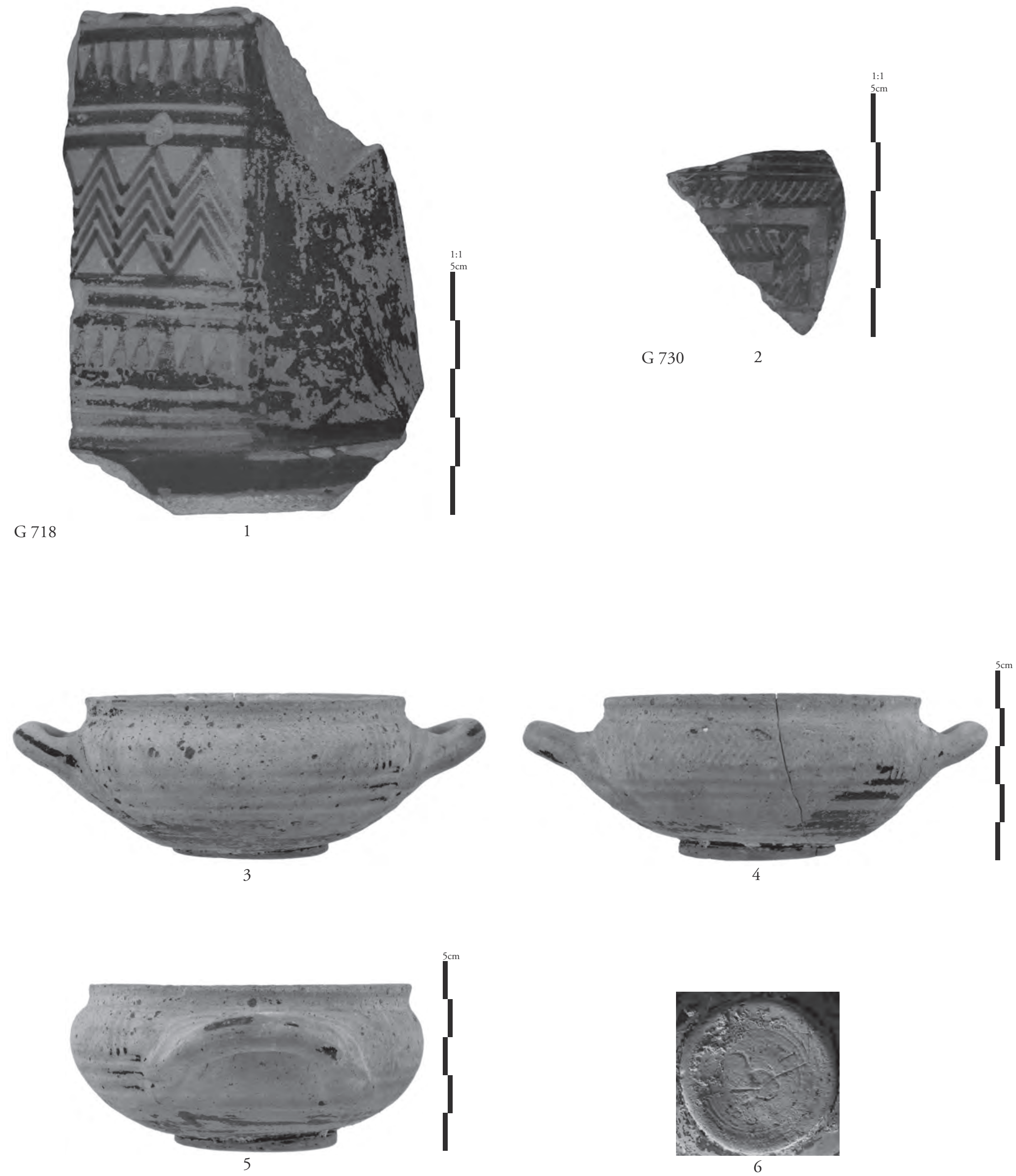

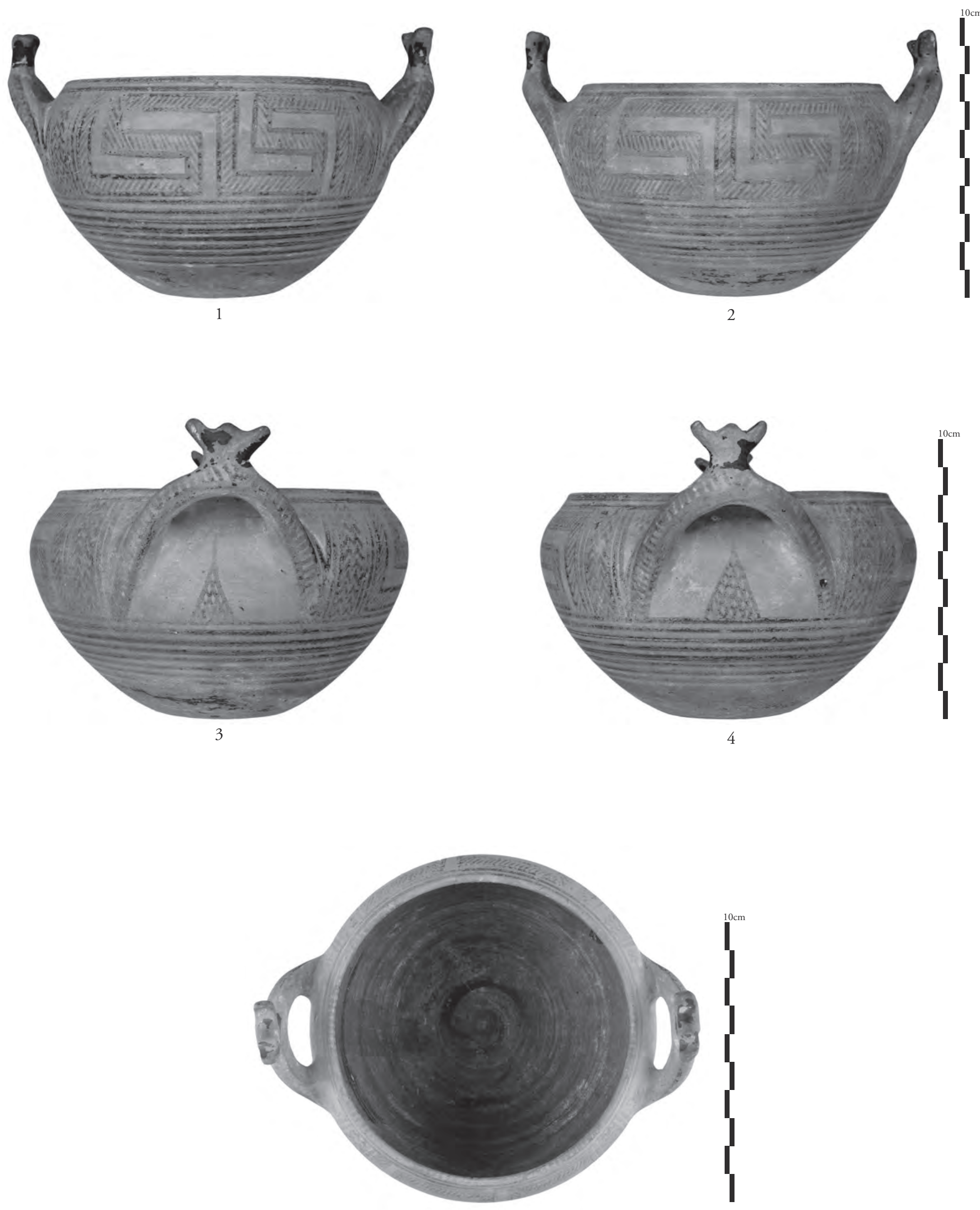

G 44

5 

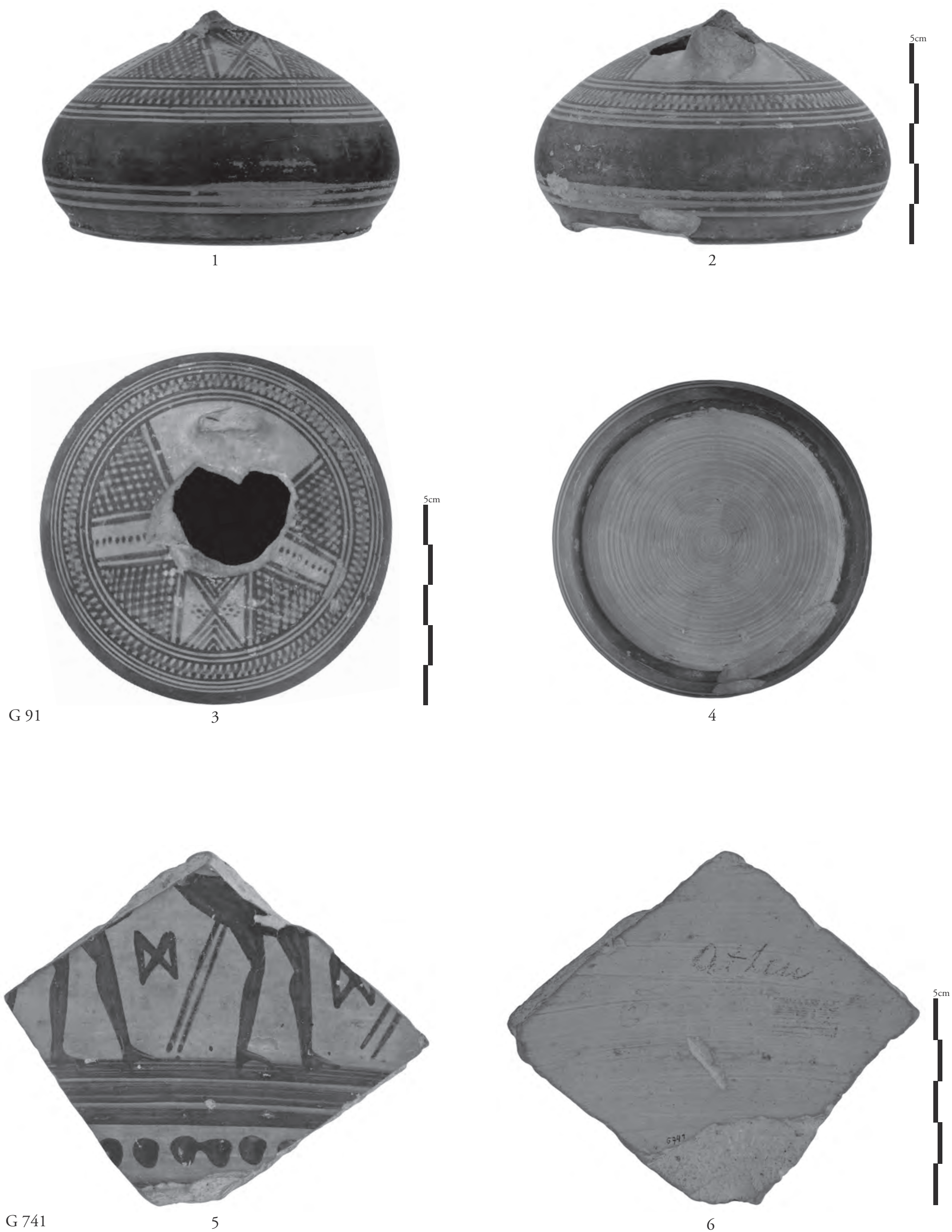

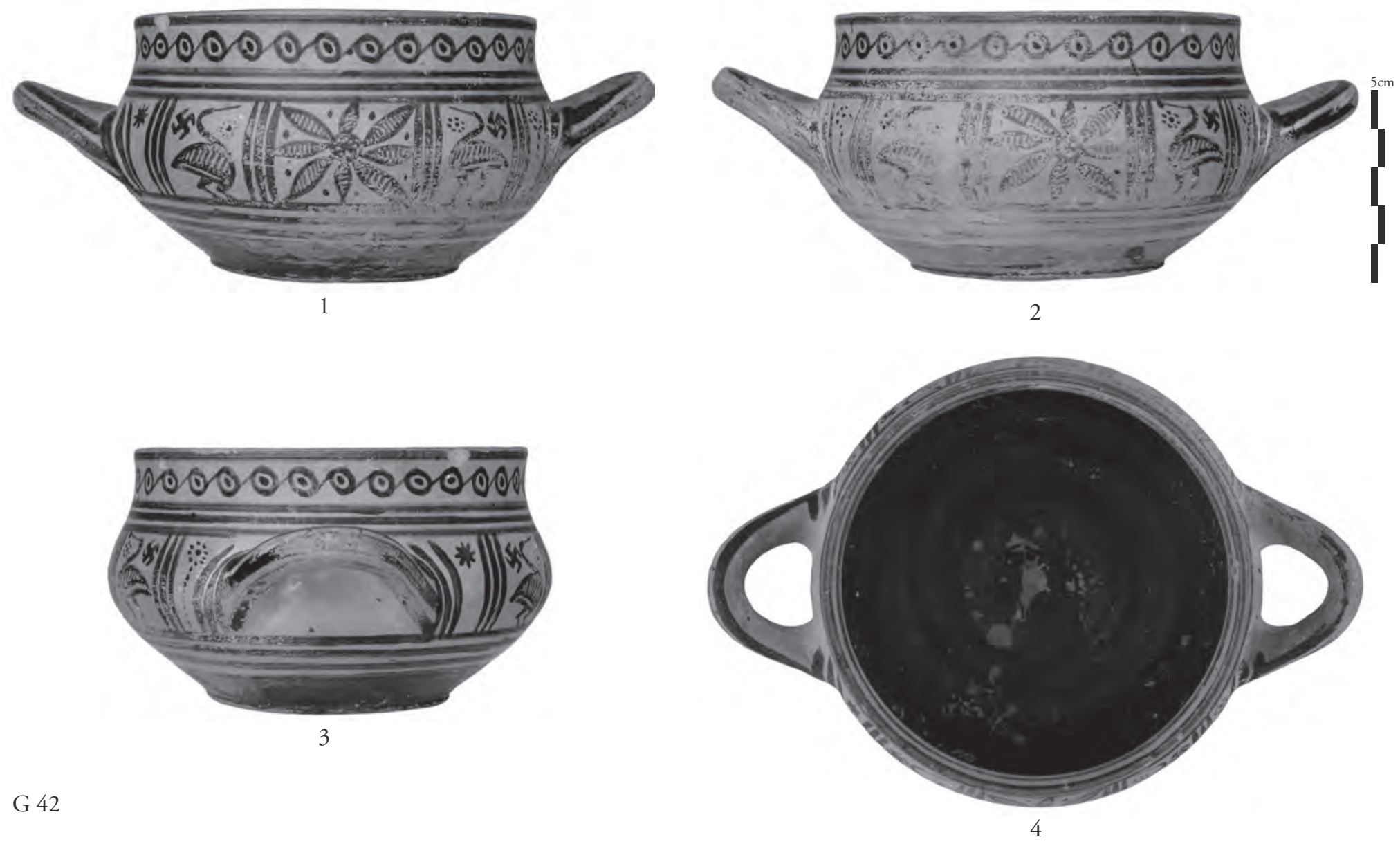

G 42
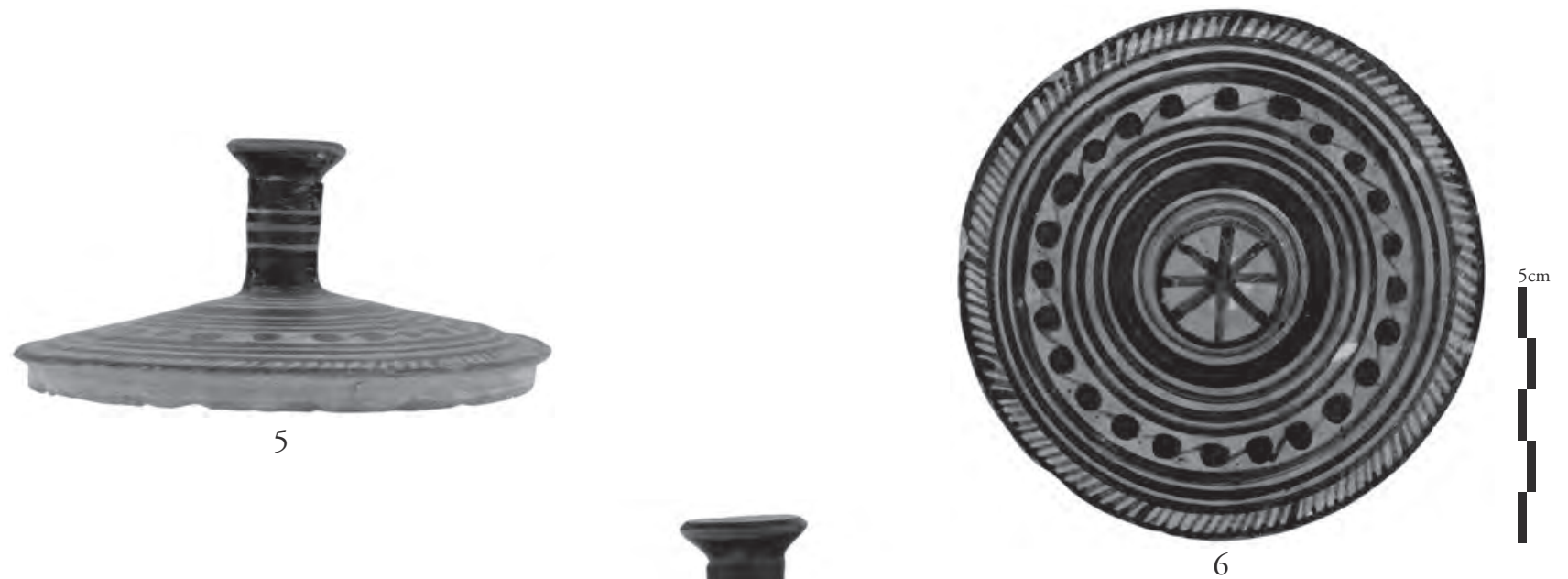

G 42a

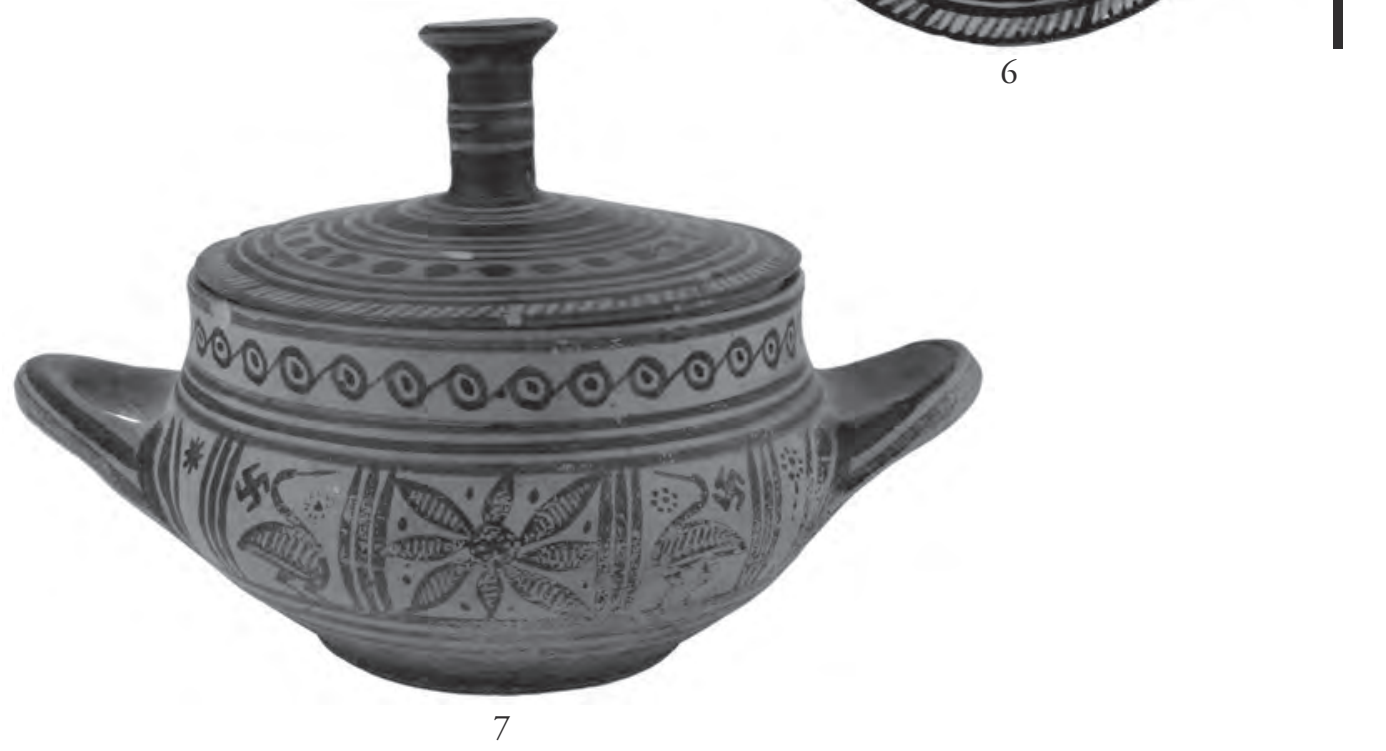



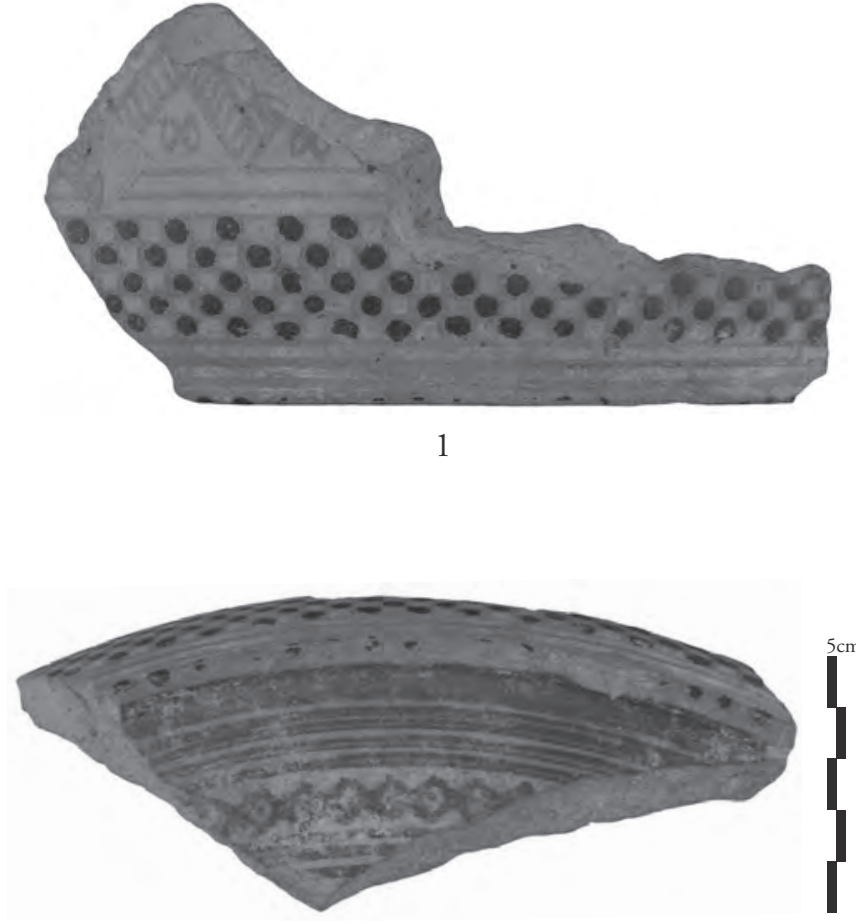

G 719
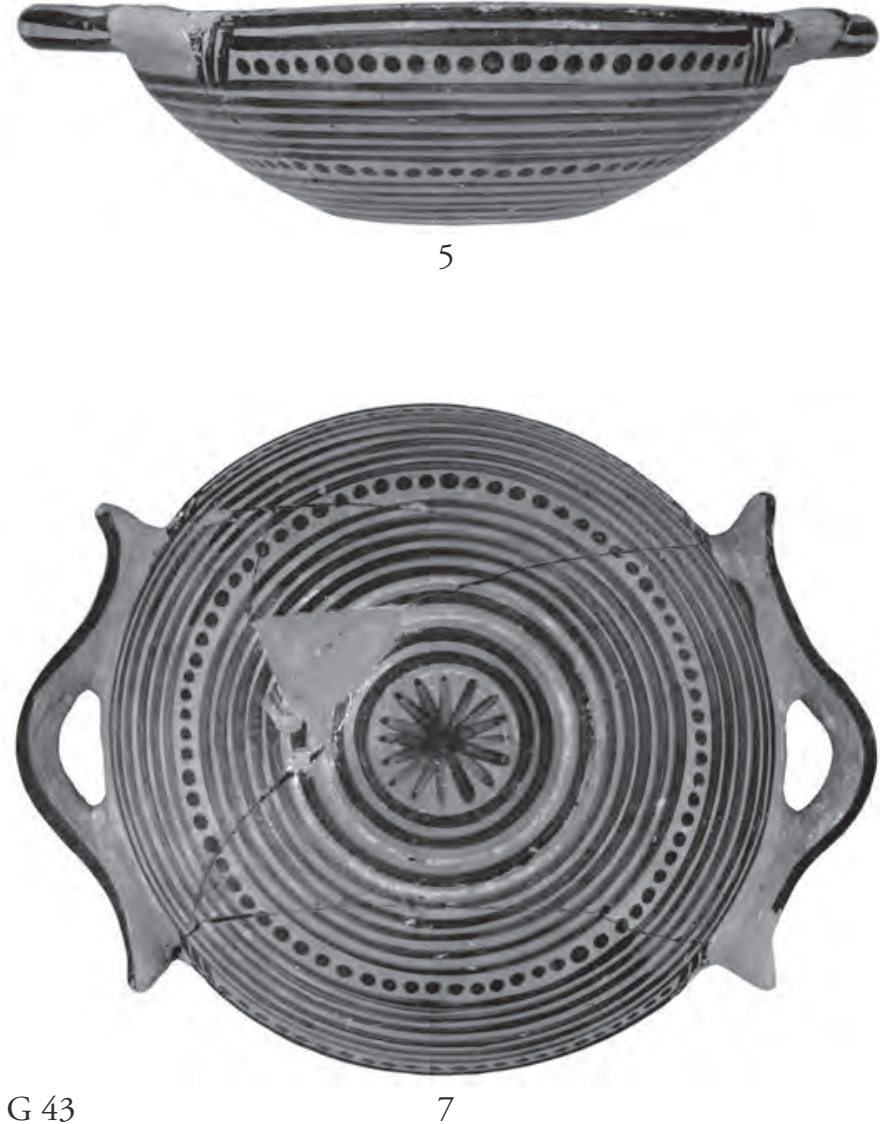

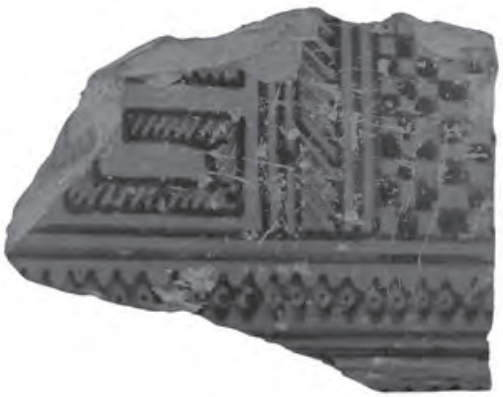

3

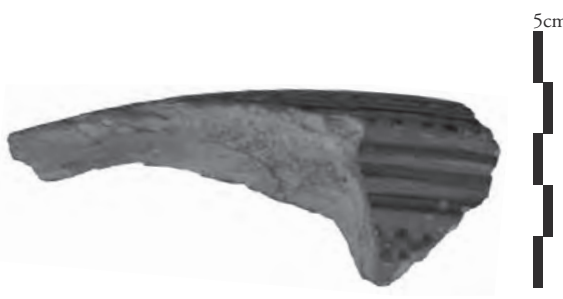

G 729
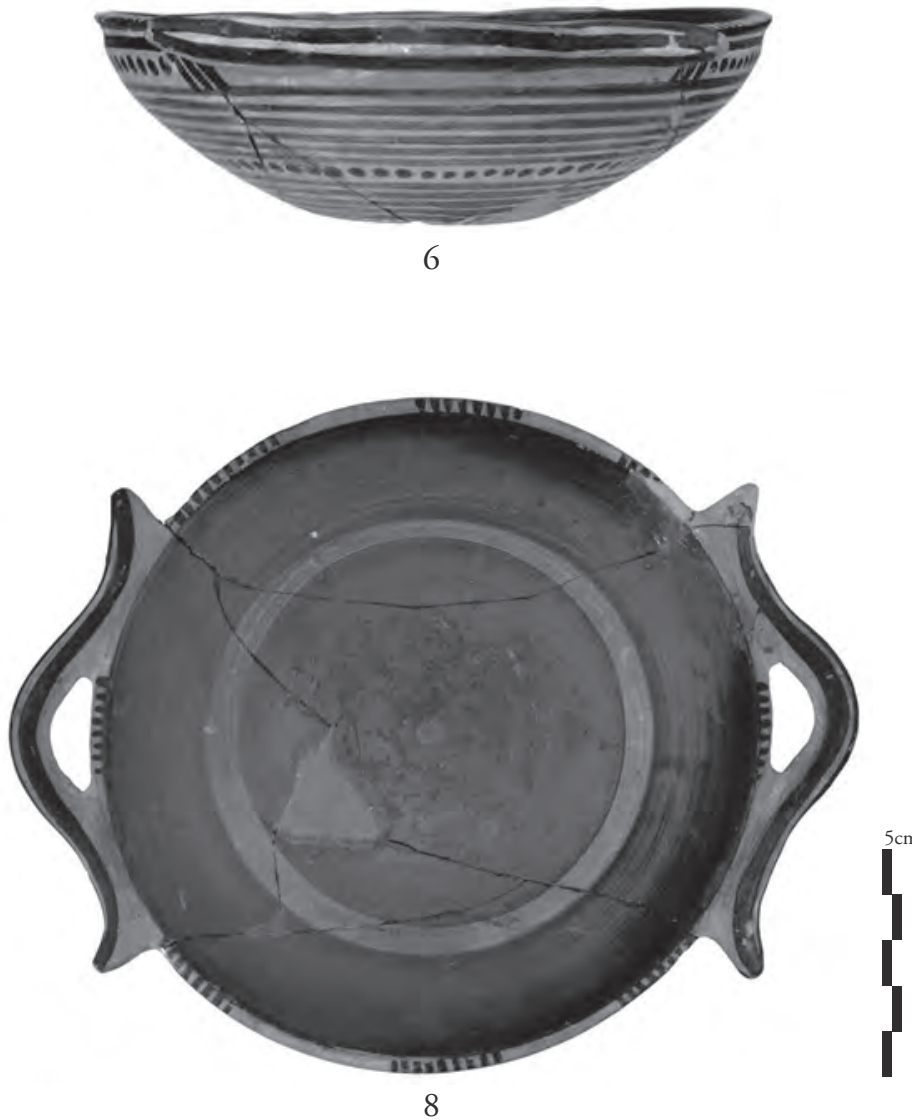


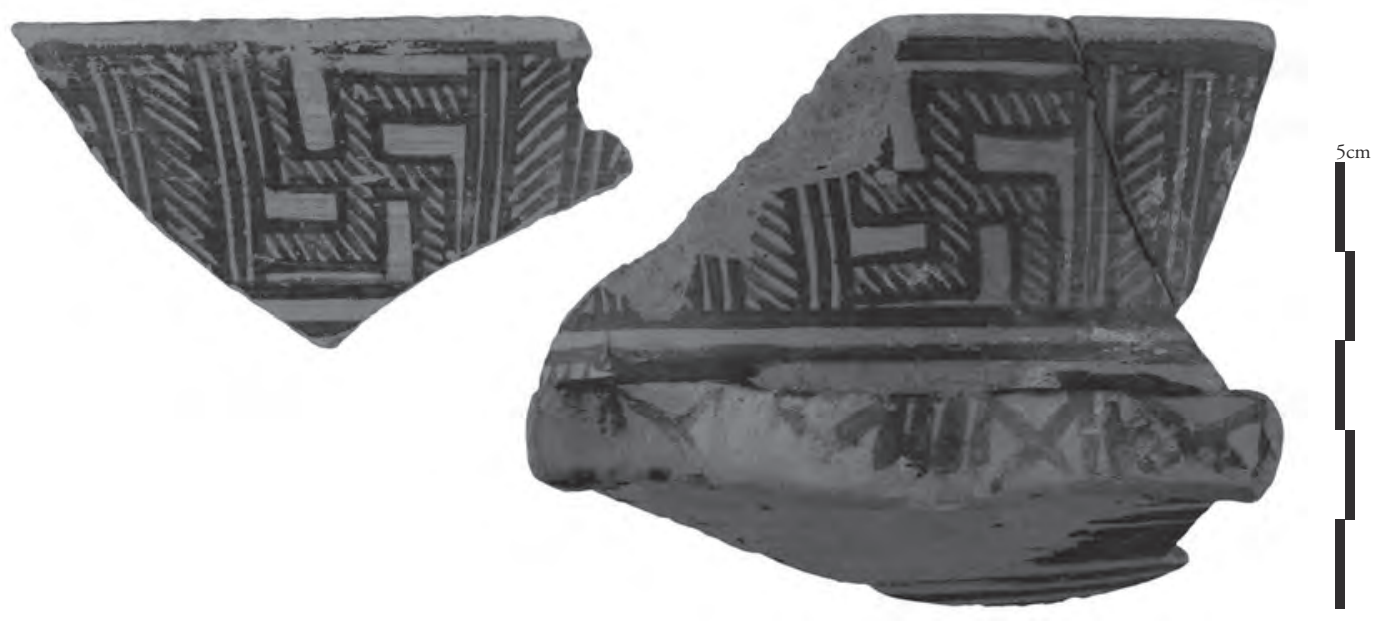

1

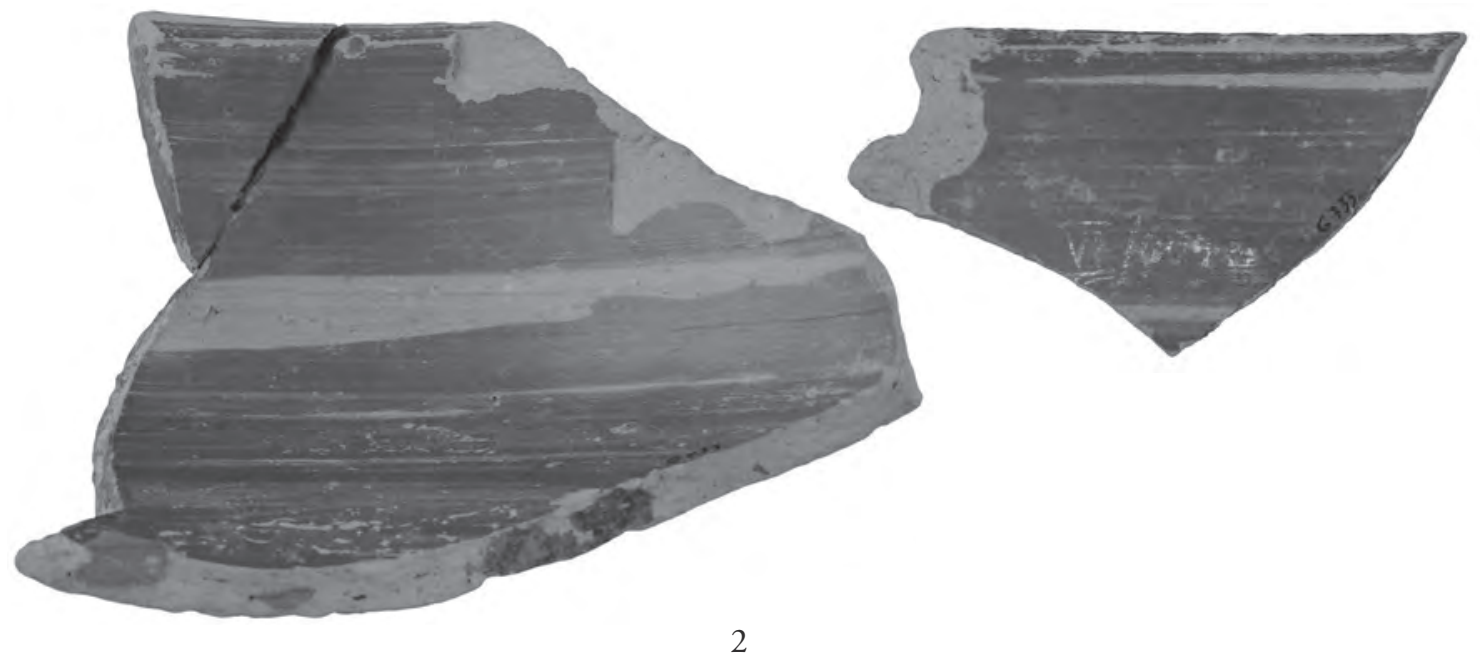

G 733

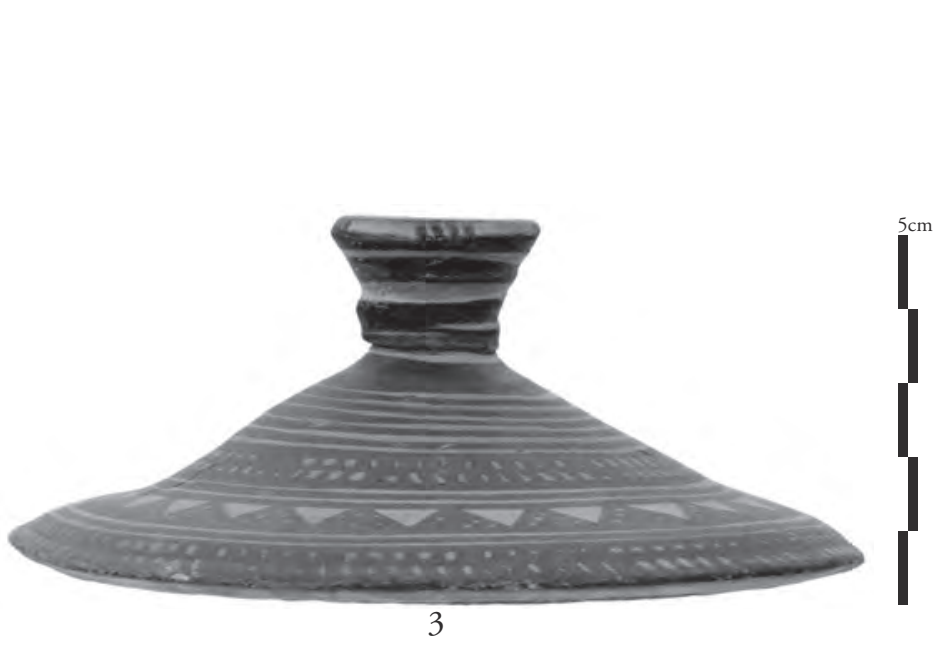

G 95

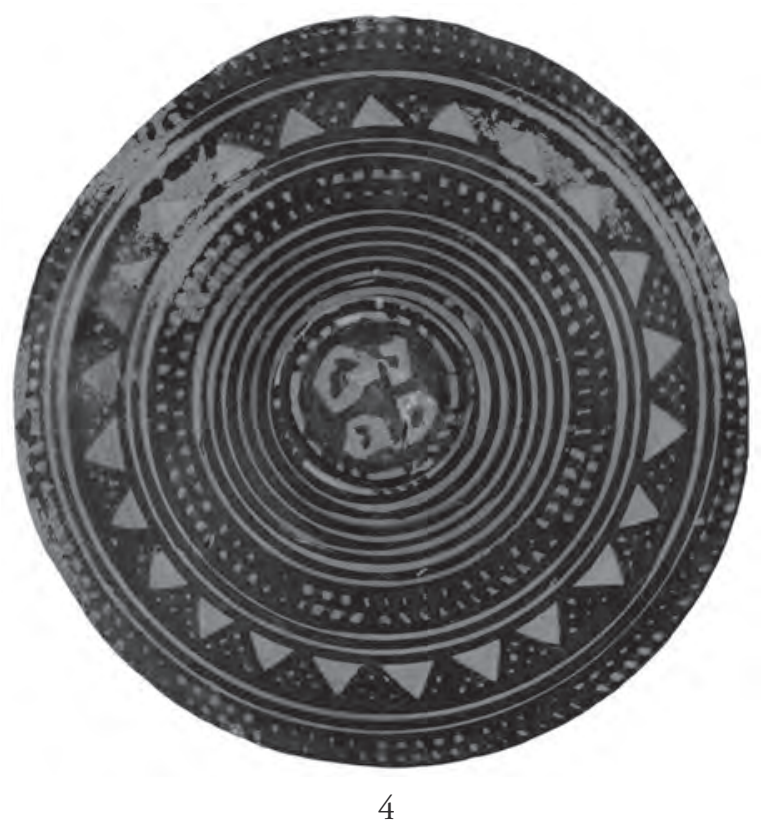




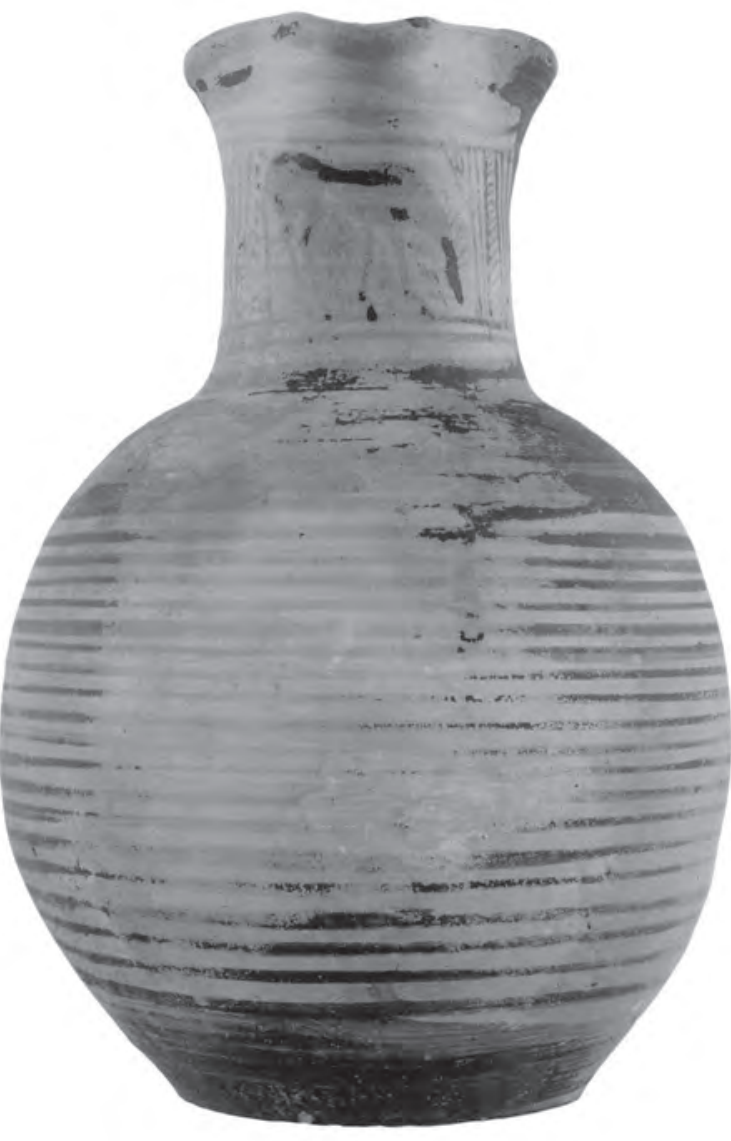

1

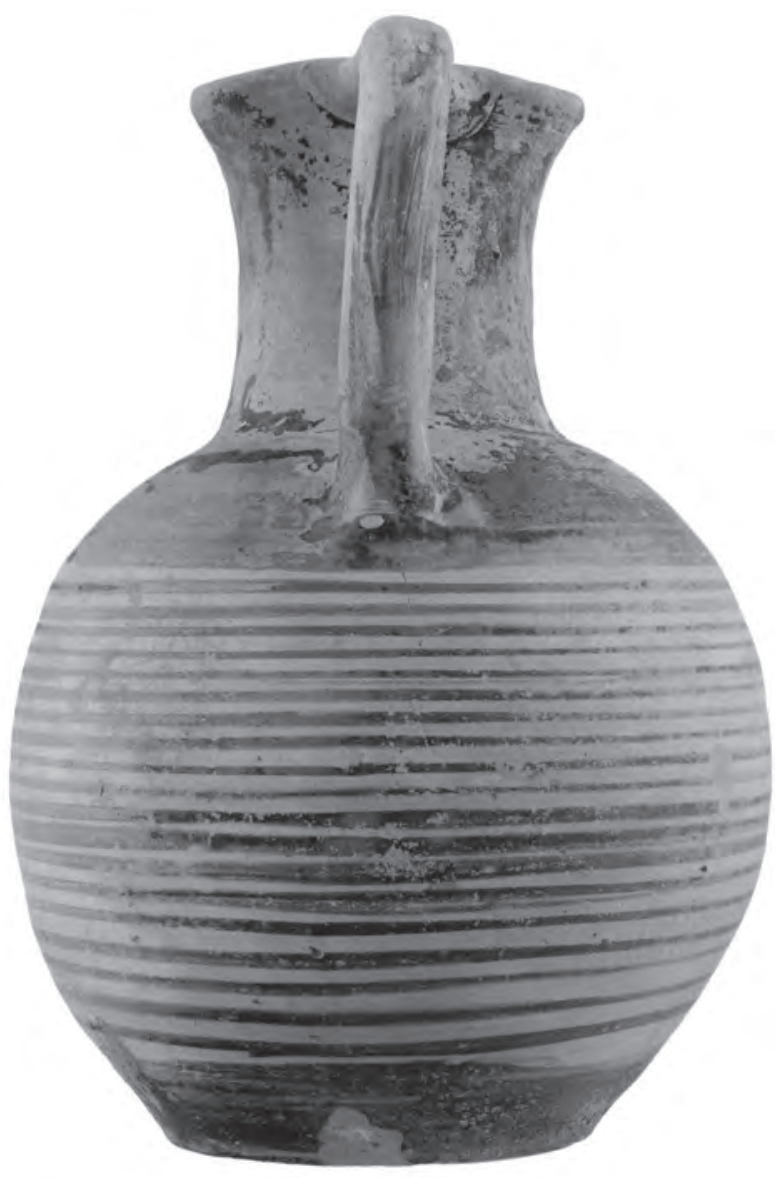

3

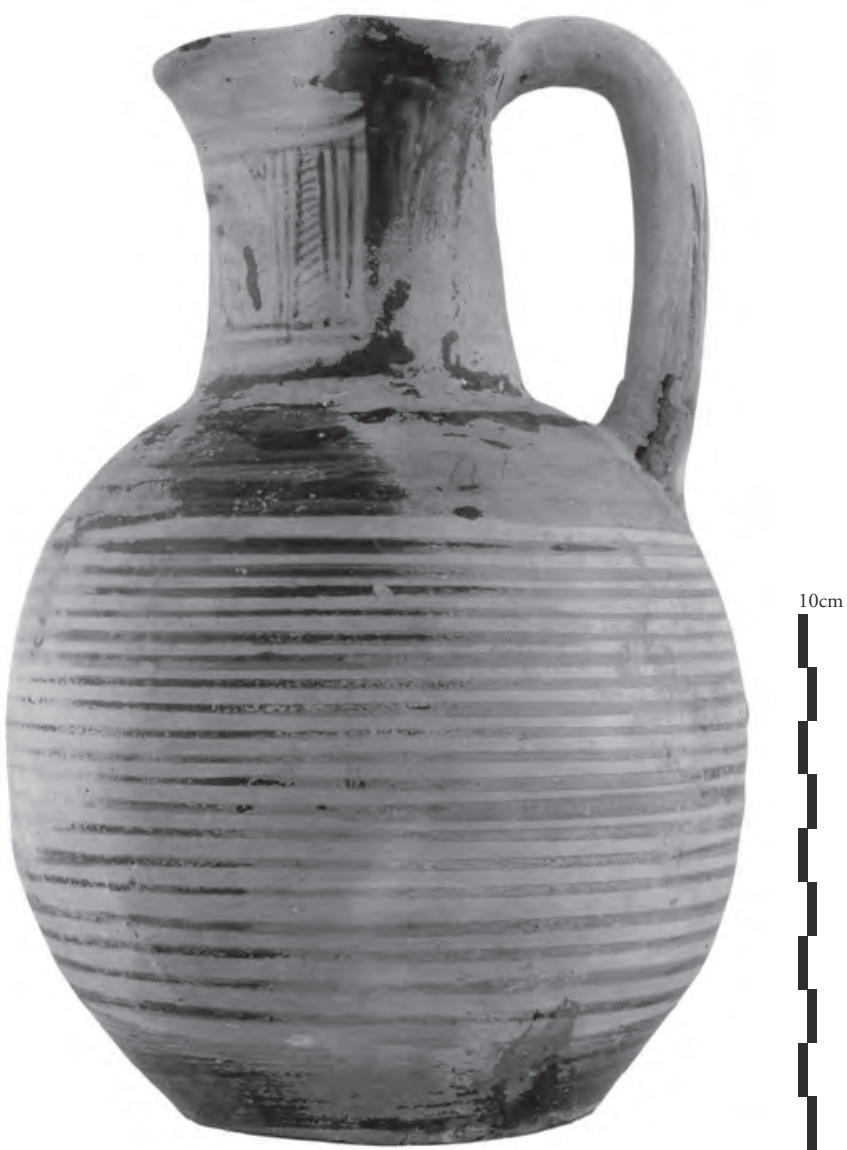

2

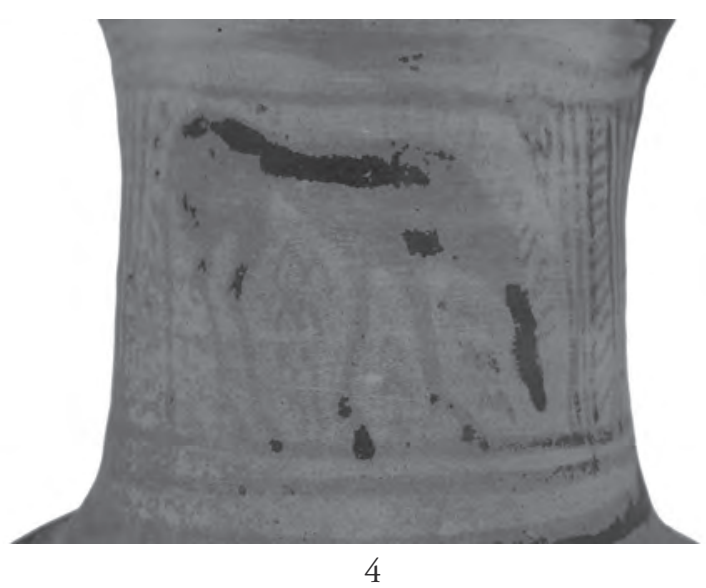



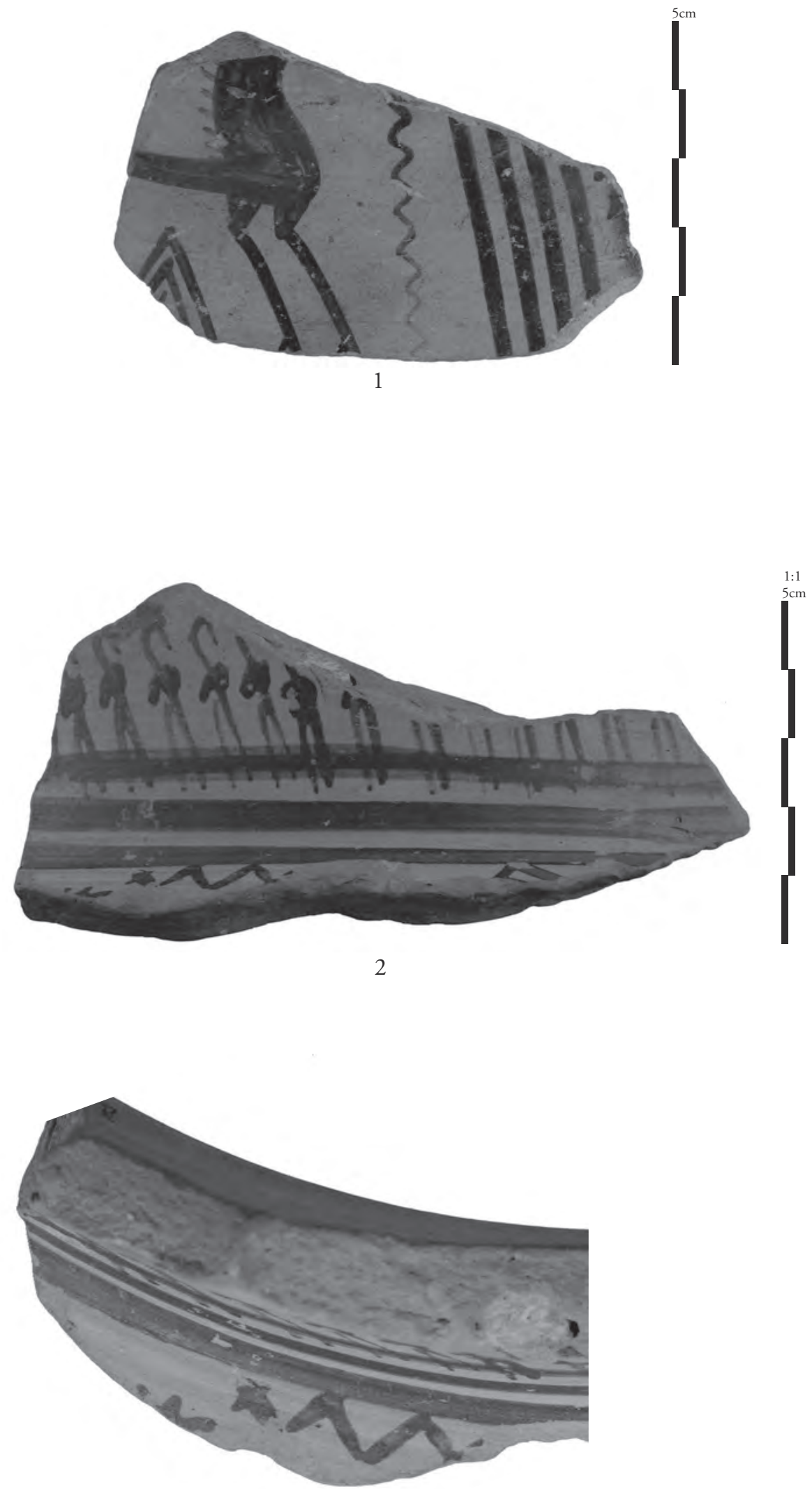

3

G 749 

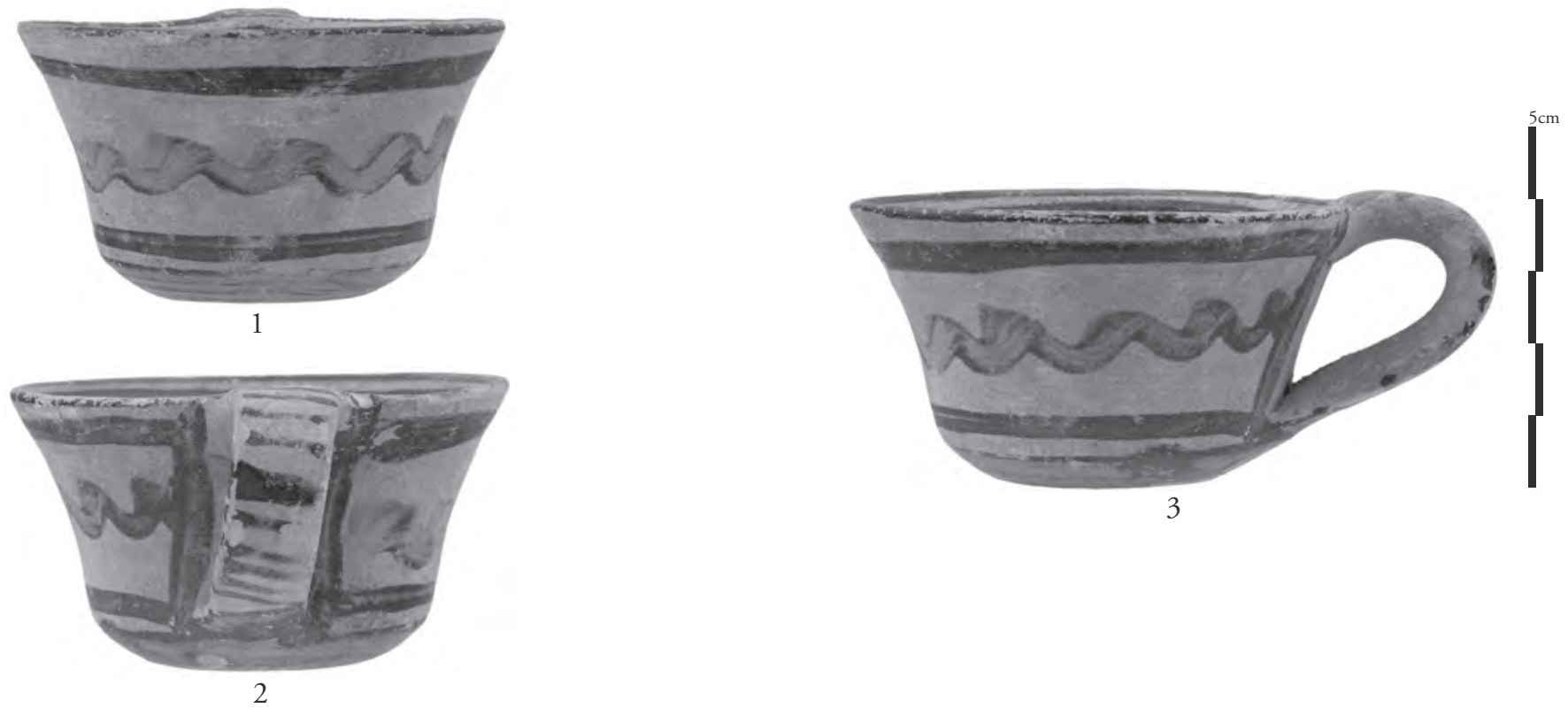

G 98
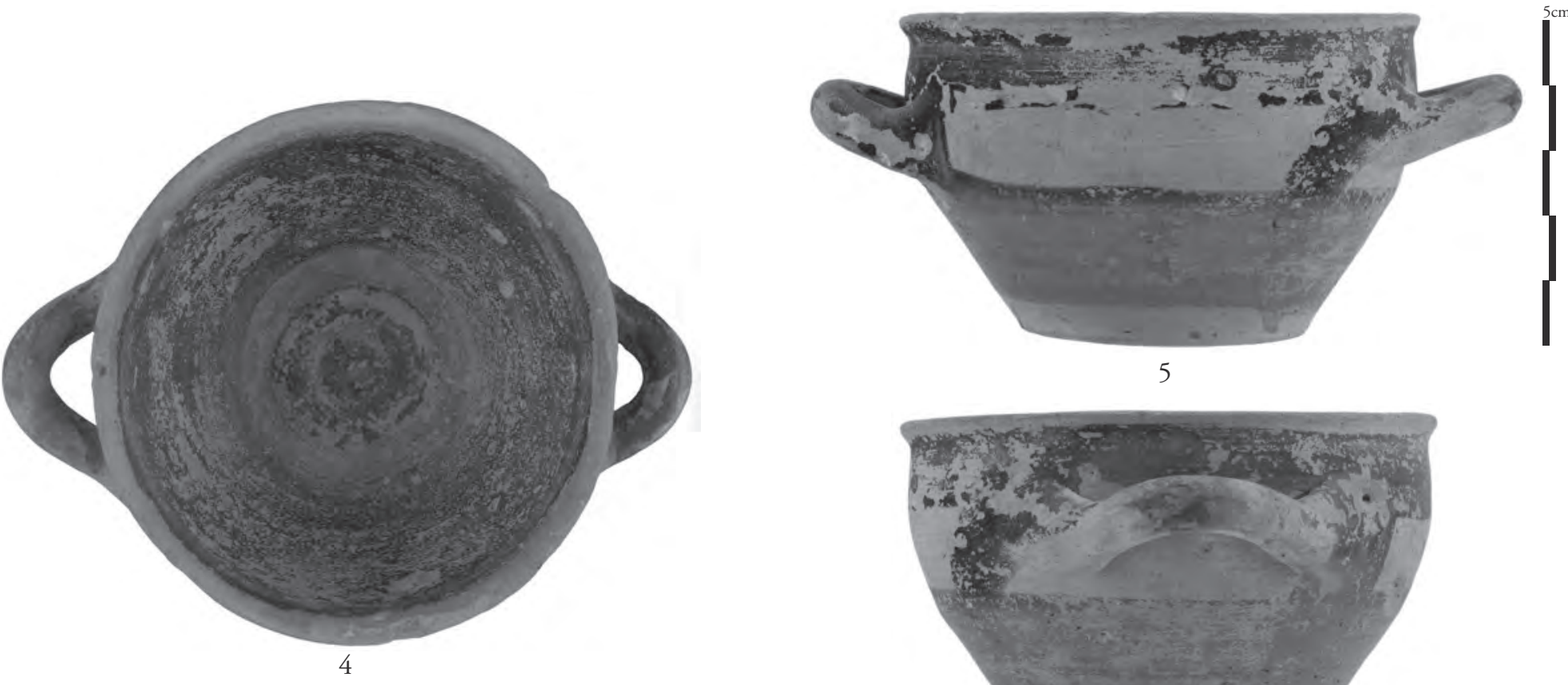

5

G 53

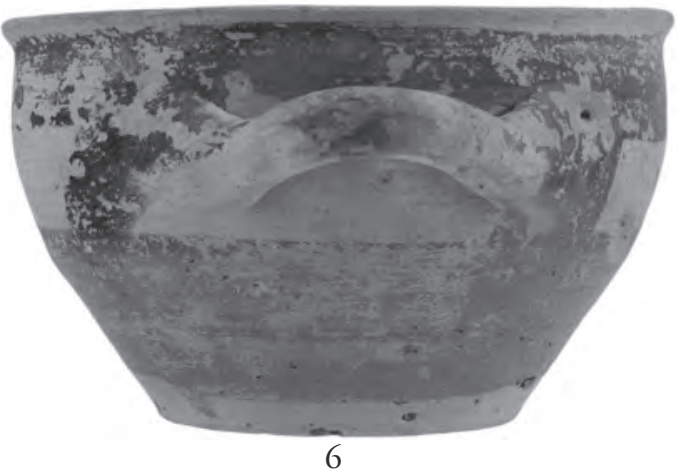

G 1038
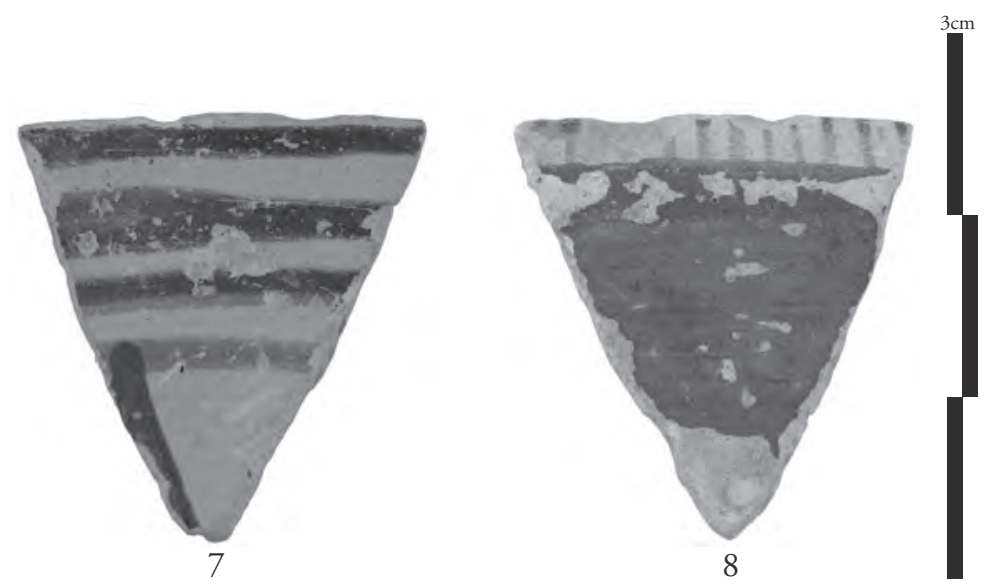

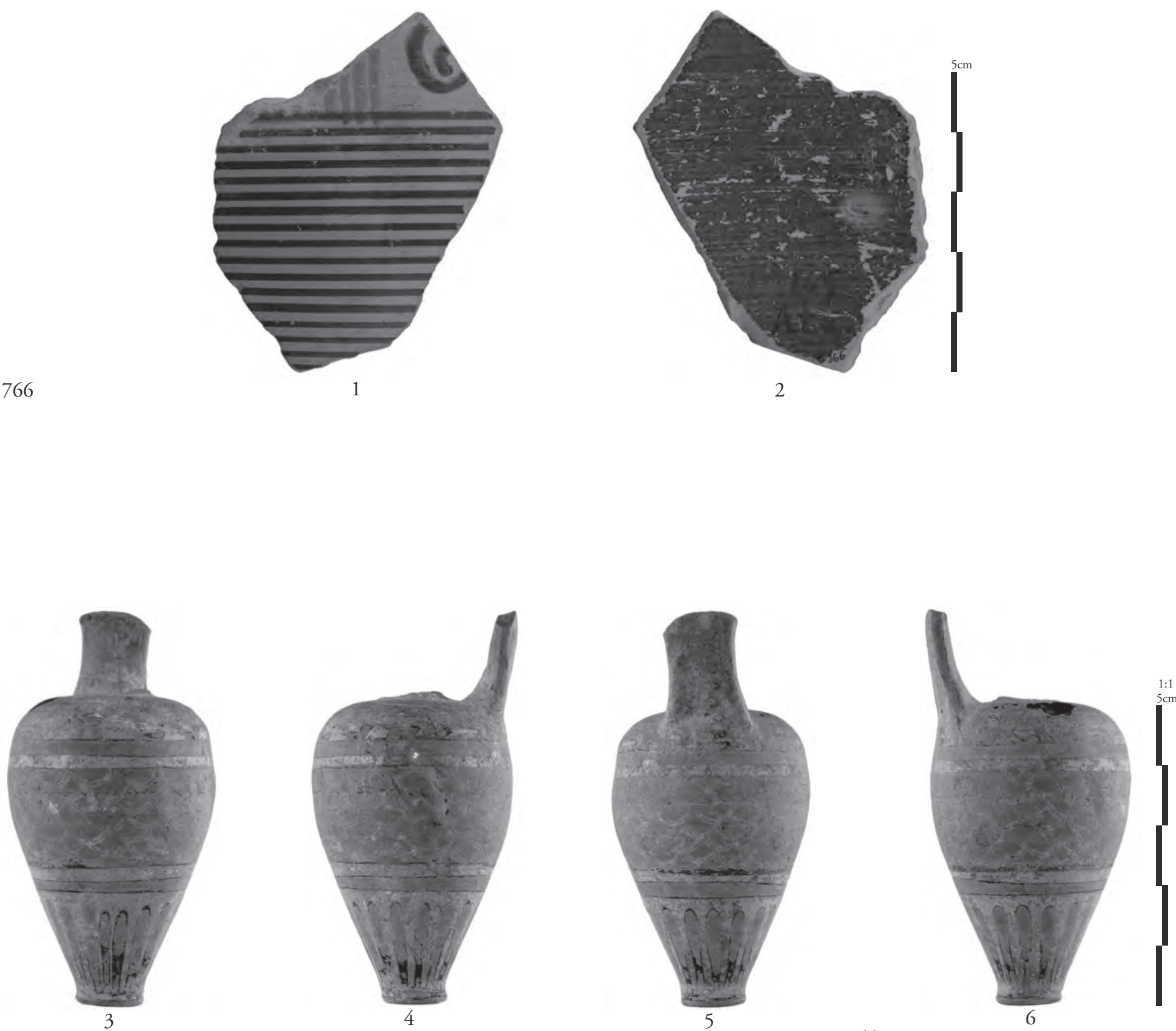

G 1382
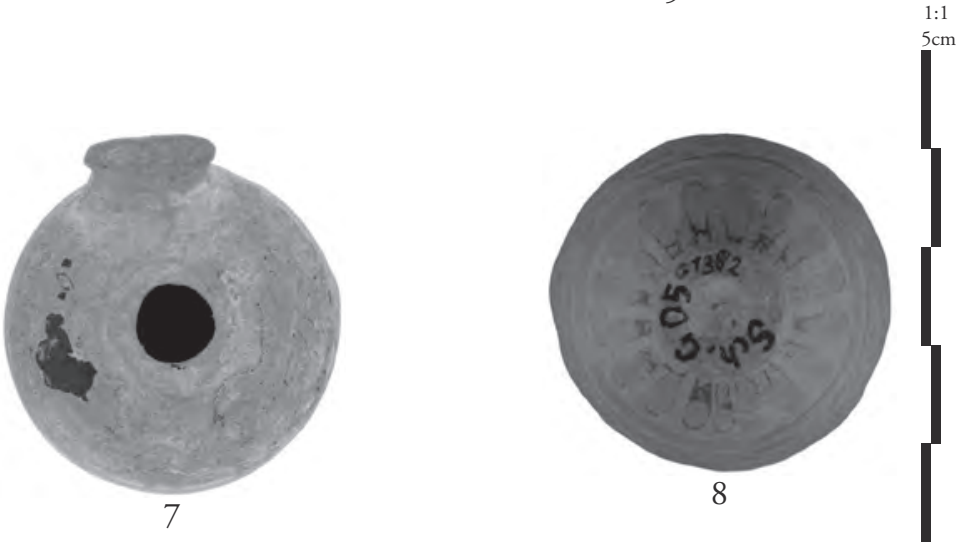

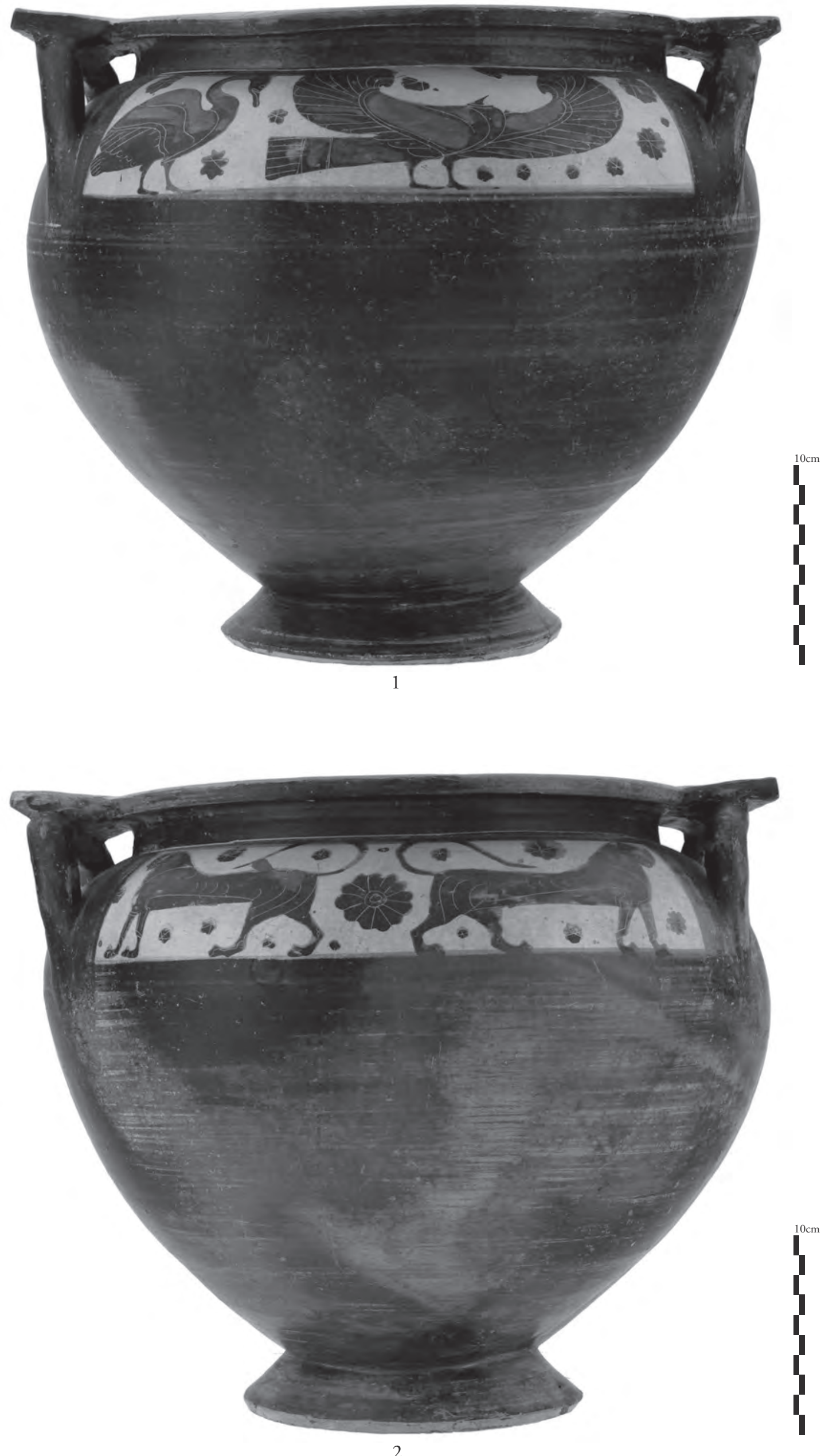

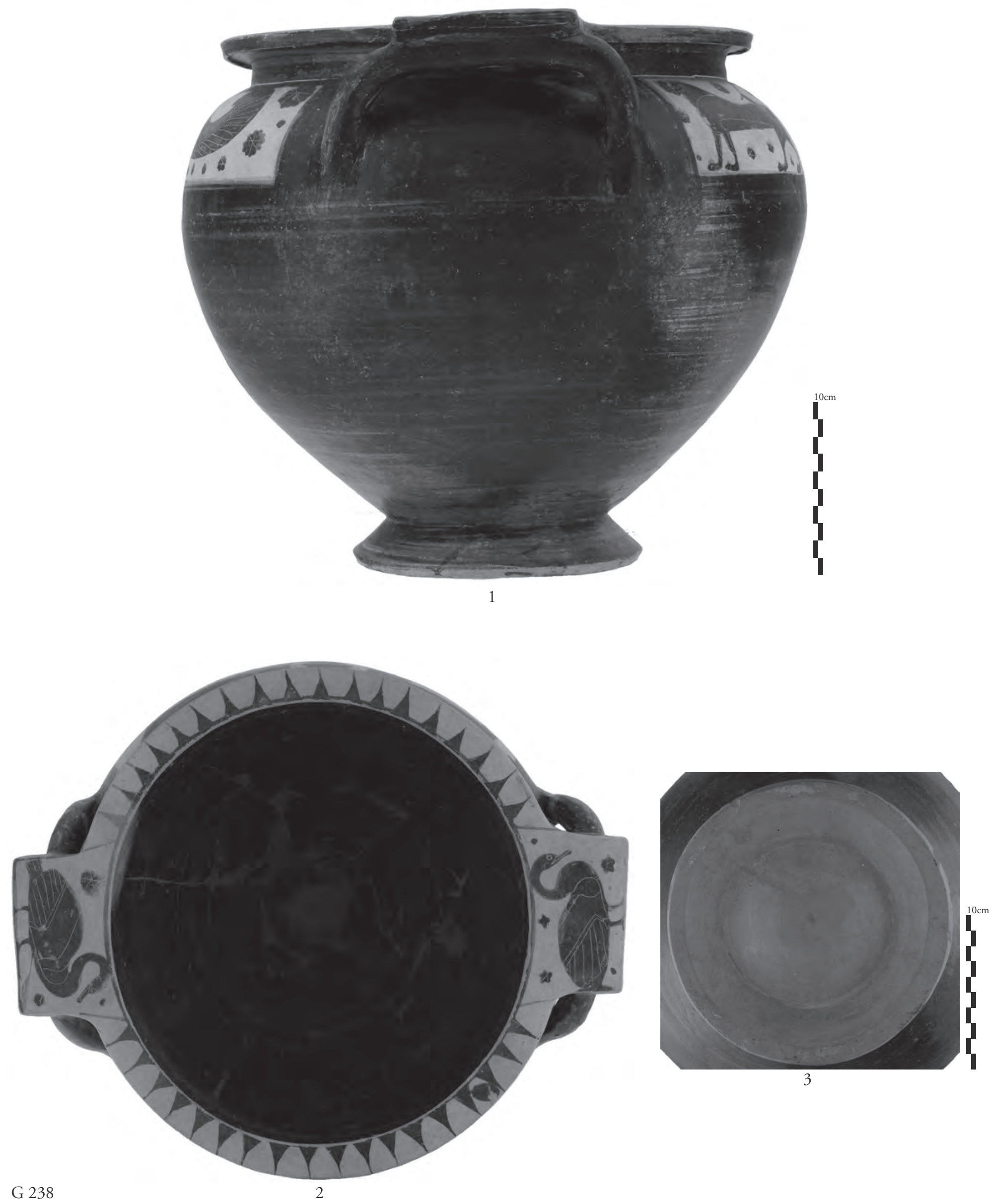

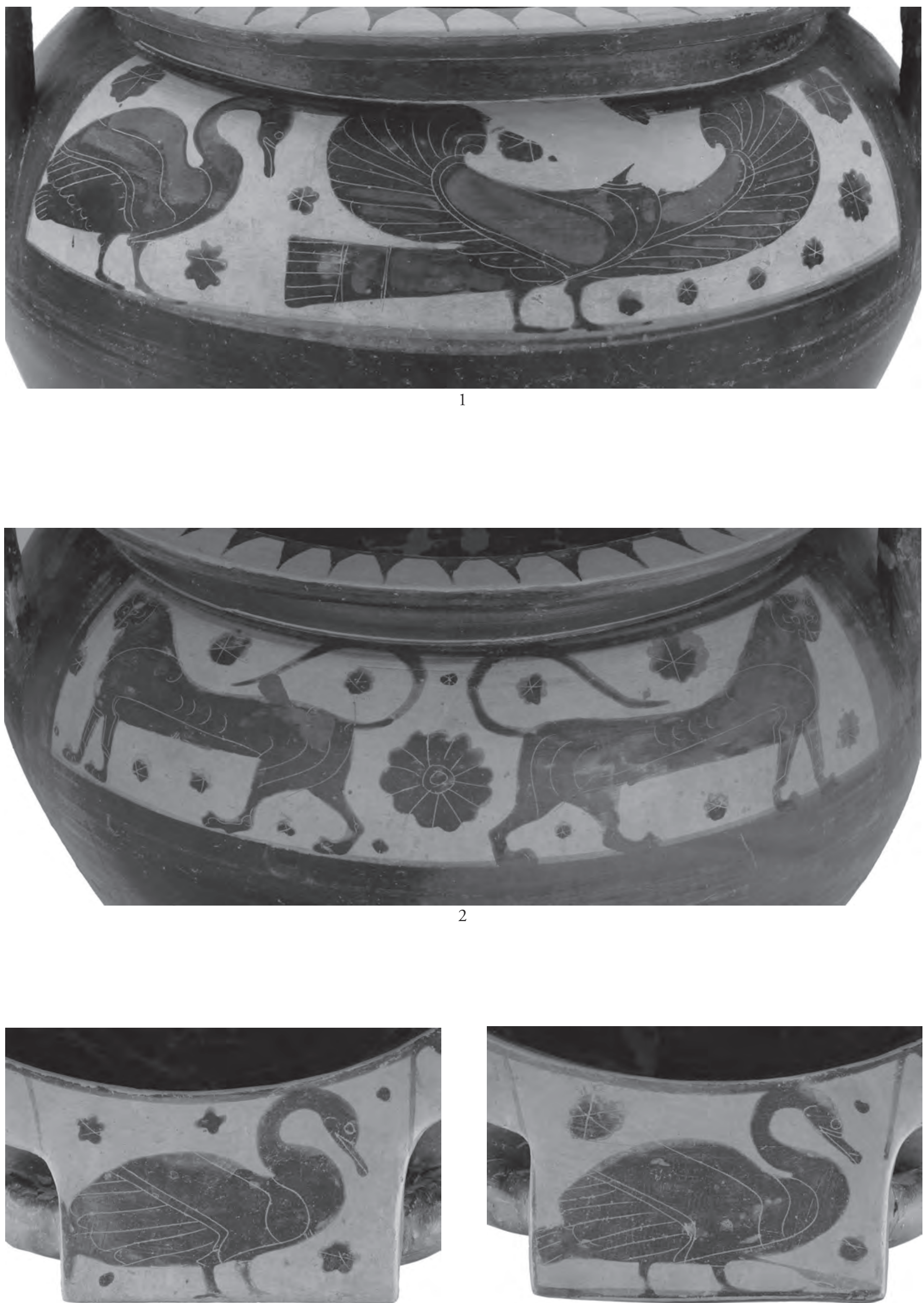

G 238

3

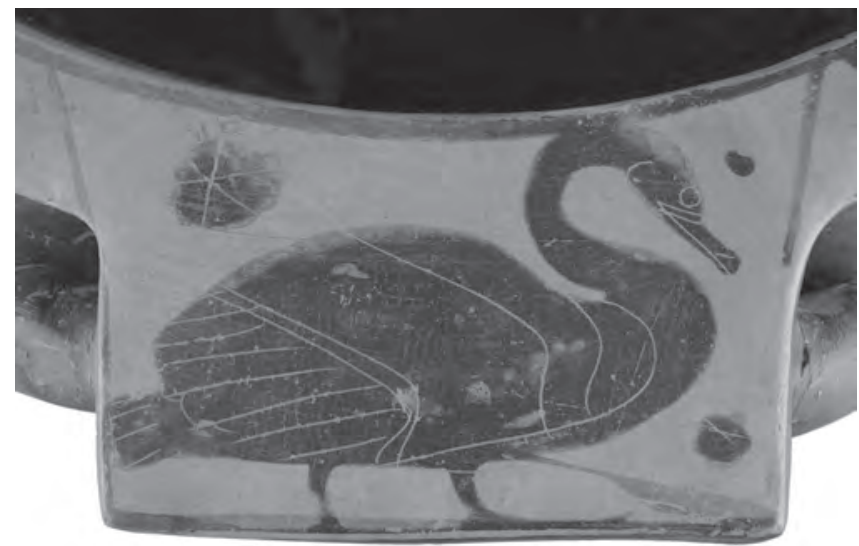

4 

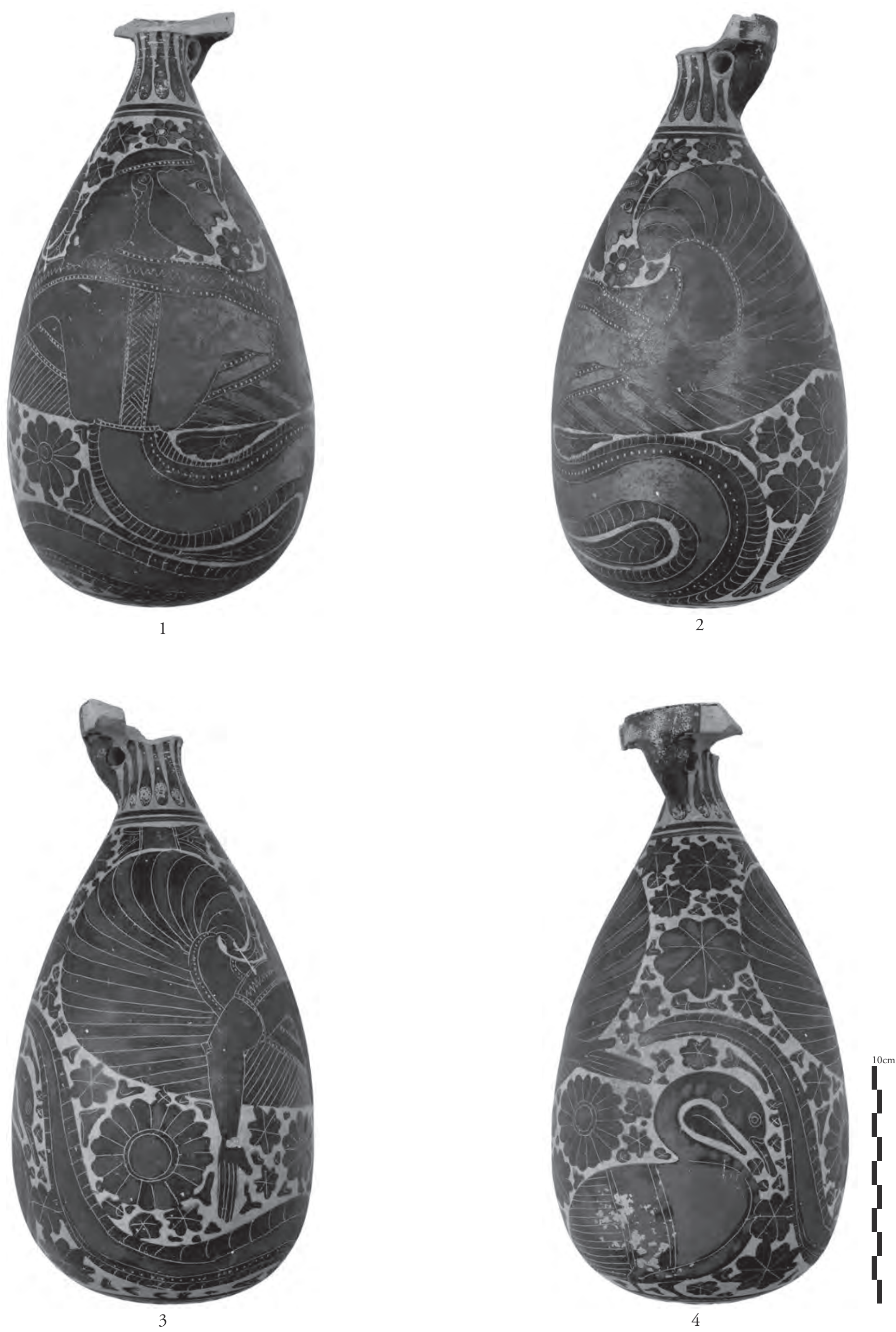

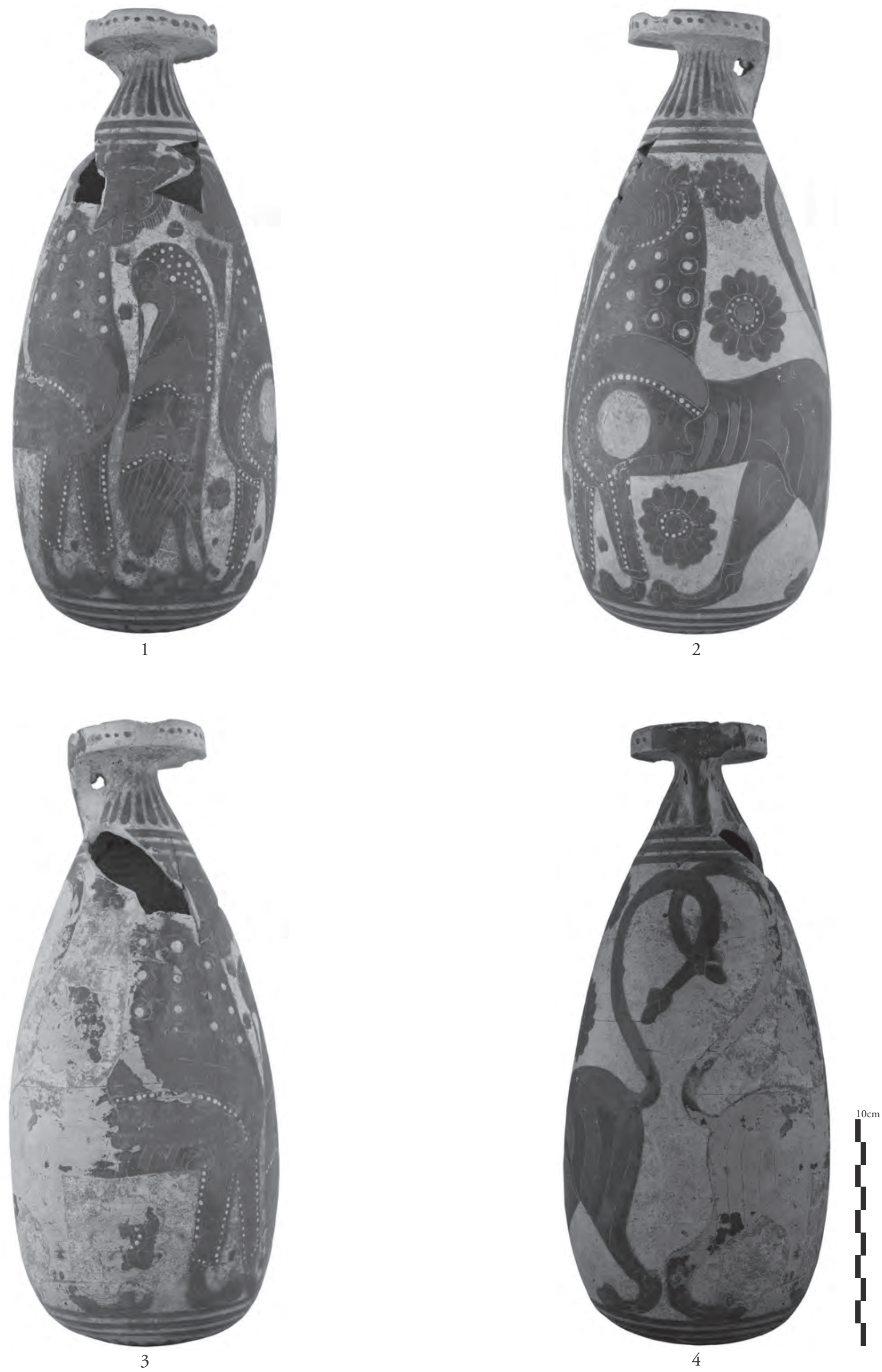

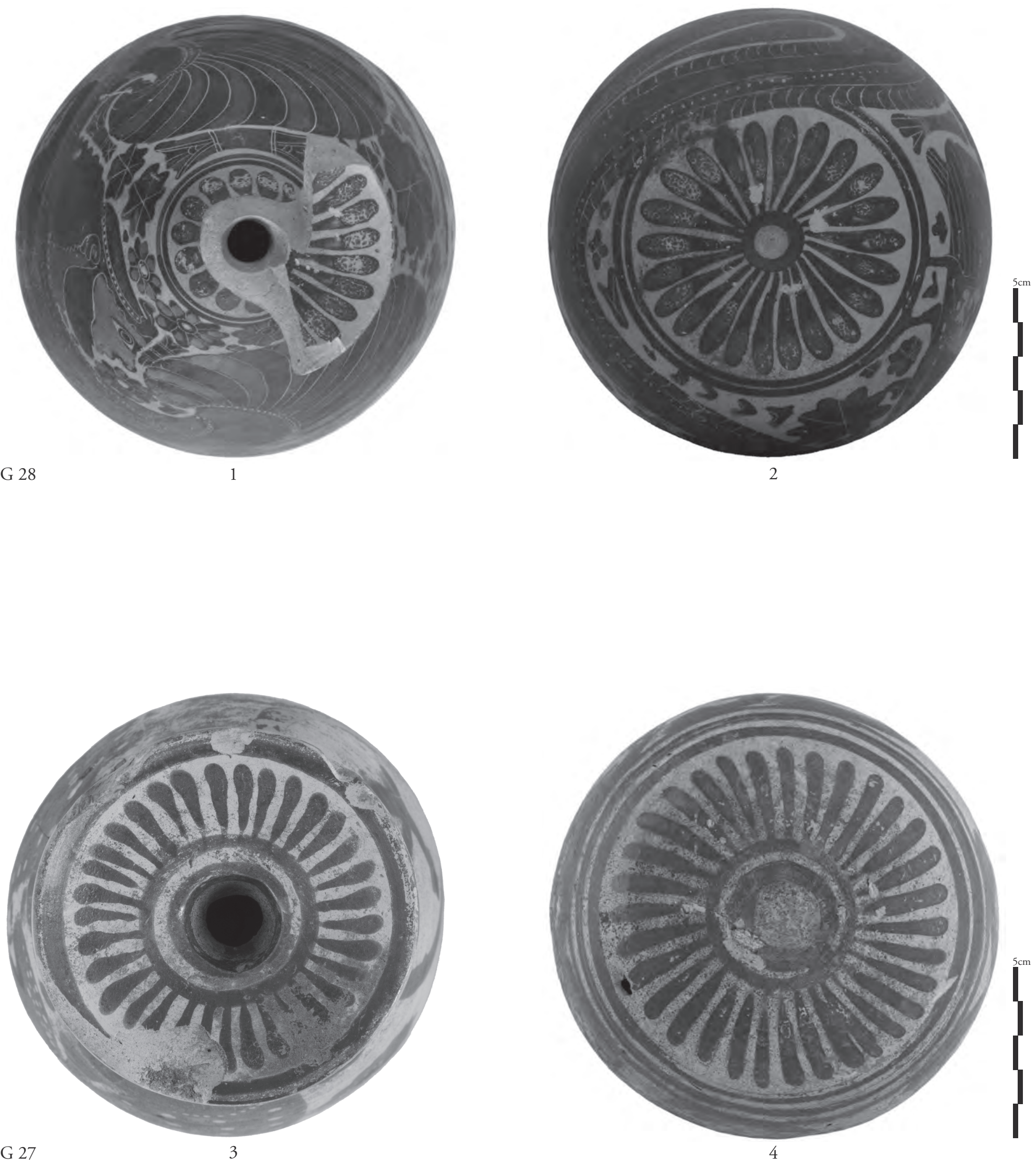


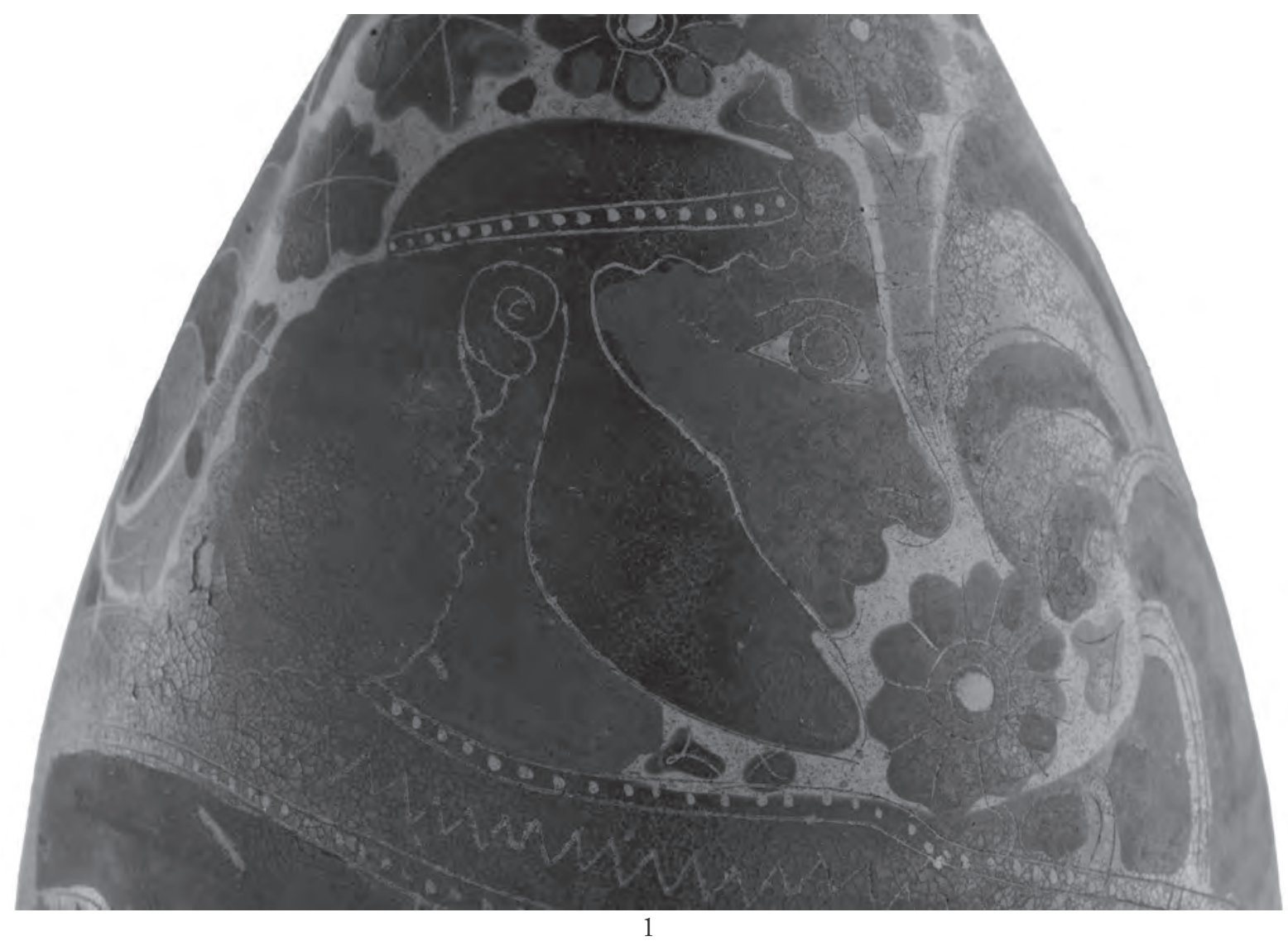

G 28
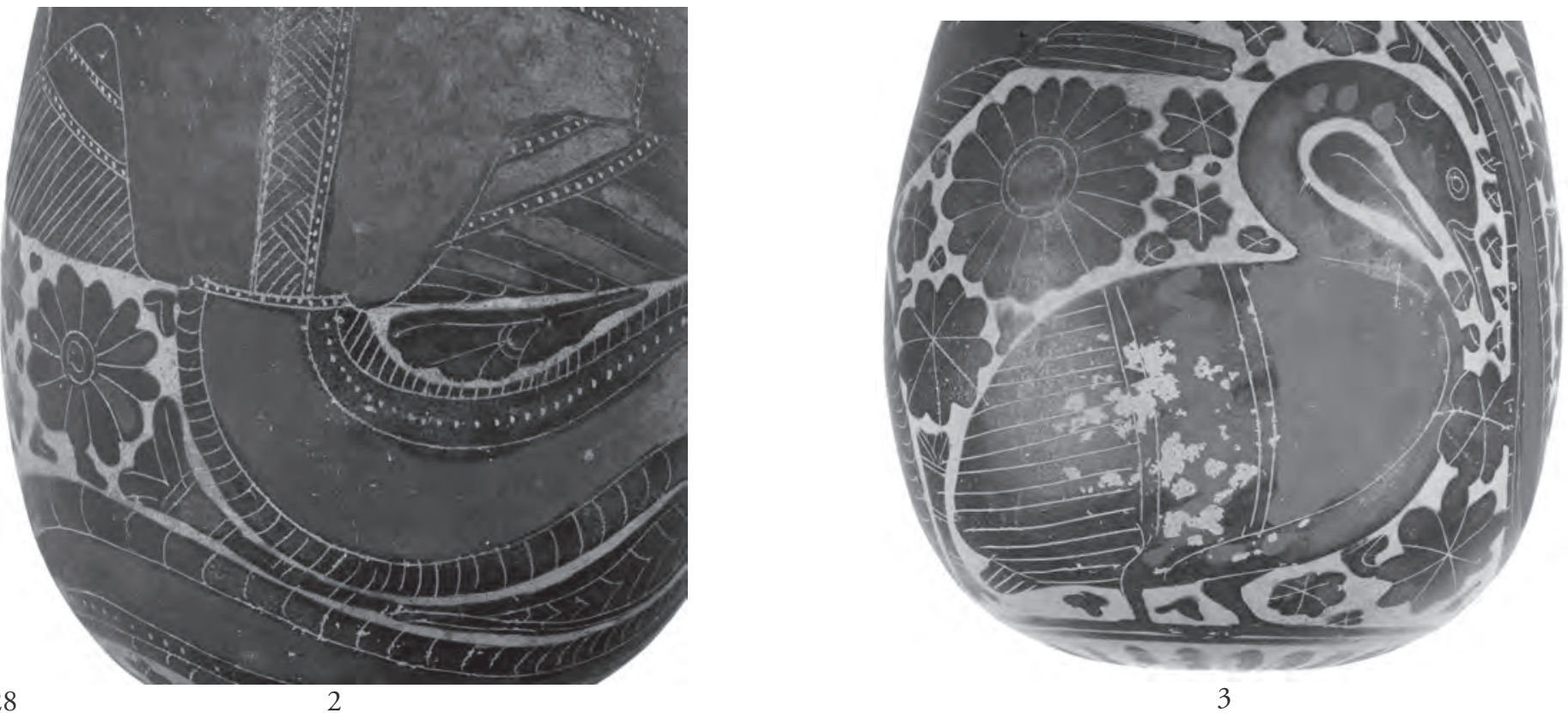

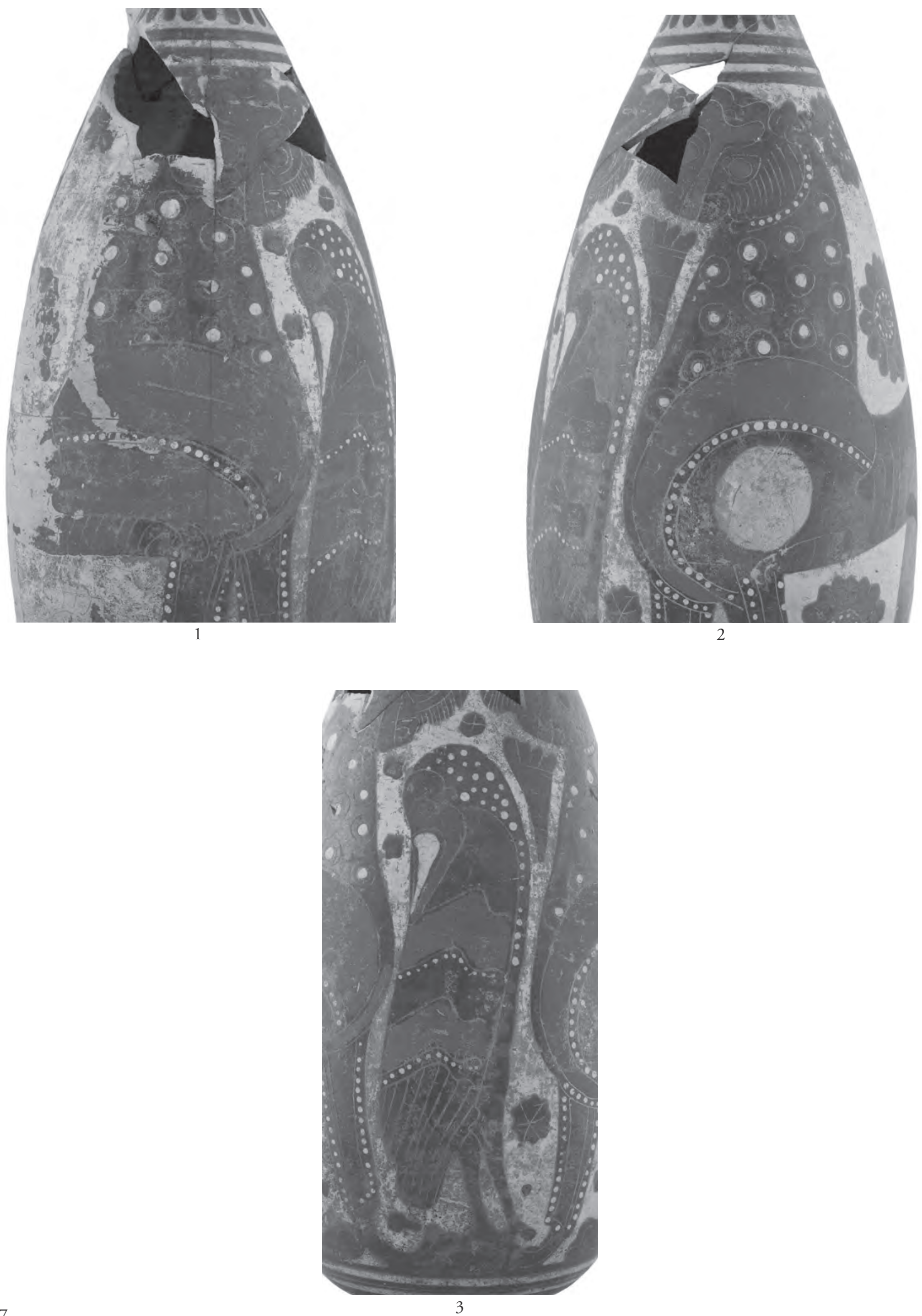

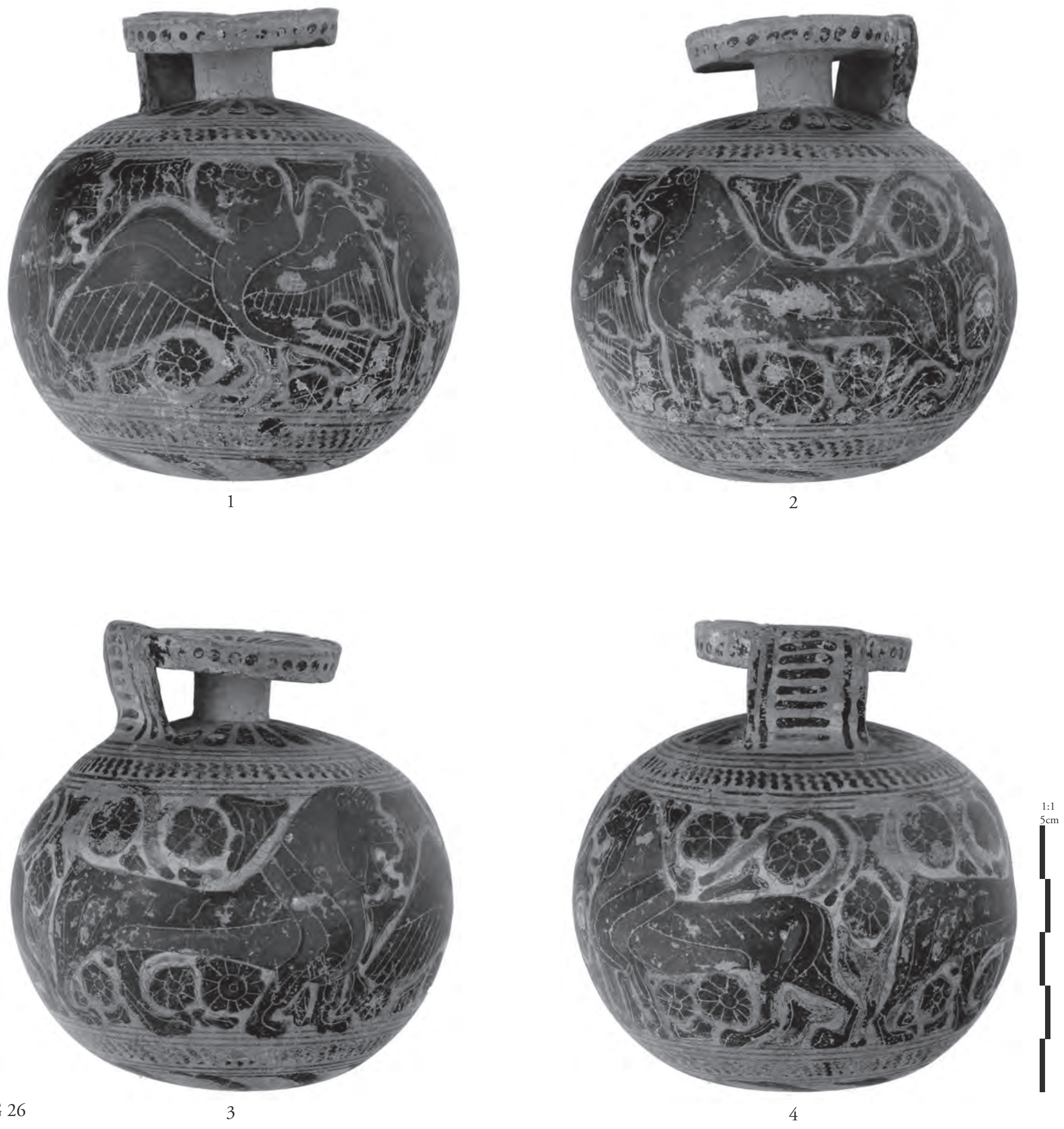

4 

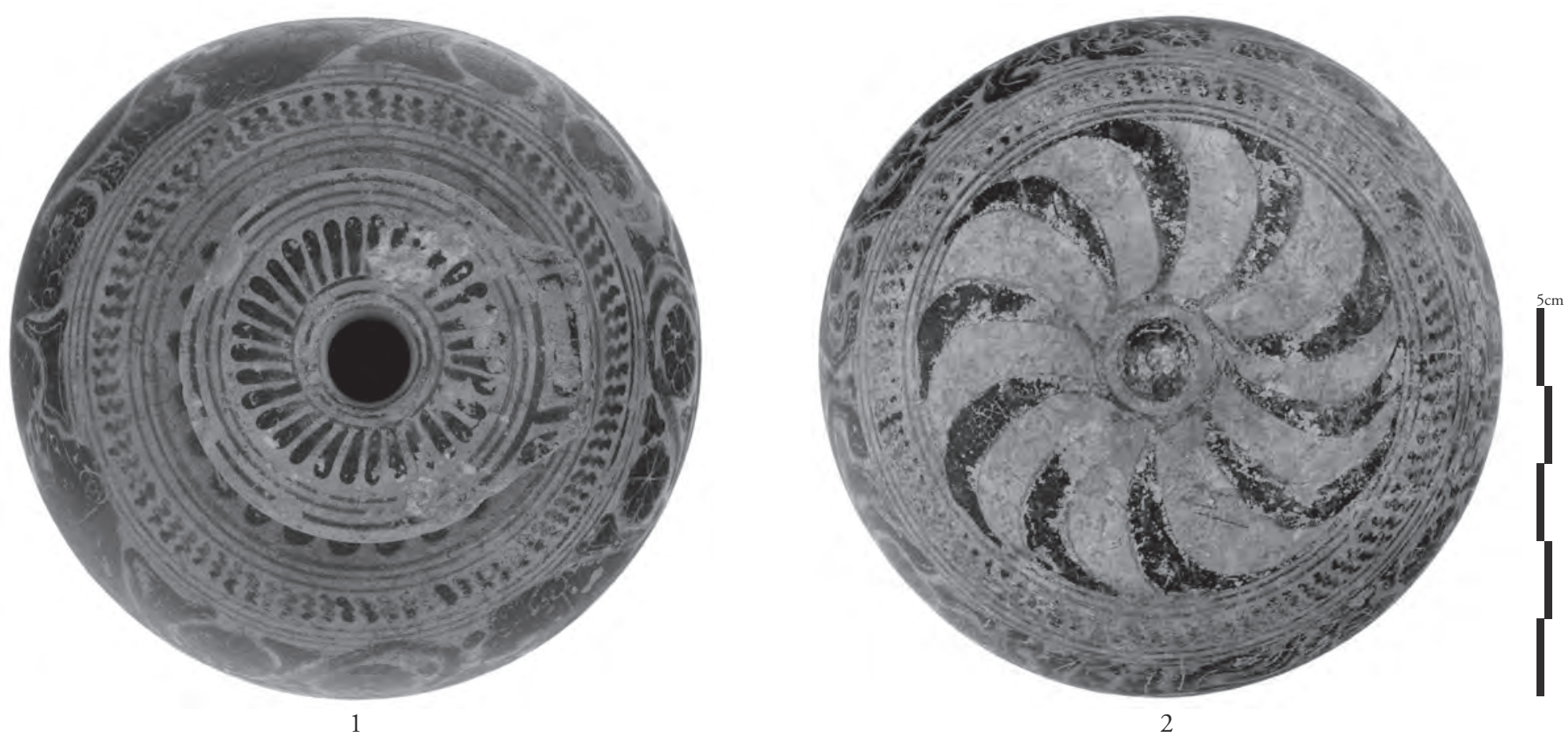

G 26

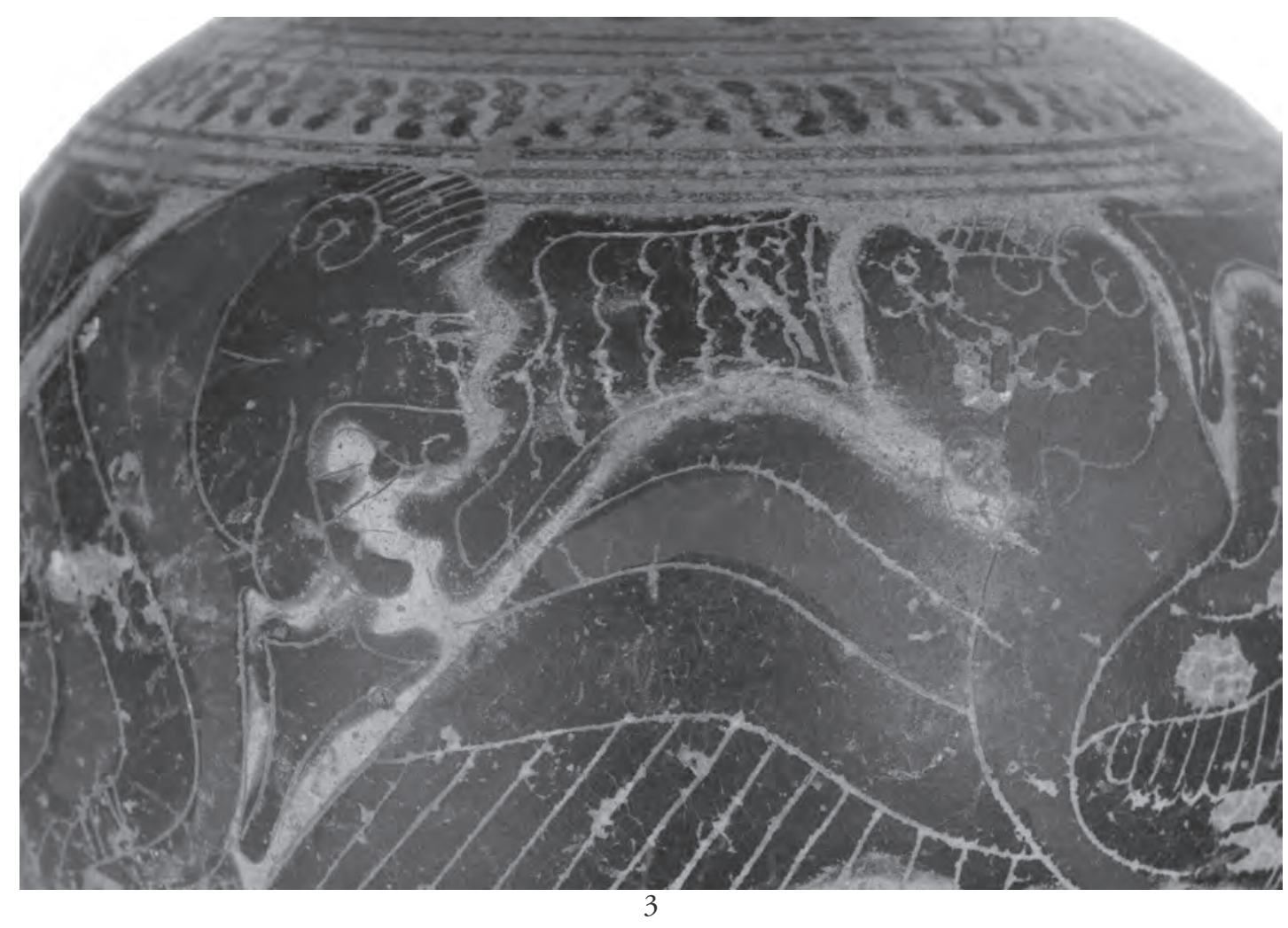



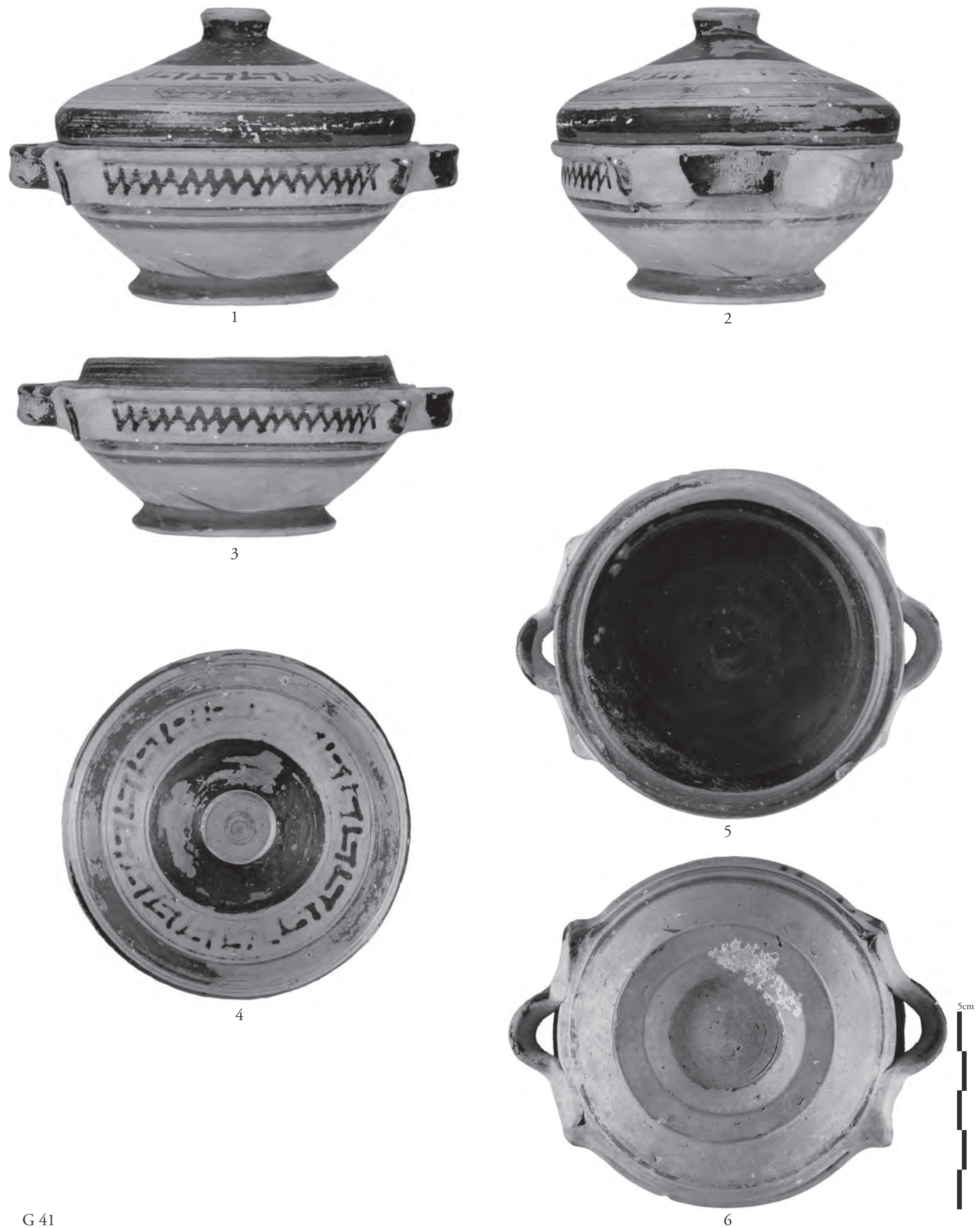

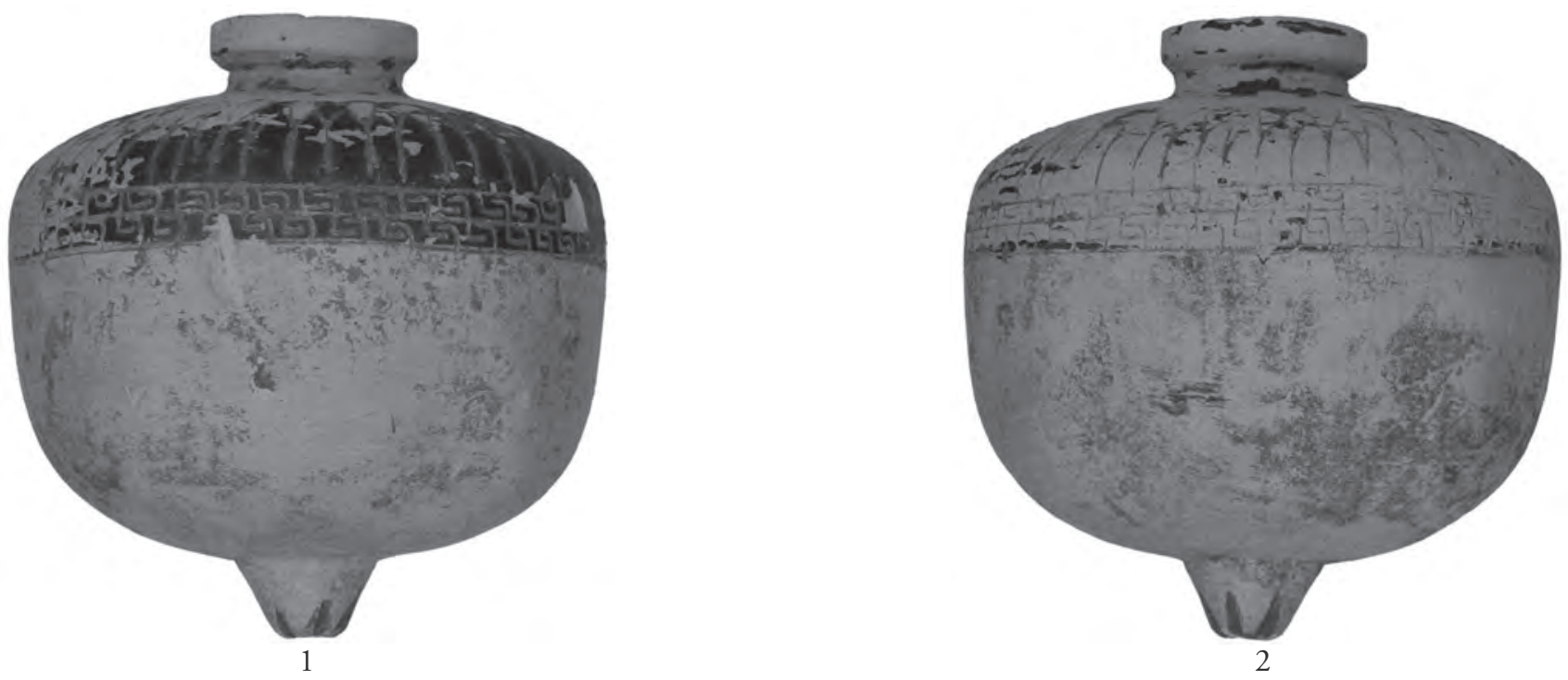

G 56
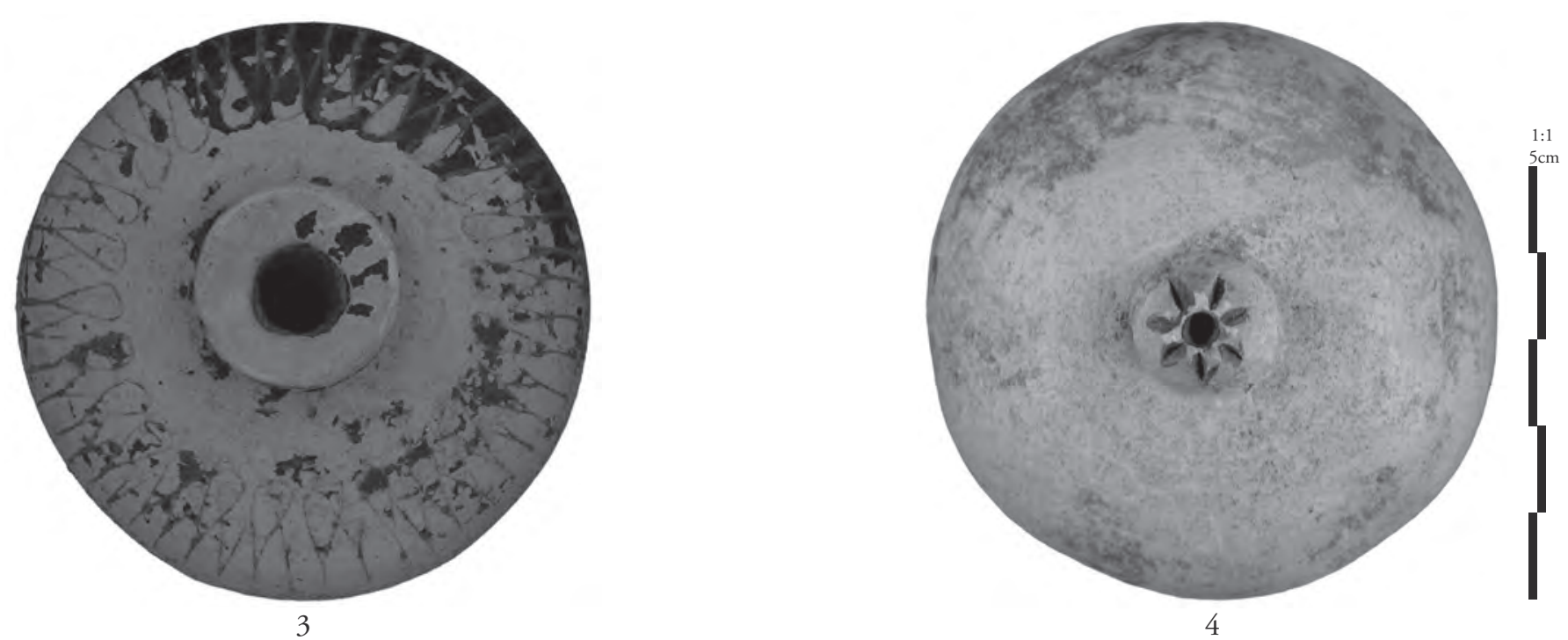

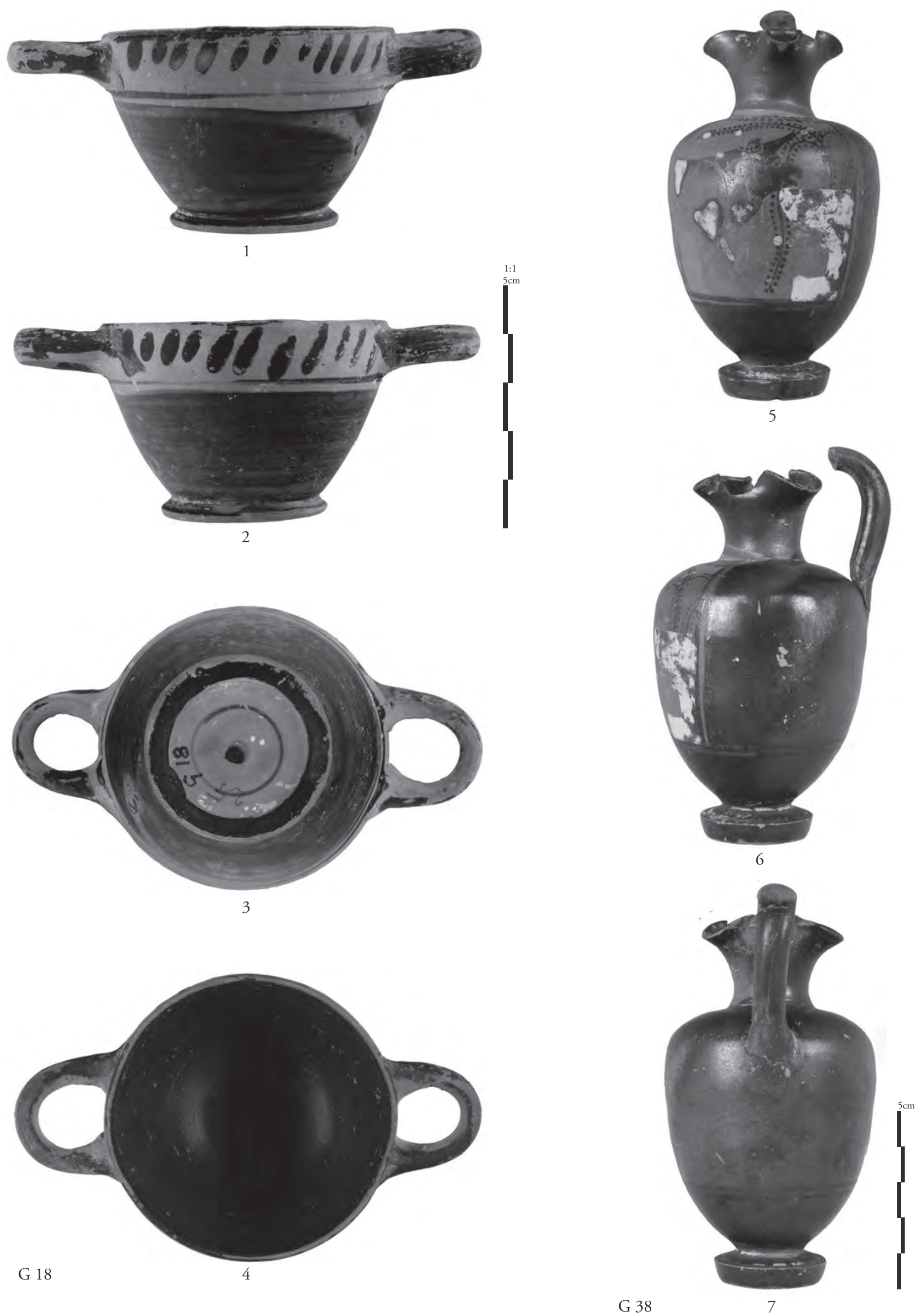


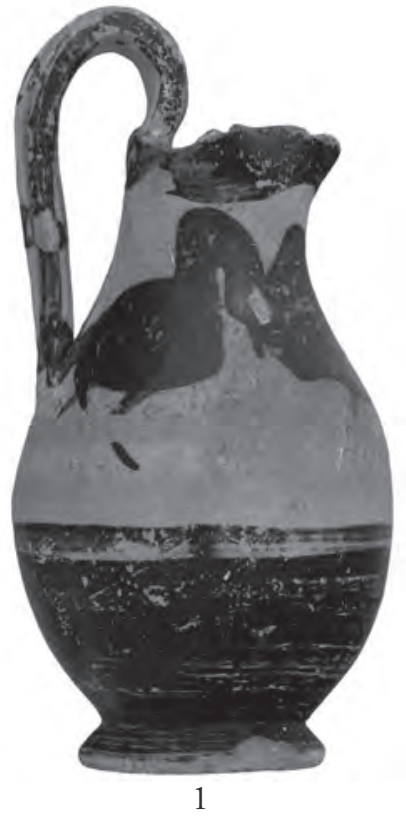

G 17
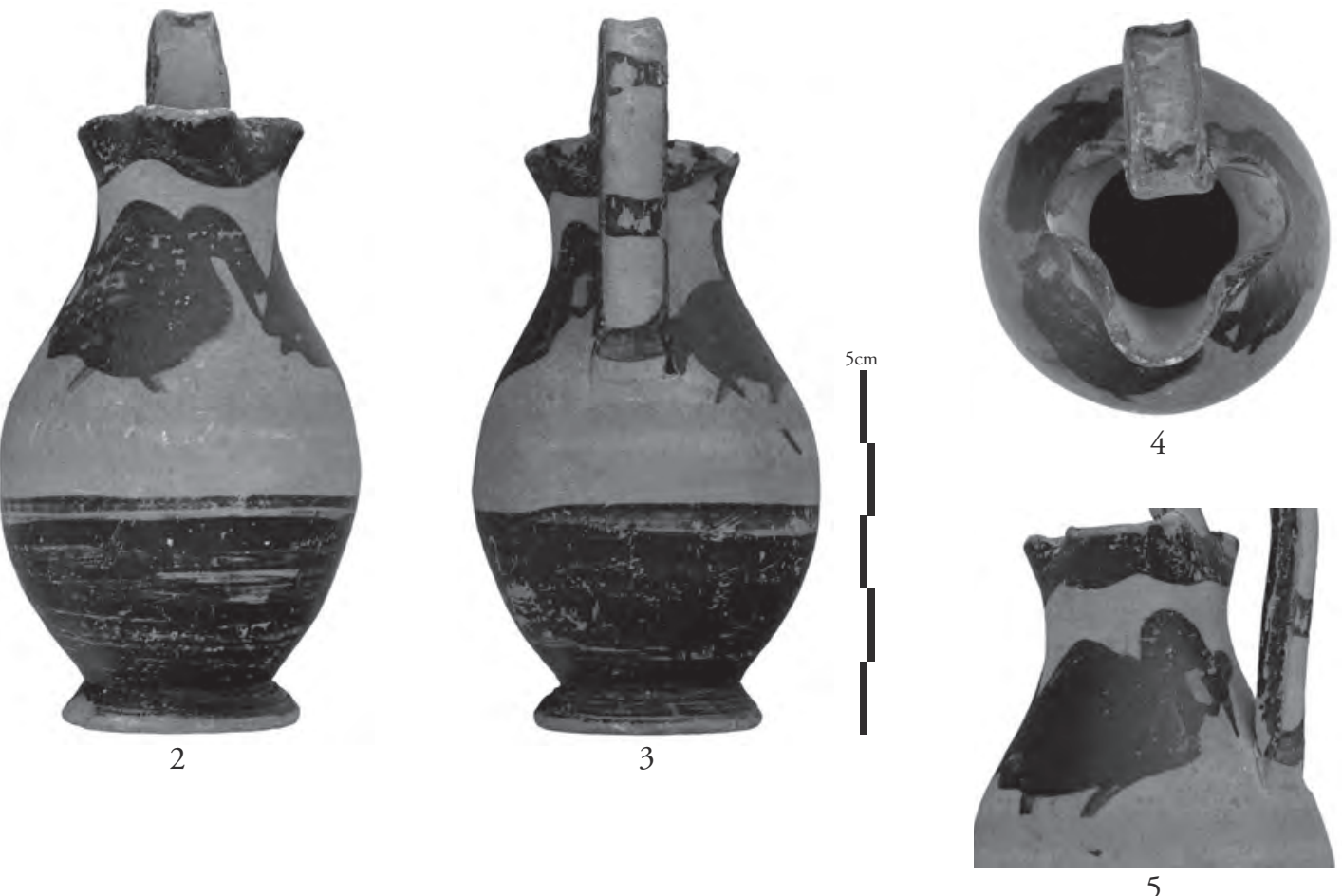

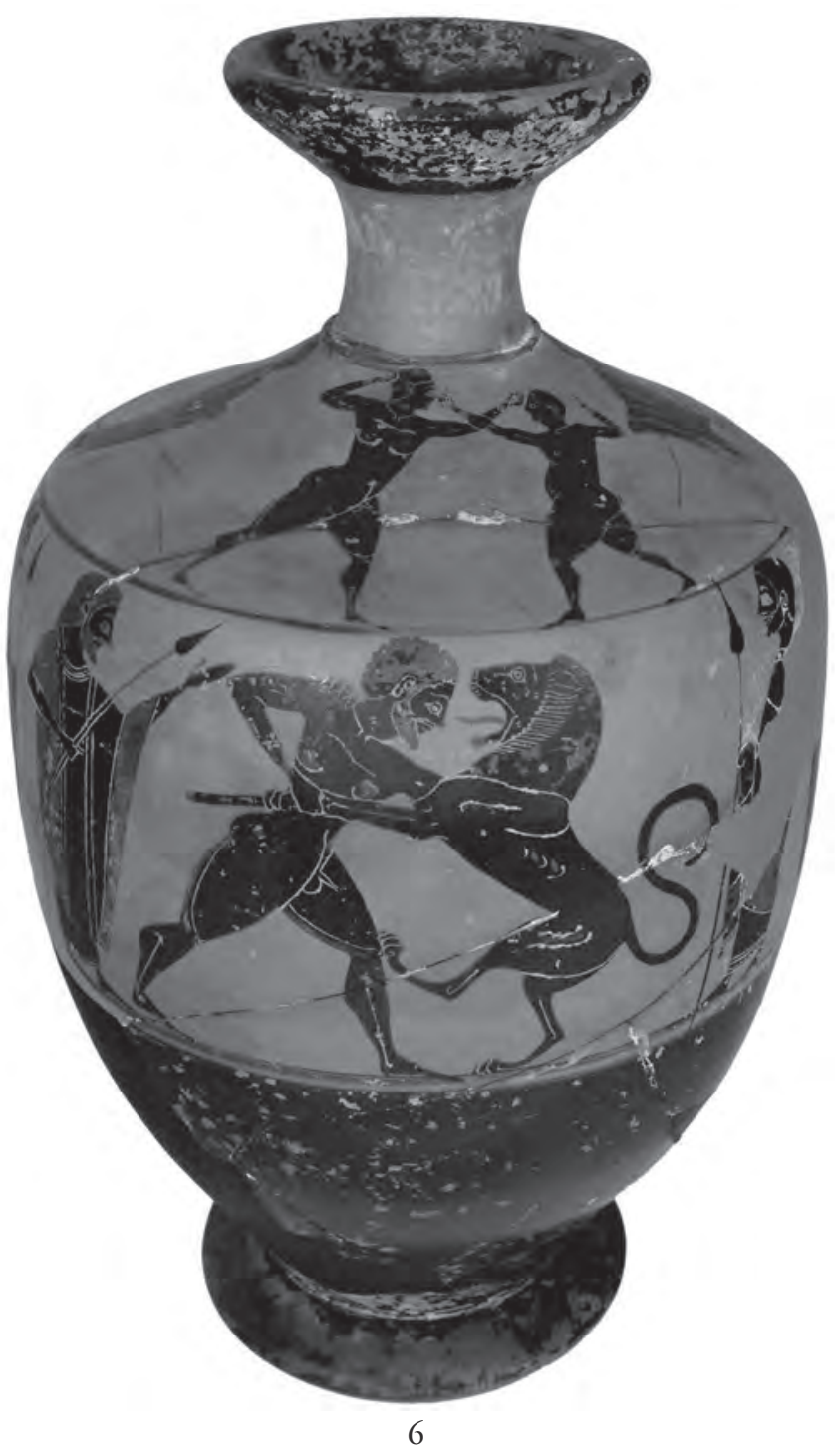



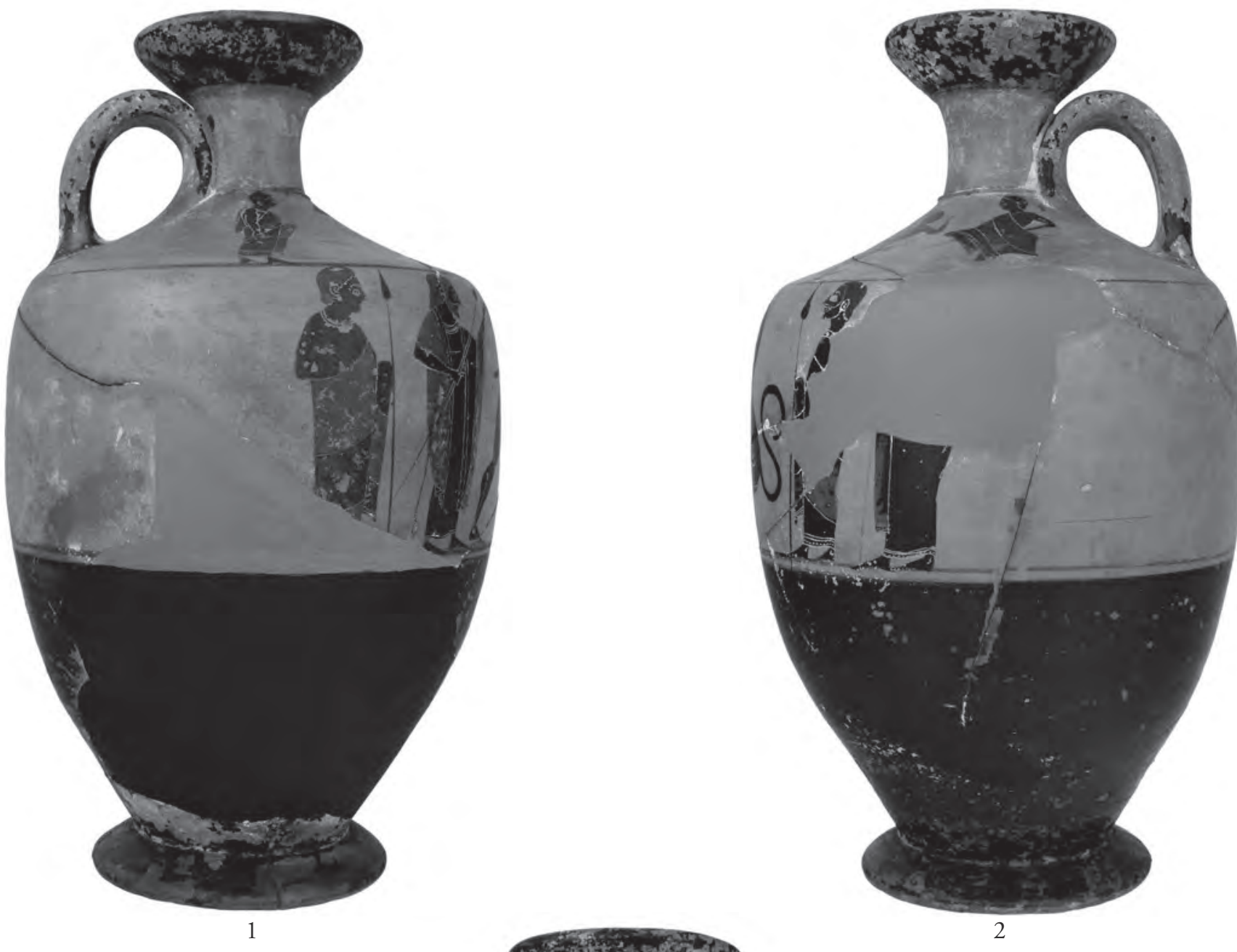

G 35

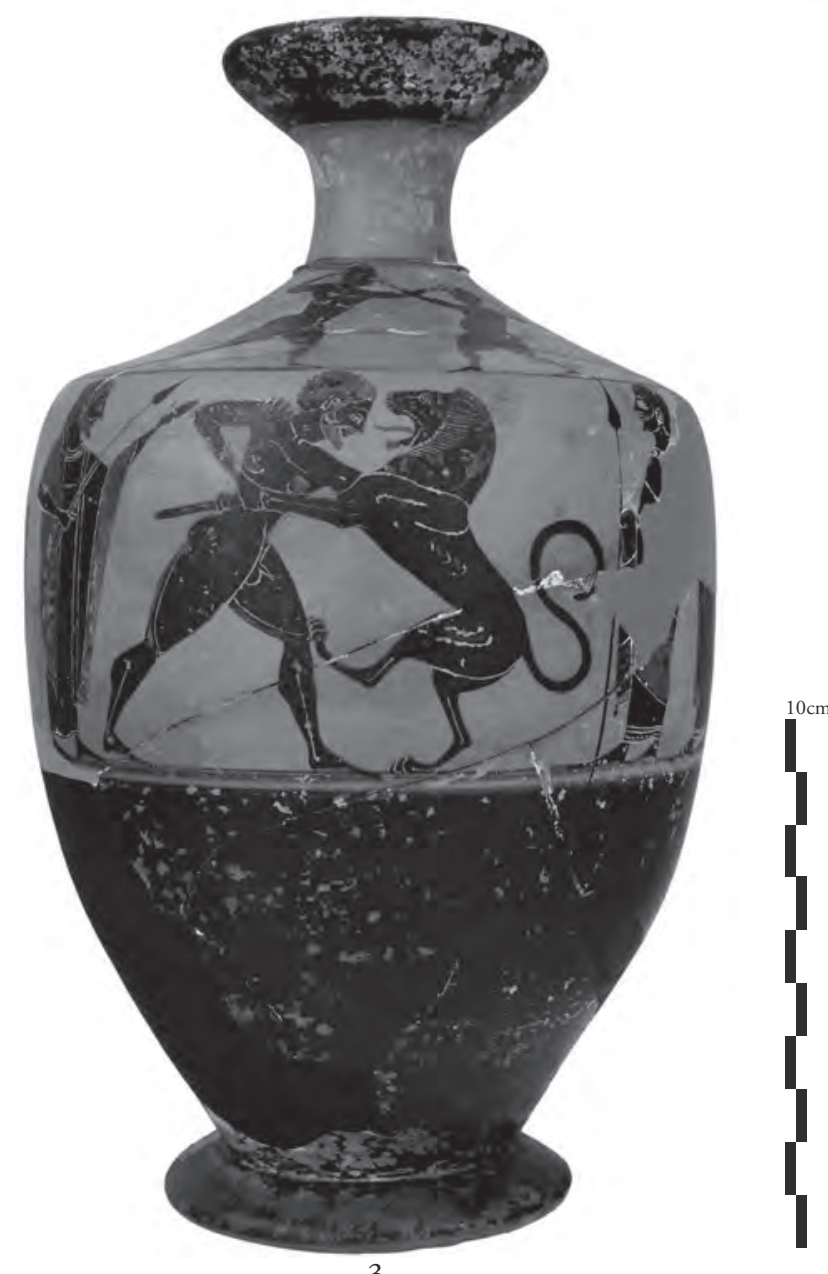



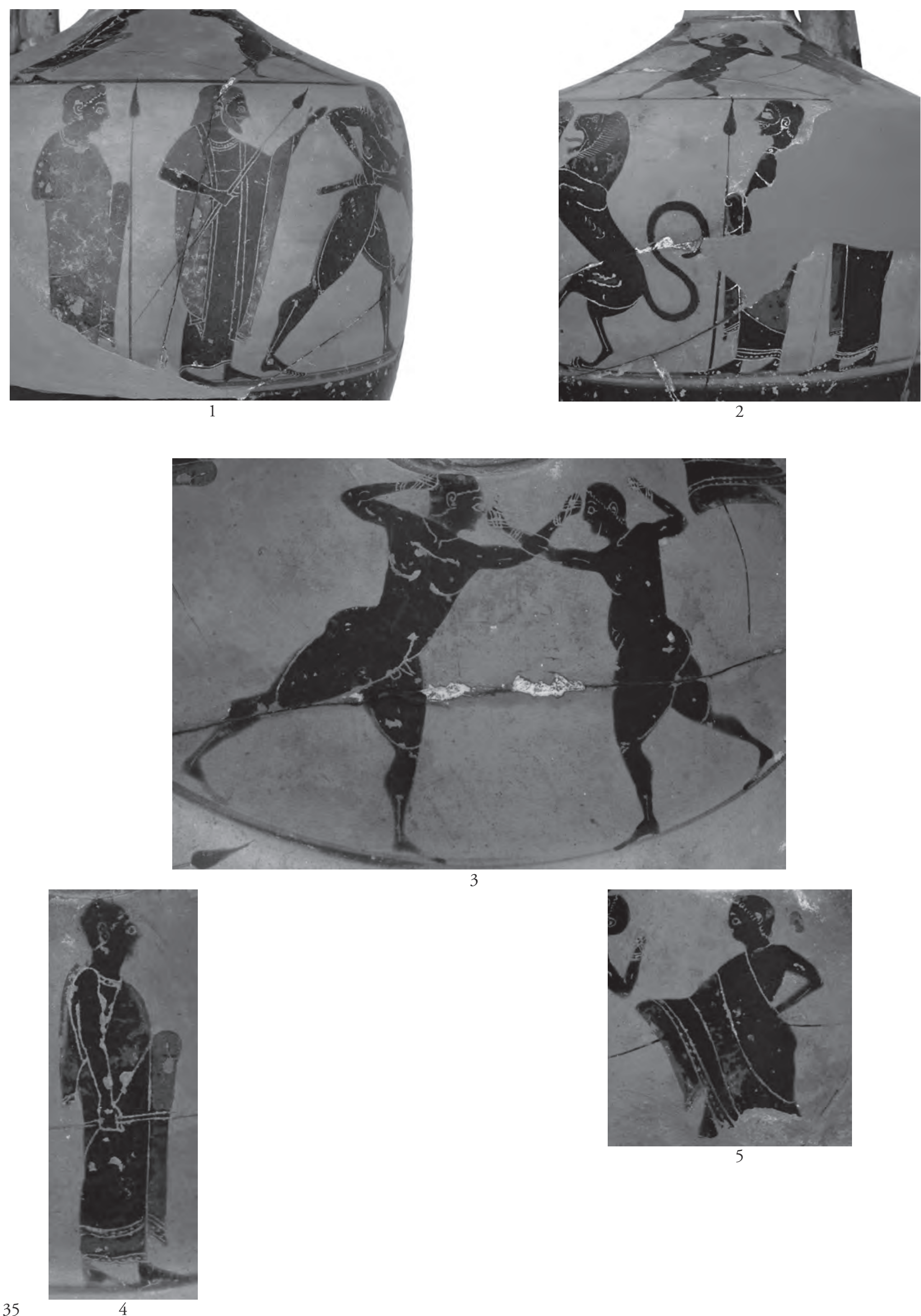

G 35 

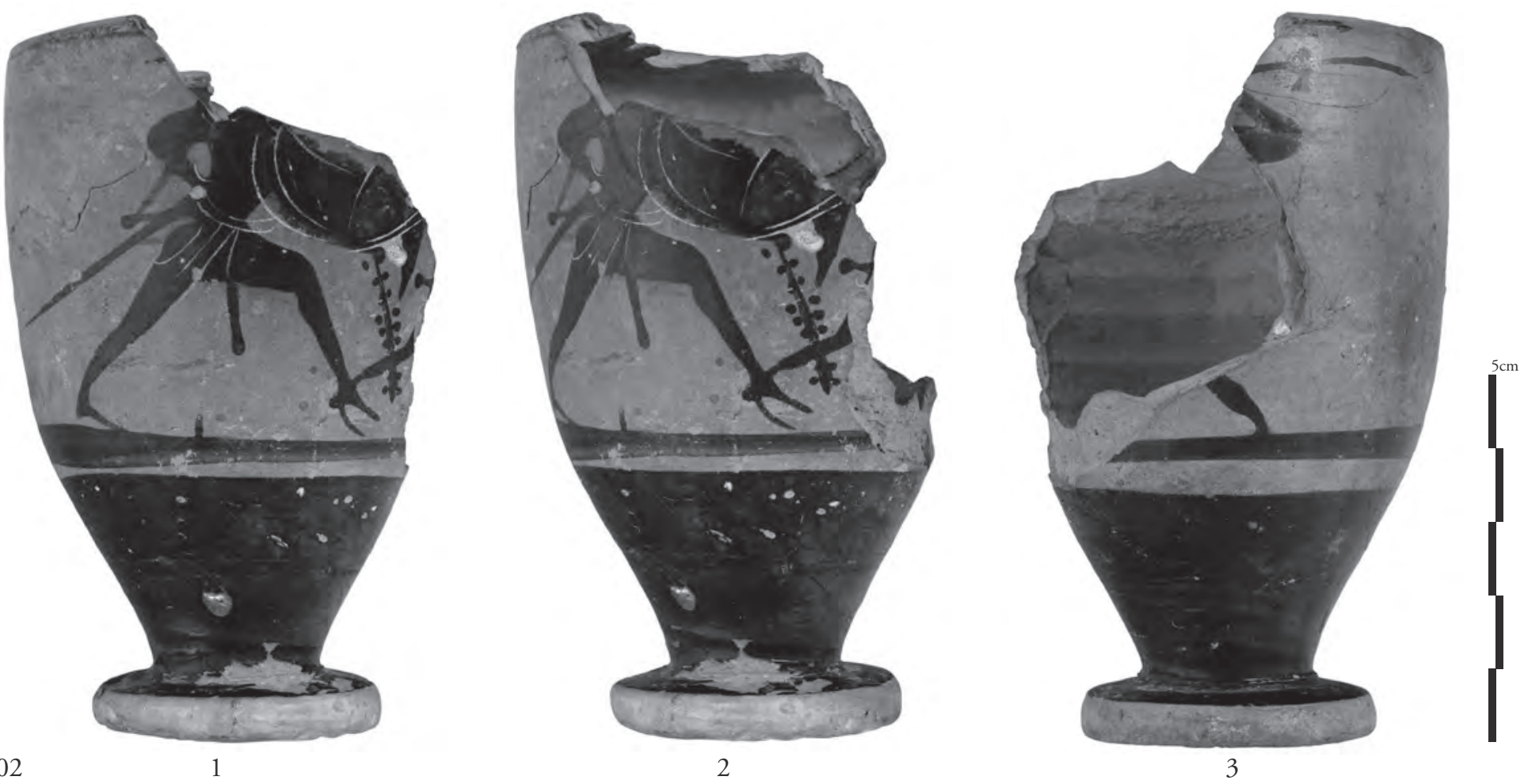

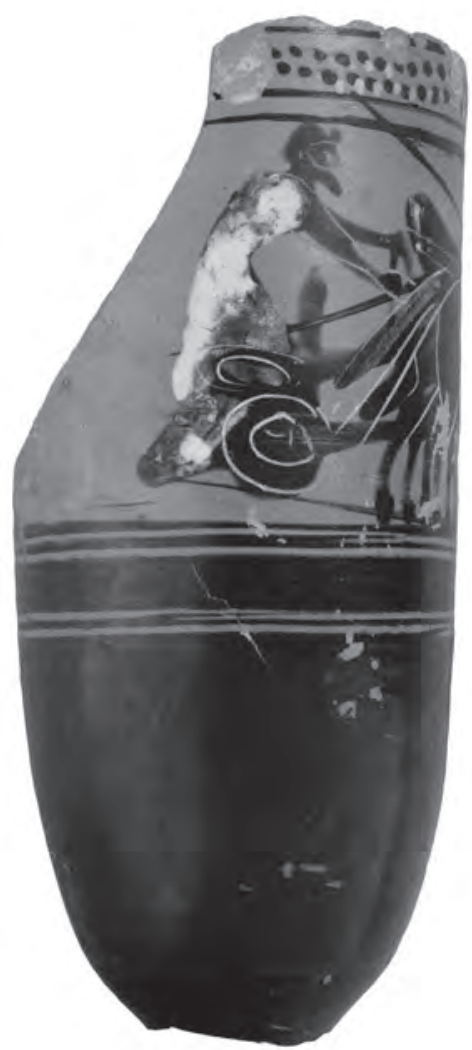

G 103

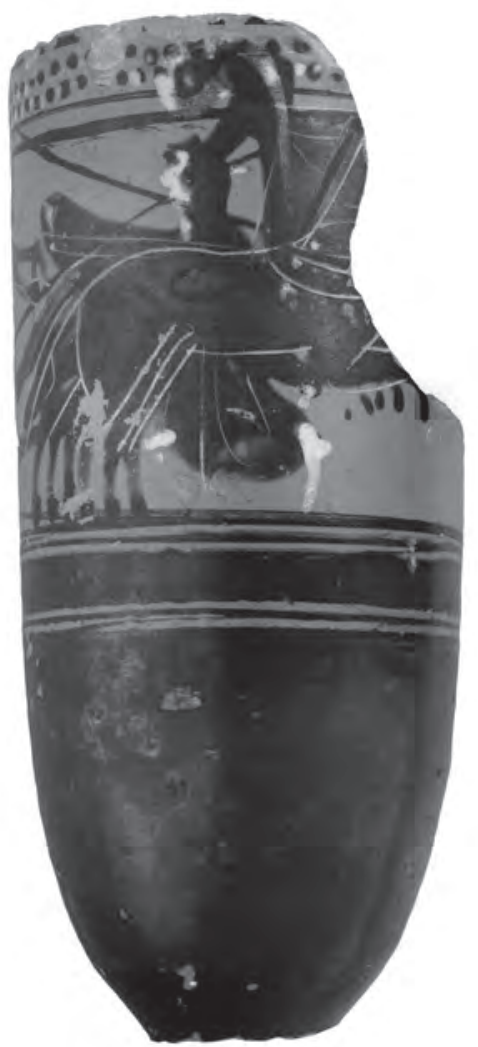

5

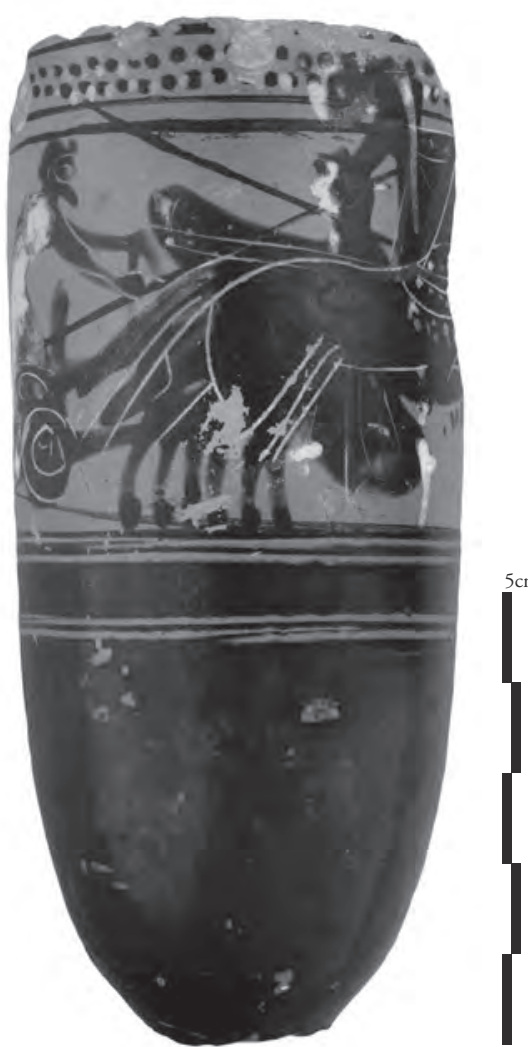

6 

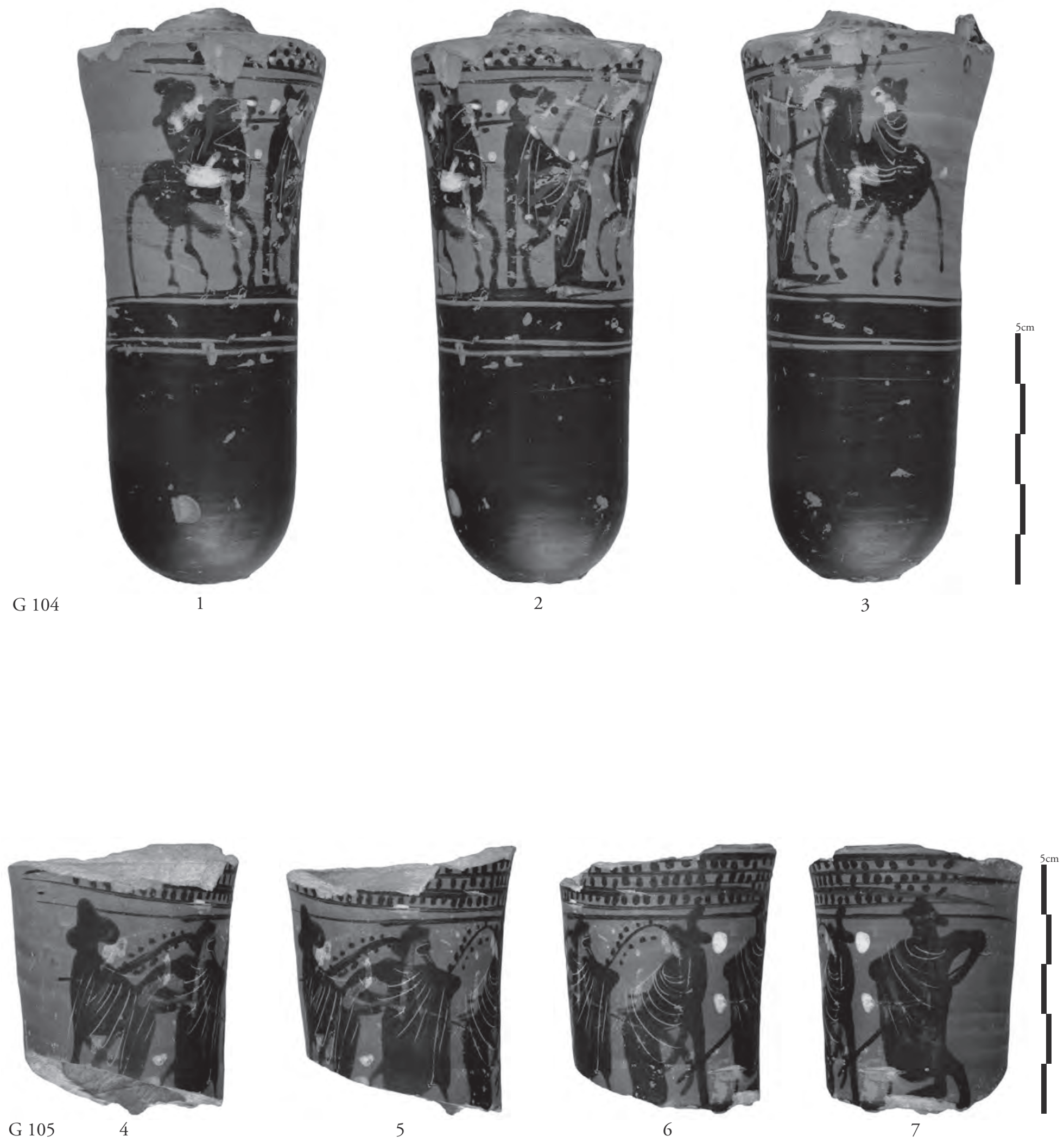

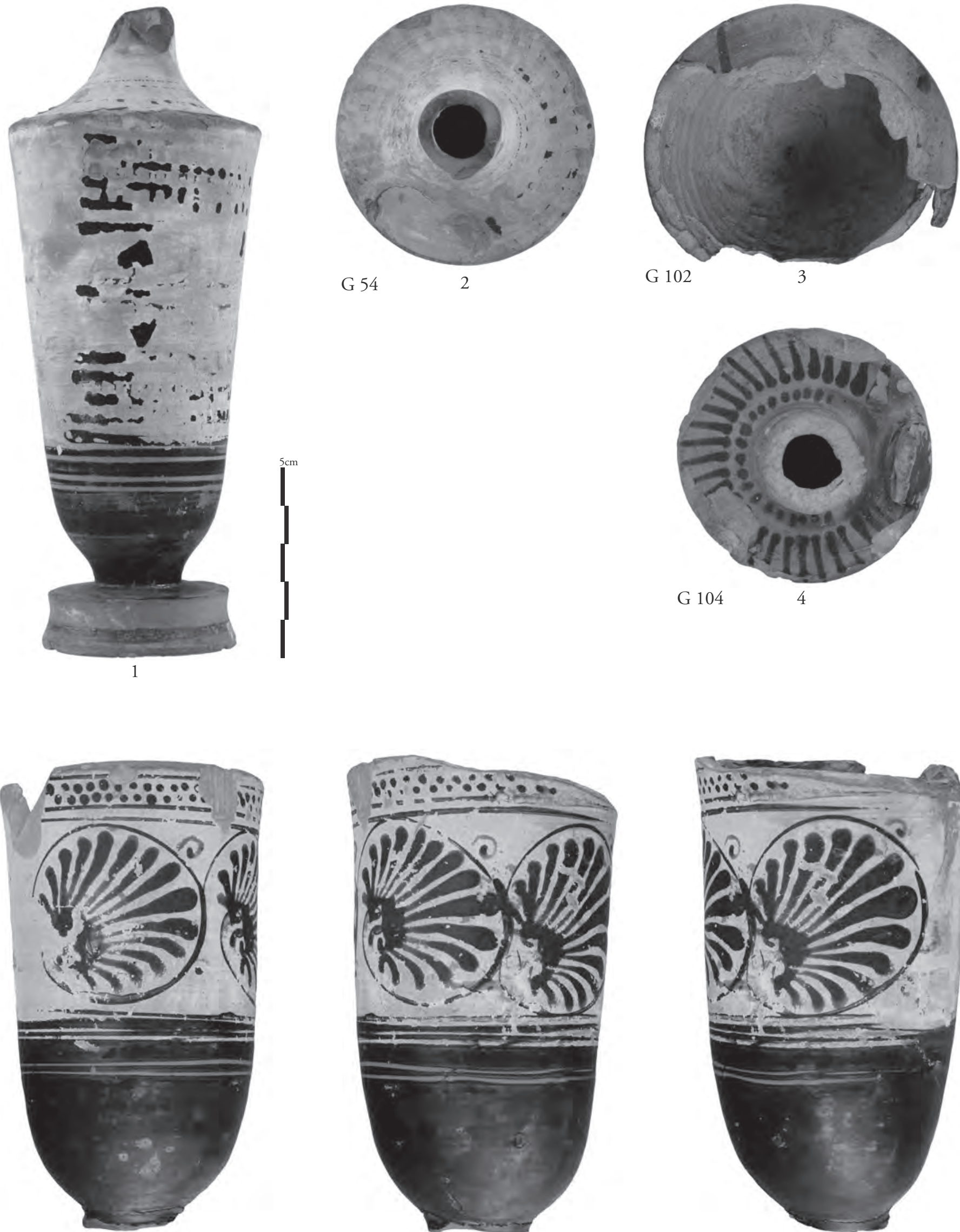

G 106

5
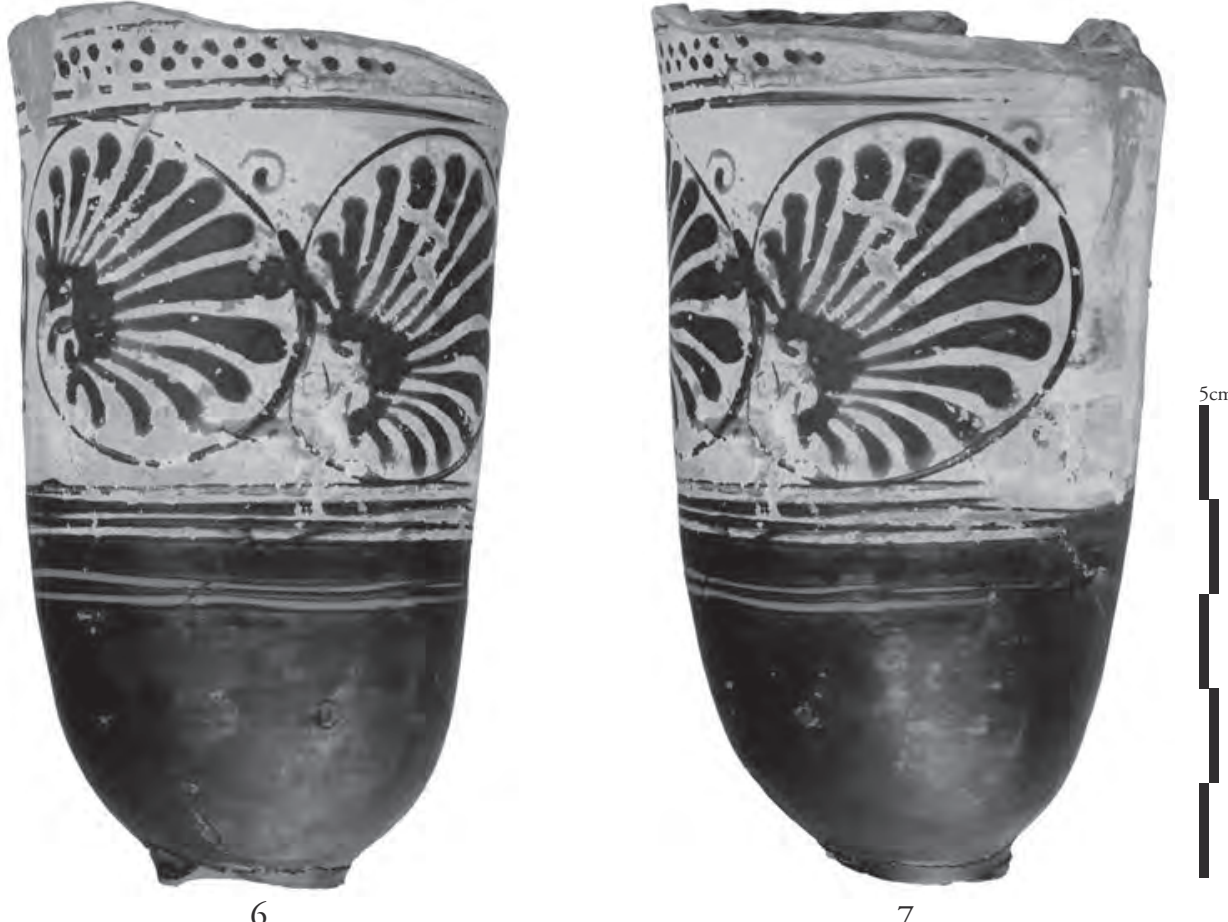

7 


$$
8_{8}
$$



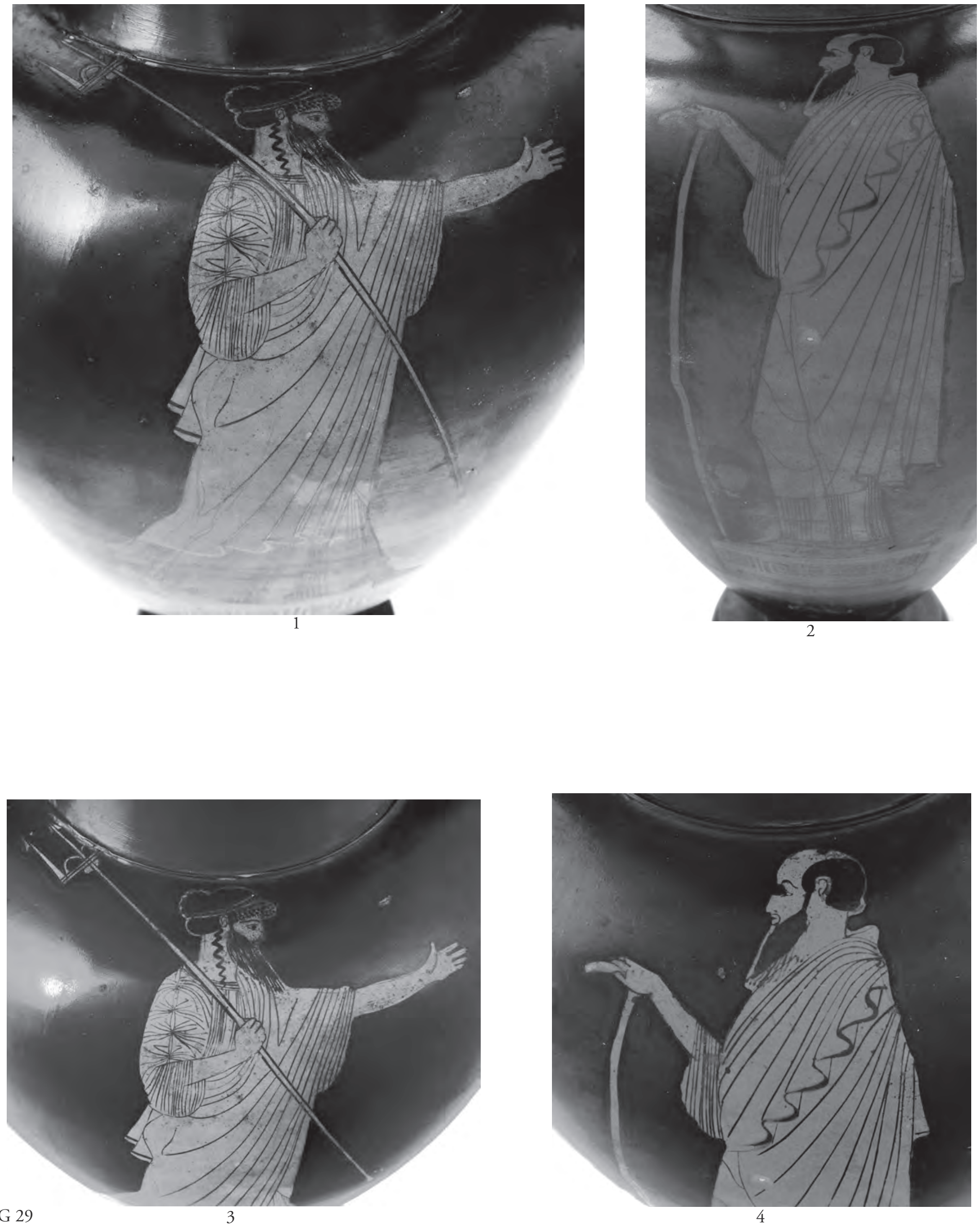


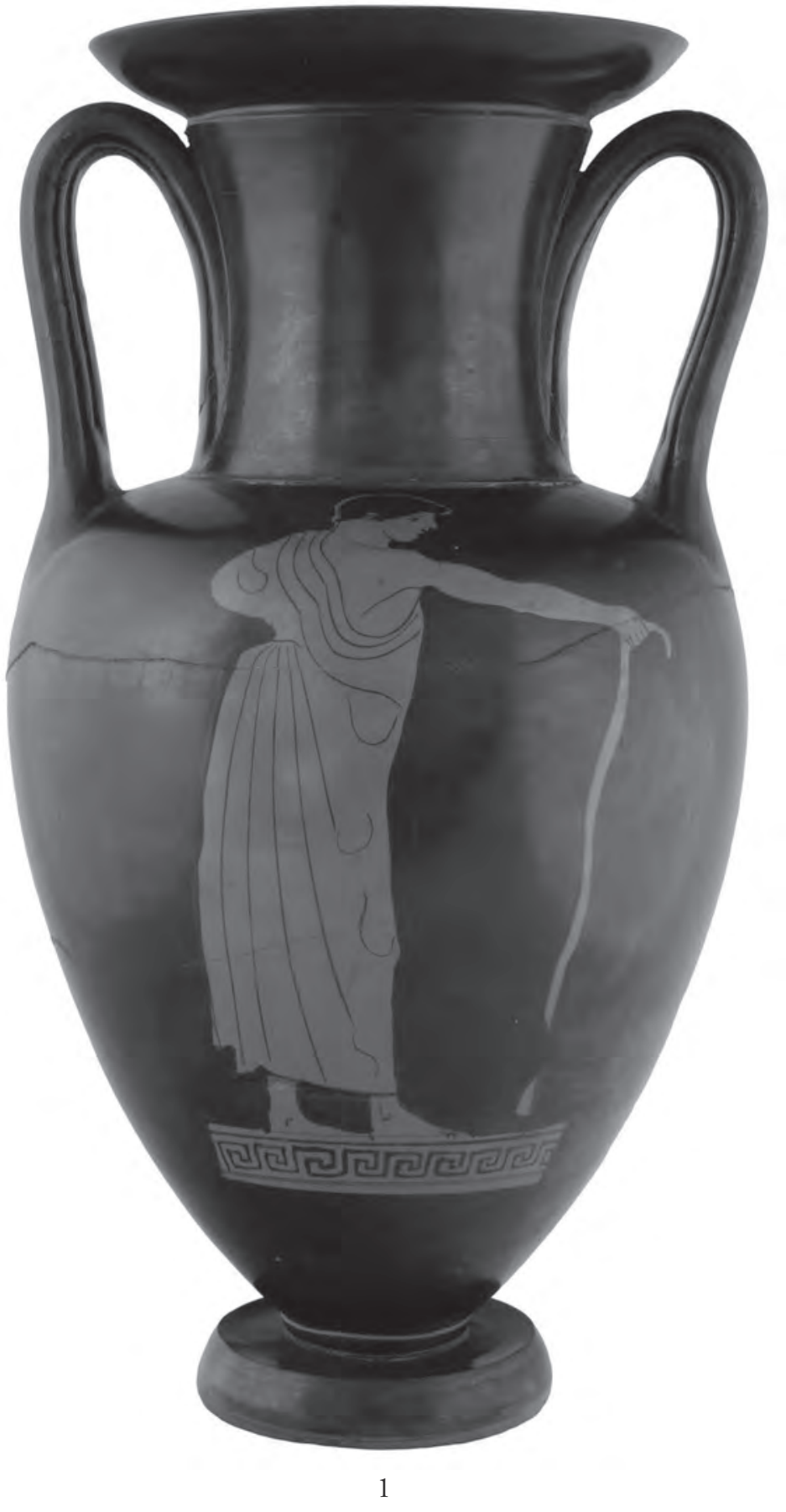

G 20

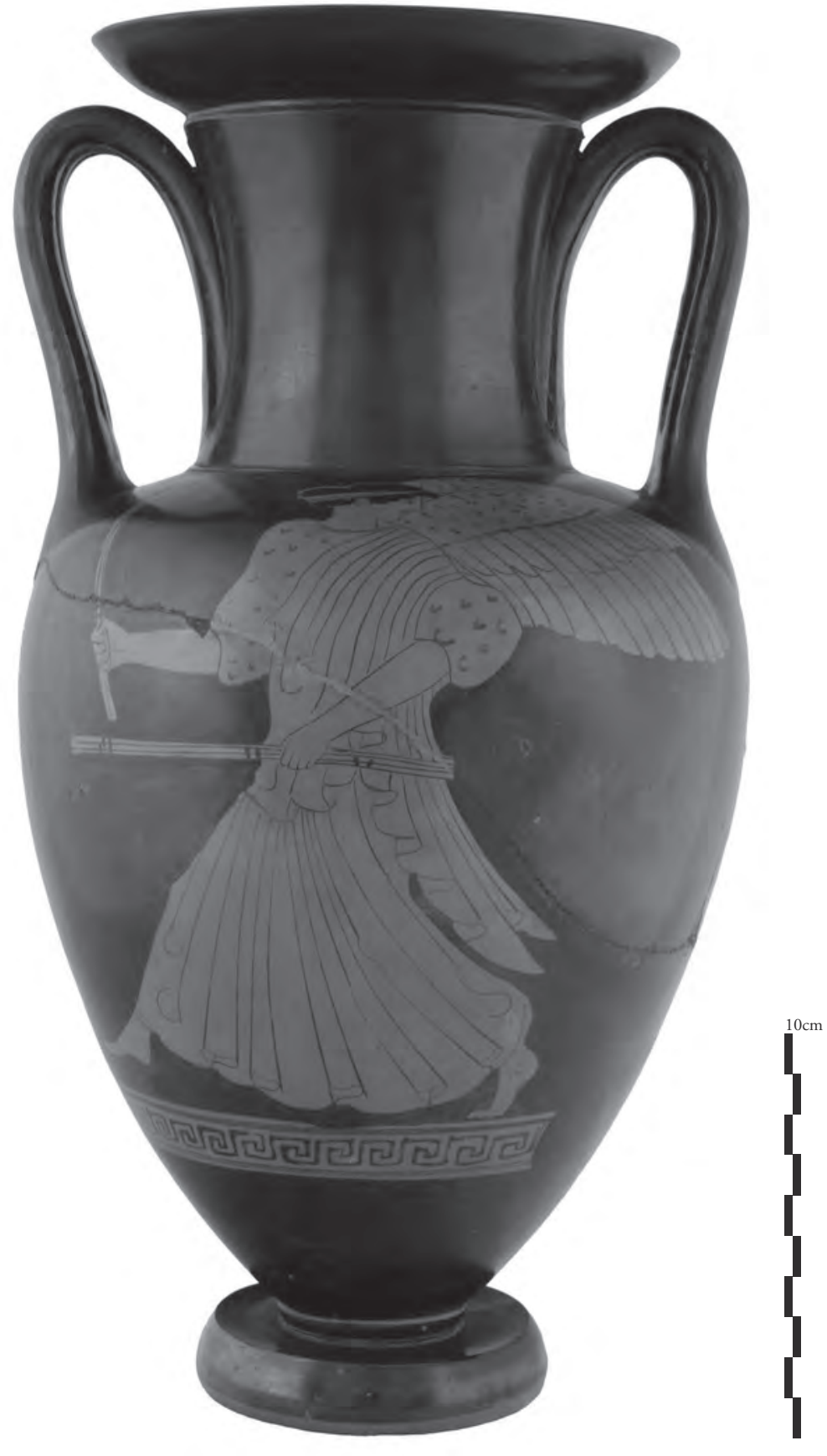



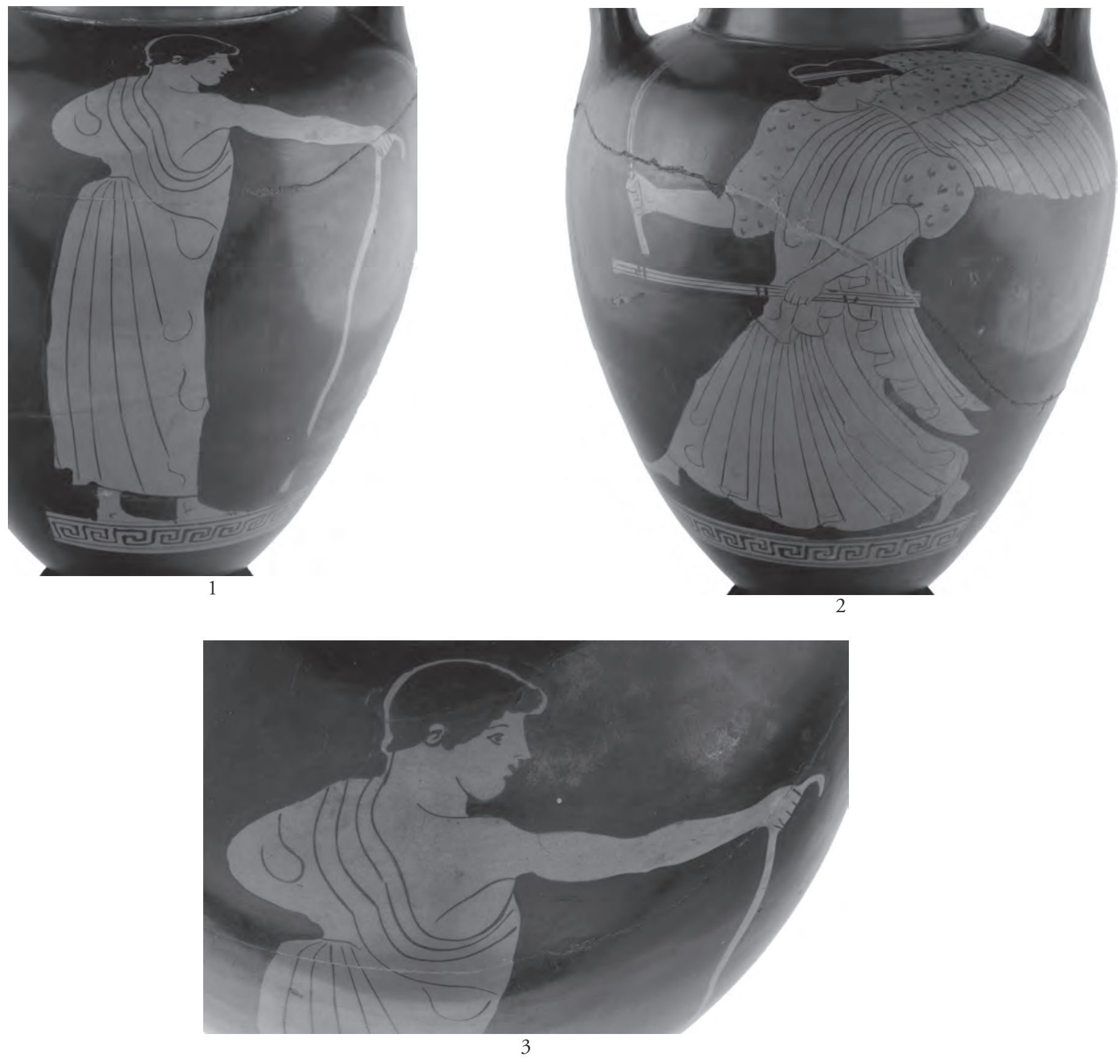

G 20

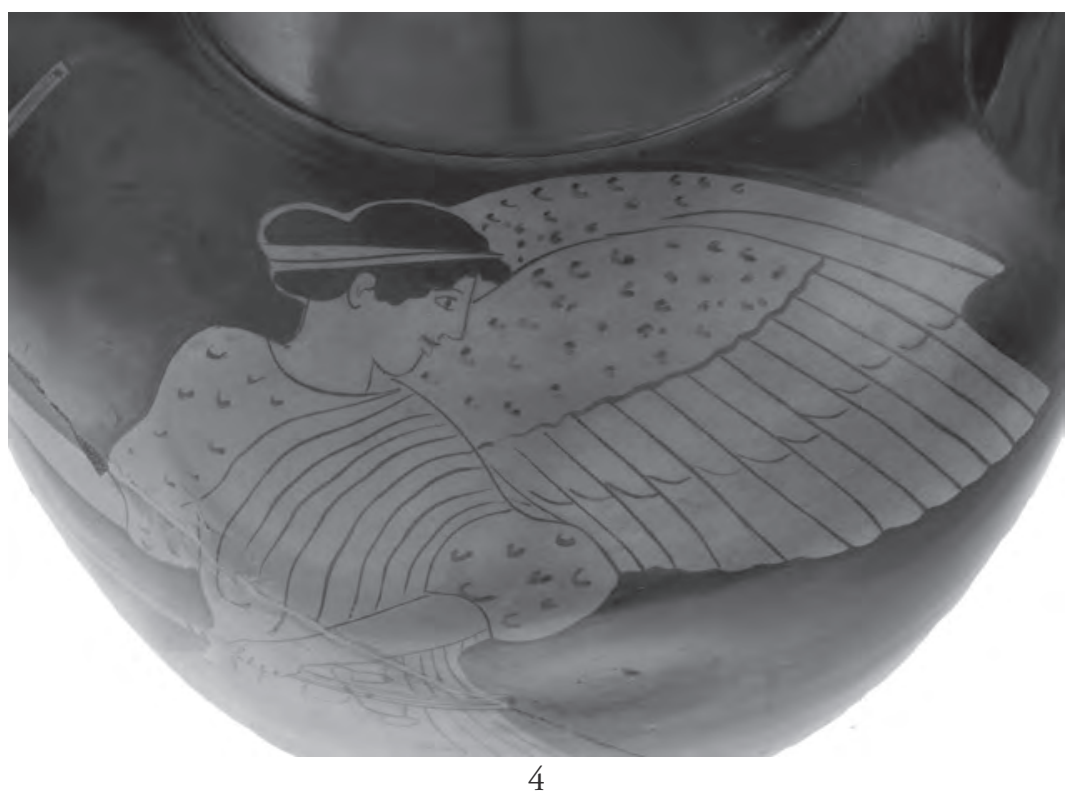



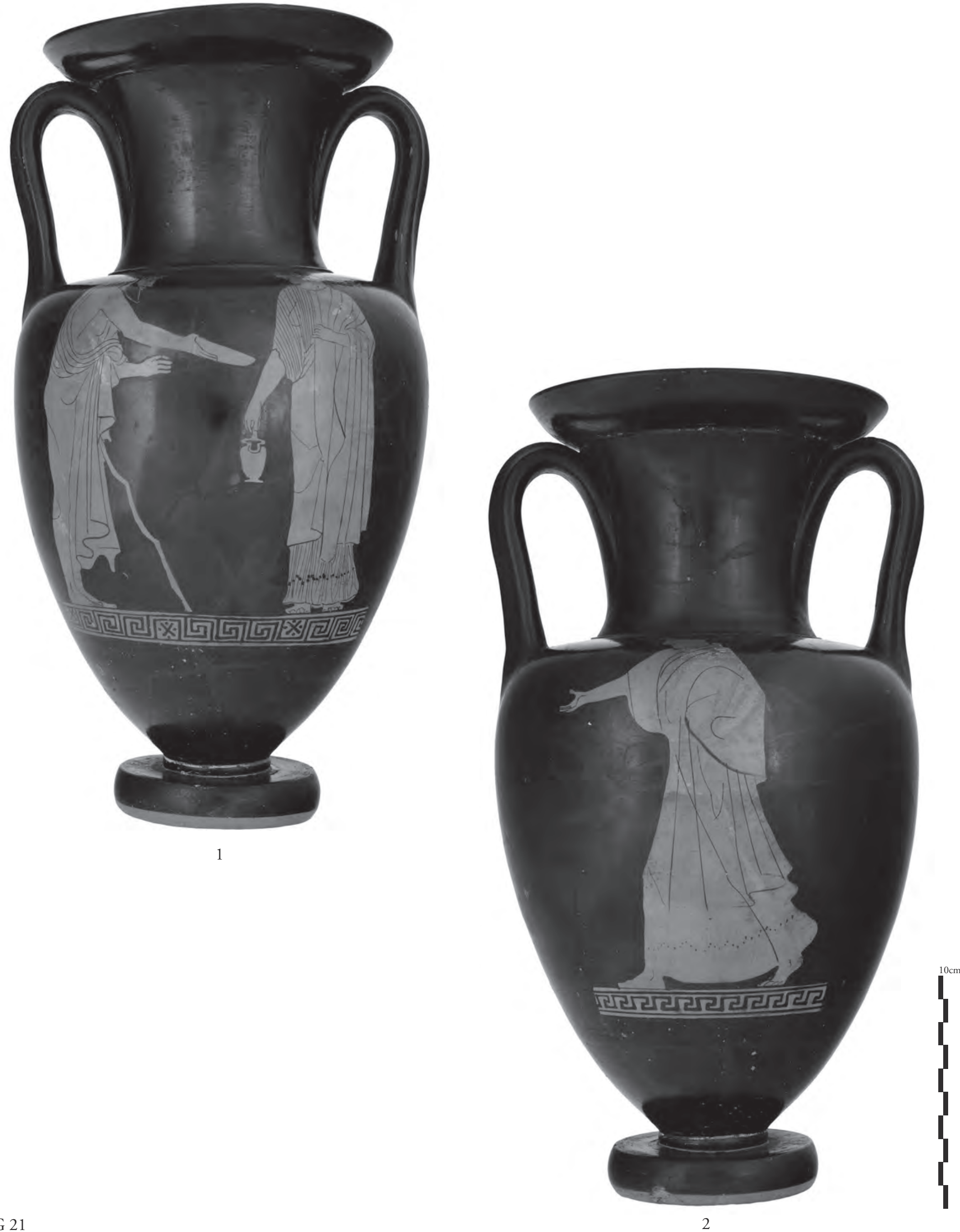

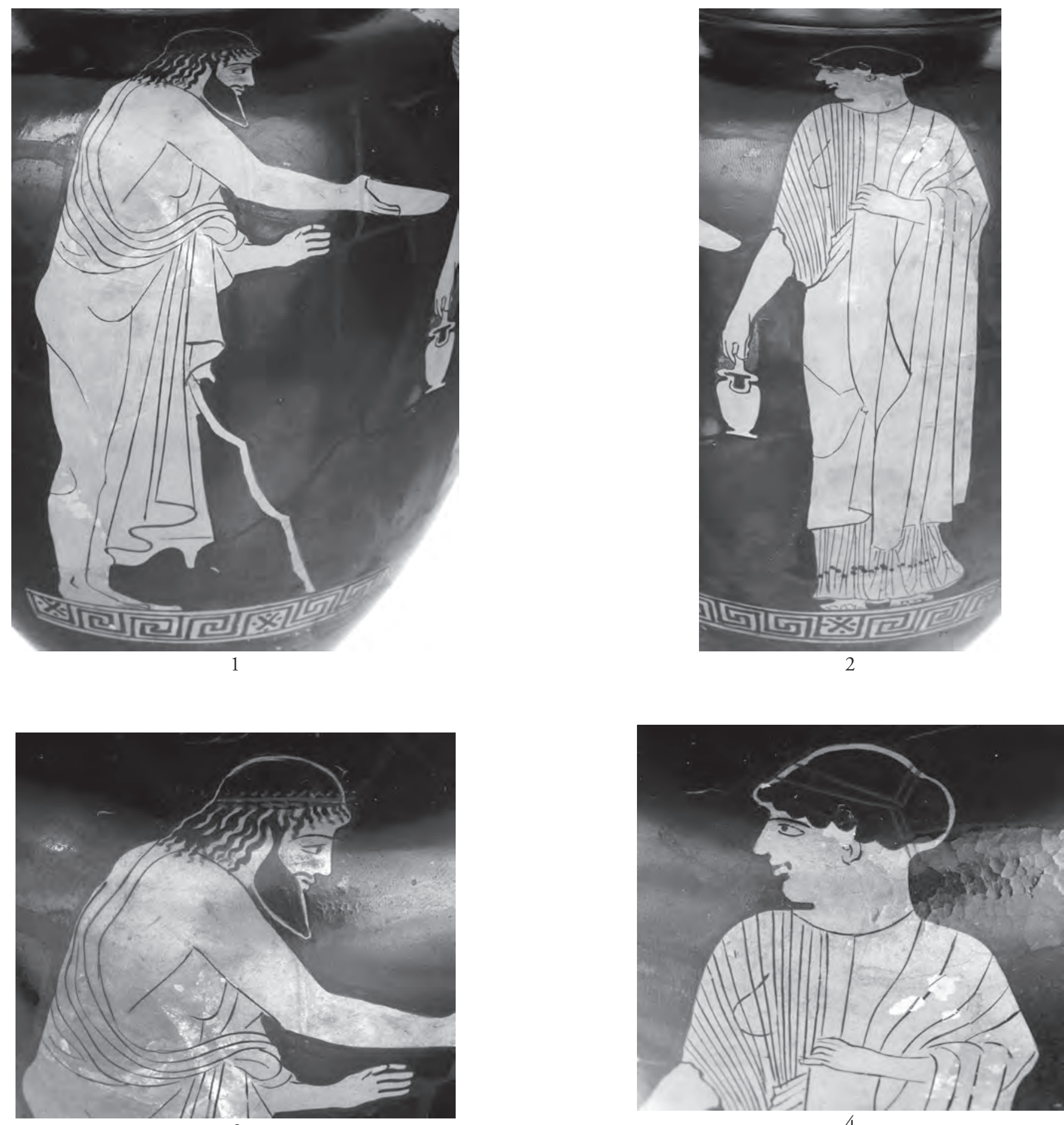

3

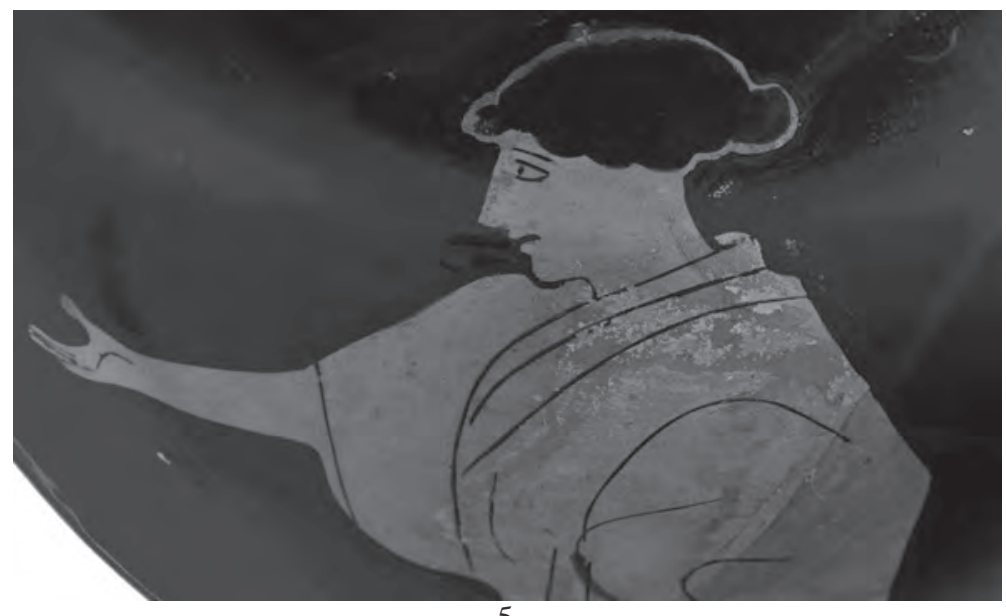




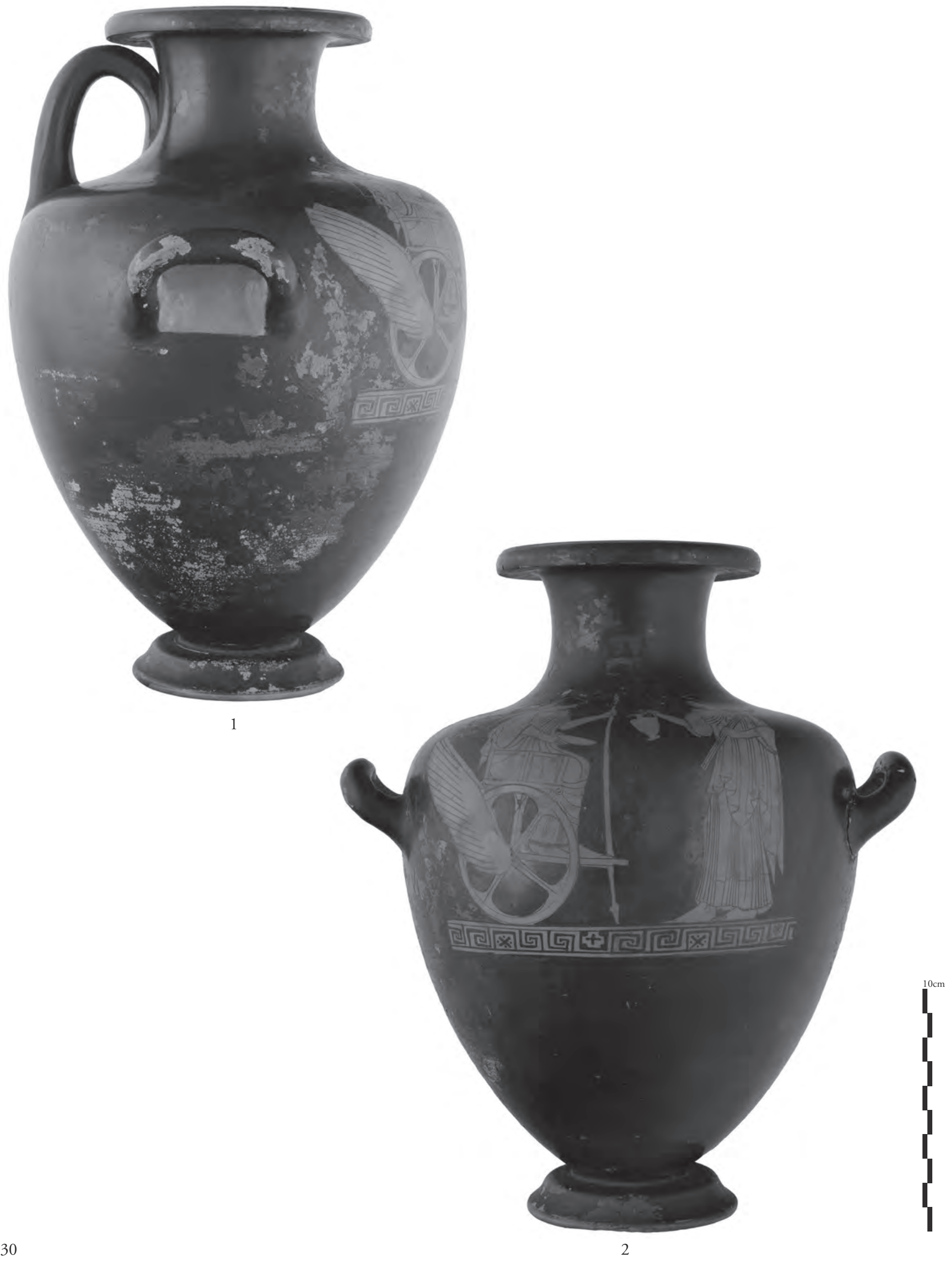




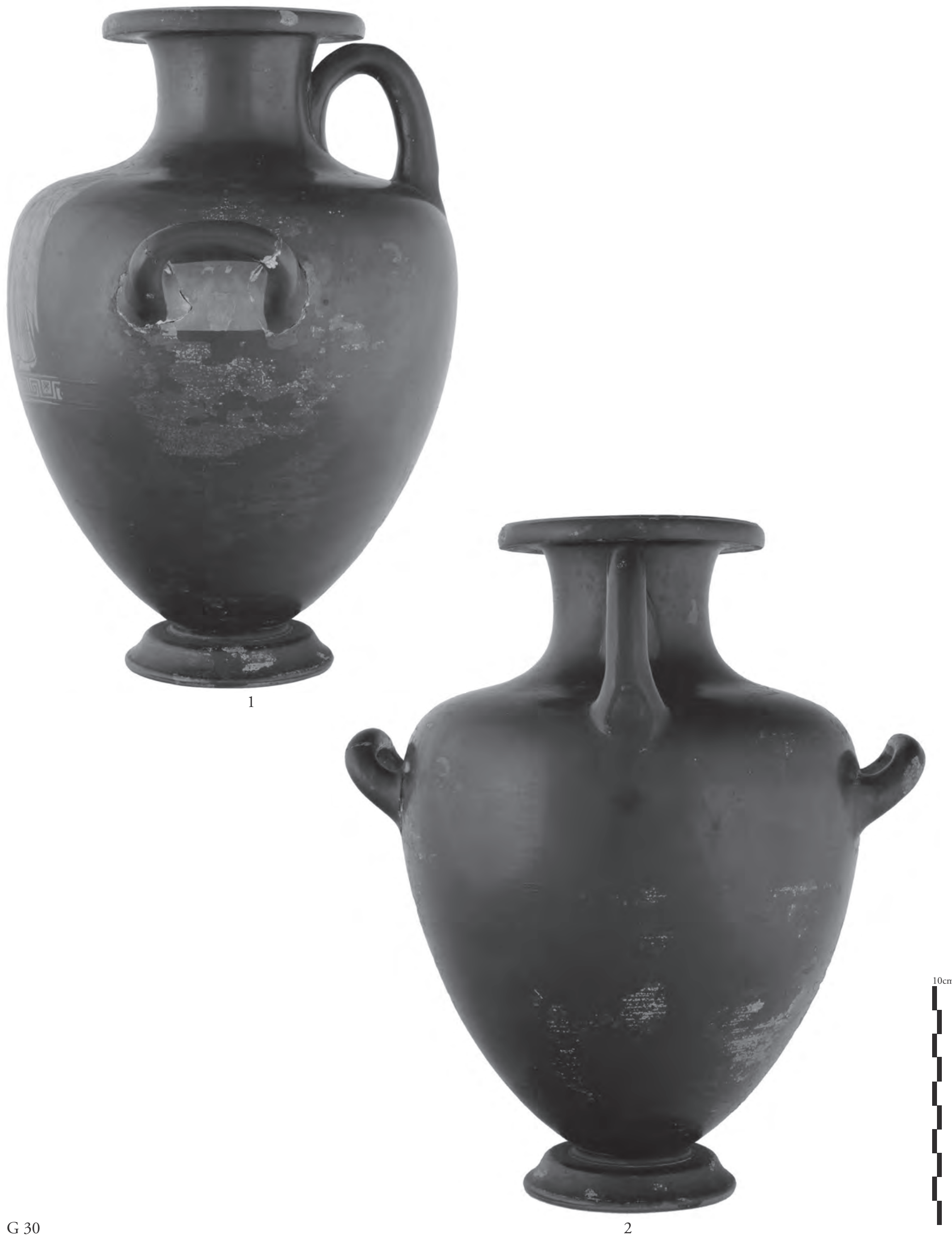



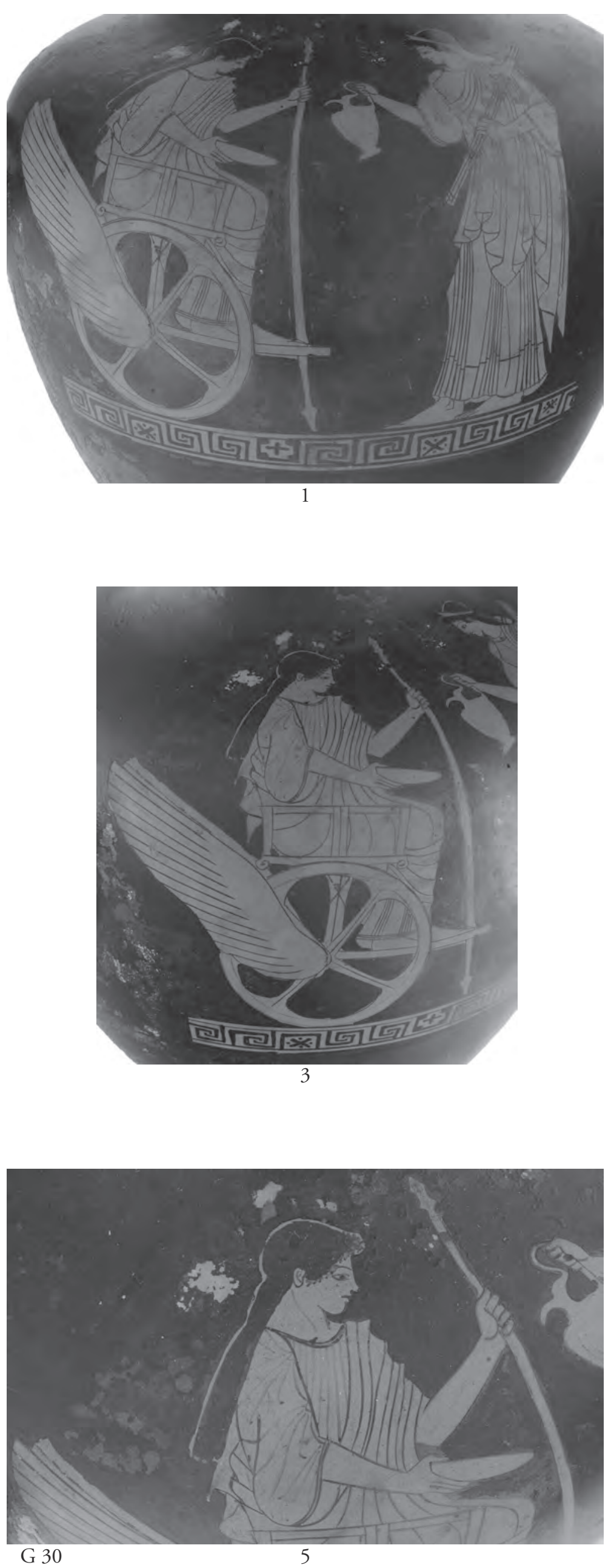
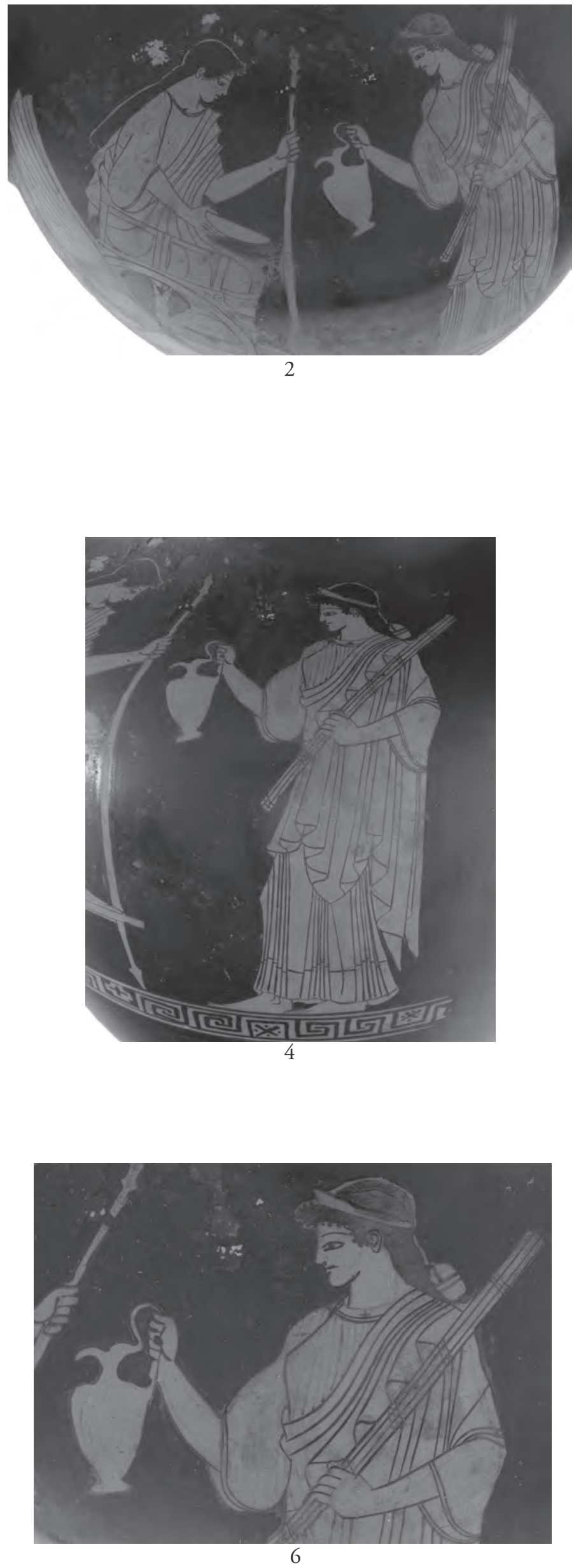

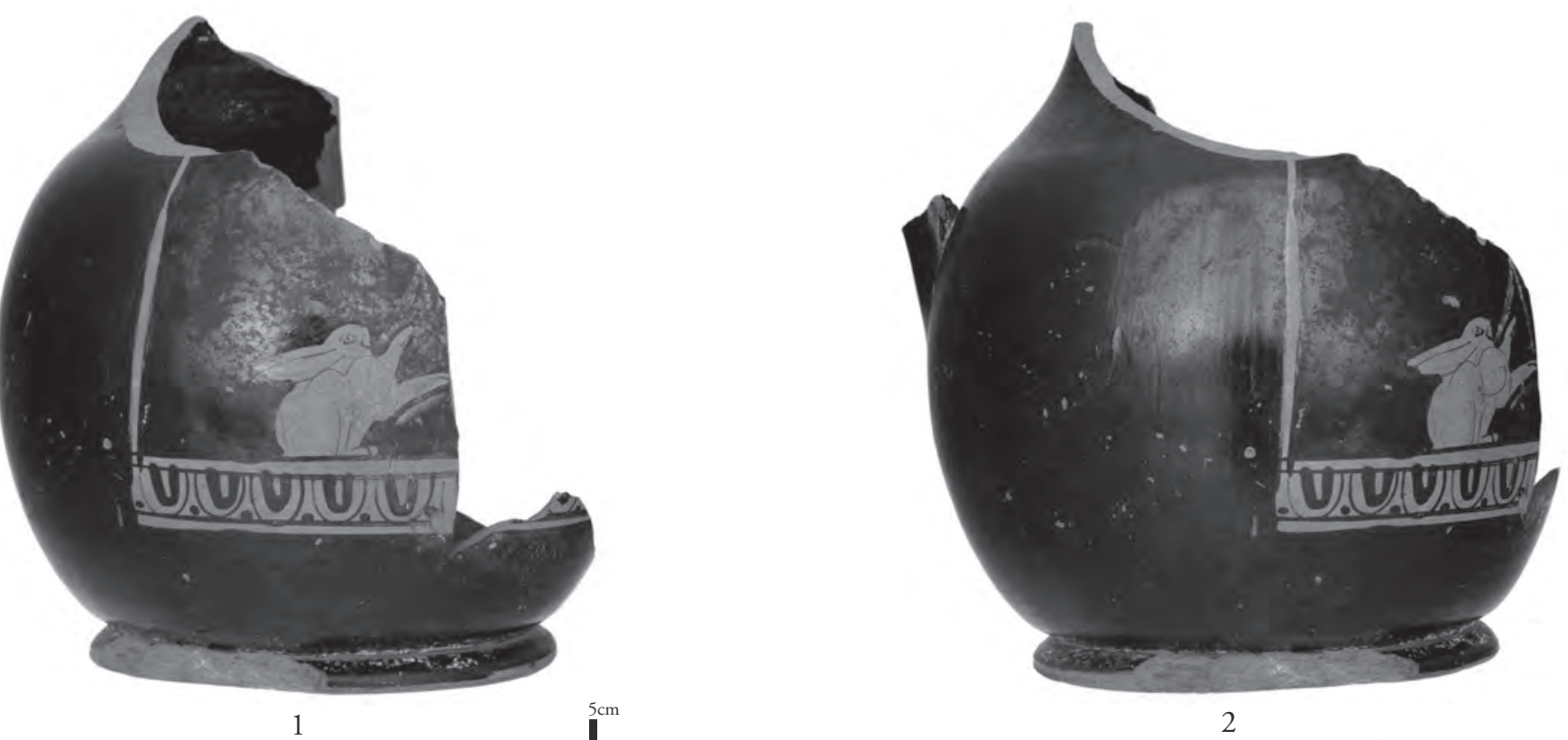

G 200
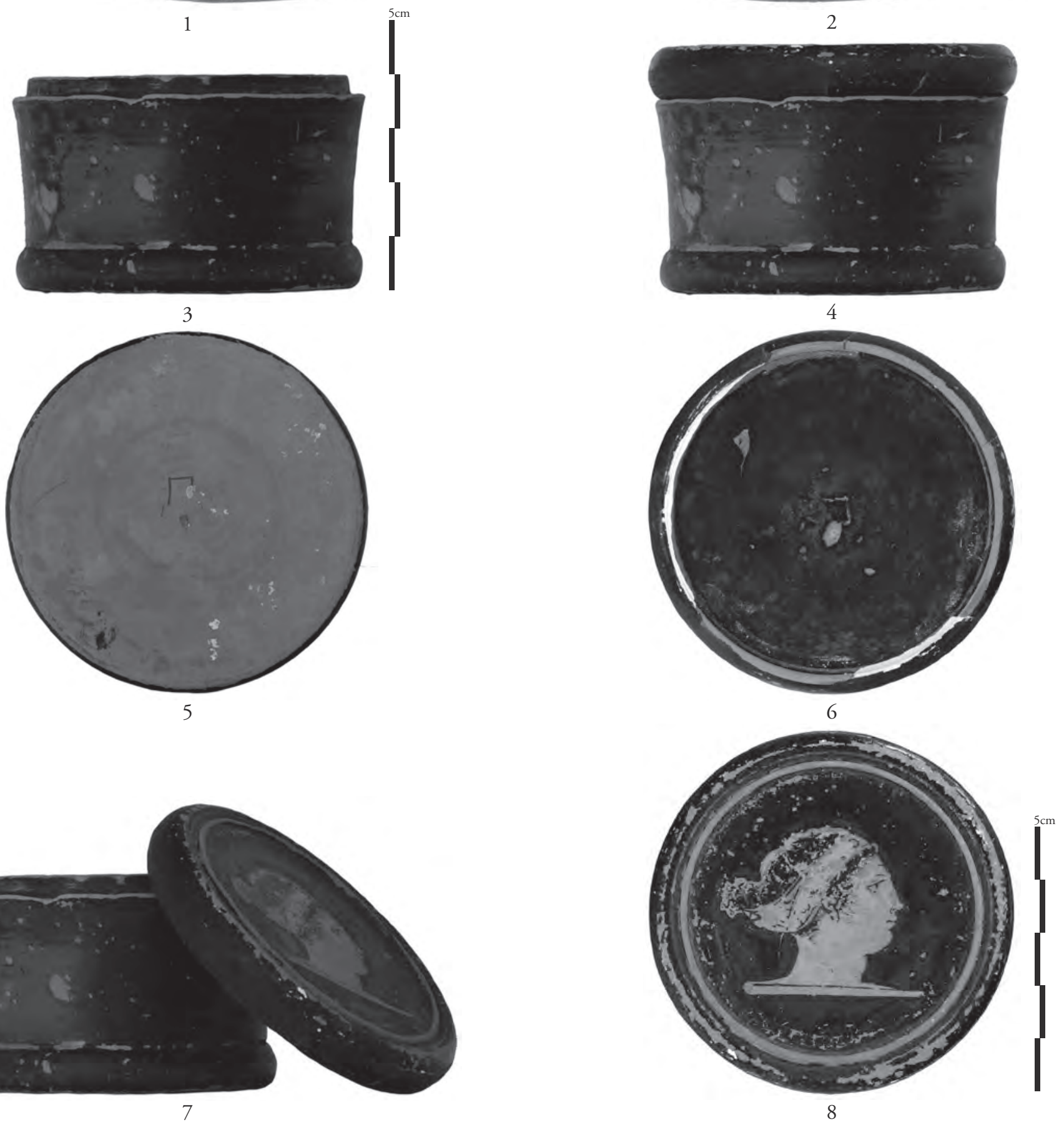

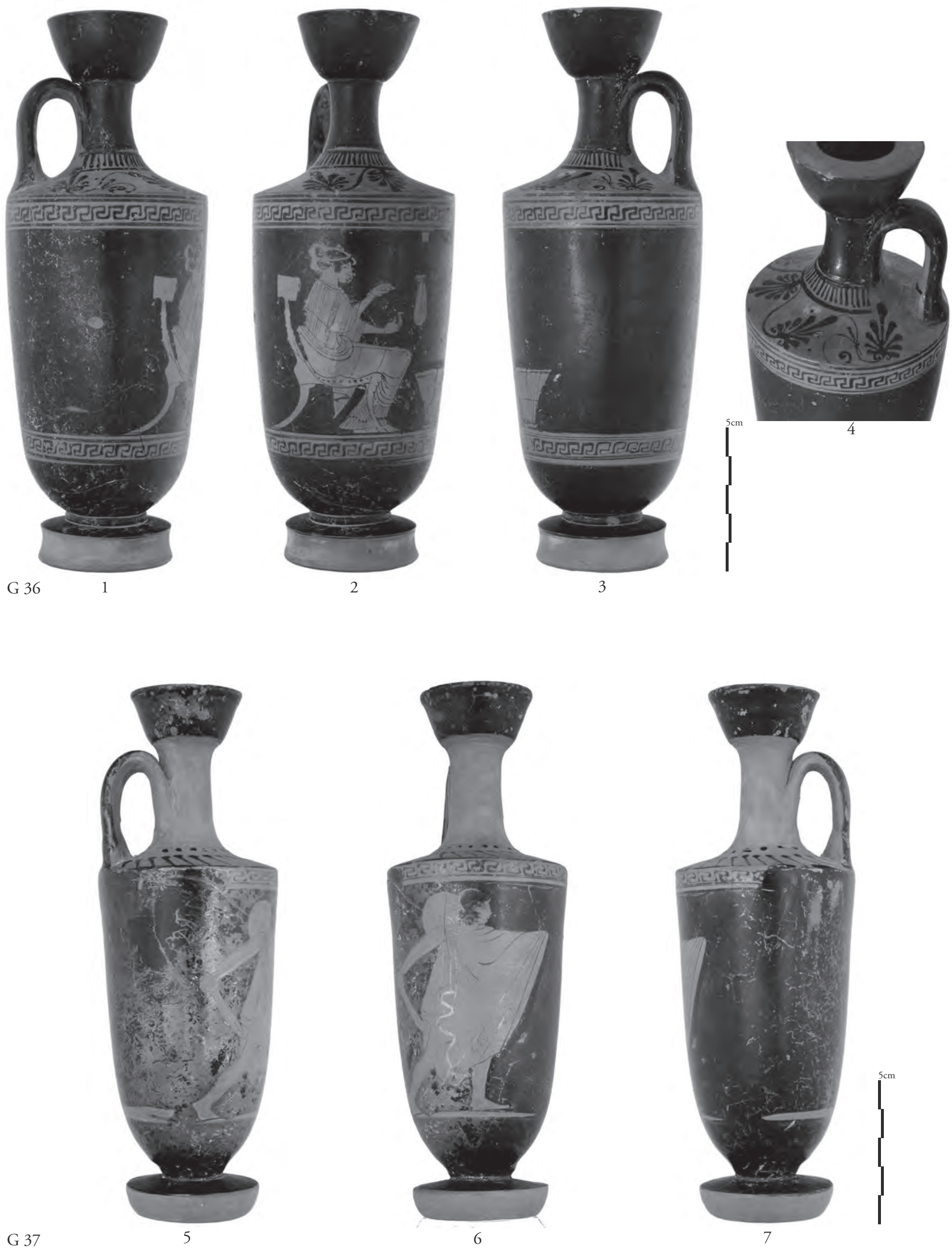
G 1
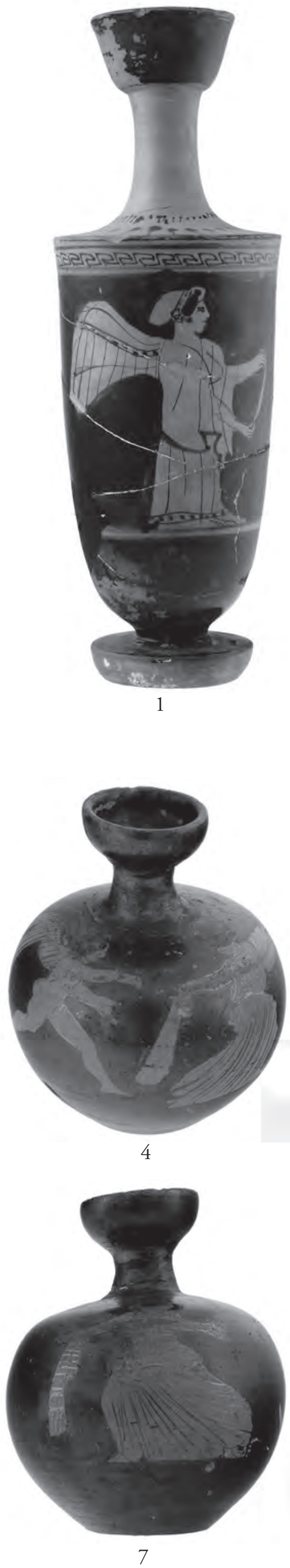

G 39
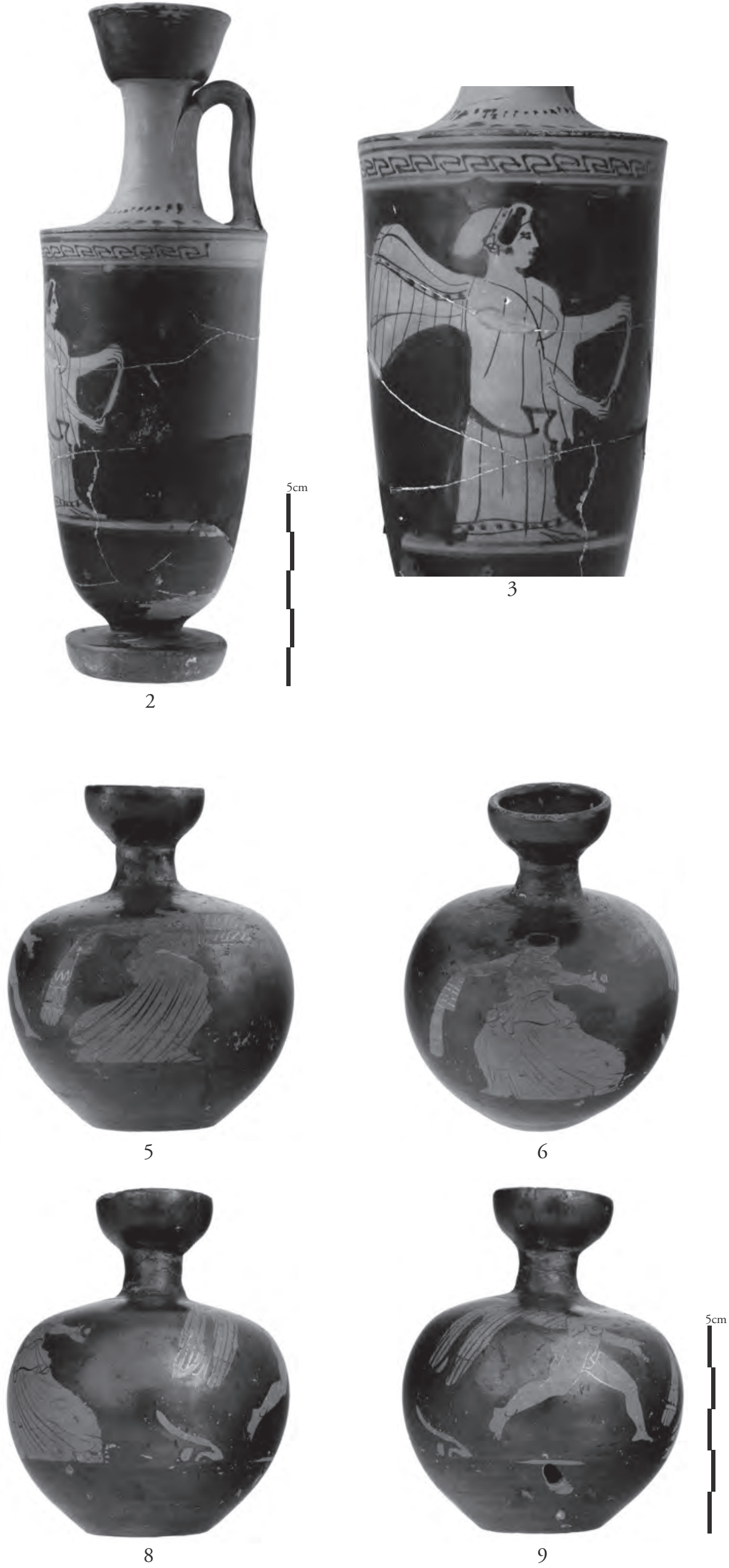


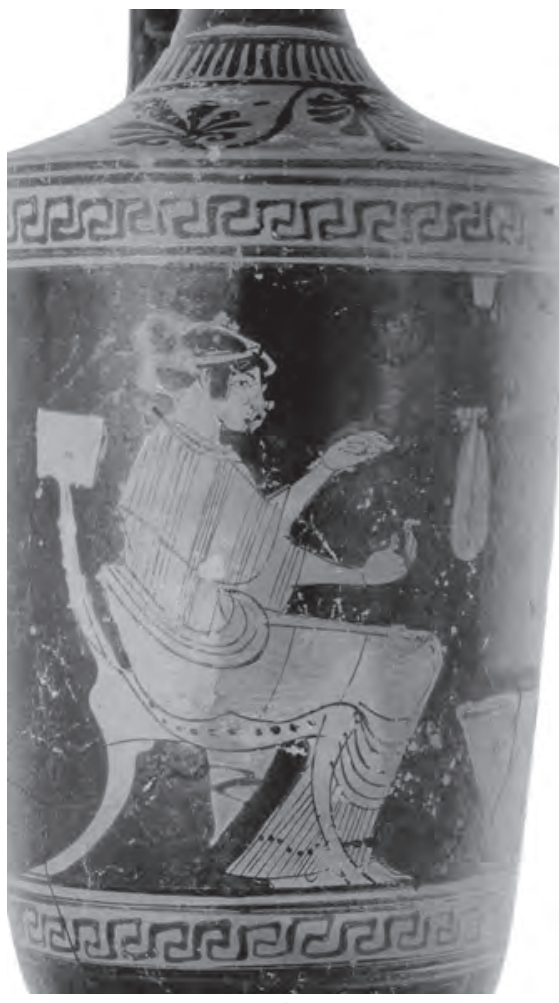

G 36

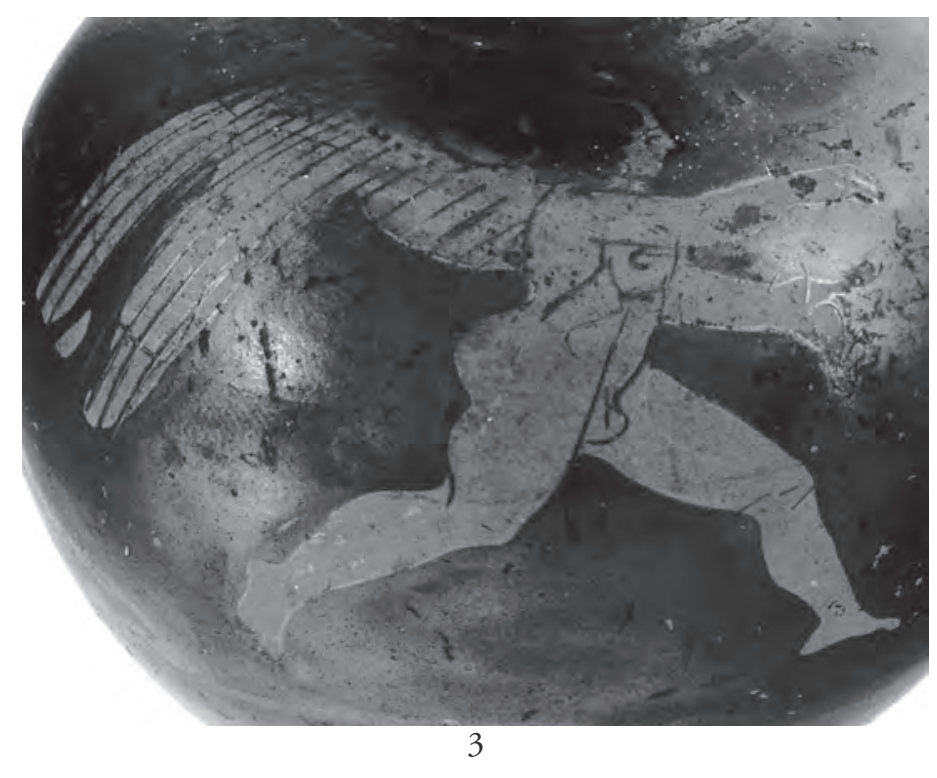

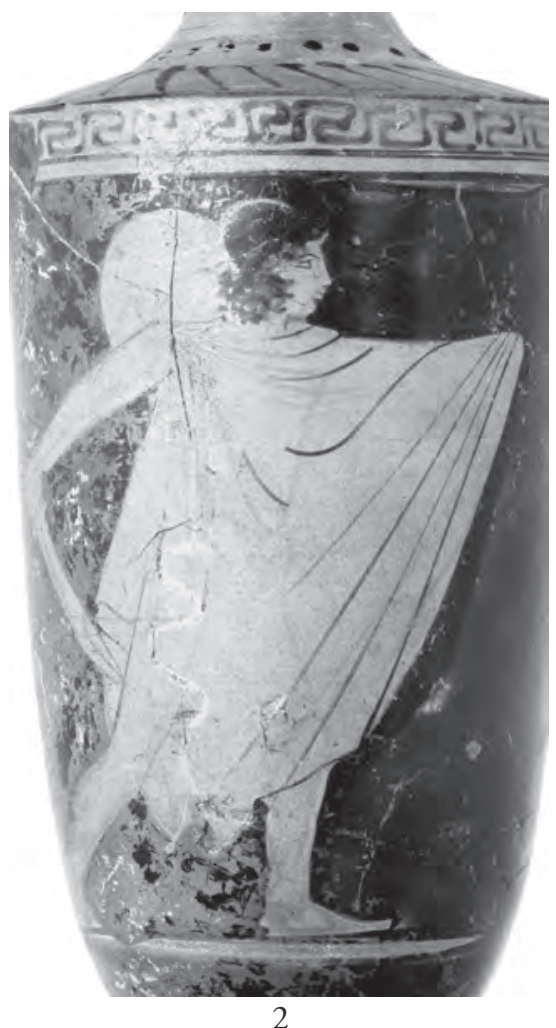

G 37

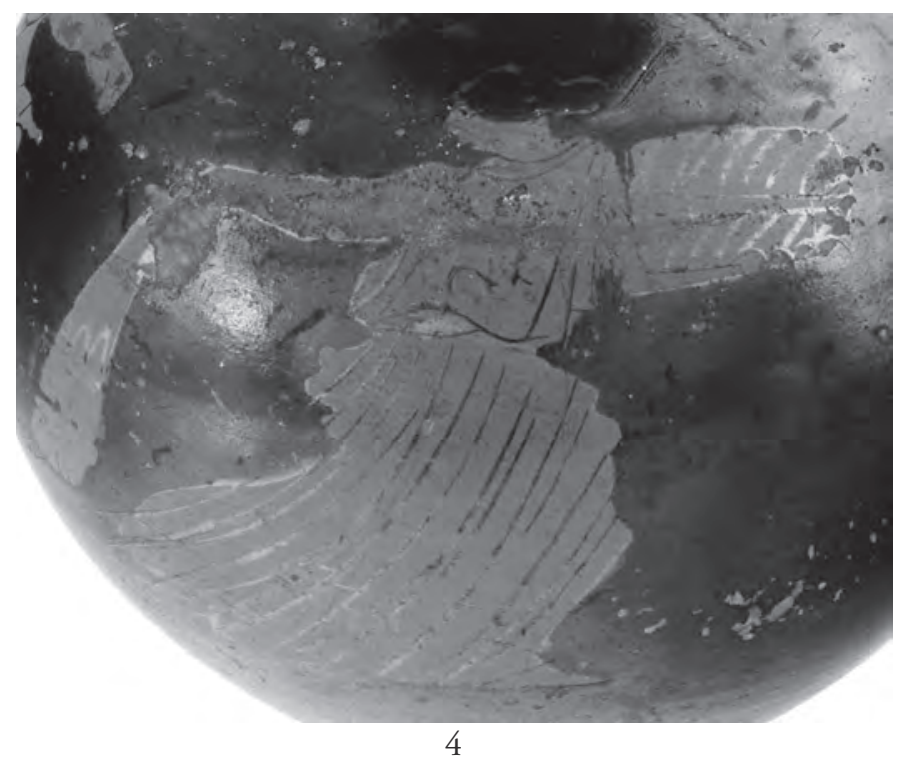

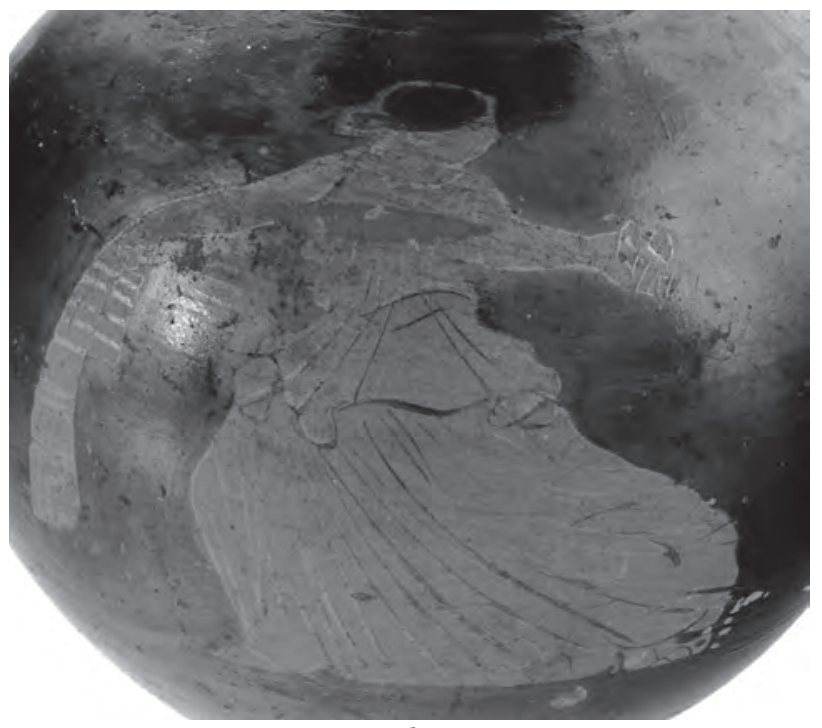



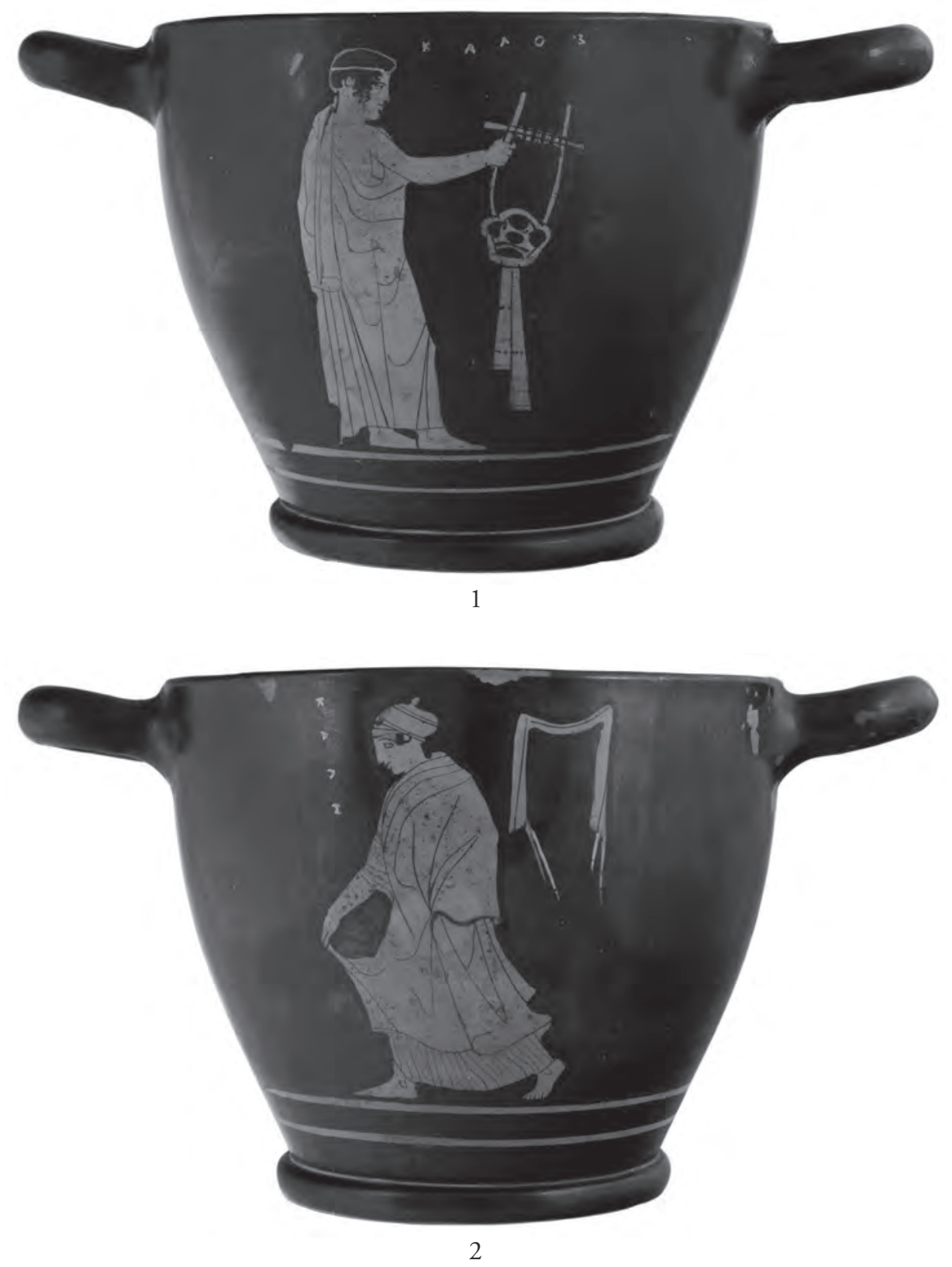

G 23

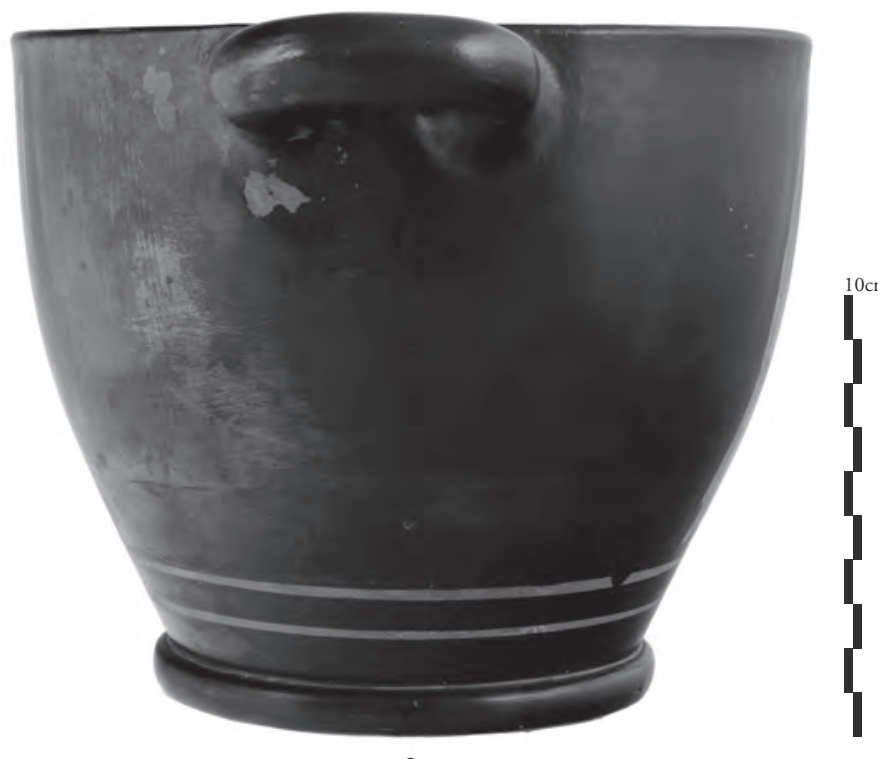




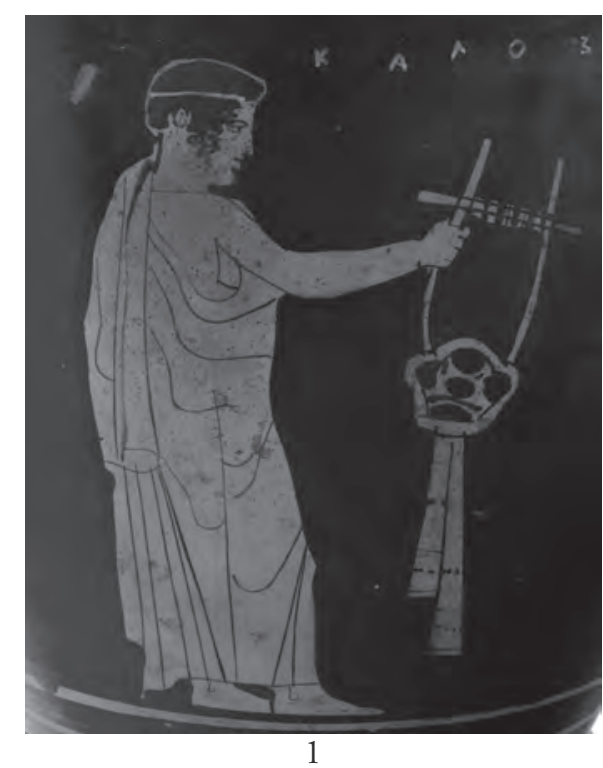

G 23
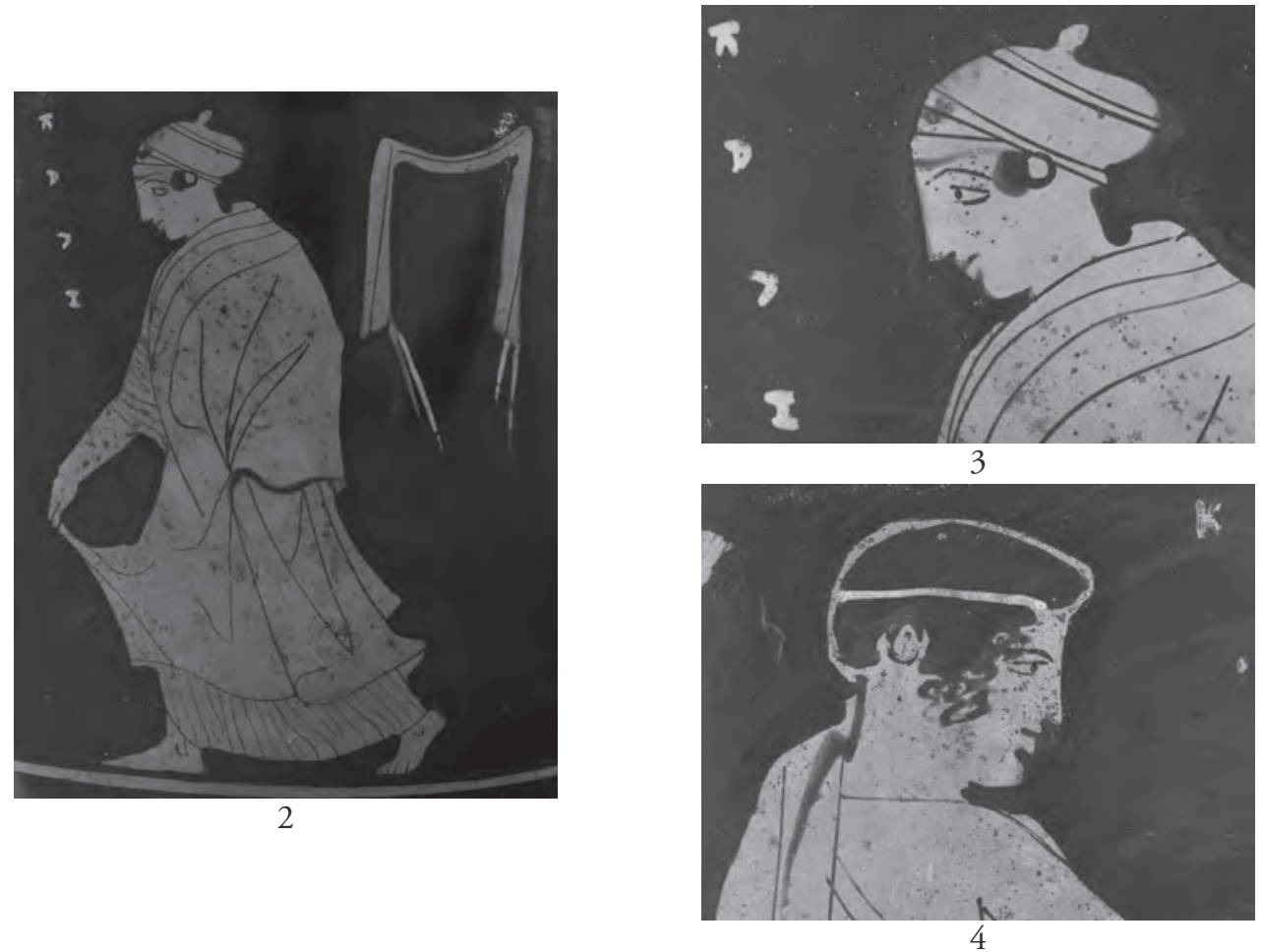

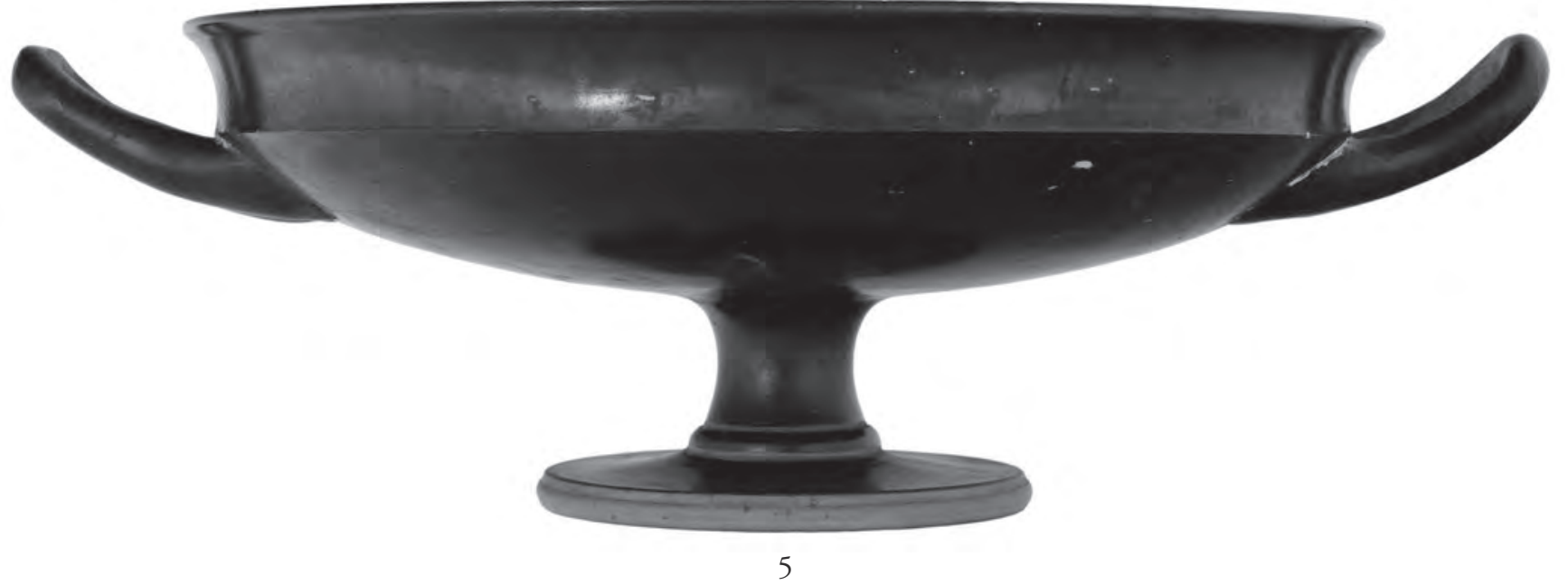

G 22

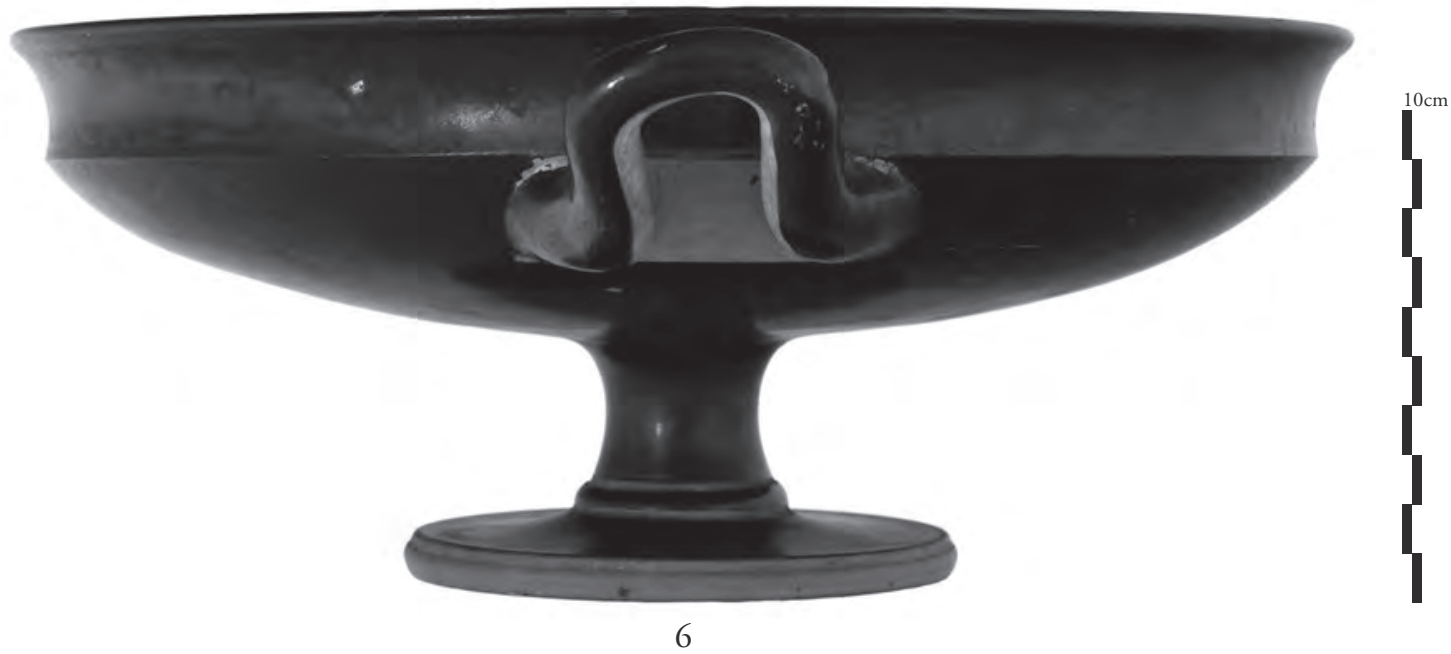



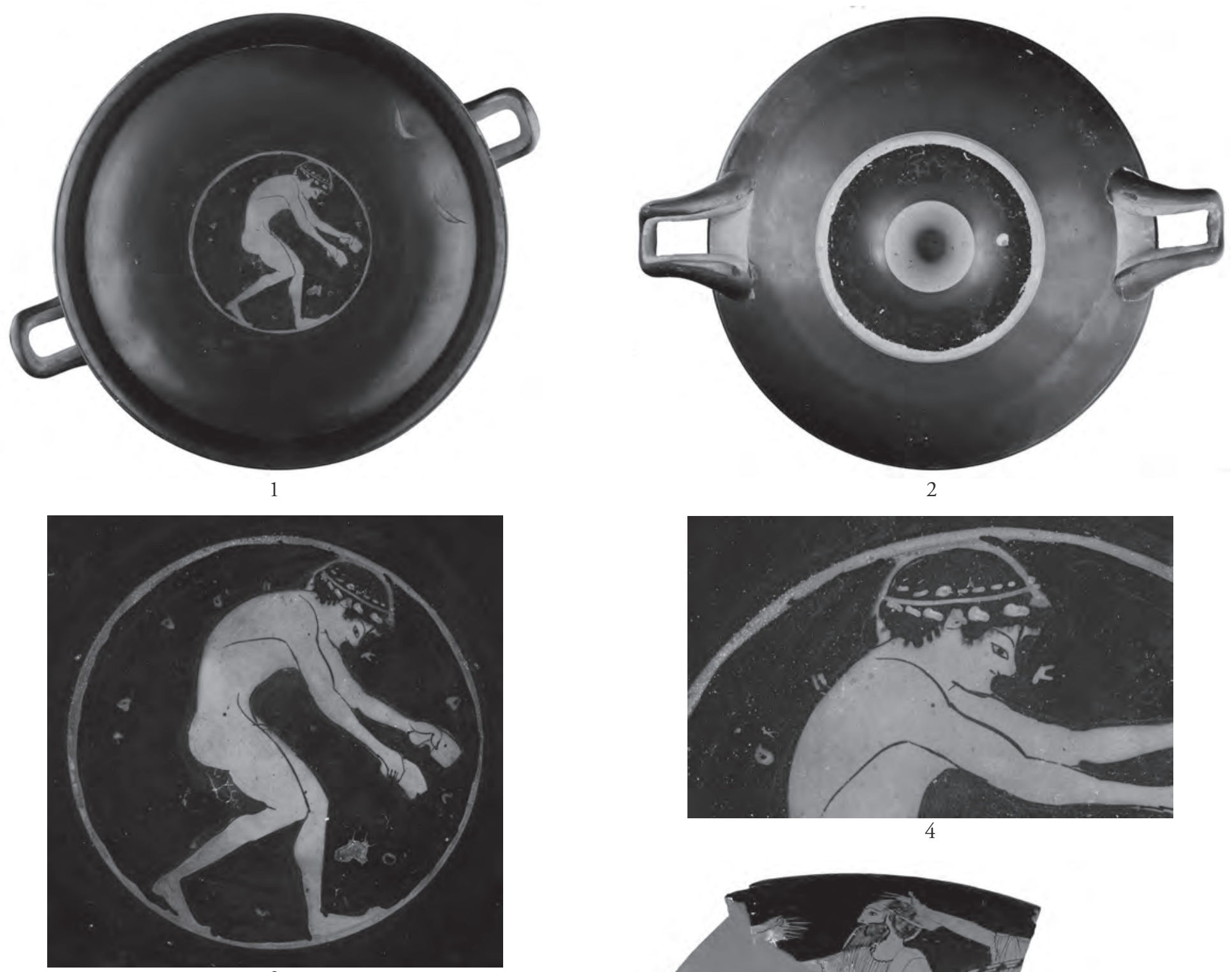

G 22
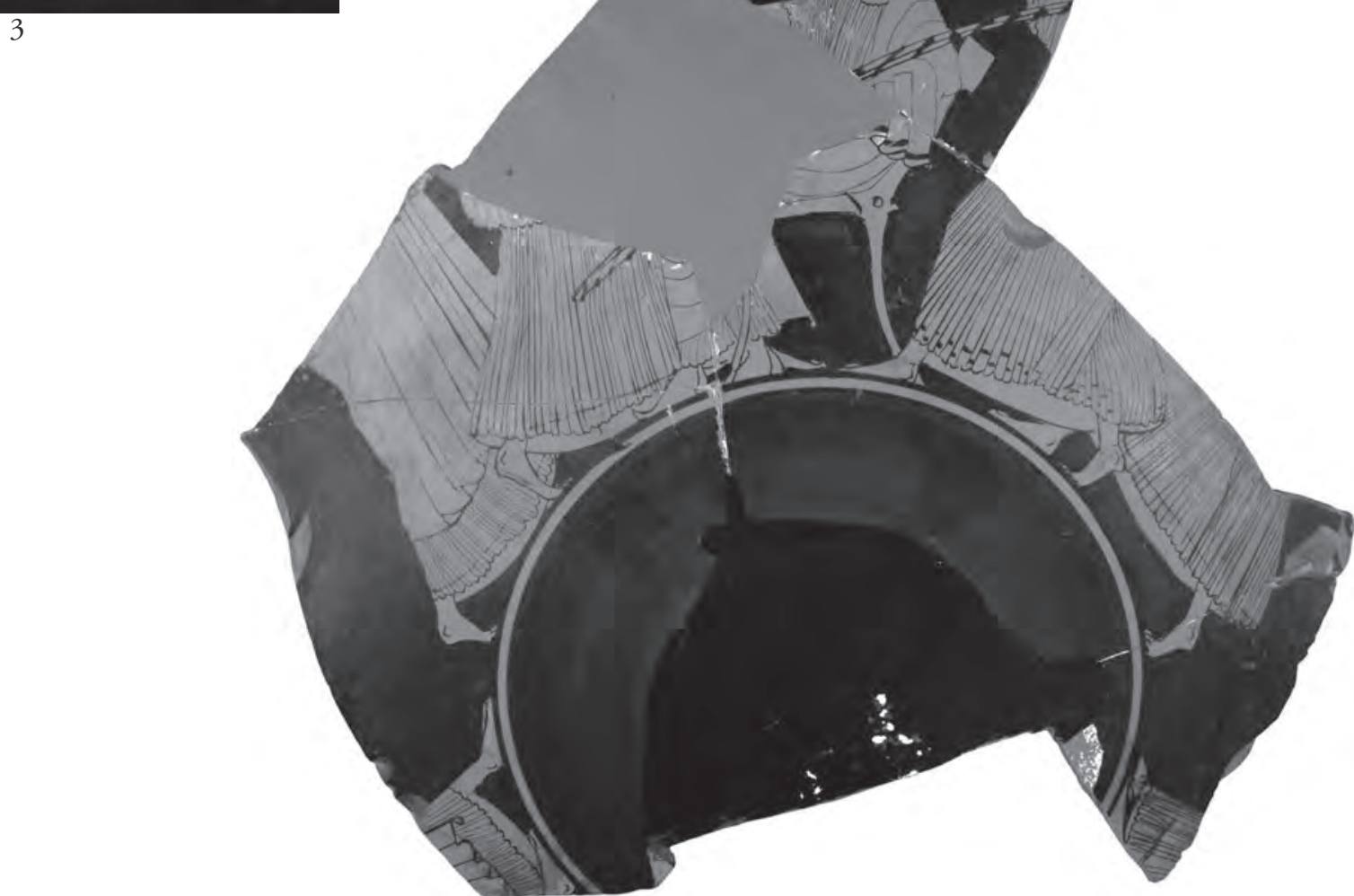

G 194 

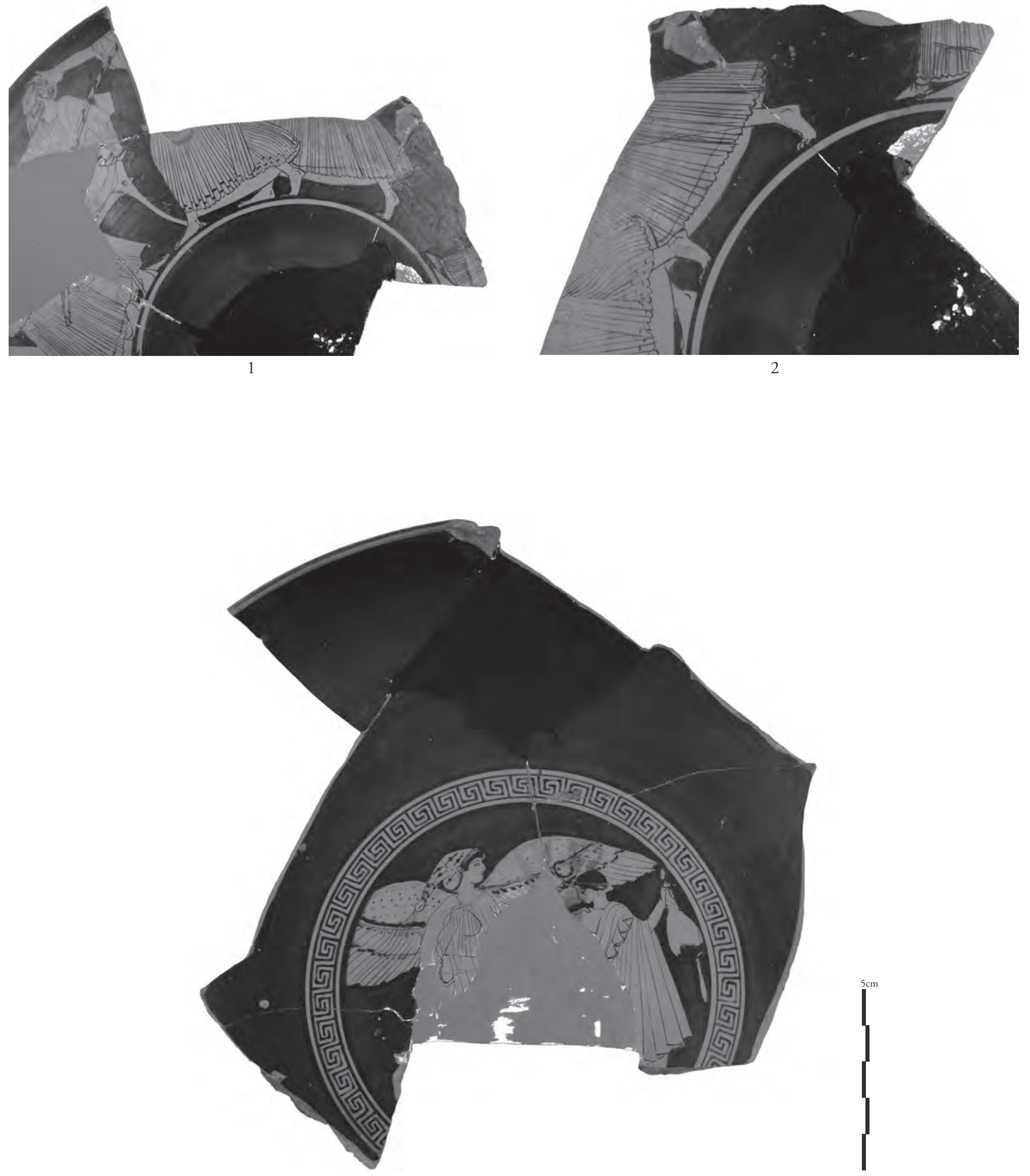

G 194 


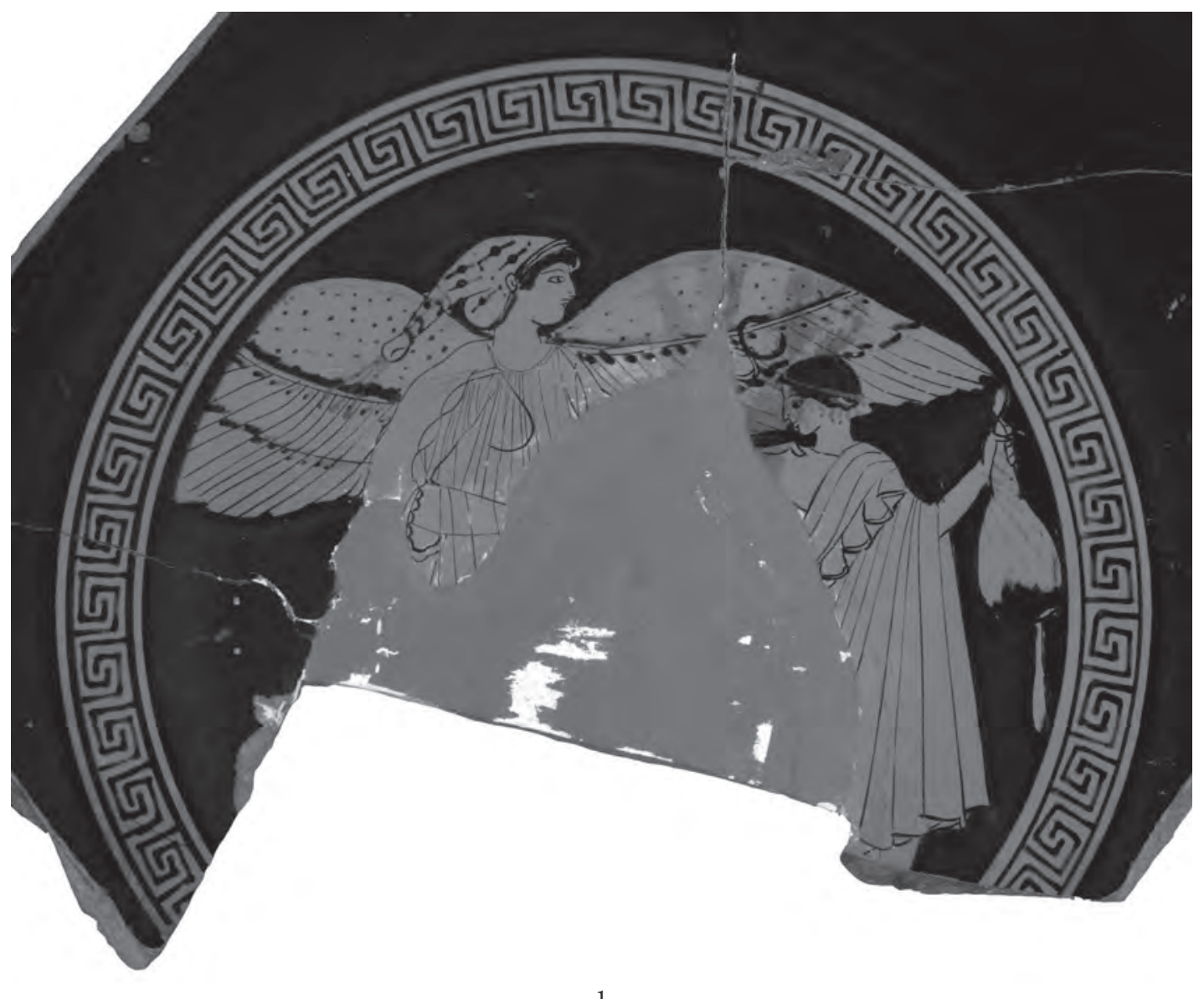

G 194
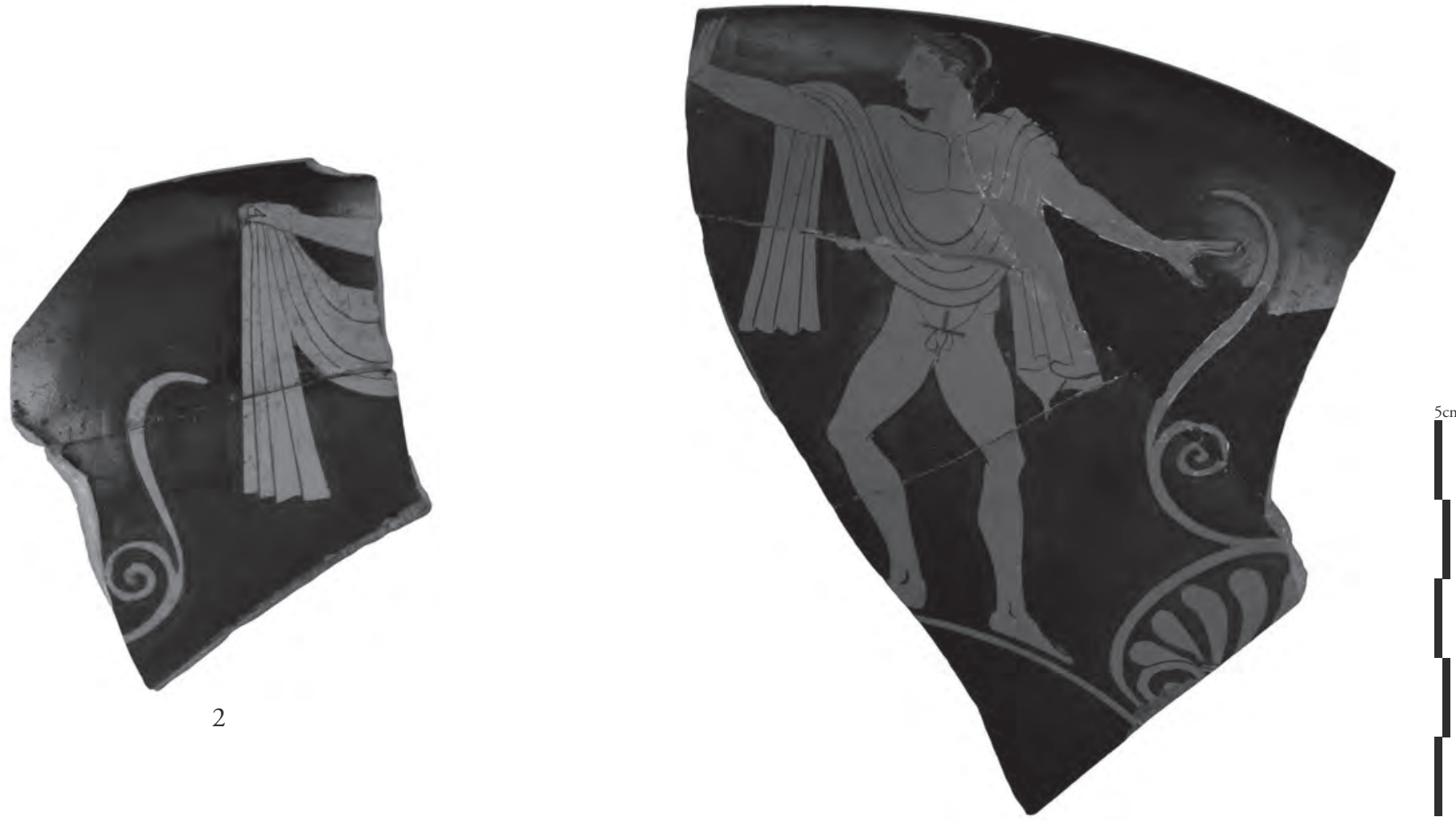

G 198 

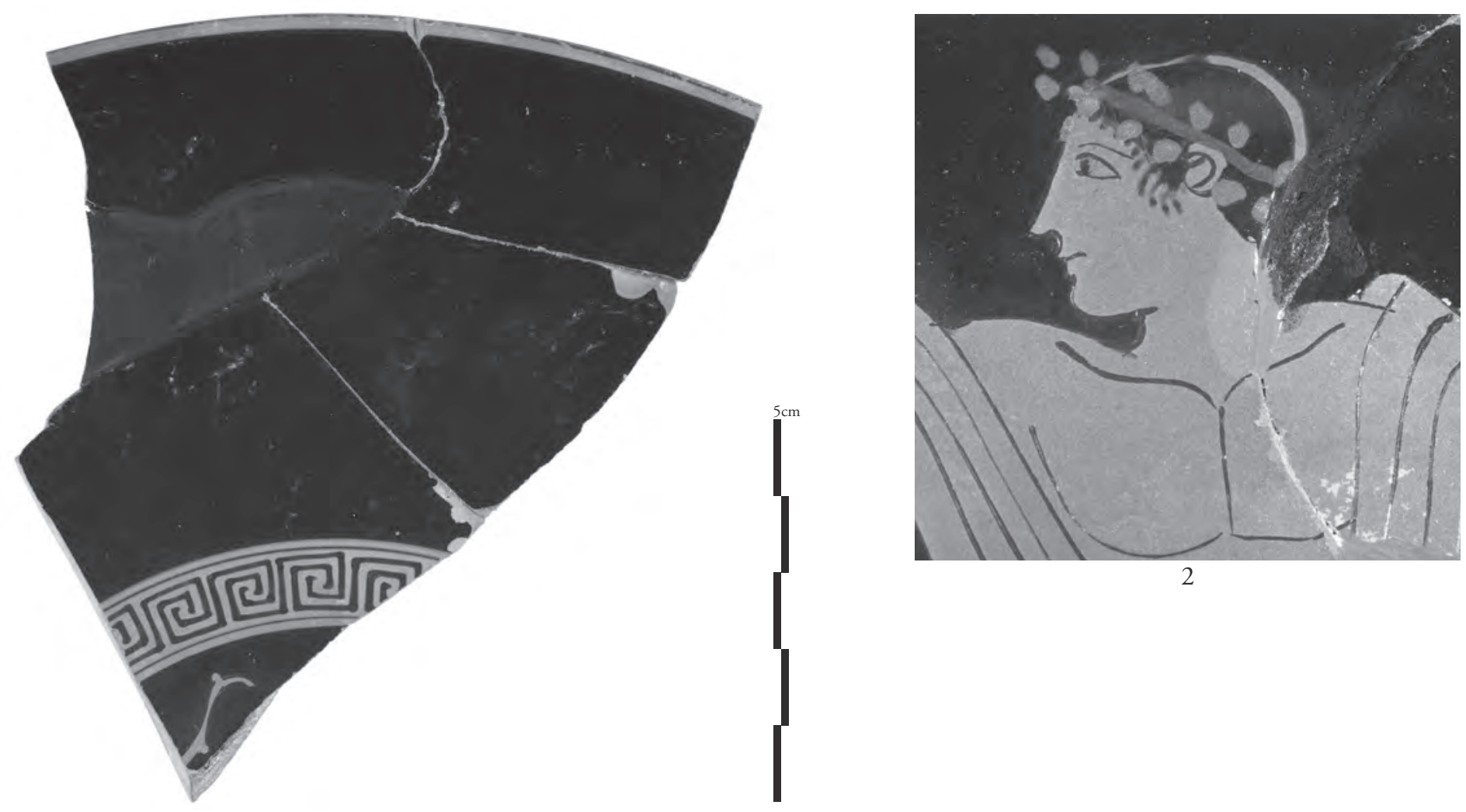

G 198

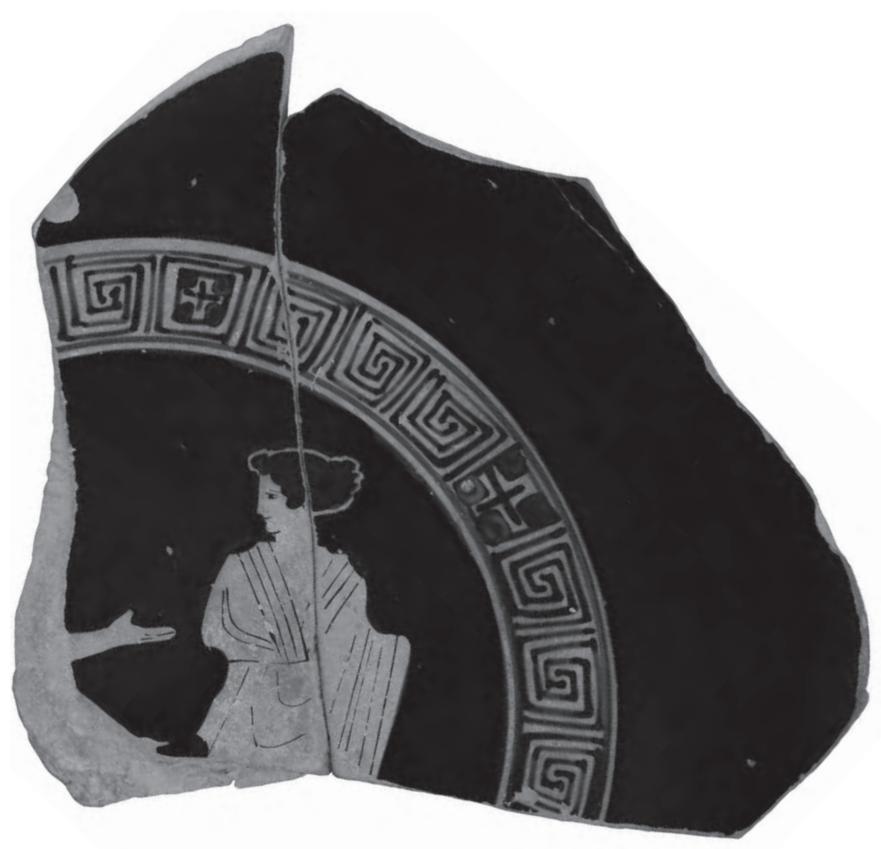

3

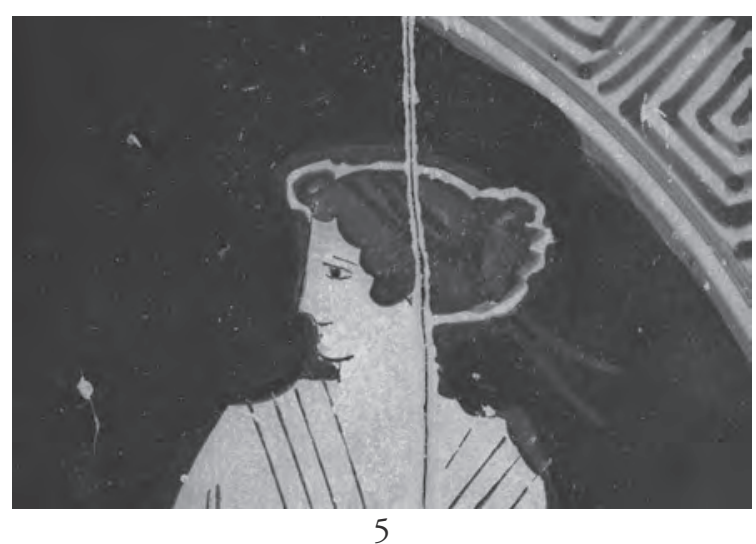




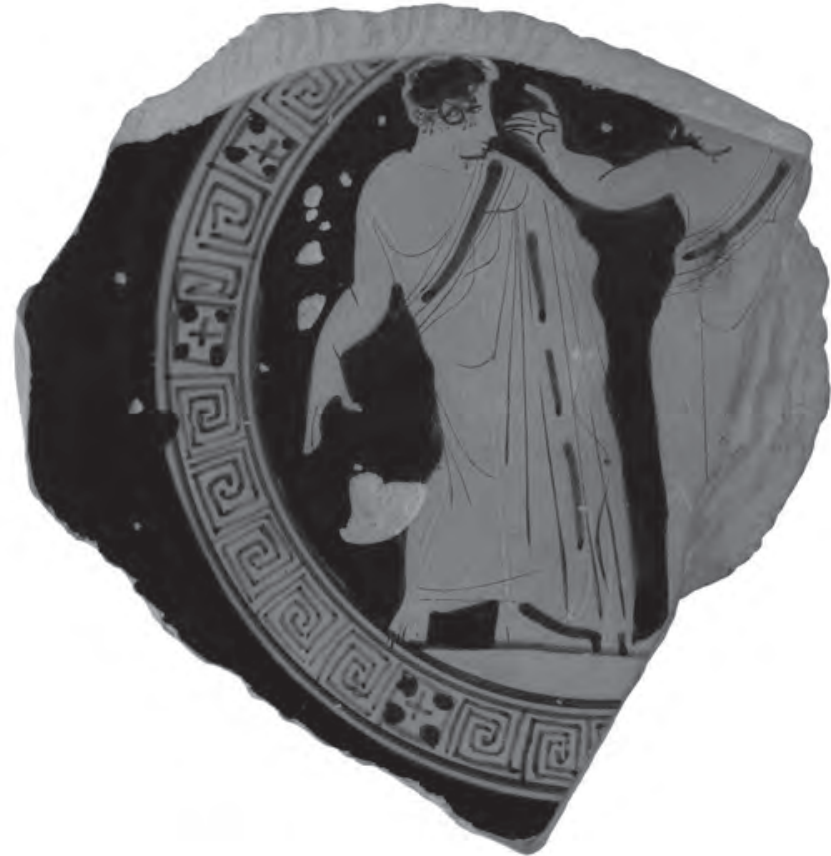

G 197

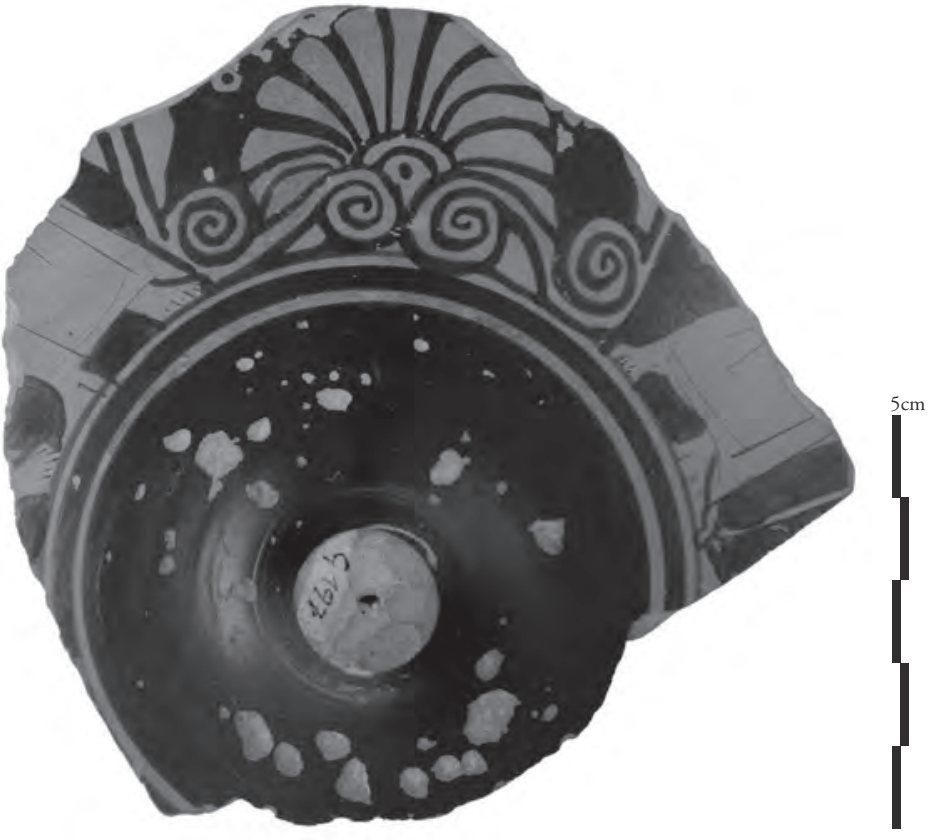

2
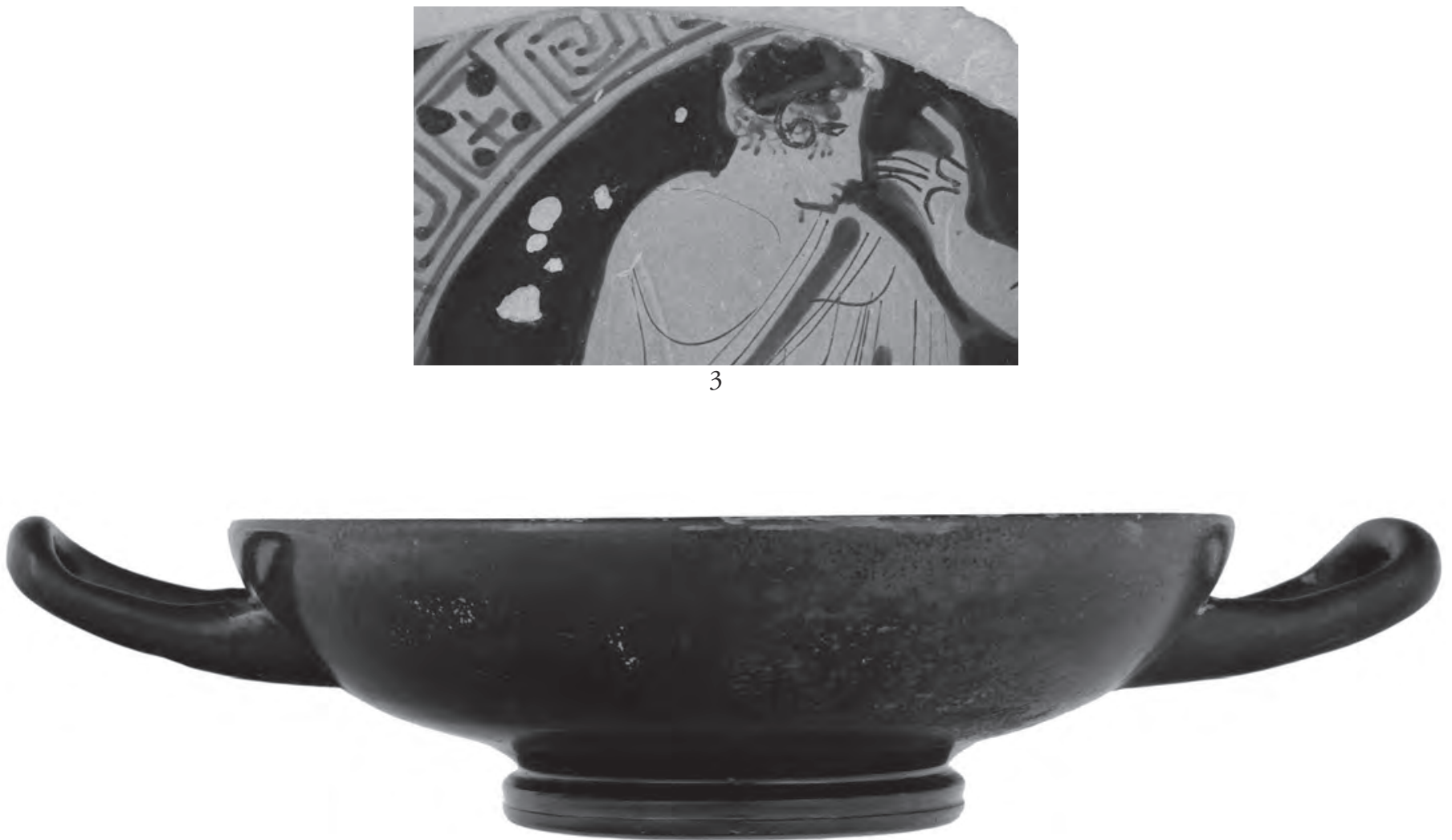

4

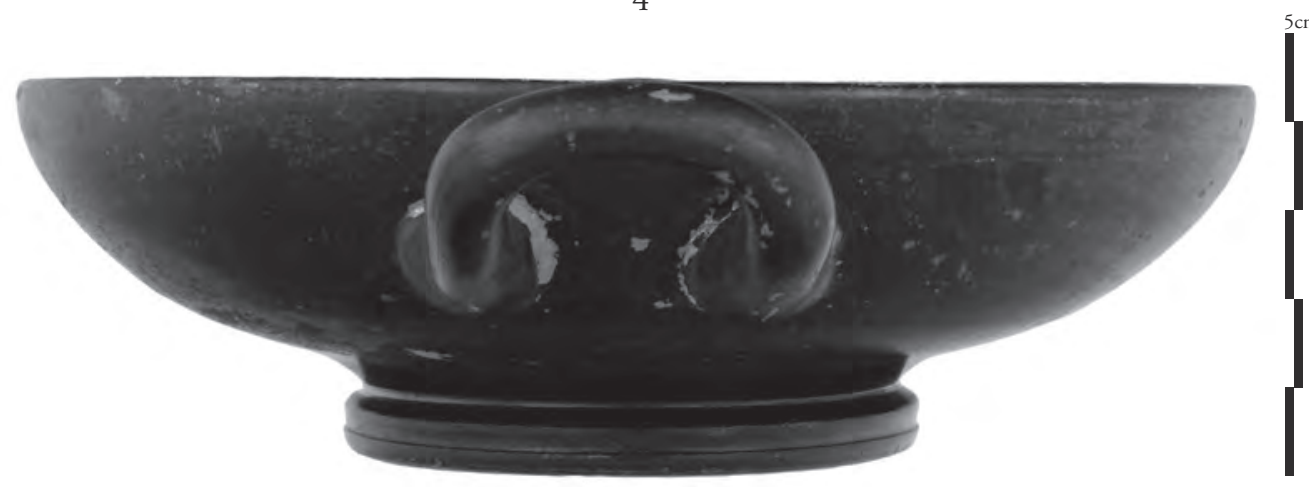




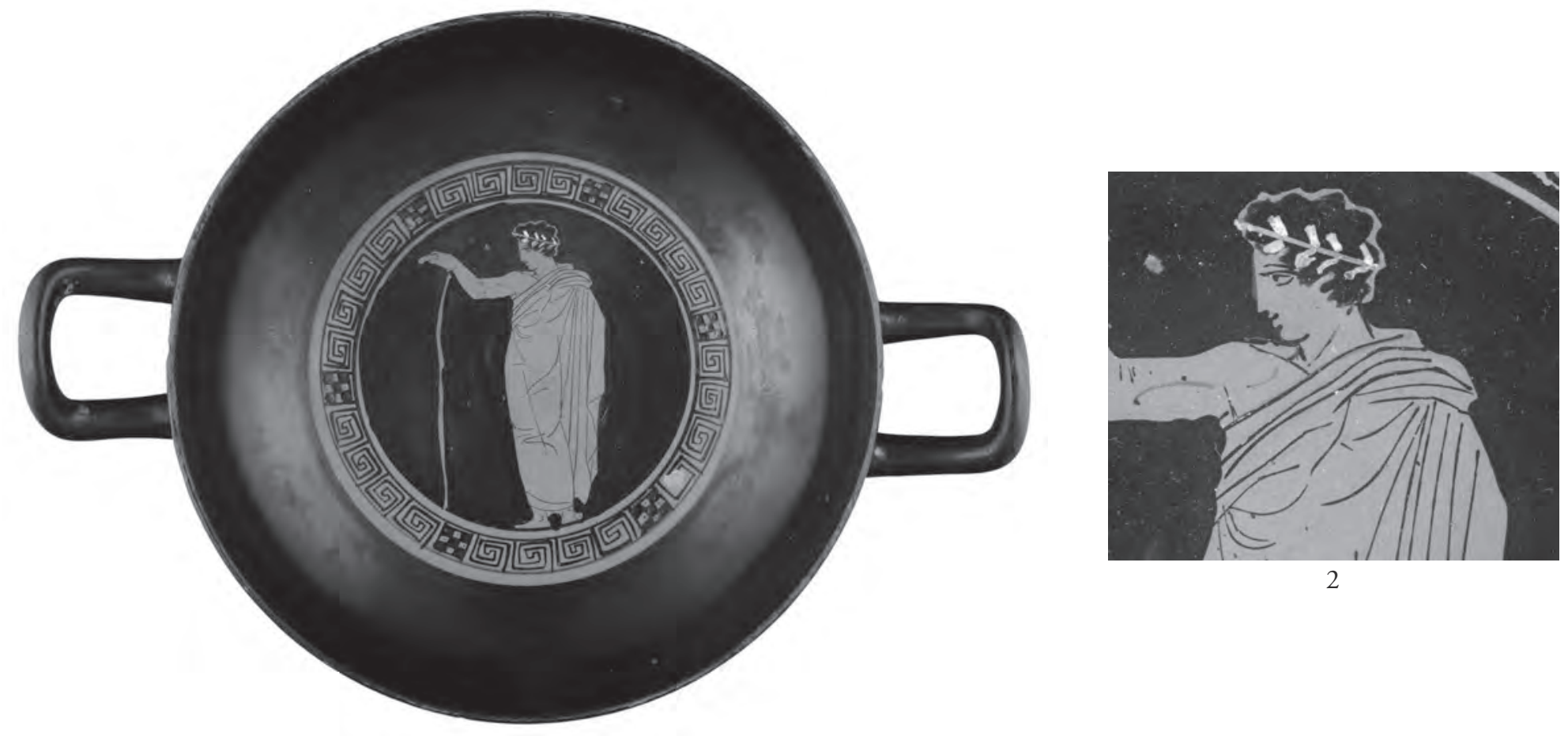

G 24
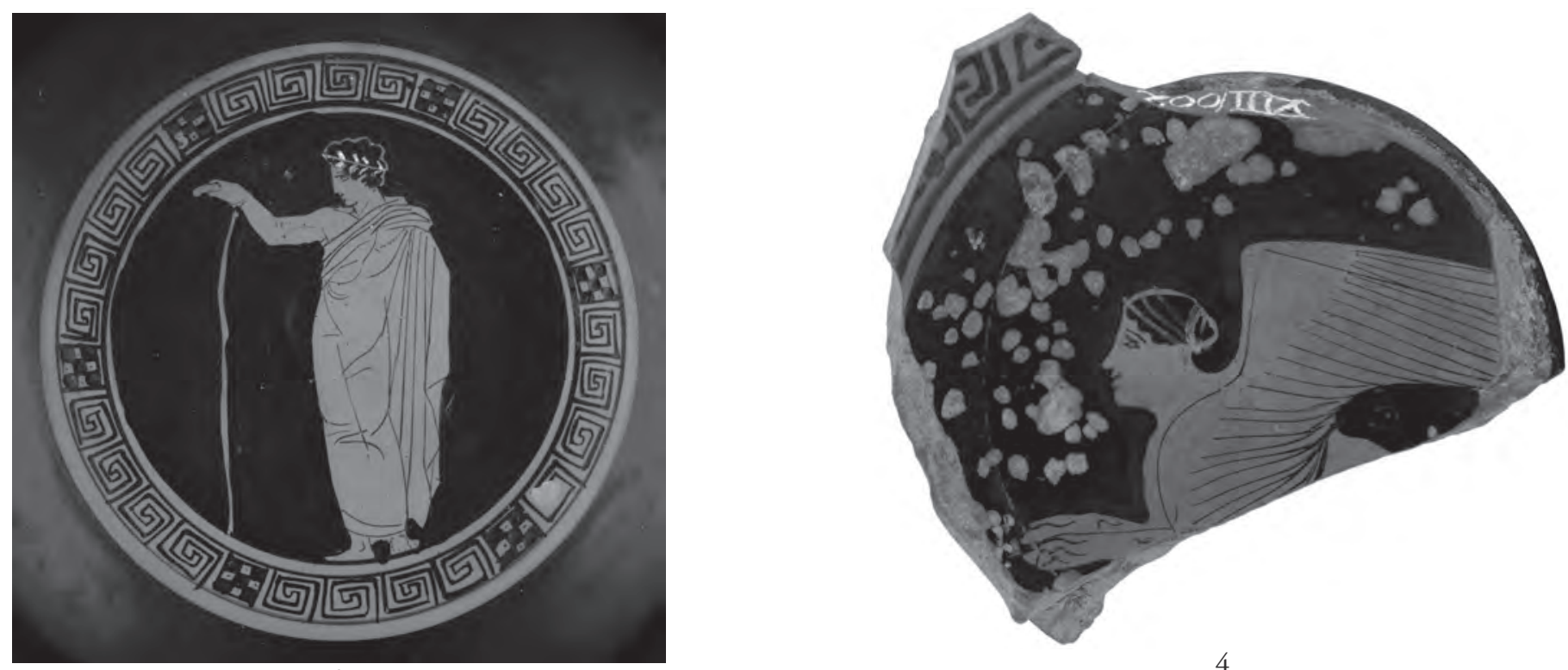

3
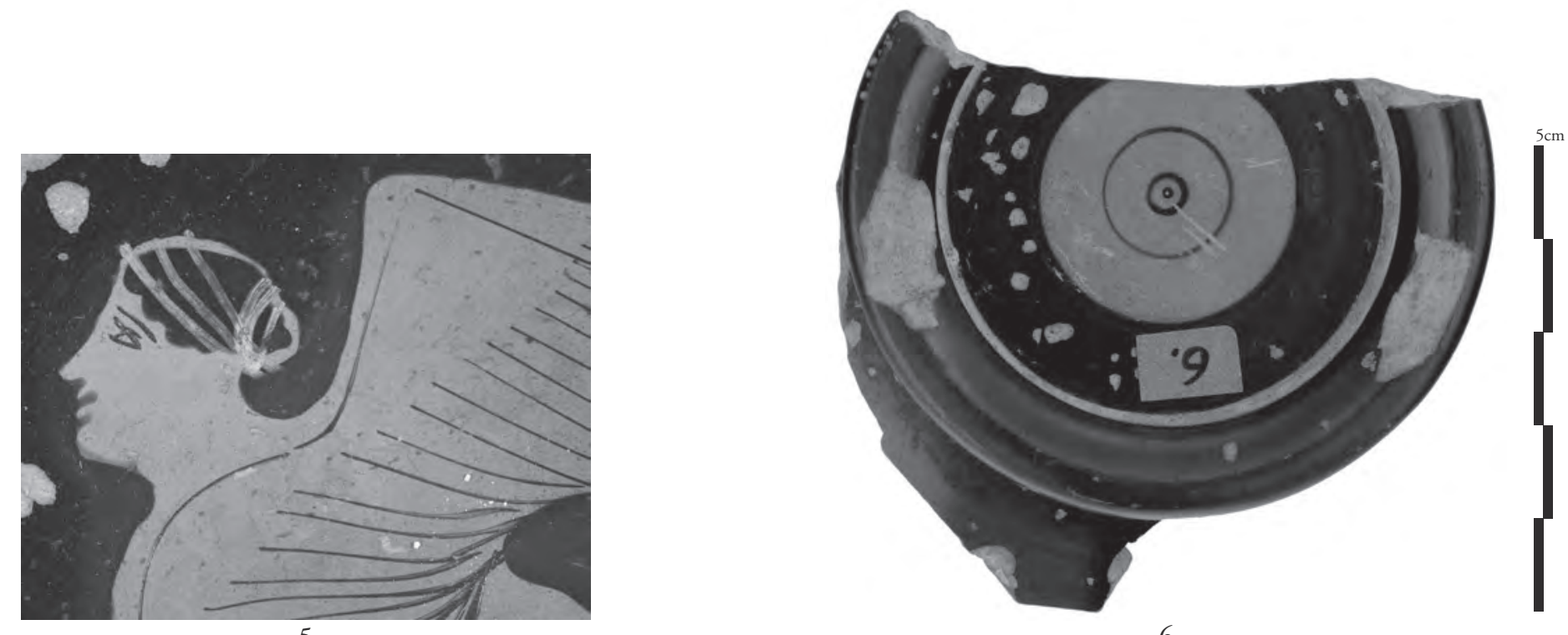

G 199 5 

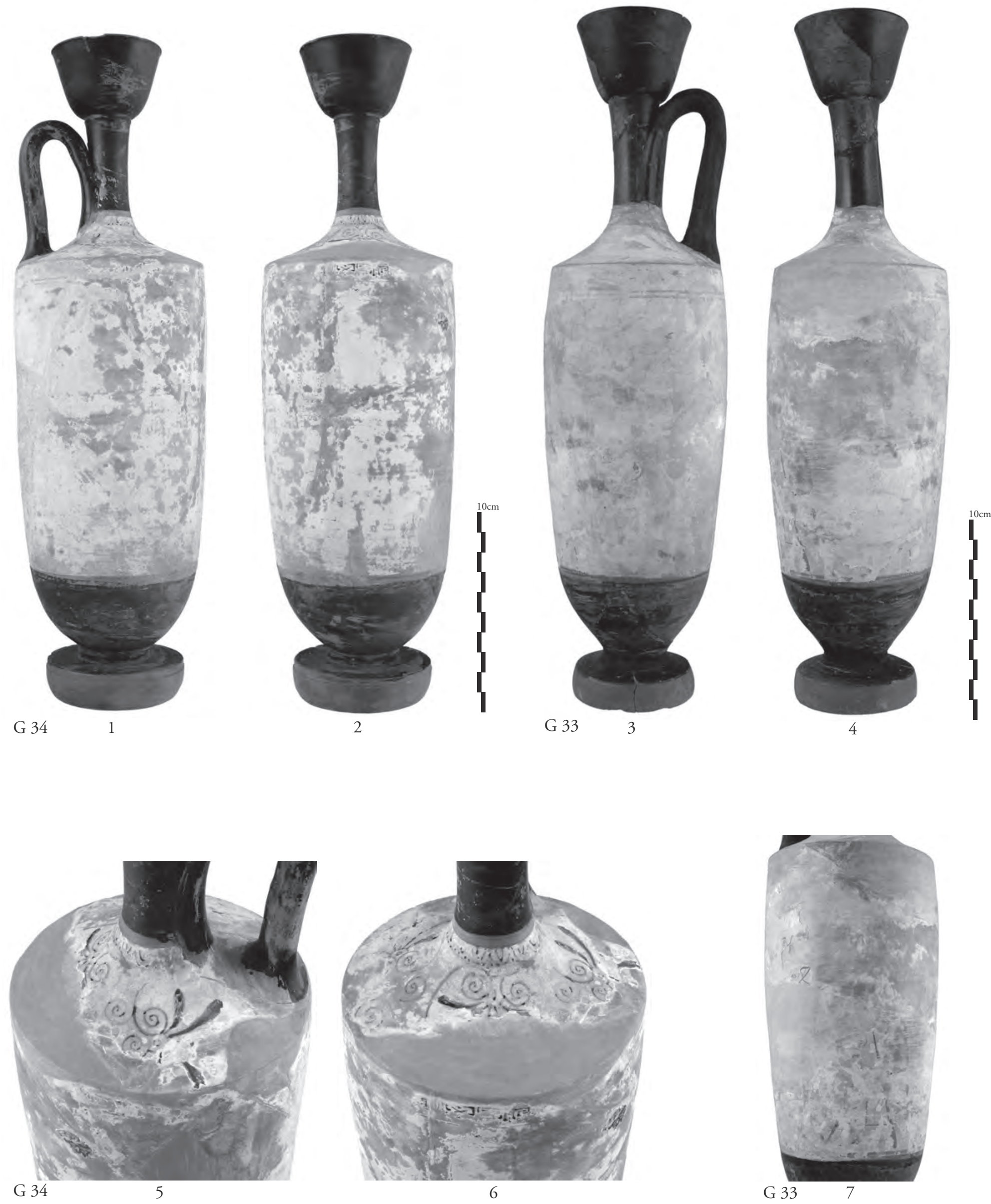

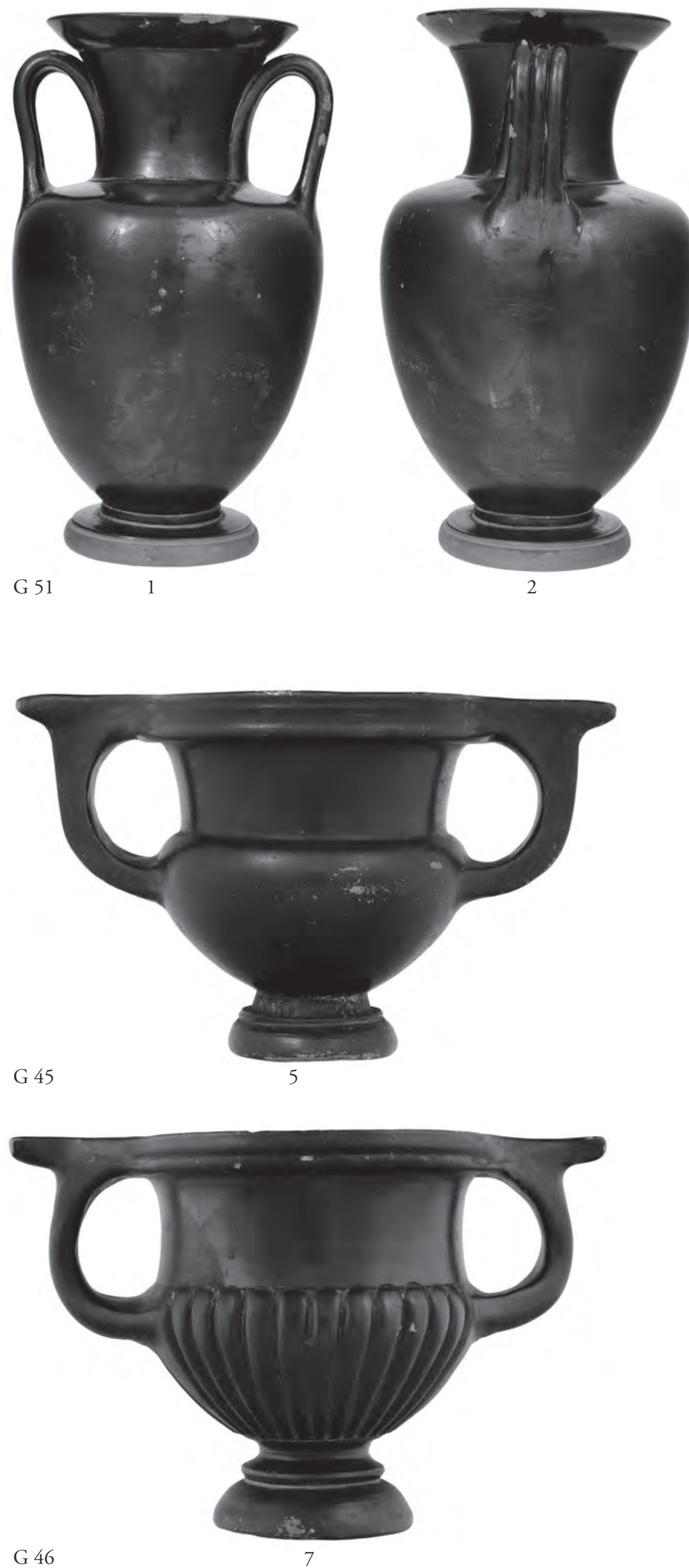
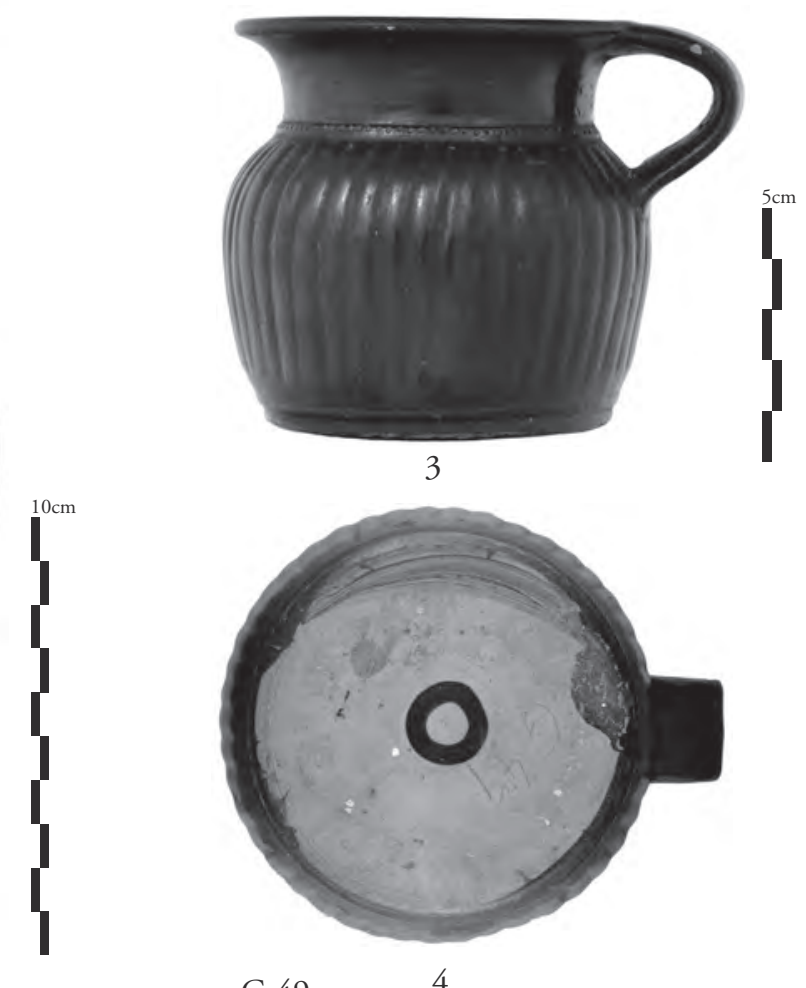

G $49 \quad 4$

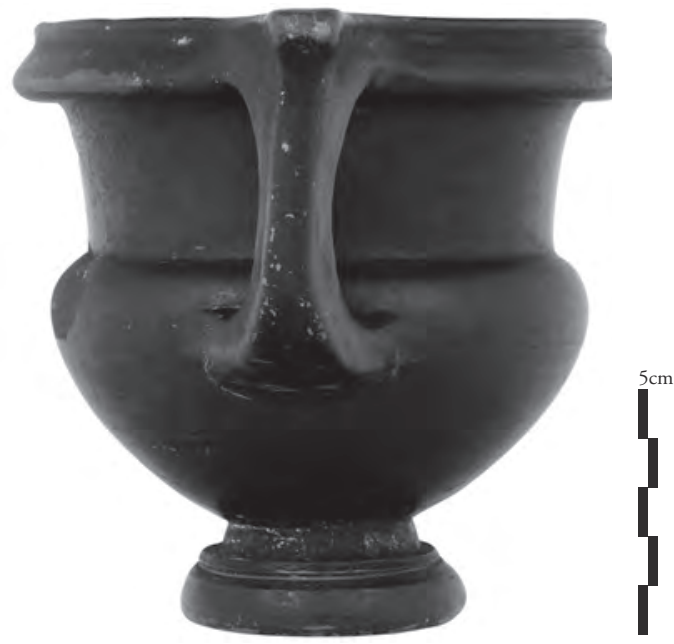

6

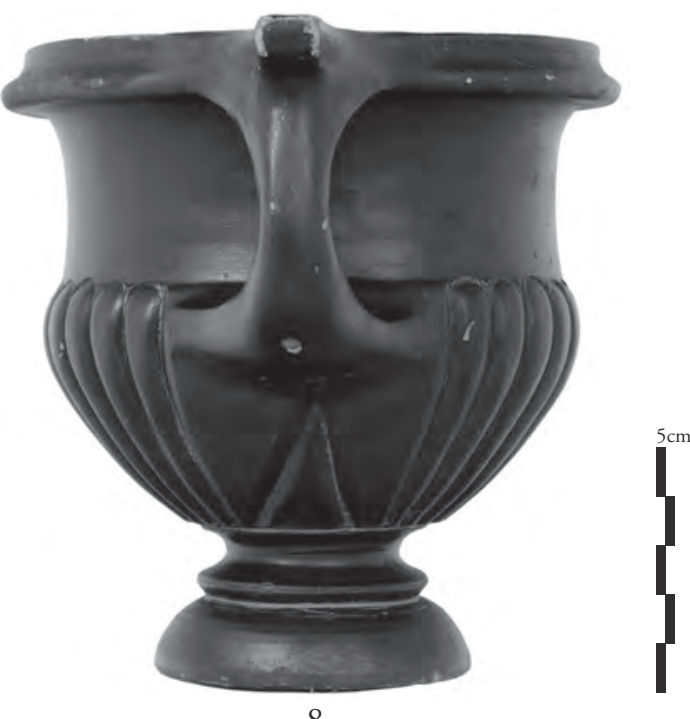



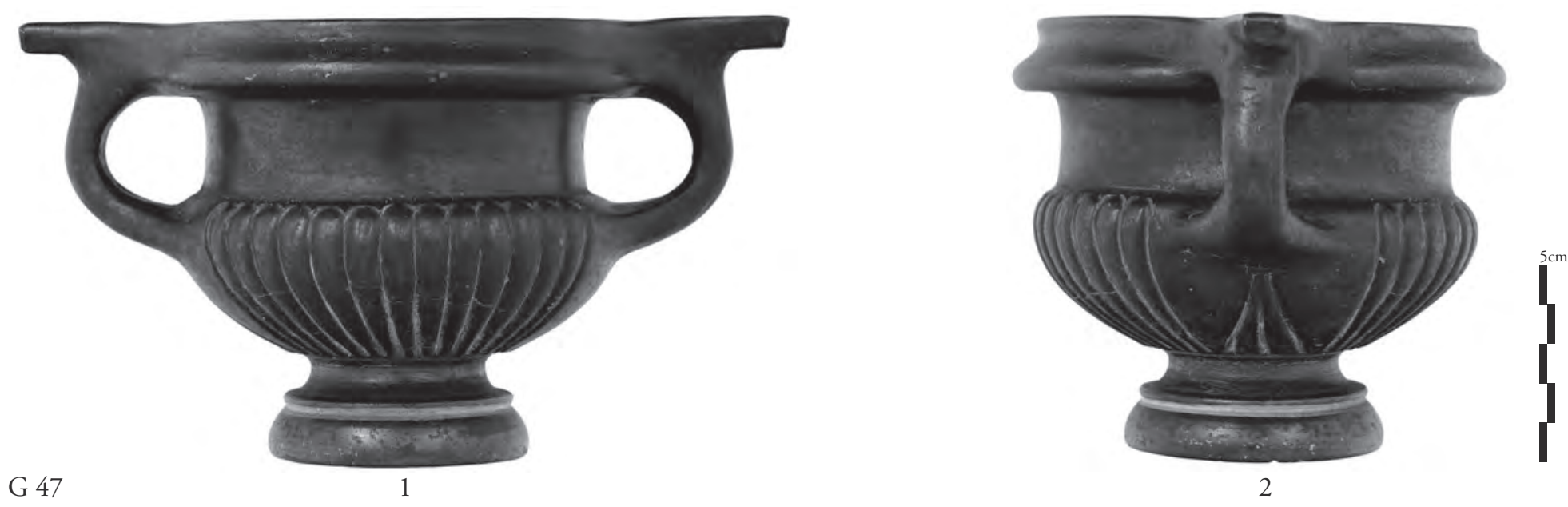

G 48
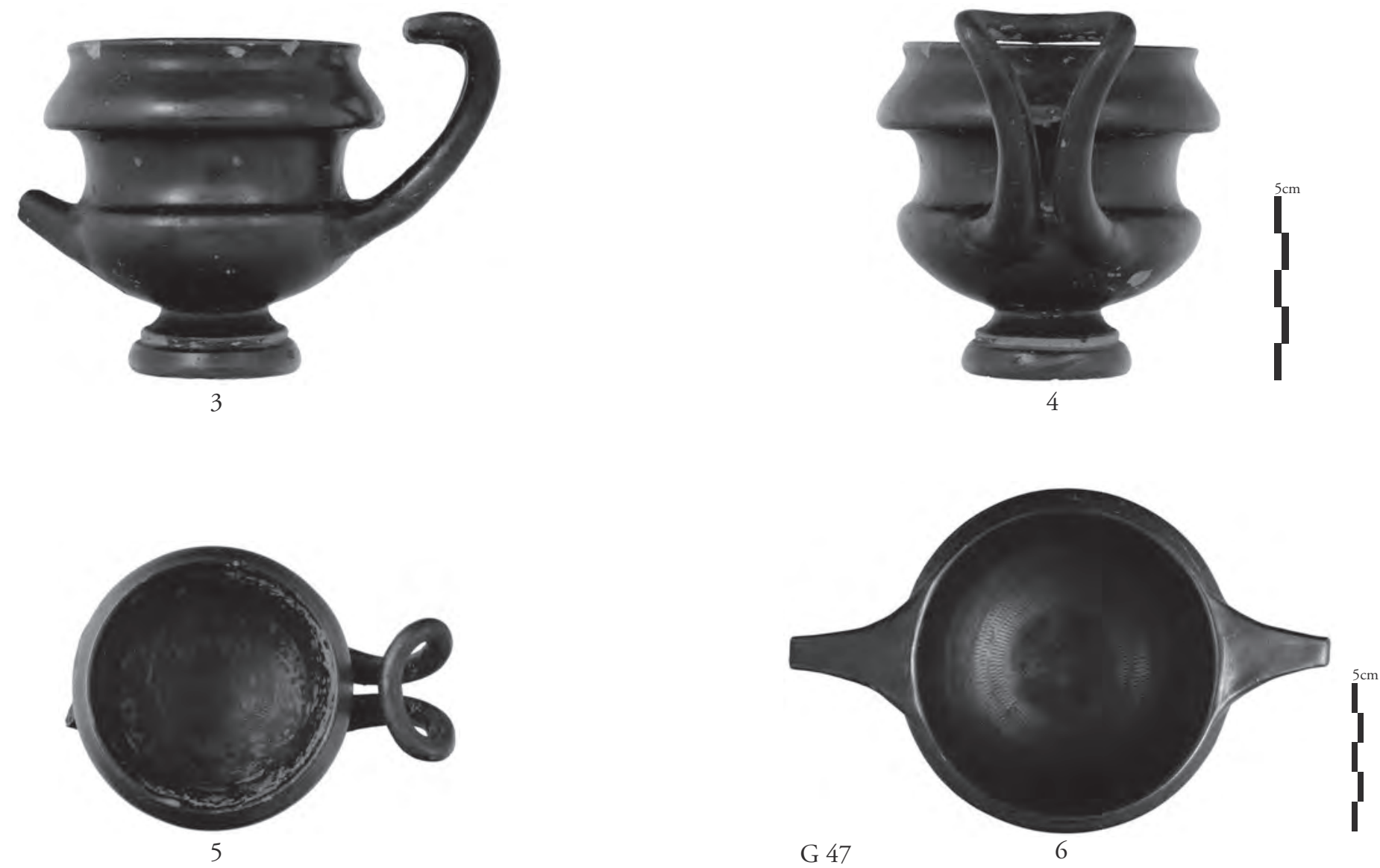

G 46
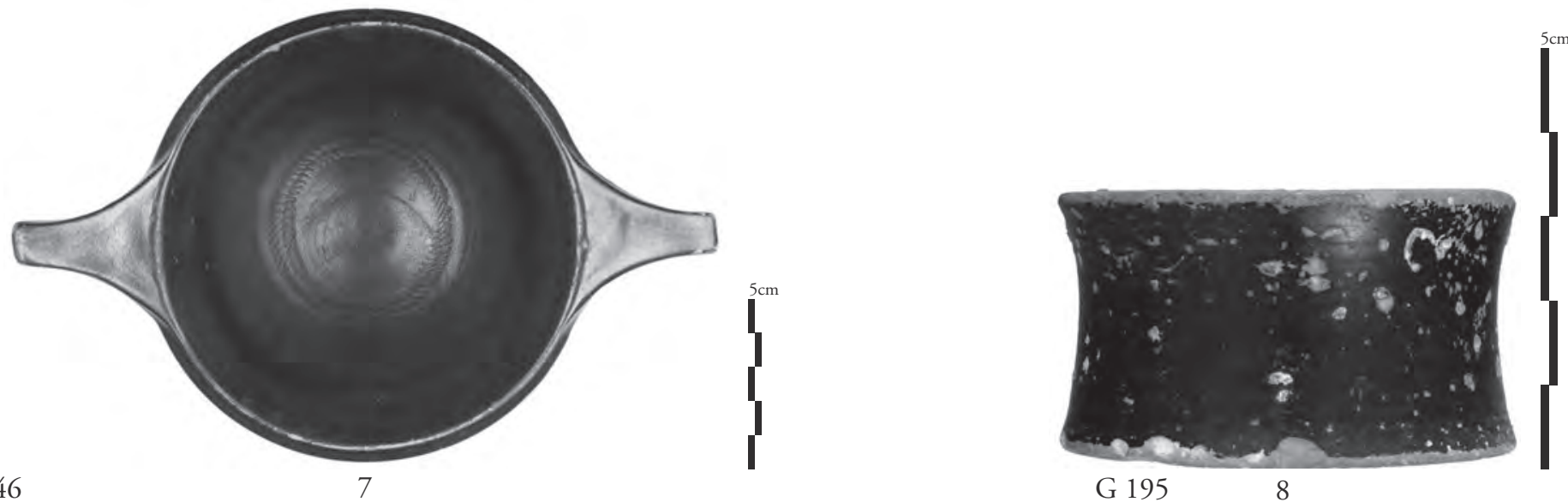

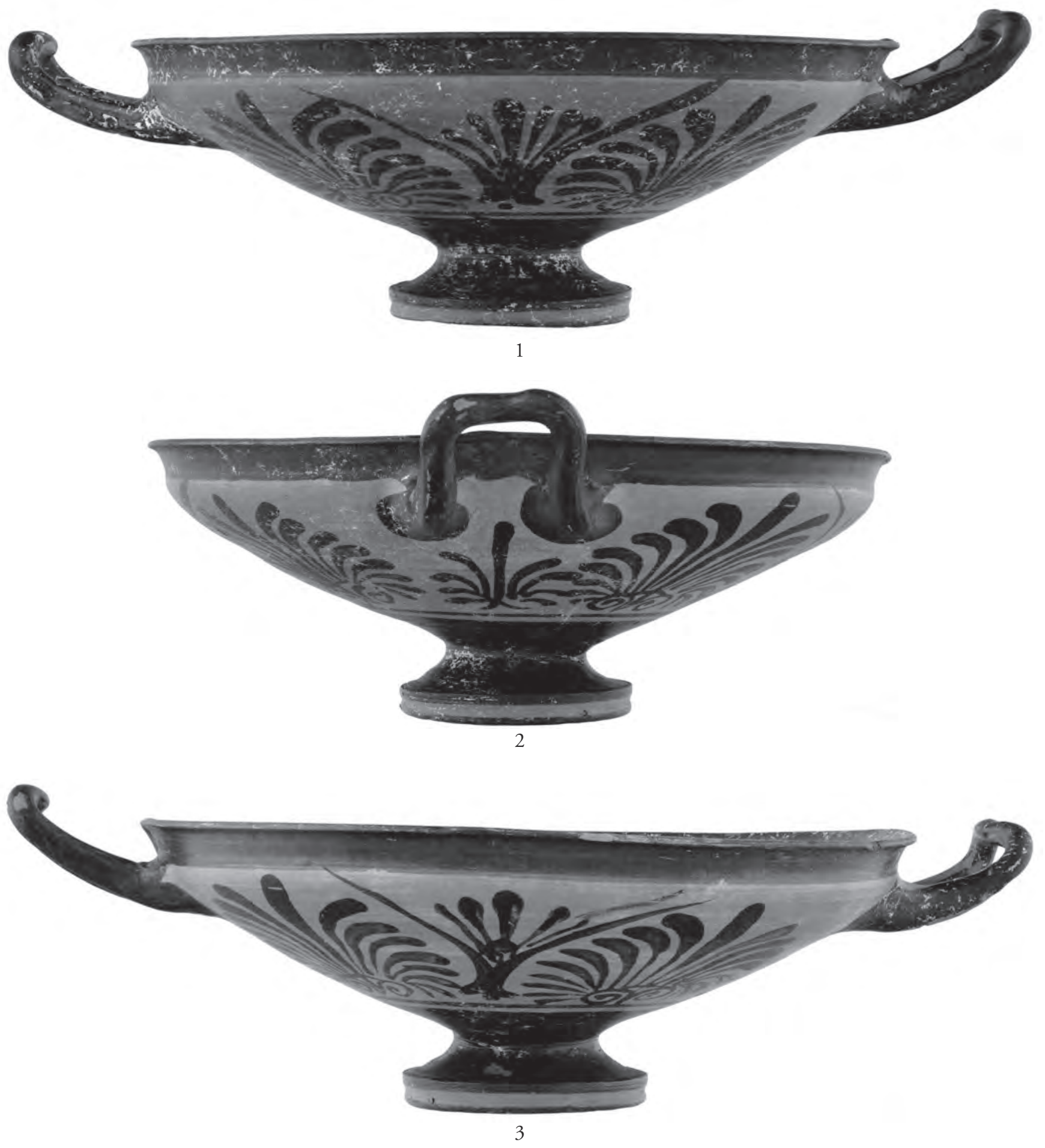

G 52

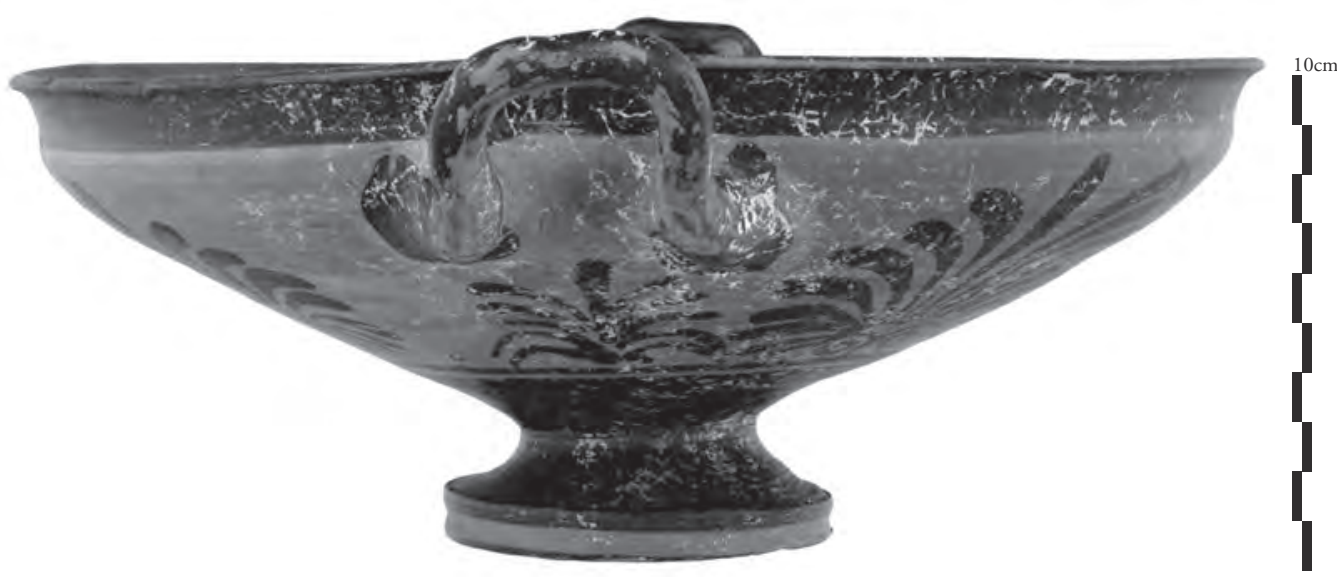



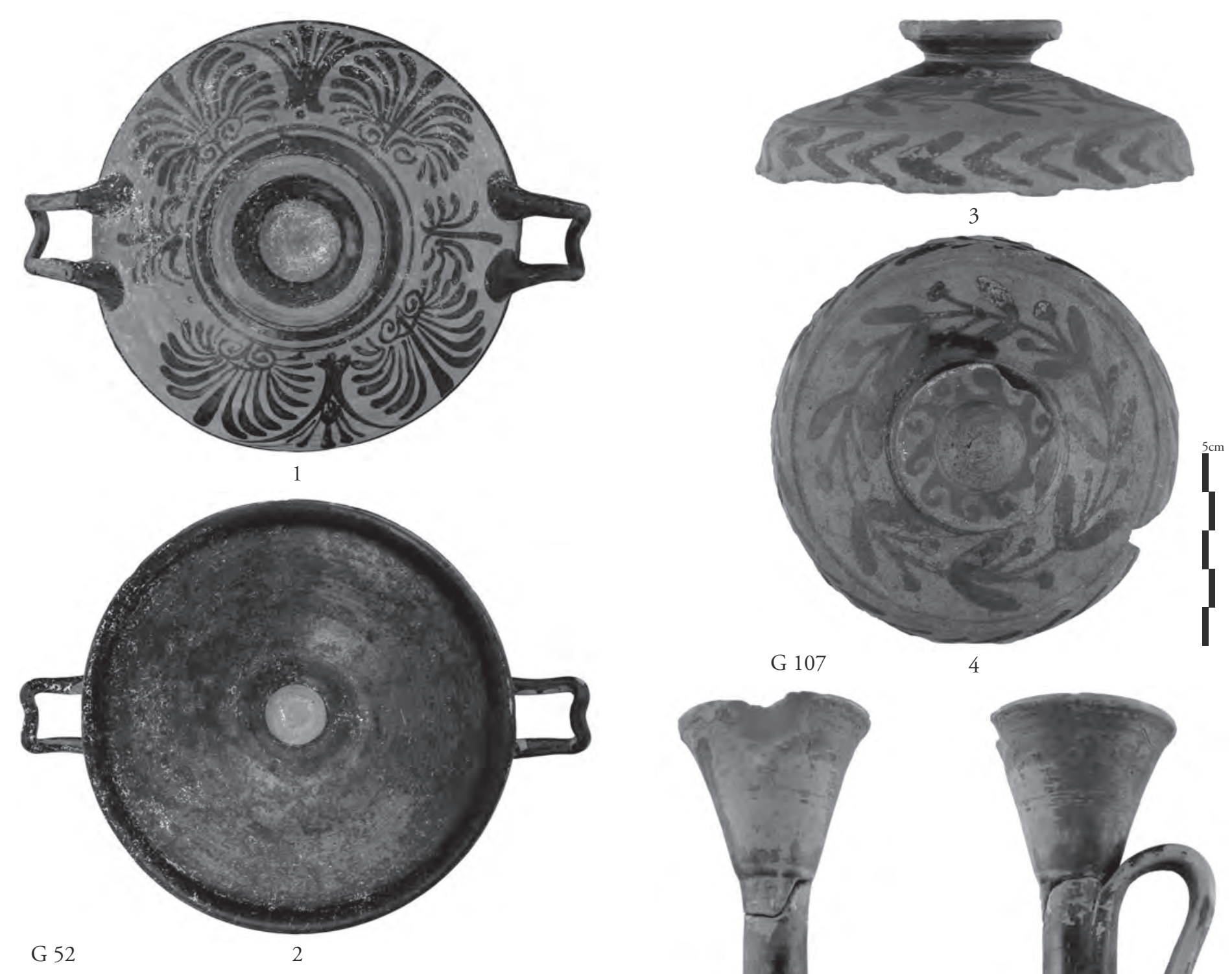

G 107
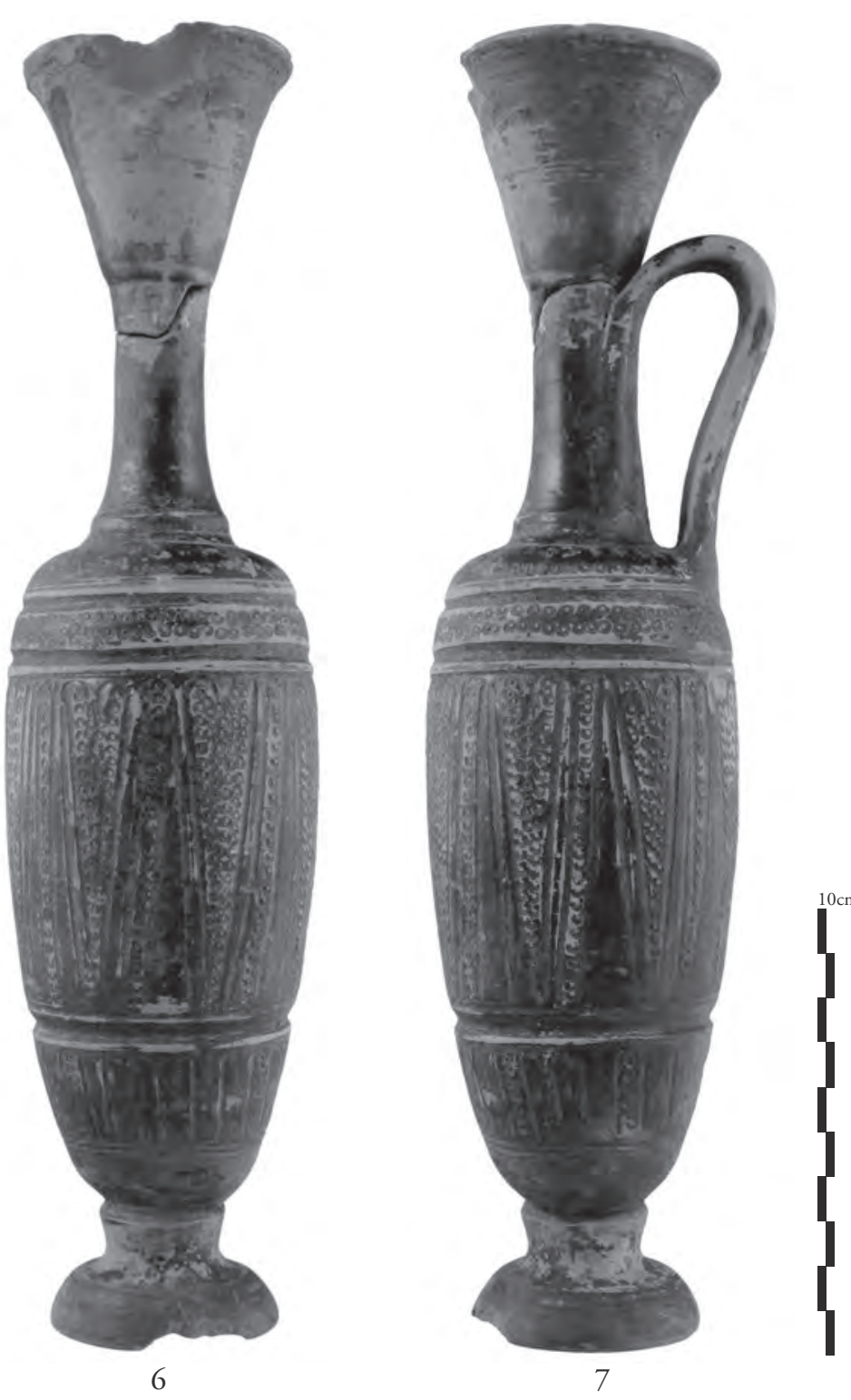

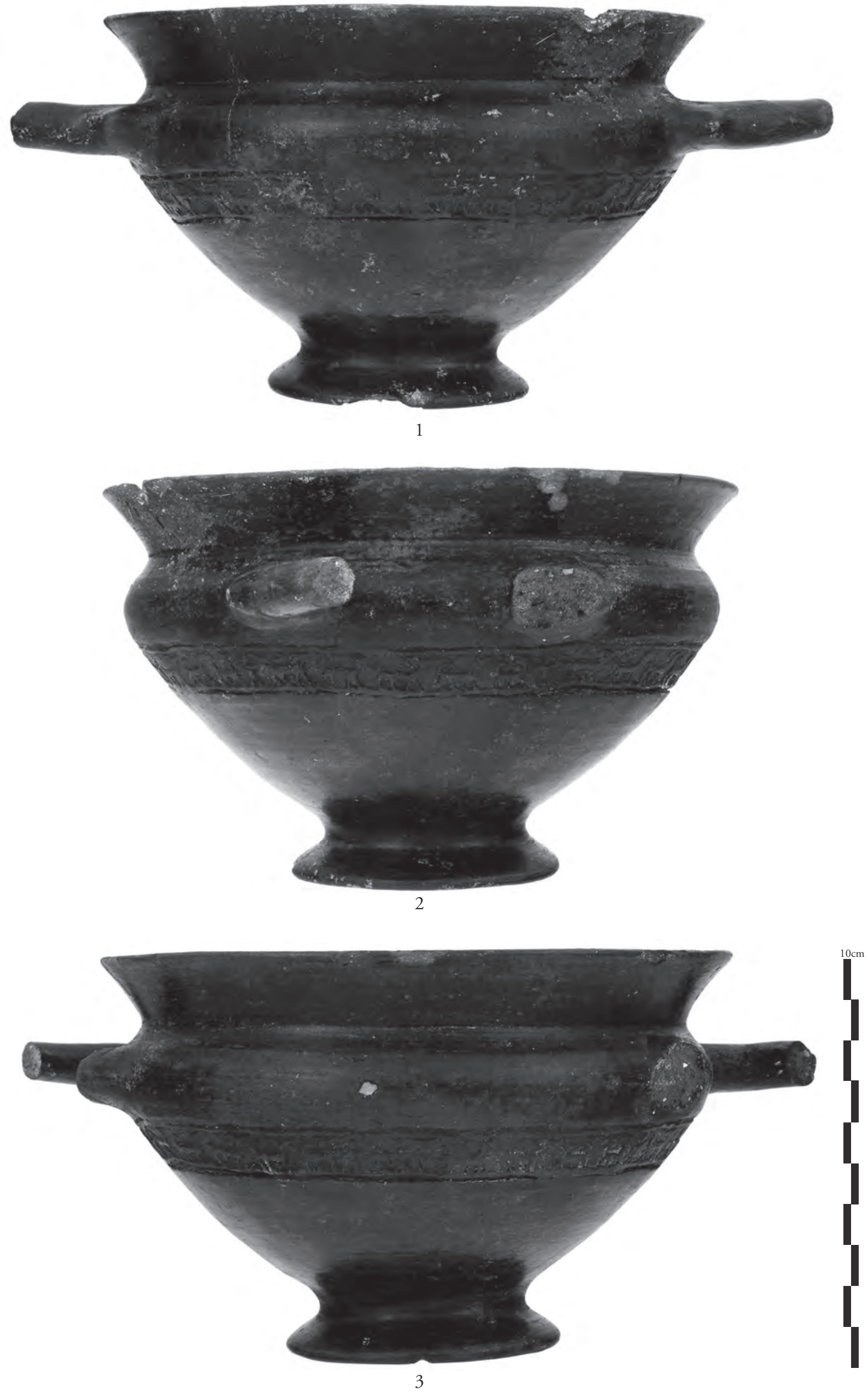

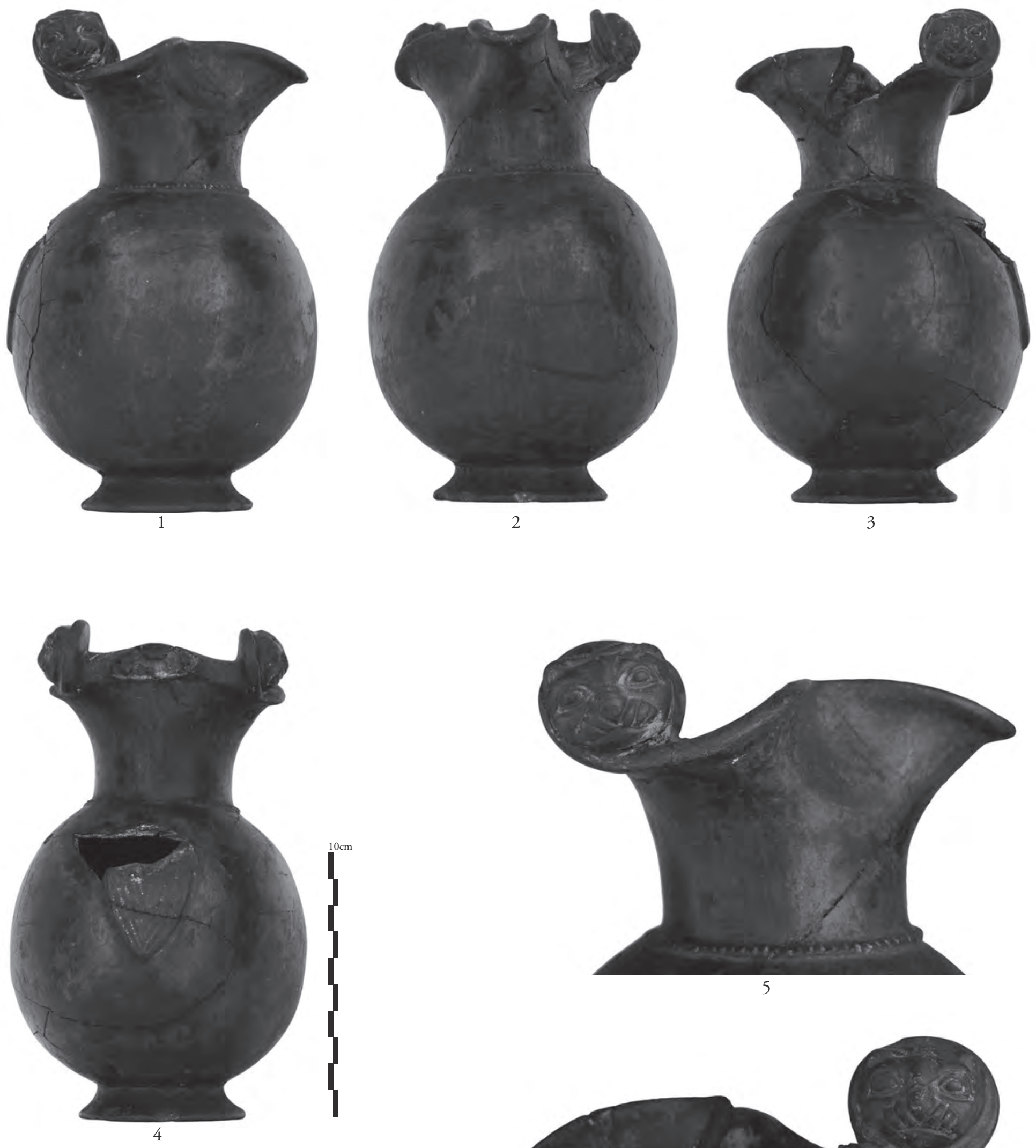

G 31

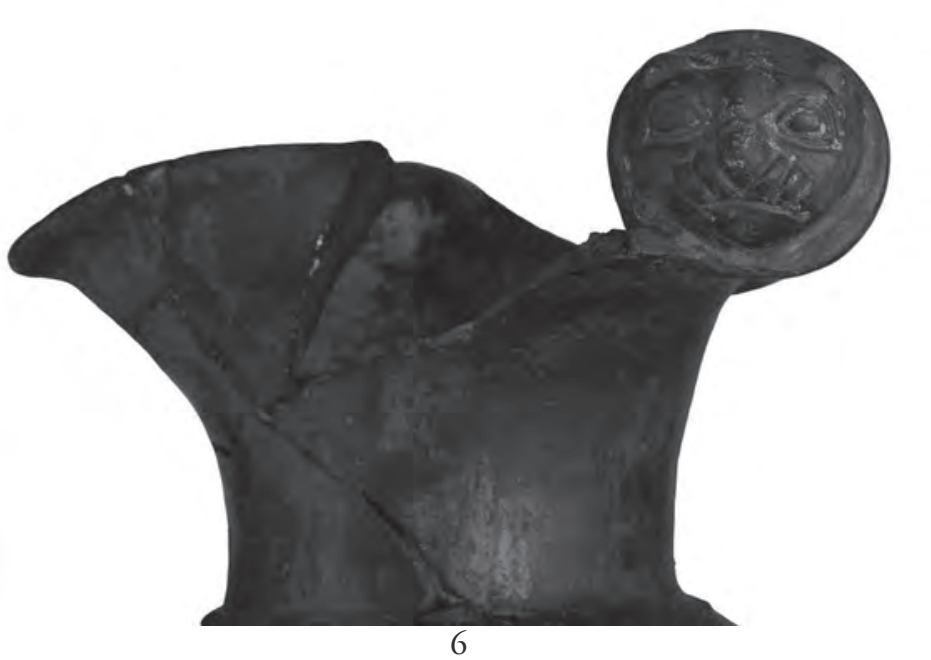



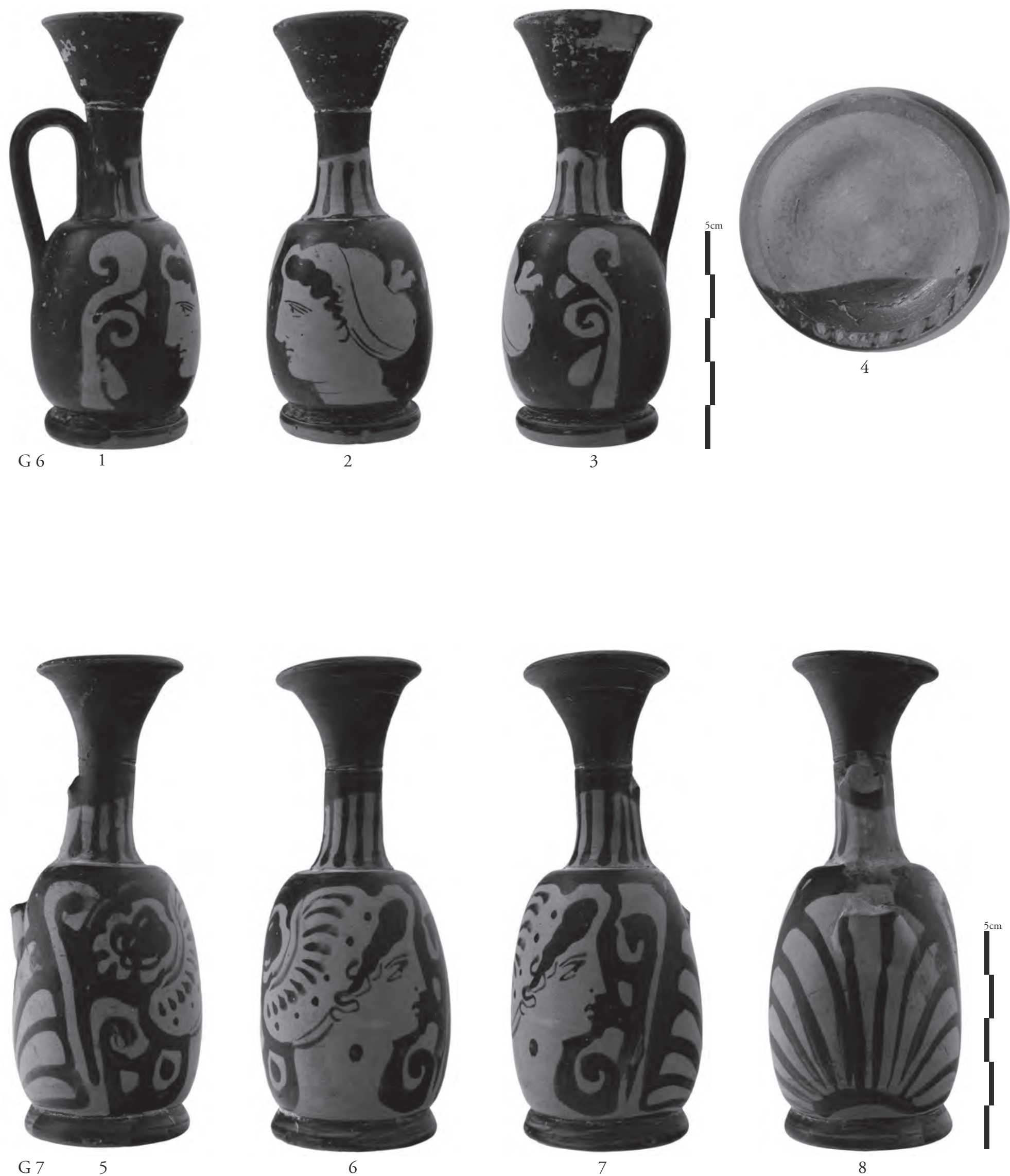


$$
\begin{aligned}
& I \\
& 80
\end{aligned}
$$



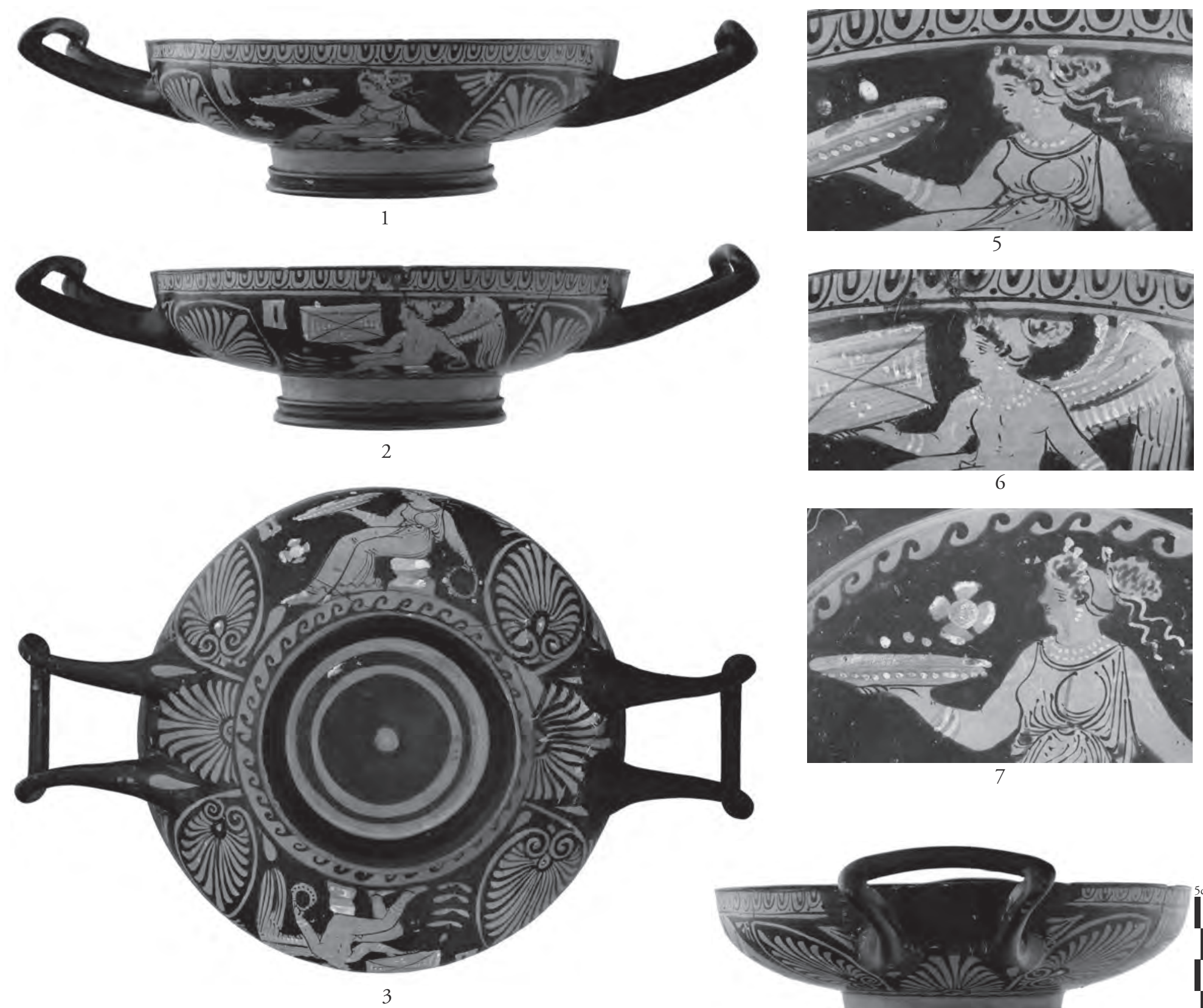

G 11

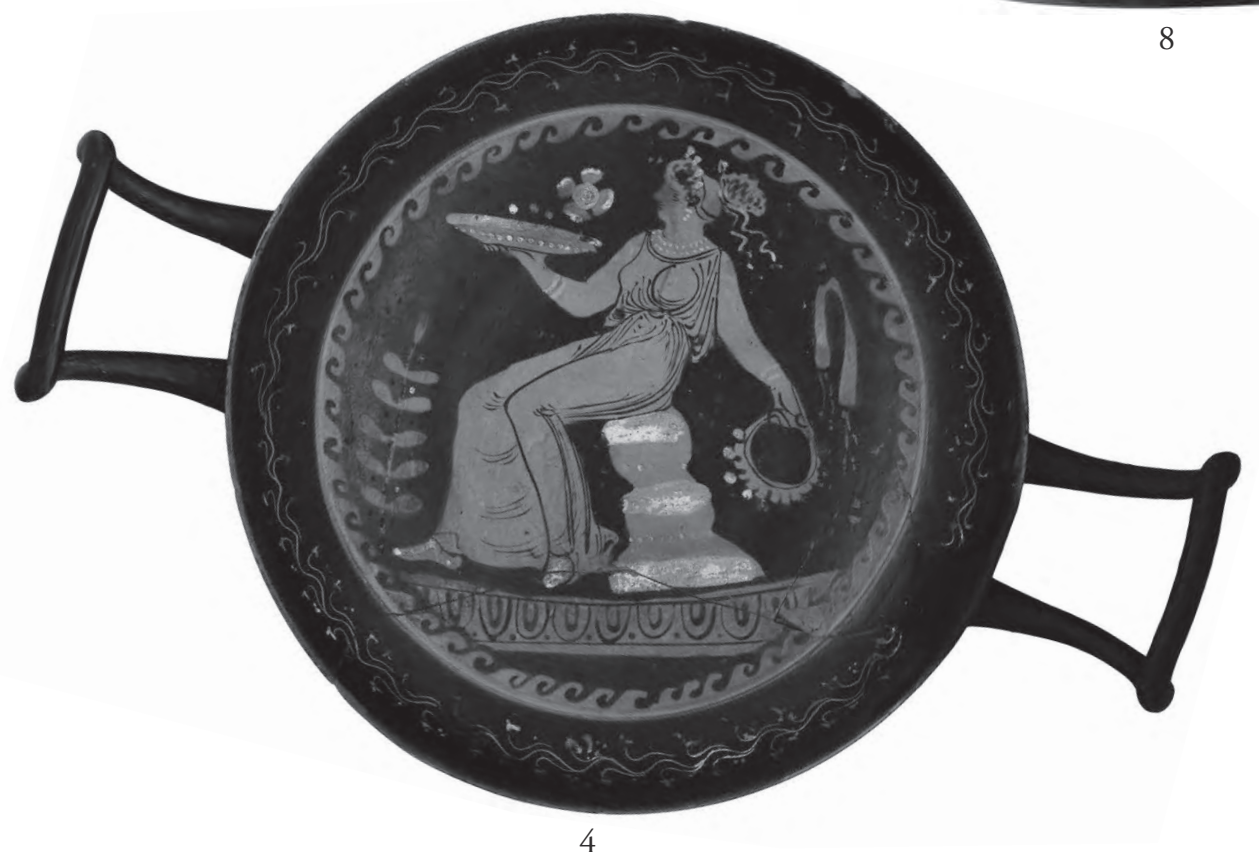



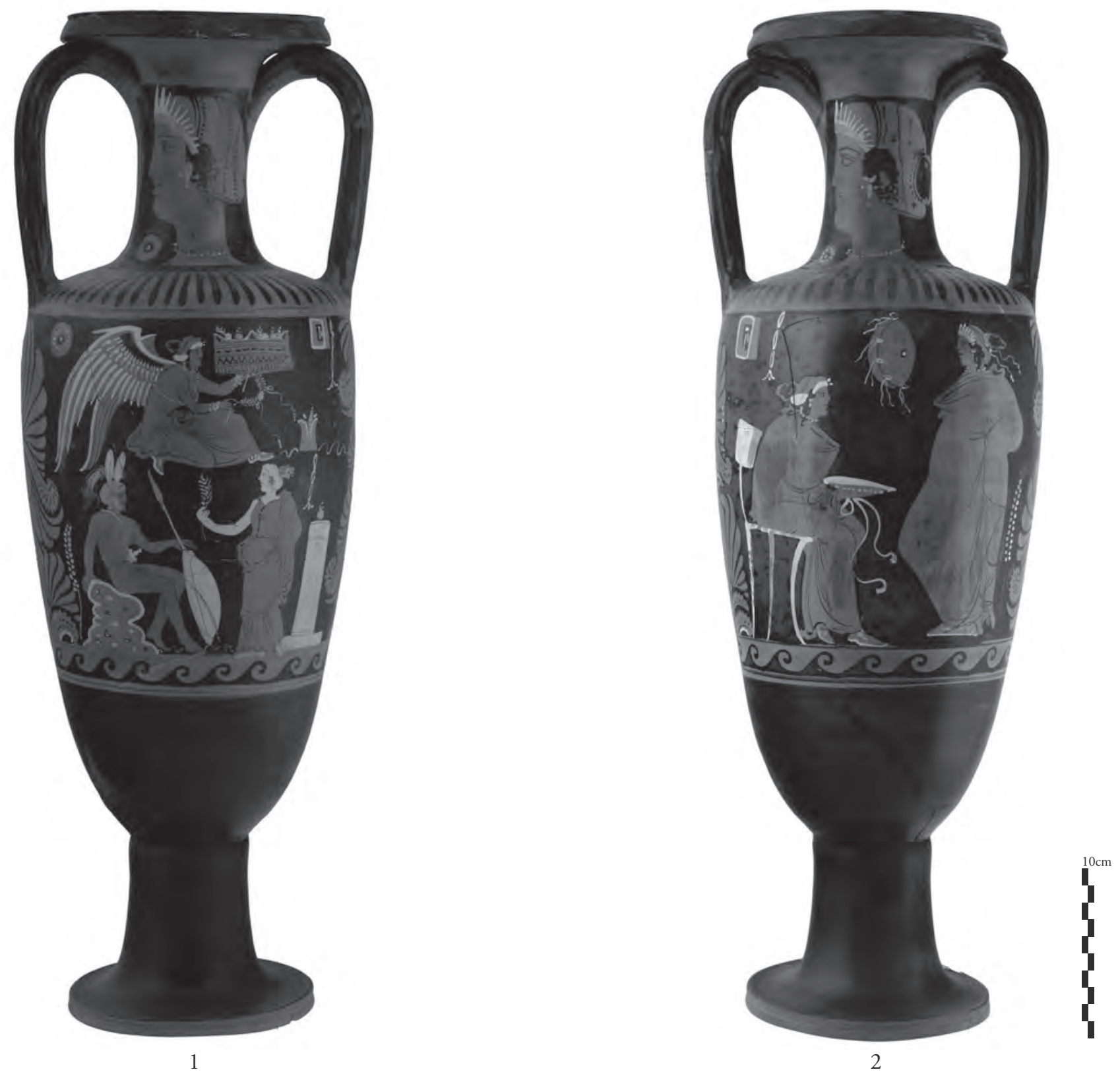

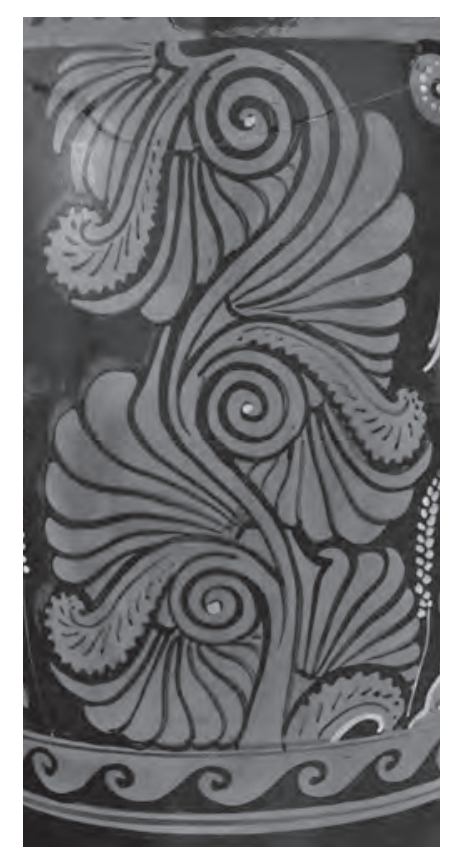

G 16

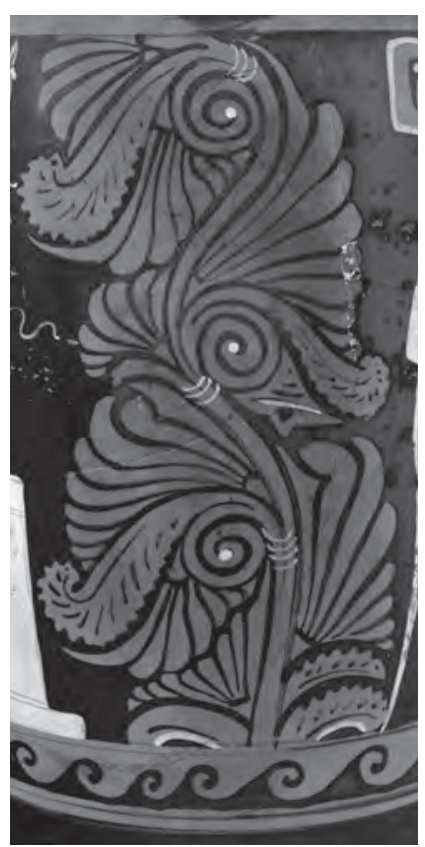

4

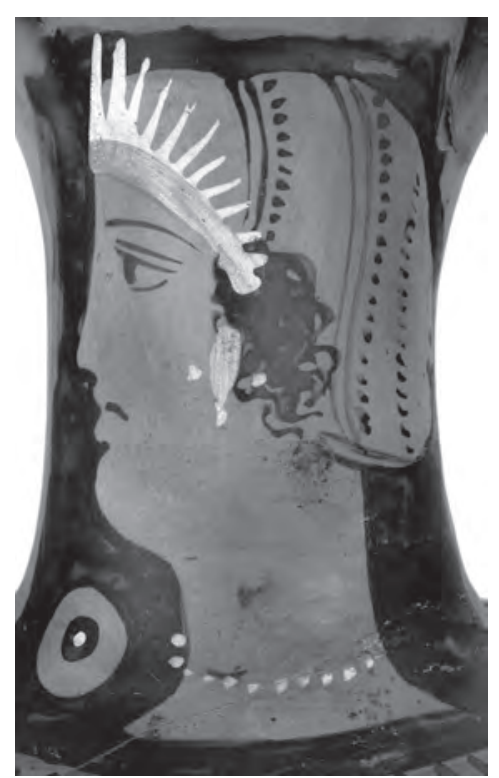

5

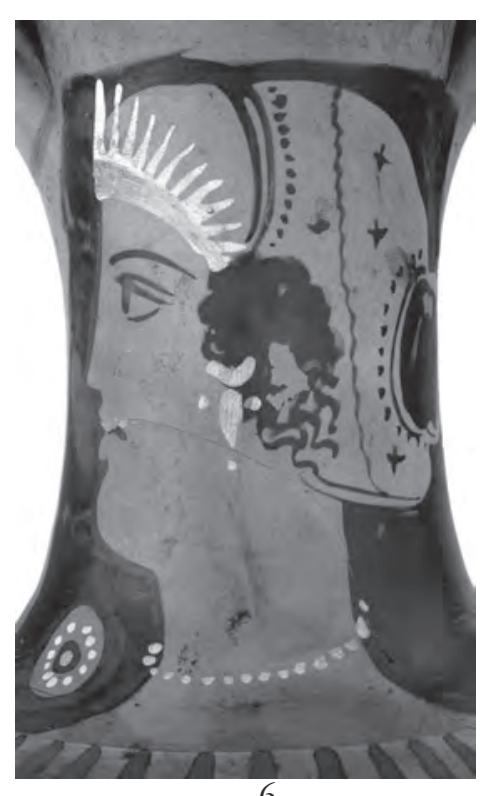

6 

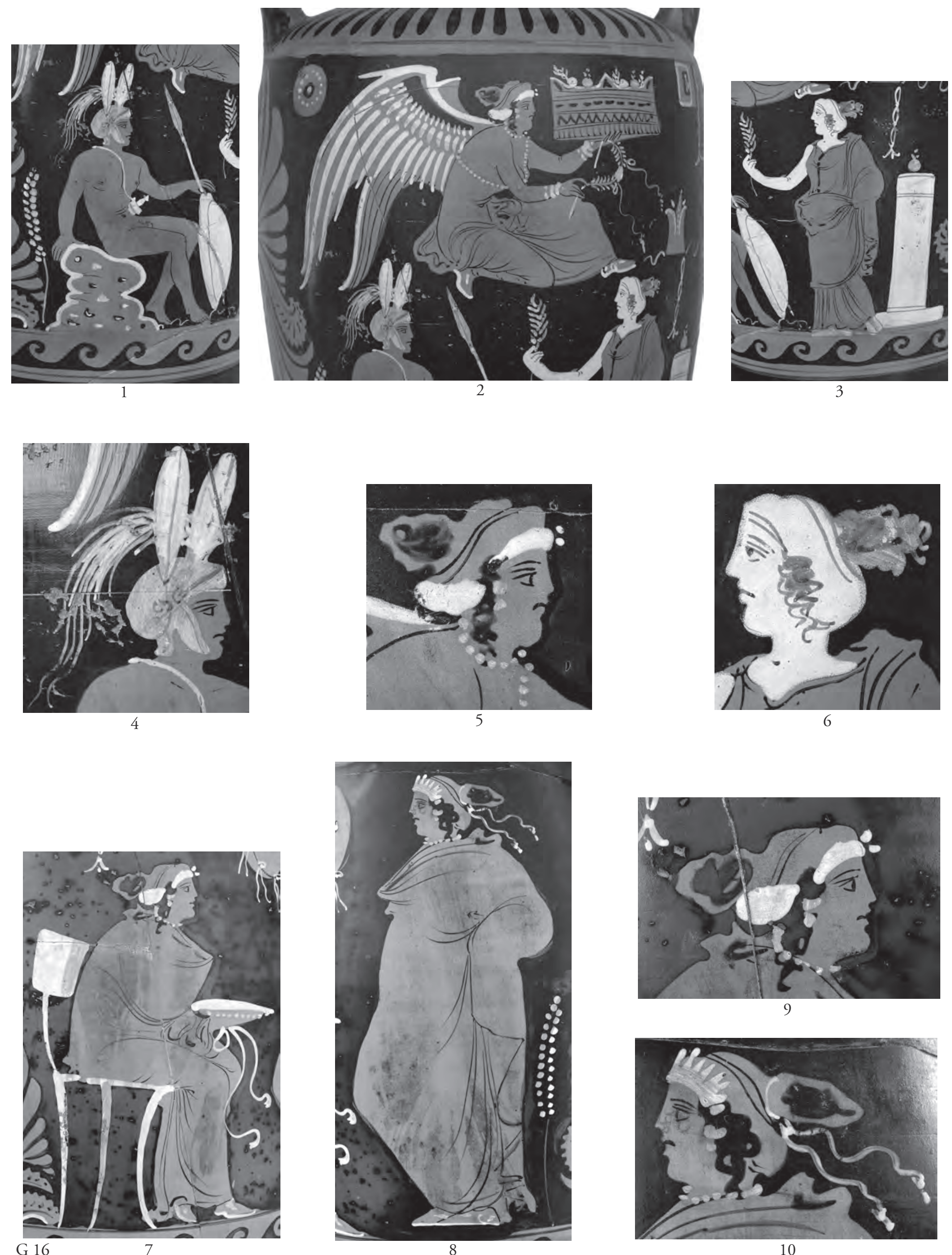

8 

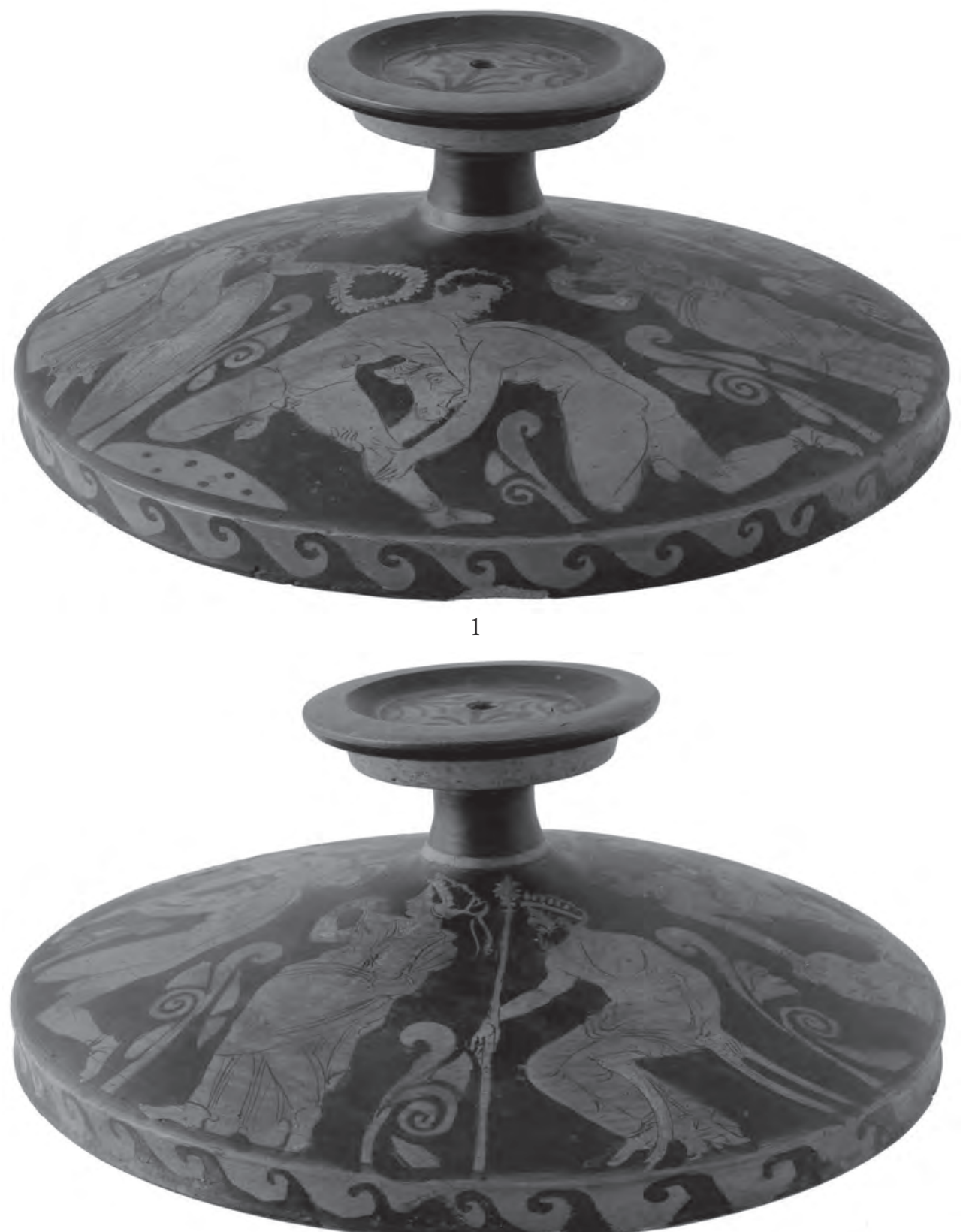

2

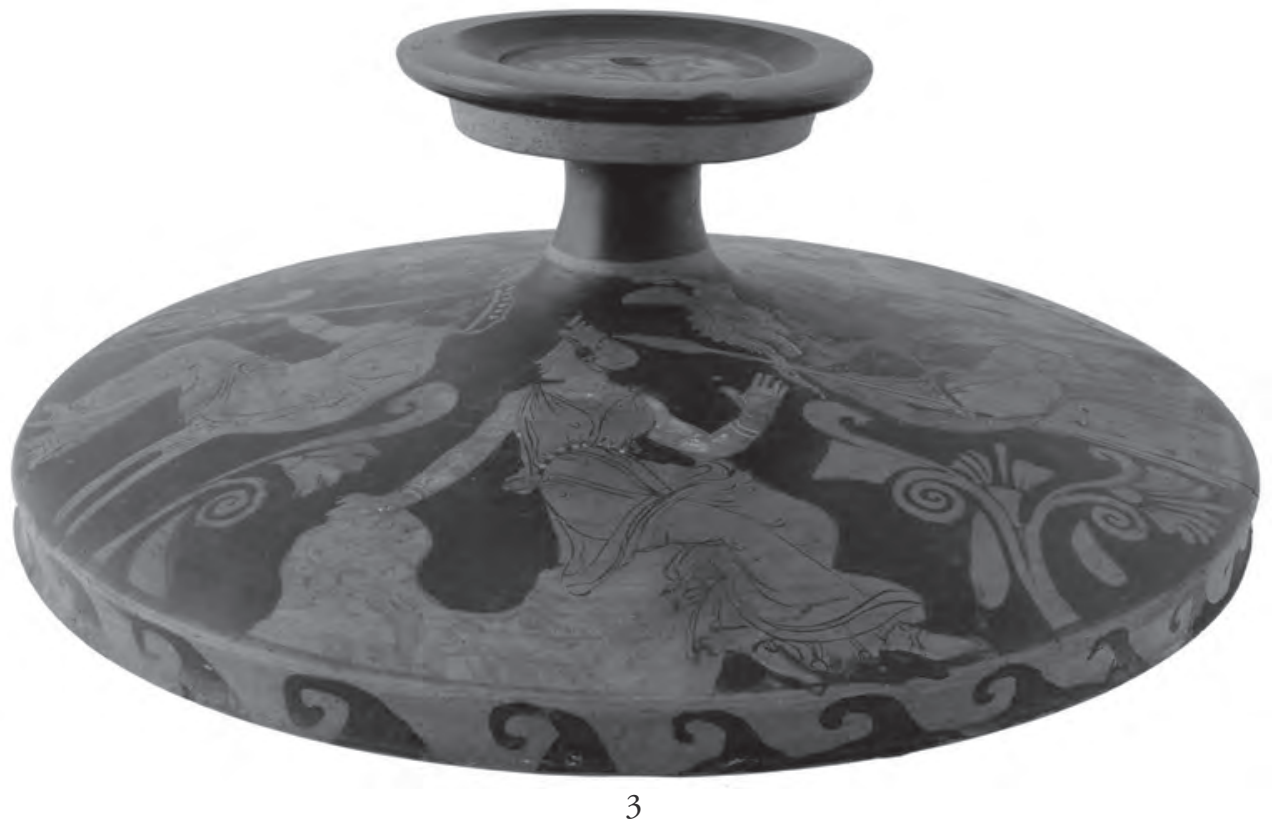



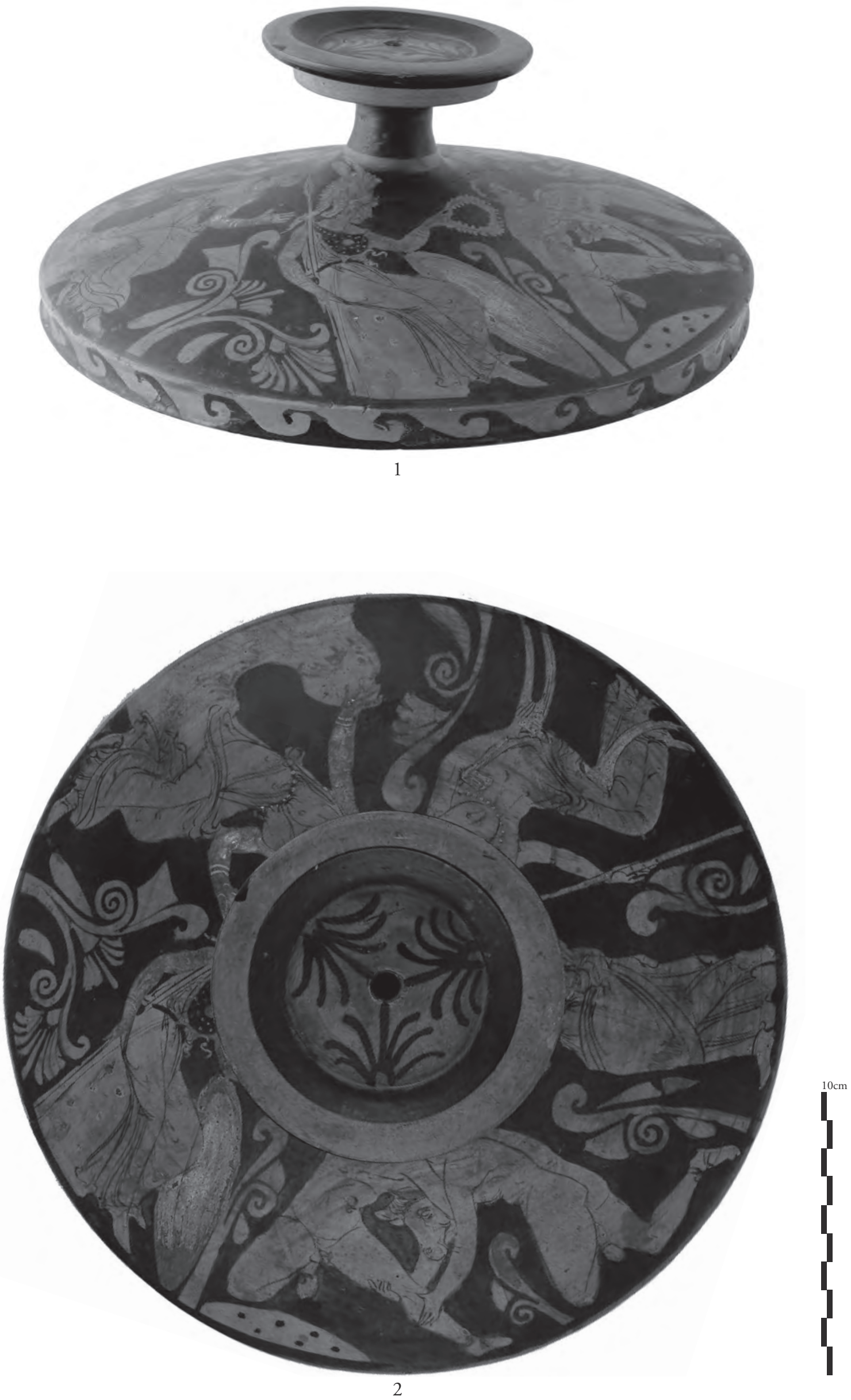

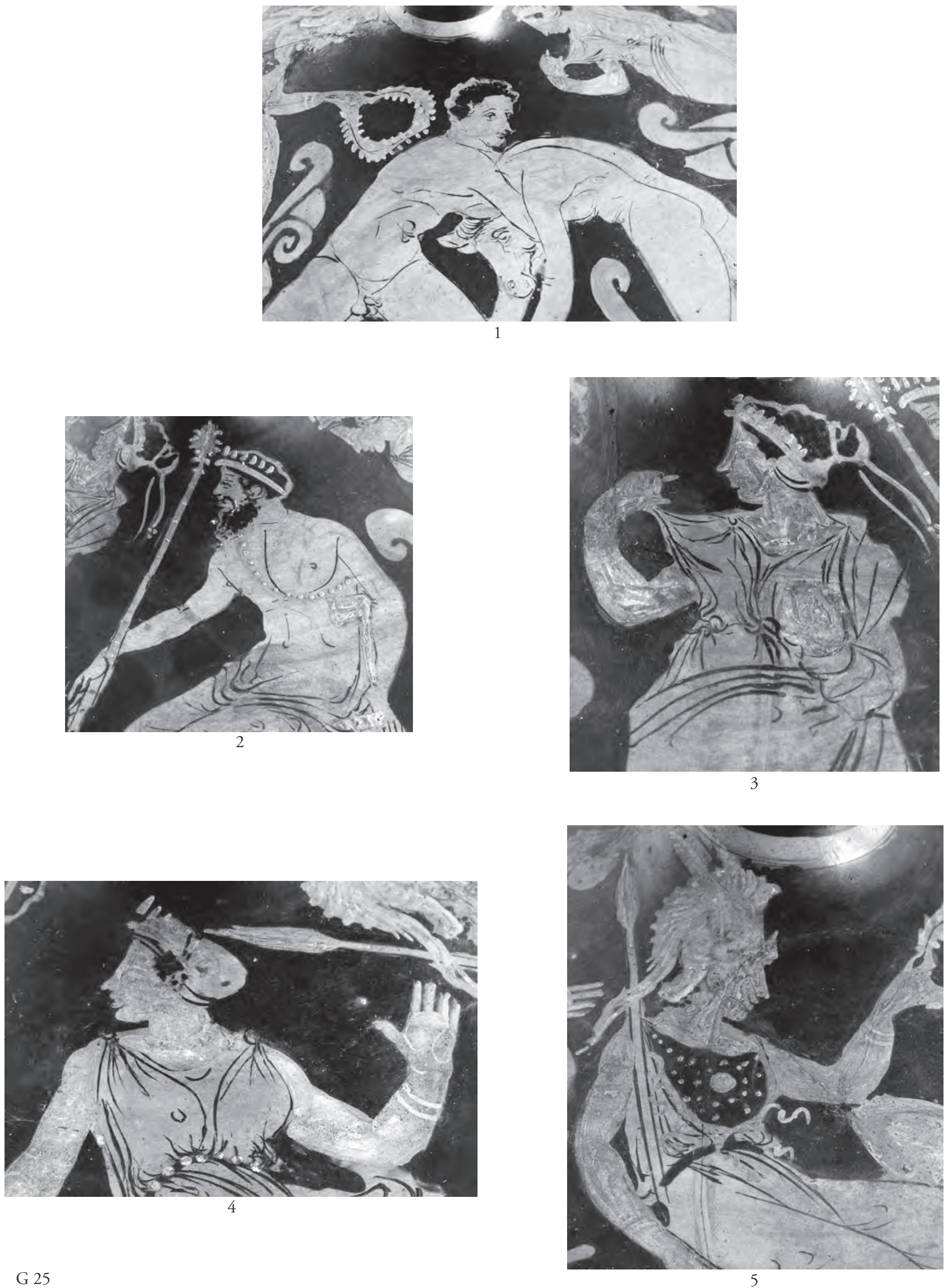

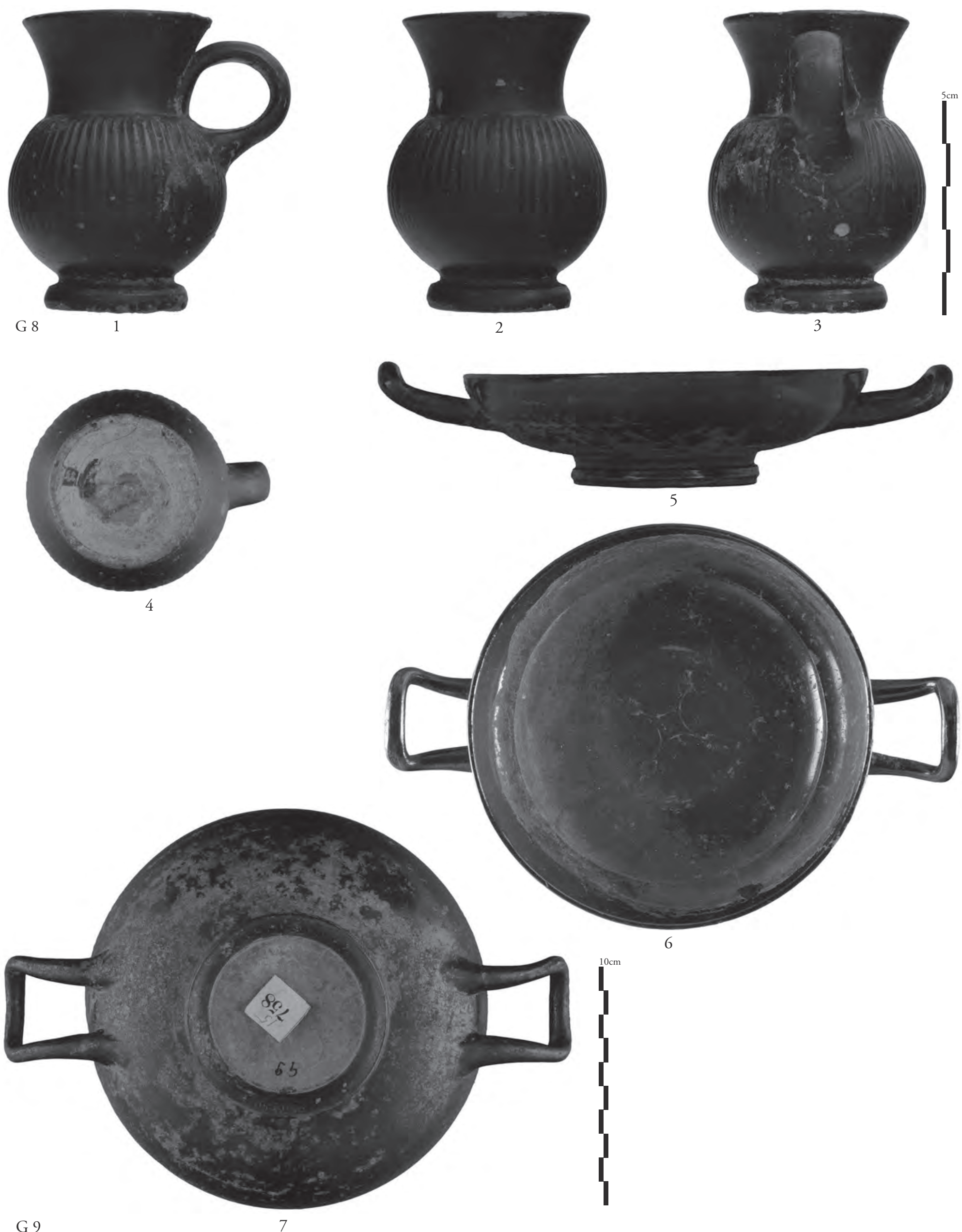


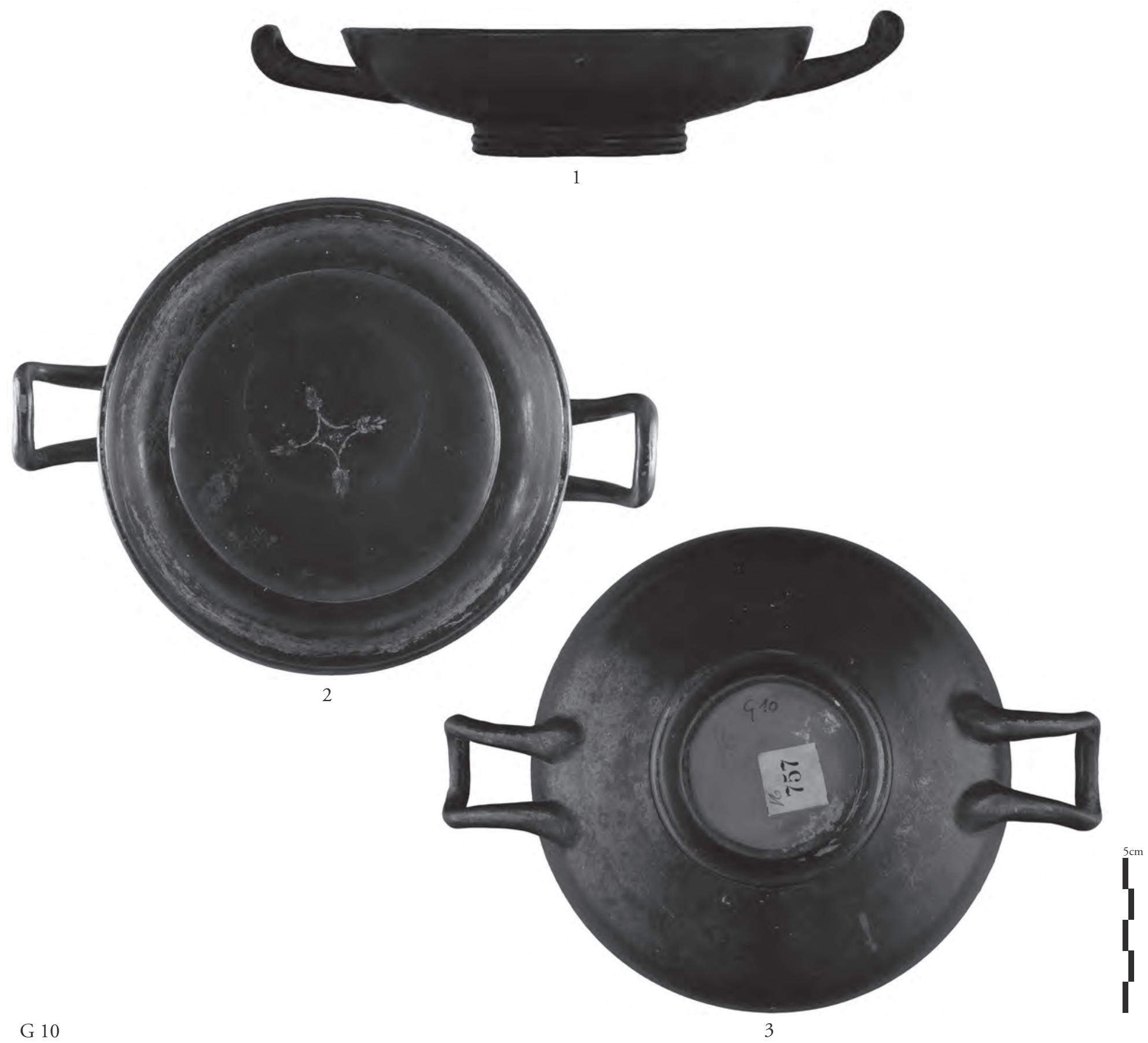

G 10

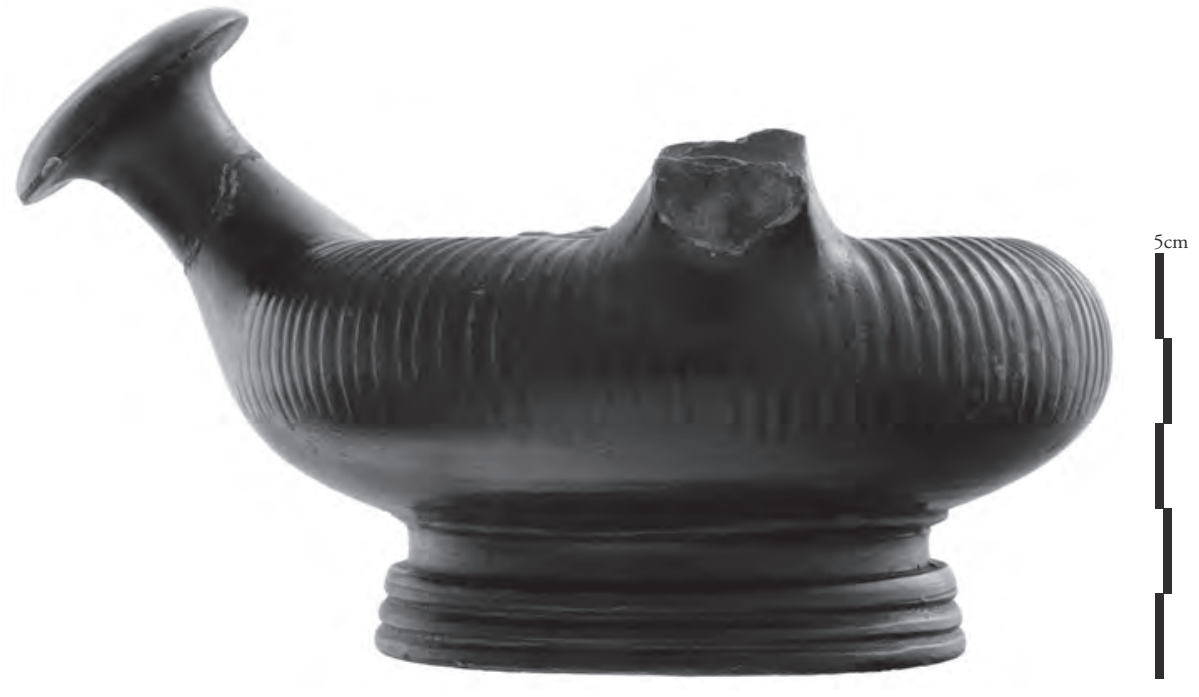

G 2

4 

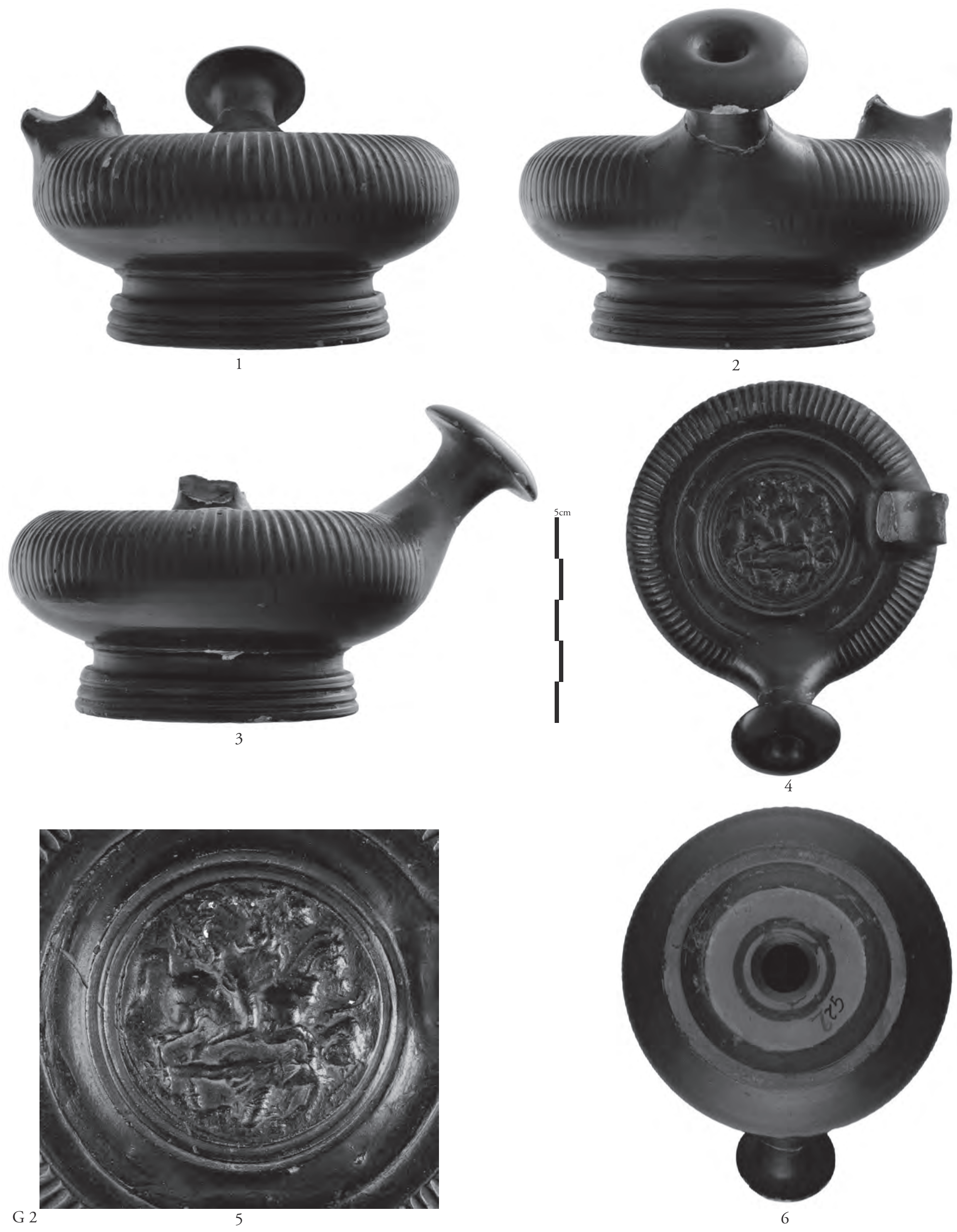

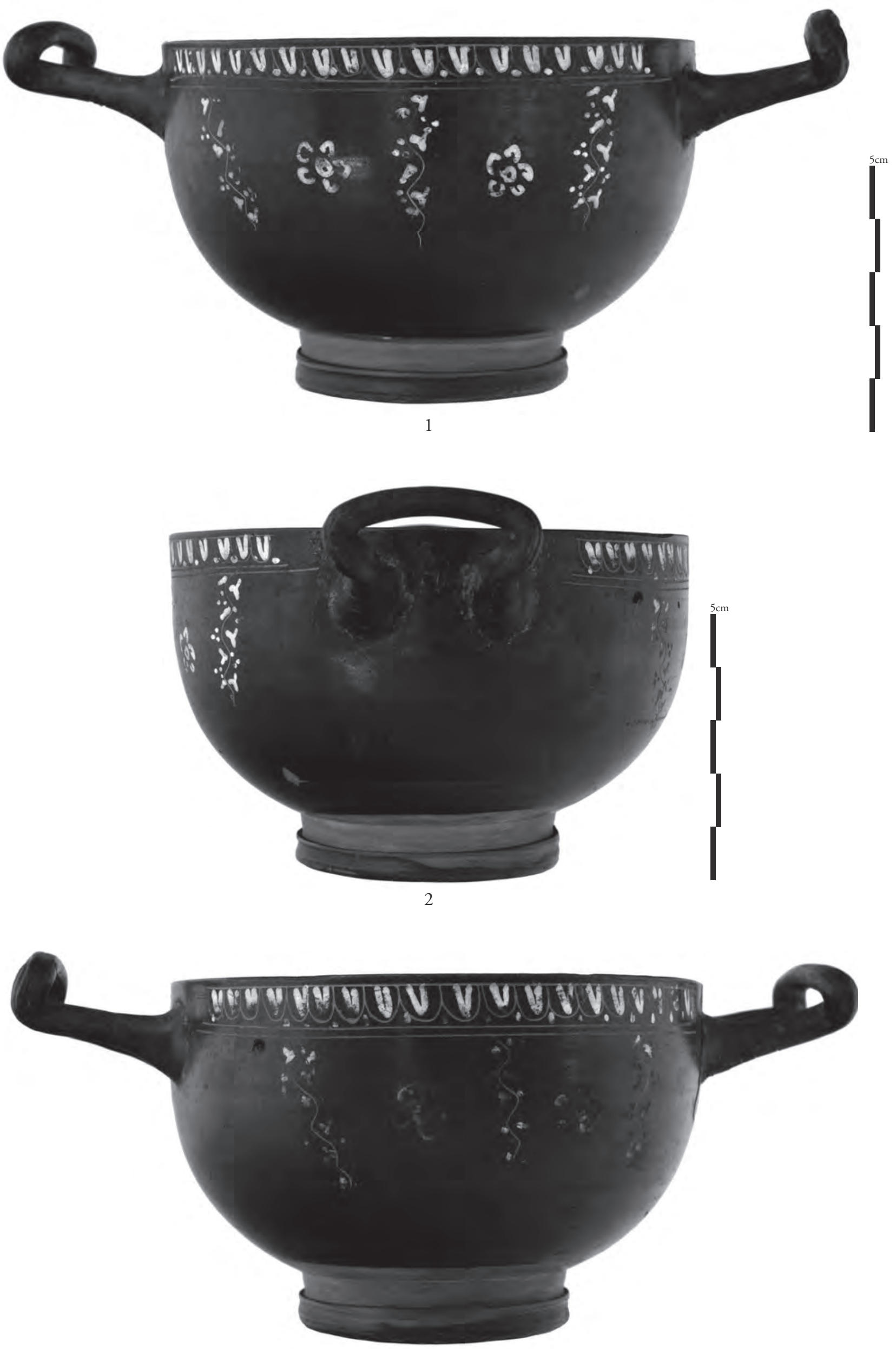

G 12 

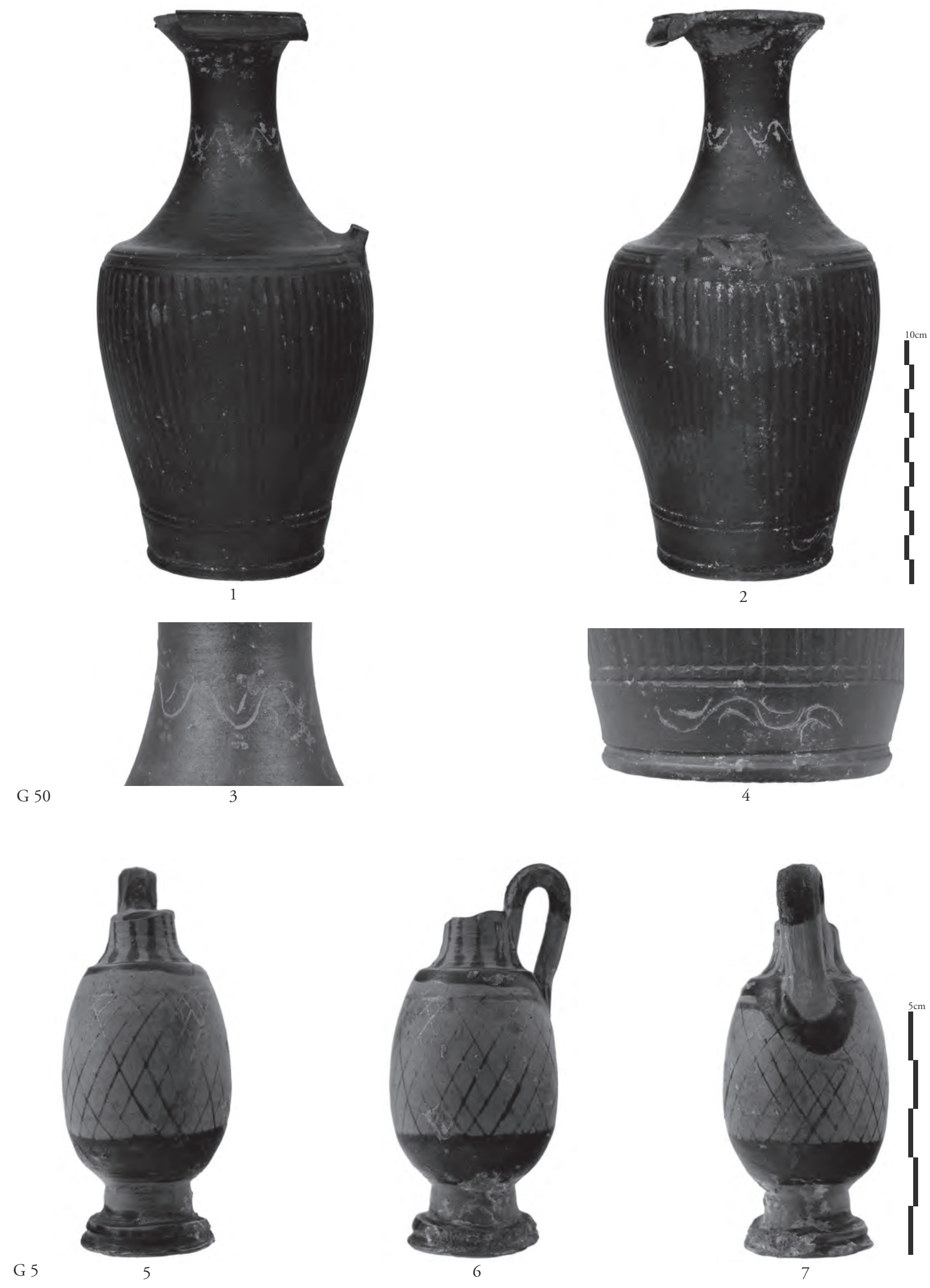


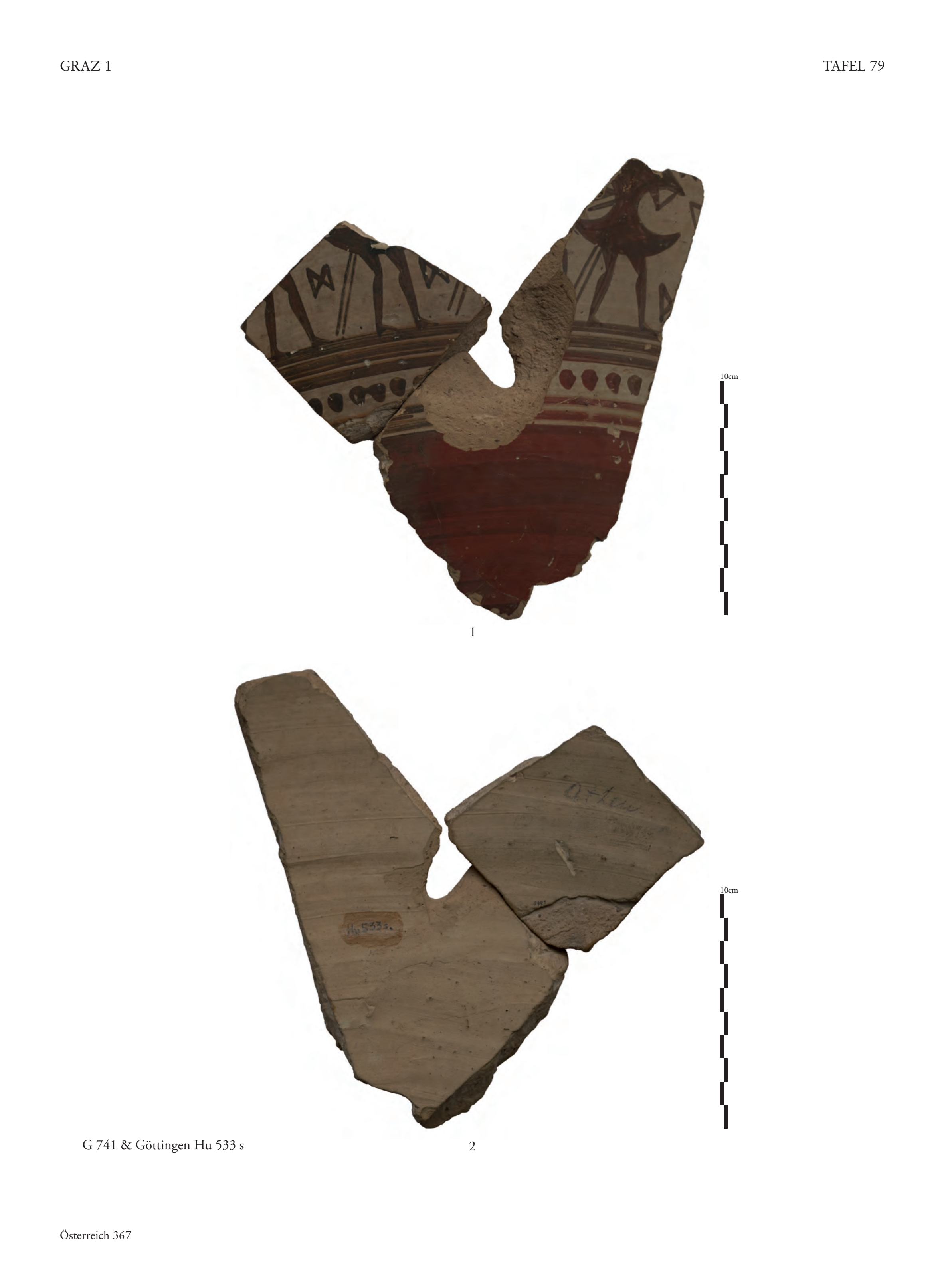



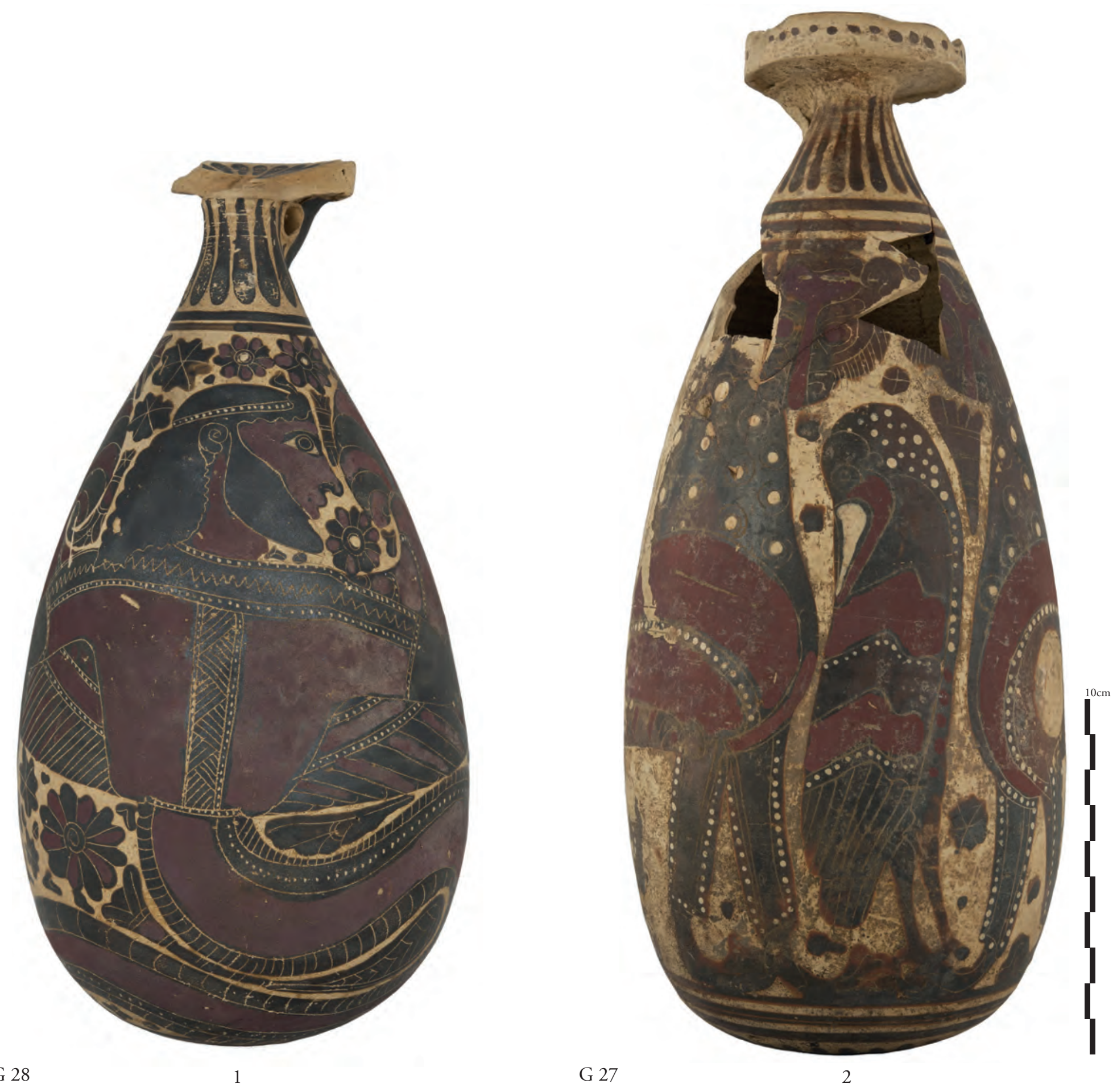


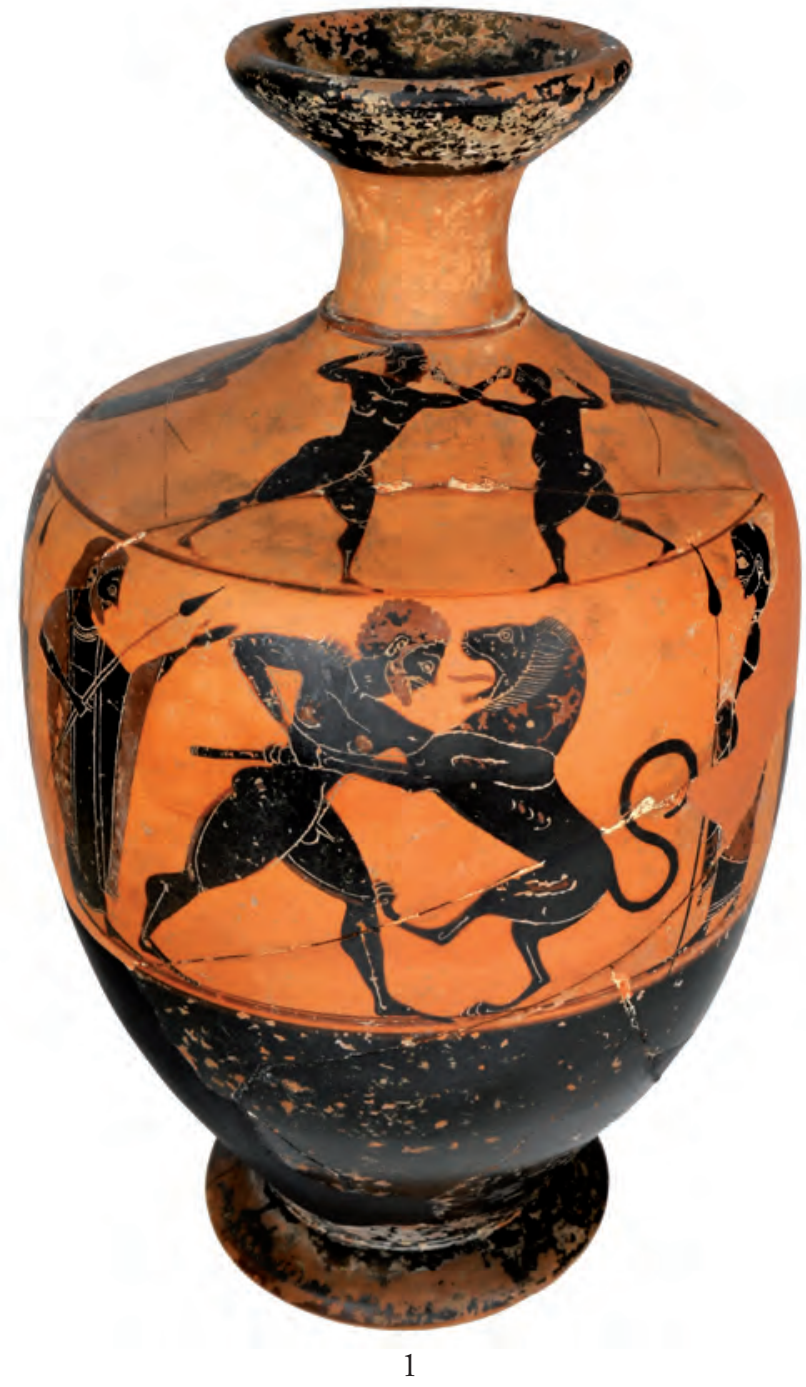

G 36

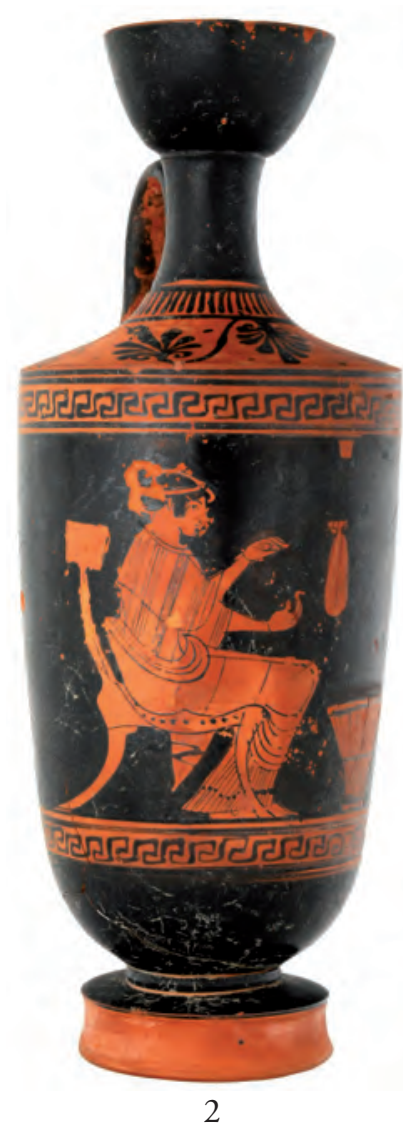




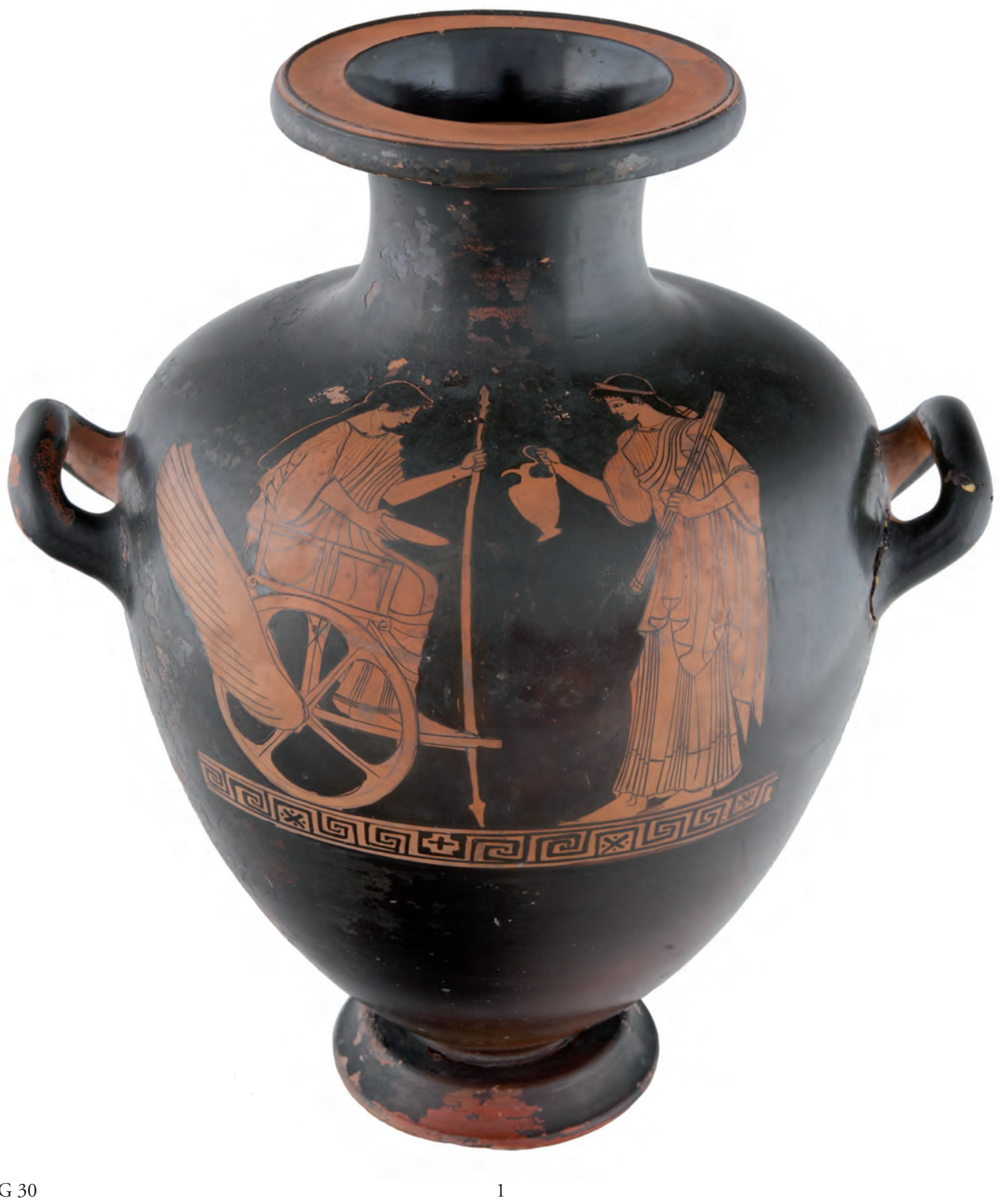



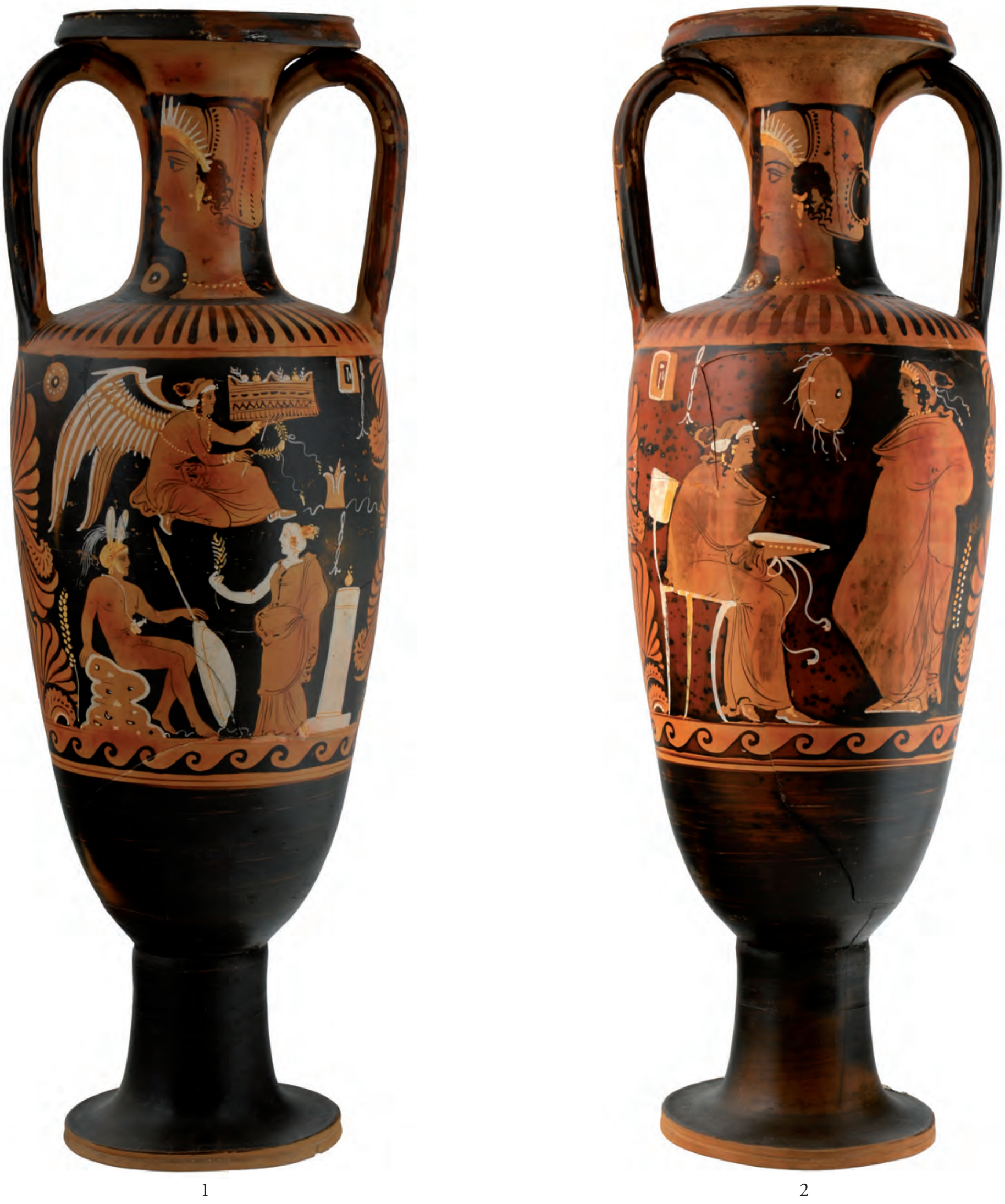

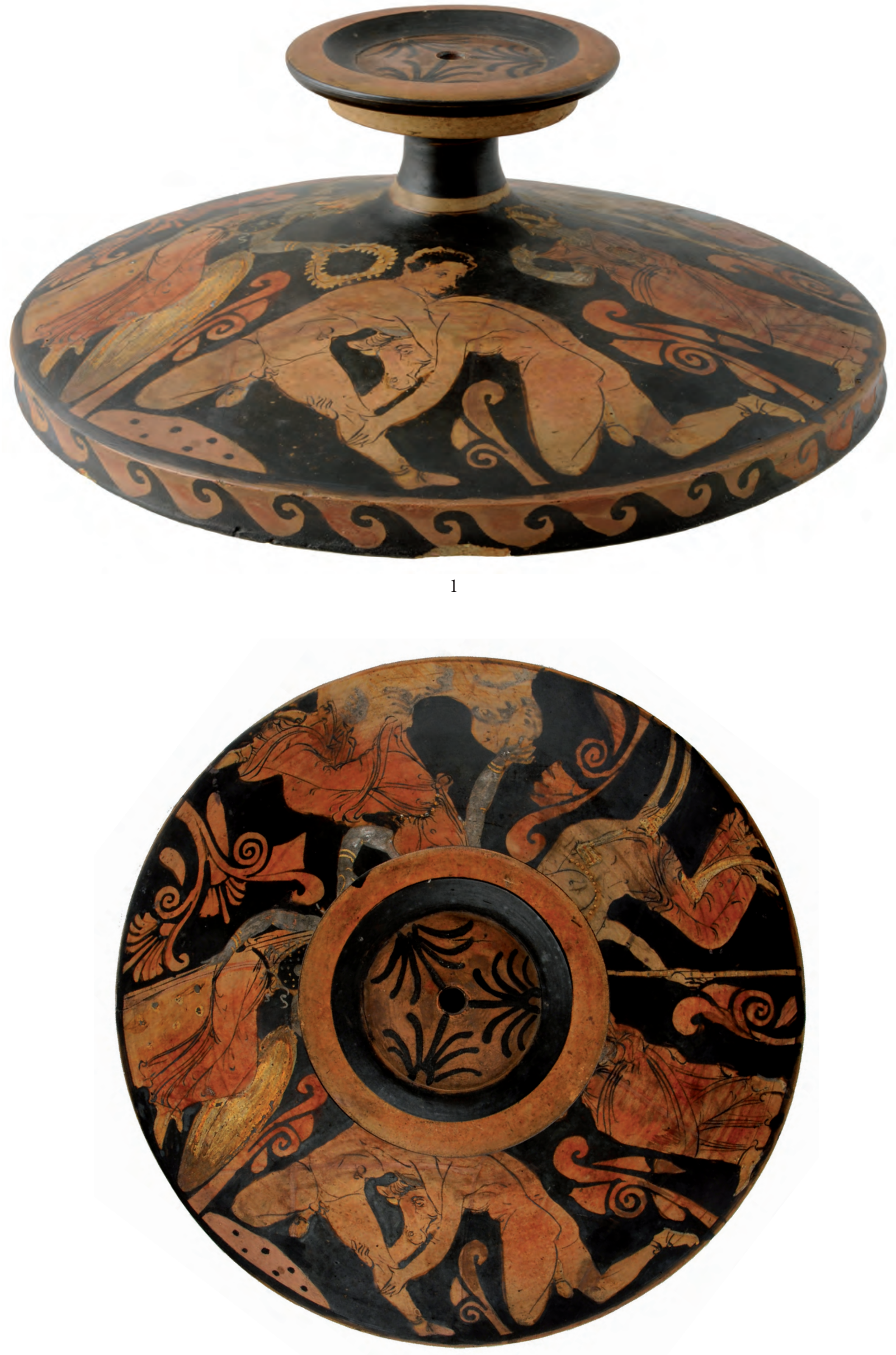

G 25 




ISBN 978-3-7001-7529-2

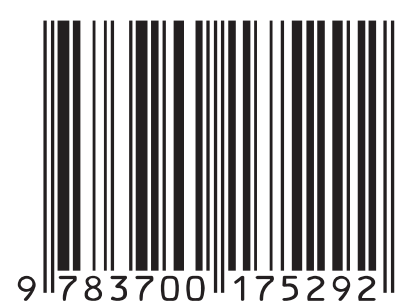

